\title{
ENERGY MATERIALS COORDINATING COMMITTEE (EMaCC)
}

Fiscal Year 1994

July 31, 1995

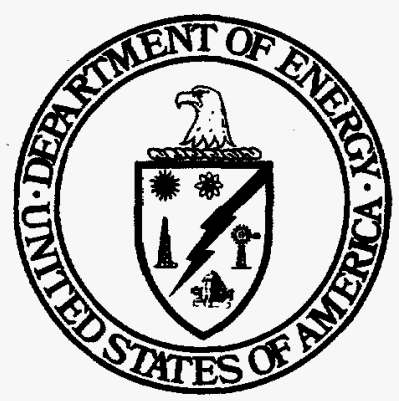

Annual Technical Report

\section{U.S. Department of Energy} Office of Energy Research Office of Basic Energy Sciences Division of Materials Sciences Washington, D.C. 20585 


\section{DISCLAMMER}

Portions of this doecrment may be illegible in electronic image products. Images are produced from the best available original document. 


\section{DISCLAIMER}

This report was prepared as an account of work sponsored by an agency of the United States Government. Neither the United States Government nor any agency thereof, nor any of their employees, make any warranty, express or implied, or assumes any legal liability or responsibility for the accuracy, completeness, or usefulness of any information, apparatus, product, or process disclosed, or represents that its use would not infringe privately owned rights. Reference herein to any specific commercial product, process, or service by trade name, trademark, manufacturer, or otherwise does not necescarily constitute or imply its endorsement, recommendation, or favoring by the United States Government or any agency thereof. The views and opinions of authors expressed herein do not necessar. ily state or reflect those of the United States Government or any agency thereof. 


\section{TABLE OF CONTENTS}

Page

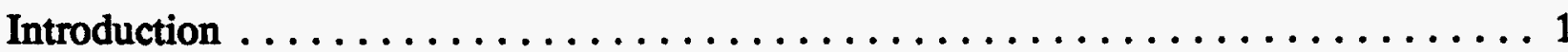

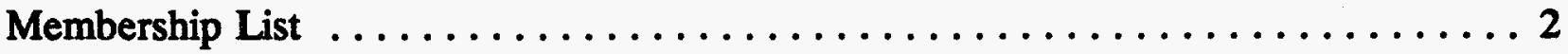

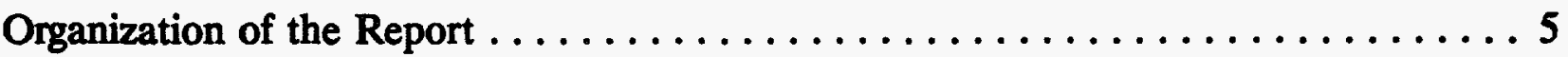

FY 1994 Budget Summary Table for DOE Materials Activities . . . . . . . . . . 6

\section{PROGRAM DESCRIPTIONS}

OFFICE OF ENERGY EFFICIENCY AND RENEWABLE ENERGY . . . . . . . . . 10

Office of Building Technologies $\ldots \ldots \ldots \ldots \ldots \ldots \ldots \ldots \ldots \ldots$

Office of Building Energy Research $\ldots \ldots \ldots \ldots \ldots \ldots \ldots \ldots \ldots$

Buildings Systems and Materials Division $\ldots \ldots \ldots \ldots \ldots \ldots \ldots$

Office of Industrial Technologies $\ldots \ldots \ldots \ldots \ldots \ldots \ldots \ldots \ldots \ldots$

Office of Waste Reduction Technologies $\ldots \ldots \ldots \ldots \ldots \ldots \ldots \ldots \ldots 21$

Industrial Energy Efficiency Division $\ldots \ldots \ldots \ldots \ldots \ldots \ldots \ldots \ldots$

Waste Material Management Division . . . . . . . . . . . . . 24

Waste Utilization and Conversion $\ldots \ldots \ldots \ldots \ldots \ldots \ldots \ldots \ldots$

Solar Materials Research $\ldots \ldots \ldots \ldots \ldots \ldots \ldots \ldots \ldots \ldots \ldots$

Office of Industrial Processes $\ldots \ldots \ldots \ldots \ldots \ldots \ldots \ldots \ldots \ldots \ldots$

Advanced Industrial Materials Program . . . . . . . . . . . . . 27

Office of Transportation Technologies $\ldots \ldots \ldots \ldots \ldots \ldots \ldots \ldots \ldots$

Office of Transportation Materials $\ldots \ldots \ldots \ldots \ldots \ldots \ldots \ldots \ldots \ldots$ 


\section{TABLE OF CONTIENTS (Continued)}

Page

OFFICE OF ENERGY EFFICIENCY AND RENEWABLE ENERGY (continued)

Office of Propulsion Systems . . . . . . . . . . . . . . . . 70

Advanced Propulsion Division $\ldots \ldots \ldots \ldots \ldots \ldots \ldots \ldots \ldots \ldots \ldots$

Electric and Hybrid Propulsion Division $\ldots \ldots \ldots \ldots \ldots \ldots \ldots \ldots$

Office of Alternative Fuels $\ldots \ldots \ldots \ldots \ldots \ldots \ldots \ldots \ldots \ldots$

Office of Utility Technologies $\ldots \ldots \ldots \ldots \ldots \ldots \ldots \ldots \ldots \ldots \ldots$

Office of Solar Energy Conversion $\ldots \ldots \ldots \ldots \ldots \ldots \ldots \ldots \ldots$

Photovoltaic Energy Technology Division $\ldots \ldots \ldots \ldots \ldots \ldots \ldots$

Office of Renewable Energy Conversion $\ldots \ldots \ldots \ldots \ldots \ldots \ldots \ldots \ldots$

Geothermal Technology Division $\ldots \ldots \ldots \ldots \ldots \ldots \ldots \ldots \ldots$

Office of Energy Management $\ldots \ldots \ldots \ldots \ldots \ldots \ldots \ldots \ldots \ldots$

Advanced Utility Concepts Division $\ldots \ldots \ldots \ldots \ldots \ldots \ldots \ldots \ldots$

Superconductivity Systems Program . . . . . . . . . . . . 94

Thermal Energy Storage Program . . . . . . . . . . . . . . 101

OFFICE OF ENERGY RESEARCH $\ldots \ldots \ldots \ldots \ldots \ldots \ldots \ldots \ldots \ldots \ldots$

Office of Basic Energy Sciences $\ldots \ldots \ldots \ldots \ldots \ldots \ldots \ldots \ldots \ldots \ldots$

Division of Materials Sciences $\ldots \ldots \ldots \ldots \ldots \ldots \ldots \ldots \ldots \ldots \ldots \ldots$

Division of Chemical Sciences . . . . . . . . . . . . . . . . . . . . . 124

Division of Engineering and Geosciences $\ldots \ldots \ldots \ldots \ldots \ldots \ldots \ldots \ldots$

Engineering Sciences Research . . . . . . . . . . . . . . . . 127

Geosciences Research . . . . . . . . . . . . . . . . . . . . . . . 147

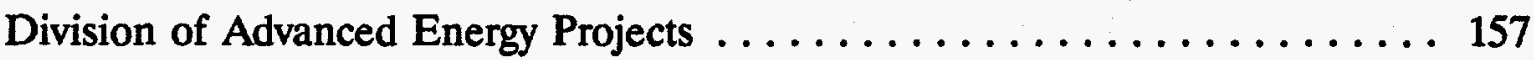

Office of Fusion Energy $\ldots \ldots \ldots \ldots \ldots \ldots \ldots \ldots \ldots \ldots \ldots \ldots$ 


\section{TABLE OF CONTENTS (Continued)}

Page

OFFICE OF ENERGY RESEARCH (continued)

Small Business Innovation Research Program $\ldots \ldots \ldots \ldots \ldots \ldots \ldots \ldots$

Small Business Technology Transfer Program $\ldots \ldots \ldots \ldots \ldots \ldots . \ldots \ldots$

OFFICE OF ENVIRONMENTAL MANAGEMENT $\ldots \ldots \ldots \ldots \ldots \ldots \ldots \ldots$

Office of Waste Management $\ldots \ldots \ldots \ldots \ldots \ldots \ldots \ldots \ldots \ldots \ldots$

High Level Waste Division $\ldots \ldots \ldots \ldots \ldots \ldots \ldots \ldots \ldots \ldots \ldots \ldots$

Office of Environmental Restoration $\ldots \ldots \ldots \ldots \ldots \ldots \ldots \ldots \ldots \ldots$

Office of Technology Development $\ldots \ldots \ldots \ldots \ldots \ldots \ldots \ldots \ldots \ldots \ldots$

OFFICE OF NUCLEAR ENERGY $\ldots \ldots \ldots \ldots \ldots \ldots \ldots \ldots \ldots \ldots \ldots \ldots$

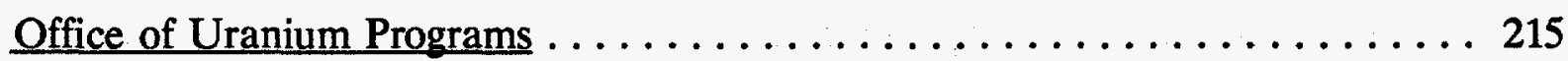

Office of Space and Defense Power Systems $\ldots \ldots \ldots \ldots \ldots \ldots \ldots \ldots \ldots \ldots$

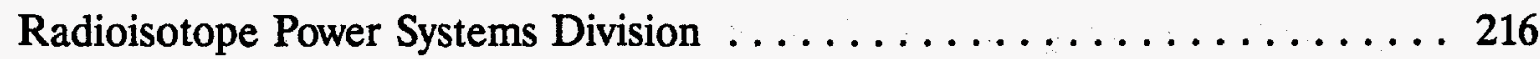

Space Reactor Power Systems Division $\ldots \ldots \ldots \ldots \ldots \ldots \ldots \ldots \ldots .218$

Thermoelectric Space Nuclear Power System Technology . . . . . . . . . . 219

Thermionic Space Nuclear Power System Technology . . . . . . . . . . 220

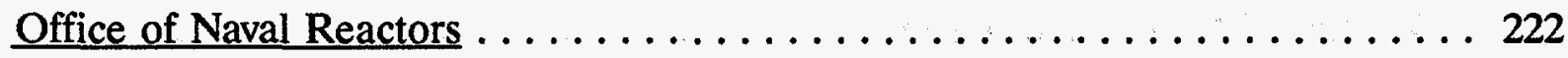

OFFICE OF CIVILIAN RADIOACTIVE WASTE MANAGEMENT $\ldots \ldots \ldots \ldots 223$ 
TABLE OF CONTENTS (Continued)

Page

OFFICE OF DEFENSE PROGRAMS $\ldots \ldots \ldots \ldots \ldots \ldots \ldots \ldots \ldots \ldots \ldots$

The Weapons Research, Development and Test Program .......... 238

Sandia National Laboratories $\ldots \ldots \ldots \ldots \ldots \ldots \ldots \ldots \ldots \ldots \ldots \ldots$

Lawrence Livermore National Laboratory . . . . . . . . . . . . . . 277

Los Alamos National Laboratory $\ldots \ldots \ldots \ldots \ldots \ldots \ldots \ldots \ldots$

OFFICE OF FOSSIL ENERGY $\ldots \ldots \ldots \ldots \ldots \ldots \ldots \ldots \ldots \ldots \ldots \ldots \ldots$

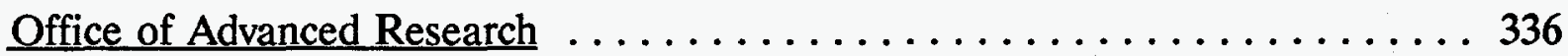

Fossil Energy AR\&TD Materials Program $\ldots \ldots \ldots \ldots \ldots \ldots \ldots \ldots$

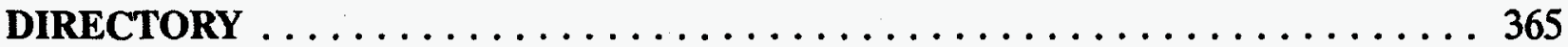

KEYWORD INDEX $\ldots \ldots \ldots \ldots \ldots \ldots \ldots \ldots \ldots \ldots \ldots \ldots \ldots \ldots \ldots$ 


\section{INTRODUCTION}

The DOE Energy Materials Coordinating Committee (EMaCC) serves primarily to enhance coordination among the Department's materials programs and to further effective use of materials expertise within the Department. These functions are accomplished through the exchange of budgetary and planning information among program managers and through technical meetings/workshops on selected topics involving both DOE and major contractors. In addition, EMaCC assists in obtaining materials-related inputs for both intraand interagency compilations.

Six topical subcommittees have been established to focus on materials areas of particular importance to the Department; the subcommittees and their respective chairmen are:

Electrochemical Technologies - Richard Kelly, ER-132, (301) 903-6051

Metals and Intermetallics - David J. Beecy, FE-72, (301) 903-2787

Radioactive Waste Containers - Alan Berusch, RW-22, (202) 586-9362

Semiconductors - Jerry Smith, ER-132, (301) 903-4269

Structural Ceramics - Charles Sorrell, EE-232, (202) 586-1514

Superconductivity - James Daley, EE-142, (202) 586-1165

Membership in EMaCC is open to any Department organizational unit; participants are appointed by Division or Office Directors. The current active membership is listed on the following four pages.

EMaCC reports to the Director of the Office of Energy Research in his or her capacity as overseer of the technical programs of the Department. This annual technical report is mandated by the EMaCC terms of reference. This report summarizes EMaCC activities for FY 1994 and describes the materials research programs of various offices and divisions within the Department.

The Chairman of EMaCC for FY 1994 was Brian G. Volintine. The compilation of this report was performed by Debbie Haught, EMaCC Executive Secretary for FY 1995, with the assistance of FM Technologies, Inc.

Dr. Cynthia Carter

Office of Energy Research

Chair of EMaCC, FY 1995 


\section{MEMBERSHIP LIST \\ DEPARTMENT OF ENERGY \\ ENERGY MATERIALS COORDINATING COMMITTEE}

\begin{tabular}{|c|c|c|}
\hline ORGAMIRATIOH & REPRESENTATIVE & PHONE NO. \\
\hline \multicolumn{3}{|c|}{ ENERGY EFFICIENCY IND RENEWABLE ENERGY } \\
\hline $\begin{array}{l}\text { Building Technologies } \\
\text { Building Systems and Materials }\end{array}$ & Peter Scofield, EE-421 & $202 / 586-9193$ \\
\hline $\begin{array}{l}\text { Industrial Technologies } \\
\text { Industrial Energy Efficiency } \\
\text { Waste Materials Management } \\
\text { Materials Processing Division } \\
\text { Advanced Industrial Materials } \\
\text { Separation Division }\end{array}$ & $\begin{array}{l}\text { Scott Richlen, EE-221 } \\
\text { Kurt D. Sisson EE-222 } \\
\text { Matthew McMonigle, EE-234 } \\
\text { Charles Sorrell, EE-232 } \\
\text { Brian Volintine, EE-233 }\end{array}$ & \begin{tabular}{|l|}
$202 / 586-2078$ \\
$202 / 586-6750$ \\
$202 / 586-2082$ \\
$202 / 586-1514$ \\
$202 / 586-1739$ \\
\end{tabular} \\
\hline $\begin{array}{l}\text { Transportation Technologies } \\
\text { Advanced Transportation Materials }\end{array}$ & $\begin{array}{l}\text { Sidney Diamond, EE-34 } \\
\text { Jim Eberhardt, EE-34 } \\
\text { Debbie Haught, EE-34 }\end{array}$ & $\begin{array}{l}202 / 586-0832 \\
202 / 586-1694 \\
202 / 586-2211 \\
\end{array}$ \\
\hline $\begin{array}{l}\text { Utility Technologies } \\
\text { Wind/Hydro/Ocean Technologies } \\
\text { Geothermal Technology } \\
\text { Photovoltaic Technology } \\
\text { Advanced Utility Concepts }\end{array}$ & $\begin{array}{l}\text { William Richards, EE-121 } \\
\text { Raymond LaSala, EE-122 } \\
\text { Richard King, EE-131 } \\
\text { James Daley, EE-142 } \\
\text { Chris Kang, EE-142 }\end{array}$ & $\left|\begin{array}{l}202 / 586-5410 \\
202 / 586-4198 \\
202 / 586-1693 \\
202 / 586-1165 \\
202 / 586-4563\end{array}\right|$ \\
\hline
\end{tabular}




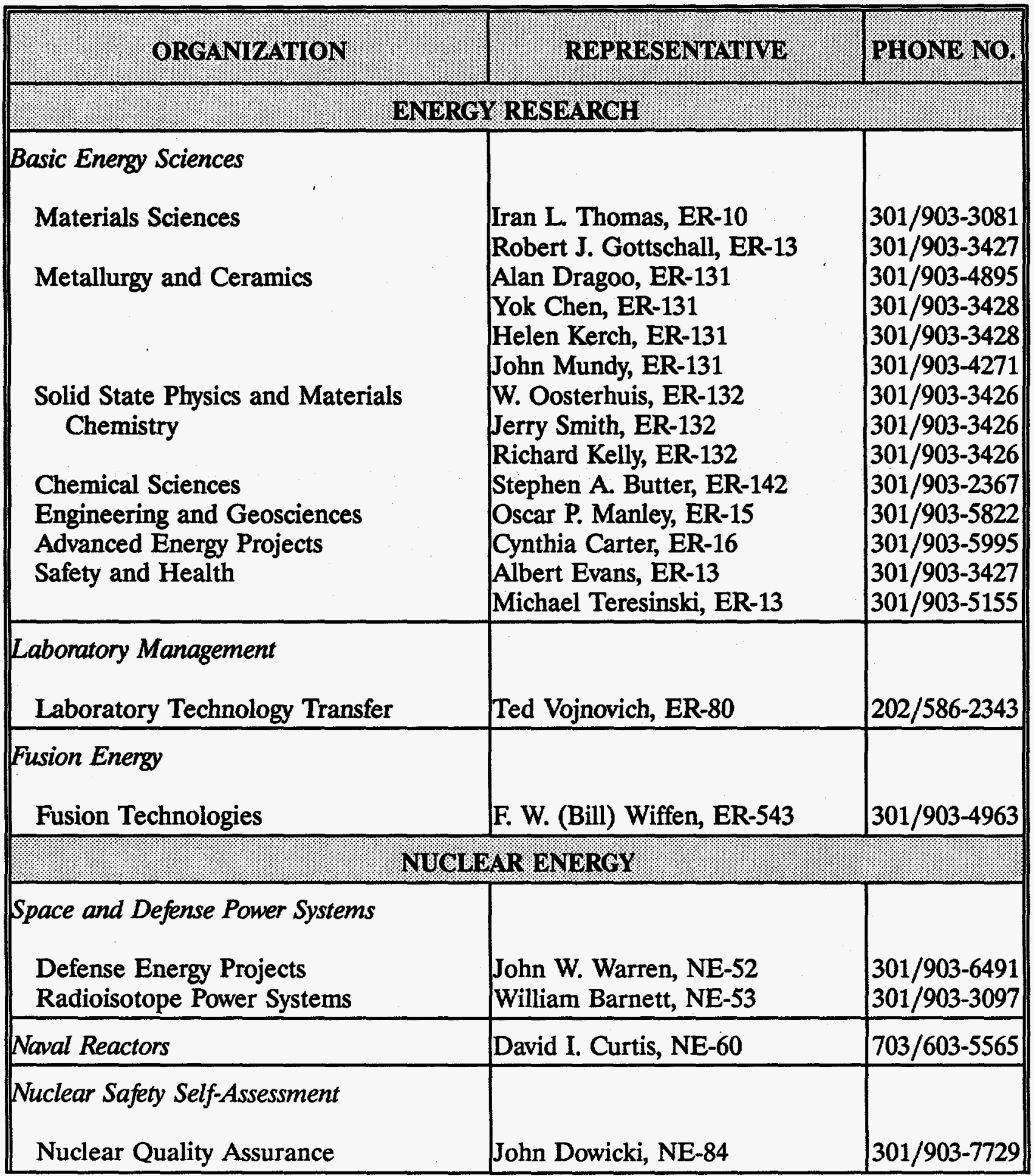




\begin{tabular}{|c|c|c|}
\hline ORGANIZATION & REPRESENTATIVE. & PHONE NO. \\
\hline \multicolumn{3}{|c|}{ DEFENSE PROGRAMS: } \\
\hline $\begin{array}{l}\text { Research and Advanced Technology } \\
\text { Research and Technology Development }\end{array}$ & Bharat Agrawal, DP-11 & $301 / 903-2057$ \\
\hline Inertial Confinement Fusion & Carl B. Hilland, DP-28 & $301 / 903-3687$ \\
\hline \multicolumn{3}{|c|}{ ENVIRONMENTAL RESTORATION AND WASTE MANAGEMENT } \\
\hline \multicolumn{3}{|l|}{ Waste Operations } \\
\hline $\begin{array}{l}\text { Technology Development } \\
\text { Transportation Management } \\
\text { Research and Development }\end{array}$ & $\begin{array}{l}\text { Michael Conroy, EM-561 } \\
\text { Stanley M. Wolf, EM-54 }\end{array}$ & $\begin{array}{l}301 / 903-7967 \\
301 / 903-7962\end{array}$ \\
\hline \multicolumn{3}{|c|}{ FOSSIL ENERGY } \\
\hline Advanced Research & $\begin{array}{l}\text { David J. Beecy, FE-72 } \\
\text { James P. Carr, FE-72 }\end{array}$ & $\begin{array}{l}301 / 903-2787 \\
301 / 903-6519 \\
\end{array}$ \\
\hline \multicolumn{3}{|c|}{ CIVILIAN RADIOACTIVE WASTE MANAGEMENT } \\
\hline Analysis and Verification & Alan Berusch, RW-2 & $202 / 586-9362$ \\
\hline
\end{tabular}




\section{ORGANIZATION OF THE REPORT}

The program descriptions consist of a funding summary for each Assistant Secretary office and the Office of Energy Research, and detailed project summaries with project goals and accomplishments.

The FY 1994 budget summary table for DOE Materials Activities in each of the programs is presented on pages 6-9. 


\section{FY 1994 BUDGET SUMMARY TABLE FOR DOE MATERIALS ACTIVITIES}

(These numbers represent materials-related activities only. They do not include those portions of program budgets which are not materials related.)

FY 1994

Office of Building Technologies

Office of Building Energy Research

Buildings Systems and Materials Division

Office of Industrial Technologies

Office of Waste Reduction Technologies

Industrial Energy Efficiency Division

Waste Material Management Division

Office of Industrial Processes

Office of Transportation Technologies

Office of Transportation Materials

Office of Propulsion Systems

Advanced Propulsion Division

Electric and Hybrid Propulsion Division

Office of Alternative Fuels
$\$ 650,000$

650,000

650,000

$\$ 29,083,000$

$21,593,000$

$18,485,000$

$3,108,000$

$7,490,000$

$\$ 31,935,000$

$18,233,000$

$12,977,000$

$7,998,000$

$4,979,000$

725,000 
FY 1994 BUDGET SUMMARY TABLE FOR

DOE MATERIALS ACTIVITIES (Continued)

Office of Utility Technologies

$\$ 31,454,000$

Office of Solar Energy Conversion

$18,100,000$

Photovoltaic Energy Technology Division

$18,100,000$

Office of Renewable Energy Conversion

600,000

Geothermal Division

600,000

Office of Energy Management

$12,754,000$

Advanced Utility Concepts Division

$12,754,000$

Superconductivity Systems Program

$12,300,000$

Thermal Energy Storage Program

454,000

Office of Energy Research

$\$ 348,260,033$

Office of Basic Energy Sciences

$297,371,424$

Division of Materials Sciences

$277,125,000$

Division of Chemical Sciences

$5,300,000$

Division of Engineering and Geosciences

$7,406,424$

Engineering Sciences Research

$4,836,821$

Geosciences Research

$2,569,603$

Division of Advanced Energy Projects

$7,540,000$

Office of Fusion Energy

$14,488,000$

Small Business Innovation Research Program

$35,030,124$

Small Business Technology Transfer Program

$1,370,485$ 
FY 1994 BUDGET SUMMARY TABLE FOR

DOE MATERIALS ACTIVITIES (Continued)

FY 1994

Office of Environmental Management

$\$ 37,914,500$

Office of Waste Management

$14,766,500$

High Level Waste Division

$14,766,500$

Office of Environmental Restoration

$2,874,000$

Office of Technology Development

$20,274,000$

Office of Nuclear Energy

$\$ 55,265,000$

Office of Space and Defense Power Systems

$12,265,000$

Radioisotope Power Systems Division

$2,425,000$

Space Reactor Power Systems Division

$9,840,000$

Office of Naval Reactors

$43,000,000^{*}$

Office of Civilian Radioactive Waste Management

$\$ 2,200,000$

This excludes $\$ 54$ million for the cost of irradiation testing in the Advanced Test Reactor (ATR). 
FY 1994 BUDGET SUMMARY TABLE FOR

DOE MATERIALS ACTIVITIES (Continued)

Omce of Defense Programs

$\$ 78,279,848$

The Weapons Research Development and Test Program

$78,279,848$

Sandia National Laboratories

Lawrence Livermore National Laboratory

$\$ 32,222,000$

Los Alamos National Laboratory

$19,030,848$

$27,027,000$

Office of Fossil Energy

$\$ 8,628,000$

Office of Advanced Research

$8,628,000$

Fossil Energy AR\&TD Materials Program

$8,628,000$

TOTAL

$\$ 623,669,381$ 


\section{OFFICE OF ENERGY EFFICIENCY AND RENEWABLE ENERGY}

The Office of Energy Efficiency and Renewable Energy seeks to develop the technology needed for the Nation to use its existing energy supplies more efficiently, and for it to adopt, on a large scale, renewable energy sources. Toward this end, the Office conducts long-term, high-risk, high-payoff $R \& D$ that will lay the groundwork for private sector action.

A number of materials $R \& D$ projects are being conducted within the Energy Efficiency and Renewable Energy program. The breadth of this work is considerable, with projects focusing on coatings and films, ceramics, solid electrolytes, elastomers and polymers, corrosion, materials characterization, transformation, superconductivity and other research areas. The level of funding indicated refers only to the component of actual materials research. 
The Office of Energy Efficiency and Renewable Energy conducts materials research in the following offices and divisions:

FY 1994

1. Office of Building Technologies

$\$ 650,000$

a. Office of Building Energy Research 650,000

(1) Buildings Systems and Materials Division 650,000

2. Office of Industrial Technologies

$\$ 29,083,000$

a. Office of Waste Reduction Technologies

(1) Industrial Energy Efficiency Division

$18,845,000$

(2) Waste Material Management Division

b. Office of Industrial Processes

3. Office of Transportation Technologies

a. Office of Transportation Materials

$18,233,000$

b. Office of Propulsion Systems

$12,977,000$

(1) Advanced Propulsion Division

$7,998,000$

(2) Electric and Hybrid Propulsion Division

$4,979,000$

c. Office of Alternative Fuels

725,000 
4. Office of Utility Technologies

$\$ 31,454,000$

a. Office of Solar Energy Conversion

$18,100,000$

(1) Photovoltaic Energy Technology Division

$18,100,000$

b. Office of Renewable Energy Conversion

600,000

(1) Geothermal Division

600,000

c. Office of Energy Management

$12,754,000$

(1) Advanced Utility Concepts Division

$12,754,000$ 


\section{OFFICE OF BUILDING TECHNOLOGIES}

FY 1994

Office of Building Technologies - Grand Total

$\$ 650,000$

Office of Building Energy Research

$\$ 650,000$

Building Systems and Materials Division

$\$ 650,000$

Materials Properties, Behavior. Characterization or Testing

$\$ 650,000$

Development of Non-CFC Foam Insulations

100,000

Evacuated Powder Panel Insulation

300,000

Gas-Filled Reflective Insulation Panel

100,000

Accelerated Lifetime Test Procedure Development

150,000 


\section{OFFICE OF BUILDING TECHNOLOGIES}

\section{Office of Building Energy Research}

The Office of Building Energy Research works to increase the energy efficiency of the buildings sector through performance of R\&D on building systems and building equipment. In addition, it conducts research to support the establishment of appliance standards and labeling and building energy performance standards. Specific objectives include providing the technology to:

- reduce energy consumption in existing buildings and in new buildings;

- increase the energy efficiency of oil and gas combustion heating systems and of oil- and gas-fired heat pump systems; and

- improve the energy efficiency of advanced electric heat pump and refrigeration systems, and of light systems.

\section{Building Systems and Materials Division}

The goal of this Division is to provide a scientific and technical basis (including model standards) for reducing the use of energy in residential and commercial buildings by 35 percent by the year 2000 from that used in 1975, while maintaining existing levels of human comfort, health and safety. The Division's primary objectives are to support research that advances the scientific and technical options for increased energy efficiency in buildings, to promote the substitution of abundant fuels for scarce fuels in buildings, and to promulgate standards for increased efficiency of energy use. To accomplish a portion of this, the Building Materials program seeks to: (1) develop new and improve existing insulating materials; (2) develop and verify analytical models that are useful to building designers and researchers for predicting the thermal performance characteristics of materials; (3) develop methods for measuring the thermal performance characteristics; and (4) provide technical assistance and advice to industry and the public. The DOE contact is Peter Scofield, (202) 586-9193. 


\section{Materials Properties, Behavior. Characterization or Testing}

1. Development of Non-CFC Foam Insulations

FY 1994

$\$ 100,000$

DOE Contact: Peter Scofield, (202) 586-9193

ORNL Contact: Ken Wilkes, (615) 574-5931

This second year of a three-year extension of a joint project with the rigid foam industry for the development of alternative blowing agents to be used as drop in replacements for the CFC blowing agents currently being used in the manufacture of foam insulation products. Prototype rigid foam boards blown with HCFC-141b and CFC-11 were sent to ORNL for testing and evaluation both in the laboratory and in outdoor test facilities. Tests are being conducted to determine mechanical and thermal properties and aging characteristics.

Keywords: CFC, Foam Insulation, Insulation Sheathing, Roofs

2. Evacuated Powder Panel Insulation

FY 1994

$\$ 300,000$

DOE Contact: Peter Scofield, (202) 586-9193

ORNL Contact: Ken Wilkes, (615) 574-5931

This project is for the development of an advanced technology super insulation concept. A layer of powder is sandwiched between two films and a soft vacuum is drawn on the powder filler. Current technology produces a R-40 per inch panel. More efficient powders and longer life encasing films are being developed.

Keywords: Insulation, Vacuum, Heat Transfer

3. Gas-Filled Reflective Insulation Panel

FY 1994

$\$ 100,000$

DOE Contact: Peter Scofield, (202) 586-9193

LBL Contact: Dariush Aresteh, (415) 486-6844

This project is for the development of a super insulation concept that utilizes layers of reflective films enclosed in a flexible film panel which is filled with low conductivity gases. Mechanisms to provide greater structural rigidity are being investigated as are low permeability films and environmentally benign low conductivity gases.

Keywords: Insulation, Reflective Films, Low Conductivity Gases 
4. Accelerated Lifetime Test Procedure Development

FY 1994

DOE Contact: Peter Scofield, (202) 586-9193

$\$ 150,000$

ORNL Contact: Ken Wilkes, (615) 574-5931

This joint project with the Appliance Research Consortium is for the development of an ASTM standard test procedure for measuring the thermal resistance and aging characteristics of insulating materials with R-values in excess of 20 per inch. The procedure requires the development of a specialized measurement configuration, the modelling of the test specimen within the test configuration, and the conduction of round robins with industry partners.

Keywords: Thermal Resistance, Test Procedures 
OFFICE OF INDUSTRIAL TECHNOLOGIES

FY 1994

Office of Industrial Technologies - Grand Total

$\$ 29,083,000$

Office of Waste Reduction Technologies

$\$ 21,593,000$

Industrial Energy Efficiency Division

$\$ 18,485,000$

Materials Properties. Behavior. Characterization or Testing

$\$ 2,857,000$

Advanced Heat Exchanger Material Technology

Development

$1,132,000$

20,000

Continuous Fiber Ceramic Composites (CFCC) Supporting Technologies

$1,705,000$

Materials Preparation. Synthesis, Deposition, Growth or Forming

CFCC Program - Industry Tasks

$\$ 6,492,000$

$6,492,000$

Device or Component Fabrication, Behavior or Testing

$\$ 9,136,000$

Ceramic Composite Heat Exchanger for the Chemical Industry

HiPHES System Design Study for Energy Production from Hazardous Wastes

HiPHES System Design Study for an Advanced Reformer

Ceramic Components for Stationary Gas Turbines in

Cogeneration Service

Long-Term Testing of Ceramic Components for Stationary

Gas Turbines

363,000

623,000

350,000

$7,200,000$

600,000 


\section{OFFICE OF INDUSTRIAL TECHNOLOGIES}

FY 1994

Office of Waste Reduction Technologies (continued)

Waste Material Management Division

$\$ 3,108,000$

Waste Utilization and Conversion

$\$ 2,308,000$

Materials Preparation, Synthesis, Deposition, Growth or Forming

$\$ 2,308,000$

Wood Wastes to Adhesives

638,000

Waste Tire Composite

Silicon Oxide Recovery-Conversion

Bioconversion of Food Wastes to Lactic Acid

$1,000,000$

670,000

Solar Materials Research

$\$ 800,000$

Materials Preparation, Synthesis, Deposition, Growth or Forming

$\$ 800,000$

Photocatalysts Based on Titanium Dioxide

Solar Materials Processing

Office of Industrial Processes

$\$ 7,490,000$

Advanced Industrial Materials Program

$\$ 7,490,000$

Materials Preparation. Synthesis, Deposition, Growth or Forming

$\$ 2,825,000$

Advanced Methods for Processing Ceramics

Synthesis and Design of Intermetallic Materials

60,000

Development of Weldable, Corrosion Resistant

490,000

Iron-Aluminide Alloys

180,000 


\section{OFFICE OF INDUSTRIAL TECHNOLOGIES (Continued)}

FY 1994

Office of Industrial Processes (continued)

Advanced Industrial Materials Program (continued)

$\$ 3,108,000$

Materials Preparation. Synthesis, Deposition. Growth or Forming (continued)

Composites Through Reactive Metal Infiltration

Magnetic Field Processing of Inorganic Polymers

Development of New Composite Aerogel Materials

Microwave Processing of Continuous Ceramic Oxide Filaments

Conducting Polymers: Synthesis and Industrial Applications

Microwave Assisted Chemical Vapor Infiltration

High Deposition Rate Ceramic Synthesis

325,000

225,000

275,000

350,000

325,000

270,000

325,000

Materials Properties, Behavior, Characterization or Testing

$\$ 500,000$

Three Dimensional X-ray Tomography of Crack-Resistant Composites

Characterization of Three-Way Automotive Catalysts

200,000

300,000

Materials Structure and Composition

$\$ 2,590,000$

High-Temperature Precipitate-Strengthened Iron-Aluminide Alloys

Metallic and Intermetallic Bonded Ceramic Composites

Advanced Ordered Intermetallic Alloy Development

Superior Metallic Alloys Through Rapid Solidification Processing by Design

Polymerization and Processing of Organic Polymers in a Magnetic Field

Microwave Joining of SiC

Microwave Processing of Materials: Glass-Ceramics

Characterization of CVI Densification of Ceramic

Composites

Biomimetic Thin Film Synthesis

260,000

430,000

165,000

225,000

300,000

80,000

85,000

120,000

325,000

Chemical Recycling of Plastics

300,000

Composites and Blends from Biobased Materials

300,000 
OFFICE OF INDUSTIRIAL TECHNOLOGIES

FY 1994

Office of Industrial Processes (continued)

Advanced Industrial Materials Program (continued)

Device or Component Fabrication, Behavior or Testing

$\$ 1,575,000$

$\mathrm{Ni}_{3} \mathrm{Al}$ Technology Transfer

750,000

Advanced Microwave Processing Concepts

240,000

Selective Inorganic Thin Films

425,000

Chemical Vapor Infiltration of $\mathrm{TiB}_{2}$ Composites

160,000 


\section{OFFICE OF INDUSTRIAL TECHNOLOGIES}

The Office of Industrial Technologies conducts research and development to conserve energy in industry. The goal of these activities is to save energy, achieve higher efficiency, provide for fuel flexibility, and increase productivity in industrial unit operations and processes. To accomplish these objectives, the Office has adopted the basic strategy of identifying, in cooperation with private industry, the technological needs of energy conservation in the industrial sector; identifying what private industry is currently doing or will not do alone; selecting the highest priority targets not being pursued by the private sector; and negotiating cost-shared contracts with private industry or contracts with national laboratories or universities to carry out the necessary research.

\section{Office of Waste Reduction Technologies}

The mission of the Office of Waste Reduction is to develop and maintain a balanced program of research and development on generic technologies which contribute to enhanced industrial energy use efficiency and which have wide application throughout industry and agriculture. The program includes activities in waste heat recovery, improved thermal energy management, combustion systems, waste products utilization including municipal solid wastes, and waste stream detoxification.

Industrial Energy Efficiency Division

\section{Materials Properties, Behavior, Characterization or Testing}

\section{Advanced Heat Exchanger Material Technology Development}

FY 1994

DOE Contact: G. Varga, (202) 586-0082

ORNL Contact: M. Karnitz, (615) 574-5150

This project conducts research to develop improved ceramic materials and fabrication processes and to expand the materials database for advanced heat exchangers. Currently the project is studying the effects of corrosive waste stream constituents on candidate ceramic and ceramic composite materials through coupon tests and exposure to high pressure exhaust gas environments and developing advanced wet forming techniques for monolithic ceramic components.

Keywords: Structural Ceramics, Corrosion-Gaseous, Industrial Waste Heat Recovery 
6. Ceramic Fiber Residue Measurement

FY 1994

$\$ 20,000$

DOE Contact: S. Richlen, (202) 586-2078

ORNL Contact: M. Karnitz, (615) 574-5150

This project determines whether whisker-like particles can be generated during the handling, processing, or machining of continuous ceramic fiber ceramic matrix composites. A test protocol has been written and is under review.

Keywords: Ceramic Composites, Whiskers

7. Continuous Fiber Ceramic Composites (CFCC) Supporting Technologies FY 1994 $\$ 1,705,000$

DOE Contact: S. Richlen, (202) 586-2078

ORNL Contact: M. Karnitz, (615) 574-5150

This project provides basic or generic support to the industry teams conducting CFCC research. Tasks include: composite design, materials characterization, test methods development, database generation, and life prediction.

Keywords: Ceramic Composites, Fiber Architecture

Materials Preparation, Synthesis, Deposition, Growth or Forming

8. CFCC Program - Industry Tasks

FY 1994

$\$ 6,492,000$

DOE Contact: S. Richlen, (202) 586-2078

The goal of the CFCC Program is to develop, in U.S. industry, the primary processing methods for the reliable and cost-effective fabrication of continuous fiber ceramic composite components for use in industrial applications. The first phase, which establishes performance requirements of applications and assesses feasibility of potential processing systems, is underway.

Keywords: Ceramic Composites, Continuous Fiber 


\section{Device or Component Fabrication, Behavior or Testing}

9. Ceramic Composite Heat Exchanger for the Chemical Industry

FY 1994

$\$ 363,000$

DOE Contact: G. Varga, (202) 586-0082

Babcock \& Wilcox Contact: D. Hindman, (804) 522-5825

The third phase of this project has been initiated to design and build a prototype module heat exchanger using ceramic composite tubes to determine their performance under industrial conditions. Currently, ceramic composite tubes are being proof-tested in a high-temperature furnace to determine their viability for actual use.

Keywords: Ceramic Composites, Structure

10. HiPHES System Design Study for Energy Production from Hazardous

FY 1994

$\$ 623,000$

DOE Contact: G. Varga, (202) 586-0082

Solar Turbines Contact: B. Harkins, (619) 544-5398

This project is in the second phase of a three-phase effort to develop high pressure heat exchange systems (HiPHES) for recovery of energy from hazardous wastes. A preliminary design of an advanced heat exchange process based on the use of ceramic composites has been developed. Research on critical material and design needs continues.

Keywords: Ceramic Composites, Heat Exchangers

11. HiPHES System Design Study for an Advanced Reformer

FY 1994

DOE Contact: G. Varga, (202) 586-0082

$\$ 350,000$

Stone \& Webster Engineering Corp. Contact: J. Williams, (617) 589-7147.

This project is in the second phase of a three-phase effort to develop high pressure heat exchange systems for an advanced convective reformer. A preliminary design of an advanced heat exchange process based on the use of ceramics has been developed. Research on critical material and design needs continues.

Keywords: Composites, Heat Exchangers 


\section{Ceramic Components for Stationary Gas Turbines in Cogeneration Service}

DOE Contact: W. Parks, (202) 586-2093

FY 1994

$\$ 7,200,000$

Solar Contact: M. Van Roode, (619) 544-5549

This project will design and test three major ceramic components in a stationary 3.5MW gas turbine for cogeneration service. The three components are the combustor, first stage rotor, and first stage nozzle. The project will culminate in a 4000 hour field demonstration of the engine.

Keywords: Structural Ceramics, Cogeneration, Gas Turbines

13. Long-Term Testing of Ceramic Components for Stationary Gas Turbines $\frac{\text { FY } 1994}{\$ 600,000}$

DOE Contact: W. Parks, (202) 586-2093

ORNL Contact: M. Ferber, (615) 576-0818

This project will test monolithic ceramics in static and cyclic fatigue for up to 10,000 hours at gas turbine utilization temperatures.

Keywords: Structural Ceramics, Cogeneration, Gas Turbines

Waste Material Management Division

Waste Utilization and Conversion

Industrial waste solid, liquid, and gaseous materials are waste because they have insufficient economic potential, thus they are landfilled or discharged to the environment. Economically useful wastes are termed by-products and constitute the objective of the Waste Utilization and Conversion program. Materials research can provide technologies to upgrade wastes or create new commodity materials so that wastes can have economic, i.e., added, value to become by-product materials of value to industry or commerce. The DOE contact is Bruce Cranford, (202) 586-9496. 


\section{Materials Preparation, Synthesis, Deposition, Growth or Forming}

14. Wood Wastes to Adhesives

FY 1994

$\$ 638,000$

DOE Contact: Charles Russomanno, (202) 586-7543

NREL Contact: Helena Chum, (303) 231-7249

Wood wastes are pyrolyzed via a vortex reactor yielding pyrolysis oils. Oils are separated to give a phenols-neutrals fraction which is used to replace phenol in various phenolic resin applications. Because petroleum-based phenol is replaced by wood-based phenol, and because the overall process is cheaper, substantial energy savings of over 200 trillion BTU/year are projected for 2010.

Keywords: Wood, Wastes, Adhesives, Pyrolysis

15. Waste Tire Composite

FY 1994

DOE Contact: Stuart Natof, (202) 586-2370

$\$ 1,000,000$

Composite Particles, Inc. Contact: Dr. Bernard Bauman, (215) 481-2449

A new process is being developed to activate the surface of finely ground waste tire rubber using chlorine. The surface-treated ground waste tire rubber can be used by molders to make new composites with cost savings and/or improved properties. This use of waste tires can result in a net savings of 80,000 BTUs per pound of tire rubber, as a result of displacing relatively energy intensive virgin materials.

Keywords: Tires, Composites, Surface Activation

16. Silicon Oxide Recovery-Conversion

FY 1994

DOE Contact: Bruce Cranford, (202) 586-9496

Dow Corning Contact: James May, (517) 496-6047

A new process is being developed to economically capture waste SiO emitted from conventional silicon production furnaces and return the SiO to the furnace to increase the conversion of $\mathrm{SiO}_{2}$ to $\mathrm{Si}$ metal. The $\mathrm{CO}$ emitted is also utilized for methanol production to improve the energy efficiency of the process. The process has been demonstrated at the pilot scale.

Keywords: Silicon Oxide, Waste Recovery, Waste Conversion 


\section{Bioconversion of Food Wastes to Lactic Acid}

DOE Contact: Merrill Smith, (202) 586-3646

ANL has been developing processes and products for the conversion of starchy waste to lactic acid and its derivative products. The primary focus of the program has been to develop rationale and integrated processes and products that can potentially result in energy savings by utilization of waste carbohydrates. Various uses for lactic acid have been investigated. The possibilities include biodegradable lactide polymers.

Keywords: Biodegradable, Starch, Lactic Acid, Lactide Plastic, Fertilizer, Mulch, Irrigation, Propylene Glycol

\section{Solar Materials Research}

The objective of solar materials research is to identify and develop viable materials processes that take advantage of the attributes of highly concentrated solar fluxes. Concentrated sunlight from solar furnaces can generate temperatures well over $2000^{\circ} \mathrm{C}$. Thin layers of the illuminated surfaces can be driven to very high temperatures in fractions of a second. Concentrated solar energy can be delivered over very large areas, allowing for rapid processing. The result is more efficient use of bulk materials and energy, potentially lower processing costs, and reduced need for strategic materials, all with a technology that does not damage the environment. Also being developed are catalysts for processes that use the sun's energy to destroy hazardous organic chemicals.

\section{Materials Preparation, Synthesis, Deposition, Growth or Forming}

\section{Photocatalysts Based on Titanium Dioxide}

FY 1994 $\$ 250,000$

DOE Contact: Frank Wilkins, (202) 586-1684

NREL Contact: Daniel M. Blake, (303) 275-3702

The objectives of this work are to develop materials that are more active photocatalysts for the oxidation of organic compounds in air or aqueous phases, determine the characteristics of titanium dioxide and modified forms that influence the activity, and test the catalysts in laboratory and pilot scale reaction systems. The ultimate goal is to make photocatalytic oxidation processes for removal of hazardous organic compounds from contaminated air and water a cost-effective treatment option. Potential catalysts are prepared by NREL, subcontractors, or obtained from commercial sources.

Keywords: Photocatalyst, Titanium Dioxide, Oxidation 
19. Solar Materials Processing

FY 1994

$\$ 550,000$

DOE Contact: Frank Wilkins, (202) 586-1684

NREL Contact: Allan Lewandowski, (303) 275-3672

The objective of this project is to develop an alternative method of processing various advanced materials using concentrated sunlight as the energy source. A number of processes have been explored including metalorganic deposition of thin films on ceramics, synthesis, production and processing of advanced ceramic powders, solar assisted chemical vapor deposition of thin films on various substrates, rapid thermal heat treating and cladding, solar production of Fullerenes, and other surface modification techniques. The project seeks to explore a wide range of technologies, assess those with commercial potential and develop the most promising technologies in conjunction with industry. Several technologies have demonstrated significant technical success and are now being explored more fully through Cooperative Research and Development Agreements.

Keywords: Solar Processing, Advanced Materials, Ceramics, Metallization, Fullerenes, Cladding, Concentrated Sunlight, Solar Furnaces

Office of Industrial Processes

\section{Advanced Industrial Materials Program}

The Advanced Industrial Materials program mission is to unite National Laboratory/ industry/university teams to commercialize materials to strengthen the competitive position of U.S. industry and save energy. The program works with materials suppliers, manufacturers and end users to identify opportunities for improving system efficiencies and product quality, and increasing service lives with the implementation of new materials. The Advanced Industrial Materials program has research efforts in four areas: Intermetallic and Metallic Alloys, Ceramics - Composites and Coatings, Ceramics - Microwave Processing, and Innovative Materials - Materials and Processing. The Program Manager is Charles A. Sorrell, (202) 586-1514.

\section{Materials Preparation, Synthesis, Deposition, Growth or Forming}

20. Advanced Methods for Processing Ceramics

FY 1994

$\$ 60,000$

DOE Contact: Charles A. Sorrell, (202) 586-1514

Georgia Institute of Technology Contact: W. B. Carter and J. K. Cochran, (404) 894-6762

Advanced methods for processing ceramic materials, such as Combustion Chemical Vapor Deposition and Rapid Polymerization of Aqueous Slurries are providing potential 
solutions for improved thermal insulation and thermal barrier coatings. Combustion chemical vapor deposition (CCVD) is a chemical vapor deposition (CVD) process that is performed in the open atmosphere without the use of a reaction chamber. The CCVD of ceramic oxide and some metal coatings involves the dissolution of reagents containing the metallic constituents of the coatings in a flammable, organic solvent. The resulting solution is burned in the open air, either in a diffusion flame or a premixed flame. Deposition will occur on the back sides (away from the flame) of substrates as well as on the front side of the substrate. Rapid Polymerization of Aqueous Slurries is a process to form polycrystalline fibers from polymerized aqueous solution. Results have demonstrated the deposition of several materials via CCVD including $\mathrm{YSZ}, \mathrm{SiO}_{2}, \mathrm{BaTiO}_{3}$, and yttrium iron garnet.

Keywords: Combustion Chemical Vapor Deposition, Coatings, Ceramic Fibers

21. Synthesis and Design of Intermetallic Materials

FY 1994

DOE Contact: Charles A. Sorrell, (202) 586-1514

$\$ 490,000$

Los Alamos National Laboratory Contacts: J. J. Petrovic, (505) 667-0125 and A. D. Rollett, (505) 667-6133

The objective of this project is to develop $\mathrm{MoSi}_{2}$-based composites that will combine good room temperature fracture toughness with excellent oxidation resistance and hightemperature strength for industrial applications. Plasma spraying has proved to be very successful for fabricating $\mathrm{MoSi}_{2}$-based gas burner nozzles. In addition, development of laminated composites of $\mathrm{MoSi}_{2}$ with $\mathrm{Al}_{2} \mathrm{O}_{3}$ interlayers has shown promising results for advanced burner nozzles. A new development has been in the synthesis of $\mathrm{Si}_{3} \mathrm{~N}_{4}-\mathrm{MoSi}_{2}$ composites where the minority silicide phase provides conductivity for electro-discharge machining and ductile reinforcement at high temperatures. Future efforts will focus on developing microstructurally realistic models of toughening for materials with combined reinforcements such as $\mathrm{SrO}_{2}$ and $\mathrm{SiC}$ and fabricating novel composites with silicides.

Keywords: Composites, Intermetallics, Toughening, Micro-mechanical Modeling

22. Development of Weldable, Corrosion Resistant Iron-Aluminide Alloys

FY 1994

$\$ 180,000$

DOE Contact: Charles A. Sorrell, (202) 586-1514

ORNL Contact: G. M. Goodwin, (615) 574-4809 and P. J. Maziasz, (615) 574-5082

Iron-aluminides show excellent corrosion/oxidation resistance to at least $1100^{\circ} \mathrm{C}$. Alloying has shown to considerably improve room-temperature ductility and hightemperature tensile and creep strength relative to binary alloy systems. The objectives of this project are to complete alloy development efforts to maximize weldability and properties improvements in $\mathrm{FeAl}$ alloys for structural applications, and to develop the 
potential for weldable $\mathrm{FeAl}$ alloys for use in weld-overlay cladding applications. Several new modifications of the FeAl/FA-385 base alloys compositions were found to have good weldability and mechanical behavior. These $\mathrm{FeAl}$ alloys are nearly as weldable as 300 series austenitic stainless steels. Weld-clad deposits of these weldable FeAl alloys have been made into type 30L austenitic stainless and 21/4 $\mathrm{Cr}-1$ Mo bainitic/martensitic steel substrates, and with proper preheat and post-weld heat treatments. Such weld-deposits are crack-free.

Keywords: Iron Aluminides, Coatings, Claddings, Thermophysical Properties

23. Composites Through Reactive Metal Infiltration

FY 1994

$\$ 325,000$

DOE Contact: Charles A. Sorrell, (202) 586-1514

Sandia National Laboratories Contact: R. E. Loehman, (505) 844-2222

Ceramic-metal composites have advantages as engineering materials because of their high stiffness-to-weight ratios, good fracture toughness, and because their electrical and thermal properties can be varied through control of their composition and microstructure. However, broader commercial application of these materials requires improvements in synthesis and processing so that high-performance parts can be produced more economically. Reactive metal infiltration is a promising new route to synthesize and process a wide range of ceramic and metal-matrix composites to near-net-shape with control of both composition and microstructure. Efforts have focused on determining the kinetics of infiltration of $\mathrm{Al}$ into dense mullite as well as identifying other metal-ceramic systems for potential reactive metal infiltration processing. Measured properties of composites and found significantly improved toughness with little loss in stiffness compared with the ceramic preform.

Keywords: Metal Matrix Composites, Reactive Metal Infiltration, Ceramics

24. Magnetic Field Processing of Inorganic Polymers

FY 1994 $\$ 225,000$

DOE Contact: Charles A. Sorrell, (202) 586-1514

Idaho National Engineering Laboratory Contact: D. C. Kunerth, (208) 526-0103

The application of magnetic fields during processing has been shown to modify the physical and chemical properties of inorganic polymers. The objective of this project is to develop the technical basis for improving the physical properties of inorganic polymers using electromagnetic fields. Current efforts focus on developing a basic understanding of magnetic field processing of polyphosphazene materials to be utilized as chemical separation membranes. The physical and chemical properties of the polyphosphazene polymers have 
been modified using magnetic fields. Results show that membrane morphologies and transport properties change with the application of magnetic fields; providing a small amount of molecular texturing. In addition, processing techniques as simple as DC magnetic fields developed by permanent magnets or microwave fields can be used.

Keywords: Polymers, Magnetic Field Processing

25. Development of New Composite Aerogel Materials

FY 1994

$\$ 275,000$

DOE Contact: Charles A. Sorrell, (202) 586-1514

Lawrence Berkeley Laboratory Contact: A. Hunt, (415) 486-5370

Aerogel materials are porous, low density, nanostructured solids with many unique properties including very low thermal conductivity, transparency, high surface area, and low sound velocity. The objective of this project is to develop new aerogel-based composites materials through sol-gel chemistry, supercritical drying, and chemical vapor infiltration. An infrared opacified silica aerogel was produced using chemical vapor infiltration methods that displayed improved thermal and physical properties. This provides higher temperature and stronger aerogel thermal insulation. The process was generalized to produce a wide variety of new composite materials. Some of these composites displayed unusual characteristics (e.g., photo-luminescence in silicon silica cornposites) due to quantum confinement effects.

Keywords: Thermal Insulation, Sol-Gel, Aerogels

26. Microwave Processing of Continuous Ceramic Oxide Filaments

FY 1994

$\$ 350,000$

DOE Contact: Charles A. Sorrell, (202) 586-1514

Los Alamos National Laboratory Contact: G. J. Vogt and J. D. Katz, (505) 665-1424

The objective of this research is to develop economic microwave processing technology for the complete manufacturing of continuous ceramic oxide filament tows from extruded solution-based gels with greater energy efficiency than conventional thermal processing. The approach is to use volumetric microwave absorption to heat ceramic oxide tows in order to drive the process drying, prefiring, and sintering in the preparation of continuous tows from solution-based gels. Microwave heating of filament tows was successfully controlled by pulse modulation of a magnetron source and by active feedback control of the pulse rate and frequency through an optical feedback sensor. Future efforts will focus on developing microwave techniques for drying, organic burnout, and sintering of sol-gel filament tows. The energy efficiency and economics of microwave processing will be directly compared to those of conventional thermal processing.

Keywords: Microwave Processing, Filaments 
27. Conducting Polymers: Synthesis and Industrial Applications

FY 1994

$\$ 325,000$

DOE Contact: Charles A. Sorrell, (202) 586-1514

Los Alamos National Laboratory Contact: S. Gottesfeld, (505) 667-0853

The process of separating pure components out of a mixture of gases is of great industrial importance. Current gas separation technologies have major shortcomings, including poor energy efficiency and the generation of secondary pollution. The objective of this project is to (1) demonstrate new conducting polymer materials for electrochemical capacitors and (2) establish new activity on conducting polymer membranes for gas separation. Current efforts are devoted to developing and characterizing electronically conducting polymers, with eventual goal of demonstrating the technology at the semiindustrial level. In addition, the high solubility of oxygen was measured in the polyaniline membranes and identified it as an important element of the exceptionally high $\mathrm{O}_{2} / \mathrm{N}_{2}$ separation factors achieved with polyaniline membranes.

Keywords: Electrically Conducting Polymers, Gas Separation, Capacitors

28. Microwave Assisted Chemical Vapor Infiltration

FY 1994 $\$ 270,000$

DOE Contact: Charles A. Sorrell, (202) 586-1514

Los Alamos National Laboratory: D. J. Devlin, (505) 667-9914

The use of microwave heating of ceramic fiber preforms is being explored as a means of developing an improved rapid process for the fabrication of composites by chemical vapor infiltration. The volumetric and preferential heating of certain materials by microwaves provides a means of establishing inverted thermal gradients in a preform. The result is the ability to rapidly infiltrate the preform developing the matrix from the inside-out. Using this technique, silicon carbide reinforced silicon-nitride composites have been fabricated. Future efforts will optimize processing to achieve sufficient density for mechanical testing of the composites.

Keywords: Microwave Processing, Chemical Vapor Infiltration, Ceramics, Composites

29. High Deposition Rate Ceramic Synthesis

FY 1994 $\$ 325,000$

DOE Contact: Charles A. Sorrell, (202) 586-1514

Sandia National Laboratories Contact: M. D. Allendorf, (415) 294-2895

Comprehensive models, including detailed gas-phase and surface chemistry coupled with reactor fluid mechanics, are required to optimize and scale-up chemical vapor deposition (CVD) processes. The objective of this project is to develop predictive 
computational models and other tools for designing, optimizing, and operating new ceramic processing technologies. Current efforts are focused on (1) deposition of silicon carbide from methyltrichorosilane, and (2) a flame-spray process for the formation of metal-ceramic and metal-polymer wear-resistant coatings. Future efforts will continue to focus on SiC deposition from chlorinated organosilanes. Results of this research should permit rapid and efficient development of new materials synthesis reactors.

Keywords: Chemical Vapor Deposition, Gas-Phase Chemistry, Modeling

Materials Properties, Behavior, Characterization or Testing

30. Three Dimensional X-ray Tomography of Crack-Resistant Composites

FY 1994 $\$ 200,000$

DOE Contact: Charles A. Sorrell, (202) 586-1514

LLNL Contact: J. H. Kinney, (415) 243-6669

Densification mechanisms in chemical vapor infiltrated (CVI) ceramic matrix composites need to be better understood if porosity is to be controlled and minimized. $\mathrm{X}$-ray tomographic microscopy (XTM) is a new technique for nondestructively imaging materials microstructures in three dimensions. The microporosity between individual filaments in the fiber bundles, the channel porosity between individual cloth layers, and the connectivity of the large through-ply holes that remain after processing can all be examined without destroying the sample. Currently a high resolution, three-dimensional tomography system has been used to quantify microstructural evolution in continuous filament composites during chemical vapor infiltration processing. Microstructural parameters such as the amount of fiber tow consolidation and changes in surface area provide information which is essential for validating process models.

Keywords: X-ray, Tomography, Composites

31. Characterization of Three-Way Automotive Catalysts

FY 1994

DOE Contact: Charles A. Sorrell, (202) 586-1514

$\$ 300,000$

ORNL Contact: E. A. Kenik, (615) 574-5066

General Motors-AC Rochester Division Contact: W. LaBarge, (313) 257-0875

Platinum-rhodium based three-way-catalysts (TWC) currently meet the required emissions standards; however, higher than optimum Pt-Rh loadings are often required to meet lifetime requirements. Understanding the changes of the TWC conversion efficiency with aging is a critical need in improving the catalysts. The objective of this project is to critically evaluate catalytic materials in as-produced and aged conditions and correlate materials and systems development to improve catalyst performance and lifetime while 
decreasing emissions. Current efforts focus on characterizing the microstructural and chemical state of both noble metals and substrates in as-produced catalyst materials with a wide range of spectroscopy and analysis techniques.

Keywords: Automotive Catalysts, Surface Analytical Analysis, Light and Electron Optical Analysis

\section{Materials Structure and Composition}

32. High-Temperature Precipitate-Strengthened Iron-Aluminide Alloys

FY 1994

DOE Contact: Charles A. Sorrell; (202) 586-1514

$\$ 260,000$

ORNL Contact: P. J. Maziasz, (615) 574-5082

FeAl-type iron-aluminide alloys have outstanding oxidation at $>1000^{\circ} \mathrm{C}$, but lack strength at $600^{\circ} \mathrm{C}$ and above, and many lack weldability. The objective of this project is to explore precipitate-strengthening effects for improved high temperature strength while also improving weldability in various intermetallic alloys, starting with FeAl-type (B2 phase) ironaluminides. New modified FeAl-type alloys have been developed which have better weldability and creep-rupture strength than the base alloys. The modified $\mathrm{FeAl}$ alloys have weldability similar to that of type $\mathbf{3 1 6}$ austenitic stainless steel, and creep-resistance similar to that of type 304 stainless steel.

Keywords: Iron Aluminide, Nickel Aluminides, Physical Properties

33. Metallic and Intermetallic Bonded Ceramic Composites

FY 1994

$\$ 430,000$

DOE Contact: Charles A. Sorrell, (202) 586-1514

ORNL Contacts: T. N. Tiegs and K. B. Alexander, (615) 574-0631

Lawrence Berkeley Laboratory Contact: R. O. Ritchie, (415) 642-0417

To improve the reliability of ceramic components, new approaches to increasing the fracture toughness of ceramics over an extended temperature range are needed. One method is the incorporation of ductile phases into ceramic matrix alloys for local plastic deformation during crack bridging processes. This deformation acts to dissipate the strain energy introduced by the applied stress, thus increasing the fracture toughness of the composite. This objective of this program is to develop ceramic composites with high fracture toughness for intermediate temperature use in wear, tribological and engine applications. Results have shown that nickel aluminide additions have been shown to be an effective toughening agent in ceramic matrices if the microstructural distribution is carefully controlled. The microstructural features yielding optimal toughening have been 
identified and composites have been fabricated with properties comparable to, or better than, commercial ceramic composites at a lower raw material cost.

Keywords: Ceramics, Composites, Nickel Aluminide

34. Advanced Ordered Intermetallic Alloy Development

FY 1994

DOE Contact: Charles A. Sorrell, (202) 586-1514

$\$ 165,000$

ORNL Contact: C. T. Liu, (615) 574-4459

Many ordered intermetallics possess unique properties and have the potential to be developed as new materials for energy related applications. The objective of this project is to develop low-density, high-strength ordered intermetallic alloys for high-temperature structural use in advanced heat engines, energy conversion systems, and other industrial systems. Current efforts are focused on (1) the development of $\mathrm{NiAl}$ and $\mathrm{TiAl}$ alloys, (2) shape memory alloys based on $\mathrm{NiAl} / \mathrm{Ni}_{3} \mathrm{Al}$ compositions, (3) $\mathrm{Ni}_{3} \mathrm{Si}$ alloys, and (4) reaction synthesis of $\mathrm{NiAl}$ and $\mathrm{Ni}_{3} \mathrm{Al}$ alloys. Evaluations of the microstructure, mechanical properties of the cast $\mathrm{NiAl}$ alloys in different environments have been completed. Chromium additions substantially reduce the air oxidation rate of $\mathrm{Ni}-19 \% \mathrm{Si}$ alloy at temperatures below $800^{\circ} \mathrm{C}$ but not above that temperature. Shape-memory alloys based on Ni-Al-Fe-B have been prepared by both conventional and innovative methods. The materials prepared by both methods show thermally activated shape-memory effects at temperatures close to $200^{\circ} \mathrm{C}$.

Keywords: Intermetallics, Ordered Alloys, Shape Memory Alloys

\section{Superior Metallic Alloys Through Rapid Solidification Processing by Design}

FY 1994

$\$ 225,000$

DOE Contact: Charles A. Sorrell, (202) 586-1514

Idaho National Engineering Laboratory Contact: J. E. Flinn, (208) 526-8127

The industrial sector requires metallic alloys whose properties, performance, and reliability extend beyond those obtained from current processing practices. These needs can be fulfilled by metallic alloys that have fine and stable (to high temperatures) microstructures. Rapid solidification processing (RSP) by design can fulfill these need through control of alloy chemistry and powder processing parameters. Significant improvements have been observed for RSP 304 SS, A286, and 718 alloys compared to their ingot metallurgy counterparts. A nickel-base alloy has been designed for the RSP approach using the knowledge from the research findings and input from the industrial sector. In addition, four Cooperative Research and Development Agreements (CRADAs) have been signed to compare the microstructure, properties and performance limits of selected alloys/ 
materials currently being used with those obtained by RSP. These materials are for high temperature electrical, corrosion and wear, and photovoltaic applications.

Keywords: Rapid Solidification, Alloys, High Temperature Microstructure

36. Polymerization and Processing of Organic Polymers in a Magnetic Field

FY 1994

$\$ 300,000$

DOE Contact: Charles A. Sorrell, (202) 586-1514

Los Alamos National Laboratory Contacts: N. E. Elliott, (505) 667-1587, R. K. Jahn, (505) 665-1751 and R. Liepins, (505) 667-2656

The purpose of this project is to demonstrate the utility of magnetic fields, to beneficially modify or control the physical, optical and electrical properties of materials through the application of magnetic fields during polymerization processing and solidification. Current efforts are focused on polysilanes processed by the magnetic field/shear technique: Of the five novel high molecular weight polysilanes processed on a polysiloxane substrate, samples with unusual infrared and mechanical properties were generated. For the formation of composites, the use of a $4.2 \mathrm{~T}$ field was sufficient to orient graphite fibrils in space. A proof-of-principle was demonstrated for 3-D composite formation.

Keywords: Organic Polymers, Magnetic Processing, Mechanical Properties

37. Microwave Joining of $\mathrm{SiC}$

FY 1994

DOE Contact: Charles A. Sorrell, (202) 586-1514

$\$ 80,000$

LANL Contact: Joel D. Katz, (505) 665-1424

FM Technologies, Inc. Contact: R. Silberglitt, (703) 425-5111

George Mason University Contact: W. Murray Black, (703) 993-4069

The objective of this project is to develop and optimize a joining method that can be applied to large scale fabrication of components such as radiant burner tubes and high temperature, high pressure heat exchangers. Microwave joining of both reaction bonded silicon carbide and sintered silicon carbide was successful and a feasibility demonstration for the reaction bonded silicon carbide and sintered silicon carbide tube assemblies was performed. Leak-tight behavior was demonstrated before and after cycling between ambient temperature and $1100^{\circ} \mathrm{C}$. The joined reaction bonded silicon carbide tube sections have average mechanical strength of $190 \mathrm{MPa}$, which is more than adequate for radiant burner and heat exchanger applications.

Keywords: Microwave Processing, Microwave Joining, SiC 
38. Microwave Processing of Materials: Glass-Ceramics

FY 1994

$\$ 85,000$

DOE Contact: Charles A. Sorrell, (202) 586-1514

ORNL Contact: M. A. Janney, (615) 576-5183

Microwave heating represents an emerging technology for high temperature processing of materials. The objective of this research is to provide clear engineering guidelines for using microwave processing in an industrial environment for high temperature applications. Results of this investigation so far indicate that microwave processing lowers the processing temperature for a zirconia-toughened alumina glass ceramic by approximately $100-150^{\circ} \mathrm{C}$. Future investigations will focus on including compositions that sinter as glasses and convert to the crystalline state.

Keywords: Microwave Processing, Sintering, Zirconia-Toughened Alumina

\section{Characterization of CVI Densification of Ceramic Composites}

FY 1994 $\$ 120,000$

DOE Contact: Charles A. Sorrell, (202) 586-1514

Georgia Institute of Technology Contact: Tom Starr, (404) 583-0579 and S. R. Stock, (404) 894-6882

The objective of this research is to understand the relationship between preform fiber architecture and densification behavior to design preforms for optimum infiltration. In collaboration with Lawrence Livermore National Laboratory, high resolution X-ray tomography will be used to observe the deposition of matrix materials in the pores of ceramic fiber preforms at various stages of the chemical infiltration process (CVI). These observations will relate local deposition rates in various regions of the composite to the surrounding network of porosity and will aid in developing a better model between gas transport and fiber architecture in CVI preforms.

Keywords: Chemical Vapor Infiltration, Ceramic Composites, Preforms

40. Biomimetic Thin Film Synthesis

FY 1994

$\$ 325,000$

DOE Contact: Charles A. Sorrell, (202) 586-1514

Pacific Northwest Laboratory Contact: G. L. Graff, (509) 375-6786

The objective of this project is to adapt the features of mineralization processes used by bioorganisms to the development of materials with improved properties over conventionally processed materials and demonstrate industrial relevance of biomimetics thin film processing for industrial coatings. Calcium phosphate films have been deposited on $\mathrm{Ti}$ metal bone implants coated with self-assembled monolayers. Use of solution techniques to 
develop oriented, fully dense films of magnetite have been successful. Solution complexation methods have been used to grow thick tin oxide coatings on plastics under mild $\mathrm{pH}$ conditions. Impermeable HDPE/Al/HDPE sandwich composite has been produced using cup drawing techniques. Future efforts will explore the potential for biomimetic processing in biomedical applications and in high-value-added products or industries such as microelectronics where the pattering advantage of biomimetics can be exploited.

Keywords: Biomimetic, Organic Interfaces, Ceramic Coatings

41. Chemical Recycling of Plastics

FY 1994

$\$ 300,000$

DOE Contact: Charles A. Sorrell, (202) 586-1514

National Renewable Energy Laboratory Contact: R. J. Evans, (303) 231-1384

The goal of this project is to identify conditions for the production of high-value chemicals from mixtures of waste plastics by the use of selective pyrolysis. Sorting the feed and purifying the products are minimized by controlling reaction conditions so that target products can be collected in high yields. Control is achieved by taking advantage of differences in reaction rates, catalysis, and co-reactants. Target waste streams are postconsumer wastes that can range from commodity plastics to high-value engineering blends. Efforts are focused on increasing the yield and purity of the monomer, caprolactam, from nylon 6 carpet. In other applications, the conversion of poly(ethylene terephthalate) (PET) to its monomer, dimethyl terephthalate has expanded from mixed plastic bottle wastes to polyester fiber textile blends. Also, the intelligent chemical processing system has demonstrated quantitative and qualitative ability to analyze carpet mixtures.

Keywords: Plastics Recycling, Pyrolysis, Waste Streams

42. Composites and Blends from Biobased Materials

FY 1994

$\$ 300,000$

DOE Contact: Charles A. Sorrell, (202) 586-1514

National Renewable Energy Laboratory Contact: S. S. Kelley and S. S. Shojaie, (303) 384-6123

The program is focused on the development of composites and blends from biobased materials for use as membranes, high-value plastics, and lightweight composites. Biobased materials include novel cellulose derivatives, wood modified with synthetic monomers, and wood fiber/synthetic plastic composites. Research efforts have focused on two areas: (1) composites and blends from cellulose derivatives, and (2) wood reinforced with synthetic monomers. The program is designed to evaluate the thermal, mechanical, and permeselective properties of these materials and relate their performance to the chemical structure and 
morphology of the composites or blends. Current efforts are focused on utilizing cellulose esters to prepare novel composites and blends. These materials have improved permeselective and/or compaction properties relative to unmodified cellulose esters.

Keywords: Biobased Materials, Composites, Thermomechanical Testing

\section{Device or Component Fabrication, Behavior or Testing}

43. $\mathrm{Ni}_{3} \mathrm{Al}$ Technology Transfer

FY 1994

$\$ 750,000$

DOE Contact: Charles A. Sorrell, (202) 586-1514

ORNL Contacts: M. L. Santella, (615) 574-4805 and V. K. Sikka, (615) 574-5112

Ductile $\mathrm{Ni}_{3} \mathrm{Al}$ and $\mathrm{Ni}_{3} \mathrm{Al}$-based alloys have been identified for a range of applications. Although significant progress has been made in the melting, casting and near-net-shape forming of nickel aluminides, some issues still remain including the need for (1) highstrength, castable composition for turbochargers, furnace furniture, and hot-die applications; (2) castability (fluidity, hot-shortness, porosity, etc.); (3) weld repairability of castings; and (4) hot fabricability of cast ingots. The objective of this research is to mature the $\mathrm{Ni}_{3} \mathrm{Al}$ and the $\mathrm{Ni}_{3} \mathrm{Al}$-based alloy technology for industrial application and commercial manufacturing, and to commercialize the $\mathrm{Ni}_{3} \mathrm{Al}$ and the $\mathrm{Ni}_{3} \mathrm{Al}$-based alloys. Significant progress was made in the maturation of nickel aluminide technology and applications including (1) the development of a new alloy for Cummins Engine Company and PCC Airfoils, Inc.; (2) the development of roller assembly for Bethlehem Steel; and (3) the transfer of welding technology to Sandusky International. Future efforts will focus on (1) optimizing alloy composition and process parameters for sand and investment castings of $\mathrm{Ni}_{3} \mathrm{Al}$-based alloys; (2) developing methods for fabricating weld wire and producing weld components; (3) developing fracture toughness and other mechanical property data on prototype components and (4) continuing technology transfer activities.

Keywords: Nickel Aluminides, Processing, Mechanical Properties

44. Advanced Microwave Processing Concepts

FY 1994

$\$ 240,000$

DOE Contact: Charles A. Sorrell, (202) 586-1514

ORNL Contact: R. J. Lauf and H. D. Kimrey, (615) 574-5176

The purpose of this project is to explore the feasibility of several advanced microwave processing concepts to develop new energy-efficient materials and processes as well as to reduce consumption of strategic metals. The project includes three tasks: (1) microwave sintering of multilayer ceramic capacitors; (2) commercialization of the variable frequency 
microwave furnace; and (3) microwave curing of polymer composites. Efforts to date have shown uniform curing of neat resin samples with no evidence of overheating.

Keywords: Microwave Processing, Multilayer Capacitors, Polymers, Composites, Variable Frequency

45. Selective Inorganic Thin Films

FY 1994

$\$ 425,000$

DOE Contact: Charles A. Sorrell, (202) 586-1514

Sandia National Laboratories contact: Mark Phillips, (505) 844-8969

The purpose of this research is to develop a new class of inorganic membranes for light gas separation and use this technology to improve on separation efficiencies currently available with polymer membranes, particularly for light alkanes. The approach is to nucleate and crystallize zeothlitic phases from sol-gel derived amorphous coatings, using porous filters and gas membranes as supports for these films. Current efforts have focused on controlling porosity in several oxide film compositions. These films have been deposited on quartz acoustic plate mode devices. Zeolite films and composite films of zeolites embedded in amorphous matrices have also been synthesized. Future efforts include utilizing nonaluminosilicate molecular sieves as membranes as well as exploring other sources of nutrient for zeolitic film crystallization.

Keywords: Coatings, Sol-Gel Processing

46. Chemical Vapor Infiltration of $\mathrm{TiB}_{2}$ Composites

FY 1994

$\$ 160,000$

DOE Contact: Charles A. Sorrell, (202) 586-1514

Oak Ridge National Laboratory Contact: T. Besmann, (615) 574-6852

This program is designed to develop a Hall-Heroult aluminum smelting cathode with substantially improved properties. The carbon cathodes in current use require significant anode-to-cathode spacing in order to prevent shorting, causing significant electrode inefficiencies. A fiber reinforced- $\mathrm{TiB}_{2}$ matrix composite would have the requisite wettability, strength, strain-to-failure, cost, and lifetime to solve this problem. The approach is to fabricate a cathode material through chemical vapor infiltration (CVI). Current efforts are focused on preparing specimens for the licensee, Advanced Innovative Technologies, Inc., and for testing at Alcoa Technical Center. The results were promising in that aluminum was produced and did flow, albeit not uniformly.

Keywords: Chemical Vapor Infiltration, Composites, Hall-Heroult Cell 


\section{OFFICE OF TRANSPORTATION TECHNOLOGIES}

FY 1994

Office of Transportation Technologies - Grand Total

$\$ 31,935,000$

Office of Transportation Materials

$\$ 18,233,000$

Materials Preparation, Synthesis, Deposition, Growth or Forming

Powder Characterization (WBS No. 1118)

Microwave Sintering (WBS No. 1124)

Cost Effective Silicon Nitride Powder (WBS No. 1125)

Cost Effective Sintering of Silicon Nitride

Ceramics (WBS No. 1127)

Cost Effective Manufacture of Silicon Nitride

Components (WBS No. 1128)

Advanced Processing (WBS No. 1141)

Improved Processing (WBS No. 1142)

Processing of Silicon Based Ceramics (WBS No. 1225)

In-Situ Toughened Silicon Nitride (WBS No.1226)

Dispersion Toughened Oxide Composites (WBS No. 1231)

Low Thermal Expansion Ceramics (WBS No. 1243)

NZP Components (WBS No. 1245)

Low Cost Aluminum Titanate/NZP Ceramics (WBS No. 1246)

Advanced Manufacturing (WBS No. 1520)

Advanced Ceramic Manufacturing (WBS No. 1521)

Advanced Ceramic Manufacturing (WBS No. 1522)

$\$ 8,224,000$

110,000

400,000

920,000

462,000

1,000

650,000

288,000

300,000

350,000

100,000

541,000

247,000

397,000

$1,779,000$

$1,679,000$

$\$ 3,963,000$

Materials Properties, Behavior, Characterization or Testing

Development of Standard Test Methods for

Evaluating the Wear Performance of Ceramics (WBS No. 2222)

Advanced Statistics Calculations (WBS No. 2313)

Microstructural Analysis (WBS No. 3111)

Microstructural Characterization of Silicon Carbide and

Silicon Nitride Ceramics for Advanced Heat Engines

(WBS No. 3114)

Project Data Base (WBS No. 3117)

Fracture Behavior of Toughened Ceramics (WBS No. 3213)
30,000
100,000
50,000

200,000
240,000
290,000 
OFFICE OF TRANSPORTATION TECHNOLOGIES

FY 1994

Office of Transportation Materials (continued)

Materials Properties, Behavior, Characterization or Testing (continued)

Cyclic Fatigue of Toughened Ceramics (WBS No. 3214)

Tensile Stress Rupture Development (WBS No. 3215)

Life Prediction Verification (WBS No. 3216)

Toughened Ceramics Life Prediction (WBS No. 3217)

Life Prediction Methodology (WBS No. 3222)

Life Prediction Methodology (WBS No. 3223)

Environmental Effects in Toughened Ceramics (WBS No. 3314)

High Temperature Tensile Testing (WBS No. 3412)

Standard Tensile Test Development (WBS No. 3413)

Non-Destructive Evaluation (WBS No. 3511)

Computed Tomography (WBS No. 3515)

Nuclear Magnetic Resonance (NMR) Imaging (WBS No. 3516)

Assessment of Magnesium for Automotive Applications

220,000

300,000

200,000

200,000

600,000

383,000

250,000

125,000

460,000

120,000

80,000

115,000

Technology Transfer and Management Coordination

$\$ 1,400,000$

Management and Coordination (WBS No. 111)

International Exchange Agreement (IEA) (WBS No. 4115)

Standard Reference Materials (WBS No. 4116)

Mechanical Property Standardization (WBS No. 4121)

950,000

200,000

150,000

100,000

Device or Component Fabrication. Behavior or Testing

$\$ 4,646,000$

Advanced Coating Technology (WBS No. 1311)

175,000

Coatings to Reduce Contact Stress Damage of

28,000

Ceramics (WBS No. 1313)

46,000

Wear Resistant Coatings (WBS No. 1331)

Thick Thermal Barrier Coating Systems for Low Heat

Rejection Diesel Engines (WBS No. 1342) 
OFFICE OF TRANSPORTATION TECHNOLOGIES

FY 1994

Office of Transportation Materials (continued)

Device or Component Fabrication. Behavior or Testing (continued)

Active Metal Brazing PSZ-Iron (WIBS No. 1411)

Surface Durability of Machined Ceramics (WBS No. 1500)

Next-Generation Grinding Wheel (WBS No. 1501)

220,000

200,000

Grindability Test (WBS No. 1502)

Chemically Assisted Grinding of Ceramics (WBS No. 1503)

Grinding Consortium (WBS No. 1503)

High Speed Grinding (WBS No. 1504)

Laser-Based NDE Methods (WBS No. 1507)

Development of "Smart" Grinding Wheel (WBS No. 1510)

Automotive Materials Development

Ultracapacitors for Electric and Hybrid Vehicles

150,000

150,000

372,000

180,000

50,000

$3,000,000$

75,000

Office of Propulsion Systems

$\$ 12,977,000$

Advanced Propulsion Division

$\$ 7,998,000$

Materials Properties, Behavior, Characterization or Testing

Advanced Turbine Supporting Research and Technology

$\$ 250,000$

250,000

Device or Component Fabrication. Behavior or Testing

$\$ 7,748,000$

Hybrid Vehicle Turbine Engine (HVTE) Technology Support

$3,725,000$

Ceramic Turbine (CT) Engine Demonstration Project

Advanced Diesel Engine Component Development Project

Advanced Piston and Cylinder Component Development

$2,873,000$

250,000

Advanced Piston and Cylinder Component Development

300,000

600,000 


\section{OFFICE OF TRANSPORTATION TECHNOLOGIES}

FY 1994

Office of Propulsion Systems (continued)

Electric and Hybrid Propulsion Division

$\$ 4,979,000$

Materials Preparation. Synthesis, Deposition. Growth

or Forming

$\$ 1,200,000$

Electrochemical Properties of Solid-State Sodium Polymer Cells

Corrosion Resistant Coatings for High-Temperature

High-Sulfur-Activity Applications

Improved Container Electrode Coatings for Sodium/Sulfur

Battery Systems

The Performance of New Materials for Polymer Electrolyte Batteries

Novel Polymer Electrolytes for Rechargeable Lithium

Batteries

Novel Solid Polymer Electrolytes for Advanced Secondary Batteries

Sol-Gel Electrolytes in Lithium Batteries

New Cathode Materials

Development of High Energy Density Cathodes for Sodium/Polymer Cells

260,000

100,000

140,000

160,000

130,000

130,000

110,000

170,000

Materials Properties, Behavior, Characterization or Testing

$\$ 2,675,000$

Surface Morphology of Metals in Electrodeposition/

Carbon Electrochemistry

Battery Materials Structure and Characterization

In Situ Spectroscopic Applications to the Study of

Rechargeable Lithium Batteries

Polymer Electrolyte for Ambient Temperature Traction

Batteries: Molecular Level Modeling for Conductivity

Optimization

160,000

Analysis and Simulation of Electrochemical Systems

240,000

Heat Transport and Thermal Management in Advanced Batteries

160,000

Electrode Surface Layers

125,000 


\section{OFFICE OF TRANSPORTATION TECHNOLOGIES}

FY 1994

Office of Propulsion Systems (continued)

Electric and Hybrid Propulsion Division (continued)

Materials Properties. Behavior. Characterization or Testing (continued)

Electrode Kinetics and Electrocatalysis

Effect of Electrocatalyst and Electrolyte Composition on Methanol/Air Fuel Cell Performance

Poisoning of Fuel Cell Electrocatalyst Surfaces:

NMR Spectroscopic Studies

215,000

Fuel Cells for Renewable Applications

Electrocatalysis of Fuel Cell Reactions

200,000

$1,000,000$

Device or Component Fabrication. Behavior or Testing

$\$ 1,104,000$

$\mathrm{Zn} / \mathrm{NiOOH}$ Cell Studies

250,000

Applied Research on Secondary $\mathrm{Zn} / \mathrm{NiOOH}$ Battery Technology

200,000

Development of a Thin-Film Rechargeable Lithium Battery for Electric Vehicles

$\mathrm{Na}$ /SRPE Electric Vehicle Batteries

150,000

Lithium-Ion Battery Testing

Novel Concepts for an Oxygen Electrode in Secondary Metal-Air Batteries

Office of Alternative Fuels

$\$ 725,000$

Materials Properties, Behavior. Characterization or Testing

$\$ 725,000$

Cold-start Assist Materials

50,000

CNG Adsorbents Demonstration

300,000

Improved Catalyst Materials and Emissions Control Systems

375,000 


\section{OFFICE OF TRANSPORTATION TECHNOLOGIES}

The Office of Transportation Technologies (OTT) seeks to develop, in cooperation with industry, technologies that are more energy-efficient and will enable the transportation sector to shift from near total dependence on petroleum to alternative fuels and electricity. Additional program goals are to increase the supply and availability of nonpetroleum fuels, and minimize the environmental impacts of transportation energy use. The Office of Transportation Technologies consists of the Office of Propulsion Systems, Office of Alternative Fuels, and Office of Transportation Materials, each having responsibility for specific technologies and program areas.

\section{Office of Transportation Materials}

The overall goal of the Materials Technology Program is to develop, in concert with the United States-based industry, an industrial technology base in cost-effective, advanced transportation-related materials and associated processing of these materials. The timely availability of these materials and processing techniques will enable the development of more energy-efficient transportation technologies capable of utilizing alternative fuels and electricity. Research and development activities focus on (a) propulsion system materials (specifically cost-effective ceramics which are critical to the development of more efficient advanced heat engines for transportation propulsion); (b) vehicle system materials (specifically lightweight materials that could aggressively reduce the weight and improve the fuel economy of vehicles without compromise to passenger comfort and safety); and (c) operation of the High Temperature Materials Laboratory.

The primary focus of the Propulsion System Materials Program is the development of reliable, cost effective ceramics to facilitate their commercial introduction in propulsion systems. After an aggressive 10-year effort that clearly demonstrated the feasibility of producing reliable engine components, the program is now focused on reducing the cost of ceramic components and improving their performance. A majority of the research is conducted by industry. The Ceramic Technology Program is managed by the Oak Ridge National Laboratory (ORNL). The DOE contact is Robert Schulz, (202) 586-8051.

The Vehicle System Materials Program is focused on the development of costeffective processing and manufacture of advanced lightweight material components that will, in the near term, continually improve the fuel economy of current production vehicles, and in the long term, allow aggressive weight reductions needed by hybrid and purely electric vehicles. Lightweight materials will be increasingly important in achieving the energy, economic, and environmental goals for the transportation sector. The DOE contact is Sidney Diamond, (202) 586-8032. 
The High Temperature Materials Laboratory (HTML) at the Oak Ridge National Laboratory is a state-of-the-art research and user facility which supports advanced materials research conducted by the Department of Energy, as well as by industry, universities, and other research and development laboratories. The HTML currently includes six user centers (equipped primarily for characterizing materials), namely materials analysis, high temperature mechanical properties, high temperature $\mathrm{x}$-ray diffraction, physical properties, ceramic specimen preparation, and residual stress measurements. A seventh center includes instrumentation for conducting sophisticated research on machining of advanced ceramic materials with the goal of working directly with industrial teams to achieve cost effective manufacturing. The DOE contact is Debbie Haught, (202) 586-2211.

\section{Materials Preparation, Synthesis, Deposition, Growth or Forming}

47. Powder Characterization (WBS No. 1118)

FY 1994

DOE Contact: Robert B. Schulz, (202) 586-8051

$\$ 110,000$

ORNL Contact: D. R. Johnson, (615) 576-6832

NIST Contact: S. Malghan, (301) 975-2000

This effort is directed toward developing a fundamental understanding of surface chemical changes which take place when silicon nitride powder is attrition milled in an aqueous environment. This project also will demonstrate the use of and establish operating conditions for high energy attrition milling of silicon nitride powder. These tasks will be accomplished by developing measurement techniques and data on the effect of milling variables on the resulting powder. It is expected that information gained from this study will serve in the identification and development of appropriate characterization procedures, process control techniques, and in certification of new Standard Reference Materials.

Keywords: Powder Characterization, Powder Processing, Reference Material, Silicon Nitride

48. Microwave Sintering (WBS No. 1124)

FY 1994

DOE Contact: Robert B. Schulz, (202) 586-8051

$\$ 400,000$

ORNL Contact: D. R. Johnson, (615) 576-6832

ORNL Contact: T. N. Tiegs, (615) 574-5173

The objective of this effort is to identify those aspects of microwave processing of silicon nitride that might: (1) accelerate densification, (2) permit sintering to high density using much lower levels of sintering aids, (3) lower the sintering temperature, or (4) produce unique microstructures, or (5) contribute to cost effectiveness of silicon nitride materials. 
Early work included investigations of the microstructure development of dense silicon nitride materials annealed in the microwave furnace and the sintering of silicon nitride powder compacts in the $2.45-$ or $28-\mathrm{GHz}$ units. While improvements were observed in the properties of the materials fabricated, the cost-effectiveness of the microwave processing was marginal. Another approach dealt with the fabrication of sintered reaction-bonded silicon nitride (SRBSN) and was done entirely in the $2.45-\mathrm{GHz}$ microwave furnace. SRBSN is a cost-effective method to fabricate silicon nitride ceramics. Raw materials costs are less than about one-quarter those for high-purity silicon nitride materials, which improves the costcompetitiveness of these materials with metal parts. Conventional SRBSN requires long nitridation times and two-step firing. By using microwave heating, nitridation times are reduced and all firing is performed in a one-step continuous process, simplifying the operation. Current activities involve the scale-up of the microwave process to large quantities of parts.

Keywords: Microwave Sintering, Silicon Nitride

49. Cost Effective Silicon Nitride Powder (WBS No. 1125)

FY 1994

$\$ 920,000$

DOE Contact: Robert B. Schulz, (202) 586-8051

ORNL Contact: S. G. Winslow, (615) 574-0965

Dow Contact: G. A. Eisman, (517) 638-7864

The objective of this effort is to develop a commercial, domestic source of highquality, low-cost ( $\$ 10 / \mathrm{lb}$ sale price) silicon nitride powder with suitable properties for forming into components for heat engine applications. There are five technical tasks (1) reference process flow sheet and cost estimate, (2) process development and scale up, (3) powder and sintered part characterization, (4) final process flow sheet and cost estimate, and (5) process demonstration.

Keywords: Cost Effective Ceramics, Silicon Nitride, Powder Synthesis, Powder Characterization

50. Cost Effective Sintering of Silicon Nitride Ceramics (WBS No. 1127)

FY 1994

$\$ 462,000$

DOE Contact: Robert B. Schulz, (202) 586-8051

ORNL Contact: T. N. Tiegs, (615) 574-5173

Southern Illinois University Contact: D. E. Wittmer, (618) 453-7006/7924

The objective of this effort is to investigate the potential of cost effective sintering of $\mathrm{Si}_{3} \mathrm{~N}_{4}$ through the development of continuous sintering techniques and the use of lower cost $\mathrm{Si}_{3} \mathrm{~N}_{4}$ powders and sintering aids. The effect of heating rate on the densification, microstructure, and properties of silicon nitride will be investigated. The effects of using 
alternate materials for the furnace belt, and nodifications in the furnace design to improve both furnace load and rate of throughput will also be determined. In addition, a prototype belt furnace will be designed and constructed.

Keywords: Cost Effective Ceramics, Silicon Nitride, Sintering

51. Cost Effective Manufacture of Silicon Nitride Components (WBS No. 1128) 1994

DOE Contact: Robert B. Schulz, (202) 586-8051

ORNL Contact: R. L. Beatty, (615) 574-4536

Golden Technologies Contact: Jack Sibold, (303) 271-7164

The objective of this effort is to develop a low-cost process for manufacture of high quality ceramic engine components based on sintered reaction bonded silicon nitride (SRBSN) technology. There are three technical tasks which address the areas of low-cost materials and processes and achievement of properties required for reliable performance. The material property goals for Phase I of this effort are a mean RT four-point flexure strength of $525 \mathrm{MPa}$ and a Weibull modulus of 15 .

Keywords: Cost Effective Ceramics, Silicon Nitride, SRBSN

52. Advanced Processing (WBS No. 1141)

FY 1994 $\$ 1,000$

DOE Contact: Robert B. Schulz, (202) 586-8051

ORNL Contact: R. L. Beatty, (615) 574-4536

Norton Contact: D. M. Tracey, (508) 393-5811

The purpose of this task is to develop and demonstrate significant improvements in processing methods, process controls, and nondestructive examination (NDE) which can be commercially implemented to produce high-reliability silicon nitride components for advanced heat engine applications at temperatures to $1370^{\circ} \mathrm{C}$. Achievement of these goals shall be sought through

- reliability optimization of aqueous colloidal forming using highly loaded suspensions and glass encapsulated HIPing

- application of the high reliability colloidal processing technique to a gas pressure sinterable (GPS) composition 
- demonstration of representative complex component fabrication in both the HIP and GPS systems.

Keywords: Nondestructive Evaluation, Silicon Nitride, Processing, Processing Controls

53. Improved Processing (WBS No. 1142)

FY 1994

DOE Contact: Robert B. Schulz, (202) 586-8051

$\$ 650,000$

ORNL Contact: D. R. Johnson, (615) 576-6832

ORNL Contact: S. D. Nunn, (615) 576-1668

The purpose of this work is to determine and develop the reliability of selected advanced ceramic processing methods. This program is being conducted on a scale that will permit the potential for manufacturing use of candidate processes to be evaluated. The principal material of interest is silicon nitride. Issues of practicality; safety, hygiene, and environmental issues; and in-process testing methods are to be addressed in addition to technical feasibility. The methodology includes selection of candidate processes and evaluation of their range of applicability to various kinds of commercially available ceramic powders. The process chosen for initial consideration is gelcasting, a process developed at ORNL.

Keywords: Powder Processing, Silicon Nitride, Gel Casting

54. Processing of Silicon Based Ceramics (WBS No. 1225)

FY 1994 $\$ 288,000$

DOE Contact: Robert B. Schulz, (202) 586-8051

ORNL Contact: D. R. Johnson, (615) 576-6832

University of Michigan Contact: T. Y. Tien, (313) 764-9449

The purpose of this effort is to optimize the properties of silicon nitride by microstructural design, specifically by developing fiber-like $\beta-\mathrm{Si}_{3} \mathrm{~N}_{4}$ grains and control of the grain-boundary phase. Optimization of the silicon carbide ceramics will be accomplished by formation of composites containing AlN polytypoids.

Keywords: Composites, Physical/Mechanical Properties, Silicon Nitride, Silicon Carbide 
55. In-Situ Toughened Silicon Nitride (WBS No. 1226)

FY 1994

DOE Contact: Robert B. Schulz, (202) 586-8051

$\$ 300,000$

ORNL Contact: T. N. Tiegs, (615) 574-5173

AlliedSignal Ceramic Components Contact: H. C. Yeh, (213) 618-7449

The purpose of this effort is to develop compositions and processes to obtain high fracture toughness and strength for silicon nitride $\left(\mathrm{Si}_{3} \mathrm{~N}_{4}\right)$-based ceramic materials through microstructure control. Under Phase I, an in situ reinforced silicon nitride material (AS800) with elongated grain microstructure was developed. The objective of this follow-on effort (Phase II) is to expand the AS800 material property database to meet the requirements for heat engine applications and to build on Phase I results to further improve material properties and processing.

Keywords: Cost Effective Ceramics, Physical/Mechanical Properties, Silicon Nitride, Toughened Ceramics

56. Dispersion Toughened Oxide Composites (WBS No. 1231)

FY 1994

DOE Contact: Robert B. Schulz, (202) 586-8051

$\$ 350,000$

ORNL Contact: D. R. Johnson, (615) 576-6832

ORNL Contact: T. N. Tiegs, (615) 574-5173

Initially this work involved development and characterization of $\mathrm{SiC}$ whiskerreinforced oxide composites for improved mechanical performance. To date most of the efforts involving $\mathrm{SiC}$ whisker-reinforced alumina, mullite, silicon nitride, and sialon have been completed. In addition, studies of whisker-growth processes were conducted to improve the mechanical properties of $\mathrm{SiC}$ whiskers by reducing their flaw sizes and, thereby, improving the mechanical properties of the composites. Currently, in situ acicular grain growth is being investigated to improve fracture toughness of silicon nitride materials. Microstructural development to promote this type of growth will be examined.

Keywords: Composites, Alumina, Silicon Carbide, SiAlON, Toughened Ceramics

57. Low Thermal Expansion Ceramics (WBS No. 1243)

FY 1994

DOE Contact: Robert B. Schulz, (202) 586-8051

$\$ 100,000$

ORNL Contact: D. R. Johnson, (615) 576-6832

ORNL Contact: D. P. Stinton, (615) 574-4556

The objective of this effort is to coordinate efforts regarding the application of lowexpansion ceramics in advanced heat engines. Contracts have been placed with Golden 
Technologies, Inc., and LoTEC, Inc., to develop cost effective processes for the fabrication of portliners. Golden is investigating $\mathrm{Al}_{2} \mathrm{TiO}_{5}$ and $\mathrm{Ca}_{1-x} \mathrm{Mg}_{\mathrm{x}} \mathrm{Zr}_{4} \mathrm{P}_{6} \mathrm{O}_{24}$ (CMZP), while LoTEC is working with NZP materials $\mathrm{Ba}_{1+x} \mathrm{Zr}_{4} \mathrm{P}_{6-2 x} \mathrm{Si}_{2 x} \mathrm{O}_{24}$ (BaZPS) and $\mathrm{Ca}_{1-x} \mathrm{Sr}_{\mathrm{x}} \mathrm{Zr}_{4} \mathrm{P}_{6} \mathrm{O}_{24}$. ORNL is assisting Golden Technologies and LoTEC with the characterization and evaluation of their compositions.

Keywords: Aluminum Titanate, NZP, CMZP, Physical/Mechanical Properties, Structural Ceramics, Ultra-low Expansion

58. NZP Components (WBS No. 1245)

FY 1994

DOE Contact: Robert B. Schulz, (202) 586-8051

$\$ 541,000$

ORNL Contact: D. P. Stinton, (615) 574-4556

LoTEC, Inc. Contact: Santosh Limaye, (801) 277-6940

The overall objective of this effort is to develop sodium-zirconium-phosphate (NZP) ceramic-based, "cast-in-place," diesel-engine portliners. Specific objectives are (1) perform materials requirements analyses, (2) successfully demonstrate metal casting around the ceramic, (3) develop a cost-effective process, and (4) develop a high-temperature database (e.g., stability, thermal cycling, thermal shock) for these materials. LoTEC will continue to develop and scale up production of sodium-zirconium-phosphate (NZP) materials developed at Penn State University.

Keywords: Structural Ceramics, Ultra-low Expansion, Zirconia

59. Low Cost Aluminum Titanate/NZP Ceramics (WBS No. 1246)

FY 1994

$\$ 247,000$

DOE Contact: Robert B. Schulz, (202) 586-8051

ORNL Contact: D. P. Stinton, (615) 574-4556

Golden Technologies, Inc. Contact: D. Coors, (303) 271-7217

The objective of this work is to develop a low-thermal-conducting, high-thermalshock-resistant, ceramic portliner which can survive casting in grey iron and diesel engine operation. Golden will be developing their own aluminum titanate material and, in addition, will scale up production of a unique CMZP material developed at Virginia Polytechnic Institute and State University.

Keywords: Structural Ceramics, Ultra-Low Expansion, Aluminum Titanate, CMZP 
60. Advanced Manufacturing (WBS No. 1520)

FY 1994

$\$ 397,000$

DOE Contact: Robert B. Schulz, (202) 586-8051

ORNL Contact: D. R. Johnson, (615) 576-6832

Kyocera Contact: E. Kraft, (206) 750-6147

The objective of this program is to develop the cost-effective manufacturing technology required for ceramic turbine rotors for use in turbochargers for heavy duty diesel truck and bus applications. A team, led by Kyocera and including Schwitzer U.S., Inc. and Caterpillar Inc., will develop and demonstrate production readiness for reliable, cost affordable, turbochargers with ceramic turborotors. Program goals include a nominal order of magnitude reduction in cost over the present cost for small quantities, and process capability for critical component attributes which is adequate for the performance and reliability specifications of the application. Silicon nitride SN 235 is the material of choice for this application.

Keywords: Components, Cost Effective Ceramics, Process Control, Silicon Nitride

61. Advanced Ceramic Manufacturing (WBS No. 1521)

FY 1994

DOE Contact: Robert B. Schulz, (202) 586-8051

$\$ 1,779,000$

ORNL Contact: A. E. Pasto, (615) 574-4956

Norton Contact: Eric Bright, (203) 653-8071

The objectives of this program are to design, develop, and demonstrate advanced manufacturing technology for the production of ceramic exhaust valves for a diesel engine using Norton Advanced Ceramics' NT 451 SiAlON. The component to be developed and tested is the exhaust valve for Detroit Diesel Corporation (DDC's) Series 149 engine. Specific objectives are to: (1) reduce manufacturing costs by at least an order of magnitude over current levels; (2) develop and demonstrate process capability values of 0.7 or less for all critical component attributes; and (3) to validate ceramic valve performance, durability, and reliability in rig and engine testing.

Keywords: Components, Cost Effective Ceramics, Process Control, SiAlON 
62. Advanced Ceramic Manufacturing (WBS No. 1522)

FY 1994

$\$ 1,679,000$

DOE Contact: Robert B. Schulz, (202) 586-8051

ORNL Contact: R. L. Beatty, (615) 574-4536

Golden Technologies, Inc. Contact: Jack Sibold, (303) 271-7164

The objective of this program is to develop a cost-competitive, viable manufacturing process for advanced ceramic engine components. To achieve this goal, two components, utilizing two materials, for two engine companies, were selected. Both components share simple, right-circular geometries and similar manufacturing processes. Key challenges in this program are to meet tight tolerances and yet maintain high yields required to meet cost objectives. Three major activities will occur in parallel: (1) Detroit Diesel Corporation component design/development, (2) Cummins component design/development, and (3) intelligent processing and statistical process control development/implementation.

Keywords: Components, Cost Effective Ceramics, Process Control

Materials Properties, Behavior. Characterization or Testing

63. Development of Standard Test Methods for Evaluating the

Wear Performance of Ceramics (WBS No. 2222)

FY 1994

$\$ 30,000$

DOE Contact: Robert B. Schulz, (202) 586-8051

ORNL Contact: D. R. Johnson, (615) 576-6832

ORNL Contact: P. J. Blau, (615) 574-5377

The goal of this effort is to improve consistency in reporting ceramic wear test data by helping to develop one or more standard test methods for quantitatively determining the wear resistance of structural ceramics in reciprocating sliding, a type of motion which is experienced by several types of engine parts. ORNL is working with ASTM to meet this objective.

Keywords: Structural Ceramics, Test Procedures, Wear

64. Advanced Statistics Calculations (WBS No. 2313)

FY 1994

DOE Contact: Robert B. Schulz, (202) 586-8051

$\$ 100,000$

ORNL Contact: M. K. Ferber, (615) 576-0818

GE Contact: C. A. Johnson, (518) 387-6421

The design and application of reliable load-bearing structural components from ceramic materials requires a detailed understanding of the statistical nature of fracture in 
brittle materials. The overall objective is to advance the current understanding of fracture statistics, especially in the areas of optimum testing plans and data analysis techniques, consequences of time-dependent crack growth on the evolution of initial flaw distributions, confidence and tolerance bounds on predictions that use the Weibull distribution and function, strength distributions in multiaxial stress fields, and goodness-of-fit-tests for the Weibull model of strength. The studies are being carried out largely by analytical and computer simulation techniques. Actual fracture data are then used as appropriate to confirm and demonstrate the resulting data analysis techniques.

Keywords: Design Codes, Life Prediction, Statistics, Weibull, Fracture, Structural Ceramics, Instrumentation or Technique Development

65. Microstructural Analysis (WBS No. 3111)

FY 1994

$\$ 50,000$

DOE Contact: Robert B. Schulz, (202) 586-8051

ORNL Contact: D. R. Johnson, (615) 576-6832

NIST Contact: S. M. Wiederhorn, (301) 975-5772

The objective of this work is to identify the mechanisms of failure in structural ceramics subjected to mechanical loads in various test temperatures and environments. This is a companion project to a related task in which advanced ceramics are characterized in tensile creep. Of particular interest is the damage that accumulates in structural ceramics as a consequence of high temperature exposure to environments and stresses normally present in heat engines. Materials to be studied include sialons, silicon nitride, and sintered silicon carbide.

Keywords: Corrosion, Failure Mechanism, Structural Ceramics, Silicon Carbide, Creep, SiAlON, Silicon Nitride

66. Microstructural Characterization of Silicon Carbide and Silicon

Nitride Ceramics for Advanced Heat Engines (WBS No. 3114)

FY 1994

$\$ 200,000$

DOE Contact: Robert B. Schulz, (202) 586-8051

ORNL Contact: D. R. Johnson, (615) 576-6832

ORNL Contact: T. A. Nolan, (615) 574-08:11

The purpose of this work is to determine the microstructure of both monolithic and composite ceramics and to relate that microstructure to mechanical properties and material performance. Specifically, the materials of interest are silicon carbides and silicon nitrides developed by U.S. manufacturers as part of this program and the Advanced Turbine Technology Applications Project (ATTAP). A major objective is to use electron microscopy and surface chemistry to characterize the chemistry, crystallography, and morphology of 
phases present with particular emphasis on the structure and chemistry of grain boundaries and other interfaces.

A second major objective is to relate those microstructural observations to available mechanical test data produced by other participants in the ATTAP and Ceramic Technology programs. Ceramic specimens from foreign sources are also characterized to provide comparative information on microstructural properties.

Keywords: Silicon Carbide, Silicon Nitride, Microstructure, Chemical Analysis, Mechanical Properties, Scanning Electron Microscopy

67. Project Data Base (WBS No. 3117)

FY 1994

$\$ 240,000$

DOE Contact: Robert B. Schulz, (202) 586-8051

ORNL Contact: D. R. Johnson, (615) 576-6832

ORNL Contact: B. L. Keyes, (615) 574-5113

The objective of this effort is to develop a comprehensive computer database containing experimental data on the properties of ceramic materials generated for the Ceramic Technology Project. This computer system should provide a convenient and efficient mechanism for the compilation and distribution of the large amounts of data involved. The database will be available in electronic form to all project participants. In addition, periodic hard copy summaries of the data, including graphical representation and tabulation of raw data, will be issued to provide convenient information sources for project participants.

Keywords: Database, Mechanical Properties, Structural Ceramics

68. Fracture Behavior of Toughened Ceramics (WBS No. 3213)

FY 1994

DOE Contact: Robert B. Schulz, (202) 586-8051

$\$ 290,000$

ORNL Contact: D. R. Johnson, (615) 576-6832

ORNL Contact: P. F. Becher, (615) 574-5157

Ceramics with reinforcing microstructures and ceramic composites offer important advantages for heat engine applications. In addition to improved fracture toughness, these materials often exhibit substantial improvement in damage, thermal shock, and slow-crackgrowth resistance. In this effort, studies are conducted to determine mechanical properties, (e.g., creep, delayed failure, strength, and toughness) at elevated temperatures for these toughened ceramics. Particular emphasis is placed on understanding how microstructure 
and composition influence the mechanical performance at elevated temperatures and the stability of these properties for extended periods.

Keywords: Toughened Ceramics, Silicon Carbide, Silicon Nitride, Alumina

69. Cyclic Fatique of Toughened Ceramics (WBS No. 3214)

FY 1994

DOE Contact: Robert B. Schulz, (202) 586-8051

$\$ 220,000$

ORNL Contact: D. R. Johnson, (615) 576-6832

ORNL Contact: K. C. Liu, (615) 574-5116

The objective of this task is to develop and demonstrate the capability of performing uniaxial tension-tension dynamic fatigue testing of structural ceramics at elevated temperature. The effort includes: (1) design, fabrication, and demonstration of a load-train column capable of concentric load transfer between grip and specimen at high temperature; and (2) development of the baseline information on the tensile fatigue behavior of structural ceramics at room and elevated temperatures.

Keywords: Cyclic Fatigue, High Temperature Properties, Toughened Ceramics, Tensile Testing, Silicon Nitride

70. Tensile Stress Rupture Development (WBS No. 3215)

FY 1994

DOE Contact: Robert B. Schulz, (202) 586-8051

$\$ 300,000$

ORNL Contact: D. R. Johnson, (615) 576-6832

ORNL Contact: K. C. Liu, (615) 574-5116

The objective of this task is to develop the test capability for performing uniaxial tensile stress-rupture and creep tests on candidate structural ceramics at high temperature in the range where time-dependent deformation can occur. Creep and creep-rupture design databases will be generated using uniaxial tensile specimens tested in the range of 1150 to $1370^{\circ} \mathrm{C}$. The resulting stress-rupture and creep data will be used to evaluate and refine existing constitutive models. New constitutive models will be developed to facilitate design analyses of high-temperature structural components and improve their reliability.

Keywords: Creep, Silicon Nitride, High Temperature Properties, Tensile Testing, TimeDependent 
71. Life Prediction Verification (WBS No. 3216)

FY 1994

$\$ 200,000$

DOE Contact: Robert B. Schulz, (202) 586-8051

ORNL Contact: D. R. Johnson, (615) 576-6832

ORNL Contact: M. K. Ferber, (615) 576-0818

The objective of this effort is to systematically verify life prediction methodologies appropriate for structural ceramic engine components. An emphasis will be to achieve predictability at a level acceptable to end users, in particular, those users associated with the manufacturing of internal combustion engine valves. This effort is comprised of four tasks: (1) characterization of material/mechanical performance, (2) life prediction analysis, (3) test of simulated engine valves, and (4) verification of life prediction methodology. A second objective is to complete the Rotor Database Generation program. The three central goals of that effort are: (1) hightemperature mechanical testing, (2) microstructural characterization of failure phenomena, and (3) the modeling of high temperature deformation in candidate silicon nitrides.

Keywords: Engines, Failure Analysis, Failure Testing, High Temperature Service, Life Prediction, Mechanical Properties, Structural Ceramics, Tensile Testing, SiAlON, Silicon Nitride

72. Toughened Ceramics Life Prediction (WBS No. 3217)

FY 1994

DOE Contact: Robert B. Schulz, (202) 586-8051

$\$ 200,000$

ORNL Contact: D. R. Johnson, (615) 576-6832

NASA - Lewis Research Center Contact: John P. Gyekenyesi, (216) 433-3210

The purpose of this research is to understand the room-temperature and hightemperature behavior of toughened ceramics as the basis for developing a life prediction methodology. A major objective is to understand the relationship between microstructure and the mechanical behavior within the bounds of a limited number of materials. A second major objective is to determine behavior as a function of time and temperature. Specifically, strength and reliability, fracture toughness, slow crack growth, and creep behavior will be determined as a function of temperature for the as-manufactured material. The same properties will also be evaluated after long-time exposure to various hightemperature isothermal and cyclic environments. These results will provide input for parallel materials development and design methodology programs. Resultant design codes will be verified.

Keywords: Creep, Fracture Toughness, High Temperature Properties, Life Prediction, Silicon Nitride, Time-Dependent 
73. Life Prediction Methodology (WBS No. 3222)

DOE Contact: Robert B. Schulz, (202) 586-8051

ORNL Contact: C. R. Brinkman, (615) 574-5106

Allison Contact: N. J. Provenzano, (313) 230-3150

The objective of this effort is to develop and demonstrate the necessary nondestructive examination (NDE) technology, material data base, and design methodology for predicting the useful life of structural ceramic components of advanced heat engines. The analytical methodology will be demonstrated through confirmatory testing of ceramic components subjected to thermal-mechanical loading conditions similar to those anticipated to occur in actual vehicular service. The project addresses fast fracture, slow crack growth, creep, and oxidation failure modes.

Keywords: Creep, Failure Analysis, Failure Testing, Oxidation, Life Prediction, Nondestructive Evaluation, Silicon Nitride

74. Life Prediction Methodology (WBS No. 3223)

FY 1994

$\$ 600,000$

DOE Contact: Robert B. Schulz, (202) 586-8051

ORNL Contact: C. R. Brinkman, (615) 574-5106

AlliedSignal Engines Contact: Dave Wu, (602) 231-1206

This Phase II program will develop the methodology required to adequately predict the useful life of ceramic components used in advanced heat engines. Phase II efforts will concentrate on predictive methodology for time- and cycle-dependent failure modes, as well as proof testing and nondestructive evaluation (NDE) methodology to enhance component reliability through screening out of low-strength components. The life prediction methodologies developed will be generic and hence will be applicable to ceramic components that operate under known temperature and stress conditions. The technical effort has been organized into six areas: (1) material baseline, (2) compressive creep methodology, (3) flaw growth methodology, (4) cyclic fatigue methodology, (5) proof test methodology, and (6) NDE reliability methodology.

Keywords: Creep, Failure Analysis, Failure Testing, Life Prediction, Nondestructive Evaluation, Silicon Nitride 
75. Environmental Effects in Toughened Ceramics (WBS No. 3314)

FY 1994

$\$ 383,000$

DOE Contact: Robert B. Schulz, (202) 586-8051

ORNL Contact: M. K. Ferber, (615) 576-0818

University of Dayton Contact: N. L. Hecht, (513) 229-4341

The objective of this task is to investigate the effects of environment on the mechanical behavior of commercially available ceramics being considered for heat engine applications.

Keywords: Fatigue, Engines, Structural Ceramics, Environmental Effects, Alumina, Zirconia, Diesel Combustion, Tensile Testing, Time-Dependent, Transformation-Toughened

76. High Temperature Tensile Testing (WBS No. 3412)

FY 1994 $\$ 250,000$

DOE Contact: Robert B. Schulz, (202) 586-8051

ORNL Contact: D. R. Johnson, (615) 576-6832

North Carolina A\&T State University Contact: J. Sankar, (919) 334-7620

The objective of this research is to test and evaluate the long-term mechanical reliability of a sintered and $\mathrm{HIPed} \mathrm{Si}_{3} \mathrm{~N}_{4}$ at temperatures up to $1300^{\circ} \mathrm{C}$. Currently, the emphasis is on analyzing the effect of thermal soaking and fatigue on the residual tensile strength of GTE's PY6 material. Microstructural/microchemical analysis of the fracture surfaces using scanning electron microscopy (SEM), transmission electron microscopy (TEM), and energy-dispersive spectral analysis (EDS) is an integral part of this effort.

Keywords: Creep, Fracture, Silicon Nitride, Structural Ceramics, Tensile Testing

77. Standard Tensile Test Development (WBS No. 3413)

FY 1994

DOE Contact: Robert B. Schulz, (202) 586-8051

$\$ 125,000$

ORNL Contact: D. R. Johnson, (615) 576-6832

NIST Contact: S. M. Wiederhorn, (301) 975-5772

This project is concerned with the development of test equipment and procedures for measuring the strength and creep resistance of ceramic materials at elevated temperatures to assist in the development of a reliable data base for use in the structural design of heat engines for vehicular applications.

Keywords: Creep, High Temperature Properties, Structural Ceramics, Tensile Testing, Test Procedures 
78. Non-Destructive Evaluation (WBS No. 3511)

FY 1994

$\$ 460,000$

DOE Contact: Robert B. Schulz, (202) 586-8051

ORNL Contact: D. R. Johnson, (615) 576-6i832

ORNL Contact: D. J. McGuire, (615) 574-4.835

The purpose of this program is to develop nondestructive evaluation (NDE) techniques in order to identify approaches for quantitative determination of conditions (including both properties and flaws) in ceramics that affect the structural performance. Those materials that have been seriously considered for application in advanced heat engines are all brittle materials whose fracture is affected by structural features whose dimensions are on the order of the dimensions of their microstructure. This work seeks to characterize those features using high frequency ultrasonics and radiography to detect, size, and locate critical flaws and to measure nondestructively the elastic properties of the host material.

Keywords: NDE, Radiography, Structural Ceramics, Ultrasonics

79. Computed Tomography (WBS No. 3515)

FY 1994

DOE Contact: Robert B. Schulz, (202) 586-8051

$\$ 120,000$

ORNL Contact: D. R. Johnson, (615) 576-6832

Argonne National Lab Contact: W. A. Ellingson, (312) 972-5068

The overall purpose of this program is to develop X-ray computed tomographic (XCT) imaging for characterizing structural ceramic materials relative to density distributions and the presence of voids, inclusions, and cracks and, further, to relate the detected variations to performance of processing variations. Currently, this technique is being used to study density distributions in composite green-state (as-cast) pressure slip-cast Advanced Turbine Technology Applications Project (ATTAP) rotors supplied by AlliedSignal Ceramic Components. AlliedSignal will then perform destructive analysis of the as-cast rotors and their findings will be correlated with the 3D X-ray microtomography data.

Keywords: Computed Tomography, Nondestructive Evaluation, Silicon Nitride, Structural Ceramics, Green State 
80. Nuclear Magnetic Resonance (NMR) Imaging (WBS No. 3516)

FY 1994

DOE Contact: Robert B. Schulz, (202) 586-8051

$\$ 80,000$

ORNL Contact: D. R. Johnson, (615) 576-6832

Argonne National Lab Contact: W. A. Ellingson, (312) 972-5068

The purpose of this work is to evaluate the potential of NMR imaging to impact the development and process control of near-net-shape gelcast ceramic components. The specific objectives of this work are to determine the utility of NMR imaging for: (1) 3D mapping of polymerization homogeneity; (2) real-time imaging of the polymerization process; (3) nondestructive evaluation of voids and flaws in the resultant components; and (4) measurement of physical properties such as degree of polymerization, viscosity, and specimen strength via correlation of these properties with measurable NMR parameters. This work is being performed in conjunction with Metals and Ceramics Division staff at Oak Ridge National Laboratory.

Keywords: Binder, Nondestructive Evaluation, Nuclear Magnetic Resonance, Silicon Nitride

81. Assessment of Magnesium for Automotive Applications

FY 1994

DOE Contact: Sidney Diamond, (202) 586-8032

$\$ 115,000$

ANL Contact: Frank Stodolsky, (202) 488-2431

An assessment is being performed at ANL to determine the feasibility and technical potential of using magnesium alloys in automotive structural and sheet applications in efforts to enhance the lightweighting and energy efficiency of conventional and advanced passenger vehicles. Magnesium alloys will be identified that have promise to meet vehicle performance requirements such as stiffness, crush behavior, corrosion resistance, fatigue resistance, flammability, and explosiveness. The ability of magnesium to respond to various forming methods will also be assessed and production cost barriers will be identified.

Keywords: Magnesium Alloys, Forming, Structural and Sheet Applications 
Technology Transfer and Management Coordination

82. Management and Coordination (WBS No. 111)

FY 1994

$\$ 950,000$

DOE Contact: Robert B. Schulz, (202) 586-8051

ORNL Contact: D. R. Johnson, (615) 576-6832

The objective of this effort is to assess the ceramic technology needs for advanced automotive heat engines, formulate technical plans to meet these needs, and prioritize and implement a long-range research and development program.

Keywords: Advanced Heat Engines, Structural Ceramics, Management, Coordination, AGT, Diesel

83. International Exchange Agreement (IEA) (WBS No. 4115)

FY 1994

DOE Contact: Robert B. Schulz, (202) 586-8051

$\$ 200,000$

ORNL Contact: D. R. Johnson, (615) 576-6i832

ORNL Contact: M. K. Ferber, (615) 576-0818

The purpose of this effort is to organize, assist, and facilitate international research cooperation on the characterization of advanced structural ceramic materials. A major objective of this research is the evolution of voluntary measurement standards for determining mechanical, physical, and structural properties for these materials. Participants in Annex II are the United States, Germany, Sweden, and Japan.

Keywords: IEA, Powder Characterization, Mechanical Properties

84. Standard Reference Materials (WBS No. 4116)

FY 1994

DOE Contact: Robert B. Schulz, (202) 586-8051

$\$ 150,000$

ORNL Contact: D. R. Johnson, (615) 576-6832

NIST Contact: S. Malghan, (301) 975-5772

This project is directed toward a critical assessment and modeling of ceramic powder characterization methodology and toward the establishment of an international basis for standard materials and methods for the evaluation of powders prior to processing. There are three areas of emphasis: (1) to divide, certify, and distribute five ceramic powders for an international round-robin on powder characterization; (2) to provide reliable data on physical (dimensional), chemical, and phase characteristics of two silicon nitride powders (a reference powder and a test powder); and (3) to conduct a statistical assessment and 
modeling of round-robin data. The round-robin is to be conducted through the auspices of the International Energy Agency.

Keywords: IEA, Reference Material, Powder Characterization

85. Mechanical Property Standardization (WBS No. 4121)

FY 1994

$\$ 100,000$

DOE Contact: Robert B. Schulz, (202) 586-8051

ORNL Contact: D. R. Johnson, (615) 576-6832

NIST Contact: G. Quinn, (301) 975-5765

The purpose of this effort is to develop mechanical test standards in support of the Ceramic Technology Project and the Advanced Turbine Technology Applications Program.

Keywords: Mechanical Properties, Test Procedures

Device or Component Fabrication, Behavior or Testing

86. Advanced Coating Technology (WBS No. 1311)

FY 1994

DOE Contact: Robert B. Schulz, (202) 586-8051

$\$ 175,000$

ORNL Contact: D. R. Johnson, (615) 576-6832

ORNL Contact: D. P. Stinton, (615) 574-4556

Sodium corrosion of $\mathrm{SiC}$ and $\mathrm{Si}_{3} \mathrm{~N}_{4}$ components in gas turbine engines is a potentially serious problem. The objective of this effort is to develop a coating that will protect the underlying $\mathrm{SiC}$ or $\mathrm{Si}_{3} \mathrm{~N}_{4}$ from sodium corrosion and provide simultaneous oxidation protection. To evaluate the behavior of potential materials such as stabilized $\mathrm{ZrO}_{2}$ or $\mathrm{HfO}_{2}$, $\mathrm{TiO}_{2}$, and $\mathrm{Ta}_{2} \mathrm{O}_{5}$ in sodium-containing atmospheres, the corrosion resistance of hot-pressed samples of these materials will first be evaluated. A chemical vapor deposition (CVD) process will be developed for the application of the most promising coatings. The effect of the combustion environment upon coating characteristics such as microstructure, strength, adherence, and other properties will then be evaluated.

Keywords: Coatings, Chemical Vapor Deposition, Engines, Silicon Carbide, Silicon Nitride, Structural Ceramics, Corrosion 
87. Coatings to Reduce Contact Stress Damage of Ceramics (WBS No. 1313) FY 1994

$\$ 28,000$

DOE Contact: Robert B. Schulz, (202) 586-8051

ORNL Contact: D. R. Johnson, (615) 576-6832

Boston University Contact: V. K. Sarin, (617) 353-2842

The objective of this effort is to develop oxidation/corrosion-resistant, high toughness, adherent coating configurations for silicon-based ceramic substrates for use in advanced gas turbine engines. Current work involves the CVD deposition of multilayered $\mathrm{Al}_{2} \mathrm{O}_{3} / \mathrm{SiO}_{2}$ coatings on $\mathrm{SiC}$ and $\mathrm{Si}_{3} \mathrm{~N}_{4}$ to form mullite.

Keywords: Adherence, Coatings, Mullite, CVD, Oxidation, Modeling, Corrosion Resistance, Structural Ceramics

88. Wear Resistant Coatings (WBS No. 1331)

FY 1994

DOE Contact: Robert B. Schulz, (202) 586-8051

$\$ 46,000$

ORNL Contact: D. P. Stinton, (615) 574-4556

Caterpillar Contact: M. H. Haselkorn, (309) 578-6624

The goal of this effort is to develop wear-resistant coatings for application to metallic components of low-heat-loss diesel engines, specifically, piston rings and cylinder liners. The following wear-resistant coatings were selected in Phase I plasma-sprayed high carbon ironmolybdenum, plasma-sprayed chromia-silica, and low temperature arc vapor deposited (LTAVD) chrome nitride. A plasma-sprayed carbon iron-molybdenum and a plasmasprayed chromia-silica were identified as wear-resistant piston-ring coatings. The three main technical tasks for Phase II are further optimization of the LTAVD chrome nitride and cast iron porcelain enamel wear coatings, process scale-up of wear-resistant plasma coatings for cylinder-liner applications, and simulated engine testing.

Keywords: Coatings, Engines, Friction, Structural Ceramics, Wear

89. Wear Resistant Coatings (WBS No. 1332)

FY 1994

DOE Contact: Robert B. Schulz, (202) 586-8051

$\$ 0$

ORNL Contact: D. P. Stinton, (615) 574-4556

Cummins Contact: Malcolm Naylor, (812) 377-7713

The objective of this program is to develop advanced wear-resistant ceramic coatings for in-cylinder components for future, high-efficiency, low-emissions diesel engines. Coatings and substrates (for piston rings and cylinder liners) are to be developed to meet the following requirements: 
- low wear as measured in laboratory rig tests which simulate the piston ringcylinder liner environment near the top ring reversal in a heavy duty diesel engine

- lower friction coefficients than for the conventional system under all test conditions

- high adherence and compatibility with substrate materials

- good thermal shock resistance

- high uniformity and reproducibility

Keywords: Adherence, Coatings, Engines, Friction, Metals, Structural Ceramics, Thermal Conductivity, Wear

90. Thick Thermal Barrier Coating Systems for Low Heat Rejection Diesel Engines (WBS No. 1342)

DOE Contact: Robert B. Schulz, (202) 586-8051

ORNL Contact: D. P. Stinton, (615) 574-4556

Caterpillar Contact: M. Brad Beardsley, (309) 578-8514

The objective of this effort is to advance the fundamental understanding of thick thermal barrier coating (TTBC) systems for application to low-heat-rejection diesel engine combustion chambers. Areas of TTBC technology that will be examined include powder characteristics and chemistry; bond coat compositions; coating design, microstructure, and thickness as they affect properties, durability, and reliability; and TTBC "aging" effects (microstructural and property changes) under diesel engine operating conditions.

Keywords: Coatings, Structural Ceramics

91. Active Metal Brazing PSZ-Iron (WBS No. 1411)

FY 1994

DOE Contact: Robert B. Schulz, (202) 586-8051

$\$ 220,000$

ORNL Contact: D. R. Johnson, (615) 576-6832

ORNL Contact: M. L. Santella, (615) 574-4805

The objective of this task is to develop strong, reliable joints containing ceramic components for applications in advanced heat engines. The current emphasis is on studying the brazing characteristics of silicon nitride and silicon carbide. The techniques of direct brazing as well as vapor coating ceramics to circumvent wetting problems are being applied 
to these materials. Work includes continuing the study of both the high temperature brazing of silicon nitride and the mechanical behavior of braze joints. The work will encompass further evaluation and application of an analysis package and approach developed specifically for silicon nitride-to-metal braze joints, and evaluating nonmetallic bonding materials for joining silicon nitride.

Keywords: Metals, Structural Ceramics, Joining/Welding, Brazing, Silicon Carbide, Silicon Nitride

\section{Surface Durability of Machined Ceramics (WBS No. 1500)}

FY 1994

DOE Contact: Robert B. Schulz, (202) 586-8051

ORNL Contact: D. R. Johnson, (615) 576-6832

ORNL Contact: P. J. Blau, (615) 574-5377

The purpose of this task is to develop, in conjunction with U.S. industry, advanced technologies and the associated scientific and economic concepts necessary to reduce costs associated with the machining of structural ceramics, especially as related to component parts for energy-efficient, low-emissions transportation systems. This effort is conducted by industry, other national laboratories, and in-house at ORNL. The ORNL research concerns two technical areas: (1) investigating the effects of machining practices on the durability of ceramics for valve and valve-set applications, (2) understanding and characterizing the detailed nature of machining-induced surface and subsurface damage and their evolution in advanced ceramic materials using a range of analytical tools.

Keywords: Cost Effective Ceramics, Machining, Silicon Nitride, Structural Ceramics

93. Next-Generation Grinding Wheel (WBS No. 1501)

FY 1994

DOE Contact: Robert B. Schulz, (202) 586-8051

ORNL Contact: P. J. Blau, (615) 574-5377

Norton Contact: Robert H. Licht, (508) 351-7815

This effort is aimed at the engineering design and development of a next-generation, superabrasive grinding wheel specifically tailored for the cylindrical grinding of silicon nitride and other advanced structural ceramic parts for automotive and truck engine applications. The intent of this effort is to significantly reduce manufacturing cost of ceramic parts and to enhance the competitiveness of U.S. industry by providing an optimized grinding wheel for ceramics.

Keywords: Cost Effective Ceramics, Machining, Silicon Nitride, Structural Ceramics, Surface Characterization and Treatment 
94. Grindability Test (WBS No, 1502)

FY 1994

$\$ 0$

DOE Contact: Robert B. Schulz, (202) 586-8051

ORNL Contact: P. J. Blau, (615) 574-5377

Chand Kare Contact: Ronald H. Chand, (508) 793-9814

The objective of this program is to develop a cost-effective method to determine the grindability of ceramics leading to cost-effective methods for machining those materials. Phase I efforts will be directed towards a review of literature related to ceramic grinding, development of a variable definition of grindability, design of grindability test experiments, and design of a ceramics grindability test system. The grindability study underway also includes establishment of correlation between the grindability number and conventional grinding practices.

Keywords: Cost Effective Ceramics, Machining, Silicon Nitride, Structural Ceramics, Surface Characterization and Treatment

95. Chemically Assisted Grinding of Ceramics (WBS No. 1503)

FY 1994

DOE Contact: Robert B. Schulz, (202) 586-8051

$\$ 150,000$

ORNL Contact: P. J. Blau, (615) 574-5377

NIST Contact: Steven M. Hsu, (301) 975-6119

The objective of this effort is to reduce ceramic machining costs by increasing the machining rate of ceramics using chemical reactions at the interface. The chemical reactions at the tips of the asperities produce a softer reaction layer which reduces contact stresses and, therefore, the extent of surface damage. $\mathrm{Si}_{3} \mathrm{~N}_{4}$ is the material of focus, even though other materials such as SiAlON and SiC may be examined for comparison.

Keywords: Cost Effective Ceramics, Machining, Silicon Nitride, Structural Ceramics, Surface Characterization and Treatment

96. Grinding Consortium (WBS No. 1503)

FY 1994

DOE Contact: Robert B. Schulz, (202) 586-8051

$\$ 150,000$

ORNL Contact: P. J. Blau, (615) 574-5377

NIST Contact: Said Jahanmir, (301) 975-6871

The purpose of this effort is to develop guidelines and recommendations for grinding optimization of advanced structural ceramics to achieve minimum cost and maximum reliability. The following steps are being taken to achieve the objective conduct grinding experiments jointly with industrial participants, determine the effect of grinding parameters 
on machining damage and strength, elucidate mechanisms of material removal and damage formation, evaluate several damage detection techniques, and transfer data and information to industry in computerized database format.

Keywords: Database, Cost Effective Ceranics, Machining, Silicon Nitride, Structural Ceramics, Surface Characterization and Treatment

97. High Speed Grinding (WBS No. 1504)

FY 1994

DOE Contact: Robert B. Schulz, (202) 586-8051

$\$ 372,000$

ORNL Contact: P. J. Blau, (615) 574-5377

Eaton Contact: Joseph A. Kovach, (216) 523.6766

The purpose of this effort is to develop a single step, rough finishing process suitable for producing high-quality silicon nitride ceramic parts at high material removal rates and at substantially lower cost than traditional, multi-stage grinding processes.

Keywords: Cost Effective Ceramics, Machining, Silicon Nitride, Structural Ceramics, Surface Characterization and Treatment

98. Laser-Based NDE Methods (WBS No. 1507)

FY 1994

DOE Contact: Robert B. Schulz, (202) 586-8051

$\$ 180,000$

ORNL Contact: D. R. Johnson, (615) 576-6832

Argonne National Lab Contact: J. S. Steckenrider, (708) 252-5169

The primary objective of this effort is to develop a laser-scattering procedure which would provide a direct indication of changes in the subsurface (and surface) during machining-both machining-induced damage such as median crack formation and surface roughness. A second objective is to evaluate dye-penetrant technology for surface-breaking crack detection as an off-line indicator.

Keywords: Machining, Nondestructive Evaluation, Structural Ceramics

99. Development of "Smart" Grinding Wheel (WBS No. 1510)

FY 1994

$\$ 50,000$

DOE Contact: Robert B. Schulz, (202) 586-8051

ORNL Contact: D. R. Johnson, (615) 576-6832

Industry Contact: TBD

The objective of this new effort is to produce a commercially viable, "smart grindingwheel" system which is suitable for both grinding research and production use. This project 
will be comprised of three tasks: (1) producing a grinding-wheel design which incorporates sensors and the means to transmit key process parameters to a computer, (2) construction of a prototype grinding-wheel system to be tested on a full-size commercial cylindrical grinder and, finally (3) demonstration of the prototype system. Acquisition cost for commercial versions of the smart-wheel system, truing and dressing practices, and handling and calibration shall also be addressed.

Keywords: Cost Effective Ceramics, Machining, Silicon Nitride, Surface Characterization, Treatment

100. Automotive Materials Development

FY 1994

DOE Contact: Sidney Diamond, (202) 586-8032

$\$ 3,000,000$

ORNL Contact: Philip S. Sklad, (615) 574-5069

This major activity in the Lightweight Materials Program is a collaborative effort between the US Automotive Materials Partnership (USAMP) and the DOE. Development of cost-effective lightweight materials and the processes needed to form or manufacture them reliably and competitively in the required quantities and production rates are addressed through focused research conducted by technical teams. The teams are selected by the technical representatives from Ford Motor Company, Chrysler Corporation, and General Motors Corporation to USAMP from among DOE's National Laboratories, suppliers to the automobile companies, private research organizations, and members of academia. Current topics of interest include advanced metal forming technology, adhesive bonding of polymers and dissimilar materials, metal matrix composites, rapid prototyping, and the utilization of modeling and simulation for optimizing materials and processes. Elements of the projects are being performed at INEL, LANL, ORNL, PNL, SNL, and the University of Texas.

Keywords: Advanced Metal Forming, Metal Matrix Composites, Rapid Protọtyping, Adhesive Bonding

101. Ultracapacitors for Electric and Hybrid Vehicles

FY 1994

DOE Contact: Sidney Diamond, (202) 5868032

$\$ 75,000$

DOE Contact: Pat Davis, (202) 586-8061

LLNL Contact: Dennis O'Brien, (510) 422-5593

The purpose of the present work is to develop deposition techniques for dielectric and conductor films that can ultimately be used in nanostructured multilayer capacitor panels. In the current work being carried out at the LLNL, it is intended that films will be first developed, deposited, and characterized and that then an effort will be made to 
synthesize a simple prototype capacitor. The Electric and Hybrid Propulsion Division of OTT has the project lead for this activity. The Office of Transportation Materials is providing partial funding of this work based on the possibility of substantially reducing the weight of electric and hybrid vehicles through the development of small, highly efficient energy storage devices.

Keywords: Nanophase Materials, Ultracapacitors

\section{Office of Propulsion Systems}

The Office of Propulsion Systems is comprised of the Advanced Propulsion Division and the Electric and Hybrid Propulsion Division. Programs supported by this office are focused on developing, with industry through cost-shared contracts, the technologies that will lead to the production and introduction of advanced heat engine propulsion systems, and electric and hybrid vehicles in the nation's transportation fleet. Materials activities of the Office of Propulsion Systems focus on integration of materials into components and testing of subsystems for advanced vehicle propulsion systems.

\section{Advanced Propulsion Division}

The Advanced Propulsion Division has two programs: (1) Light Duty Engine Technologies Program focused on Turbine Engine Technologies and Advanced Automotive Piston Engine Technologies; and (2) Heavy Duty Engine Technologies Program focused on Advanced Diesel Engine Technology. Materials activities supported by the Advanced Propulsion Division and managed through the NASA Lewis Research Center for component and coating applications are included in this report. The DOE contacts are Thomas Sebestyen, (202) 586-8012 for Turbine Engine Technologies; Patrick Sutton, (202) 586-8058 for Advanced Automotive Piston Engine Technologies; and John Fairbanks, (202) 586-8066 for Advanced Diesel Engine Technologies.

\section{Materials Properties, Behavior, Characterization or Testing}

\section{Advanced Turbine Supporting Research and Technology}

FY 1994

DOE Contact: Thomas Sebestyen, (202) 586-8012

$\$ 250,000$

NASA Contact: Thomas Strom, (216) 433-3408

The objective of this program is to evaluate commercially available structural and glass ceramic material specimens exposed to combustion products at temperatures up to $2500^{\circ} \mathrm{F}$ for periods up to 3,500 hours. Activities include development of design codes for structural component evaluation; research on non-destructive evaluation of ceramic 
components to improve reliability; and examination of the effects of corrosive sea salts and other adverse environments on the durability of ceramics.

Keywords: Structural Ceramics, Non-Destructive Evaluation, Silicon Carbide, Silicon Nitride, Gas Turbine Engines

Device or Component Fabrication, Behavior or Testing

103. Hybrid Vehicle Turbine Engine (HVTE) Technology Support

FY 1994

DOE Contact: Thomas Sebestyen, (202) 586-8012

$\$ 3,725,000$

NASA Contact: Paul Kerwin, (216) 433-3409

Allison Engine Company Contact: Steve Berenyi, (317) 230-6971

The Advanced Turbine Technology Applications Project (ATTAP) has been redirected to support the DOE Hybrid Vehicle Program by focusing on turbine engines in the 20-60kW size for hybrid vehicle application. In support of the advanced Hybrid Vehicle Turbine Engine (HVTE), Allison is designing, fabricating, and testing low-emission combustors, ceramic hot section components, a high performance ceramic regenerator core and seal system and cost effective high temperature insulation system. Test rigs and test bed engines are being used to evaluate full-scale component and subsystem reliability and durability at cyclic operating conditions that are typical of automotive use at up to $2500^{\circ} \mathrm{F}$.

Keywords: Structural Ceramics, Component Design, Silicon Carbide, Silicon Nitride, Gas Turbine Engines, Rig and Engine Testing

104. Ceramic Turbine (CT) Engine Demonstration Project

FY 1994 $\$ 2,873,000$

DOE Contact: Thomas Sebestyen, (202) 586-8012

NASA Contact: Thomas Strom, (216) 433-3408

AlliedSignal Engine Contact: Jay Smyth, (602) 231-4306

, This project will provide early ceramic turbine field experience by demonstrating the reliability and durability of ceramic components in actual engine application. In support of gas turbine auxiliary power unit (APU) development for the DOE Hybrid Vehicle Program, AlliedSignal began introducing ceramic first stage turbine nozzles and blades into its proven (all-metal) GTCP 331-200 gas turbine APU engine. Laboratory and field testing is continuing to address remaining critical design and production concerns related to structural ceramics in gas turbine engines. In addition, efforts are intensified to scale-up and 
demonstrate commercial engine ceramic component manufacturing in coordination with ceramic suppliers and the Propulsion System Materials element of DOE's Materials Technology Program.

Keywords: Structural Ceramics, Component Design, Fabrication, Gas Turbine Engines, Component Test

105. Advanced Diesel Engine Component Development Project

FY 1994

DOE Contact: John W. Fairbanks, (202) 586-8066

$\$ 250,000$

NASA Contact: J. C. Wood, (216) 433-3419

Detroit Diesel Corporation Contact: Theodore Freiheit, (313) 592-7224

The objective of the project is to develop advanced technology diesel engine components and integrate these into a test bed engine to demonstrate reduced emissions and improved fuel economy. Advanced seramic and metallic materials are being investigated and used in structural, insulative, and tribological component applications.

Keywords: Structural Ceramics, Low Heat Rejection Diesel Engines, Thermal Barrier Coatings, Component Designs, Composite Materials

106. Advanced Piston and Cylinder Component Development

FY 1994

DOE Contact: John W. Fairbanks, (202) 586-8066

$\$ 300,000$

NASA Contact: J. C. Wood, (216) 433-3419

Caterpillar Inc. Contact: G. L. Waltz, (309) 578-6549

The objective of the project is to develop advanced technology diesel engine components and integrate these into a test bed engine to demonstrate reduced emissions and improved fuel economy. Advanced ceramic and metallic materials are being investigated and used in structural, insulative, and tribological component applications. Zirconia coatings are being used on piston crowns and composite pistons are being tested.

Keywords: Structural Ceramics, Low Heat Rejection Diesel Engines, Thermal Barrier Coatings, Component Designs, Composite Materials 
107. Advanced Piston and Cylinder Component Development

FY 1994

$\$ 600,000$

DOE Contact: John W. Fairbanks, (202) 586-8066

NASA Contact: M. J. Valco, (216) 433-3717

Cummins Engine Contact: T. Yonushonis, (812) 377-7078

The objective of the project is to develop advanced technology diesel engine components and integrate these into a test bed engine to demonstrate reduced emissions and improved fuel economy. Advanced ceramic and metallic materials are being investigated and used in structural, insulative and tribological component applications. Castin-place titanium nitride exhaust port liners are emerging with improved reliability. Several powder metallurgy parts are being tested and mullite coatings are being used on piston crowns.

Keywords: Structural Ceramics, Low Heat Rejection Diesel Engines, Thermal Barrier Coatings, Component Designs, Composite Materials

\section{Electric and Hybrid Propulsion Division}

The Electric and Hybrid Propulsion Division has three major programs Battery Development, Fuel Cell Development, and Systems Development for electric vehicles. The DOE Program Manager is Kenneth Heitner, (202) 586-2341 for Battery Development; Robert Kost, (202) 586-2334 for Fuel Cells Development; and Albert Landgrebe, (202) 5862480 for Exploratory Research in support of Batteries and Fuel Cells.

Materials Preparation. Synthesis, Deposition. Growth or Forming

108. Electrochemical Properties of Solid-State Sodium Polymer Cells

FY 1994

$\$ 260,000$

DOE Contact: JoAnn Milliken, (202) 586-2480

Lawrence Berkeley Laboratory Contact: L. C. De Jonghe, (510) 486-4881

The objective of this project is to investigate the viability of all-solid-state cells based on $\mathrm{Na}$ or $\mathrm{Na}$ alloy negative electrodes, polymeric electrolytes, and metal oxide positive electrodes. Emphasis is placed on developing a suitable cathode material not only in terms of performance but also in terms of cost and environmental impact. The approach is to synthesize and characterize manganese oxides for use as a cathode in $\mathrm{Na} /$ polymer cells and employ $\mathrm{AC}$ and DC techniques (e.g., galvanostatic charging and discharging, four probe techniques, and pulse testing) to characterize solid state batteries, as well as the properties of the individual components and interfaces. Results have shown that $\mathrm{Na}_{0.44} \mathrm{MnO}_{2}$ cathodes in a $\mathrm{Na}$ /polymer cell can insert $0.55 \mathrm{Na} / \mathrm{Mn}$ over a voltage range of $3.4-2.0 \mathrm{~V}$ at 0.1 $\mathrm{mA} / \mathrm{cm}^{2}$, corresponding to a capacity of $160 \mathrm{mAh} / \mathrm{g}$, a theoretical specific energy of 440 
$\mathrm{Wh} / \mathrm{kg}$ and a theoretical energy density of $1450 \mathrm{Wh} / \mathrm{L}$. Future effort will focus on the synthesis, characterization and testing of manganese oxides with large tunnels to accommodate $\mathrm{Na}$ ions, measurement of transport properties in $\mathrm{Na} /$ polymer cells, and $\mathrm{Na}$ /polymer cell testing to optimize its performance.

Keywords: Batteries, Solid-State Cells, Electric Vehicles, Polymeric Electrolytes

109. Corrosion Resistant Coatings for High Temperature High-Sulfur-Activity FY 1994 Applications

DOE Contact: JoAnn Milliken, (202) 586-2480

Illinois Institute of Technology Contact: J. R. Selman, (312) 567-6914

The objective of this research is to develop corrosion-resistant coatings for cell components that are exposed to high-sulfur-activity environments in $\mathrm{Na} / \mathrm{S}$ and $\mathrm{Li} / \mathrm{FeS}{ }_{2}$ cells. This research is intended to assist in developing the technology for the production of Mo and molybdenum carbide coatings. Such coatings can be utilized to produce low-cost containers and current collector materials in non-aqueous, alkali/sulfur, and other moltensalt cells. Plasma-enhanced chemical vapor deposition (CVD) was employed as the new technique for the preparation of thin protective films at much lower temperatures than by thermally driven CVD. Theoretical studies were conducted to understand the deposition process. Results to date have shown that the evaporation and deposition rate are correlated with the equilibrium pressure of $\mathrm{Mo}(\mathrm{CO})_{6}$ and other process variables. This project has been completed.

Keywords: Corrosion, Plasma-Enhanced CVD, Kinetic-Gas Theory

110. Improved Container Electrode Coatings for Sodium/Sulfur Battery Systems

FY 1994

$\$ 100,000$

DOE Contact: JoAnn Milliken, (202) 586-2480

Environmental Research Institute of Michigan Contact: T. K. Hunt, (313) 667-2113

The objective of this project is to develop improved corrosion-resistant coatings for high-temperature secondary batteries by sputter-deposition techniques. Research is underway to determine the utility of titanium films as durable, corrosion protective, conductive coatings for the sulfur electrodes in $\mathrm{Na} / \mathrm{S}$ batteries. Several series of sputterdeposited TiN coatings were applied to $\mathrm{Al}$ coupons and the resulting samples soaked in 
$\mathrm{Na}_{2} \mathrm{~S}_{4}$ at temperatures up to $390^{\circ} \mathrm{C}$ for 500 hours. The sputtering conditions were modified during the test series and the latter coatings showed no visible signs of corrosion following the $\mathbf{5 0 0}$ hour exposure. This project has been completed.

Keywords: Coatings, Na/S Batteries, Sputter-Deposition

111. The Performance of New Materials for Polymer Electrolyte Batteries

FY 1994

DOE Contact: JoAnn Milliken, (202) 586-2480

$\$ 140,000$

Northwestern University Contact: D. F. Shriver, (708) 491-5655

The objective of this project is to synthesize polymer electrolytes based on aluminosilicate-polyether hybrid polyelectrolyte with improved low-temperature performance and high cation transport number. These polymer electrolytes should be useful in rechargeable $\mathrm{Li} /$ polymer batteries. Initial efforts have focused on cell testing with simple polymer-salt electrolytes. This includes cycling with a cathode consisting of $85 \% \mathrm{Li}_{\mathbf{x}} \mathrm{MnO}_{2}$, $10 \%$ carbon, $5 \%$ binder, and a Li-metal anode. The data from these cells will provide a baseline for comparison with more advanced polyelectrolytes such as aluminosilicatepolyether hybrid polyelectrolyte.

Keywords: Polymer Electrolytes, Electrochemical Cells

112. Novel Polymer Electrolytes for Rechargeable Lithium Batteries

FY 1994

DOE Contact: JoAnn Milliken, (202) 586-2480

$\$ 160,000$

Case Western University Contact: M. Litt, (216) 368-4174

The objective of this research is to develop advanced polymeric electrolytes for rechargeable $\mathrm{Li}$ batteries. Thin polymeric films will be cast and characterized by spectroscopic, nuclear magnetic resonance, thermal and electrochemical techniques. Two types of polymer materials are under investigation sulfonated and phosphonated polybenzimidazole polymers, and novel poly (4,5-dimethyleneimidazole and hydroxy imidazole) polymers. Currently, efforts are focused on preparing the polymer electrolytes. Once the electrolytes have been synthesized and evaluated electrochemically, efforts will be expanded to include sulfonated PEEK, sulfonated and phosphonated PPE and soluble polyphenylenes.

Keywords: Polymeric Electrolytes, Li Batteries 
113. Novel Solid Polymer Electrolytes for Advanced Secondary Batteries

FY 1994

DOE Contact: JoAnn Milliken, (202) 586-2480

$\$ 130,000$

University of Dayton Contact: D. G. Glasgow, (513) 229-2517

The objective of this research program is to synthesize and characterize new polymer electrolytes that contain crown ethers which could improve the Li-ion transport. The systems proposed are doped polymers with side chains having the ability to form liquid crystalline mesophases. Synthesis of the three polymers required for this program has been initiated. Future efforts will focus on completing synthesis of polymer electrolytes and characterization of the polymers with respect to ionic conductivity, dimensional stability, and interfacial stability.

Keywords: Polymeric Electrolytes, Li Batteries, Ion Transport

114. Sol-Gel Electrolytes in Lithium Batteries

FY 1994

$\$ 130,000$

DOE Contact: JoAnn Milliken, (202) 586-2480

Rutgers University Contact: L. C. Klein, (908) 932-2096

The objective of this research project is to optimize the synthesis of polymer electrolytes by sol-gel processing of alkali/silicate components, which involves combining the components in liquid form prior to chemically reacting the solution with water to form a gel. These materials should produce solid electrolyte compositions that can be applied directly to electrode materials for rechargeable $\mathrm{Li}$ batteries. The approach used in this investigation is to select oxide components that are Li-ion conductors and are thermodynamically stable. Calculations will be conducted to determine the thermodynamic stability of the various oxide materials. Compositions that are predicted to have increased stability will be selected from this analysis and prepared for evaluation.

Keywords: Sol-Gel Electrolytes, Li Batteries, Polymer Electrolytes

115. New Cathode Materials

FY 1994

DOE Contact: JoAnn Milliken, (202) 586-2480

$\$ 110,000$

State University of New York Contact: M. S. Whittingham, (607) 777-4623

The objective of this project is to synthesize and evaluate oxides of tungsten, molybdenum, and first-row transition metals for alkali-metal intercalation electrodes which are useful as positive electrodes in advanced nonaqueous rechargeable batteries. Mild hydrothermal techniques will be used for the synthesis of molybdenum oxides, or, in cases where the hydrothermal technique does not lead to compounds with the highest oxidation state, electrochemical oxidation from an aqueous alkaline solution will be used to drive the 
cations to their highest oxidation state. Once completed, research will be expanded to synthesize and test vanadium and manganese oxides.

Keywords: Intercalation Electrodes, Rechargeable Batteries

116. Development of High Energy Density Cathodes for Sodium/Polymer CellsFY 1994

DOE Contact: JoAnn Milliken, (202) 586-2480

$\$ 170,000$

SRI International Contact: S. Smedley, (415) 859-6173

The major objective of this research is to develop high-performance organic polydisulfide positive electrodes for use in low-temperature (ambient to $100^{\circ} \mathrm{C}$ ) $\mathrm{Na} /$ polymer cells. This will be achieved by the synthesis and characterization of hexathiobenzene-based compounds and their derivatives for positive electrodes. Specific parameters under investigation include the nature of any heteroatoms or side chains added to the base polymer, the structure of the polymer, the cathode thickness, the voltage stability window of the cathode, the degree of loading of the positive electrode material, the electrode construction technique, and the operating temperature of the cell. Electrodes will be judged on the basis of capacity density, energy density, discharged rate capability, and cyclability. Current efforts are concentrated on synthesis of electrode materials and on cell design and electrode construction techniques.

Keywords: Cathodes, $\mathrm{Na}$ /polymer Cells, Electrochemical Analysis

\section{Materials Properties, Behavior, Characterization or Testing}

117. Surface Morphology of Metals in Electrodeposition/

Carbon Electrochemistry

FY 1994

$\$ 240,000$

DOE Contact: JoAnn Milliken, (202) 586-2480

Lawrence Berkeley Laboratory Contact: K. Kinoshita and C. Tobias, (510) 486-4260

The objective of this project is to develop a pragmatic understanding of the component processes and their interactions in the macrocrystallization of metals necessary for the design and optimization of rechargeable galvanic cells. This project involves investigation of: (1) the role of electric field and solution-side mass transport in the electrocrystallization of metals, mechanisms of initiation, growth and propagation of imperfections, and development of surface textures; (2) the characterization of gases at electrodes with emphasis on their effect on ohmic resistance and mass transfer; and (3) the role of physicochemical properties of carbonaceous materials on their ability to reversibly intercalate $\mathrm{Li}$. Results have shown that a hemispherical protrusion as small as $\mathbf{5 0}$ micron radius can be attached to the surface of a micromosaic electrode. In addition a 
mathematical model has been completed to understand the hydrodynamics of flow over protrusions. Future efforts will extend the numerical modeling to study mass transport for flows in a turbulent region and evaluate the dynamics of bubble phenomena in electrolytic gas evolution.

Keywords: Macrocrystallization of Metals, Galvanic Cells, Li Batteries

118. Battery Materials Structure and Characterization

FY 1994

DOE Contact: JoAnn Milliken, (202) 586-2480

$\$ 100,000$

Brookhaven National Laboratory Contact: J. McBreen, (516) 282-4071

The objective of this research is to elucidate the molecular aspects of materials and electrode processes in batteries and to use this information to develop electrode and electrolyte structures with good performance and long life. Current efforts have included in situ extended $\mathrm{x}$-ray absorption fine structure (EXAFS) studies of Bi-doped manganese oxides and ex situ studies of lithium manganese oxides and nickel oxide electrodes that were cycled in $\mathrm{Zn} / \mathrm{NiOOH}$ cells. Results have shown that doping of manganese oxides with Group VIB metal oxides improved the rate capabilities of the electrode in an electrolyte consisting of $\mathrm{LiClO}_{4} / \mathrm{PC}$-DME. Future efforts will focus on EXAFS studies of additives in nickel oxide and zinc electrodes as well as studies of molybdenum and tungsten oxide electrodes.

Keywords: Electrodes, Batteries, EXAFS

119. In Situ Spectroscopic Applications to the Study of Rechargeable Lithium Batteries

FY 1994 $\$ 135,000$

DOE Contact: JoAnn Milliken, (202) 586-2480

Case Western Reserve University Contact: D. A. Scherson, (216) 368-5186

The purpose of this project is to use in situ spectroscopic techniques to investigate the electrochemical phenomena that occur at $\mathrm{Li}$ /electrolyte interfaces during charge/discharge cycling. Two cell technologies are being investigated $\mathrm{Li} /$ polymer electrolyte and $\mathrm{Li} / \mathrm{FeS}_{2}$. The approach is to conduct experimental studies under ultrahigh vacuum conditions to examine the reactivity of $\mathrm{Li}$ at the $\mathrm{Li}$ /polymer and $\mathrm{Li} /$ liquid electrolyte interfaces. To date, temperature programmed desorption studies have shown that ultra-clean Li exposed to PC produces alkyl carbonate and lithium hydride and Fourier 
Transform Infrared Spectroscopy (FTIR) indicates that no reaction occurs at the Li/PEO interface. Efforts will continue to investigate the interfacial reactions at the Li/electrolyte interfaces and develop a high-vacuum environmental chamber to conduct ATR/FTIR measurements of the $\mathrm{Li}$ /polymer interface.

Keywords: Spectrographic Analysis, Electrochemical Phenomena, Electrolytes

120. Polymer Electrolyte for Ambient Temperature Traction Batteries: Molecular Level Modeling for Conductivity Optimization

FY 1994 $\$ 160,000$

DOE Contact: JoAnn Milliken, (202) 586-2480

Northwestern University Contact: M. A. Ratner, (708) 491-5371

The goal of this research is to apply molecular dynamics and Monte Carlo simulations to understand the conduction process in polymer electrolytes, and its modification by such parameters as temperature, density, ion species, polymer chain basicity, and interionic correlations. The results of this study should be beneficial in the development of improved polymer electrolytes for rechargeable Li batteries for electric vehicle applications.

Keywords: Batteries, Electric Vehicles, Polymeric Electrolytes

121. Analysis and Simulation of Electrochemical Systems

FY 1994 $\$ 240,000$

DOE Contact: JoAnn Milliken, (202) 586-2480

University of California, Berkeley Contact: J. Newman, (510) 642-4063

The objective of this program is to improve the performance of electrochemical cells used in the interconversion of electrical energy and chemical energy by identifying the phenomena which control the performance of a system. These phenomena are incorporated into a mathematical model which can predict system behavior. The models aid in the recognition of important parameters that are crucial to the optimization of a given electrochemical system. Computer techniques with electrochemical engineering principles permit the calculation of complex interactions without gross mathematical and physical approximations. Results have identified the physical process taking place in the galvanostatic charge and discharge of a $\mathrm{Li} /$ polymer/insertion cell. In addition, a mathematical model has been developed that elucidates the dynamic changes in the secondary cell. Future efforts will continue to focus on modeling the behavior of electrochemical capacitors and metal hydride cells.

Keywords: Electrochemical Phenomena, Galvanostatic Charge/Discharge 
122. Heat Transport and Thermal Management in Advanced Batteries

FY 1994

$\$ 160,000$

DOE Contact: JoAnn Milliken, (202) 586-2480

University of California, Berkeley Contact: J. W. Evans, (510) 642-3807

This project was initiated in FY 1994 to investigate, by mathematical modeling and experimental measurement, heat generation and transport in advanced secondary batteries for EV applications. The objectives of this project are to evaluate the management of the temperature of the battery for optimum performance and avoiding temperature excursions damaging to the battery. Initial investigations will focus on $\mathrm{Li}$ /polymer batteries that are under development to operate in the temperature range of approximately 60 to $140^{\circ} \mathrm{C}$ which is required to obtain sufficient polymer conductivity and to avoid overheating.

Keywords: Thermal Modeling, Advanced Batteries

123. Electrode Surface Layers

FY 1994

DOE Contact: JoAnn Milliken, (202) 586-2480

$\$ 125,000$

Lawrence Berkeley Laboratory Contact: F. R. McLarnon, (510) 486-4260

Advanced in situ and ex situ characterization techniques are being used to study the structure, composition, and mode of formation of surface layers on electrodes used in rechargeable batteries. The objective of this research is to identify film properties that improve the rechargeability, cycle-life performance, specific power, specific energy, stability, and energy efficiency of electrochemical cells. Sensitive techniques such as ellipsometry, light scattering, Raman spectroscopy and scanning electron microscopy will be utilized to monitor the formation of surface layers on secondary battery electrodes. In addition, foreign ions will be incorporated in porous nickel electrodes to improve the cycle performance in an alkaline electrolyte.

Keywords: Ion Implantation, Electrodes, Rechargeable Batteries

124. Electrode Kinetics and Electrocatalysis

FY 1994

$\$ 100,000$

DOE Contact: JoAnn Milliken, (202) 586-2480

Lawrence Berkeley Laboratory Contact: P. N. Ross, Jr., (510) 486-6226

Physically meaningful mechanistic models are essential for the interpretation of electrode behavior and are useful in directing the research on new classes of materials for electrochemical energy conversion and storage devices. The objective of this project is to develop an atomic-level understanding of the processes taking place in complex electrochemical reactions at electrode surfaces. Researchers are employing LEED to study 
single crystals; HREM for carbon electrode materials; and EXAFS for organometallic catalysts. LEIS and AES are being utilized to study the composition of sputtered and UHVannealed polycrystalline Pt-Ru bulk alloys for methanol electrocatalysis. Future efforts will consider methanol electrooxidation on $\mathrm{Pt}-\mathrm{Ru}$ electrocatalyst particles.

Keywords: Spectrographic Analysis, Electrocatalysts, Electrooxidation

125. Effect of Electrocatalyst and Electrolyte Composition on Methanol/Air Fuel Cell Performance

DOE Contact: JoAnn Milliken, (202) 586-2480

Lawrence Berkeley Laboratory Contact: E. J. Cairns and P. N. Ross, (510) 486-6226

There is a strong need to develop a fuel cell that can electrochemically oxidize liquid fuels, and the successful development of a direct-methanol fuel cell (DMFC) would represent a major advance for fuel-cell-powered vehicles. However, some major obstacles such as oxidation rate must be addressed before acceptable performance can be attained. The objective of this project is to elucidate the mechanism of methanol electrooxidation on electrocatalysts for DMFCs. Results have shown that the optimum surface composition of $\mathrm{Pt}-\mathrm{Ru}$ varied with temperature and the shift in optimum composition with temperature can be attributed to a shift in the rate-determining step from $\mathrm{CH}_{3} \mathrm{OH}$ adsorption/ dehydrogenation at room temperature to the surface reaction between the dehydrogenated intermediate and surface oxygen at $60^{\circ} \mathrm{C}$.

Keywords: Electrooxidation, Fuel Cells

126. Poisoning of Fuel Cell Electrocatalyst Surfaces: NMR Spectroscopic Studies

FY 1994

$\$ 200,000$

DOE Contact: JoAnn Milliken, (202) 586-2480

Lawrence Berkeley Laboratory Contact: E. J. Cairns, (510) 486-5028

Platinum is the most active single-component catalyst for $\mathrm{CH}_{3} \mathrm{OH}$ electrooxidation in DMFCs; however, poisoning reactions at the surface render the anode ineffective under target operation conditions. The objective of this research is to obtain information on the nature of the poisoning intermediate(s) in $\mathrm{CH}_{3} \mathrm{OH}$ electrooxidation on Pt-based electrocatalysts by NMR. Experiments are currently underway to determine the feasibility of NMR to detect surface poisons during methanol electrooxidation.

Keywords: NMR, Electrooxidation, Fuel Cells 
127. Fuel Cells for Renewable Applications

FY 1994

DOE Contact: JoAnn Milliken, (202) 586-2480

$1,000,000$

Los Alamos National Laboratory Contact: S. Gottesfeld, (505) 667-0853

The primary focus of this program is to develop efficient and cost-effective polymer electrolyte fuel cells (PEFC) for transportation applications. The specific goals of the program are to: (1) reduce the cost of the $\mathrm{Pt}$ catalyst and ionomeric membrane, (2) increase the efficiency and power density of the PEFC, (3) optimize the system for operation on reformed organic fuels and air, (4) achieve stable, efficient, long-term operation, and (5) solve key technical issues that impede the development of the DMFC. Two patents have been awarded describing the developments in membrane catalyst layers for fuel cells and the use of the thermoplastic (TBA+) form of the ionomer. Efforts will continue to focus on improving the performance and life of PEM fuel cells and identifying new low-cost components for these fuel cells.

Keywords: Fuel Cells, Proton Exchange Membranes, Methanol Oxidation

128. Electrocatalysis of Fuel Cell Reactions

FY 1994

DOE Contact: JoAnn Milliken, (202) 586-2480

Brookhaven National Laboratory Contact: J. McBreen, (516) 282-4513

The purpose of this project is to increase the understanding of electrocatalysis on a molecular level and to apply this knowledge to improve the performance of fuel cells for transportation applications. The goals are to reduce the Pt requirements for solid PEFCs, to develop non-Pt catalysts for oxygen reduction, and to identify catalysts for the direct oxidation of methanol. The approach is to use X-ray absorption (XAS) to study the chemical/electrochemical properties of fuel cell electrocatalysts. XAS results have shown that the electrocatalysis of small organic molecules on $\mathrm{Pb}$-modified $\mathrm{Pt}$ cannot be attributed to adsorption of oxygen species on $\mathrm{Pb}$, rather the disordered nature of the $\mathrm{Pb}$ adlayer. This project has been completed.

Keywords: Fuel Cells, Electrocatalysts, X-Ray Absorption 


\section{Device or Component Fabrication, Behavior or Testing}

129. $\mathrm{Zn} / \mathrm{NiOOH}$ Cell Studies

FY 1994

$\$ 250,000$

DOE Contact: JoAnn Milliken, (202) 586-2480

Lawrence Berkeley Laboratory Contact: E. Cairns and F. McLarnon, (510) 486-4260

The purpose of this project is to investigate the behavior of $\mathrm{Zn}$ electrodes in alkaline $\mathrm{Zn} / \mathrm{NiOOH}$ cells to improve their lifetime and performance. $\mathrm{Zn} / \mathrm{NiOOH}$ batteries would provide superior performance and lower life-cycle costs compared to $\mathrm{Cd} / \mathrm{NiOOH}$ and $\mathrm{MH} / \mathrm{NiOOH}$ batteries. The approach of this project is to determine the performance and cycle life of alkaline $\mathrm{Zn} / \mathrm{NiOOH}$ cells using realistic cell components and operating conditions as well as utilize analytical instruments such as X-ray diffraction analysis and XAS to understand changes to cell components resulting from charge/discharge cycling. $\mathrm{X}$-ray photoelectron spectroscopy results have shown that the $\mathrm{NiOOH}$ electrode in the $\mathrm{Zn} / \mathrm{KOH} / \mathrm{NiOOH}$ cells do not chemically react with the $\mathrm{Zn}$ species under cycling conditions with a $\mathrm{KOH}-\mathrm{KF}-\mathrm{K}_{2} \mathrm{CO}_{3}$ electrolyte. Future efforts will focus on: (1) evaluating lightweight low-cost NiOOH electrodes in model $\mathrm{Zn} / \mathrm{NiOOH}$ cells, (2) evaluating novel separator and wick materials that may provide better wetting characteristics, and (3) establishing a CRADA with Energy Research Corporation to further technology transfer.

Keywords: Electrodes, Batteries, Electric Vehicles

130. Applied Research on Secondary $\mathrm{Zn} / \mathrm{NiOOH}$ Battery Technology

FY 1994 $\$ 200,000$

DOE Contact: JoAnn Milliken, (202) 586-2480

Acme Electric Corporation Contact: M. Anderman, (602) 921-0470

The objectives of this project are to evaluate the Lawrence Berkeley Laboratory (LBL) electrolyte composition for extending the cycle life of $\mathrm{Zn} / \mathrm{NiOOH}$ cells, and to develop these cells for EV applications. Cells containing the LBL electrolyte were fabricated and results have shown that 175 charge/discharge cycles were completed. A visual examination of the electrodes showed a drastic improvement (reduction) in electrode shape change compared to the electrodes cycled in the standard, highly-alkaline electrolyte. Future efforts will be aimed at achieving comparable performance with 20 -Ah cells to that obtained by LBL.

Keywords: Electrodes, Batteries, Electric Vehicles 
131. Development of a Thin-Film Rechargeable Lithium Battery for Electric Vehicles

DOE Contact: JoAnn Milliken, (202) 586-24880

Oak Ridge National Laboratory Contact: J. B. Bates (615) 574-4143

The objective of this research is to identify methods for depositing acceptable thinfilm electrodes for rechargeable $\mathrm{Li}$ batteries. These methods are being applied to develop solid-state $\mathrm{Li} / \mathrm{Li}_{x} \mathrm{Mn}_{2} \mathrm{O}_{4}$ rechargeable thin-film $\mathrm{Li}$ batteries for electric vehicle applications. The batteries are expected to have several important advantages as power sources high specific energy and energy density, long cycle lifetimes, and a wide temperature range of operation. Accomplishments have included fabrication of $\mathrm{Li} / \mathrm{Li}_{x} / \mathrm{Mn}_{2} \mathrm{O}_{4}$ cells in which the cathode was deposited at temperatures below $150^{\circ} \mathrm{C}$ by if magnetron sputtering and fabrication of thin-film cells capable of sustaining current densities of several $\mathrm{mA} / \mathrm{cm}^{2}$, having a specific power of $30 \mathrm{~W} / \mathrm{g}$ at an $85 \mathrm{C}$ discharge rate. Efforts will focus on improving the performance of $\mathrm{Li}_{\mathrm{x}} \mathrm{Mn}_{2} \mathrm{O}_{4}$ cathode films deposited at low temperatures and investigate the performance of a hybrid solid-state $\mathrm{Li}_{-} \mathrm{Li}_{\mathrm{x}} \mathrm{Mn}_{2} \mathrm{O}_{4}$ cell.

Keywords: Electric Vehicles, Thin-Film Batteries, Solid-State Electrodes

\section{Na/SRPE Electric Vehicle Batteries}

FY 1994 $\$ 200,000$

DOE Contact: JoAnn Milliken, (202) 586-2480

PolyPlus Battery Company Contact: May-Ying Chu (510) 841-4313

The purpose of this project is to demonstrate the cycling capability of cells containing $\mathrm{Na}$ negative and organosulfur-based positive electrodes, and develop a low-cost highperformance $\mathrm{Na}$ /polymer cell that utilizes an organosulfur-based positive electrode. The proposed batteries will be mechanically sturdy, have a reliable electrical performance, operate between 50 and $80^{\circ} \mathrm{C}$, and are expected to be immune to thermal cycling. To date, approximately 80 laboratory $\mathrm{Na}$ /solid redox polymerization electrode (SRPE) cells have been constructed and testing has been initiated. Future efforts will include formulating a low-cost cell design and demonstrating the performance scaling of cells to 10 times larger than current test cells.

Keywords: Electrodes, Batteries, Electric Vehicles 


\section{Lithium-Ion Battery Testing}

FY 1994

$\$ 200,000$

DOE Contact: JoAnn Milliken, (202) 586-2480

Lawrence Livermore National Laboratory Contact: S. Mayer, (510) 423-4897

The objective of this project is to evaluate the performance of Li-ion cells to determine their cycle life and energy/power characteristics under controlled conditions. In this study, cells manufactured by the Sony Corporation for use in portable electronic devices were tested. The capacity and specific energy of cells that were charged to $4.2 \mathrm{~V}$ were about $1 \mathrm{Ah}$ and $>94 \mathrm{Wh} / \mathrm{kg}$, respectively. Cycle life exceeded 300 cycles under Dynamic Stress Test at $100 \%$ DOD, and 2800 cycles at $44 \%$ DOD. This project has been completed.

Keywords: Li Batteries, Dynamic Stress Testing

134. Novel Concepts for an Oxygen Electrode in Secondary Metal-Air Batteries

FY 1994 $\$ 104,000$

DOE Contact: JoAnn Milliken, (202) 586-2480

Eltech Research Corporation Contact: E.J. Rudd, (216) 357-4073

The objective of this research is to develop improved bifunctional air electrodes for electrically rechargeable $\mathrm{Zn} /$ air cells. The successful development of bifunctional air electrodes depends on selecting electrochemically stable support materials and electrocatalysts for $\mathrm{O}_{2}$ reduction and evolution, and the fabrication of suitable porous structures that are capable of extended operation. In this program, the properties of corrosion-resistant substrates such as semi-graphitic carbon, graphite or non-carbon materials were investigated. Results show that electrodes with a graphitized acetylene black for the support and $\mathrm{NiCo}_{2} \mathrm{O}_{4}$ and either CoTMPP or $\mathrm{La}_{0.6} \mathrm{Ca}_{0.4} \mathrm{CoO}_{3}$ as electrocatalysts have operated for over 100 cycles in $35 \% \mathrm{KOH}$ at room temperature.

Keywords: Metal-Air Batteries, Bifunctional Air Electrodes, Zn/Air Cells

\section{Office of Alternative Fuels}

The Office of Alternative Fuels has three major programs Biofuels Production, Alternative Fuels Utilization, and the Alternative Motor Fuels Act (AMFA) fleet test program. Materials technologies for alternative fuels are being addressed by the Office of Transportation Materials and other DOE offices. The DOE contact for biofuels is John Ferrell, (202) 586-6745, and the DOE contacts for alternative fuels are John Russell, Richard Wares, or Steve Goguen, (202) 586-8053. 


\section{Materials Properties, Behavior. Characterization or Testing}

135. Cold-start Assist Materials

FY 1994

$\$ 50,000$

DOE Contract S. Goguen, (202) 586-8053

Oak Ridge National Laboratory Contact: R. Graves, (615) 574-2036

This project examines a wide variety of materials to determine their exothermic properties during phase change. The heat released would be utilized to vaporize alcohol automotive fuels to enhance their cold-starting characteristics.

Keywords: Phase-Change Materials, Alcohol Fuels

136. CNG Adsorbents Demonstration

FY 1994 $\$ 300,000$

DOE Contact: M. Gurevich, (202) 586-8053

BNL Contact: J. Wegrzyn, (516) 282-7917

This project screens and evaluates materials for their effectiveness in adsorbing natural gas. An adsorbent placed in a storage vessel could hold sufficient compressed natural gas (CNG) to reduce working pressure to $500 \mathrm{psi}$. This would permit introduction of complex geometry (shaped) automotive tanks configured to take advantage of interior vehicle "dead space" as well as reducing overall weight requirements. Net result would be increased range.

Keywords: Natural Gas Adsorbent Materials, Alternative Fuels

137. Improved Catalyst Materials and Emissions Control Systems

FY 1994

DOE Contact: S. Goguen, (202) 586-8053

$\$ 375,000$

Oak Ridge National Laboratory Contact: R. Graves, (615) 574-2036

This project is being conducted in a. CRADA between AC Delco and Oak Ridge National Laboratory. The focus of the effort is to determine deactivation mechanisms in catalysts and thereby propose improvements in materials that will extend catalyst life. The project is co-funded by other DOE offices. Relationships between catalyst microstructure, bench tests, and engine test cell results are being developed.

Keywords: Alternative Fuels, Catalyst, Catalyst Performance 


\section{OFFICE OF UTILITY TECHNOLOGIES}

FY 1994

Office of Utility Technologies - Grand Total

$\$ 31,454,000$

Office of Solar Energy Conversion

$\$ 18,100,000$

Photovoltaic Energy Technology Division

$\$ 18,100,000$

Materials Preparation, Synthesis, Deposition, Growth or Forming

$\$ 13,200,000$

Amorphous Silicon for Solar Cells

Polycrystalline Thin Film Materials for Solar Cells

Deposition of III-V Semiconductors for High-Efficiency Solar Cells

$4,500,000$

$7,500,000$

$1,200,000$

Materials Properties, Behavior. Characterization or Testing

$\$ 2,500,000$

Materials and Device Characterization

$2,500,000$

Device or Component Fabrication, Behavior or Testing

$\$ 2,400,000$

High-Efficiency Crystal Silicon Solar Cells

$2,400,000$

Office of Renewable Energy Conversion

$\$ 600,000$

Geothermal Division (GD)

$\$ 600,000$

Materials Preparation, Synthesis, Deposition, Growth or Forming

$\$ 90,000$

Thermally Conductive Composites for Heat Exchangers

90,000

Materials Properties, Behavior. Characterization or Testing

Advanced High Temperature Geothermal Well Cements

Advanced High Temperature Chemical Systems for for Lost Circulation Control

Corrosion Mitigation in Highly Acidic Steam Condensates

$\$ 510,000$

390,000

20,000

100,000 
OFFICE OF UTILITY TECHNOLOGIES

Office of Energy Management

$\$ 12,754,000$

Advanced Utility Concepts Division

$\$ 12,754,000$

Superconductivity Systems Program

Device or Component Fabrication, Behavior or Testing

$\$ 12,300,000$

Wire Technology Project

$5,500,000$

Systems Technology

$5,600,000$

Superconductivity Partnership Initiative

$1,200,000$

Thermal Energy Storage Program

$\$ 454,000$

Materials Properties, Behavior Characterization or Testing

$\$ 140,000$

High Temperature Composite Phase Change Material

Geochemistry Dynamics Associated with Ground

Water Heating

40,000

100,000

Device or Component Fabrication, Behavior or Testing

\$ 314,000

Phase Change Thermal Storage for Domestic Water Heating

59,000

Complex Compound Therrnal Energy Storage System

255,000 


\section{OFFICE OF UTILITY TECHNOLOGIES}

\section{Office of Solar Energy Conversion}

\section{Photovoltaic Energy Technology Division}

The National Photovoltaics program sponsors high-risk, potentially high-payoff research and development in photovoltaic energy technology that will result in a technology base from which private enterprise can choose options for further development and competitive application in U.S. electrical markets. The objective of materials research is to overcome the technical barriers currently limiting the efficiency and cost of photovoltaic cells. Theoretical conversion efficiency of photovoltaic cells is limited by the portion of the solar spectrum to which the cell's semiconductor material can respond, and by the extent to which these materials can convert each photon to electricity. The practical efficiency is constrained by the amount of light captured by the cell, the cell's uniformity, and a variety of loss mechanisms for the photo-generated carriers. Cost is affected by the expense and amount of materials required, the complexity of processes for fabricating the appropriate materials, and the complexity and efficiency of converting these materials into cells.

\section{Materials Preparation, Synthesis, Deposition, Growth or Forming}

\section{Amorphous Silicon for Solar Cells}

FY 1994

DOE Contact: Richard King, (202) 586-1693

$\$ 4,500,000$

NREL Contact: Werner Luft, (303) 384-6452

This project performs applied research upon the deposition of amorphous silicon alloys to improve solar cell properties. Efficient solar energy conversion is hindered by improper impurities or undesired structure in the deposited films and the uniformity of the films over large $\left(1000 \mathrm{~cm}^{2}\right)$ areas. The films are deposited by plasma enhanced chemical vapor deposition (glow discharge), thermal chemical vapor deposition and sputtering. The long term goal of this effort is to develop the technology for 12 percent efficient solar cells with an area of about $1000 \mathrm{~cm}^{2}$. Achieving that goal should enable amorphous silicon to be a cost-effective electrical generator.

Keywords: Amorphous Materials, Coatings and Films, Semiconductors, Chemical Vapor Deposition, Sputtering and Solar Cells 
139. Polycrystalline Thin Film Materials for Solar Cells

FY 1994

DOE Contact: Richard King, (202) 586-1693

$\$ 7,500,000$

NREL Contact: Kenneth Zweibel, (303) 384-6441

This project performs applied research upon the deposition of CuInSe $\mathrm{C}_{2}$ and CdTe thin films for solar cells. Research centers upon improving solar cell conversion efficiency by depositing more nearly stoichiometric films, by controlling interlayer diffusion and lattice matching in heterojunction structures and by controlling the uniformity of deposition over large $\left(1000 \mathrm{~cm}^{2}\right)$ areas. The films are deposited by chemical and physical vapor deposition, electrodeposition and sputtering. The long term goal for this effort is to develop the technology for 15 percent efficient solar cells with areas of about $1000 \mathrm{~cm}^{2}$. Achieving this goal would enable polycrystalline thin fillm material to be a cost-effective electrical generator.

Keywords: Coatings and Films, Semiconductors, Chemical Vapor Deposition, Physical Vapor Deposition, Electrodeposition, Sputtering and Solar Cells

140. Deposition of III-V Semiconductors for High-Efficiency Solar Cells

FY 1994

DOE Contact: Richard King, (202) 586-1693

$\$ 1,200,000$

NREL Contact: John Benner, (303) 384-6496

This project performs applied research upon deposition of III-V semiconductors for high efficiency solar cells, both thin film for flat plate applications and multilayer cells for concentrator applications. Research centers upon depositing layers precisely controlled in terms of composition, thickness and uniformity and studying the interfaces between the layers. The materials are deposited by chemical vapor deposition, liquid phase epitaxial growth and molecular beam epitaxial growth. The long term goal of this area is to develop 35 percent efficient concentrator cells and 24 percent $100 \mathrm{~cm}^{2}$ one-sun cells for flat plate applications. Achieving these goals would enable systems using these technologies to be cost-effective electrical generators.

Keywords: Semiconductors, Chemical Vapor Deposition, Solar Cells (Liquid Phase Epitaxial Growth, Molecular Beam Epitaxial Growth) 


\section{Materials Properties, Behavior, Characterization or Testing}

\section{Materials and Device Characterization}

FY 1994

DOE Contact: Richard King, (202) 586-1693

$\$ 2,500,000$

NREL Contact: Larry Kazmerski, (303) 231-1115

This project measures and characterizes materials and device properties. The project performs surface and interface analysis, electro-optical characterization and cell performance and material evaluation to study critical material/cell parameters such as impurities, layer mismatch and other defects that limit performance and lifetime. Techniques that are used include deep level transient spectroscopy, electron beam induced current, secondary ion mass spectroscopy, scanning electron microscopy and scanning transmission electron microscopy.

Keywords: Semiconductors, Nondestructive Evaluation, Surface Characterization, Microstructure and Solar Cells

Device or Component Fabrication, Behavior or Testing

142. High-Efficiency Crystal Silicon Solar Cells

FY 1994

DOE Contact: Richard King, (202) 586-1693

$\$ 2,400,000$

NREL Contact: John Benner, (303) 384-6496

SNLA Contact: David Hasti, (505) 844-8161

This project performs applied research upon crystal silicon devices to improve solar-to-electric conversion efficiency. The project employs new coatings and/or dopants and other treatments to reduce electron-hole recombination at cell surfaces or in the bulk material. Control of point defects in crystalline silicon is being studied by a variety of techniques.

Keywords: Semiconductors, Solar Cells, Crystal Silicon

Office of Renewable Energy Conversion

\section{Geothermal Division (GD)}

The primary goal of the geothermal materials program is to ensure that the private sector development of geothermal energy resources is not constrained by the availability of technologically and economically viable materials of construction. This requires the performance of long-term high risk GD-sponsored materials research and development. 
Materials Preparation, Synthesis, Deposition, Growth or Forming

143. Thermally Conductive Composites for Heat Exchangers

FY 1994

$\$ 90,000$

DOE Contact: R. LaSala, (202) 586-4198

BNL Contact: L. E. Kukacka, (516) 282-3065

This project is investigating thin thermally conductive polymer-based composites for use as corrosion and scale-resistant liner materials on carbon steel tubing used in shell and tube heat exchangers in binary geothermal processes or for bottoming cycles in multi-stage flash plants. Corrosion and scaling on the brine side of carbon steel tubing in shell and tube heat exchangers have been major problems in the operation of geothermal processes. Compared to the cost of high alloy steels, a considerable economic benefit could result from the utilization of a proven corrosion resistant polymer concrete material if sufficient heat transfer and anti-fouling properties can be derived. The work consists of determinations of the effects of compositional and processing variables on the thermal and fouling properties of the composite, and measurements of the physical and mechanical properties after exposure to hot brine in the laboratory and in plant operations. The effects of anti-oxidant additives on the fouling coefficient and scale adherence are also being evaluated. Results to date from field tests performed in FY 1994 with flowing hypersaline brine under heat exchange conditions indicate heat transfer and fouling coefficients similar to those for high alloy stainless steels. Further improvements by the inclusion of anti-oxidants are anticipated.

Keywords: Composites, Polymers, Corrosion, Heat Transfer, Scale-Resistant, Fabrication Technology, Fouling Coefficient

\section{Materials Properties. Behavior. Characterization or Testing}

144. Advanced High Temperature Geothermal Well Cements

FY 1994

DOE Contact: R. LaSala, (202) 586-4198

$\$ 390,000$

BNL Contact: L. E. Kukacka, (516) 282-3065

Lightweight $(<1.2 \mathrm{~g} / \mathrm{cc})$, environmentally benign, chemically and thermally resistant well cements are needed to reduce the potential for lost circulation problems during well completion operations and to insure long-term well integrity. Materials designed for temperatures $>400^{\circ} \mathrm{C}$ will be needed as higher temperature resources are developed. Cements resistant to brines containing high concentrations of $\mathrm{CO}_{2}$ at temperatures $>150^{\circ} \mathrm{C}$ are also needed. Emphasis is being placed on high temperature rheology, phase chemistry, and the mechanical, physical, and chemical resistance properties of the cured materials. Retarding admixtures required to maintain pumpability during placement operations are 
also being identified. To date, phosphate bonded calcium aluminate cement formulations containing hollow aluminosilicate microspheres appear to meet the design criteria and preparations for large-scale mixing and field placement are underway.

Keywords: Cements, Material Degradation, Strength, Phase Transformation, Bulk Characterization, Drilling, Carbonation, Retarders, Well Completions

\section{Advanced High Temperature Chemical Systems for Lost} Circulation Control

DOE Contact: R. LaSala, (202) 586-4198

BNL Contact: L. E. Kukacka, (516) 282-3065

The cost of correcting lost circulation problems occurring during well drilling and completion operations constitutes 20 to 30 percent of the cost of a geothermal well. The objective of the program is to develop advanced high temperature chemical systems which are pumpable at high temperature and which upon curing will yield an expandable, high strength, brine-resistant, cementitious material. Emphasis is being placed upon high temperature rheology, phase chemistry, and the mechanical, physical and chemical resistance properties of the cured material. Optimization of the formulations with respect to various placement technologies is also being conducted. To date, formulations containing calcium phosphate cements have been optimized for placement at temperatures $<100^{\circ} \mathrm{C}$. Engineering-scale placement and downhole testing is scheduled for FY 1995.

Keywords: Cement, Pumpable Slurries, Strength, Transformation, Bulk Characterization, Permeability, Hydrothermal Stability

\section{Corrosion Mitigation in Highly Acidic Steam Condensates}

FY 1994

DOE Contact: R. LaSala, (202) 586-4198

$\$ 100,000$

BNL Contact: L. E. Kukacka, (526) 282-3065

Increased $\mathrm{HCl}$ gas concentrations in the steam produced from geothermal wells at The Geysers in Northern California have resulted in severe corrosion problems in casings in the upper regions of wells where condensation may occur, in the well-head, transmission piping and cooling towers, and on turbine blades. The objective of the program is to optimize and field test polymers and polymer matrix composites for utilization as corrosion resistive liners on carbon steel and aluminum components exposed to low $\mathrm{pH}$ steam condensates at temperatures up to $\sim 200^{\circ} \mathrm{C}$. Emphasis is being placed on polymer and 
composite composition, metal surface modification, installation procedures and techniques for joining lined pipe sections.

Keywords: Polymers, Polymer Matrix Composites, Acid, Durability, Fabrication Techniques, Field Tests

Office of Energy Management

\section{Advanced Utility Concepts Division}

The Advanced Utility Concepts Division supports research and development of advanced energy storage and electrochemical conversion systems that will facilitate the substitution of renewable energy sources for fossil fuels-measures that will increase the reliability and efficiency of the energy economy. The goal is to provide reliable, inexpensive devices to mitigate the temporal and spatial mismatches between energy supply and energy demand. The research is divided into four subprograms: Superconductivity Systems, Utility Battery Storage, Thermal Storage, and Hydrogen Energy.

Superconductivity Systems Program

Device or Component Fabrication, Behavior or Testing

147. Wire Technology Project

FY 1994

$\$ 5,500,000$

DOE Contact: Jim Daley, (202)586-1165

Argonne National Laboratory: U. Balu Balachandran, (708) 252-4250

Brookhaven National Laboratory: David Welch, (516) 282-3517

Los Alamos National Laboratory: Dean Peterson, (505) 665-3030

National Renewable Energy Laboratory: Richard Blaugher, (303) 384-6518

Oak Ridge National Laboratory: Robert Hawsey, (615) 574-8057

Sandia National Laboratory: Thomas Bickel, (505) 845-9301

American Superconductor Contact: G. N. Bart Riley, (508) 836-4200

Intermagnetics General Contact: Pradeep Haldar, (518) 782-1122

The wire technology project is the key to eventual commercialization of superconductivity systems. Subtasks in the project are as follows:

1. Phase Development - Researchers developed a two-powder process that consists of reacting $\mathrm{Pb}$-doped $\mathrm{Bi}-2212$ with $\mathrm{CaCuO}_{2}$ within an $\mathrm{Ag}$ tube. This process yields $\mathrm{Bi}-2223$ with significantly improved phase purity compared to conventional processes, which is important for fabricating long lengths of wire having uniform and reproducible properties. 
2. Improvement of Transport Current - Researchers developed improved techniques to correlate transport properties and microstructure in the same grain boundary. Current-voltage, $I(V)$, measurements can distinguish between flux depinning and weak links, and a single parameter, $J_{c}$, which can be compared from sample-to-sample and lab-to-lab, can be extracted from fits to I(V) curves.

3. AC Losses - HTS Materials development has matured enough so that prototype construction for applications such as ac fault-current limiters for power utility systems is underway. Low-loss ac downlinks, each consisting of only four sinterforged $\mathrm{Bi}-2223$ bars, were produced for service at $1000 \mathrm{~A}$ rms per downlink in a 77-4.2 $\mathrm{K}$ gradient to serve a current limiter operated in liquid $\mathrm{He}$.

4. Critical Currents and Microstructure of HTS Materials - In collaboration with General Electric, Intermagnetics General, American Superconductor, IBM, and others, a range of HTS materials were irradiated with high energy heavy ions in order to introduce nearly ideal, columnar defects for flux pinning. Splayed columnar defects, resulting from the irradiation, resulted in enhanced current flow in magnetic fields.

5. Characterization of $\mathrm{Bi}(2223,2212) / \mathrm{Ag}$ tapes - In order to determine the limiting factors for $J_{c}$ in currently available tapes and to help guide further development of these tapes, researchers constructed special equipment to permit detailed measurements of the behavior of the resistive transitions of the tapes under applied magnetic fields at various temperatures, i.e. $4.2,27$, and $54-90 \mathrm{~K}$. Researchers made measurements for a number of $\mathrm{Bi}(2212,2223) / \mathrm{Ag}$ tapes fabricated by Intermagnetics General Corporation.

6. Thick Films - Researchers processed 10-20 micron thick films generated by screen printing precursor powders of the $\mathrm{Pb}$-, $\mathrm{Sr}$ - substituted $\mathrm{Tl}-1223$ material onto both insulating $\mathrm{LaAlO}_{3}$ and metallic $\mathrm{Ag}$ foil substrates.

7. Process Development for T1-1223 Wires and Tapes - Researchers developed high-current Ag-sheathed tapes containing $\mathrm{Pb}$-, Sr-doped Tl-1223 powders, which have excellent performance in magnetic fields at $77 \mathrm{~K}$. The Tl-free starting powders are chemically prepared using the Sandia co-precipitation process and then fabricated into wires and tapes using either the standard powder in tube method (PIT) or by extrusion techniques. 
8. Tl-1223 Electrodeposition - NR.EL extensively studied the electrodeposition process to improve reproducibility and stoichiometry control. The electrodeposition process produces a precursor film that is extremely reactive and is therefore conducive to rapid production of high quality superconducting films. This improved process produced films on $\mathrm{Ag}$ foil with outstanding critical current densities $\left(\mathrm{J}_{\mathrm{c}}\right): 7 \times 10^{4} \mathrm{~A} / \mathrm{cm}^{2}$ at $77 \mathrm{~K}$ in zero field and $14 \times 10^{4} \mathrm{~A} / \mathrm{cm}^{2}$ at $0.4 \mathrm{~T}$ for $\mathrm{H}$ parallel to the c-axis.

9. Bi-2223/Bi-2212 Wire - Researchers conducted processing studies of tapes containing mixtures of $\mathrm{Bi}-2223$ precursors. Improvements led to $J_{\mathrm{c}}(77 \mathrm{~K})$ values above $26,000 \mathrm{~A} / \mathrm{cm}^{2}$ in short length. Processing studies of $\mathrm{Bi}-2212$ wires in collaboration with Oxford Instruments yielded values of $\mathrm{J}_{c}(4.2 \mathrm{~K}, 2 \mathrm{~T})$ of above $100,000 \mathrm{~A} / \mathrm{cm}^{2}$.

10. Y123 Thin Film Technology - Activities extended technology to production of thick films on both ceramic and metal surfaces. Thick Y123 films up to 8 microns were successfully deposited by pulsed laser deposition onto a buffer layer. The associated $\mathrm{J}_{\mathrm{c}}$ and $\mathrm{I}_{\mathrm{c}}$ were over $800,000 \mathrm{~A} / \mathrm{cm}^{2}$ and $25 \mathrm{~A}$, respectively, at $77 \mathrm{~K}$ for Y123 film (1.4 microns) formed on a ceria buffer layer deposited on polycrystalline nickel.

11. Characterization of Superconducting Properties of HTS Wire Configurations Researchers conducted studies of $J_{c}$ dependence as a function of tape orientation with respect to magnetic field and of the current direction along and normal to the tape axis.

12. Experimentation Using Liquid Neon Refrigerant - This work enabled the characterization of HTS tapes at $27 \mathrm{~K}$ and at higher field levels than previously possible. This resource will be further developed to be offered as a national user facility to industry and other collaborators in conjunction with the National High Magnetic Field Laboratory (NHMFL) at Los Alamos. The NHMFL satellite at Los Alamos was used in studying the behavior of HTS tapes subjected to very high magnetic fields up to $18 \mathrm{~T}$.

13. High Energy Proton Bombardment - Proton bombardment of Bi-2212 wire led to substantially improved flux pinning and improved current carrying in magnetic fields. The experiment was conducted with IBM, Oak Ridge, Argonne, and SUNY-Buffalo and used $0.8 \mathrm{GeV}$ protons from Los Alamos' 
meson facility. The irreversibility line for Bi-2212 was dramatically increased, resulting in the enhancement of operating temperature from 30 up to $50 \mathrm{~K}$ in a magnetic field of 2 telsa.

Keywords: Phase Development, Transport Current, AC Losses, Microstructure, Thick Film, Electrodeposition, Flux Pinning, Bismuth, Thallium

148. Systems Technology

FY 1994

DOE Contact: Jim Daley, (202)586-1165

$\$ 5,600,000$

Argonne National Laboratory: U. Balu Balachandran, (708) 252-4250

Brookhaven National Laboratory: David Welch, (516) 282-3517

Los Alamos National Laboratory: Dean Peterson, (505) 665-3030

National Renewable Energy Laboratory: Richard Blaugher, (303) 384-6518

Oak Ridge National Laboratory: Robert Hawsey, (615) 574-8057

Sandia National Laboratory: Thomas Bickel, (505) 845-9301

American Superconductor Contact: G. N. Bart Riley, (508) 836-4200

Intermagnetics General Contact: Pradeep Haldar, (518) 782-1122

General Electric Research \& Development, J. Eric Tkaczyk, (518) 387-5004

Oxford Instruments, Inc. Contact: Ken R. Marken, (908) 541-1300

The systems technology project includes long length wire and coil manufacture. Some preliminary systems development is also undertaken. Project subtasks are as follows:

1. Thallium Conductor Development - Work on Tl-based conductors is carried out in cooperation with General Electric, Intermagnetics General, IAP, and on the base program. Microstructural studies of spray-pyrolyzed Tl-1223 deposits focus on correlating flux morphology with current carrying capability.

2. Thermo-Mechanical Processing of BSCCO Conductors - The effects of oxygen partial pressure in the carrier gas and pyrolysis temperature on the phase content of aerosol powers were measured. The processing of PIT conductor containing aerosol powers is being conducted in cooperation with American Superconductors.

3. Development of BSCCO-2212 Composite Conductors - Ceramic-silver composite conductors have been fabricated in lengths greater than 100 meters using both powder-in-tube and dip-coated methods.

4. Stability and Protection in High- $T_{c}$ Superconducting Devices - Researchers investigated design and operational issues facing HTS magnets and developed design options that make these magnets economically competitive. 
5. AC Applications of HTS Wires and Coils - Activities were conducted in collaboration with American Superconductor. The tasks were: electrical measurements of small HTS coils, theoretical calculations concerning the stability and protection of HTS coils, and design calculations and cryogenic engineering.

6. Demonstration of a Magnetic Refrigerator for HTS Electric Power Applications - Oak Ridge developed a prototype 50-W (40K) magnetic refrigerator. Fabrication and component testing activities were completed in coordination with Astronautics.

7. Development of Practical HTS Coils for Power Applications - Progress was made in resolving limitations on achieving long lengths in the bismuth-andthallium based tapes as illustrated by increased values of $J_{c}$ in extended lengths.

8. Long-length BSCCO Wire Production - The program between Argonne and Intermagnetics General concentrates on producing long, uniform lengths of conductors exhibiting good mechanical and superconducting properties for commercial operation at $>35 \mathrm{~K}$.

9. Development of Tl-1223 Conductors for High-temperature, High-field Applications - Researchers made Tl-1223 wire using variants of the two-powder process and have determined the microstructure in tapes made by SUNYBuffalo, which have the highest $\mathbf{J}_{c}$ in the U.S.

10. Resolving Limitations on Achieving Long Lengths in the Bismuth-and-Thalliumbased Tapes as Illustrated by the Increased Values of $J_{c}$ in Extended Lengths Los Alamos and Martin Marietta initiated a productive collaboration directed towards development of practical HTS coils for power applications. Several HTS coils were successfully processed and are being evaluated.

Additional Applications:

1. Work on current leads consists of collaborative projects with Superconductivity,Inc., Babcock \& Wilcox, and ZerRes Corp. Results indicate a boiloff one-tenth that of the best conventional leads, and a demonstration that DC currents produce essentially the same boiloff as $60 \mathrm{~Hz}$ AC currents with the same rms amplitude. Researchers developed an intermediate-temperature heat intercept for use with HTS leads that has a low thermal resistance, but very high electrical resistance. 
2. Superconducting bearing work - Research was conducted in a collaborative project with Commonwealth Research Corp. (CRC) and involves substantial CRC funding to ANL. DOE funds are used to develop bulk HTS levitators; CRC funds are used to evaluate the levitation properties, develop HTS bearings, and to test flywheel energy storage using these bearings. In a small bell-jar vacuum chamber, researchers evaluated the performance of HTS bearings with the levitated mass of $400 \mathrm{~g}$ and measured coefficients of friction for these bearings as low as $3 \times 10^{-7}$. In a larger stainless-steel vacuum chamber, researchers levitated rotors up to $12 \mathrm{~kg}$.

3. Laboratory-scale conductors have been fabricated with $J_{c}$ 's of $32,900 \mathrm{~A} / \mathrm{cm}^{2}$ (77K, self field, 1 micro $\mathrm{V} / \mathrm{cm}$ ). Production-scale wires have been fabricated at ASCs pilot plant with lengths greater than $1 \mathrm{~km}$ and $J_{c}$ 's of $12,700 \mathrm{~A} / \mathrm{cm}^{2}$ (77K, self field)

4. Recent efforts are directed at the development of a continuous fabrication process for TI(1223) tape conductors. Researchers demonstrated the fabrication of 3 micron thick polycrystalline films with high critical current density and strong-linked behavior in applied magnetic fields.

Keywords: Thallium Conductor, Composite Conductors, Stability and Protection, AC Application, Coils, Long Length Wire

149. Superconductivity Partnership Initiative

FY 1994

DOE/Golden Field Office Contact: Jeff Hahn, (303) 275-4775

$\$ 1,200,000$

General Electric Co. Contact: Harley Lake, (518) 387-7895

Martin Marietta Contact: Eddie Leung, (619) 974-1166

Reliance Electric Company Contact: Rich Schiferl, (216) 266-6253

Electric Power Research Institute Contact: Don Von Dollen, (415) 855-2679

The Superconductivity Partnership Initiative supports industry development of superconductivity systems. In FY 94, projects are underway for a superconducting 100 MVA generator (General Electric), fault-current limiter (General Dynamics), and $125 \mathrm{HP}$ motor (Reliance, Electric Company). In addition, a transmission cable project, in the past sponsored by the Electric Power Research Institute and Pirelli Cable, is being considered for funding in FY 1994. All of these projects will incorporate high-temperature superconducting wire. Four Department of Energy National Laboratories are currently directly supporting the Superconductivity Partnership Initiative Projects: Argonne, Los Alamos, Oak Ridge, and Sandia. 
Project subtasks are as follows:

1. Generator - Results of the generator project, in FY 94, included generator assessment activities including defining the applications, establishing a conceptual generator design, developing a preliminary generator design and initiating the performance analysis of the generator in the utility system. In addition, wire and coil development activities will be started and include wire development, fabrication, and coil design and development. Generators represent a large established worldwide market with growth projections forecasting that over $1000 \mathrm{GW}$ of new generation capacity will be needed in the next 10 years, with $173 \mathrm{GW}$ needed in the U.S.

2. Fault Current Limiter - In FY 94, the fault-current limiter project undertook conceptual studies of various device designs, provided a market survey for current limiter applications, completed an energy benefit assessment, conduct a network interface assessment, determined conductor requirements, and analyzed the economic potential of fault current limiters. Fault current limiters can be used on transmission and distribution systems to improve system flexibility, reliability and performance.

3. Motor - Electrical and mechanical design and thermal analysis was completed. In addition, the construction of the components for a motor prototype will be nearly completed, with assemibly and testing to follow in FY 95. Superconducting motors can have a large impact on electrical energy utilization through reduced losses and size compared to conventional iron core motors. Reduced losses and smaller size will be the driving force for the commercial introduction of superconducting motors in industrial applications.

4. High Temperature Superconducting Power Cable - The first phase of the contract calls for the development and fabrication of a 30-meter prototype $115 \mathrm{KV}$ HTS underground power transmission cable which will be tested at a utility site. Additionally, the project will conclude with design of a 3-phase, 100 meter cable system.

Keywords: Generator, Motor, Fault Current Limiter, Transmission Cable 


\section{Thermal Energy Storage Program}

\section{Materials Properties. Behavior. Characterization or Testing}

150. High Temperature Composite Phase Change Material

FY 1994

$\$ 40,000$

PNL Contact: W. Kevin Winegardner, (509) 375-3839

Mississippi State University Contact: Professor G. A. Adebiyi, (601) 325-3260

The objective of the work is to develop high temperature sensible/latent heat storage media for use in a packed bed regenerator for the capture and reuse of waste heat. The near-term application of this technology is recovery of heat currently exhausted into the air by flue gases in high-temperature industrial processes. The composite material consists of a ceramic matrix (sponge) in which a phase change material (salt eutectic) is imbibed forming a composite phase change material (CPCM). A high temperature test facility was designed, constructed, and used in experiments to validate the model subsequently used for parametric studies to identify key variables and parameters influencing thermodynamic efficiencies. Use of the test facility to evaluate the performance of CPCM pellets revealed poor stability of the material.

Keywords: Heat Storage, Phase Change Materials, Composites

\section{Geochemistry Dynamics Associated with Ground Water Heating}

FY 1994

PNL Contact: W. Kevin Winegardner, (509) 375-3839

$\$ 100,000$

PNL Technical Contact: Dr. E. A. Jenne, (509) 376-4412

The objective of this effort is to obtain the equilibrium and kinetic data required to accurately predict important geochemical reactions and permeability reduction in an aquifer during thermal energy injection, storage and recovery. Geochemical studies were used to acquire the former equilibrium data. Computer software has been developed to reliably identify the need for water treatment to avoid carbonate scaling and clogging and to calculate the portion of the water that must be treated at any given temperature, and the capacity requirements of various treatments. Software includes a package, $\mathrm{H}_{20}$ treat, specifically developed to aid engineers in the design and siting of aquifer heat storage systems.

Keywords: Minerals, Permeability, Aquifer 
Device or Component Fabrication, Behavior or Testing

152. Phase Change Thermal Storage for Dornestic Water Heating

FY 1994

$\$ 59,000$

PNL Contact: W. Kevin Winegardner, (509) 375-3839

University of Florida - Gainsville Contact: Professor D. Yogi Goswami, (904) 392-0851

The objective of this work is to develop new thermal energy storage prototypes that double the energy density of conventional electrically heated storage water heaters but occupy the same volume. Prototypes based on two concepts are being performance tested. One prototype uses a bed of high density polyethylene pellets whose internal structure has undergone crosslinking. The crosslinking step allows the pellets to store significant amounts of energy in a phase transition and maintain the structural integrity of the pellet. The second design uses a sensible heat concept and stores the required amount of energy via large temperature changes in the storage medium.

Keywords: Phase Change Materials, Encapsulation, Corrosion

153. Complex Compound Thermal Energy Storage System

FY 1994

PNL Contact: W. Kevin Winegardner, (509) 375-3839

$\$ 255,000$

Rocky Research Contact: Dr. Uwe Rockenfeller, (702) 293-0851

The objective of this work is to develop an advanced chill storage system using ammoniated complex compounds. The application for this technology is for load shifting and peak load reduction in industrial refrigeration and residential and commercial air conditioning systems. The storage concept uses the chemical adsorption of ammonia vapor on an inorganic metal salt. Suitable media for the various applications will be identified and the performance of the media, in terms of amount and rate of adsorption and desorption characterized. A prototype unit is being designed and fabricated.

Keywords: Adsorption Refrigeration, Adsorbing Materials, Complex Compound 


\section{OFFICE OF ENERGY RESEARCH}

FY 1994

Office of Energy Research - Grand Total

$\$ 348,260,033$

Office of Basic Energy Sciences

$\$ 297,371,424$

Division of Materials Sciences

$\$ 277,125,000$

Materials Preparation, Synthesis, Deposition, Growth or Forming

$\$ 32,680,000$

Materials Structure and Composition

$\$ 34,230,000$

Properties, Behavior, Characterization or Testing

$\$ 101,810,000$

Facilities and Equipment

$\$ 108,405,000$

Division of Chemical Sciences

$\$ 5,300,000$

Heterogeneous Catalysis

$\$ 870,000$

Materials Preparation, Synthesis, Deposition. Growth or Forming

$\$ 200,000$

Materials Structure and Composition

Advanced Battery Research and Development

$\$ 670,000$

$\$ 2,700,000$

Materials Preparation, Synthesis, Deposition, Growth or Forming

$\$ 1,300,000$

Materials Structure and Composition

$\$ 120,000$

Materials Properties, Behavior, Characterization or Testing

$\$ 850,000$

Device or Component Fabrication, Behavior or Testing

$\$ 430,000$ 


\section{OFFICE OF ENERGY RIESEARCH (Continued)}

FY 1993

Office of Basic Energy Sciences (continued)

Division of Chemical Sciences (continued)

Materials Precursor Chemistry

$\$ 1,730,000$

Materials Preparation, Synthesis, Deposition, Growth or Forming

$\$ 990,000$

Materials Structure and Composition

$\$ 740,000$

Division of Engineering and Geosciences

$\$ 7,406,424$

Engineering Sciences Research

$\$ 4,836,821$

Materials Properties, Behavior, Characterization or Testing

$\$ 4,836,821$

Bounds on Dynamic Plastic Deformation

126,000

Continuous Damage Mechanics - Critical States

An Investigation of the Effects of History Dependent

Damage in Time Dependent Fracture Mechanics

Micromechanical Viscoplastic Stress-Strain Model

with Grain Boundary Slicling

Micromechanical Viscoplastic Stress-Strain Model with Grain Boundary Sliding

An Analytical-Numerical Alternating Method for 3-D

Inelastic Fracture and Integrity Analysis of

Pressure-Vessels and Piping at Elevated Temperatures

In-Flight Measurement of the Temperature of Small,

High Velocity Particles

50,441

93,125

50,440

51,332

60,718

485,000

Intelligent Control of Thermal Processes

530,000

Elastic-Plastic Fracture Analysis Emphasis on

Surface Flaws

430,000

Modeling of Thermal Plasma Processes

233,000 


\section{OFFICE OF ENERGY RESEARCH (Continued)}

\section{FY 1994}

\section{Office of Basic Energy Sciences (continued)}

\section{Division of Engineering and Geosciences (continued)}

\section{Engineering Sciences Research (continued)}

Materials Properties. Behavior, Characterization or Testing (continued)

Nondestructive Evaluation of Superconductors

200,000

Stress Induced Phase Transformations

66,751

Pulse Propagation in Inhomogeneous Optical Waveguides

84,272

Multivariable Control of the Gas-Metal/Arc Welding

Process

165,870

Metal Transfer in Gas-Metal Arc Welding

128,622

Modeling and Analysis of Surface Cracks

205,640

Thermal Plasma Processing of Materials

279,602

Development of Measurement Capabilities for the

Thermophysical Properties of Energy-Related Fluids

573,000

Low Resistivity Ohmic Contacts Between Semiconductors and High- $T_{c}$ Superconductors

108,000

Thin Film Characterization and Flaw Detection

90,452

The Evolution of a Hele-Shaw Interface and Related

Problems in Dendritic Crystal Growth

66,118

Experiments on the Gas Dynamics of the

High Velocity Oxy-Fuel (HVOF) Thermal Spray Process

Transport Properties of Disordered Porous Media

from the Microstructure

Effect of Forced and Natural Convection on Solidification of Binary Mixtures

Inelastic Deformation and Damage at High Temperature

Flux Flow, Pinning and Resistive Behavior in

Superconducting Networks

Application of Magnetomechanical Hysteresis

Modelling to Magnetic Techniques for Monitoring

Neutron Embrittlement and Biaxial Stress

94,142

Stability and Stress Analysis of Surface Morphology

of Elastic and Piezoelectric Materials 
OFFICE OF ENERGY RIESEARCH (Continued)

FY 1994

Office of Basic Energy Sciences (continued)

Division of Engineering and Geosciences (continued)

Engineering Sciences Research (continued)

Materials Properties. Behavior. Characterization or

Testing (continued)

Energy Changes in Transfornaing Solids

174,600

Optical Techniques for Superconductor Characterization

Degenerate Four-Wave Mixing as a Diagnostic of

Plasma Chemistry

Effective Elastic Properties and Constitutive Equations for

Brittle Solids Under Compression

3-D Experimental Fracture Analysis at High Temperature

Geosciences Research

$\$ 2,569,603$

Materials Preparation, Synthesis, Deposition. Growth or Forming

$\$ 275,000$

An Investigation of Organic Anion-Mineral Surface Interactions During Diagenesis

Transition Metal Catalysis in the Generation of Petroleum and Natural Gas 


\section{OFFICE OF ENERGY RESEARCH (Continued)}

FY 1994

Office of Basic Energy Sciences (continued)

Division of Engineering and Geosciences (continued)

Materials Properties, Behavior, Characterization or Testing (continued)

Oxygen and Cation Diffusion in Oxide Materials

238,270

Grain Boundary Transport and Related Processes in

Natural Fine-Grained Aggregates.

New Method for Determining Thermodynamic Properties

of Carbonate Solid-Solution Minerals

302,000

Investigation of Ultrasonic Wave Interactions with

Fluid-Saturated Porous Rocks

Three-Dimensional Imaging of Drill Core Samples Using Synchrotron-Computed Microtomography

Thermodynamics of Minerals Stable Near the Earth's Surface

Theoretical Studies of the Adsorption of Gold Complexes

and Flotation Collectors onto Sulfide Mineral Surfaces

Transport Phenomena in Fluid-Bearing Rocks

Structure and Reactivity of Ferric Oxide and Oxyhydroxide

Surfaces: Quantum Chemistry and Molecular Dynamics

Micromechanics of Failure in Brittle Geomaterials

Energetics of Silicate Melts from Thermal-Diffusion Studies

Cation Chemisorption at Oxide Surfaces and Oxide-Water

Interfaces: X-Ray Spectroscopic Studies and Modeling

Division of Advanced Energy Projects

$\$ 7,540,000$

Materials Preparation, Synthesis, Deposition, Growth

or Forming

$\$ 4,466,000$

Combustion Synthesis and Engineering of Nanoparticles for

Electronic, Structural and Superconductor Applications

Creation and Destruction of $\mathrm{C}_{60}$ and Other Fullerene Solids

Synthesis and Properties of High Strength Nanolayered

Composites

127,500

171,000

169,000

204,000

145,000

35,000

144,000

Optimally Controlled Interior Manipulation of Solids

186,000

301,000

315,000

349,000 
OFFICE OF ENERGY RIESEARCH (Continued)

FY 1994

Office of Basic Energy Sciences (continued)

Division of Advanced Energy Projects (continued)

Materials Preparation, Synthesis, Deposition, Growth or Forming (continued)

Design of Materials with Photonic Band Gaps

High-Flux, Large-Area Carbon-Cluster Beams for Thin Film

Deposition and Surface Modification

Novel Composite Coatings for Hligh Temperature Friction and

Wear Control

Synthesis of Advanced Composite Ceramic Precursor Powders

by the Electric Dispersion Reactor

Development of an Ion Replacement Electrorefining Method

Evaporation Through Tungsten to Achieve High-Rate Vapor

Phase Processing of Intermetallics

Ultrasonic and Dielectric Noninvasive Diagnostics for

Sintering of Ceramic Composites

Compact $\mathrm{MeV}$ Ion Implantation

Thermoelectric Quantum Wells

Porous Carbons: Controlling Structure, Composition and

Performance

297,000

355,000

260,000

325,000

450,000

291,000

358,000

294,000

350,000

335,000

Materials Properties, Behavior. Characterization or Testing

$\$ 1,018,000$

Nonlinear Optics in Doped Fibers

Feasibility of a Novel Approach for Fast, Economical

366,000

Determination of Radiation Damage in Nuclear Reactor Cores

330,000

Hot Carrier Solar Cells

Atomic and Nanoscale Engineering of Thermophotovoltaic Semiconductor Using Scanning Probe Microscopy Techniques

177,000 


\section{OFFICE OF ENERGY RESEARCH (Continued)}

FY 1994

Division of Advanced Energy Projects (continued)

Device or Component Fabrication. Behavior or Testing

$\$ 2,056,000$

Ultrafast Molecular Electronic Devices

Photo-Induced Electron Transfer From a Conducting

Polymer to Buckminsterfullerene: A. Molecular

Approach to High Efficiency Photovoltaic Cells

Superconducting Bitter Magnets

Blue-Emitting Devices Based on Gallium Nitride

Solid State Multi-Layered Batteries

PV-Powered, Electrochromic Windows

405,000

283,000

300,000

319,000

419,000

330,000

Office of Fusion Energy

$\$ 14,488,000$

Materials Properties, Behavior, Characterization or Testing

$\$ 14,488,000$

Structural Materials Development

Repair Welding of Fusion Reactor Components

Insulating Ceramics for Fusion

Modeling Irradiation Effects in Solids

Fusion Systems Materials

Structural Materials for Fusion Systems

Development of Radiation-Hardened Ceramic Composites for Fusion Applications

Radiation Effects and Micromechanics of SiC/SiC Composites

Damage Analysis and Fundamental Studies for

Fusion Reactor Materials Development

Development of Lithium-Bearing Ceramic Materials

for Tritium Breeding in Fusion Reactors

Post-Irradiation Examination of Lithium-Bearing Ceramic

Materials for Tritium Breeding in Fusion Reactors

ITER Materials Development for Plasma Facing Components

ITER Structural Materials Development

ITER Ceramic Materials

Radiation Hardened Fiber Optics for ITER Fusion Diagnostic

Systems

389,000

90,000

290,000

60,000

$2,355,000$

$1,791,000$

49,000

97,000

180,000

250,000

500,000

$3,000,000$

630,000

358,000

50,000 


\section{OFFICE OF ENERGY RESEARCH (Continued)}

FY 1994

Office of Fusion Energy (continued)

Materials Properties, Behavior. Characterization or Testing (continued)

ITER Materials Evaluation

ITER Structural Materials Evaluation

Development of $\mathrm{Nb}_{3} \mathrm{Sn}$ Superconducting Wire for the ITER

Magnet Program

$1,459,000$

840,000

Structural Materials Development for the Conduit of ITER

Cable-in-Conduit-Conductors

$1,000,000$

$1,100,000$

Small Business Innovation Research Program

$\$ 35,030,124^{*}$

Materials Preparation, Synthesis, Deposition, Growth or Forming

$\$ 16,358,332$

Phase I Projects:

$\$ 2,465,397$

Low Cost, High Purity Silicon by Alkaline Glycolic

Digestion of Silica

75,000

High Speed Sheet Growth of Thin Silicon Films

An Innovative Approach for Large Area Photovoltaic

Material Processing

Low Cost Solar Cell Leads for Use in Photovoltaic Modules

Very Low-Cost/High-Efficiency Thin-Film Silicon Photovoltaic

Technology

Improved Activated Carbon for Hydrogen Storage

A Superplastic Oxide Dispersion Strengthened Magnesium

Alloy for Automotive Applications

Low Cost Synthesis of Nanocrystalline Silicon Carbide Starting with Fullerene Precursors

75,000

74,940

75,000

74,992

73,821

74,350

75,000

A Ceramic Material and Process for Use in Monolithic Ceramic Cross-Flow Filters

74,937

Includes 84 new Phase I and 31 new Phase II projects initiated in FY 1994 and 22 Phase II projects initiated in FY 1993. The funding shown for each Phase II project is the total allocated for the duration of the project (up to two years). 


\section{OFFICE OF ENERGY RESEARCH (Continued)}

Small Business Innovation Research Program (continued)

Materials Preparation. Synthesis, Deposition. Growth

or Forming (continued)

Phase I Projects: (continued)

High Temperature Brazing of Silicon Carbide

74,492

Molecular Composite Plastics for Lightweight Green Cars

74,749

Surface Hardening of Polymeric Composites by High Energy Ion Irradiation

74,769

A Novel Method for Manufacture of High Temperature

Superconducting Coils for High Temperature Operation

Design and Applications of Close-Spaced Thermionic

Converters with Novel Isothermal Electrodes

Development of Metal Hydride Materials for High

Coefficient of Performance Heat Pumps

75,000

74,342

74,999

Growth of Lutetium Phosphate Scintillator Crystals

for Positron Emission Tomography

75,000

Top-Seeded Solution Growth of Lutecium Phosphate from Potassium Pyrophosphate Flux

74,159

Production of Carbon-11-Labeled Compounds for Positron

Emission Tomography with a Low Energy Accelerator

74,981

74,983

Sapphire-Metal Joining for Low-Loss Gyrotron Windows

Innovations in Stabilizers

75,000

An Innovative Technique to Bond One Dimensional Carbon-

Carbon Composites to Dispersion Strengthened Copper

Advanced Low-Stress Brazing of Plasma-Facing Fusion

Components with High Energy Electron Beams

75,000

Joining of Aluminum to Carbon-Carbon Composites for

Fusion Reactor Applications

73,994

75,000

75,000

Ductile Joining of Beryllium to Copper

A Multilayer Silicon Carbide Fiber Coating for Toughened,

Neutron Radiation-Resistant Silicon Carbide/Silicon

Carbide Composites

72,057 
OFFICE OF ENERGY RESEARCH (Continued)

FY 1994

Small Business Innovation Research Program (continued)

Materials Preparation, Synthesis, Deposition, Growth. or Forming (continued)

Phase I Projects: (continued)

Niobium Titanium Multifilamentary Materials with Silicon in the Matrix

A Novel Approach to Fabrication of Niobium-Tin Conductor with Artificial Pinning Centers

High Quality Chemically Vapor Deposited Niobium Coatings for Superconducting Radio Frequency Cavities

Niobium-Titanide Tin/Copper Multifilamentary Superconducting

Wire with Niobiuim/Titanium Composite Filaments

75,000

75,000

75,000

74,995

Development of Niobium-Titanium-Tantalum Artificial Pinning

Center Superconductors for Very High Field Applications

Jet Vapor Deposition of Thick Filrns for the Production of Radioactive Beams of Chemically Active Elements

Microchannel Plates Fabricated by Track Etch Lithography

Radiation-Hard and Solar Blind Ultraviolet X-ray Chemically

Vapor Deposited-Diamond Photoiode Detectors

74,954

75,000

74,981

73,902

Phase II Projects: (First Year)

$\$ 8,393,382$

Multi Layer, Quantum Well Layer Film Thermoelectrics

595,070

Production of Carbon Materials from Biomass

599,988

Oxide Dispersion Strengthened Silver for Use in High-

Temperature Superconductor Composite Wires

600,000

Low Temperature Deposition of Titanium Nitride

599,677

Coated Micrograin Carbides for Wear Resistance

599,577

Composite Plasma-Polymer Membranes

599,916

Improved Coated-Metal Hydrogen Extraction Membranes

599,314

Methods of Improving Internal-Tin. Niobium-Tin for

Fusion Applications

600,000

Advanced Nondestructive Evaluation for Quality Assurance

of Divertor Plate Armor Tiles in Plasma Fusion Reactors

600,000 


\section{OFFICE OF ENERGY RESEARCH (Continued)}

FY 1994

Small Business Innovation Research Program (continued)

Materials Preparation, Synthesis, Deposition, Growth. or Forming (continued)

Phase II Projects: (First Year) (continued)

Dense, High Conductivity, Copper/Aluminum/Beryllium

Functionally Gradient, Plasma Facing Components

599,995

Flexible Electrochromic Window Materials Based on Poly

(Diphenyl Amine) and Related Conducting Polymers

599,893

Advanced Window Materials Based on Conducting Polymer/

Sol-Gel Ceramic Composites

An Innovative Approach for the Formation of Silicon

Carbide/Silicon Carbide Composites

Doping of Chemically Vapor Infiltrated Silicon Carbide

to Enhance Thermal Conductivity

600,000

599,952

600,000

Phase II Projects: (Second Year)

$\$ 5,499,553$

Development of a Novel Reverse-Osmosis Membrane with High

Rejections for Organic Compounds

Development of a Process to Synthesize Tubular Fullerenes

Continuous Production of Fullerenes from Hydrocarbon

Precursors

Preparation of Low-Density Microcellular Matearials from

Fullerenes

New Gadolinium-Boron Compounds for Neutron Capture Therapy

Refractory Metal Coatings on Carbon/Carbon Composites for

First Wall Applications

A Thermal Composite Plasma Facing Material

A Niobium-Tin Multifilamentary Composite Superconductor

with Artificial Copper (Bronze) Inclusions

A Porous Metal Heat Exchanger Cooled Microwave Cavity

Development of Silicon Carbide Ceramic Composites for

Fusion Reactor Applications

Radiation Damage Resistant Silicon for Particle Physics

Detectors

499,911

500,000

500,000

500,000

500,000

500,000

500,000

499,848

499,794

500,000

500,000 
OFFICE OF ENERGY RESEARCH (Continued)

FY 1994

Small Business Innovation Research Program (continued)

Materials Properties, Behavior. Characterization or Testing

$\$ 2,223,643$

Phase I Projects:

$\$ 1,124,040$

A Long Life Zinc-Oxide-Titanium-Oxide Sorbent

75,000

High Temperature Thermally Stable Multi-Layer Quantum

Well Films

75,000

74,987

Hydrogen Permeation Barriers for Bimodal Reactors

Fracture Toughness Testing with Minimal Material

74,811

A Novel High Strength Ceria-Zirconia Toughened Alumina Ceramic

with Superior High Temperature Corrosion and Erosion

Resistance

75,000

Rare Earth Endohedral Fullerenes as New Nonlinear Optical Materials 75,000

X-ray Absorption Spectroscopy for Trace Analysis of Chemical

Phase and Composition

An Apparatus for Structural Analysis of High Temperature

Materials Using Synchrotron Radiation

74,674

A Novel Detector for Neutron Diffraction Studies

74,978

75,000

An Analytical Research Materials Characterization

Facility Based on Synchrotron IRadiation

Application of the Meandering Winding Magnetometer

to an In-Situ Determination of Age Related Degradation

Improvement in the Loss and Critical Current Density

Properties of Internal-Tin Niobium-Tin

A Feasibility Study to Correlate Vanadium (Chromium,

Titanium) Alloy Weld Strength with Weld Chemistry

Improvement in the Characteristics of Ternary Niobium

Titanium Tantalum Alloys

74,710

75,000

75,000

74,910

75,000

Activated Optical Ceramics: A New Class of Materials

for Environmental Monitoring

74,970 


\section{OFFICE OF ENERGY RESEARCH (Continued)}

FY 1994

Small Business Innovation Research Program (continued)

Materials Properties, Behavior. Characterization or Testing (continued)

Phase II Projects: (First Year)

$\$ 599,672$

A Testing Process to Define Electrode Current Wear Mechanisms and Develop Improved Electrodes

599,672

Phase II Projects: (Second Year)

$\$ 499,931$

A Novel Energy-Efficient Membrane System for the Recovery of Volatile Organic Contaminants from Industrial Process Gases

499,931

Device or Components Fabrication, Behavior or Testing

$\$ 16,448,149$

Phase I Projects:

$\$ 2,621,134$

Monolithic Integration of Thin Film Photovoltaics on Insulated Metal Substrates

74,924

Development of a Low Cost High Concentration Photovoltaic

Dense Array Module for Use with Reflective Concentrators

Non-Precious Metal Catalysts for Proton Exchange Membrane

Fuel Cells by Ion Beam Synthesis

Contamination Tolerant Anodes for Polymer Electrolyte

Membrane Fuel Cells

Contamination Tolerate Anodes for Proton Exchange Membrane

Fuel Cells

Metal Carbide Nanoclusters for Polymer Electrolyte Membrane

Fuel Cells

A New Semiconductor Radiation Sensor for Expedited Waste

Site Characterization

An Acoustic Plate Mode Aqueous Mercury Sensor

An Off-Line-Locked Laser Diode Sensor (OLDS)

High Energy Resolution Cadmium-Zinc-Telluride Semiconductor

Radiation Detectors

74,314

75,000

75,000

75,000

75,000

74,922

74,600

75,000

74,955 


\section{OFFICE OF ENERGY FIESEARCH (Continued)}

Small Business Innovation Research Program (continued)

Materials Properties, Behavior. Characterization or Testing (continued)

Device or Components Fabrication. Behavior or Testing (continued)

Phase I Projects: (continued)

Gas Separation Membranes Based on Permselective Films of Buckminsterfullerenes

Fullerene Based Catalysts for Heavy Oil Upgrading

75,000

Coal Ash Tiles by Microwave Processing

Development of Expansive Cements Using Dry Flue Gas

Desulfurization Solid Wastes

75,000

Metal Monoliths for Conversion of Natural Gas to Liquid Fuel

Oxygen-Evolving Anodes for the Electrolysis of Calcium Oxide

A Long Life Perovskite Oxygen Electrode for Calcium Oxide Processing in Nuclear Fuel Cycles

A Low Emission Alkali Metal Thermal to Electric Converter Automotive Power System

Advanced Catalysts for Ultra-Low Emission Control in Natural Gas Fueled Vehicles

A Membrane Reactor for the Production of Hydrogen Fuel from Hydrocarbon Liquids

Economical Photochromic Films for Solar Thermal Control

Thermophotovoltaic Generator Efficiency Improvement

74,500

High-Performance Membranes for Gas, Vapor, and Liquid Separations

Organic-Inorganic Composite Membranes for Gas Separation and Vapor Permeation

Electrode Materials for Rechargeable Lithium Batteries

Novel High Performance Glassy Polymer Composite Membranes for Gas Separation

Highly Selective Membranes for the Separation of Organic Vapors Using Super-Glassy Polymers 
OFFICE OF ENERGY RESEARCH (Continued)

FY 1994

Small Business Innovation Research Program (continued)

Device or Components Fabrication, Behavior or Testing (continued)

Phase I Projects: (continued)

A Continuous Cryopump/Pellet-Fabrication Apparatus for Fusion

74,649

Innovative Electrochemical Sensors for In-Situ Real-Time Monitoring of Lead in Aqueous Media

Fluoroionophores for Use in a Fiber Optic Sensor for Mercuric Ions

Potentiometric Sensors for Lead and Mercury

A Compressed Xenon Gamma Sensor for Environmental Measurements

Fiber Optic Sensors for Heavy Metal Cations

Innovative Sorbents for the Selective Removal of Heavy Metals from Groundwater

An Ultra-Compact Cesium Iodide/Mercuric Iodide Gamma-Ray Scintillation Spectrometer

Phase II Projects: (First Year)

Glass-Ceramic Construction Tiles from Coal-Fired Boiler Flyash

599,861

A High Repetition-Rate, High Power, All-Solid-State Pulsed Driver for Electrodeless Inductive Thrusters

Demonstration of an Integrated Carbon Dioxide/Thermal Management System for Carbonate Fuel Cells

Porous Aluminum Nitride Part Fabrication to Support Advanced Battery Development

Capacitive Energy Storage Using High Surface Area Transition Metal Compounds

Advanced Ceramic Fibers for a Carbonate Fuel Cell Matrix 599,950 An In-Situ Particle Sensor for Metal Forming Processes 


\section{OFFICE OF ENERGY FIESEARCH (Continued)}

FY 1994

Small Business Innovation Research Program (continued)

Device or Components Fabrication, Behavior or Testing (continued)

Phase II Projects: (First Year) (continued)

On-Chip Infrared-Spectral Sensors by Superconducting Detector Arrays

Radiation Resistant Radio Frequency Feedthrough Insulators for Fusion Applications

Helium-Cooled Divertors with Low-Activation Materials and Simple Fabrication Techniques

Niobium-Tin Superconducting Wire with Built-in Niobium Surface

Coating to Limit Inter-Strand Eddy Currents in Cables

Ceramic Filters for Ultrafine Particulate Separation in

Combustion Gas Environments

A Carbonate Fuel Cell Monolith for Low-Cost and High

Power Density Operation

592,568

600,000

599,918

599,978

600,000

599,993

Phase II Projects: (Second Year)

$\$ 4,967,381$

Digital Processing Electronics for X-Ray Detector Arrays

A Cold/Thermal Beam Bender Using Capillary Optics to

Increase the Number of End-Guide Instrument Positions

A Thomson-Scattering Plasma Diagnostic for Materials

Testing and Divertor Concept Testing

Eddy-Current Nondestructive Testing Methods for On-Line

Detection of Cable Manufacturing Defects

Low-Cost Microstrip Detectors on Conductivity-Modified

Polyimide

High Strength Mono- and Multi-filament High Temperature

Superconductors for High Field Applications

Fabrication of Niobium-Aluminum Superconducting Strands

Using Mechanical Alloying and Other Techniques

Durable, Low Cost Ceramic Materials for Use in Hot Gas

Filtration Equipment

500,000

474,458

500,000

499,996

499,938

499,988

499,962

493,071 


\section{OFFICE OF ENERGY RESEARCH (Continued)}

FY 1994

Small Business Innovation Research Program (continued)

Device or Components Fabrication. Behavior or Testing (continued)

Phase II Projects: (First Year) (continued)

High Cation Mobility Lithium Polymer Batteris

499,968

A Real-Time X-ray Detector

500,000

Small Business Technology Transfer Program

$\$ 1,370,485$

Materials Preparation, Synthesis, Deposition, Growth or Forming

Phase I Projects:

Preparation of Monolithic Porous Carbon Materials Using Controlled Functionalization of Fullerenes

A Continuous Chemical Manufacturing Process for Direct Production of Titanium Powder with a Reagent Recycle

100,000

974,725

Device or Component Fabrication, Behavior or Testing

$\$ 295,760$

Phase I Projects:

$\$ 295,760$

Feasibility of Nitride Phosphors for Thin Film Electroluminescent

Displays

100,000

97,829

An Integrated X-ray Sensor

97,931

Improved Mineral Insulated Cables for Fusion Reactor Diagnostics 


\section{OFFICE OF ENERGY RESEARCH}

The Office of Energy Research advances the science and technology foundation for the Department and the Nation to achieve efficiency in energy use, diverse and reliable energy sources, a productive and competitive economy, improved health and environmental quality, and a fundamental understanding of matter and energy. The Director of Energy Research is responsible for six major outlay programs: Basic Energy Sciences, Fusion Energy, Health and Environmental Research, High Energy and Nuclear Physics, Superconducting Supercollider, and Scientific Computing. The Director also advises the Secretary on DOE physical research programs, university-based education and training activities, grants, and other forms of financial assistance.

The Office of Energy Research conducts materials research in the following offices and divisions:

- Office of Basic Energy Sciences: Division of Engineering and Geosciences; Division of Materials Sciences; Division of Advanced Energy Projects; and Division of Chemical Sciences

- Office of Health and Environmental Research: Division of Physical and Technology Research

- Office of Fusion Energy

Materials research is carried out through the DOE national laboratories, other federal laboratories, grants to universities, and grants to industry.

\section{Office of Basic Energy Sciences}

The Office of Basic Energy Sciencess supports research to advance the scientific and technical knowledge and skills needed to develop and use new and existing energy resources in an economically viable and environmentally sound manner. The largest portion of materials-related research is carried out through the Division of Materials Sciences.

Basic Energy Sciences carries out strategic materials research at all nine DOE multiprogram laboratories, two single program laboratories and one specific-mission laboratory. The multiprogram laboratories are Argonne National Laboratory, Brookhaven National Laboratory, Idaho National Engineering Laboratory, Lawrence Berkeley Laboratory, Lawrence Livermore National Laboratory, Los Alamos National Laboratory, Pacific Northwest Laboratory and the Sandia Laboratories in New Mexico and California. The multiprogram laboratories conduct significant research activities for other DOE 
programs such as Energy Efficiency, Fossil Energy, Nuclear Energy, and Defense Programs. The single program laboratories are Ames Laboratory at Iowa State University and the National Renewable Energy Laboratory. The specific-mission laboratory is the Stanford Synchrotron Radiation Laboratory. Ames Laboratory and the Stanford Synchrotron Radiation Laboratory are funded by the Division of Materials Sciences and the Division of Chemical Sciences.

In addition, the Division of Materials Sciences also funds a program, which consisted of 50 research projects in FY 1994, at the Frederick Seitz Materials Research Laboratory at the University of Illinois. The Laboratory is also funded by the State of Illinois.

Advanced materials preparation and characterization capabilities are available to academic and industrial researchers at 14 major user centers located at several of the multipurpose and special purpose laboratories. These user facilities are funded by the Division of Materials Sciences and the Division of Chemical Sciences.

Basic Energy Sciences contributes to the advancement of economic and competitive U.S. industry through Cooperative Research and Development Agreements (CRADAs), Small Business Innovation Research awards (SBIRs), use of the major user centers by industrial researchers, informal collaborations, direct research grants, and training of students. As of March 1994, 143 CRADAs involving about 110 companies originated in work sponsored by the Office of Basic Energy Sciences at the national laboratories. Industrial researchers are among the major users of advanced characterization facilities. During FY 1994, among the 3,467 scientists who conducted X-ray and neutron beam experiments at Basic Energy Sciences-supported user facilities, there were 434 industrial scientists from 92 U.S. companies. Support for research and development on new energyrelated materials, processes and instrumentation by small businesses is funded through the Small Business Innovation Research Program, which is administered through the Division of Advanced Energy Projects. This program funded 212 Phase I projects in FY 1994.

\section{Division of Materials Sciences}

The largest portion of the strategic, materials-related research program in DOE is located in the Division of Materials Sciences. The program incorporates the full range of materials science, including efforts in high-temperature superconductors, radiation effects, synthesis and processing, computation and theory, nonequilibrium and artificially structured materials, interfacial structure and dynamics, materials reliability and life prediction, semiconducting and photovoltaic materials, polymeric materials, magnetic materials, ceramic materials, and metals and alloys. The operating funds for FY 1994 for the Division of Materials Sciences were $\$ 277,125,000$. These funds were allocated to 458 projects. 
A goal of the program is to increase the understanding of materials properties, behavior, and phenomena in those classes of materials that are or might be important to the mission of the Department of Energy. Research sponsored by the Division of Materials Sciences is conducted by metallurgists, ceramists, solid state physicists, and materials chemists in 124 different institutions, including DOE laboratories, universities, and to a lesser extent at industrial laboratories. Some of the materials research has a specific relationship to identified energy technologies (e.g., photovoltaic phenomena for solar energy conversion, fast-ion diffusion for solid electrolytes in fuel cells and batteries); some is related to many energy technologies simultaneously (e.g., hydrogen embrittlement, corrosion, intermetallic alloys, high temperature structural metals and ceramics); and some is important to fundamental understanding of new experimental or theoretical research tools. Finally, through a substantial number (229 in FY 1994) of research grants to universities, the Division of Materials Sciences fosters the training of new scientific and technical personnel for academia, national laboratories, and inclustry.

A collaborative thrust on critical problems relevant to the synthesis and processing of advanced materials is fostered through the Center for Excellence in Synthesis and Processing of Advanced Materials. The Center consists of 12 Department of Energy Laboratories encompassing a diversity of unique and highly relevant professional skills, facilities, and instruments. The management of the Center has focussed on multiinstitutional interaction and collaboration amongst its member institutions as well as numerous partnerships with industry and academia. Special objectives of the Center are: (1) to develop synthesis and processing methodologies to control structure, and thereby materials properties, from atomic to the macroscopic scale; (2) to discover and develop highpayoff, advanced materials; and (3) to reduce the time span and cost, with attention to environmental and energy concerns, for materials commercialization by integrating synthesis and processing collaboration between the Department of Energy technologists and industry.

A second goal of the program is the development of new forefront analytical instruments and facilities that are used to probe the structure and behavior of matter. Through the operation of 14 major user centers, this program carries a major responsibility for many of the nation's premier research facilities. These facilities include three neutron sources, two synchrotron radiation sources, processing facilities, and four centers for electron beam microcharacterization.

A new synchrotron source, the 1-2 GeV Advanced Light Source (ALS) at Lawrence Berkeley Laboratory, was commissioned in FY 1993. A second major synchrotron radiation facility is under construction, the 6-7 GeV Advanced Photo Source (APS) at Argonne National Laboratory. The APS is scheduled for completion in FY 1997. This machine will provide the brightest source of photons in the hard X-ray region. 
The material science programs of the Division of Materials Sciences are grouped into three subprograms:

- Metallurgy and Ceramics seeks to understand the synergistic relationship between synthesis, processing, structure, properties, and behavioral parameters of materials.

- Solid State Physics is concerned with understanding the interactions of electrons, atoms, and defects and their role in determining the structure and properties of condensed matter.

- Materials Chemistry focuses on understanding the chemical properties of materials and their relationship to composition, structure, and specimen environment.

For information about specific programs the appropriate DOE contact listed in the accompanying table may be contacted by calling (301) 903-3427. The reader also is referred to DOE publication Materials Sciences Programs Fiscal Year 1994 (DOE/ER-0648 dated April 1995). This publication contains summaries of all funded programs, summaries of all Small Business Innovation Research programs; and descriptions of major user facilities and other user facilities. Limited copies may be obtained by calling (301) 903-3427.

\begin{tabular}{|c|c|}
\hline NAME: & PROGRAM AREA \\
\hline \multicolumn{2}{|c|}{ DIVISION OF MATERIALS SCIENCES } \\
\hline Robert J. Gottschall & Acting Director, ER-13 \\
\hline \multicolumn{2}{|c|}{ Environment, Safety and Health, ER 13} \\
\hline \multicolumn{2}{|l|}{ Albert E. Evans } \\
\hline \multicolumn{2}{|l|}{ Michael F. Teresinski } \\
\hline \multicolumn{2}{|c|}{ Metallurgy and Ceramics Branch, ER-131 } \\
\hline Robert J. Gottschall & Electron Beam, Microcharacterization, Facilities \\
\hline Alan L. Dragoo & Ceramics \\
\hline Otto Buck & Mechanical Behavior, NDE \\
\hline John N. Mundy & Physical Behavior, Irradiation Effects \\
\hline
\end{tabular}




\begin{tabular}{|c|c|}
\hline NAMis. & PROGRAM AREA. \\
\hline Yok Chen & Physical Behavior, Irradiation Effects \\
\hline Michael E. Kassner & Mechanical Behavior \\
\hline Helen M. Kerch & Microstructure, Processing \\
\hline Arthur B. Denison & Magnetic Materials, Condensed Matter Physics \\
\hline \multicolumn{2}{|c|}{ Solid State Physics and Matelials Chemistry Branch, ER 132 } \\
\hline William T. Oosterhuis & Neutron and X-ray Facilities \\
\hline Richard D. Kelley & Materials Chemistry, Polymers, Surface Science \\
\hline Jerry J. Smith & Solid State Physics, Surface Science \\
\hline Manfred Leiser & Solid State Theory \\
\hline Harold L. Davis & Solid State and Surface Theory \\
\hline Dale Koelling & $\begin{array}{l}\text { Solid State Theory, Magnetism, Advanced } \\
\text { Computational Methods }\end{array}$ \\
\hline
\end{tabular}

\section{Division of Chemical Sciences}

The Division of Chemical Sciences supports research important to fossil chemistry, combustion, advanced fusion concepts, photoconversion, catalysis, separations chemistry, actinide and lanthanide chemistry, thermophysical properties of complex fluids, nuclear waste processing, and environmental remediation. Research related to materials is carried out in the areas of heterogeneous catalysis, advanced battery technology, and materials precursor chemistry. The operating budget for FY 1994 for materials-related programs was $\$ 5,300,000$ and was allocated to 41 projects in heterogeneous catalysis, advanced batteries and materials precursor chemistry.

The program in catalysis emphasizes fundamental chemical, physical, materials and engineering aspects related to catalytic chemistry. Research into fundamental aspects of heterogeneous catalysis overlaps in several areas with complementary efforts in the Division of Materials Sciences. Among these areas are the synthesis of oxides having large surface areas and large pore volumes, but fairly small pores. This includes single and mixed oxides which are either crystalline or amorphous. Another area of overlap is the characterization of thin oxide films on metals. These materials not only have important relationships to industrial catalysts but also are intrinsically interesting and allow the types of detailed 
studies of ceramic type properties normally associated with single crystals. Structural studies on bimetallic crystals as model catalysts constitutes a second area of overlap. This area is closely tied to alloy physics. Finally, the reactive decomposition chemistry of chlorocarbons on single crystals has a strong relationship to corrosion and lubrication.

The Advanced Battery Research and Development program supports research to develop new generic battery technology focused on the non-automotive consumer market with emphasis on improvements in battery size, weight, life, and recharge cycles. Areas of research include materials development and characterization, battery component development and interactions, characterization methodologies, and systems development and modeling. Although both primary and secondary battery systems are considered, the greatest emphasis is placed on rechargeable (i.e., secondary) battery systems. The program covers a broad spectrum of research including investigations of lithium cells, metal hydrides, bifunctional air electrodes, fundamental studies of composite electrode structures, failure and degradation of active electrode materials, thin-film electrodes, electrolytes, and interfaces. Characterization and methodologies include problems of electrode morphology, zinc corrosion, separator/electrolyte stability, stable microelectrodes, and the transport properties of electrode and electrolyte materials and surface films. Investigations in computational chemistry, modeling, and simulations, including property predictions, phenomenological studies of reactions and interactions at critical interfaces, film formation, phase change effects on electrodes and characterization of crystalline and amorphous materials are also of interest.

Chemical Sciences-supported materials precursor chemistry centers on the chemistry of advanced materials precursors, including the synthesis of novel inorganic and organometallic and polymeric structures which could serve as precursors to ceramics and other advanced materials. The research is represented by the following areas: catalysis to link monomeric/polymer building blocks; the mechanisms of oligomerization steps; electronic theories to predict precursors for new ceramics; emerging advanced materials based on complex oxides; single source precursors to multicomponent oxides; the design of materials with tailored properties; and the synthesis and characterization of complex 3dimensional structures.

The Division of Chemical Sciences manages several large scientific facilities. Four of these are user-oriented: the Combustion Research Facility at Sandia/California, the High Flux Isotope Reactor at Oak Ridge National Laboratory, the Stanford Synchrotron Radiation Laboratory at Stanford University and the National Synchrotron Light Source at Brookhaven National Laboratory. The National Synchrotron Light Source is operated in conjunction with the Division of Materials Sciences.

For information about specific programs the appropriate DOE staff listed below may be contacted by calling (301) 903-5804. The reader also is referred to DOE publication 
Summaries of FY 1994 Research in the Chemical Sciences (DOE/ER-0144/12 dated September 1994) for summaries of all funded programs, summaries of Small Business Innovation Research programs; and descriptions of major user and other special facilities. Limited copies may be obtained by calling the telephone number given above.

\begin{tabular}{|l|l|}
\hline \multicolumn{1}{|l|}{ Environmental Safety and Health } \\
\hline Robert S. Marianelli & \\
\hline Sat Goel & \\
\hline Ted Tomczak & Fundamental Interactions \\
\hline & Chief \\
\hline Allan H. Laufer & Photochemical and Radiation Sources \\
\hline Mary E. Gress & Chemicall Physics \\
\hline William H. Kirchhoff & Atomic Fhysics \\
\hline J. V. Martinez & Processes and Techniques \\
\hline Strephen A. Butter & Chemical Energy \\
\hline Robert L. Beyerlein & Chemical Energy \\
\hline Steven G. Barnhart & Advanced Battery Program \\
\hline William S. Millman & Chemical Energy \\
\hline Harry J. Dewey & Separations and Analysis \\
\hline
\end{tabular}

\section{Division of Engineering and Geosciences}

Materials research in the Division ol: Engineering and Geosciences is sponsored by two different research programs, as described below.

The BES Engineering Research Program was started in 1979 to help resolve the numerous serious engineering issues arising from efforts to meet U.S. energy needs. The program supports fundamental research on broad, generic topics in energy related 
engineering-topics not as narrowly scoped as those addressed by the shorter term engineering research projects sponsored by the various DOE technology programs. Special emphasis is placed on projects which, if successfully concluded, will benefit more than one energy technology.

The broad goals of the BES Engineering Research Program are: (1) To extend the body of knowledge underlying current engineering practice so as to create new options for enhancing energy savings and production, for prolonging useful equipment life, and for reducing costs without degradation of industrial production and performance quality; and (2) To broaden the technical and conceptual base for solving future engineering problems in the energy technologies. The DOE contact for this program is Oscar P. Manley, (301) 903-5822.

The BES Geosciences Research Program supports research that is fundamental in nature and of long-term relevance to one or more energy technologies, national security, energy conservation, or the safety objectives of the Department of Energy. It is also concerned with the extraction and utilization of such resources in an environmentally acceptable way. The purpose of this program is to develop geoscience or geosciencesrelated information relevant to one or more of these Department of Energy objectives or to develop the broad, basic understanding of geologic materials and processes necessary for the attainment of long-term Department of Energy goals. In general, individual research efforts supported by this program may involve elements of several different energy objectives. The DOE contact for this program is William C. Luth, (301) 903-5822.

\section{Engineering Sciences Research}

\section{Materials Properties, Behavior. Characterization or Testing}

154. Bounds on Dynamic Plastic Deformation

FY 1994

$\$ 126,000$

DOE Contact: Oscar P. Manley, (301) 903-5822

Argonne National Laboratory Contact: C. K. Youngdahl, (312) 972-6149

Analytical studies are being performed to develop load correlation parameters which can be used in approximating or bounding the dynamic plastic deformation of structures. In many applications where the load is transmitted to the structure through a fluid, details of the load history and spatial distribution significantly affect the final plastic deformation. The objective of the program is to devise load correlation parameters based on various weighted integrals of the time-space load distributions which can be used to characterize the effects of the load without resorting to detailed numerical analysis. These load correlation parameters have three important uses: to perform design and safety analyses of structures over a wide range of design variables and loadings; to validate computer programs which 
have a nonlinear dynamic plasticity capability; and to correlate experimental simulations with actual or predicted events. The dynamic plastic deformation of some basic structural configurations will be analyzed for loadings which vary both in magnitude and region of application with time. Load correlation parameters will be hypothesized and their usefulness in predicting final plastic deformation will be determined. The analyses will be based initially on a rigid, perfectly plastic material model and small deformation response, but will be extended to include strain hardening, and initial elastic response period, and large deformation interactions.

Keywords: Plastic Deformation

155. Continuous Damage Mechanics - Critical States

FY 1994 $\$ 50,441$

DOE Contact: Oscar P. Manley, (301) 903-5822

Arizona State University Contact: D. Krajcinovic, (602) 965-8656

The research during the fourth, and last, year of the research was focused almost entirely on the two tasks: (1) response of microcrack weakened solids in the vicinity of the critical state, and (2) initial exploration of the use of Preisach model in fatigue analyses.

The studies of critical states were concentrated on fundamental issues such as the determination of the proximity parameter, universal parameters, order parameter and differences between the elastic and traditional (conduction) percolation problems. It was demonstrated that the second order phase (connectivity) transition takes place only in stress (load) controlled conditions. In contrast, localization (emergence of shear bands) of the deformation occurs in the strain (displacement) controlled tests.

Initial exploration of the Preisach model were focused on ductile behavior using parallel bar models. Important conclusions were related to the thermodynamics of the process, including differences between locked-in and dissipated work.

Keywords: Metals: Ferrous, Fracture, Fatigue, Creep

156. An Investigation of the Effects of History Dependent

Damage in Time Dependent Fracture Mechanics

FY 1994 $\$ 93,125$

DOE Contact: Oscar P. Manley, (301) 903-5822

Battelle Memorial Institute Contact: F. Brust, (614) 424-5034

The demands for structural systems to perform reliably under severe operating conditions continue to increase. Modern energy production facilities experience degradation and damage because they operate in severe high-temperature environment where time 
dependent straining and damage may lead to structural failures. The goal of this research is to study the high temperature damage and failure processes and to further develop a method for predicting this behavior in an effort to increase structural life. In particular, we focus on time dependent damage which occurs under history-dependent loading conditions, i.e., transient conditions.

The types of time dependent (creep) damage considered in this program include: sustained load creep, variable load creep, and variable load creep with thermal gradients. During the first year of this study, the implications of using Norton's creep law on various integral parameters used to characterize crack tip phenomena were evaluated as a function of time. Other constitutive laws for time dependent materials such as those of Murakami and Ohno are being implemented into the finite element code. In addition, constitutive property data and high temperature creep crack growth data are being obtained on stainless steel. These experiments will be used to verify analytical predictions and characterize time and history dependent damage during crack nucleation and growth.

The results from this work will be used by practicing engineers to enhance the life of high temperature structural systems during the design phase.

Keywords: Fracture Mechanics, History Dependent Damage, High Temperature

157. Micromechanical Viscoplastic Stress-Strain Model with Grain Boundary Sliding

FY 1994

$\$ 50,440$

DOE Contact: Oscar P. Manley, (301) 903-5822

University of Connecticut Contact: E. H. Jordan, (203) 486-2371

The first part of this project has focused on developing and experimentally verifying methods of predicting the deformation response of polycrystalline metals from models of single crystal deformation, based on crystallographic slip. In the ongoing research, the goal is to try to predict the degree of heterogeneity of deformation and verify these predictions experimentally. The existing self-consistent model is to be completed by a second model based on periodicity which is expected to be both more realistic and more computationally burdensome. The degree of heterogeneity of deformation will be studied by different experimental techniques. Neutron diffraction experiments are planned in which diffraction from a few grains at a time is studied to determine lattice strains in individual grains. Many grains will be surveyed to get a statistical measure of heterogeneity of grains including no surface grains. The Moire strain analysis will also be done on large grained samples. The material studied is the same one used in the first phase, so that all the single crystal mechanical properties are accurately known. The data collected will provide a unique complete set of data to test the ability of the models in this program and other models with respect to their ability to predict the degree of heterogeneity of deformation. Comparison 
of the Moire data and the neutron diffraction data will also provide insight into the difference between surface grain behavior and interior grain behavior. Developing models that realistically predict grain to grain heterogeneity and verifying those models is a basic element in modeling mechanical behavior. Heterogeneity is particularly important to fatigue in which the most unfavorably oriented grain is the site of failure.

Keywords: Micromechanical, Viscoplasticity, Grain Boundary, Crystallographic Slip, High Temperature, Experiments

158. Micromechanical Viscoplastic Stress-Strain Model with Grain Boundary Sliding

DOE Contact: Oscar P. Manley, (301) 903-5822

Engineering Science Software, Inc., Contact: K. P. Walker, (401) 231-3182

This project is joint with the University of Connecticut project described above. See the previous paragraph for a description.

Keywords: Micromechanical, Viscoplasticity, Grain Boundary, Crystallographic Slip, High Temperature, Constitutive Model

159. An Analytical-Numerical Alternating Method for 3-D Inelastic

Fracture and Integrity Analysis of Pressure-Vessels and Piping at Elevated Temperatures

DOE Contact: Oscar P. Manley, (301) 9903-5822

Georgia Institute of Technology Contact: S. Atluri, (404) 894-2758

This research effort involves the application of highly efficient and accurate analytical- numerical alternating methods for the non-linear analysis of surface-flawed pressure vessels and piping under (1) elastic-plastic fracture, (2) high-temperature creep and viscoplastic fracture, and (3) pressurized thermal shock conditions. These procedures are highly efficient because only the uncracked structure is modeled numerically (finite element and boundary element approaches) and the severity of the stress state due to the presence of the 3-dimensional flaw is accounted for entirely analytically. This procedure is a novel application of the Schwartz-Neumann alternating method, which is a superposition method for linear problems, being extended to the nonlinear problems of elastoplasticity and creep through the generalized mid-point radial return mapping procedures which return the elastic estimates of stress in the cracked body to the appropriate yield surface. This effort is being conducted in collaboration with researchers at the University of Washington (see Number 33) where some seminal experimental work is being conducted to verify and validate the analytical work done at Georgia Tech. 
Keywords: Fracture, Failure Analysis

\section{In-Flight Measurement of the Temperature of Small, High Velocity Particles}

DOE Contact: Oscar P. Manley, (301) 903-5822

Idaho National Engineering Laboratory Contact: J. R. Fincke, (208) 526-2031

The measurement of temperature, velocity, enthalpy, and species concentration in high temperature gases such as weakly ionized thermal plasmas has considerable importance in the areas of plasma thermal spray and the thermal plasma synthesis of materials. In particular, the dynamics of the plasma, the interaction of the plasma with its surroundings and the behavior of particles immersed in the plasma surrounding it are important in the understanding, development and optimization of plasma process that involve fine powders. Laser based measurement techniques have been developed at this laboratory and are being applied to the study of thermal plasmas. In addition to the laser techniques enthalpy probes coupled to a mass spectrometer also provide temperature, velocity and concentration information. The experimental data produced is used to benchmark the modeling work done under a related program in "Modeling of Thermal Plasma Processes" (see J. Ramshaw, INEL).

Keywords: Plasma Processing, Particle/Plasma Interaction

161. Intelligent Control of Thermal Processes

FY 1994 $\$ 530,000$

DOE Contact: Oscar P. Manley, (301) 903-5822

Idaho National Engineering Laboratory Contacts: H. B. Smartt, (208) 526-8333 and J. A. Johnson, (208) 526-9021

This project addresses intelligent control of thermal processes as applied to materials processing. Intelligent control is defined as the combined application of process modeling, sensing, artificial intelligence, and control theory to process control. The intent of intelligent control is to produce a good product without relying on post-process inspection and statistical quality control procedures. The gas metal arc welding process is used as a model system; considerable fundamental information on the process has been developed at INEL and MIT during the past six years. Research is being conducted on an extension of the fundamental process physics, application of neural network-like dynamic controllers and signal/image processors, and development of noncontact sensing techniques.

Tasks include physics of nonlinear aspects of molten metal droplet formation, transfer, and substrate thermal interaction; understanding substrate thermal interaction; understanding the relationship of neural network structure and associated learning algorithm 
to model development and learning dynamics in neural networks with the objective of obtaining a fundamental understanding of network transfer functions; and advanced sensing, including the propagation and interaction of ultrasound in metallic solid and liquid media.

Keywords: Welding, Ultrasonic Sensing, Optical Sensing

162. Elastic-Plastic Fracture Analysis Emphasis on

Surface Flaws

FY 1994

$\$ 430,000$

DOE Contact: Oscar P. Manley, (301) 903-58322

Idaho National Engineering Laboratory Contact: W. G. Reuter, (205) 526-0111

The objective is to improve design and analytical techniques for predicting the integrity of flawed structural components. The research is primarily experimental, with analytical evaluation guiding the direction of experimental testing. Tests are being conducted on a material (a modified ASTM A-710) exhibiting a range of fracture toughness but essentially constant yield and ultimate tensile strength. As test temperature increases, the specimen configuration-fracture toughness relationship complies initially with requirements for linear elastic-fracture mechanics and extends beyond the range of a $\mathrm{J}$-controlled field. Presently, compact tension and bend specimens are being used to develop state-of-the-art fracture mechanics.

Metallographic techniques are being used to measure crack tip opening displacement and remaining ligament size for comparison with analytical models. Other techniques including microphotography and the replicating of the crack tip region, for future metallographic examination, are being used to complement the above measurements to identify limits and capabilities of each technique. Moire interferometry techniques are being used to evaluate and quantify the deformation in the crack region. These data are being used to experimentally measure $J$ and CTOI for standard (CT and SENB) specimens as well as for specimens containing surface cracks.

The above tests have been supplemented by using specimens fabricated from aluminum (dimple rupture only) and titaniun. The titanium specimens are being used to study the fracture behavior and the ability of existing models to predict failure for weldments. Moire interferometry techniques are being used to study the local constitutive behavior and the fracture process at the crack tip region of the weldment.

Keywords: Fracture, Metals: Ferrous 
DOE Contact: Oscar P. Manley, (301) 903-5822

Idaho National Engineering Laboratory Contacts: J. D. Ramshaw, (208) 526-9240 and C. H. Chang, (208) 526-2886

Optimization of thermal plasma processing techniques requires a better understanding of the space- and time-resolved flow and temperature distributions in the plasma plume and of the interaction between the plasma and a particulate phase. This research is directed toward the development of a comprehensive computational model of thermal plasma processes and plasma-particle interactions capable of providing such information. The model is embodied in the LAVA computer code for two- or threedimensional transient or steady state thermal plasma simulations. LAVA uses a rectangular mesh with an excluded volume function to represent geometrical obstructions and volume displaced by particles. Simple highly vectorizable numerics are utilized, with rapid steady state and low-speed flow options. The plasma is represented as a multicomponent fluid governed by the transient compressible Navier-Stokes equations. Real gas physics is allowed for by temperature-dependent specific heats and transport properties. Multicomponent diffusion is calculated in a self-consistent effective binary diffusion approximation, including ambipolar diffusion of charged species. Both k-epsilon and subgrid-scale turbulence models are included. Dissociation, ionization, and plasma chemistry are represented by means of general kinetic and equilibrium chemistry routines. Discrete particles interacting with the plasma will be represented by a stochastic particle model similar to that previously used to model liquid sprays. This model allows for spectra of particle sizes, shapes, temperatures, etc., thereby capturing the important statistical aspects of the problem. It will include submodels for the various plasma-particle and particle-particle interaction processes, including melting, evaporation, condensation, nucleation, agglomeration, and coalescence.

Keywords: Plasma Processing, Optimization, Computational Model

164. Nondestructive Evaluation of Superconductors

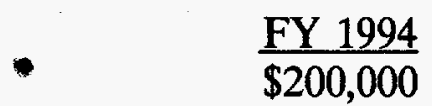

DOE Contact: Oscar P. Manley, (301) 903-5822

Idaho National Engineering Laboratory Contact: K. L. Telschow, (208) 526-1264

The purpose of this task is to perform fundamental research which will lead to the development and application of new nondestructive evaluation (NDE) techniques and devices for the characterization of high-temperature superconducting materials. In the near future, application of these new superconductors will require NDE methods for evaluating the properties of wires, tapes and coatings. Microstructural and, particularly, superconducting properties must be measured noninvasively in a manner capable of providing spatial information so that fabrication processes can be optimized. Although the 
fabrication of these ceramic materials is being pursued by many different techniques at present, there is enough similarity in the different superconducting materials and the fabricated forms to begin research into NDE measurement techniques. In FY89 this project began identifying techniques that can determine critical superconducting properties on a local scale. This has resulted in the use of $\mathrm{AC}$ induced currents in conjunction with DC transport currents to determine critical currents and dissipation locally. The analysis of these measurements is being carried out with the aid of the London and "Critical State" models for supercurrent flow in these materials. These results are being correlated with material microstructure information and other measurement techniques.

Keywords: NDE, Superconductors

165. Stress Induced Phase Transformations

FY 1994 $\$ 66,751$

DOE Contact: Oscar P. Manley, (301) 903-5822

University of Illinois Contact: H. Sehitoglu, (217) 333-4112

Understanding stress-induced phase transformations is of paramount importance in modeling the behavior of engineering materials and components. From the material behavior standpoint, transformations generate internal (micro) stresses which alter the constitutive behavior, and from the component standpoint transformation strains may result in dimensional changes and alteration of macroscopic stress fields. The transformation strains are strong functions of the applied stress state since favorably oriented planes transform in the course of loading. Several unique experiments under combined shear stress-hydrostatic pressure are conducted on steels, containing retained austenite, in order to measure and study anisotropic transformation strains. Test specimens are subjected to externally applied pressures in excess of $700 \mathrm{MPa}$. The compressive hydrostatic stresses would increase the extrinsic ductility of the rnaterial, and hence permit high magnitudes of the stress-induced and strain-induced transformations. Based on these experiments, the work will set the background to evaluate the theories proposed, and lay the foundation for new ones with particular emphasis on complex changes in transformation strains. The basic information obtained from the work will generate improved understanding of transformation under contact loadings and transformation toughening phenomenon in metallic and nonmetallic materials.

Keywords: Phase Transformation, Stress, Strain 
166. Pulse Propagation in Inhomogeneous Optical Waveguides

Fy 1994

DOE Contact: Oscar P. Manley, (301) 903-5822

$\$ 84,272$

University of Maryland Contact: C. Menyuk, (301) 455-3501

Our research, which was originally focused on light propagation in inhomogeneous optical fibers, has broadened in scope to include studies of solid state rib waveguides and Y-junctions which are used to guide and switch light. The work on optical fibers is divided into two research projects.

The first project concerns long-distance communication using solutions. We have been particular concerned with the effects of randomly varying birefringence, and we have shown that its effect is benign. From the basic equations we were able to show from an appropriate ordering expansion that the nonlinear Schrodinger equation is the lowest order equation and, hence, we expect its behavior to dominate the soliton evolution even in a highly birefringent fiber, as long as the birefringence is rapidly varying. We have also studied optical fiber soliton switches based on trapping and dragging. To do the work on optical fibers, we have collaborated with scientists at AT\&T Bell Laboratories. The first solid state project was to find the effect of a quantum well on the propagation characteristics of a rib waveguide. Using a planar guide as reference, we were able to show that the effect of the real geometry is qualitatively small but can have a significant quantitative effect.

The second solid-state project is to determine the effect of dry-etching on the modeholding characteristics of the device. As a consequence of the etching, the height at which the junction splits can vary. We showed that the rounding has a very small effect, in contrast to blunting which occurs when the materials are chemically wet etched.

Keywords: Optical Fibers, Pulse Propagation, Inhomogeneities, Imperfections

167. Multivariable Control of the Gas-Metal/Arc Welding Process

FY 1994

$\$ 165,870$

DOE Contact: Oscar P. Manley, (301) 903-5822

MIT Contact: David E. Hardt, (617) 253-2429

The Gas-Metal Arc Welding Process (GMAW) is a highly productive means for joining metals and is being used increasingly for structures and pressure vessels. The overall objective of this work is to examine the problem of simultaneous regulation of all real-time attributes of a weld. Past work has established the viability of independent control of thermal characteristics and the present work is examining the geometric aspects of weld pool control. 
One objective of this work is to develop basic process modeling and control schemes to allow independent regulation of the weld bead width and height. A control model relating wirefeed and travel speed to width and height was developed using transfer function identification techniques applied to a series of step welding tests. We are developing a control system to independently regulate the weld bead width and the width of the heat affected zone. Initial work is concentrating on simulation of wide seam welding using an analytical heat transfer model as well as a finite difference process model. A key issue in the problem is the strong coupling between the inputs (current and travel speed) and the outputs. The use of high frequency transverse motion of the torch is being investigated as a means of overcoming this coupling. Once the control latitude is increased, a two variable control scheme based on both video and infrared sensing will be implemented.

Finally, the depth of penetration of a weld is the most important indicator of weld strength, yet it is the one variable that is essentially impossible to measure directly. A realtime depth estimator has been developed based on solution of an inverse heat transfer problem. Surface temperature measurements from the top and bottom of the weld have shown accurate and rapid convergence and development of a depth control system based on this estimator is now being processed.

This project is a collaborative program with INEL.

Keywords: Welding, Control

168. Metal Transfer in Gas-Metal Arc Welding

FY 1994 $\$ 128,622$

DOE Contact: Oscar P. Manley, (301) 903-5822

MIT Contacts: T. W. Eagar and J. Lang, (617) 253-3229

The present research is part of a cooperative program among faculty at MIT and staff at the Idaho National Engineering Laboratory (INEL) to develop a sound understanding of the arc welding process and to develop sensing and control methods that can be used to automate the gas-metal arc process.

The research during the current year has reviewed methods of filtering the voltage and current waveforms during pulsed current welding in order to extract signals which can be used to control the process. A new process control system has been developed and integrated with the welding equipment. Work has begun to study methods of mechanically controlling droplet detachment from the welding electrode.

Keywords: Welding, Control 
169. Modeling and Analysis of Surface Cracks

FY 1994

$\$ 205,640$

DOE Contact: Oscar P. Manley, (301) 903-5822

MIT Contacts: David M. Parks, (617) 253-0033 and F. A. McClintock, (617) 253-2219

This research focuses on the analysis of ductile crack initiation, growth and instability in part-through surface-cracked plates and shells. The overall approach consists of careful calculations of crack front stress and deformation fields, and correlation of cracking with experimental observations being conducted at the Idaho National Engineering Laboratory. Recently, significant progress has been achieved in developing and applying a two-parameter description of crack front fields.

Simplified engineering applications of surface crack analysis are being developed in the context of the line-spring model. Specific enhancements include improved elastic-plastic procedures for the practically important case of shallow surface cracks, as well as simple methods for calculating the T-stress along surface cracks fronts.

Detailed elastic-plastic stress analyses of cracked structural geometries provide a basis for interpreting experimental observations, for quantitatively assessing inherent limitations of nonlinear fracture mechanics methodology, and for extending these boundaries through development of two-parameter characterization of crack tip fields. Simplified but accurate analytical methods are also under development for analysis of surface-cracked plates and shells. Emphasis is placed on better understanding complex three-dimensional features of elastic-plastic crack tip fields.

Keywords: Fracture

170. Thermal Plasma Processing of Materials

FY 1994

$\$ 279,602$

DOE Contact: Oscar P. Manley, (301) 903-5822

University of Minnesota Contact: E. Pfender, (612) 625-6012

The objective of this research project is to study analytically and experimentally specific thermal plasma processes for materials treatment. Processes of interest include the synthesis of ultrafine ceramic powders and of films.

During the past year our efforts have concentrated on characterizing the thermal plasma chemical vapor deposition (TPCVD) process of diamond films onto various substrates. Modeling of the situation close to the substrate indicates extremely steep temperature and concentration gradients pointing to the important of thermal diffusion. 
Very high diamond deposition rates up to $1 \mathrm{~mm} / \mathrm{hr}$ have been observed with a plasma reactor with recirculation eddies. A series of diagnostic studies have been initiated to facilitate an understanding of the main reasons for the observed high deposition rates.

Keywords: Plasma Processing, Plasma Diagnostics

\section{Development of Measurement Capabilities for the Thermophysical Properties of Energy-Related Fluids}

FY 1994

$\$ 573,000$

DOE Contact: Oscar P. Manley, (301) 903-5822

National Institute of Standards and Technology Contacts: R. Kayser, (301) 975-2483 and J. M. H. Sengers, (301) 975-2463

The major objective of this project is to develop state-of-the-art experimental apparatus that can be used to measure the thermophysical properties of a wide range of fluids and fluid mixtures important to the energy, chemical, and energy-related industries and to carry out carefully selected benchmark measurements on key systems. The research is being done jointly by two groups within the Thermophysics Division of the NIST Chemical Science and Technology Laboratory; one group is located in the Gaithersburg, MD, laboratories and the other at the Boulder laboratories. The specific measurement capabilities to be developed in this project include new apparatus for transport properties (thermal conductivity and viscosity), for thermodynamic properties (pressure-volumetemperature data and enthalpy), for phase equilibria properties (vapor-liquid equilibria, coexisting densities, and dilute solutions), and for dielectric properties (dielectric constant). These new apparatus will extend significantly the existing state of the art for properties measurements and make it possible to study a wide range of complex fluid systems (e.g., highly polar, electrically conducting, and reactive fluids) under conditions which have been previously inaccessible. This project also includes benchmark experimental measurements on systems containing alternative refrigerants, on aqueous solutions, and on carefully selected systems with species of diverse size and polarity that are important to the development of predictive models for energy-related fluids.

Keywords: Thermophysical Properties, Mixtures, Fluids, High Temperature, High Pressure 
172. Low Resistivity Ohmic Contacts Between Semiconductors and High-T Superconductors

FY 1994

$\$ 108,000$

DOE Contact: Oscar P. Manley, (301) 903-5822

National Institute of Standards and Technology Contacts: J. Moreland, (303) 497-3641 and J. W. Ekin, (303) 497.5448

The purpose of this project is to fabricate and characterize high- $T_{c}$ superconductor/ semiconductor contacts. Developing a method for optimizing the current capacity of such contact will extend the application of high- $\mathrm{T}_{\mathrm{c}}$ superconductors to hybrid superconductor/ semiconductor technologies. These technologies include integrated circuit interconnects (both on-chip and package) and proximity superconductor/semiconductor/superconductor SNS Josephson junctions. Presently, these are among the most promising high- $T_{c}$ superconductor applications, but an essential first step is the development of reliable, stable, ohmic contacts between semiconductors and the high- $T_{c}$ oxide superconductors.

The initial phase of this program is to determine the compatibility of various metals and alloys (Au and $\mathrm{Al}$ alloys and $\mathrm{W}$, for example) as contact materials for superconducting YBCO and other high $T_{c}$ materials. Once a good combination has been established, patterned YBCO/normal metal contacts will be deposited onto semiconductor wafer surfaces. We have purchased a sputter co-deposition system for YBCO thin films and have adapted three other vacuum systems for contact deposition including two sputtering systems and an evaporator.

Keywords: High-Tc Superconductors, Semiconductors, Contact, Low Resistivity

173. Thin Film Characterization and Flaw Detection

FY 1994

$\$ 90,452$

DOE Contact: Oscar P. Manley, (301) 903-5822

Northwestern University Contact: J. D. Achenbach, (312) 491-5527

The work on this project is concerned with applications of the scattered field approach to the detection and characterization of cracklike flaws. The work is both analytical and numerical in nature.

The efficacy of ultrasonic methods to detect and characterize a crack depends on topographical features of the crack faces, the presence of inhomogeneities in the crack's environment, and on the mechanical properties in the near-crack region. In this work the effects on the scattered ultrasonic field of various features of fatigue and stress corrosion cracks, such as partial crack closure, the presence of microcracks and microvoids, and neartip zones of different mechanical properties have been investigated. Most of the results have been obtained by formulating a set of singular integral equations for the fields on the 
boundaries of the scattering obstacles. These equations have been solved numerically by the boundary element method, and the scattered fields have subsequently been obtained by using representation integrals.

For the configurations examined in this work, crack closure has the most significant effect on far-field scattering.

Keywords: Non-Destructive Evaluation, Superconductors, Scattering

\section{The Evolution of a Hele-Shaw Interface and Related Problems in Dendritic Crystal Growth}

FY 1994

$\$ 66,118$

DOE Contact: Oscar P. Manley, (301) 903-5822

Ohio State University Contact: S. Tanveer, (614) 292-4972

A cell consisting of two parallel plates separated by a thin layer of liquid, the socalled Hele-Shaw cell, serves as a model of a porous medium. For example, one can readily observe the displacement of a more viscous fluid by a less viscous one, such as is taken advantage of in secondary oil recovery methods.

Most mathematical models of the displacement process studied to date have dealt with steady states and their stability. Under those conditions solutions can be obtained even if the surface tension at the interface between the two fluids is ignored. As to the initial value problem, it has been found that ignoring surface tension leads to an ill-posed problem in the sense that nonphysical cusps form at the interface in a finite time. Experimentally it is found that when the surface tension is small no steady state is reached and the interface continues to deform into a finer and finer fractal-like structure.

Recent work by the proposer has revealed that it is possible to imbed the ill-posed problem into a well-posed one so as to clarify what happens when the surface tension tends to zero. For the proposed research detailed calculations will be carried out to examine how the singularities in the model equations are related to the evolution of the shape of the interface. Second, the results obtained for the Hele-Shaw cell will be extended to study the time evolution of the surface of a growing crystal with dendrites. Third, statistics of the observed patterns will be related to the statistical distribution of singularities in the model equations. Next, more general boundary conditions will be considered to conform to a broader class of physically realistic situations. Finally, some intrinsically nonlinear aspects of dendritic growth will be examined.

Keywords: Crystal Growth, Dendrites 
175. Experiments on the Gas Dynamics of the High Velocity Oxy-Fuel (HVOF) Thermal Spray Process

FY 1994

$\$ 94,142$

DOE Contact: Oscar P. Manley, (301) 903-5822

Pennsylvania State University Contact: G. Settles, (814) 863-1504

This researach program involves an experimental study of the gas dynamics of highvelocity oxy-fuel (HVOF) thermal sprays, a promising new technology in the fields of materials, manufacturing, and the extension of the useful life of large equipment. HVOF relies on combustion to melt and propel solid particles at high speeds onto a surface to be coated. The principles of gas dynamics govern the expansion of this gas/particle stream from high stagnation conditions to produce a supersonic jet. The current scientific basis of the HVOF process is poorly understood; dramatic improvements in the HVOF thermal spray are likely by applying the principles of gas dynamics which is a well-developed field in the disciplines of high-speed aerodynamics and propulsion. The specific approach is to use a properly-shaped nozzle and an appropriate pressure ratio to demonstrate that a perfectly-expanded supersonic jet constitutes the central physical principle upon which the HVOF thermal spray can be based. In such case the temperature-time history of the sprayed particles can be tailored to achieve coatings with specific properties, and to minimize oxidation due to mixing with the surrounding air.

Keywords: Surface Coatings, HVOF Sprays

176. Transport Properties of Disordered Porous Media from the Microstructure

DOE Contact: Oscar P. Manley, (301) 903-5822

Princeton University Contact: S. Torquato, (609) 258-4600

This research program is concerned with the quantitative relationship between transport properties of a disordered heterogeneous medium that arise in various energyrelated problems (e.g., thermal or electrical conductivity, trapping rate, and the fluid permeability) and its microstructure. Attention will be focused on studying the effect of porosity, spatial distribution of the phase elements, interfacial surface statistics, anisotropy, and size distribution of the phase elements, on the effective properties of models of both unconsolidated media (e.g., soils and packed beds of discrete particles) and consolidated media (e.g., sandstones and sintered materials). 
Both theoretical and computer-simulation techniques have been employed to quantitatively characterize the microstructure and compute the transport properties of disordered media.

Keywords: Disordered Media

\section{Effect of Forced and Natural Convection on Solidification of Binary Mixtures}

DOE Contact: Oscar P. Manley, (301) 903-5822

Purdue University Contact: F. Incropera, (317) 494-5688

This study deals with the influence of combined convection mechanisms on the solidification of binary systems. A major accomplishment of research performed to date has been the development and numerical solution of a continuum model, which uses a single set of equations to predict transport phenomena in the liquid, "mushy" (two-phase), and solid regions of the mixture. Calculations have been performed for two-dimensional, aqueous salt solutions involving forced convection, thermo/solutal natural convection, and/or thermo/diffusocapillary convection. The calculations have revealed a wide variety or rich and robust flow conditions, including important physical features of the solidification process which have been observed experimentally but have heretofore eluded prediction. These features include double-diffusive layering in the melt, development of an irregular liquidus front, remelting of solid, development of flow channels in the mushy region, and the establishment of characteristic macrosegregation patterns (regions of significantly different composition) in the final solid.

The primary objective of current studies is to determine the manner in which externally imposed forces influence thermo-solutal convection in the mushy and liquid regions during solidification of a binary mixture. A special goal is to determine means by which the forces may be used to offset or dampen thermo/solutal convection, thereby reducing macrosegregation and attendant casting defects. Separate consideration is being given to the effects of magnetic and centrifugal forces on solidification in binary metallic alloys and aqueous salt solutions, respectively. Predictions based on the continuum model are being compared with measurements obtained for metallic $(\mathrm{Pb}-\mathrm{Sn})$ and aqueous $\left(\mathrm{NH}_{4}\right.$ $\mathrm{Cl}-\mathrm{H}_{2} \mathrm{O}$ ) systems.

Keywords: Solidification, Convection, Binary Alloys, Salt Solutions, Magnetic Fields, Centrifugal Forces 
178. Inelastic Deformation and Damage at High Temperature

DOE Contact: Oscar P. Manley, (301) 903-5822

Rensselaer Polytechnic Institute Contact: Erhard Krempl, (518) 266-6432

A combined theoretical and experimental investigation is performed to study the biaxial deformation and failure behavior of engineering alloys under low-cycle fatigue conditions at elevated temperature. The purpose is to characterize the material behavior in mathematical equations which are ultimately intended for use in inelastic stress analysis and life prediction. Creep-fatigue interaction and ratchetting are of special concern. The long-term goal is the development of a finite element program that can directly calculate the life-to-crack initiation of a component under a given load history.

Keywords: Fracture, Damage

179. Flux Flow, Pinning and Resistive Behavior in Superconducting Networks

FY 1994 $\$ 70,519$

DOE Contact: Oscar P. Manley, (301) 903-5822

University of Rochester Contact: S. Teitel, (716) 275-4039

The motion of vortex structures, in response to applied currents, is a major source of resistance in superconducting networks in magnetic fields. Systems of interest include regular Josephson junction arrays and type II superconductors, such as the new granular high $\mathrm{T}_{\mathrm{c}}$ ceramics. Numerical simulations of finite temperature, current carrying networks will be carried out to provide a characterization of vortex response in non-equilibrium situations. For periodic networks, current-voltage (I-V) characteristics will be computed and compared with experimental results. The effects on resistivity of transitions from pinned to unpinned or to melted vortex structures, will be investigated. For disordered networks, the effects of pinning in producing metastable vortex structures leading to glassy behavior will be explored.

To date, simulations have been carried out for the "fully frustrated" two dimensional regular Josephson junction array. I-V characteristics were computed and reasonable agreement found with experiment. Behavior was explained within a simple physical model, in which correlations between vortices is crucial for producing the critical excitations leading to vortex flow resistance.

Keywords: Flux Flow, Pinning, Vortex Motion, Superconductors 
180. Application of Magnetomechanical Hysteresis Modelling to Magnetic Techniques for Monitoring Neutron Embrittlement and Biaxial Stress

DOE Contact: Oscar P. Manley, (301) 903-5822

Southwest Research Institute Contact: M. Sablik, (512) 522-3342

The project objective is to study the effects of neutron embrittlement and biaxial stress on signals from various magnetic measurement techniques in steels. It is expected that interaction between experiment and modeling will lead to design of efficient magnetic measurement procedures for monitoring neutron embrittlement and biaxial stress. Project research is important for safety monitoring in the nuclear power and gas industries.

Magnetic measurement techniques to be assessed are: (1) magnetic hysteresis loop measurement of properties like coercivity and permeability; (2) magabsorption, which measures the impedance of an rf coil brought close to a magnetic sample; (3) Barkhausen noise analysis; (4) magnetically induced velocity change (MIVC) of an ultrasonic wave; and (5) harmonic analysis of an ac magnetic hysteresis loon. The model of Sablik et al for magnetic hysteresis and uniaxial stress effects on magnetic properties will be extended to conditions of biaxial stress and neutron embrittlement. The effects of these conditions on magnetic probe signals (1)-(5) will be modeled and compared to experiment. In the case of neutron embrittlement, measurements will be made on steel samples characterized by Charpy tests after previous exposure to various neutron fluences.

Keywords: Magnetic NDE Techniques, Neuttron Embrittlement, Biaxial Stress

\section{Stability and Stress Analysis of Surface Morphology of Elastic and} Piezoelectric Materials.

DOE Contact: Oscar P. Manley, (301) 903-5822

Stanford University Contact: H. Gao, (415) 725-2560

The goal of this research is to investigate the mechanical effects of surface morphology of elastic dielectric and piezoelectric materials. In particular, the project will study the stability of a flat surface against diffusional perturbations and the stress concentration caused by slightly undulating surfaces.

The surface morphology of materials will be studied by using a unified perturbation procedure based on the notion of thermodynamic forces and the energy momentum tensor. The thermodynamic forces on material inhomogeneities such as interfaces and inclusions are a measure of the rate at which the total energy of a physical system varies with the configurational change of these inhomogeneities. Within the general methodology, any type of material and loading condition can be studied as long as the proper forces can be 
identified. By using corresponding material conservation laws discovered previously, a systematic analysis of surfaces of piezoelectric solids will be made. Preliminary studies have shown that under sufficiently large stresses, surfaces of materials become unstable against a range of diffusional perturbations bounded by two critical wave lengths. Even a slight undulation caused by these unstable diffusional perturbations, such as micro-level bumps and troughs, can result in a significant stress concentration along a material surface. These concentrations may lead to mechanical failures along the surface and may have more consequences for piezoelectric materials where the deformation is coupled to an applied electric field. There are also suggestions that the stress distributions in a body may be sensitive to the surface morphology.

Keywords: Stress Analysis, Surface Morphology, Elastic, Dielectric, Piezoelectric Materials

182. Energy Changes in Transforming Solids

FY 1994

DOE Contact: Oscar P. Manley, (301) 903-5822

$\$ 174,600$

Stanford University Contacts: George Herrmann, David M. Barnett, (415) 723-4143

Heterogenization techniques developed with DOE support. The methods have been extended to provide a number of universal formulae valid for the average stresses between two holes or inclusions, for inclusions with imperfect interfaces, and for stresses in cylindrical and plane layered media. A new methodology to establish conservation laws for dissipative systems has been advanced, and a theory of stressed solids prone to damage has been formulated based on the Gibbs free energy.

Another portion of our research has as its objective the development of further understanding of subsonic and supersonic surface waves and interfacial and bulk waves in anisotropic linear elastic solids. New investigations of so-called "generalized surface waves" and Stoneley waves in pre-stressed anisotropic bimaterials have also been undertaken.

Keywords: Stress Analysis, Materials Science

183. Optical Techniques for Superconductor Characterization

FY 1994

DOE Contact: Oscar P. Manley, (301) 903-5822

Stanford University: G. S. Kino, (415) 497-0205

The aim of this project is to develop a photothermal microscope for noncontact testing of materials. Techniques of this kind are particularly well suited to the determination of thermal parameters, and anisotropy of small samples. 
One example of the work is the measurement of high temperature superconductors over a range of temperatures from room ternperature through the critical temperature $T_{c}$ down to $20^{\circ} \mathrm{K}$. A modulated laser beam, focused to less than $1 \mathrm{~m}$ diameter, impinges through a sapphire window onto a sample of $\mathrm{Bi}-\mathrm{Ca}-\mathrm{Sr}-\mathrm{Cu}-\mathrm{O}$ in a helium cryostat and periodically modulates its temperature. This process excites a thermal wave, which can be detected by the variation in reflected signal amplitude of a second focused laser beam, due to the change of refractivity with temperature. The sample can be rotated under the beams and the thermal diffusion coefficient, its anisotropy and its magnitude can be measured from the phase delay of the thermal wave. By measuring 'the amplitude of the thermal wave, material phase changes associated with superconductivity can be measured. A pronounced peak in amplitude is seen at the critical temperature $T_{c}$. Even stronger effects of this type are observed with charge density waves in a variety of materials.

Keywords: Nondestructive Evaluation, Acoustic Sensors

184. Degenerate Four-Wave Mixing as a Diagnostic of Plasma Chemistry

FY 1994

$\$ 195,907$

DOE Contact: Oscar P. Manley, (301) 903-5822

Stanford University Contact: R. Zare, (415) 723-3062

A need exists for in situ nonintrusive diagnostics for probing trace and highly reactive radical intermediates in nonequilibrium plasma used for chemical vapor deposition. We propose applying a novel nonlinear spectroscopic technique, degenerate four-wave mixing (DFWM). The DFWM signal is a coherent scattered beam at frequency which is generated by the nonlinear response of the medium to the interaction of three incident waves at the same frequency. The signal is enhanced by a resonant transition and offers a form of Doppler-free spectroscopy with extremely high spectral, spatial, and temporal resolution. Signal detection is remote and does not suffer from background interference from the bright plasma source. In addition, the phase conjugate nature of the signal eliminates optical aberration. The environment we propose to study is an atmospheric-pressure rf-inducivelycoupled plasma and the target radicals include $\mathrm{CH}, \mathrm{CH}_{2}, \mathrm{C}_{2}, \mathrm{C}_{2} \mathrm{H}$, and $\mathrm{CH}_{3}$ that are important in plasma synthesis of diamond thin films. The spatial sensitivity of DFWM will be used to study the coupling of gas-phase and gas-surface chemistry by measuring temperature and concentration profiles. The proposed research will advance diagnostic techniques for plasma environments and provide a better understanding of the plasma chemistry of diamond synthesis.

Keywords: Plasma, Four-Wave Mixing 
185. Effective Elastic Properties and Constitutive Equations for Brittle Solids Under Compression

FY 1994

$\$ 60,324$

DOE Contact: Oscar P. Manley, (301) 903-5822

Tufts University Contact: Mark Kachanov, (617) 628-5000, ext. 2821

The knowledge of effective elastic properties of solids with cracks appears to be of increasing engineering importance. Extensive microcracking in structural elements working under conditions of high temperatures or irradiation, microcracking in composite materials under fatigue conditions may noticeably reduce the stiffness of the material and make it anisotropic. Understanding and prediction of these changes are essential for proper design and strength and lifetime assessments.

A new approach to many cracks problems based on interrelating the average tractions on individual cracks is introduced. Its advantages are that it yields simple analytical results which are quite accurate up to very high crack densities and that it can be applied to crack arrays or arbitrary geometry. Relation between deterioration of elastic properties and "damage" is discussed.

Keywords: Fracture, Elasticity

186. 3-D Experimental Fracture Analysis at High Temperature

FY 1994

DOE Contact: Oscar P. Manley, (301) 903-5822

$\$ 69,282$

University of Washington Contact: Albert Kobayashi, (206) 543-5488

This research deals with a detailed experimental investigation of the nonlinear deformation and failure of surface-flawed pressure vessels and piping. It includes (1) elasticplastic fracture, and (2) high-temperature creep and viscoplastic fracture. The objective of this effort is to acquire an understanding of the mechanics of the initial phases of failure and, thereby, provide better designs and life assessments of critical structural parts. This effort is being conducted in collaboration with Georgia Technical Institute which is performing the theoretical research of the overall and crack-tip fields.

Keywords: Fracture, Failure Analysis

\section{Geosciences Research}

The BES Geosciences Research Program supports research that is fundamental in nature and of long-term relevance to one or more energy technologies, national security, energy conservation, or the safety objectives of the Department of Energy. It is also concerned with the extraction and utilization of such resources in an environmentally 
acceptable way. The purpose of this program is to develop geoscience or geosciencesrelated information relevant to one or more of these Department of Energy objectives or to develop the broad, basic understanding of geologic materials and processes necessary for the attainment of long-term Department of Energy goals. In general, individual research efforts supported by this program may involve elements of several different energy objectives. The DOE contact for this Program is William C. Luth, (301) 903-5822.

\section{Materials Preparation, Synthesis, Deposition, Growth or Forming}

\section{An Investigation of Organic Anion-Mineral Surface Interactions} During Diagenesis

DOE Contact: W. C. Luth, (301) 903-5822

SNL Contacts: Patrick Brady and Randall Cygan, (505) 844-7216

The research is to investigate adsorption of anionic carboxylate and phenolate groups onto aluminosilicate surfaces in order to evaluate the role of organic acids as (1) catalysts for mineral dissolution and porosity evolution in deep basins, and (2) controlling agents of coupled dissolution and growth of during diagenesis. Combined experimental and theoretical approaches are used to investigate the mechanisms and reaction rates of organic anion adsorption. T-dependent adsorption of oxalate, acetate, salicylate and benzoate anions onto selected aluminosilicate surfaces are being measured, as are dissolution rates of alumina (as corundum), tremolite, albite, kaolinite and precipitation rates of kaolinite, in solutions containing various organic acids, at temperatures of $30-90^{\circ} \mathrm{C}$. Theoretical investigations are testing mechanistic connections between metal-anion complexation, anion adsorption, and mineral growth with the new experimental data. The influence of surfacesite chemistry and bonding are being investigated, in an attempt to establish general crystalchemical rules for predicting the extent of organically-controlled reactions during diagenesis.

Keywords: Surface reactions, Aluminosilicate Minerals, Adsorption Mechanisms

188. Transition Metal Catalysis in the Generation of Petroleum and Natural Gas

DOE Contact: W. C. Luth, (301) 903-5822

Rice University Contact: Frank D. Mango, (713) 527-4880

Light hydrocarbons in petroleum, including natural gas $\left(\mathrm{C}_{1}-\mathrm{C}_{4}\right)$, are conventionally viewed as products of progresssive thermal breakdown of kerogen and oil. Alternatively, transition metals, activated under the reducing conditions of diagenesis, can be proposed as catalysts in the generation of light hydrocarbons. Transition metal-rich kerogeneous sedimentary rocks were reacted under reducing conditions at temperatures for which the 
substrates alone, $\mathrm{N}$-octadecene + hydrogen, are stable indefinitely. Catalytic activity was measured to be on the order of $10^{-7} \mathrm{~g} \mathrm{CH}_{4} / \mathrm{d} / \mathrm{g}$ kerogen, suggesting robust catalytic activity over geologic time at moderate sedimentary temperatures.

Keywords: Transition Metals, Catalysis, Petroleum

\section{Materials Structure and Composition}

\section{Infrared Spectroscopy and Hydrogen Isotope Geochemistry of} Hydrous Silicate Glasses

FY 1994

$\$ 153,000$

DOE Contact: W. C. Luth, (301) 903-5822

Caltech Contacts: S. Epstein, (818) 356-6100 and E. Stolper, (818) 356-6504

The focus of this project is the combined application of infrared (IR) spectroscopy and stable isotope geochemistry to the study of dissolved components in silicate melts and glasses. Different species of dissolved water and carbon dioxide (e.g., molecules of $\mathrm{H}_{2} \mathrm{O}$ and hydroxyl groups, molecules of $\mathrm{CO}_{2}$ and carbonate ion complexes) have been analysed to understand volatile transfer reactions in liquids and glasses. The partitioning of $\mathrm{H}$ isotopes between vapor and hydroxyl groups and molecules of $\mathrm{H}_{2} \mathrm{O}$ dissolved in rhyolitic melts was measured. Concentrations of $\mathrm{H}_{2} \mathrm{O}$ and $\mathrm{CO}_{2}$ in volcanic glasses and $\mathrm{CO}_{2}$ in rhyolitic liquid were measured at pressures up to 1500 bars. The fractionation of $\mathrm{O}$ isotopes between $\mathrm{CO}_{2}$ vapor and rhyolitic glass and melt was measured. The kinetics of $\mathrm{OH}$-forming reactions in silicate glasses were studied. Diffusion of water in basaltic melts and of water and $\mathrm{CO}_{2}$ in rhyolitic glasses and melts was studied. Results were used to understand oxygen "self-diffusion" in silicate minerals and glasses and enhanced oxygen diffusion under hydrothermal conditions.

Keywords: Infrared Spectroscopy, Silicate Minerals, Glasses, Silicate Liquids, Speciation

Materials Properties, Behavior, Characterization or Testing

190. Cation Diffusion Rates in Selected Silicate Minerals

$\frac{\text { FY } 1994}{\$ 85,000}$

DOE Contact: W. C. Luth, (301) 903-5822

Sandia National Laboratory Contacts: Randall T. Cygan, H. R. Westrich and

Craig S. Schwandt, (505) 844-7216

Objectives of this research are to determine experimental cation diffusion coefficients for garnet and pyroxene minerals at temperatures less than $1000^{\circ} \mathrm{C}$ for evaluating disequilibrium behavior in geological, nuclear waste, energy, and materials applications. A new thin-film technique for preparation of diffusion couples was developed in ordere to 
measure the relativel slow diffusion of $\mathrm{Mg}^{2+}, \mathrm{Mn}^{2+}$, and $\mathrm{Ca}^{2+}$ in garnets and pyroxenes. Depth profiles of tracer isotopes are then evaluated using an ion microprobe. Comparison of the diffusion coefficients determined under various oxygen fugacities provides information about the diffusion mechanism and the defect structure of the mineral sample. Results suggest a slower mechanism for magnesium diffusion in pyrope for relatively reducing conditions.

Keywords: Cation Diffusion, Garnets, Pyroxenes, Silicate Minerals, Diffusion Mechanism, Defect Structure

191. Shear Strain Localization and Fracture Evolution in Rocks

FY 1994

DOE Contact: W. C. Luth, (301) 903-5822

$\$ 72,000$

Northwestern University Contact: J. W. Rudnicki, (708) 491-3411

Prediction of the causative stresses, location, orientation, thickness, and spacing of fractures in fault zones is important to energy production, waste disposal, and mineral technologies. This study examines the relation of fractures to the macroscopic constitutive description and microscale mechanisms of deformation by testing a standard theory of localization that describes faulting as an instability of the constitutive description of homogeneous deformation. A new, more realistic nonlinear constitutive model, based on the growth and interaction of microcracks which produces increased bulk compliance, is being developed and calibrated with axisymmetric compression tests. Numerical studies (at SNL) will evaluate the complications of realistic geometries and boundary conditions. Preliminary results suggest that the response to an abrupt change in the pattern of deformation is completely nonlinear and cannot be approximated accurately by incrementally linear models, as is often done. This nonlinear response may therefore be critical to the evolution of typical fault zones.

Keywords: Shear Strain Localization, Fracture Evolution, Constitutive Description, Nonlinear Behavior

192. Poroelasticity of Rock

FY 1994

DOE Contact: W. C. Luth, (301) 903-5822

$\$ 59,833$

University of Wisconsin Contact: H. F. Wang, (608) 262-5932

The objective of this project is to improve treatment of poroelastic problems involving the coupled processes of deformation and fluid flow by obtaining improved theoretical estimates of the poroelastic coefficients and by performing experiments designed to test and extend the theory. The dynamic elastic constants, pore pressure buildup (Skemptons) coefficient, permeability, and low-frequency shear modulus and attenuation 
have all been measured for synthetic sandstones (prepared from glass beads) for comparison with natural sandstones. The theoretical component of the project led to an extension of the effective pressure law for permeability. By combining theoretical estimates and experimental data for the bulk modulus of the synthetic sandstones, it was demonstrated that a theory sensitive to microstructure can predict the modulus reduction to porosities of $\mathbf{4 0}$ percent.

Keywords: Poroelasticity, Coupled Processes, Deformation, Fluid Flow, Permeability

193. Oxygen and Cation Diffusion in Oxide Materials

FY 1994

$\$ 238,270$

DOE Contact: W. C. Luth, (301) 903-5822

LLNL Contact: F. J. Ryerson, (510) $422-6170$

University of California at Los Angeles Contact: K. D. McKeegan, (310) 825-2779

The objective of this work is to measure the diffusion parameters for various cations and oxygen in important rock-forming minerals to constrain both geochemical transport processes and diffusive mechanisms affecting physical properties such as creep and electrical conductivity. Oxygen self-diffusion coefficients have been measured for three natural clinopyroxenes, a natural anorthite, a synthetic magnesium aluminate spinel, and a synthetic akermanite over oxygen fugacities ranging from the $\mathrm{Ni}-\mathrm{NiO}$ to $\mathrm{Fe}-\mathrm{FeO}$ buffers. The oxygen self-diffusion coefficients of the three clinopyroxenes are indistinguishable. At a given temperature, oxygen diffuses about 100 times more slowly in diopside than indicated by previous bulk-exchange experiments. New data for anorthite, spinel, and akermanite agree well with prior results obtained by gas-solid exchange and depth profiling methods at different oxygen fugacities, indicating that diffusion of oxygen in these nominally iron-free minerals is not greatly affected by $\mathrm{fO}_{2}$.

Keywords: Diffusion, Minerals, Plastic Deformation

194. Grain Boundary Transport and Related Processes in Natural Fine-Grained Aggregates

FY 1994

$\$ 302,000$

DOE Contact: W. C. Luth, (301) 903-5822

Brown University Contacts: R. A. Yund, (401) 863-1931 and J. R. Farver, (401) 868-193x

The objective of this study is the direct measure of diffusional transport rates in rocks and how the rates vary with mineralogy and microstructure, as well as temperature and pressure. The results provide much needed data on the nature of grain boundaries in rocks and the rate of transport of chemical components through rocks. Grain boundary diffusion of oxygen and cations in monominerallic aggregates of feldspar and of calcite, and aggregates of feldspar plus quartz were determined with the ion microprobe (SIMS). 
Calcium grain boundary diffusion rates in Ca-rich feldspar aggregates are several orders of magnitude slower than oxygen, and than potassium in K-rich feldspar. This suggests that differences in size and formal charge of chemical species may play an important role in their relative grain boundary diffusion rates. TEM analysis of microstructures suggests that the equilibrium distribution of water in feldspar aggregates is that of isolated pockets. Studies continue in order to evaluate the role of pressure and nonhydrostatic stresses on fluid-feldspar interfacial energies and microstructures.

Keywords: Diffusion, Rocks, Quartz, Feldspar, Microstructures

195. New Method for Determining Thermodynamic Properties of Carbonate Solid-Solution Minerals

FY 1994

$\$ 78,000$

DOE Contact: W. C. Luth, (301) 903-5822

UC Davis Contacts: P. A. Rock, (916) 752-0940 and W. E. Casey, (916) 752-3211

Incorporation of metals into calcium carbonate minerals is an important pathway for elimination of potentially toxic metals from natural waters. The thermodynamic properties of the resulting solution are, however, poorly known because of difficulties with the solubility measurements. This project uses a new method of measurement which avoids some of these difficulties. The new method is an electrochemical double cell including carbonates and no liquid junction. The cell is an advance over conventional techniques because: (1) reversibility can be directly establishe; (2) models of solute speciation are not required; (3) the measurements do not perturb the chemistry significantly.

Keywords: Carbonate Minerals, Solubility, Electrochemical Cell

196. Investigation of Ultrasonic Wave Interactions with Fluid-Saturated Porous Rocks

FY 1994

$\$ 161,000$

DOE Contact: W. C. Luth, (301) 903-5822:

Ohio State University Contacts: L. Adler, (614) 292-1266 and P.B. Nagy, (614) 292-3655

The research involves the investigation of ultrasonic wave propagation over a wide frequency range in fluid-saturated porous materials. Two new techniques, based on direct generation of surface waves by edge excitation, are being developed for the inspection of highly permeable natural rocks: (1) low-frequency (100 to $500 \mathrm{kHz}$ ) shear transducers were used to launch and receive the ultrasonic surface wave. With this technique, Rayleigh-type surface modes were generated on the free surface of both dry and water-saturated specimens; (2) ultrasonic waves transmitted through air-filled porous plates were used to study the frequency-dependent propagation of slow compressional waves in porous materials. An interferometric technique for noncontact detection of ultrasonic vibrations on diffusely 
reflecting rough surfaces provides clear evidence of propagation of the new slow surface mode on the free surface of a fluid-saturated porous solid when the pores are closed at the surface by capillary forces.

Keywords: Porous Materials, Surface Waves, Ultrasonic Wave Propagation

197. Three-Dimensional Imaging of Drill Core Samples Using

FY 1994

$\$ 150,000$

DOE Contact: W. C. Luth, (301) 903-5822

BNL Contact: Keith Jones, (516) 282-4588

SUNY, Stony Brook Contact: W. B. Lindquist, (516) 632-8361

Synchrotron radiation makes feasible the use of high resolution computed microtomography (CMT) for non-destructive measurements of the structure of different types of drill core samples. The goal of this work is to produce three-dimensional images of rock drill core samples with spatial resolution of 1 micron. CMT images are postprocessed (filtered) to provide specific grain/pore identification to each voxel in the image The pore topology is analyzed statistically to yield information on disconnected pore volumes, throat areas, pore connectivity and tortuosity. Current effort is on development of software to analyze the 3-dimensional connectivity and shape of the pore space using the medial axis theorem from computational geometry.

Keywords: Synchrotron Radiation, Computed Microtomography, Pore Structure, Drill Cores

198. Thermodynamics of Minerals Stable Near the Earth's Surface

FY 1994

DOE Contact: W. C. Luth, (301) 903-5822

$\$ 145,000$

Princeton University Contact: A. Navrotsky, (609) 258-4674

The purpose of this work is to expand our data base and understanding of the thermochemistry of minerals and related materials through a program of high temperature solution calorimetric studies. The technique of oxide melt calorimetry (in molten $2 \mathrm{PbO} \cdot \mathrm{B}_{2} \mathrm{O}_{3}$ ) has been extended to volatile-bearing phases. Measured mixing enthalpies of amphibole solid solutions are insensitive to OH-F substitution, but depend strongly on alkali ion substitution in the large A-site. Measured mixing enthalpies of open-framework zeolites are insensitive to species incorporation in the cavities, suggesting that there are few limitations on the variety of (metastable) structures that can be synthesized. Measured mixing enthalpies of damaged zircons are on the order of twice the heat of formation from 
component oxides, consistent with damage on the scale of near-neighbors and with greatly increased solubility in aqueous fluids.

Keywords: Thermochemistry, Solution Calorimetry, Amphiboles, Micas, Zircons

199. Theoretical Studies of the Adsorption of Gold Complexes and Flotation Collectors onto Sulfide Mineral Surfaces

DOE Contact: W. C. Luth, (301) 903-5822

University of Maryland Contact: John Tossell, (301) 314-1868

The project involves quantum mechanical (Hartree Fock) calculations of relative stabilities of species participating in dissolution and precipitation of gold on sulfide minerals. Although the solubility and surface adsorption of aqueous Au species on sulfide minerals are important agents of ore deposition, current understanding is limited by lack of information on surface complexation sites and speciation. Calculated site geometries and stabilities will be used to evaluate reactivity of various As and Sb sulfide mineral surfaces, addressing questions such as how structural differences among amorphous and crystalline forms of $\mathrm{As}_{2} \mathrm{~S}_{3}$ influence interactions with surface water and Au complexes. Flotation processes to concentrate Au from ore rely on selective adsorption of oxysulfide collector molecules on Au-bearing sulfide minerals. Calculations of relative energies of molecular orbitals of various $C$-containing sulfide collectors (xanthates and/or carbamates) and $\mathrm{P}(\mathrm{OH})_{3}$ complexes with $\mathrm{Au}+, \mathrm{Au}_{2}$, and $\mathrm{Au}(\mathrm{SH})$ will help to identify candidate collector molecules with improved efficiency.

Keywords: Surface Complexation, Gold Sulfides, Metal Transport

200. Transport Phenomena in Fluid-Bearing Rocks

FY 1994

DOE Contact: W. C. Luth, (301) 903-5822

$\$ 144,000$

Renssalaer Polytechnic Institute Contact: E. B. Watson, (518) 276-6475

The research involves two parts: (1) determining the solubility and diffusivity of selected rock-forming minerals and mineral assemblages in deep $\mathrm{C}-\mathrm{O}-\mathrm{H}$ fluids, and (2) measuring the permeability of fluid-bearing synthetic rocks. A new procedure is being developed for measuring mineral solubilities and component diffusivities in fluids at pressures above $1 \mathrm{GPa}$, by measuring the total mass of transported component across a thermal gradient in dumbbell-shaped capsules at constant $P(>1 \mathrm{GPa})$. Diffusivities are obtained from independent measurements of the component flux through different $T$ gradients. In the second portion of the investigation, rocks synthesized at high $(P>1 \mathrm{GPa})$ pressures in the presence of differing fluid compositions and consequently porosity structure, will be analyzed at ambient conditions to determine permeability using dihedral angle 
measurements and bulk fluid (air) diffusion through the samples. Direct imaging of the pore structure will also be attempted with Scanning Electron Microscopy and synchrotron $\mathrm{X}$-ray tomography.

Keywords: Diffusivity, Solubility, C-O-H Fluids, Porosity Structure, Rock Permeability

201. Structure and Reactivity of Ferric Oxide and Oxyhydroxide Surfaces: Ouantum Chemistry and Molecular Dynamics

FY 1994 $\$ 127,500$

DOE Contact: W. C. Luth, (301) 903-5822

PNL Contacts: Jim Rustad, David Sherman and Andrew Felmy, (509) 376-1134

The research is a theoretical investigation of the surface structure and reactivity of proton binding sites of ferric oxides and hydroxides. The surfaces of these common minerals are known to bind metals, oxy-anions, and organic chelates through mechanisms that are as yet poorly understood. The approach combines crystalline Hartree-Fock calculations for the ferric (hydr)oxides with a molecular dynamics (MD) model for water currently being developed by in collaboration with $\mathrm{J}$. W. Halley of the University of Minnesota, in order to evaluate: (1) structures and relative stabilities of various ferric (hydr)oxide surfaces; (2) the most reactive sites for proton adsorption, indicated by relative proton affinities in vacuo; (3) solvation corrections to relative surface energies and relative proton binding energies; (4) improvements in thermodynamic models of proton adsorption resulting from better predictions of surface structure, site types, and proton binding energies.

Keywords: Proton Adsorption, Surface Structure, Surface Reactivity, Ferric Oxides, Ferric Hyrdoxides

202. Micromechanics of Failure in Brittle Geomaterials

FY 1994

$\$ 171,000$

DOE Contact: W. C. Luth, (301) 903-5822

SUNY - Stony Brook Contact: Teng-Fong Wong, (516) 632-8240

SNL Contact: Joanne Fredrich, (505) 846-0965

Differences in the onset of brittle failure in low-porosity and high-porosity rocks depend on the cementation, initial damage state and deformation history. However, efforts to predict failure are hindered by the inability to account for initial crack density and ductile intergranular phases. For example, although cementation increases brittle strength and reduces porosity, the toughening mechanism is not well understood. This project aims to resolve this question with a systematic study of microstructures induced in experimentally deformed samples (both pre- and post- failure) of (1) high-porosity carbonate rocks, in which plastic grain deformation and plastic pore collapse are thought to be important; 
(2) sandstones of higher porosity but varying degree of cementation; (3) low-porosity crystalline rocks (as a test of models on rocks with distinct mechanical properties).

Keywords: Brittle Failure, Plastic Deformation, Experimental Rock Deformation, Cementation

203. Energetics of Silicate Melts from Thermal-Diffusion Studies

FY 1994

$\$ 169,000$

DOE Contact: W. C. Luth, (301) 903-5822

Columbia University Contacts: David Walker, (914) 359-2900 and Marie Johnson, (914) $365-8712$

University of California at Davis Contact: C. Lesher, (916) 752-9779

The research is to measure thermodynamic and kinetic properties of multicomponent fluid silicate systems that form the basis for predictive models of chemical diffusion, mineral dissolution, and complexation. Measurements of self and chemical diffusion of Sr and Nd in aluminosilicate melts have been obtained. Quantitative predictions of ion mobility based on Darken's theory have been extended to $\mathrm{Pb}$ and $\mathrm{Hf}$. Measurements of thermal, self and chemical diffusion in the system $\mathrm{CaO}-\mathrm{MgO}-\mathrm{SiO}_{2}$ are underway as the basis for extending the experimental data base to other major components in silicate melts.

Keywords: Multicomponent Diffusion, Silicate Melts, Thermal Diffusion

204. Cation Chemisorption at Oxide Surfaces and Oxide-Water Interfaces:

X-Ray Spectroscopic Studies and Modeling

FY 1994

$\$ 204,000$

DOE Contact: W. C. Luth, (301) 903-5822

Stanford University Contacts: G. E. Brown and G. A. Parks, (415) 723-9168

The research focuses on reactions and reaction mechanisms between aqueous metal ions and oxide surfaces representative of those found in the earth's crust as an aid to developing large-scale models of contaminant transport. Objectives are to (1) characterize reactions by direct sorption measurements, in-situ synchrotron-based $\mathrm{x}$-ray absorption spectroscopy (XAS) of atomic environments at solid-water interfaces, and UV/Vis/IR spectroscopy; (2) investigate how these properties are affected by the solid surface and fluid composition; and (3) develop molecular-scale and macroscopic models for the sorption process. The reactions involve aqueous $\mathrm{Co}$ (II) and $\mathrm{Pb}(\mathrm{II})$ with $\mathrm{Al}_{2} \mathrm{O}_{3}$ (corundum), $\mathrm{Fe}_{2} \mathrm{O}_{3}$, and $\mathrm{TiO}_{2}$, and the effect of organic liquids. New measurements of $\mathrm{Pb}$ (II) sorption on powdered corundum indicate sorption of polymeric species, suggesting that substrate structure is influencing the surface $\mathrm{Pb}$ (II) complexation. Comparative studies of the role of 
organic complexation on the sorption of $\mathrm{Cu}$ (II) on the surface of amorphous $\mathrm{SiO}_{2}$ and on powdered corundum are aimed at specifying surface complexation mechanisms.

Keywords: Surface Complexation, Interface Reactions, Synchrotron X-ray Absorption Spectroscopy

\section{Division of Advanced Energy Projects}

The Division of Advanced Energy Projects (AEP) provides support to explore the feasibility of novel, energy-related concepts that evolve from advances in basic research. These concepts are typically at an early stage of scientific definition and, therefore, beyond the scope of ongoing applied research or technology development programs. The AEP also supports high-risk, exploratory concepts that do not readily fit into a program area but could have applications that may span several disciplines or technical areas.

The Division provides a mechanism for converting basic research findings to applications that eventually could impact the Nation's energy economy. AEP does not support ongoing, evolutionary research or large scale demonstration projects. Technical topics include physical, chemical, materials, engineering, and biotechnologies. Projects can involve interdisciplinary approaches to solve energy-related problems. The DOE contact for this program is Walter M. Polansky, (301) 903-5995.

\section{Materials Preparation, Synthesis, Deposition, Growth or Forming}

205. Combustion Synthesis and Engineering of Nanoparticles for Electronic, Structural and Superconductor Applications

FY 1994 $\$ 186,000$

DOE Contact: Walter M. Polansky, (301) 903-5995

Alfred University Contact: Gregory C. Stangle, (607) 871-2798

The investigation will: (1) produce nanoparticles of multicomponent oxide ceramic materials by a combustion synthesis technique that is readily scaled up; (2) apply proven, in-house grain-boundary engineering methods to fine-tune microstructure evolution during densification; (3) use conventional and rapid sintering techniques to densify consolidated nanoparticle compacts; and (4) characterize the material at each stage. Expected results include: (a) the synthesis of nanoparticles of complex composition for use in several applications (such as $\mathrm{YBa}_{2} \mathrm{Cu}_{3} \mathrm{O}_{7-\mathrm{x}}$, a high-temperature superconductor with uses, e.g., in magnetic flux trapping and high-speed capacitor applications; yttria-stabilized zirconia for, e.g., high surface toughness materials for high-temperature applications; and $\mathrm{BaTiO}_{3}$, a material expected to possess superparaelectric properties when nanocrystalline); (b) the development and reduction to practice of a generic, widely applicable process; and (c) the evaluation of the energy efficiency and commercialization potential of the process. The 
proposed study will enlist three U.S.-based companies to aid in focusing the research toward the commercialization of successful research results.

Keywords: Nanoparticles, Ceramics, Superconductors, Electronic Materials

206. Creation and Destruction of $\mathrm{C}_{60}$ and Other Fullerene Solids

FY 1994 $\$ 301,000$

DOE Contact: Dr. Walter M. Polansky, (301) 903-5995

University of Arizona Contact: Donald R. Huffman, (602) 621-4804

This work will focus on the creation and destruction of fullerenes to produce new materials of interest to the Department of Energy. It is now known that, besides the famous $\mathrm{C}_{60}$ molecule (buckminsterfullerene), hundreds of other fullerenes, with masses of up to 600 carbon atoms, are also synthesized in the Krätschmer-Huffman process. The physics underlying the creation of the fullerenes is poorly understood and the major portion of this work will be a systematic study of the process. This will involve construction of a new, fullyinstrumented smoke-chamber, that will be used in a methodical exploration of fullerene yield versus production conditions. Recent reports of the successful seeding of chemical vapor deposition (CVD)-grown diamond films using thin films of $\mathrm{C}_{70}$, and of the roomtemperature conversion of solid $\mathrm{C}_{60}$ into diamond powder via non-hydrostatic compression, indicate that some of the first important commercial applications of the fullerenes may involve their destruction as a means of synthesizing high-performance materials. This work will include a systematic study of the destruction and modification of the various fullerenes by chemical reaction, electromagnetic radiation, and electron bombardment.

Keywords: Fullerenes, Diamond Powders, Buckyballs

207. Synthesis and Properties of High Strength Nanolayered Composites

FY 1994

$\$ 315,000$

DOE Contact: Walter M. Polansky, (301) 903-5995

Los Alamos National Laboratory Contact: Michael Nastasi, (505) 667-7007

The objective of this project is to synthesize and evaluate ultra high strength vapordeposited nanoscale materials both in the monolithic and composite form. Such materials have been shown to posses strengths that are within a factor of three or four of the theoretical shear strength $\approx \mu / 15$, where $\mu$ is the shear modulus. Synthesis of nanoscale materials presents the opportunity to develop a basic understanding of the deformation and fracture mechanisms that operate close to the theoretical limit of strength of materials to enable a new technological breakthrough, namely mechanical miniaturization. The availability of the fine-scale ultra high strength materials would provide the basis for fabricating, among others, miniature activators, springs, and diaphragms, for biomedical or 
sensor applications. The primary performance task will be to synthesize ductile materials with ultra high strength for application in mechanical miniaturization.

Keywords: Nanostructures, Composites, Mechanical Miniaturization

208. Optimally Controlled Interior Manipulation of Solids

FY 1994

DOE Contact: Walter M. Polansky, (301) 903-5995

$\$ 349,000$

Princeton University Contact: Herschel Rabitz, (609) 258-3917

This project is concerned with the development of a technique for modification of the interior solids without the necessity of opening up the material. The technique is based on the concept of designing and creating temporally and spatially tailored laser pulses that deposit energy on the surface for the purpose of launching an intense acoustic wave that focuses within the solid. Taking account of the relatively large illumination area on the surface and the focusing nature of the acoustic waves, it should be possible to minimally disrupt the surface while still attaining significant degrees of interior modification at the target volume. A central feature of this new materials processing method is its reliance on destructive and constructive interference between the ensuing shear and compressional acoustic waves. The research will include a theoretical design component. An established capability for interior manipulation of solids would open up many opportunities including interior annealing, induced phase transitions, induced chemical reactions, crack arresting, controlled defect site generation, and interior welding.

Keywords: Interior Processing of Materials, Acoustic Manipulation

209. Design of Materials with Photonic Band Gaps

FY 1994

$\$ 297,000$

DOE Contact: Walter M. Polansky, (301) 903-5995

Ames Laboratory Contact: Kai-Ming Ho, (515) 294-1960

This project is intended to design, fabricate and characterize a new class of composite materials which possess forbidden ranges of frequencies, in which electromagnetic waves cannot propagate in any direction. These materials are called "photonic crystals" and the forbidden frequencies are called "photonic gaps" and they can be regarded as photonic analogues of electronic semiconductors with electronic gaps. This class of material will exhibit many interesting physical properties and will find important practical applications in lasers, mirrors, resonators, filters, and quantum optical devices. Theory will be directed at designing periodic dielectric structures that give the optimal frequency gap for various applications with special emphasis on the fabricability of these structures, especially in the sub-micron length scale where these materials will find applications in optical measurements. Experimental effort will apply theoretical results to fabricate structures in the micron and 
sub-micron length scales, using micro-fabrication patterning and etching techniques. The effect of disorder, defects and structural imperfections on the propagation of electromagnetic waves through these photonic crystals will be studied.

Keywords: Patterning, Plutonics, Optical Devices

210. High Flux, Large-Area Carbon-Cluster Beams for Thin Film Deposition and Surface Modification

FY 1994 $\$ 355,000$

DOE Contact: Walter M. Polansky, (301) 903-5995

Argonne National Laboratory Contact: Dieter M. Gruen, (708) 252-3513

Fullerenes, such as $\mathrm{C}_{60}$ or buckminsterfullerene, are kinetically stable carbon cluster molecules, but are thermodynamically unstable with respect to diamond and graphite by $\sim 5 \mathrm{kcal} / \mathrm{mol} \mathrm{C}$. The fact that $\mathrm{C}_{60}$ has a vapor pressure of $\sim 10^{-3} \mathrm{Torr}$ at $500^{\circ} \mathrm{C}$ opens up the possibility of generating high-flux, high-energy carbon-cluster ion beams for thin-film deposition (including diamond films) and surface modification. A microwave-driven electron cyclotron resonance (ECR) plasma source will be used to generate the fullerene ion beams. The substrate impact energy will be controlled independently of the plasma parameters by biasing the substrate. End-Hall optics will be combined with the ECR plasma to provide additional control of beam characteristics. The ECR facility will be used to synthesize and characterize, by a variety of techniques, diamond films, diamond-like films, and carbonimplanted layers on large areas with high-deposition rates. The effort is directed toward producing high-quality films at low-substrate temperatures in a manner that can be adapted to industrial processes.

Keywords: Fullerenes, Ion Beams, Diamond, Diamond-like Carbon

\section{Novel Composite Coatings for High 'Temperature Friction and Wear Control}

FY 1994

$\$ 260,000$

DOE Contact: Walter M. Polansky, (301) 903-5995

Oak Ridge National Laboratory Contact: Theodore M. Besmann, (615) 574-6852

Chemical vapor deposition (CVD) techniques offer the opportunity to create very uniform self-lubricating composites which slowly wear away to expose pockets of lubricants which then spread across the surface. In CVD gaseous reactants are allowed to flow over a heated substrate where they react and deposit a solid coating. Solid lubricants have higher use temperatures and higher load-bearing capacities than do liquid lubricants. Consequently, they find use in applications where liquid lubricants prove inadequate. It has been noted that because buckminsterfullerene $\left(\mathrm{C}_{60}\right)$ is a spherical macromolecule and is thought to be very stable and slow to react with other substances, it should make an 
excellent lubricant. This project utilizes the controlled wear of a hard matrix to reveal the embedded high-temperature, solid lubricant. Such a composite coating would be produced by CVD, which has been demonstrated capable of producing multiphase coatings of controlled composition and microstructure. The $\mathrm{C}_{60}$ phase cannot be simultaneously formed during deposition, as can other of the proposed lubricants. The material can be incorporated into a coating, however, by entrainment in the coating gases.

Keywords: Chemical Vapor Deposition, Fullerenes, Composites

\section{Synthesis of Advanced Composite Ceramic Precursor Powders by the Electric Dispersion Reactor}

DOE Contact: Walter M. Polansky, (301) 903-5995

Oak Ridge National Laboratory Contact: Michael T. Harris, (615) 574-1275

The use of high-intensity-pulsed electric fields for droplet size control in dispersed liquid systems is being investigated. This technology has been utilized in a device called the electric dispersion reactor (EDR) to carry out the synthesis of micron-sized particles for the production of precursor powders of advanced ceramic materials. In this approach, pulsed electric fields are employed to create dispersions of microscopic conducting (aqueous-based) drops in nonconducting (organic) liquids. Each of these droplets becomes a localized microreactor where reactants in the organic phase diffuse into the aqueous droplets in which precipitation and gelation occur, while water and reaction products diffuse into the organic phase. The particle morphology is altered by varying reactant compositions in the liquidliquid system while achieving intraparticle stoichiometric consistency. This leads to the production of high-quality precursor powders which, in turn, yields dense, consistent greenbody material. Furthermore, this method requires far less energy expenditures than conventional approaches which rely on such inefficient operations as solids blending, mixing, and grinding to accomplish the formation of mixed-oxide precursor material.

Keywords: Ceramics, Ceramic Precursors

213. Development of an Ion Replacement Electrorefining Method

FY 1994

$\$ 450,000$

DOE Contact: Walter M. Polansky, (301) 903-5995

Argonne National Laboratory Contact: Zygmunt Tomczuk, (708) 252-7294

The objective of this project is to investigate promising methods for carrying out a new metal separation and purification process called ion replacement electrorefining. The challenge and program focus lies in developing a counter electrode that can serve in a sequential and, if possible, reversible manner as a cathode during metal dissolution and an anode during metal separation/deposition. The key goal is to produce a clean separation 
between actinide and non-actinide elements, such as required for the separation of spent nuclear reactor fuel. One potential use for the ion replacement electrorefining method is the reprocessing of spent metal fuel from an Integral Fast Reactor (IFR), but it is also adaptable to the separation of transuranic elements from spent fuel and waste generated by the light water nuclear reactor (LWR) industry and the defense nuclear programs. In the case of the IFR, the proposed process offers a simplification of the conventional pyrometallurgical electrorefining process under development within the IFR program. For LWR and defense waste applications, the ion replacement electrorefining method could be used in conjunction with processes that incorporate reduction of actinide element compounds (usually oxides) to a metallic form.

Keywords: Separations, Actinides, Electrorefining

\section{Evaporation Through Tungsten to Achieve High-Rate Vapor Phase Processing of Intermetallics}

FY 1994

$\$ 291,000$

DOE Contact: Walter M. Polansky, (301) 903-5995

General Electric Company Contact: David W. Skelly, (518) 387-6534

Modification of current practice of electron beam processes has been found to enhance chemistry uniformity and deposition rates through the addition or tungsten to the evaporation pool to permit much higher pool temperatures and stable pool dynamics. The objective of this research is to define optimum operating conditions for achieving economic deposition of controlled-chemistry, controlled-thickness Ni-base superalloys, NbTi-base metallic materials, and high strength, high temperature intermetallic phases. The approach will be to: evaluate process stability during prolonged evaporation through a tungsten-rich liquid pool; measure the effect of tungsten concentration in the pool on the evaporation process; characterize the influence of electron beam scan rate and scan pattern on the deposit chemistry and deposition rate; characterize the influence of the source temperature profile on deposit chemistry and deposition rate; determine evaporation conditions for $\mathrm{Ni}$ base alloys containing Ta and Mo; and extend the electron beam evaporation-throughtungsten processing to higher melting intermetallic phases and NbTi-base metals. The understanding derived from this investigation will have significant impact on the ability to fabricate advanced designs of turbine blades.

Keywords: Superalloys, Intermetallics, Electron Beam Processing, Turbine Blades 


\section{Ultrasonic and Dielectric Noninvasive Diagnostics for Sintering of Ceramic Composites}

DOE Contact: Walter M. Polansky, (301) 903-5995

Johns Hopkins University Contact: Moshe Rosen, (410) 516-8678

The potential advantages of using microwaves to process ceramics have been recognized for more than three decades. However, a profound understanding of how materials interact with microwaves during sintering is still lacking. Measurement of the dielectric and mechanical properties of a material during microwave processing in real-time can provide the necessary theoretical and experimental insight into understanding this interaction that can subsequently be applied for the optimization of microwave processing of materials. In the course of this project, in situ, nonintrusive diagnostics for microwave sintering of ceramic materials will be developed. The essence of the project is a specially designed system for ultrasonic and dielectric probes to be integrated within the microwave furnace. The ultrasonic data can be ultimately related to the densification process during sintering of ceramics, while the dielectric characteristics are connected to the absorption mechanism of the microwave energy by the ceramic material. Acquisition of such data during sintering will shed light on the sintering kinetics and its mechanism and, consequently, provide an understanding of the optimal sintering conditions needed to achieve maximum densification and the desired material properties.

Keywords: Microwave Sintering, Ceramics, Noninvasive Diagnostics

216. Compact MeV Ion Implanter

FY 1994

$\$ 294,000$

DOE Contact: Walter M. Polansky, (301) 903-5995

Lawrence Berkeley Laboratory Contact: Simone Anders, (510) 486-6745

A new kind of $\mathrm{MeV}$ ion implanter will be developed, the distinguishing features of which will be its relatively small size and low cost. The heart of the device will be a novel kind of ion source by means of which high charge state ions will be produced, thereby allowing the production of high energy ion beams ( $1 \mathrm{MeV}$ and above), using only modest accelerating voltages (one to several hundred $\mathrm{kV}$ ). The ion source will be a repetitively pulsed vacuum spark source, and the implantation facility will thus also generate repetitively pulsed, large area, metal ion beams. By virtue of the relatively low voltages employed the implanter will be much more compact and of much lower cost than present state-of-the-art facilities which employ singly charged ions and megavolt power supplies. From the perspective of new physics, a novel kind of ion source will be developed - vacuum arc ion sources have been developed but not vacuum spark ion sources, and it is in the latter that the highly stripped ions are to be found, yielding high energy at modest voltage. From the perspective of new technology, this is an entirely new approach to doing $\mathrm{MeV}$ ion 
implantation, making high energy surface modification techniques feasible for a vastly broader field of users than at present.

Keywords: Ion Source, Ion Implanter, Ion Beams, Surface Treatment

217. Thermoelectric Quantum Wells

FY 1994

$\$ 350,000$

DOE Contact: Walter M. Polansky, (301) 903-5995

Lawrence Livermore National Laboratory Contact: Joseph C. Farmer, (510) 423-6574

Solid state thermoelectric devices have no moving parts and can be used to convert heat directly into electricity. Such devices can also be used as chlorofluorocarbon (CFC)-free refrigerators, provided that an external voltage is applied. Unfortunately, thermoelectric devices are not as efficient as their mechanical counterparts. However, theoretical physicists at the Massachusetts Institute of Technology have recently used quantum mechanics to design a new class of thermoelectric materials that may improve the efficiency (figure of merit) of thermoelectric devices to a point where they are competitive with conventional internal combustion engines and CFC-based refrigerators. Process technology developed at Lawrence Livermore: National Laboratory for the fabrication of Xray optics is now being used to synthesize these new multilayer thermoelectric thin films. Multilayers are being made by alternately sputtering quantum well and barrier layers onto a moving substrate from dual magnetrons. A number of multilayer films, including hightemperature $\mathrm{Si}_{0.8} \mathrm{GeO}_{.2} / \mathrm{Si}$ and low-temperature $\mathrm{Bi}_{0.9} \mathrm{Sb}_{0.1} / \mathrm{PbTe}_{0.8} \mathrm{Se}_{0.2}$, are being synthesized and evaluated. This research can lead to new materials and devices.

Keywords: Quantum Wells, Thermoelectric Devices

218. Porous Carbons: Controlling Structure, Composition and Performance

FY 1994

$\$ 335,000$

DOE Contact: Walter M. Polansky, (301) 9013-5995

Lawrence Livermore National Laboratory Contact: Richard W. Pekala, (510) 422-0152

This research examines the synthesis and processing conditions necessary to tailor the local structure and composition of porous carbons for potential applications in energy storage devices. Carbon aerogels are being formed from resorcinol-formaldehyde and phenolic-furfural precursors. These porous carbons have low electrical resistivity, an ultrafine pore size distribution, high surface area (400 to 1100 square meters per gram, roughly the size of one or two basketball courts), and a solid matrix composed of interconnected particles or fibers. Preliminary data show that these materials are attractive electrodes for double layer capacitors. The project investigates sol-gel polymerization of multifunctional organic monomers, the phase separation of polymer/solvent mixtures, the 
formation of porous composites, intrinsic chemical doping, and pyrolysis in controlled atmospheres. A variety of characterization tools are being used to study the structure and properties of porous carbons. The overall objective is to develop a fundamental understanding of how morphology, chemical composition, and local order affect the electrochemical performance of porous carbons. The potential payoff from this research is the development of new energy storage devices with superior performance.

Keywords: Porous Carbons, Energy Storage Devices

Materials Properties, Behavior, Characterization or Testing

219. Nonlinear Optics in Doped Fibers

FY 1994

DOE Contact: Walter M. Polansky, (301) 903-5995

$\$ 366,000$

Stanford University Contact: Richard H. Pantell, (415) 723-2564

The objective of this project is to develop a novel and simple technology for optical, all-fiber switches based on the third order nonlinear effect in doped, single-mode fibers. The principle is that when exciting a transition near resonance the electronic distribution changes and so does the contribution of this transition to the refractive index of the material. In this novel approach, a fiber doped with an appropriate impurity, is excited optically near an absorption resonance of the impurity to produce strongly enhanced nonlinear susceptibilities. Modeling shows that it is then possible to reduce the pump and length requirements by several orders of magnitude each, and to produce a $\pi$ phase shift in centimeter lengths with milliwatts of pump power. A variety of impurities will be investigated. For picosecond response times, the reduction in the pump power-fiber length product is predicted to be 7-8 orders of magnitude over undoped silica. Erbium and neodymium doped fibers will also be studied. This investigation is anticipated to open the door to the first low-power, ultra-short switches and modulators made with single-mode optical fibers, operated with a low-power, long-lifetime laser diode. There are a variety of energy applications for the proposed research, including oil exploration, control of power substations, and management of consumer distribution systems.

Keywords: Optical Switch, Nonlinear Optic, Optical Fibers 
220. Feasibility of a Novel Approach for Fast. Economical Determination of Radiation Damage in Nuclear Reactor Cores

DOE Contact: Walter M. Polansky, (301) 903-5995

University of Michigan Contact: Gary S. Was, (313) 763-4675

The objective of this project is to determine the feasibility of using proton irradiation as a radiation damage tool, resulting in order-of-magnitude savings in time and cost over current methods to study radiation damage. 'The feasibility will be established through the application of proton irradiation to the determination of the mechanism of irradiation assisted stress corrosion cracking (IASCC) in light water reactors (LWRs). The emphasis of the technical program will be on the role of grain boundary chemistry and microstructural changes on IASCC. High energy proton irradiation has recently been shown to produce grain boundary segregation of the major alloying elements and impurities, and a microstructure that is comparable to that produced by neutron irradiation in a fraction of the time and at a fraction of the cost. This program is designed to uncover the effects of grain boundary impurity segregation, chromium depletion, and the irradiated microstructure on IASCC. It involves both experimental and computational efforts. The plan also calls for investigation of the dose, dose rate, temperature and injected hydrogen effects and comparison with available neutron irradiation data.

Keywords: Radiation Damage, Stress Corrosion Cracking, Irradiated Microstructures

221. Hot Carrier Solar Cells

FY 1994 $\$ 330,000$

DOE Contact: Walter M. Polansky, (301) 903-5995

National Renewable Energy Laboratory Contact: Mark C. Hanna, (303) 384-6620

This project focused on the development and understanding of a new kind of high efficiency solar cell, called a Hot Carrier Solar Cell (HCSC), which may have the potential to double the maximum efficiency of conventional solar cells. The ultimate thermodynamic conversion efficiency of an optimized HCSC is 66 percent, compared to 31 percent for an optimized conventional single bandgap solar cell. This project will attempt to utilize the excess kinetic energy of higher energy (hot) carriers generated by the absorption of high energy photons in the solar spectrum, which is normally unavailable for useful work. The HCSC employs a new superlattice structure to absorb the solar photons and to inhibit hot carriers from cooling in the photovoltaic device. Hot carriers from the superlattice region are collected in high bandgap contacts to produce a higher photovoltage. With this combination, the photocurrent and photovoltage of the cell can be separately controlled and optimized. This project will synthesize HCSCs, measure their performance and properties, 
compare them to appropriate conventional solar cells, and develop a theoretical model for predicting the device characteristics of the HCSC.

Keywords: Hot Carrier Solar Cells, High Efficiency Energy Conversion

222. Atomic and Nanoscale Engineering of Thermophotovoltaic Semiconductors Using Scanning Probe Microscopy Techniques

FY 1994 $\$ 177,000$

DOE Contact: Walter M. Polansky, (301) 903-5995

National Renewable Energy Laboratory Contact: Lawrence L. Kazmerski, (303) 275-3711

This project uses scanning probe microscopies for the atomic-scale engineering of semiconductors leading to advances in understanding their improvement, and their use in energy-conversion thermophotovoltaic (TPV) structures and devices. This project consists of three interrelated segments: (1) preparation of selected GalnAs and GalnAsP alloy surfaces having suitable compositions; (2) use of modern electronic structure theory to predict the properties of these semiconductor surfaces before and after atomic-scale engineering takes place and to provide guidance for the experiments; and the central and primary activity, (3) evolution of the novel atomic processing microscope to image, process (including atom removal and placement), and characterize these semiconductors with the same nanoscale spatial resolutions and to produce nanometer-scale optimized TPV structures for the next generation of these energy conversion devices.

Keywords: Thermophotovoltaics, Atomic Force Microscopy

\section{Device or Component Fabrication, Behavior or Testing}

\section{Ultrafast Molecular Electronic Devices}

FY 1994

DOE Contact: Walter M. Polansky, (301) 903-5995

Argonne National Laboratory Contact: Michael R. Wasielewski, (708) 252-3538

The objective of this project is to apply the fundamental chemistry of ultra-fast photoinitiated electron transfer reactions to produce high speed, energy efficient molecular electronic devices. These molecules, designed around electron donor-acceptor molecules, will act as opto-electronic switches on a picosecond time scale. Photo-excitation of these molecules with visible light results in very efficient charge separation reactions that set the on or off state of the molecular switch. Two types of switches will be developed: (1) a bistable electron transfer switch that will use a light pulse of one color to store information in the solid state in the form of a long-lived charge separation, and a light pulse of a second color to recover it; and (2) a field effect switch that will use the electric field generated by one charge separated electron donor-acceptor pair to influence the on or off state of a 
second donor-acceptor pair. These electro-optic switch molecules will be assembled in ordered arrays on surfaces using self-assembled monolayer and liquid crystal polymer technology. Potential applications of this technology are optical computing, wavelength selective gates and switches, laser detectors, electro-optic devices, modulators, and memories.

Keywords: Opto-electronic Switches, Liquicl Crystals, Photo-initiated Electron Transfer

224. Photo-Induced Electron Transfer Frorn a Conducting Polymer to Buckminsterfullerene: A Molecular Approach to High Efficiency Photovoltaic Cells

DOE Contact: Walter M. Polansky, (301) 901-5995

University of California, Santa Barbara Contact: Paul Smith, (805) 893-8104

The recently-discovered photoinduced electron transfer, with subpicosecond transfer rate, in composites of a conducting polyrner, MEH-PPV, and a molecular acceptor, buckminsterfullerene, $\mathrm{C}_{60}$, opens a new opportunity for photovoltaic research. Since the charge transfer takes place $\sim 1000$ times faster than the radiative and/or non-radiative decay of photoexcitations, the quantum efficiency for charge transfer and charge separation is near unity. Photoinduced electron transfer across the donor-acceptor rectifying heterojunction offers potential for solar cell applications, using materials that exhibit a unique combination of properties: electronic and optical properties of semiconductors and metals in combination with the attractive mechanical properties and the processing advantages of polymers. The potential advantages of an all-polymer heterojunction solar cell include low cost, large area, and flexibility. The goal of the proposed research is to build upon this novel molecular approach to photoinduced charge separation and charge transfer, with quantum efficiency approaching unity, and to create a capability to efficiently produce flexible, "plastic" solar cells for large areas.

Keywords: Fullerenes, Photovoltaics, Solar Cells

225. Superconducting Bitter Magnets

FY 1994

$\$ 300,000$

DOE Contact: Walter M. Polansky, (301) 903-5995

Massachusetts Institute of Technology Contact: Leslie Bromberg, (617) 253-6919

A novel process for manufacturing high temperature superconducting magnets, using thick-film superconducting material on structural plates, is described. The technique is similar to that used in constructing Bitter magnets. The superconductor is manufactured in the required shape, avoiding the need to develop ductile wires. The structural metal plate serves as the material as well as the quench protector. A dielectric with high electrical 
resistivity is placed between the conductor and the metal plate (copper, aluminum, composite materials). This method can be utilized for manufacturing solenoidal, toroidal, saddle, and other types of magnets with both high- $T_{c}$ and low- $T_{c}$ superconductors. This project will address issues faced in this type of magnet construction (quench protection, materials compatibility, stability, and cooling). Interaction with the manufacturers to improve the performance of superconducting materials for this application will be maintained. It is expected that in the final phase of this program, magnets will be constructed and tested. The project is in collaboration with the Plasma Fusion Center at the Massachusetts Institute of Technology and the Superconductivity Technology Center at Los Alamos National Laboratory.

Keywords: Bitter Magnets, Superconductivity

\section{Blue-Emitting Devices Based on Gallium Nitride}

FY 1994

DOE Contact: Walter M. Polansky, (301) 903-5995

Lawrence Berkeley Laboratory Contact: Michael D. Rubin, (510) 486-7124

The purpose of this project is to convert the recent breakthroughs in growth of gallium nitride $(\mathrm{GaN})$ into practical ultraviolet and blue light emitting diodes and lasers. Short-wavelength semiconductor devices based on GaN are needed for many important applications such as energy-efficiency illumination, high-density optical data storage, flatscreen color displays, underwater communications, and high-temperature electronics. One of the principal technical problems that limits device applications has been achieving controllable properties with addition of $\mathrm{Mg}$. It was discovered that good quality material could be readily obtained by a variety of doping methods including ion implantation, diffusion and co-evaporation of $\mathrm{Mg}$. The defect studies which guide the improvements in the growth process will be continued. The technology will be transferred to HewlettPackard, where it will be reproduced in a large-scale commercial growth system.

Keywords: Gallium Nitride, Blue-Emitting Devices

227. Solid State Multi-Layered Batteries

FY 1994

$\$ 419,000$

DOE Contact: Walter M. Polansky, (301) 903-5995

Lawrence Livermore National Laboratory Contact: Richard M. Bionta, (510) 423-4846

The purpose of this project is to develop thin film solid-electrolyte batteries fabricated by the advanced multilayer sputtering techniques developed for X-ray optics. This technique allows the battery to be constructed in situ by depositing the anode, electrolyte, and cathode as distinct layers. Solid-electrolyte batteries have long been attractive because of their shelf-life and compatibility with severe environments. Recently, 
rechargeable lithium cells that operate at ambient temperature have been developed based on ionically conducting solid polymer electrolytes. This project will concentrate on the development of thin-film solid-electrolyte cells constructed of lithium based inorganic materials fabricated by multilayer sputtering. The ability of this fabrication technique to discretely layer or compositionally grade thin films provides a unique opportunity to investigate the effect of electrode-electrolyte interface structure on cell performance. Finally, the computer control associated with this fabrication technique will allow the deposition of multiple cells in a bipolar configuration with either series or parallel connection. It is anticipated that this research will directly lead to power sources for modern electronic circuits (i.e., microsensors, memory elements, displays, and timers).

Keywords: Solid State Batteries, Solid Electrolyte Batteries, Multilayer Fabrication

228. PV-Powered. Electrochromic Windows

FY 1994

DOE Contact: Walter M. Polansky, (301) 903-5995

$\$ 330,000$

National Renewable Energy Laboratory Contact: David K. Benson, (303) 384-6462

This project will develop a retrofit window treatment for architectural windows. The window treatment will be a combination of thin-film photovoltaic cells and an electrochromic coating, both deposited onto a flexible polymer film. The coated polymer film will be applied to the interior surfaces of existing building windows and used to modulate the solar transmittance into the building thereby providing automatic solar-gain control and daylighting control functions which will reduce heating, cooling, and lighting energy usage in the building. This kind of "smart" window covering has the potential to balance the performance of the window, giving it a net energy benefit. It has been predicted to be able to reduce the cooling power demand of a south-facing window in a climate such as southern California by about 40 percent. At present, an estimated 1-1.5 percent of the total cooling energy need in buildings and 10-30 percent of the peak electric utility power demand is caused by windows amounting to about a $1500 \mathrm{MW}$ increase in electric utility peak electric power demand each year due to new windows at a national operating cost of about $\$ 10$ billion. New photovoltaic and electrochromic coating designs and new processes for their deposition onto flexible polymer substrates will be developed in this project.

Keywords: Electrochromic Windows, Smart Windows, PV-Powered Windows

\section{Office of Fusion Energy}

The mission of the Office of Fusion Energy (OFE) is to develop fusion as an environmentally attractive, commercially viable, and sustainable energy source for the Nation and the world. This mission will be accomplished by parallel activities to develop the science and technology base for fusion, the conduct of large-scale experiments to explore 
the physics and demonstrate the components of fusion technologies, and the construction and operation of fusion power plants that will culminate in a demonstration power plant.

A significant component of the fusion energy program is the development and validation of the materials required for the fusion systems. Materials must be developed that will meet the unique requirements of fusion, as well as the standard requirements of a high efficiency, high reliability power generating system. The unique requirements of fusion are the result of the intense neutron environment, dominated by the $14 \mathrm{MeV}$ neutrons characteristic of the deuterium-tritium fusion reaction. For performance, the materials must have slow and predictable degradation of properties in this neutron environment. For safety and environmental considerations, materials must be selected with activation products that neither decay too rapidly (affecting such safety factors as system decay heat) nor too slowly (affecting the waste management concerns for end-of-life system components). Materials that meet these requirements are referred to as "Low Activation Materials." Programs to develop the materials for plasma-facing components, for diagnostic and control systems, for structures in the high neutron flux regions, for the production of tritium in the blanket, and for the superconducting magnets required for confinement are sponsored by OFE.

The fusion program in the United States is conducted with a high degree of international cooperation. Of particular importance is the International Thermonuclear Experimental Reactor (ITER) engineering design activity, conducted in partnership with the European Union, Japan, and the Russian Federation. Approximately half of the materials work sponsored by OFE is in support of the ITER collaboration

\section{Materials Properties. Behavior. Characterization or Testing}

229. Structural Materials Development

FY 1994 $\$ 389,000$

DOE Contact: F. W. Wiffen (301) 903-4963

ANL Contact: D. L. Smith (708) 252-4837

This program is directed at the development of advanced, low activation structural materials for application in fusion power system first wall and blankets. Emphasis at ANL is on the development of vanadium-base alloys and on chemical corrosion/compatibility of the structural materials with other system materials. The vanadium alloy development is focused on the V-Cr-Ti system, with the goals of identifying promising candidate compositions, determining the properties of candidate alloys, and evaluating the response to irradiation conditions that simulate anticipated fusion system operation. The 
compatibility studies include vanadium and other candidate structural materials, and focus on the effects of exposure to projected coolents, especially liquid lithium.

Keywords: Vanadium, Compatibility, Lithium, Irradiation Effects, Alloy Development

230. Repair Welding of Fusion Reactor Components

FY 1994

DOE Contact: F. W. Wiffen, (301) 903-4963

$\$ 90,000$

Auburn University Contact: B. A. Chin, (205) 844-3322

Repair welding of metal components that have been in service under neutron irradiation is limited by the tendency of the material to crack during welding. This program is identifying the mechanisms of the weld cracking and the association with transmutationproduced helium. Experiments on the effects of stress state on the growth of helium bubbles is expected to lead to methods to mitigate the weld cracking problem in irradiated steels.

Keywords: Steels, Welding, Irradiation Effects

231. Insulating Ceramics for Fusion

FY 1994

DOE Contact: F. W. Wiffen, (301) 903-4963

$\$ 290,000$

LANL Contact: E. H. Farnum, (505) 665-5:23

The goals of this project are to determine the changes in electrical, optical and structural properties of ceramic insulators in predicted fusion service, especially the effects of neutron irradiation. An understanding of the effects of radiation and of the controlling mechanisms are used to select or develop inaterials capable of extended life for use in fusion systems.

Keywords: Ceramics, Electrical Properties, Irradiation Effects

232. Modeling Irradiation Effects in Solids:

FY 1994

DOE Contact: F. W. Wiffen, (301) 903-4963

$\$ 60,000$

LLNL Contact: T. Diaz de la Rubia, (510) $422-6714$

Large scale computer simulation and experimental data on irradiation effects are combined to extend the understanding of the primary damage processes in solids. Special 
attention is given to the energy range appropriate for the $14 \mathrm{MeV}$ neutrons produced in D-T fusion, and to the materials of interest for fusion systems.

Keywords: Modeling, Irradiation Effects

233. Fusion Systems Materials

FY 1994

$\$ 2,355,000$

DOE Contact: F. W. Wiffen, (301) 903-4963

ORNL Contacts: E. E. Bloom, (615) 574-5053 and A. F. Rowcliffe, (615) 574-5057

This program is directed at the development and qualification of structural materials and insulating ceramics for use in components of fusion power systems exposed to the intense neutron flux. Candidate low activation structural material systems include ferritic/ martensitic steels, vanadium alloys and $\mathrm{SiC} / \mathrm{SiC}$ composites. Investigations focus on the most critical questions or limiting properties in each of these systems: ferritic/martensitic steels - DBTT transition shifts and fracture toughness, vanadium alloys - effects of irradiation on fracture toughness and compatibility in proposed coolant systems, $\mathrm{SiC} / \mathrm{SiC}$ composites - definition of the effects of irradiation on properties and structure. The insulating ceramic activity is initially developing an understanding of irradiation effects in alumina, spinel, and other materials. The greatest concern is to establish the permanent and transient changes in electrical properties, requiring measurement while the specimen is under irradiation. Work on these two material classes involves irradiation in fission reactors, including HFIR, EBR-II, and HFBR, as partial simulation of the fusion environment.

Keywords: Ceramics, Steels, Vanadium, Silicon Carbide, Composites, Irradiation Effects, Electrical Properties

234. Structural Materials for Fusion Systems

FY 1994

$\$ 1,791,000$

DOE Contact: F. W. Wiffen, (301) 903-4963

PNL Contact: R. H. Jones, (509) 376-4276

The goal of this program is to develop an understanding of radiation effects that provides a basis for development of irradiation insensitive materials. The objective is low activation materials for use as structures in divertor, first wall, and blanket components of fusion systems. Irradiation in fission reactors is used to simulate fusion conditions, with measurement of physical and mechanical properties used to track irradiation effects. A 
modeling activity complements the experinental measurements. The ultimate goal is optimized ferritic steels, vanadium alloys, and $\mathrm{SiC} / \mathrm{SiC}$ composite materials for fusion power plant use.

Keywords: Steels, Vanadium, Silicon Carbide, Composites, Irradiation Effects, Modeling

235. Development of Radiation-Hardened Ceramic Composites for Fusion Applications

FY 1994

$\$ 49,000$

DOE Contact: F. W. Wiffen, (301) 903-4963

RPI Contact: D. Steiner, (518) 276-4016

This research is directed at furthering the understanding of the effects of irradiation on the $\mathrm{SiC} / \mathrm{SiC}$ composite system, as the basis for developing superior composite materials for fusion structural applications. The focus of the work is on the evaluation of improved fibers and alternative interface layer materials.

Keywords: Silicon Carbide, Composites

236. Radiation Effects and Micromechanics of $\mathrm{SiC} / \mathrm{SiC}$ Composites

FY 1994

$\$ 97,000$

DOE Contact: F. W. Wiffen, (301) 903-4963

UCLA Contact: N. M. Ghoniem, (310) 825.4866

The goal of this program is to develop an understanding of the basic processes of neutron damage production, microstructural evolution, chemical compatibility, and micromechanics of fracture in $\mathrm{SiC} / \mathrm{SiC}$ composite materials. This basic knowledge of materials behavior is used to model the effects of irradiation and the service performance of $\mathrm{SiC} / \mathrm{SiC}$ components in fusion power systems. The critical goal is helping to evaluate the feasibility of using $\mathrm{SiC} / \mathrm{SiC}$ in this application.

Keywords: Silicon Carbide, Composites, Modeling, Irradiation Effects

237. Damage Analysis and Fundamental Studies for Fusion

Reactor Materials Development

FY 1994

$\$ 180,000$

DOE Contact: F. W. Wiffen, (301) 903-4963

UCSB Contacts: G. R. Odette, (805) 893-3525 and G. E. Lucas, (805) 893-4069

This research is directed at developing a fundamental understanding of both the basic damage process and microstructural evolution that take place in a material during neutron 
irradiation. This understanding is used with empirical data to develop physically-based models of irradiation effects. The focus is on the fracture properties of vanadium alloys, austenitic and ferritic stainless steels, including helium effects, to (a) develop an integrated approach to integrity assessment, (b) develop advanced methods of measuring fracture properties, and (c) analyze the degradation of the mechanical properties of austenitic stainless steels. The program contributes to the assessment of the feasibility of using these alloys in ITER and other fusion systems.

Keywords: Vanadium, Steels, Irradiation Effects, Fracture

238. Development of Lithium-Bearing Ceramic Materials for Tritium Breeding in Fusion Reactors

FY 1994

$\$ 250,000$

DOE Contact: S. Berk, (301) 903-4171

ANL Contact: C. Johnson, (708) 252-7533

Research activities are focused on critical issues of ceramic breeder blankets for fusion reactors, including ceramic breeder material tritium retention and release, ceramic breeder and beryllium irradiation response, chemical compatibility of ceramic breeder materials and beryllium with blanket coolant and structural materials, and heat transfer and temperature control in ceramic breeder materials. Small-scale laboratory experiments are performed to study tritium transport characteristics and to benchmark computer models of tritium transport. Computer models are tested against data on irradiation of lithium-oxide and lithium-zirconate materials in a fast-spectrum fission reactor. There is good agreement between model predictions and experimental data in the area of transient tritium release.

Keywords: Ceramics, Compatibility, Tritium Release, Modeling, Lithium Ceramics

239. Post-Irradiation Examination of Lithium-Bearing Ceramic Materials for Tritium Breeding in Fusion Reactors

FY 1994 $\$ 500,000$

DOE Contact: S. Berk, (301) 903-4171

PNL Contact: G. Hollenberg, (509) 376-5515

Research activities are for post-irradiation examinations (PIE) of the ceramic breeder materials irradiated in the Fast Flux Test Facility. The PIE is conducted as part of the BEATRIX-II program under an International Energy Agency agreement between the US, Japan, and Canada. PIE involves capsule disassembly, neutron radiography, plenum gas analysis, photography, mensuration characterization, tritium inventory measurements, microstructural characterization, and thermal conductivity measurements. PIE for specimens from the BEATRIX-II Phase 1 irradiation (lithium-oxide irradiated to 5 percent lithium 
atom burnup) have been mostly completed and PIE on the Phase 2 specimens (lithium-oxide and lithium-zirconate irradiated to 5 percent lithium atom burnup) is nearing completion.

Keywords: Ceramics, Lithium Ceramics, Tritium Release

\section{International Thermonuclear Experimental Reactor (ITER) Materials Development for Plasma Facing Components}

FY 1994

$\$ 3,000,000$

DOE Contact: M. M. Cohen, (301) 903-4253

SNL Contact: M. Ulrickson, (505) 845-3020

Research activities include: improved techniques for joining beryllium to copper alloys, determination of the tritium retention of beryllium, improvement of the thermal conductivity of plasma sprayed beryllium, development of radiation damage resistant carbonfiber composites, determination of erosion rates of beryllium, tungsten and carbon under normal and disruption conditions, and thermal fatigue testing of beryllium and carbon-fiber composites. The joining techniques being investigated include diffusion bonding, induction brazing, electroplating, and inertial welding. Tritium retention and permeation measurements have been conducted on the Tritium Plasma Experiment. The improvements in the plasma spray technique are centered on improving the beryllium powder and selection of the proper powder sizes. Highly oriented pitch based carbon fibers have been used to produce carbon-fiber composite for neutron irradiation. The erosion rates are measured on both plasma simulators and tokamaks. The thermal fatigue testing is carried out on electron beam test systems. The ITER Industrial Partnership (McDonnell-Douglas, Westinghouse, Rocketdyne, General Atomics, and University of Illinois) is involved in the joining studies, erosion rate studies, and fatigue testing.

Keywords: Plasma-Facing Components, Beryllium, Carbon-Fiber Composite, Joining, Erosion, Thermal Fatigue

241. ITER Structural Materials Development

FY 1994

DOE Contact: F. W. Wiffen, (301) 903-4963

$\$ 630,000$

ANL Contact: D. L. Smith, (708) 252-4837

The ITER structural materials program is working toward the establishment of a database on the main candidate materials for use in the divertor, first wall, blanket and shield structures. The ANL program is evaluating candidate vanadium alloys. The early stages of this work are concentrating on baseline properties, irradiation effects, and compatibility with coolant fluids. Issues of fabrication, joining, and protective coatings are being incorporated as the program progresse:s.

Keywords: Vanadium, Irradiation Effects, Compatibility 
242. ITER Ceramic Materials

FY 1994

$\$ 358,000$

DOE Contact: F. W. Wiffen, (301) 903-4963

LANL Contact: E. H. Farnum, (505) 665-5223

The ITER will require ceramic materials in a number of the heating, current drive, and diagnostic elements of the plant. Behavior of these systems can be limited by their electrical, optical and/or structural properties. A program of in situ and post irradiation measurements to determine the effects of irradiation on these properties is conducted at LANL and other sites, with the goals of developing the properties database on candidate materials that will allow system designers to effectively include these components in the ITER plant.

Keywords: Ceramics, Electrical Properties, Optical Properties, Irradiation Effects

\section{Radiation Hardened Fiber Optics for ITER Fusion Diagnostic Systems}

$\frac{\text { FY } 1994}{\$ 50,000}$

DOE Contact: F. W. Wiffen, (301) 903-4963

NRL Contact: D. L. Griscom, (202) 404-7087

This work evaluates the effects of fusion system irradiation on optical fibers and selects and/or develops fibers that are radiation resistant in use in diagnostic applications. Experiments on available fibers use gamma sources, spallation neutron sources, and fission reactors to characterize degradation of optic properties during and after irradiation. The most resistant fibers will be studied in more detail, and the data used to formulate potentially more resistant fiber compositions.

Keywords: Optical Fibers, Optical Properties, Irradiation Effects

244. ITER Materials Evaluation

FY 1994

$\$ 1,459,000$

DOE Contact: F. W. Wiffen, (301) 903-4963

ORNL Contact: E. E. Bloom, (615) 574-5053, and A. F. Rowcliffe, (615) 574-5057

ITER requires structural materials and insulating ceramics for use in a range of system components exposed to the neutrons produced by the fusion reaction. ORNL's part of the ITER materials program is directed at the selection of promising compositions of austenitic stainless steels, copper alloys, and vanadium alloys and assisting in the development of the database needed for the use of these materials. Irradiation effects, compatibility and weldability of these materials are under study. The insulating ceramics work is focused on the electrical properties under irradiation, and the in situ measurement 
techniques to determine this response are being developed. The work at ORNL emphasizes the use of the HFIR to perform the irradiations in support of the ITER materials development and evaluation.

Keywords: Steels, Copper, Vanadium, Ceramics, Irradiation Effects, Electrical Properties

245. ITER Structural Materials Evaluation

FY 1994

DOE Contact: F. W. Wiffen, (301) 903-4963

$\$ 840,000$

PNL Contact: R. H. Jones, (509) 376-4276

Materials systems of interest to ITER for use as structural materials in the divertor, first wall, and blankets are under evaluation to select the most attractive candidates in each system, and to develop the property database on these. The PNL program is evaluating copper alloys, stainless steels, and vanadium alloys for the ITER program. While the emphasis is on irradiation effects, especially on fracture properties, the program at PNL also is examining hydrogen effects and compatibility with water cooling.

Keywords: Steels, Copper, Vanadium, Irradiation Effects, Compatibility

246. Development of $\mathrm{Nb}_{3} \mathrm{Sn}_{3}$ Superconducting Wire for the ITER Magnet Program

FY 1994 $\$ 1,000,000$

DOE Contact: M. M. Cohen, (301) 903-4253

MIT Contact: J. Minervini, (617) 253-5503

Activities include development of $\mathrm{Nb}_{3} \mathrm{Sn}$ superconducting wire primarily for use in the high field magnets of the ITER model coils. Aggressive target specifications for high critical current density in the 12-13 tesla magnetic field range have been set and an industrial development program has begun to produce large quantities of this wire. U.S. superconducting wire industries involved include Intermagnetics General Corp./Advanced Superconductors Inc., Teledyne Wah Chang Albany, Oxford Superconducting Technologies, and Supercon. Characterization of critical superconducting properties and ac losses has been carried out with measurements in university and national laboratories, including establishment of standardized samples and test procedures.

Keywords: Superconductors, Magnet Materials, $\mathrm{Nb}_{3} \mathrm{Sn}$ 


\section{Structural Materials Development for the Conduit of ITER}

Cable-in-Conduit-Conductors

FY 1994

$\$ 1,100,000$

DOE Contact: M. M. Cohen, (301) 903-4253

MIT Contact: J. Minervini, (617) 253-5503

Activities include fabrication of conduit for the conductors of the central solenoid and toroidal field model coils for ITER. The conduit material, Incoloy alloy 908, was developed via collaboration of INCO Alloys International and MIT. Work is proceeding on development of the database for this material. Alloy 908 has a low coefficient of expansion and minimizes the compressive strain in the $\mathrm{Nb}_{3} \mathrm{Sn}$ superconductor upon cool down from the heat treatment temperature of approximately $1000 \mathrm{~K}$ to the operation temperature of $4 \mathrm{~K}$. Industrial processing by various methods to finished conduit shape has been a priority.

Keywords: Conduit, Incoloy, Magnet Materials

\section{Small Business Innovation Research Program}

The Small Business Innovation Research (SBIR) program is mandated by the Small Business Innovation Development Act of 1982 and the Small Business Research and Development Enhancement Act of 1992. The program is designed for implementation in a three-phase process, with Phase I determining, insofar as possible, the scientific or technical merit and feasibility of ideas proposed for investigation. The period of performance in this initial phase is about six months and awards prior to FY 1993 were limited to $\$ 50,000$; in FY 1993 and FY 1994, the award size was increased to $\$ 75,000$. Phase II is the principal research or research and development effort and is performed in a period of up to two years. Phase II awards were limited to \$500,000 until FY 1994, when the maximum was increased to $\$ 600,000$. Under Phase III, commercial applications of the research or research and development are to be pursued by small businesses with nonFederal capital or, alternatively, Phase III may involve follow-on non-SBIR Federal contracts for products or processes desired by the Government.

The materials-related projects, like all other projects in the DOE SBIR program, were selected using the specific evaluation criteria listed in the program solicitation. Conclusions were reached on the basis of detailed reports returned by reviewers drawn from DOE laboratories, universities, private industry, and government. In the Phase II technical evaluation process, in the case in which two or more grant applications were judged to be of approximately equal scientific and technical merit, preference was given to those applications that had demonstrated third phase, non-Federal capital commitments.

The work supported in this program represents high-risk research, but the potential benefits are also high if the objectives are met. Brief descriptions of all DOE SBIR projects 
(not just those of interest in materials research) are given in the following publications: Abstracts of Phase I Awards. 1994 (DOE/ER-0630 and -0606), Abstracts of Phase II Awards, 1994 (DOE/ER-0628), and Abstracts of Phase II Awards, 1993 (DOE/ER-0600). Copies of these publications may be obtained by calling Mrs. Kay Etzler on (301) 903-5867.

Materials Preparation. Synthesis, Deposition, Growth or Forming

\section{Phase I Projects:}

Low Cost, High Purity Silicon by Alkaline Glycolic Digestion of Silica - DOE Contact Alec Bulawka, (202) 586-5633; AstroPower, Inc. Contact Mr. Thomas J. Stiner, (302) 366-0400

High Speed Sheet Growth of Thin Silicon Films - DOE Contact Alec Bulawka, (202) 586-5633; AstroPower, Inc. Contact Mr. Thomas J. Stiner, (302) 366-0400

An Innovative Approach for Large Area Photovoltaic Material Processing - DOE Contact Alec Bulawka, (202) 586-56.33; International Solar Electric Technology, Inc. Contact Dr. Bulent Basol, (310) 216-4427

Low Cost Solar Cell Leads for Use in Photovoltaic Modules - DOE Contact Alec Bulawka, (202) 586-5633; Solar Engineering Applications Corporation Contact Mr. Neil Kaminar, (408) 986-9231

Very Low-Cost/High-Efficiency Thin-Film Silicon Photovoltaic Technology - DOE Contact Alec Bulawka, (202) .586-5633; Spire Corporation Contact Mr. Patrick N. McDonnell, (617) 275-6000

Improved Activated Carbon for Hydrogen Storage - DOE Contact JoAnn Milliken, (202) 586-2480; Arcanum Corporation Contact Mr. Helmut F. Stern, (313) 665-4421

A Superplastic Oxide Dispersion Strengthened Magnesium Alloy for Automotive Applications - DOE Contact Sidney Diamond, (202) 586-8032; Chesapeake Composites Corporation Contact Dr. Alexander Brown, (302) 324-9110

Low Cost Synthesis of Nanocrystalline Silicon Carbide Starting with Fullerene Precursors - DOE Contact Clifford Smith, (412) 892-4518; Materials and Electrochemical Research Corporation Contact Dr. R. O. Loutfy, (602) 574-1980

A Ceramic Material and Process for Use in Monolithic Ceramic Cross-Flow Filters DOE Contact Thedore J. McMahon, (304) 291-4865; Blasch Precision Ceramics, Inc. Contact Mr. David W. Bobrek, (518) 372-9416 
High Temperature Brazing of Silicon Carbide - DOE Contact Charles Thomas, (412) 892-5731; Busek Company, Inc. Contact Mrs. J. Budny, (617) 449-3929

Molecular Composite Plastics for Lightweight Green Cars - DOE Contact Robert Astheimer, (301) 903-4410; Maxdem, Inc. Contact Dr. Matthew Marrocco, (909) 394-0644

Surface Hardening of Polymeric Composites by High Energy Ion Irradiation - DOE Contact Robert Astheimer, (301) 903-4410; UES, Inc. Contact Mr. Robert W. Vukusich, (513) 426-6900

A Novel Method for Manufacture of High Temperature Superconducting Coils for High Temperature Operation - DOE Contact Cynthia Carter, (301) 903-5997; IGC Advanced Superconductors, Inc. Contact Mr. B. A. Zeitlin, (203) 753-5215

Design and Applications of Close-Spaced Thermionic Converters with Novel Isothermal Electrodes - DOE Contact Cynthia Carter, (301) 903-5997; Space Power, Inc. Contact Mr. Joseph A. Dodson, (408) 434-9500

Development of Metal Hydride Materials for High Coefficient of Performance Heat Pumps - DOE Contact Cynthia Carter, (301) 903-5997; Thermal Electric Devices, Inc. Contact Dr. Charles Stein, (505) 272-7505

Growth of Lutetium Phosphate Scintillator Crystals for Positron Emission Tomography - DOE Contact Gerald Goldstein, (301) 903-5348; ALEM Associates/ Radiation Monitoring Devices Contact Dr. Alexander Lempicki, (617) 353-9581

Top-Seeded Solution Growth of Lutecium Phosphate from Potassium Pyrophosphate Flux - DOE Contact Gerald Goldstein, (301) 903-5348; Deltronic Crystal Industries, Inc. Contact Mr. Stuart Samuelson, (201) 361-2222

Production of Carbon-11-Labeled Compounds for Positron Emission Tomography with a Low Energy Accelerator - DOE Contact Gerald Goldstein, (301) 903-5348; Science Research Laboratory, Inc. Contact Dr. Jonah Jacob, (617) 547-1122

Sapphire-Metal Joining for Low-Loss Gyrotron Windows - DOE Contact T. V. George, (301) 903-4957; FM Technologies, Inc. Contact Dr. Frederick M. Mako, (703) 425-5111

Economical and Reliable Niobium-Tin Conductors via Innovations in Stabilizers DOE Contact T. V. George, (301) 903-4957; IGC Advanced Superconductors, Inc. Contact Mr. B. A. Zeitlin, (203) 753-5215 
An Innovative Technique to Bond One Dimensional Carbon-Carbon Composites to Dispersion Strengthened Copper - DOE Contact T. V. George, (301) 903-4957; Materials and Electrochemical Research Corporation Contact Dr. R. O. Loutfy, (602) $574-1980$

Advanced Low-Stress Brazing of Flasma-Facing Fusion Components with High Energy Electron Beams - DOE Contact T. V. George, (301) 903-4957; Science Research Laboratory, Inc. Contact Dr. Jonah Jacob, (617) 547-1122

Joining of Aluminum to Carbon-Carbon Composites for Fusion Reactor Applications -DOE Contact T. V. George, (301) 903-4957; Surmet Corporation Contact Dr. Suri A. Sastri, (617) 272-3250

Ductile Joining of Beryllium to Copper - DOE Contact T.V. George, (301) 903-4957; Surmet Corporation Contact Dr. Suri A. Sastri, (617) 272-3250

A Multilaver Silicon Carbide Fiber Coating for Toughened, Neutron Radiation-Resistant Silicon Carbide/Silicon Carbide Composites - DOE Contact F. W. Wiffen, (301) 903-4963; Hyper-Therm, Inc. Contact Mr. Wayne S. Steffier, (714) $375-4085$

Niobium Titanium Multifilamentary Materials with Silicon in the Matrix - DOE Contact Jerry Peters, (301) 903-5228; IGC Advanced Superconductors, Inc. Contact Mr. B. A. Zeitlin, (203) 753-5215

A Novel Approach to Fabrication of Niobium-Tin Conductor with Artificial Pinning Centers - DOE Contact Jerry Peters, (301) 903-5228; IGC Advanced Superconductors, Inc. Contact Mr. BB. A. Zeitlin, (203) 753-5215

High Quality Chemically Vapor Deposited Niobium Coatings for Superconducting Radio Frequency Cavities - DOE Contact Jerry Peters, (301) 903-5228; Sumi Tech, Inc. Contact Mrs. Mallika D. Ilindra, (703) 552-8334

Niobium-Titanide Tin/Copper Multifilamentary Superconducting Wire with Niobium/Titanium Composite Filaments - DOE Contact Jerry Peters, (301) 903-5228; Supercon, Inc. Contact Ms. Elaine Drew, (508) 842-0174

Development of Niobium-Titanium-Tantalum Artificial Pinning Center Superconductors for Very High Field Applications - DOE Contact Jerry Peters, (301) 903-5228; Supercon, Inc. Contact Ms. Elaine Drew, (508) 842-0174 
Jet Vapor Deposition of Thick Films for the Production of Radioactive Beams of Chemically Active Elements - DOE Contact Richard Rinkenberger, (301) 903-3613; Jet Process Corporation Contact Mr. Jerome J. Schmitt, (203) 786-5130

Microchannel Plates Fabricated by Track Etch Lithography - DOE Contact Richard Rinkenberger, (301) 903-3613; Spire Corporation Contact Mr. Patrick N. McDonnell, (617) 275-6000

Radiation-Hard and Solar Blind Ultraviolet X-Ray Chemically Vapor DepositedDiamond Photodiode Detectors - DOE Contact Richard Rinkenberger, (301) 903-3613; Vactronic Laboratory Equipment, Inc. Contact Mr. Robert Salat, (516) $567-0520$

Phase II Projects: (First Year)

Multi Laver, Quantum Well Layer Film Thermoelectrics - DOE Contact John Warren, (301) 903-6491; Hi-Z Technology, Inc. Contact Mr. Norbert B. Elsner, (619) 535-9343

Production of Carbon Materials from Biomass - DOE Contact David Boron, (202) 586-0080; Advanced Fuel Research, Inc. Contact Dr. David G. Hamblen, (203) 528-9806

Oxide Dispersion Strengthened Silver for Use in High-Temperature Superconductor Composite Wires - DOE Contact Cynthia Carter, (301) 903-5997; American Superconductor Corporation Contact Mr. Edward P. Hamilton, (617) 923-1122

Low Temperature Deposition of Titanium Nitride - DOE Contact Cynthia Carter, (301) 903-5997; ISM Technologies, Inc. Contact Mr. Robert J. Stinner, (619) $530-2332$

Coated Micrograin Carbides for Wear Resistance - DOE Contact Cynthia Carter, (301) 903-5997; Ultramet Contact Mr. Craig N. Ward, (818) 899-0236

Composite Plasma-Polymer Membranes - DOE Contact Robert Marianelli, (301) 903-5804; Bend Research, Inc. Contact Dr. Walter C. Babcock, (503) 382-4100

Improved Coated-Metal Hydrogen Extraction Membranes - DOE Contact Robert Marianelli, (301) 903-5804; REB Research and Consulting Contact Dr. Robert E. Buxbaum, (517) 332-0243 
Methods of Improving Internal-Tin Niobium-Tin for Fusion Applications - DOE Contact Warren Marton, (301) 903-4965; IGC Advanced Superconductors, Inc. Contact Mr. B. A. Zeitlin, (203) 753-5215

Advanced Nondestructive Evaluation for Quality Assurance of Divertor Plate Armor Tiles in Plasma Fusion Reactors - DOE Contact Warren Marton, (301) 903-4965; Karta Technology, Inc. Contact Dr. G. P. Singh, (210) 681-9102

Dense. High Conductivity, Copper/Aluminum/Beryllium Functionally Gradient, Plasma Facing Components -DOE Contact Warren Marton, (301) 903-4965; Plasma Processes Contact Ms. Cheri M. McKechnie, (205) $881-7572$

Flexible Electrochromic Window Materials Based on Poly (Diphenyl Amine) and Related Conducting Polymers - DOE Contact Sam Taylor, (202) 586-9214; Ashwin-Ushas Corporation, Inc. Contact Dr. P. Chandrasekhar, (908) 462-1270

Advanced Window Materials Based on Conducting Polymer/Sol-Gel Ceramic Composites - DOE Contact Sam Taylor, (202) 586-9214; Gumbs Associates, Inc. Contact Dr. Ronald W. Gumbs, (908) 257-9049

An Innovative Approach for the Formation of Silicon Carbide/Silicon Carbide Composites - DOE Contact F.W. Wiffen, (301) 903-4963; Lanxide Corporation Contact Mr. Robert J. Ferris, (302) 456-6216

Doping of Chemically Vapor Infiltrated Silicon Carbide to Enhance Thermal Conductivity - DOE Contact F.W. Wiffen, (301) 903-4963; Materials and Electrochemical Research Corporation Contact Dr. J. C. Withers, (574) 674-1980

Phase II Projects: (Second Year)

Development of a Novel Reverse-Osmosis Membrane with High Rejections for Organic Compounds - DOE Contact Robert Marianelli, (301) 903-5804; Bend Research, Inc. Contact Dr. Scott B. McCray, (503) 382-4100

Development of a Process to Synthesize Tubular Fullerenes - DOE Contact Robert Marianelli, (301) 903-5804; Materials and Electrochemical Research Corporation Contact Dr. J. C. Withers, (602) 574-1980

Continuous Production of Fullerenes from Hydrocarbon Precursors - DOE Contact Robert Marianelli, (301) 903-5804; TDA Research, Inc. Contact Mr. John D. Wright, (303) $422-7918$ 
Preparation of Low-Density Microcellular Materials from Fullerenes - DOE Contact Robert Marianelli, (301) 903-5804; TDA Research, Inc. Contact Dr. William L. Bell, (303) $420-4329$

New Gadolinium-Boron Compounds for Neutron Capture Therapy - DOE Contact Gerald Goldstein, (301) 903-3213; Boron Biologicals, Inc. Contact Dr. Bernard F. Spielvogel, (919) 832-2044

Refractory Metal Coatings on Carbon/Carbon Composites for First Wall Applications -DOE Contact Marvin Cohen, (301) 903-4253; Applied Sciences, Inc. Contact Mr. Jyh-Ming Ting, (513) 766-2020

A Thermal Composite Plasma Facing Material - DOE Contact Marvin Cohen, (301) 903-4253; Energy Science Laboratories, Inc. Contact Dr. Timothy R. Knowles, (619) $552-2034$

A Niobium-Tin Multifilamentary Composite Superconductor with Artificial Copper (Bronze) Inclusions - DOE Contact Marvin Cohen, (301) 903-4253; Supercon, Inc. Contact Dr. Dingan Yu, (508) 842-0174

A Porous Metal Heat Exchanger Cooled Microwave Cavity - DOE Contact T. V. George, (301) 903-4957; Thermacore, Inc. Contact Mr. John H. Rosenfeld, (717) $569-6551$

Development of Silicon Carbide Ceramic Composites for Fusion Reactor Applications - DOE Contact F. W. Wiffen, (301) 903-4963; Materials and Electrochemical Research Corporation Contact Dr. J. C. Withers, (602) 574-1980

Radiation Damage Resistant Silicon for Particle Physics Detectors - DOE Contact William Watson, (214) 708-2417; IntraSpec, Inc. Contact Mr. John Walter, (615) 483-1859

Materials Properties, Behavior. Characterization or Testing

Phase I Projects:

A Long Life Zinc-Oxide-Titanium-Oxide Sorbent - DOE Contact Ronald K. Staubly, (304) 291-4991; TDA Research, Inc. Contact Mr. Michael E. Karpuk, (303) 940-2301

High Temperature Thermally Stable Multi-Laver Ouantum Well Films - DOE Contact Bill Barnett, (301) 903-3097; Hi-Z Technology, Inc. Contact Mr. Norbert B. Elsner, (619) 535-9343 
Hydrogen Permeation Barriers for Bimodal Reactors - DOE Contact John Warren, (301) 903-6491; Thermacore, Inc. Contact Mr. Richard W. Longsderff, (717) $569-6551$

Fracture Toughness Testing with Minimal Material - DOE Contact Dennis Harrison, (301) 903-2884; Packer Engineering, Inc. Contact Dr. James A. Begley, (412) $921-6441$

A Novel High Strength Ceria-Zirconia Toughened Alumina Ceramic with Superior High Temperature Corrosion and Erosion Resistance - DOE Contact Cynthia Carter, (301) 903-5997; Selee Corporation Contact Mr. Kenneth R. Butcher, (704) 697-2411

Rare Earth Endohedral Fullerenes as New Nonlinear Optical Materials - DOE Contact Cynthia Carter, (301) 903-5997; TDA Research, Inc. Contact Mr. Michael E. Karpuk, (303) 940-2301

X-ray Absorption Spectroscopy for Trace Analysis of Chemical Phase and Composition - DOE Contact Manfred Leiser, (301) 903-3426; Advanced Fuel Research, Inc. Contact Dr. David G. Hamblen, (203) 528-9806

An Apparatus for Structural Analysis of High Temperature Materials Using Synchrotron Radiation - DOE Contact Manfred Leiser, (301) 903-3426; Containerless Research, Inc. Contact Dr. Paul C. Nordine, (708) 467-2678

A Novel Detector for Neutron Diffraction Studies - DOE Contact Manfred Leiser, (301) 903-3426; Radiation Monitoring Devices, Inc. Contact Dr. Gerald Entine, (617) 926-1167

An Analytical Research Materials Characterization Facility Based on Synchrotron Radiation - DOE Contact Manfred Leiser, (301) 903-3426; X-Ray Analytics, Ltd. Contact Dr. Kevin L. D’Amico, (708) 887-9941

Application of the Meandering Winding Magnetometer to an In-Situ Determination of Age Related Degradation - DOE Contact Oscar Manley, (301) 903-5822; Jentek Sensors, Inc. Contact Dr. Neil J. Goldfine, (617) 254-5552

Improvement in the Loss and Critical Current Density Properties of Internal-Tin Niobium-Tin - DOE Contact T.V. George, (301) 903-4957; IGC Advanced Superconductors, Inc. Contact Mr. B. A. Zeitlin, (203) 753-5215 
A Feasibility Study to Correlate Vanadium (Chromium. Titanium) Alloy Weld Strength with Weld Chemistry - DOE Contact F. W. Wiffen, (301) 903-4963; Charles Evans and Associates Contact Mr. James E. Plank, (415) 369-4567

Improvement in the Characteristics of Ternary Niobium Titanium Tantalum Alloys DOE Contact Jerry Peters, (301) 903-5228; IGC Advanced Superconductors, Inc. Contact Mr. B. A. Zeitlin, (203) 753-5215

Activated Optical Ceramics: A New Class of Materials for Environmental Monitoring - DOE Contact Caroline Purdy (301) 903-7672; ALEM Associates Contact Dr. Alexander Lempicki, (617) 236-1025

Phase II Projects: (First Year)

A Testing Process to Define Electrode Current Wear Mechanisms and Develop Improved Electrodes - DOE Contact Charles Thomas, (412) 892-5731; Montec Associates, Inc. Contact Mrs. Cynthia K. Farrar, (406) 494-2596

Phase II Projects: (Second Year)

A Novel Energy-Efficient Membrane System for the Recovery of Volatile Organic Contaminants from Industrial Process Gases - DOE Contact Dan Kung, (708) 252-2023; Bend Research, Inc. Contact Dr. Scott B. McCray, (503) 382-4100

Device or Component Fabrication, Behavior or Testing

Phase I Projects:

Monolithic Integration of Thin Film Photovoltaics on Insulated Metal Substrates DOE Contact Alec Bulawka, (202) 586-5633; Energy Photovoltaics, Inc. Contact Mr. David A. Jackson, (609) 587-3000

Development of a Low Cost High Concentration Photovoltaic Dense Array Module for Use with Reflective Concentrators - DOE Contact Alec Bulawka, (202) 586-5633; SunPower Corporation Contact Dr. Richard Swanson, (408) $991-0908$

Non-Precious Metal Catalysts for Proton Exchange Membrane Fuel Cells by Ion Beam Synthesis - DOE Contact JoAnn Milliken, (202) 586-2480; Electrochem, Inc. Contact Dr. Radha Jalan, (617) 932-3383 
Contamination Tolerant Anodes for Polymer Electrolyte Membrane Fuel Cells DOE Contact JoAnn Milliken, (202) 586-2480; ICET, Inc. Contact Mr. Srinivasan Sarangapani, (617) 769-6064

Contamination Tolerant Anodes for Proton Exchange Membrane Fuel Cells - DOE Contact JoAnn Milliken, (202) 586-2480; Lynntech, Inc. Contact Dr. G. Duncan Hitchens, (409) 693-0017

Metal Carbide Nanoclusters for Polymer Electrolyte Membrane Fuel Cells - DOE Contact JoAnn Milliken, (202) 586-2480; TDA Research, Inc. Contact Mr. Michael E. Karpuk, (303) 940-2:301

A New Semiconductor Radiation Sensor for Expedited Waste Site Characterization - DOE Contact Caroline Purdy, (301) 903-7672; Aurora Technologies Corporation Contact Dr. J. F. Butler, (619) 549-4645

An Acoustic Plate Mode Aqueous Mercury Sensor - DOE Contact Paul Hart, (301) 903-7456; BIODE, Inc. Contact Dr. Douglas McAllister, (207) 883-1492

An Off-Line-Locked Laser Diode Sensor (OLDS) - DOE Contact Paul Hart, (301) 903-7456; Spectral Sciences, Inc. Contact Dr. Fritz Bien, (617) 273-4770

High Energy Resolution Cadmium-Zinc-Telluride Semiconductor Radiation Detectors - DOE Contact Ken Sheely, (202) 586-1620; Opire Corporation Contact Mr. Patrick N. McDonnell, (617) 275-6000

Gas Separation Membranes Based on Permselective Films of Buckminsterfullerenes - DOE Contact Charles Thomas, (412) 892-5731; CeraMem Corporation Contact Dr. Robert L. Goldsmith, (617) 899-0467

Fullerene Based Catalysts for Heavy Oil Upgrading - DOE Contact Udaya Rao, (412) 892-4743; TDA Research, Inc. Contact Mr. Michael E. Karpuk, (303) 940-2301

Coal Ash Tiles by Microwave Processing - DOE Contact Mary Ashbaugh, (304) 291-4966; Chemat Technology, Inc. Contact Mr. Patrick Lin, (818) 727-9786

Development of Expansive Cements Using Dry Flue Gas Desulfurization Solid Wastes - DOE Contact Mary Ashbaugh, (304) 291-4966; Praxis Engineers, Inc. Contact Ms. Suzanne C. Shea, (408) 945-4282 
Metal Monoliths for Conversion of Natural Gas to Liquid Fuel - DOE Contact Rodney D. Malone, (304) 291-4723; Alabama Cryogenic Engineering, Inc. Contact Ms. Mary T. Hendricks, (205) 536-8629

Oxygen-Evolving Anodes for the Electrolysis of Calcium Oxide - DOE Contact Eli Goodman, (301) 903-2966; EMEC Consultants Contact Dr. Rudolf Keller, (412) $325-3260$

A Long Life Perovskite Oxygen Electrode for Calcium Oxide Processing in Nuclear Fuel Cycles - DOE Contact Eli Goodman, (301) 903-2966; Eltron Research, Inc. Contact Ms. Eileen E. Sammells, (303) 440-8008

A Low Emission Alkali Metal Thermal to Electric Converter Automotive Power System - DOE Contact Robert Astheimer, (301) 903-4410; Advanced Modular Power Systems, Inc. Contact Dr. Thomas K. Hunt, (313) 677-4260

Advanced Catalysts for Ultra-Low Emission Control in Natural Gas Fueled Vehicles - DOE Contact Robert Astheimer, (301) 903-4410; Goremotive Industries, Inc. Contact Mr. Arthur D. Sweet, (818) 884-0015

A Membrane Reactor for the Production of Hydrogen Fuel from Hydrocarbon Liquids - DOE Contact Robert Astheimer, (301) 903-4410; Membrane Technology and Research, Inc. Contact Ms. E. G. Weiss, (415) 328-2228

Economical Photochromic Films for Solar Thermal Control - DOE Contact Cynthia Carter, (301) 903-5997; EIC Laboratories, Inc. Contact Dr. A.C. Makrides, (617) $769-9450$

Thermophotovoltaic Generator Efficiency Improvement - DOE Contact Cynthia Carter, (301) 903-5997; Quantum Group, Inc. Contact Dr. Mark Goldstein, (619) $457-3048$

High-Performance Membranes for Gas. Vapor, and Liquid Separations - DOE Contact Robert Marianelli, (301) 903-5804; Bend Research, Inc. Contact Dr. Rod Ray, (503) 382-4100

Organic-Inorganic Composite Membranes for Gas Separation and Vapor Permeation-DOE Contact Robert Marianelli, (301) 903-5804; CeraMem Corporation Contact Dr. Robert L. Goldsmith, (617) 899-0467 
Electrode Materials for Rechargeable Lithium Batteries - DOE Contact Robert Marianelli, (301) 903-5804; Materials and Electrochemical Research Corporation Contact Dr. J. C. Withers, (602) 574-1980

Novel High Performance Glassy Polvmer Composite Membranes for Gas Separation - DOE Contact Robert Marianelli, (301) 903-5804; Membrane Technology and Research, Inc. Contact Ms. E. G. Weiss, (415) 328-2228

Highly Selective Membranes for the Separation of Organic Vapors Using Super-Glassy Polymers - DOE Contact Robert Marianelli, (301) 903-5804; Membrane Technology and Research, Inc. Contact Ms. E. G. Weiss, (415) 328-2228

A Continuous Cryopump/Pellet-Fabrication Apparatus for Fusion - DOE Contact T. V. George, (301) 903-4957; Cryogenic Applications F, Inc. Contact Dr. Christopher A. Foster, (615) 435-5433

Innovative Electrochemical Sensors for In-Situ Real-Time Monitoring of Lead in Aqueous Media - DOE Contact Caroline Purdy, (301) 903-7672; ANDCARE, Inc. Contact Mrs. Carolyn J. Henkens, (919) 544-8220

Fluoroionophores for Use in a Fiber Optic Sensor for Mercuric Ions - DOE Contact Caroline Purdy, (301) 903-7672; Covalent Associates, Inc. Contact Dr. Victor R. Koch, (617) 938-1140

Potentiometric Sensors for Lead and Mercury - DOE Contact Caroline Purdy, (301) 903-7672; ICET, Inc. Contact Dr. S. Sarangapani, (617) 769-6064

A Compressed Xenon Gamma Sensor for Environmental Measurements - DOE Contact Caroline Purdy, (301) 903-7672; Contact Dr. John Kevin Markey, (203) 230-0894

Fiber Optic Sensors for Heavy Metal Cations - DOE Contact Caroline Purdy, (301) 903-7672; Research International, Inc. Contact Ms. Joyce M. Brien, (206) 486-7831

Innovative Sorbents for the Selective Removal of Heavy Metals from Groundwater DOE Contact Jeffrey Walker, (301) 903-7966; Foster-Miller, Inc. Contact Mr. Adi R. Guzdar, (617) 890-3200

An Ultra-Compact Cesium Iodide/Mercuric Iodide Gamma-Ray Scintillation Spectrometer - DOE Contact Michael O'Connell (202) 586-9311; Xsirius, Inc. Contact Dr. Jan S. Iwanczyk (805) 484-8300 


\section{Phase II Projects: (First Year)}

Glass-Ceramic Construction Tiles from Coal-Fired Boiler Flyash - DOE Contact Mary B. Ashbaugh, (304) 291-4966; Vortec Corporation Contact Dr. James G. Hnat, (215) 489-2255

A High Repetition-Rate, High Power. All-Solid-State Pulsed Driver for Electrodeless Inductive Thrusters - DOE Contact John Warren, (301) 903-6491; Science Research Laboratory, Inc. Contact Dr. Jonah Jacob, (617) 547-1122

Demonstration of an Integrated Carbon Dioxide/Thermal Management System for Carbonate Fuel Cells - DOE Contact Clifford Carpenter, (304) 291-4041; Energy Research Corporation Contact Dr. Hans Maru, (203) 792-1460

Porous Aluminum Nitride Part Fabrication to Support Advanced Battery Development - DOE Contact Cynthia Carter, (301) 903-5997; Advanced Refractory Technologies, Inc. Contact Mr. Keith A. Blakely, (716) 875-4091

Capacitive Energy Storage Using High Surface Area Transition Metal Compounds DOE Contact Cynthia Carter, (301) 903-5997; Chemat Technology, Inc. Contact Ms. Xin Qin, (818) 727-9786

Advanced Ceramic Fibers for a Carbonate Fuel Cell Matrix - DOE Contact Bruce Harrington, (304) 291-5427; Energy Research Corporation Contact Dr. Hans Maru, (203) 792-1460

An In-Situ Particle Sensor for Metal Forming Processes - DOE Contact Manfred Leiser, (301) 903-3426; Advanced Fuel Research, Inc. Contact Dr. David G. Hamblen, (203) 528-9806

Development of a High Spatial Resolution Neutron Detector - DOE Contact Manfred Leiser, (301) 903-3426; BioTraces, Inc. Contact Dr. A. K. Drukier, (301) 864-0816

A High Resolution Scintillator-Based Neutron Detector - DOE Contact Manfred Leiser, (301) 903-3426; Nanoptics, Inc. Contact Dr. James K. Walker, (904) 378-6620

On-Chip Infrared-Spectral Sensors by Superconducting Detector Arrays - DOE Contact Robert Marianelli, (301) 903-5804; Advanced Fuel Research, Inc. Contact Dr. David G. Hamblen, (203) 528-9806 
Radiation Resistant Radio Frequency Feedthrough Insulators for Fusion Applications - DOE Contact Warren Marton, (301) 903-4965; Composite Technology Development, Inc. Contact Dr. Naseem A. Munshi, (303) 447-2226

Helium-Cooled Divertors with Low-Activation Materials and Simple Fabrication Techniques - DOE Contact Warren Marton, (301) 903-4965; Creare, Inc. Contact Mr. Robert A. Hicken, (603) 643-3800

Niobium-Tin Superconducting Wire with a Built-in Niobium Surface Coating to Limit Inter-Strand Eddy Currents in Cables - DOE Contact Warren Marton, (301) 903-4965; Supercon, Inc. Contact Ms. Elaine Drew, (508) 842-0174

Ceramic Filters for Ultrafine Particulate Separation in Combustion Gas Environments - DOE Contact Richard Tischer, (412) 892-4891; Materials and Electrochemical Research Corporation Contact Dr. J. C. Withers, (602) 574-1980

A Carbonate Fuel Cell Monolith for Low-Cost and High Power Density Operation DOE Contact Venkat Venkataraman, (304) 291-4105; Energy Research Corporation Contact Dr. Hans Maru, (203) 792-1460

Phase II Projects: (Second Year)

Digital Processing Electronics for X-Ray Detector Arrays - DOE Contact Manfred Leiser, (301) 903-3426; X-Ray Instrumentation Associates Contact Dr. William K. Warburton, (415) 903-9980

A Cold/Thermal Beam Bender Using Capillary Optics to Increase the Number of End-Guide Instrument Positions - DOE Contact Manfred Leiser, (301) 903-3426; X-Ray Optical Systems, Inc. Contact Dr. Qi-fan Xiao, (518) 442-5250

A Thomson-Scattering Plasma Diagnostic for Materials Testing and Divertor Concept Testing - DOE Contact Charles Finfgeld, (301) 903-3423; Princeton Scientific Instruments, Inc. Contact Dr. Dirck L. Dimock, (908) 274-0774

Eddy-Current Nondestructive Testing Methods for On-Line Detection of Cable Manufacturing Defects - DOE Contact William Watson, (214) 708-2417; SE Systems, Inc. Contact Dr. Duane P. Johnson, (510) 293-3000

Low-Cost Microstrip Detectors on Conductivity-Modified Polyimide - DOE Contact William Watson, (214) 708-2417; Spire Corporation Contact Dr. Anton C. Greenwald, (617) 275-6000 
High Strength Mono- and Multi-filament High Temperature Superconductors for High Field Applications - DOE Contact Gerald Peters, (301) 903-5228; IGC Advanced Superconductors, Inc. Contact Dr. Leszek R. Motowidlo, (203) 753-5215

Fabrication of Niobium-Aluminum Superconducting Strands Using Mechanical Alloying and Other Techniques - DOE Contact Gerald Peters, (301) 903-5228; IGC Advanced Superconductors, Inc. Contact Mr. G. M. Ozeryansky, (203) 753-5215

Durable, Low Cost Ceramic Materials for Use in Hot Gas Filtration Equipment DOE Contact Norman Holcombe, (304) 291-4829; Industrial Filter and Pump Manufacturing Company Contact Mr. Paul Eggerstedt, (708) 656-7800

High Cation Mobility Lithium Polymer Batteries - DOE Contact Al Landgrebe, (202) 586-1483; Covalent Associates, Inc. Contact Dr. Larry A. Dominey, (617) $938-1140$

A Real-Time X-ray Detector - DOE Contact Stan Sobczynski, (202) 586-1878; Advanced Technology Materials, Inc. Contact Mr. David Kurtz, (203) 794-1100

\section{Small Business Technology Transfer Program}

The Small Business Technology Transfer (STTR) program, now completing its first year, was established as a three-year pilot program in compliance with the Small Business Research and Development Enhancement Act of 1992, Public Law 102-564. Grant applications are solicited from small science- and technology-based U.S. firms (with 500 employees or less) in collaboration with a non-profit research institution (e.g. National laboratories and universities). Awards are made competitively to the small business with the collaborating research institution serving as a subcontractor. STTR supports innovative $R \& D$ and encourages conversion of that $R \& D$ into commercial applications of economic benefit to the Nation. The STTR program is designed for implementation in three phases, with Phase I determining, insofar as possible, the scientific or technical merit and feasibility of ideas proposed for investigation. The period of performance in this initial phase is about nine months, and awards are limited to $\$ 100,000$. Phase II is the principal research or R\&D effort, and only Phase I awardees can compete for Phase II awards of up to $\$ 500,000$ in FY 1995 for work to be performed in a period of up to two years. In Phase III, commercial application of the research or R\&D is pursued using non-Federal funding or, alternatively, it may involve follow-on non-STTR Federal contracts for products or services desired by the Government.

The materials-related projects, like all other projects in the STTR program and the SBIR program, were selected on the basis of scientific and technical merit, as judged against the specific criteria listed in the solicitation. Conclusions were reached on the basis of 
reviews performed by personnel in DOE laboratories, universities, private industry, and government.

As in the SBIR program, these projects represent high-risk research, but the potential benefits are also high if the objectives are met. Brief descriptions of all DOE STTR projects, not only those of interest in materials research, are given in Abstracts of Phase I Awards 1994 (DOE/ER-0623).

Materials Preparation, Synthesis, Deposition, Growth or Forming

Phase I Projects:

Preparation of Monolithic Porous Carbon Materials Using Controlled Functionalization of Fullerenes - DOE Contact Rick Peavy, (202) 586-7907; TDA Research, Inc. Contact Mr. Michael E. Karpuk, (303) 940-2301; Research Institute: Sandia National Laboratory

A Continuous Chemical Manufacturing Process for Direct Production of Titanium Powder with a Reagent Recycle - DOE Contact Robert Astheimer, (301) 903-4410; Kroftt-Brakston International, Inc. Contact Dr. Donn R. Armstrong, (708) 655-3065; Research Institute: Argonne National Laboratory

Device or Component Fabrication, Behavior or Testing

\section{Phase I Projects:}

Feasibility of Nitride Phosphors for Thin Film Electroluminescent Displays - DOE Contact Charles Fowler, (202) 586-5834; Planar Systems, Inc. Contact Dr. Christopher N. King, (503) 690-1100; Research Institute: Los Alamos National Laboratory

An Integrated X-ray Sensor - DOE Contact Richard Rinkenberger, (301) 903-3613; ARACOR Contact Mr. Ed LeBaker, (408) 733-7780; Research Institute: Lawrence Berkeley Laboratory

Improved Mineral Insulated Cables for Fusion Reactor Diagnostics - DOE Contact T. V. George, (301) 903-4957; DELTA M Corporation Contact Mr. A. D. White, (615) 483-1569; Research Institute: Oak Ridge National Laboratory 
OFFICE OF ENVIRONMENTAL MANAGEMENT

FY 1994

Office of Environmental Management - Grand Total

$\$ 37,914,500$

Office of Waste Management

$\$ 14,766,500$

High Level Waste Division

$\$ 14,766,500$

Materials Preparation, Synthesis, Deposition, Growth or Forming

$\$ 8,036,000$

Technical Support to West Valley Demonstration Project

Sulfur Polymer Cement

Ceramic Final Forms

Microencapsulation in Final Forms

Final Waste Form Program

CIF Blowdown and Ash Stabilization

Macroencapsulation

Glass Formulation

$2,071,000$

342,000

300,000

67,000

$2,800,000$

70,000

15,000

$2,371,000$

Materials Properties, Behavior, Characterization or Testing

$\$ 6,730,500$

Materials Characterization Center Testing of West Valley Formulation Glass

Development of Test Methods and Testing of West Valley Reference Formulation Glass

Process and Product Quality Optimization for the

West Valley Waste Form

Waste Form Qualification

Iron-Enriched Basalt Testing

384,500

564,000

422,000

$5,000,000$

360,000

Office of Environmental Restoration

$\$ 2,874,000$

Materials Preparation, Synthesis, Deposition, Growth or Forming

$\$ 2,874,000$

Minimum Additive Waste Stabilization (MAWS)

$2,874,000$ 
OFFICE OF ENVIRONMIENTAL MANAGEMENT

Office of Technology Development

FY 1994

$\$ 20,274,000$

Materials Preparation. Synthesis, Deposition, Growth or Forming

$\$ 13,376,000$

Polymer Solidification

Microwave Solidification

Polymer Solidification National Effort

Expedited Development-Polymer Macroencapsulation

Fixed Hearth Plasma Treatment Process

Fixed Hearth Plasma Radioactive Waste Test

PHP Slag Chemistry and Slag/Metal Processing (ANL-W)

Phosphate-Bonded Ceramic Waste Forms

Mixed Waste Treatability - Thermoplastic Final Forms

High Temperature Melter Systems Evaluation

MAWS Plasma Testing and Support

$2,450,000$

$2,197,000$

485,000

237,000

$2,075,000$

$1,200,000$

400,000

300,000

600,000

$1,335,000$

$2,097,000$

Materials Properties. Behavior, Characterization or Testing

$\$ 6,898,000$

Vitrify to Delist to Dispose

Vitrification of Rocky Flats Waste

Plasma Hearth Process Radioactive Waste Test - Idaho

Waste Form Performance Criteria

Vitreous Ceramic Compositional Envelope Study

Arc Melter Vitrification

Graphite DC Plasma Arc Melter

$1,798,000$

750,000

$1,800,000$

180,000

500,000

900,000

970,000 


\section{OFFICE OF ENVIRONMENTAL MANAGEMENT}

The Office of Environmental Management (EM) was established to effectively coordinate and manage the Department's activities to remediate the DOE Defense Complex and to properly manage waste generated by current operations. This new office combines nuclear waste management and the environmental clean-up elements that were spread across four offices:

1. Office of Waste Management - The Office of Waste Management uses current technologies to minimize production of DOE-generated waste, alters current processes to reduce waste generation, and works with the Office of Technology Development to develop innovative technologies for the treatment and disposal of present and future waste streams. The mission of the Office is to minimize, treat, store, and dispose of DOE waste to protect human health, safety, and the environment.

2. Office of Environmental Restoration - The Office of Environmental Restoration directs the cleanup of inactive facilities and sites contaminated by waste generated from past nuclear operations. The mission of the Office is to ensure that risks to the environment and to human health and safety posed by inactive and surplus facilities and sites are either eliminated or reduced to prescribed, acceptable levels.

3. Office of Technology Development - The Office of Technology Development is responsible for managing the national program of environmental applied research and technology development. The Office manages and directs research, development, demonstration, testing, and evaluation programs and activities that are designed to provide complete innovative technologies and technology systems to address the major problems facing the Office of Environmental Management.

4. Office of Facility Transition and Management - One of the Office of Environmental Management (EM) goals is to ensure that the risks to human health and safety and to the environment posed by inactive and surplus facilities are either eliminated or reduced to prescribed, acceptable levels. The Office of Facility Transition and Management was established within EM to develop and institutionalize a Departmental process for the timely and effective transfer of surplus facilities and to implement that process in transitioning surplus facilities to EM for final disposition. 
Five Focus Areas were formed to focus the EM-wide technology development activities on DOE's most pressing environmental management problems and are co-led by all EM offices:

- Contaminated Plume Containment: and Remediation

- Landfill Stabilization

- High-Level Waste Tank Remediation

- Mixed Waste Characterization, Treatment, and Disposal

- Facility Transition

Materials development work may be performed in any of these five Focus Areas. Funding levels are reported for the total project, which includes materials development and demonstration. For most projects, materials development accounts for less than $25 \%$ of the funds.

\section{Office of Waste Management}

\section{High Level Waste Division}

The objective of the High Level Waste Division is to conduct waste management activities for ending interim storage of high-level waste and achieving permanent disposal of high-level waste at the Savannah River Site in South Carolina. Additionally, Congress directed the Department in 1980 to demonstrate the solidification of liquid high-level waste at West Valley (New York) which originated at the nation's only commercial plant to reprocess spent nuclear fuel. At both of these sites a program is in place to immobilize the high-level waste in preparation for geologic disposal.

At Savannah River and West Valley, high-level waste will be immobilized in a borosilicate glass prepared in a liquid-fed ceramic joule-heated melter. The Defense Waste Processing Facility at Savannah River is beginning nonradioactive operations in preparation for radioactive operation. West Valley is constructing the vitrification cell. For these two projects, materials research focuses on verifying the product consistency of the waste form based on a reference formulation chosen some time ago. 
Materials Preparation, Synthesis, Deposition. Growth or Forming

248. Technical Support to West Valley Demonstration Project

FY 1994

DOE Contact: W. S. Ketola, (716) $942-4314$

$\$ 2,071,000$

PNL Contact: W. F. Bonner, (509) 376-3340

Pacific Northwest Laboratory (PNL) provides technical assistance to the West Valley Demonstration Project in characterizing high-level waste samples taken from the West Valley tanks; characterizing operating conditions for ion exchange processes that remove cesium and plutonium from the high level supernate; fabrication of a radioactive glass sample made from actual West Valley high-level wastes; and characterizing individual process operations to show overall control of the vitrification process and the final waste form.

Keywords: Ion Exchange, Borosilicate Glass, Process Control, Radioactive Waste Host

249. Sulfur Polymer Cement

FY 1994

DOE Contact: Jamie Johnson, (301) 903-7114

$\$ 342,000$

The work consists of demonstrating the technical feasibility of sulfur polymer cement (SPC) as an immobilization technique for producing a final waste form for alpha low level stored waste. Major areas of focus include determining the longevity of SPC encapsulated waste forms and determining waste types that may be compatible with SPC encapsulation. The workscope also includes obtaining resolution to technical issues to aid in developing conceptual design direction for SPC process and equipment requirements, providing support for a full-scale equipment demonstration of SPC encapsulation techniques, and providing support for attendance at ASTM Subcommittee 34.07 (Mixed Radioactive Hazardous Waste).

Keywords: Polymer, Cement, Final Waste Form, Sulfur

250. Ceramic Final Forms

FY 1994

DOE Contact: Ronald D. Streit, (510) $422-7045$

$\$ 300,000$

LLNL Contact: Robert Hoppert, (510) 423-2420

Operations of the Mixed Waste Management Facility (MWMF) will yield ash-like residues (oxides, nitrates, etc. containing RCRA metals and radioactive elements) from the organic components of low-level mixed waste. These residues will be stabilized as a durable 
and leach-resistant ceramic waste form produced by traditional high-temperature powder technologies. Formulations for various input waste streams are being optimized.

Keywords: Ceramic, Final Waste Form, Ash

251. Microencapsulation in Final Forms

FY 1994

DOE Contact: Ronald D. Streit, (510) 422-7045

$\$ 67,000$

LLNL Contact: Robert Hoppert, (510) 423-2420

Operations of the Mixed Waste Management Facility (MWMF) will yield residues from the destruction of organic components of low-level mixed waste. Salts containing RCRA metals and radioactive elements will be stabilized by microencapsulation in polyethylene or in a thermosetting polymer. Volatile inorganic solids will be microencapsulated in sulfur polymer cement. These technologies are being optimized for MWMF operations.

Keywords: Final Waste Form, Encapsulation, Polymer

252. Final Waste Form Program

FY 1994

DOE Contact: Michael Torbert, (301) 903-7109

In support of the Oak Ridge Reservation (ORR) LDR Federal Facility Compliance Agreement as well as the Federal Facility Compliance Act, a program is underway to demonstrate, at the bench-scale level, applicable final waste forms for sludges, soils, other treatment residues, and secondary wastes. The primary focus of this activity is to demonstrate appropriate grout waste forms as a first alternative, glass waste forms as a second alternative, and thermoplastic waste forms as a third alternative. This work is being done on actual ORR wastes and supports the LDR FFCA, and the design of the ORR Mixed Waste Treatment Facility. It will provide technology support to ORR privatization activities. This activity will support a joint CRADA with Savannah River Technical Center and SEG.

Keywords: Final Waste Form, Grout, Glass, Thermoplastic, Bench-Scale 
253. CIF Blowdown and Ash Stabilization

FY 1994

$\$ 70,000$

DOE Contact: Kurt Fisher, (301) 903-7412

This activity will develop stabilization technology for the Consolidated Incineration Facility (CIF) blowdown and ash waste streams. The current focus of this activity is developing a cementitious waste form.

Keywords: Stabilization, Cement

254. Macroencapsulation

FY 1994

DOE Contact: Hannibal Joma, (510) 423-8394

$\$ 15,000$

This study is designed to stabilize radioactive and hazardous constituents by "grouting" or amalgamating in order to limit the leachability of these constituents. This study uses the LDR BDAT for lead pieces and elemental mercury to affect treatment.

Keywords: Macroencapsulation, Lead, Stabilization

255. Glass Formulation

FY 1994

DOE Contact: Denny Wynne, (301) 903-4967

$\$ 2,371,000$

This activity includes evaluation of alternatives within glass formulation, structure and chemistry studies, and durability studies. This activity supports design of the low-level waste Vitrification Facility at Hanford.

Keywords: Glass, Vitrification, Low-Level Waste

Materials Properties, Behavior. Characterization or Testing

256. Materials Characterization Center Testing of West Valley Formulation Glass

FY 1994 $\$ 384,500$

DOE Contact: W. S. Ketola, (716) 942-4314

PNL Contact: G. L. Smith, (509) 372-1957

Materials Characterization Center (MCC) is evaluating the chemical durability of glasses whose compositions are within the expected range of composition of the West Valley Demonstration Project borosilicate glass waste form. These include nonradioactive glass containing surrogate elements for radionuclides and radioactive glass doped with appropriate 
radionuclides. The MCC also began testing of a small sample of glass containing actual West Valley high-level waste.

Keywords: Radioactive Waste Host

\section{Development of Test Methods and Testing of West Valley Reference} Formulation Glass

DOE Contact: W. S. Ketola, (716) $942-3414$

$\$ 564,000$

PNL Contact: P. B. Macedo, (202) 319-5329

Vitreous State Laboratory (VSL) of the Catholic University of America (CUA) continues to develop test methods for nonradioactive and radioactive borosilicate glass waste forms for the West Valley Demonstration Project and is studying means to maximize the region of acceptable quality around the point of optimal durability for the borosilicate waste form.

Keywords: Radioactive Waste Host

258. Process and Product Ouality Optimization for the West Valley Waste Form

FY 1994

$\$ 422,000$

DOE Contact: W. S. Ketola, (716) $942-4314$

AU Contact: L. D. Pye, (607) 871-2432

Alfred University (AU) is studying properties and crystallization behavior of the West Valley borosilicate glass reference composition in anticipation of providing methods for control of product quality during routine manufacture of the West Valley Demonstration Project waste form.

Keywords: Radioactive Waste Host, Borosilicate Glass

259. Waste Form Qualification

FY 1994

DOE Contact: W. Pearson, (803) 557-1066

$\$ 5,000,000$

WSRC Contact: M. J. Plondinec, (803) 725-2170

These studies provide fundamental data for start-up of the Defense Waste Process Facility, for waste compliance activities, and for acceptance of borosilicate glass at a repository. Site specific testing is included.

Keywords: Waste, Waste Form, Borosilicate Glass, Waste Acceptance Specifications 
260. Iron-Enriched Basalt Testing

FY 1994

$\$ 360,000$

DOE Contact: Jamie Johnson, (301) 903-7114

The work consists of continuing development of a final waste form (Iron-Enriched Basalt) for the Idaho Waste Processing Facility (IWPF). Activities include:

- Modeling slag and offgas process chemistry for several waste streams using a computer model to simulate the process chemistry and mass flow balance;

- Conducting studies and tests to determine methods to retain High Vapor Pressure Metals (HVPM) in an Iron-Enriched Basalt (IEB) waste form and;

- Reviewing the development needs for IEB as a waste form for the IWPF including IEB development work being planned/performed by other projects (e.g., Buried Waste Integrated Demonstration, Pit 9 Project).

Keywords: Final Waste Form, Basalt

\section{Office of Environmental Restoration}

The Office of Environmental Restoration directs the assessment and cleanup of inactive facilities and sites contaminated by waste generated from past nuclear operations. The Environmental Restoration program assessment and cleanup activities include remedial actions and decontamination and decommissioning. Remedial actions are concerned with all aspects of the assessment and cleanup of inactive release sites. The tasks associated with remedial actions encompass (1) site discovery, preliminary assessment, and site inspection; (2) site characterization, analysis of cleanup alternatives, and selection of remedy; (3) cleanup and site closure; and (4) site compliance monitoring. Most remedial action activities are concerned with contaminated soil and groundwater.

Materials Preparation, Synthesis, Deposition, Growth or Forming

261. Minimum Additive Waste Stabilization (MAWS)

FY 1994

$\$ 2,874,000$

DOE Field Office Contact: Rod Warner, (513) 648-3156

DOE HQ Program Manager: David Kozlowski, (301) 427-1858

ANL Contact: Nick Beskid, (708) 252-6677

This project demonstrated soil washing in combination with vitrification of Fernald OU-1 sludges and soils. Work included the testing of the 0.25 cu.yd./hr soil wash unit and $300 \mathrm{~kg} /$ day joule heated melter. This project was completed after producing several 
thousand $\mathrm{kg}$ of glass from OU-1 high fluoride sludges and soils contaminated with uranium and thorium.

Keywords: Vitrification, Soil Washing, Glass

\section{Office of Technology Development}

The Office of Technology Development (TD) has the mission to facilitate EM's 30year goal by developing and implementing new technologies to assist DOE in achieving compliance with all applicable statutes and regulations. The TD program is designed to make new, innovative, and effective technology available for use and transfer it to the field offices.

Certain areas of TD's program focus on materials research in order to provide better, faster, safer and less expensive approaches to identify, characterize and clean up DOE's waste problem. In the area of soil and groundwater remediation, as well as waste retrieval processing, TD is investigating various types of cement and polymer technologies for stabilization and containment of wastes. The applicability of these substances is being demonstrated, tested, and evaluated for implementation at specific sites. Technology development and demonstrations into glasses and ceramics are being pursued to better understand high-temperature technologies, useful for containment of contaminated soils. Vitrification and plasma technologies are being developed for treating specific mixed waste streams. TD will continue to fund these materials research projects, as well as others, to provide the basis for other applied research in the TD program.

\section{Materials Preparation, Synthesis, Deposition, Growth or Forming}

262. Polymer Solidification

FY 1994

$\$ 2,450,000$

DOE Field Office Contact: Sherri Rudolph, (303) 966-5788

DOE HQ Program Manager: Alison Johnson, (301) 903-7923

EG\&G Rocky Flats Contact: Andrea Faucette, (303) 966-6420

Polymer encapsulation of mixed wastes encloses waste products in thermoplastic materials using commercially available processing technologies. The configuration under development at the Rocky Flats Environmental Technology Site uses a twin-screw extruder to microencapsulate waste. The process aims at meeting applicable disposal site, EPA, and DOT acceptance criteria for various wastes. Microencapsulation involves combining thermoplastic polymers (i.e. polyethylene) with dried waste; melting, mixing, and extruding the combination in a commercially-available extruder; and allowing the molten plastic to cool and solidify. Hazardous constituents are immobilized in the plastic matrix. Nitrate salts, bypass sludge, incinerator ash, and secondary wastes are the target streams. Microencapsu- 
lation tests of a variety of waste streams have been performed with the extruded waste forms meeting TCLP leach test performance limits. Waste loadings from 40 percent to 60 percent were successfully demonstrated for surrogate bypass sludge, spray dried nitrate salts (saltcrete stream), DETOX solution, and analytical lab solutions (nitrate, chloride salts).

Keywords: Alternative Final Waste Form, Polymer Solidification, Hydroxide Sludge, Polyethylene

\section{Microwave Solidification}

FY 1994

DOE Field Office Contact: Sherri Rudolph, (303) 966-5788

$\$ 2,197,000$

DOE HQ Program Manager: Alison Johnson, (301) 903-7923

EG\&G Rocky Flats Contact: Greg Sprenger, (303) 966-3159

The microwave solidification project is developing a method to immobilize wastes for compliance with EPA disposal regulations and to minimize the volume of wastes for storage and disposal. Microwave solidification uses $915 \mathrm{MHz}$ microwave energy to vitrify waste solids. Dried waste and glass formers are fed into drums and melted "in the drum" from applied microwave heating. This technology is being evaluated as a potential method to treat several mixed wastes, including process sludges, incinerator ash, and miscellaneous wastes, such as crucibles and foundry materials. Four tests on samples of actual transuranic precipitation sludge from the Rocky Flats Plant were vitrified in a bench scale $(6 \mathrm{~kW})$ system. A 60 percent to 70 percent volume reduction and 60 percent to 70 percent waste loading were achieved. Simulated waste was vitrified in a $20 \mathrm{Kw}-915 \mathrm{Mhz}$ pilot scale system with 75 percent volume reduction achieved. Such large size reductions result in significant disposal cost savings compared to baseline technologies.

Keywords: Alternative Final Waste Form, Microwave Solidification, Vitrification, In Drum Melting

\section{Polymer Solidification National Effort}

FY 1994

DOE Field Office Contact: Steve Webster, (708) 252-2093

$\$ 485,000$

DOE HQ Program Manager: Alison Johnson, (301) 903-7923

Brookhaven NL Contact: Paul Kalb, (516) 282-7644

The objective of this project was to demonstrate a pilot scale system for the polymer microencapsulation of surrogate wastes such as Rocky Flats nitrate salts using a single screw extruder. The demonstration incorporated many aspects of the process including the drying of the salts, the encapsulation of the salts, and the testing of the waste forms for compliance with disposal criteria. This process is applicable for forming final waste forms for several waste streams including precipitated hydroxide sludge, soils, ground glass, beryllium dust, 
and others. This process produces a highly durable, leach resistant waste form that produces a much smaller volume of waste for final disposal compared to cementation. The smaller volume saves money in storage, transport and disposal. By using an off-the-shelf extruder with minor modifications, equipment costs were reduced for small waste streams.

Keywords: Alternative Final Waste Form, Polymer Microencapsulation, Solidification, Nitrate Salts, Polymer Extrusion

265. Expedited Development-Polymer Macroencapsulation

FY 1994

DOE Field Office Contact: Sherri Rudolph, (303) 966-5788

$\$ 237,000$

DOE HQ Program Manager: Alison Johnson, (301) 903-7923

EG\&G Rocky Flats Contact: Joseph Lucerna, (303) 966-7229

This project developed macroencapsulation of debris and lead waste and produced an expedited radioactive demonstration of the technology. Macroencapsulation involves suspending bulk mixed waste (i.e., waste contaminated with both radioactive and hazardous constituents) materials, debris, or lead in a drum and filling in around the waste with molten polyethylene or with thermoset plastics, such as epoxy. Upon cooling, the polymer hardens, surrounding and immobilizing the hazardous constituents. This will allow wastes stored at Rocky Flats and other sites to meet land disposal restrictions. Macroencapsulation tests of bulk debris surrogates for $U$ and Be-fines contaminated solids have been successfully completed. The task is a continuation of FY93 work and included in FY94 the complete cold testing with surrogate waste, and the purchase of a full scale extruder for use during hot testing of actual waste. Work also included the preparation of test and safety plans for conducting the hot demonstration of real waste in accordance with all internal and external policies and procedures, and the performance of a hot demonstration and documentation of the results.

Keywords: Polymer Macroencapsulation, Alternative Final Waste Form, Debris, Lead, Thermoset Plastic

266. Fixed Hearth Plasma Treatment Process

FY 1994

DOE Field Office Contact: Thomas Williams, (208) 526-2460

$\$ 2,075,000$

DOE HQ Program Manager: Paul Hart, (301) 903-7456

EG\&G Idaho Contact: Steve Bates, (208) 526-6970 .

This technology, the Plasma Hearth Process (PHP), converts entire drums of lowlevel mixed waste (LLMW) directly into an enhanced waste form without extensive pretreatment or characterization. Organics are destroyed while metals and inorganics are melted, creating a vitrified slag and molten metal. The process is characterized by high- 
efficiency destruction of organics, encapsulation of heavy metals and radionuclides in the vitrified final waste form, large volume reduction of waste to be disposed, possible recycling of metals, low off-gas flow rates, and the capability of processing many waste types in a single-step process. The non-radioactive proof-of-principle concept demonstration has been completed. The remaining work in this task focuses on design, fabrication, and demonstration of a near full-scale pilot system for non-radioactive operation.

Keywords: Plasma, Final Form, Low-Level Mixed Waste, Full-Scale

267. Fixed Hearth Plasma Radioactive Waste Test

FY 1994

$\$ 1,200,000$

DOE Field Office Contact: Steve Webster, (708)-252-2822

DOE HQ Program Manager: Paul Hart, (301) 903-7456

ANL-W Field Contact: Grant McClellan, (208) 533-7257

This project involves the design and construction of the facility modifications to house the bench-scale Plasma Hearth Process to be tested in the Plasma Hearth Process Radioactive Waste Test - Idaho. It also includes tasks to develop the mechanisms by which actual waste can be repackaged for testing in the bench-scale system, the radioactive waste forms produced by the process can be sampled and analyzed, and the pertinent analysis to be made to ensure safe operation of the plasma system in the ANL-W TREAT facility. Waste operations and sampling and analysis during the bench-scale demonstration are covered in the task.

Keywords: Plasma, Final Form, Low-Level Mixed Waste, Bench-Scale

268. Plasma Hearth Process (PHP) Slag Chemistry and Slag/Metal Processing (ANL-W)

FY 1994

$\$ 400,000$

DOE Field Office Contact: Steve Webster, (708)-252-2822

DOE HQ Program Manager: Paul Hart, (301) 903-7456

Argonne National Laboratory Contact: Ankur Purohit, (708) 252-6670

The purpose of this task is to define the design basis and validate the final design of the slag and metal removal and handling system to be built for the field-scale radioactive plasma hearth process (PHP) system by SAIC and Retech, Inc. Initial slag/metal separation tests have been completed at the STAR Center for design validation. This task will ensure that the design will meet DOE nuclear facility design and safety requirements for plutonium service, will allow an actual facility to operate in a production mode making acceptable slag and metal products, and will reflect the best applicable practices from the primary metal production industries with particular emphasis being in the electric steel making processes. 
Keywords: Plasma, Final Form, Low-Level Mixed Waste, Field-Scale

269. Phosphate-Bonded Ceramic Waste Forms

FY 1994

$\$ 300,000$

DOE Field Office Contact: Steve Webster (708) 252-2822

DOE HQ Program Manager: Paul Hart, (301) 903-7456

Argonne National Laboratory Contact: A. Wagh, (708) 252-4295,

Chemically-bonded ceramics (CBCs) are being investigated as an alternative final waste form for streams that cannot be handled by other established methods. Phosphate bonded ceramics are a subclass of CBCs and have several advantages over other systems for stabilization and encapsulation of LLMW. These include insolubility in water, hightemperature stability, and the ability to cure at room temperatures. Studies are underway to stabilize waste streams containing liquid mercury, mercury-contaminated aqueous liquids, toxic and heavy metal containing materials, salt cakes, beryllium wastes, and pyrophorics by encapsulating them in phosphate-bonded ceramics. Feasibility tests on ash and salt wastes were completed at Argonne National Laboratory in FY94.

Keywords: Alternate Final Waste Form, Ceramics, Phosphate

270. Mixed Waste Treatability - Thermoplastic Final Forms

FY 1994

$\$ 600,000$

DOE Field Office Contact: Steve Webster (708) 252-2822

DOE HQ Program Manager: Paul Hart, (301) 903-7456

Brookhaven National Laboratory Contact: P. Kalb, (516) 282-7644

The focus of this project will be on the evaluation and demonstration of polyethylene and modified sulfur cement encapsulation of mixed wastes, which contains high chloride, mercury, and tritium. Brookhaven National Laboratory has developed several polymer solidification final waste form processes for the treatment of DOE waste. Treatability studies using the encapsulation agents on the surrogate wastes were completed in FY94. A field-scale demonstration of polyethylene encapsulation of high-nitrate surrogate mixed waste was accomplished in FY94 using a fully integrated single-screw process.

Keywords: Thermoplastic, Alternate Final Waste Form, Polyethylene, Solidification

271. High Temperature Melter Systems Evaluation

FY 1994

DOE Field Office Contact: Tom Williams (208) 526-2460

$\$ 1,335,000$

DOE HQ Program Manager: Grace Ordaz, (301) 903-7440

Catholic University Contact: Ian Pegg, (202) 319-6700 
This project investigated innovative methods of vitrification that provide higher temperature processing capabilities. High temperature processing is desirable where there is insufficient fluxing agents available within the wastes. Higher temperatures, however, can also increase volatilization which is undesirable. Vitrification methods under consideration include microwave, plasma, and high-temperature joule heating which will allow a cold cap of unmelted materials to minimize volatilization. The project tested each of these methods at bench-scale. Those showing the most promise will be scaled up.

Keywords: Vitrification, High Temperature

272. MAWS Plasma Testing and Support

FY 1994

DOE Field Office Contact: Gary Staats (412) 892-6741

$\$ 2,097,000$

DOE HQ Program Manager: Grace Ordaz, (301) 903-7440

Catholic University Contact: Jeff Ruffner, (406) 494-7412

This project included the testing of several high-metals content feeds in the Plasma Centrifugal Furnace and general engineering/technical support in high temperature processing areas for a future MAWS demonstration. A small-scale plasma unit was purchased for expedited testing on a variety of wastes in support of slag waste form compositional envelope development. This was required before full-scale testing in the larger PACT 6 plasma unit.

Keywords: Plasma, Centrifugal Furnace, MAWS

Materials Properties, Behavior. Characterization or Testing

273. Vitrify to Delist to Dispose

FY 1994

DOE Field Office Contact: M. O'Rear, (803) 725-5541

$\$ 1,798,000$

DOE HQ Program Manager: Paul Hart, (301) $903-7456$

Savannah River Site Contact: Denny Bickford, (803) 725-3737

Vitrification involves converting wastes, which are primarily inorganic in nature, into a durable, leach-resistant glass. Emphasis has been placed on broadening the number of waste streams applicable to vitrification by establishing the processing envelopes for specific representative waste streams. Surrogates of radioactive waste streams have been vitrified in pilot-scale demonstrations conducted at Clemson University in FY94. In addition, a pilotscale radioactive demonstration on actual Savannah River Site M-area sludge was conducted at Catholic University. A major effort was initiated in FY94 to identify an actual mixed waste stream and procure the equipment to assemble a transportable field-scale vitrification unit. The waste stream, Oak Ridge WETF (an inorganic wastewater treatment residue) 
sludge, was successfully vitrified at the bench-scale at Oak Ridge. A field-scale radioactive demonstration using the transportable vitrification system will commence in September, 1995 at the Oak Ridge K-25 Site.

Keywords: Vitrification, Low-Level Mixed Waste, Joule Heated Glass Melter

274. Vitrification of Rocky Flats Waste

FY 1994

DOE Field Office Contact: Deborah Trader, (509) 376-1831

$\$ 750,000$

DOE HQ Program Manager: Paul Hart, (301) 903-7456

Pacific Northwest Laboratory: Richard Peters, (509) 376-3903

This project determined the vitrification process envelop for three actual waste streams. The process envelopes were defined in terms of waste stream compositional variability, glass forming additives, and the limits of incorporation of troublesome species. The process envelopes were determined by a combination of crucible tests, pilot-scale melter runs and vitrification processing modeling. Leaching tests show that the mixed waste glasses are generally as durable or more durable than high-level waste glasses.

Keywords: Vitrification, Low-Level Mixed Waste, Joule Heated Glass Melter

275. Plasma Hearth Process (PHP) Radioactive Waste Test - Idaho

FY 1994

DOE Field Office Contact: Thomas Willianns, (208) 526-2460

$\$ 1,800,000$

DOE HQ Program Manager: Paul Hart, (301) 903-7456

EG\&G Idaho Contact: Steve Bates, (208) 526-6970

This project involved the design, construction, testing, and evaluation of a bench-scale Plasma Hearth Process. The primary goal of this work was to assess the performance of the PHP on actual radioactive wastes and to determine the fate of the radionuclides contaminating the waste upon treatment. The successful conclusion of this project will ensure that the PHP can be employed in radioactive service. In addition data collected in this work will improve the simulation of radionuclides in full-scale systems by surrogates.

Keywords: Plasma, Final Form, Low-Level Mixed Waste, Bench-Scale 
276. Waste Form Performance Criteria

FY 1994

DOE Field Office Contact: Steve Webster, (708) 252-2822

$\$ 180,000$

DOE HQ Program Manager: Paul Hart, (301) 903-7456

Brookhaven National Laboratory Contact: Eena-Mai Franz, (516) 282-7103

This project involved the completion of the Waste Form Performance Criteria and Testing/Evaluation Methods that could be used as guidance in judging viability of a waste form as a physical-chemical barrier to releases of radionuclides and RCRA regulated hazardous components. This report was published in August 1994 and is available through NTIS as document DOE/MWIP-30.

Keywords: Waste Form, Performance Criteria

277. Vitreous Ceramic Compositional Envelope Study

FY 1994

DOE Field Office Contact: Steve Webster, (708) 252-2822

$\$ 500,000$

DOE HQ Program Manager: Grace Ordaz, (310) 903-7440

ANL Contact: Dave Wronkiewicz, (708) 252-7263

This project is part of a larger effort to develop acceptable glass and ceramic waste forms. By better understanding the compositional effects on glass performance and identifying compositional areas where good performance is assured the MAWS program can rapidly screen potential combinations of waste that might be good candidates for vitrification. This project specifically looks at vitrified waste forms where there is a tendency to form stable crystals upon slow cooling.

Keywords: Composition, Characterization, MAWS

278. Arc Melter Vitrification

FY 1994

$\$ 900,000$

DOE HQ Program Manager: Jaffer Mohiuddin, (301) 903-7965

EG\&G Idaho Contact: Kevin Kostelnik, (208) 526-9642

The objective of this project was to demonstrate the applicability of Arc Melter Vitrification for the treatment of mixed wastes and contaminated soils and in providing an extremely durable waste form for disposal. The field-scale unit can process a nominal 1.5 tons per hour of buried waste type feeds and soils. The feed capabilities are limited by the screw feed system. A full-scale unit would handle objects larger than a 55 gallon drum. 
University, industry, in addition to other laboratory participants, are being solicited to accelerate the potential for technology transfer.

Keywords: Arc, Melter, Vitrification

279. Graphite DC Plasma Arc Melter

FY 1994

DOE HQ Program Manager: Jaffer Mohiuddin, (301) 903-7965

$\$ 970,000$

EG\&G Idaho Contact: Kevin Kostelnik, (208) 526-9642

The objective of this project was to demonstrate the applicability of the Graphite DC Plasma Arc Melter for treating mixed wastes and contaminated soils and for providing an extremely durable waste form for disposal. This pilot-scale unit is expected to process a nominal 0.5 to 1.5 ton per hour of buried type feeds and soils. This furnace includes analytical instruments for making spatially resolved measurements of furnace and glass temperatures and on-line measurements of exhaust emissions, both in the furnace chamber and the off-gas.

Keywords: Graphite, DC, Plasma, Arc, Melter 


\section{OFFICE OF NUCLEAR ENERGY}

Office of Nuclear Energy - Grand Total

FY 1994

Office of Space and Defense Power Systems

$\$ 55,265,000$

Radioisotope Power Systems Division

$\$ 12,265,000$

$\$ 2,425,000$

Materials Preparation, Synthesis, Deposition, Growth or Forming

$\$ 2,055,000$

Development of Improved Thermoelectric Materials for Space Nuclear Power Systems

360,000

Development of an Improved Process for the Manufacture of DOP-26 Iridium Alloy Blanks, Product Characterization and Exploratory Alloy Improvement Studies

Carbon-Bonded Carbon Fiber Insulation Production Maintenance, Manufacturing Process Development and Product Characterization

560,000

Materials Properties, Behavior, Characterization or Testing

Development of an Improved Carbon-Carbon Composite Graphite Impact Shell Replacement Material

$\$ 370,000$

370,000

Space Reactor Power Systems Division

$\$ 9,840,000$

Thermoelectric Space Nuclear Power Systems Technology

$\$ 3,205,000$

SP-100 Ground Engineering System Project

$3,205,000$ 
OFFICE OF NUCLEAR ENERGY (Continued)

FY 1994

Space Reactor Power Systems Division (continued)

Thermionic Space Nuclear Power System Technology

$\$ 6,635,000$

Thermionic Fuel Element (TFE) Verification Program (DOE)

$4,300,000$

Thermionic Space Nuclear Reactor Design and

Technology Demonstration Plan (DOD)

$1,800,000$

Space Power and Propulsion Application Studies

535,000

Office of Naval Reactors

$\$ 43,000,000^{*}$

This excludes $\$ 54$ million for the cost of irradiation testing in the Advanced Test Reactor (ATR). 


\section{OFFICE OF NUCLEAR ENERGY}

The Office of Nuclear Energy conducts materials research and development through the Office of Uranium Enrichment, which became the Office of Uranium Programs on September 5, 1993, the Office of Civilian Reactor Development, the Office of Space and Defense Power Systems, and the Office of Naval Reactors. Summarized below are the areas of research in which the Department is currently engaged.

\section{Office of Uranium Programs}

The Department of Energy was authorized by the Atomic Energy Act of 1954, as amended, to provide toll uranium enrichment services. Customers delivered natural uranium containing about 0.7 percent uranium 235 to one of DOE's plants and, for a fee, DOE returned material enriched to $2-5$ percent in the isotope uranium 235 for use in nuclear power reactors.

Revenues received by DOE for the enrichment of uranium were retained and used for the specific purposes of offsetting costs incurred by the Department in providing uranium enrichment service activities as authorized by Section 201 of Public Law 95-238, not withstanding the provisions of Section 3617 of the Revised Statutes (31 USC 484). The sum appropriated is reduced as uranium enrichment revenues are received during a fiscal year so as to result in no net fiscal year appropriations.

At present in the United States, uranium is enriched in gaseous diffusion plants that force uranium hexafluoride $\left(\mathrm{UF}_{6}\right)$ gas through porous barriers. These plants are located at Portsmouth, Ohio, and Paducah, Kentucky. A diffusion plant at Oak Ridge, Tennessee, used since World War II, was placed in standby in 1985 and shut down in 1987. In 1985, the DOE determined that of all the new and competing processes under study the UraniumAtomic Vapor Laser Isotope Separation (U-AVLIS) process had the best potential for providing the lowest cost uranium enrichment in the future.

As a precursor to potential privatization of uranium enrichment in the United States, a federal agency, the United States Enrichment Corporation (USEC) was created. In conformance to the USEC's mission, most of the gaseous diffusion activities that were the responsibility of DOE were transferred to the USEC on July 1,1993. U-AVLIS activities were transferred to the USEC on October 1, 1993. The gaseous diffusion plants are now being operated by the USEC under a lease arrangement with DOE.

Materials R\&D activities in FY 1994 within the Office of Uranium Programs were varied and, for the most part, classified Restricted Data. The DOE contact is William VanDyke, (301) 903-4201. 


\section{Office of Space and Defense Power Systems}

\section{Radioisotope Power Systems Division}

The Radioisotope Power Systems Division responsibilities include the development, system safety and production of radioisotope powered thermoelectric generators (RTG) and dynamic power systems for NASA and DOD space and terrestrial applications and advancing base technologies for these power systems. Thus, applied materials research programs are supported in the areas of thermoelectric materials and devices, high temperature heat source materials, materials systems compatibility and safety related materials characterization and testing.

\section{Materials Preparation, Synthesis, Deposition, Growth or Forming}

280. Development of Improved Thermoelectric Materials for

Space Nuclear Power Systems

FY 1994

$\$ 360,000$

DOE Contact: W. Barnett, (301) 903-3097

Iowa State University, Ames Laboratory Contact: B. Cook, (515) 294-9673

The prime objective of this program is to apply and exploit the capabilities of the mechanical alloying process for the development of improved performance silicongermanium (Si-Ge) type thermoelectric materials. The goal or target properties are average Figure of Merits, $\mathrm{Z}$ of 0.8 and $1.2 \times 10^{-3} /{ }^{\circ} \mathrm{C}$ over the temperature range 300 to $1000^{\circ} \mathrm{C}$ for "P" and "N" type materials, respectively. About 15 percent of the program was directed at exploring new potential thermoelectric materials.

During FY 1994, emphasis continued to be placed on the optimization of the mechanical alloying process and associated consolidation parameters for the production of low oxygen improved performance Si-Ge thermoelectric materials. A cooperative program was initiated with Martin Marietta Astro Space for the demonstration of improved Si-Ge thermoelectrics in a Unicouple device, an 18 couple module. Scale-up of the hot isostatic pressing consolidation process yielded product suitable for Unicouple manufacture. Thermoelectric properties of production material was fully characterized. Exploration of techniques for the addition of nano-size second phase particulates was continued.

Keywords: Mechanical Alloying, Consolidation of Powder, Powder Synthesis, Semiconductors, Thermoelectrics 
281. Development of an Improved Process for the Manufacture of DOP-26

Iridium Alloy Blanks. Product Characterization, and Exploratory Alloy Improvement Studies

FY 1994

$\$ 1,135,000$

DOE Contact: W. Barnett, (301) 903-3097

RNL Contacts: E. P. George, (615) 574-5085 and E. K. Ohriner, (615), 574-8519

An iridium alloy, DOP-26 (i.e., Ir-0.3 wt.\% W with Th and $\mathrm{Al}$ dopant additions), serves as the fuel clad or capsule material for isotope heat sources employed in recent and contemporary space power systems for NASA deep space missions. This program is aimed at the optimization of the new improved process route previously selected for the production of DOP-26 iridium alloy sheet, namely a consumable vacuum arc cast/extrusion/"warm" rolling route. The effectiveness of this production process was further demonstrated in the FY 1994 production of DOP-26 alloy blanks, foil and clad vent sets for the Cassini Mission. Production yields have continued to exceed our goals.

Studies of bare rolling, of blank stock and bare forming of cups was initiated.

Continued product characterization studies, particularly for simulated service conditions, continued to show behaviors equivalent or superior to the prior process product.

Studies of alternate iridium alloy doping agents were continued. The objective is to maintain or exceed the properties of the DOP-26 alloy at a significantly lower thorium dopant level. An iridium alloy containing $0.3 \mathrm{wt} . \% \mathrm{~W}$ with dopant additions of $40 \mathrm{appm}$ cerium and 15 appm thorium was selected for scale-up to a nominal six kilogram consumable arc melted ingot.

Keywords: Consumable Arc Melt, Extrusion, Noble Metal

282. Carbon-Bonded Carbon Fiber Insulation Production Maintenance, Manufacturing Process Development and Product Characterization

FY 1994

$\$ 560,000$

DOE Contact: W. Barnett, (301) 903-3097

ORNL Contact: C. E. Weaver, (615) 574-9978

Carbon-bonded carbon fiber (CBCF) type thermal insulation material is employed in Isotopic General Purpose Heat Source (GPHS) Module assemblies for use in current GPHS-RTG (radioisotope thermoelectric generator). This material was originally employed in GPHS-R7Gs for the Galileo/NASA (1989 launch) and Ulysses/NASA-ESA (1990 launch) Missions. Material produced for the Cassini Mission (1997 launch) was made with a replacement carbon fiber (new vendor, former source not available) utilizing an optimized process and process controls. The FY 1994 program encompassed (1) maintenance of 
capability for both tube and plate billet production through the year, and (2) characterization of Cassini CBCF insulation thermal conductivity. Evaluation of three available data analysis algorithms has led to the selection of the Clark and Taylor algorithm for current use in processing thermal diffusivity data. During FY 1994 characterization efforts have been focused on experimental evaluation of short term (i.e., 5 to 760 seconds) high temperature $\left(2200\right.$ to $\left.3000^{\circ} \mathrm{C}\right)$ exposures on the degree of graphitization and its influence on thermal conductivity. A review of analytical methods for extrapolating thermal conductivity measurements in the ambient to $2000^{\circ} \mathrm{C}$ range to temperatures circa $4000^{\circ} \mathrm{C}$ was initiated.

Keywords: Insulators/Thermal, High Temperature Service, Fibers

\section{Materials Properties, Behavior, Characterization or Testing}

\section{Development of an Improved Carbon-Carbon Composite Graphite Impact Shell Replacement Material}

DOE Contact: W. Barnett, (301) 903-3097

Oak Ridge National Laboratory Contact: G. R. Romanowski, (616) 574-4838

The Graphite Impact Shell (GIS), a component of the General Purpose Heat Source isotopic heat source module is a closed end/capped tubular shape machined from AVCO 3D-CC fine weave pierced fabric material. It is anticipated that a change in the fiber reinforcement architecture from the current orthogonal structure to a cylindrical type structure will enhance energy absorption in high velocity impact. The current program is a feasibility study of commercially available and experimental materials.

During FY 1994 impact tests were conducted on 23 of 38 candidate materials representing at least two levels of densification for each architectural variant. Impact testing was performed at $55 \mathrm{~m} / \mathrm{s}$ using a copper mass simulant to match the typical mass of a GPHS fueled clad. Force versus time was measured at the impact face. Testing and data analysis is continuing.

Keywords: Composites, Carbon-Carbon

\section{Space Reactor Power Systems Division}

The Space Reactor Power Systems Division (NE-52) has the responsibility to technically direct the unique federal functions in the United States of developing, demonstrating, and delivering nuclear reactor power systems for military and civilian space missions, and for special military terrestrial applications. Programs involve the design, testing, and validation of nuclear power systems for use in space and harsh environments. 
Activities include space nuclear reactor power and propulsion system design and assessment; nuclear reactor fuels materials and components development and performance demonstration; heat transport, power conversion, and shielding technology, components, and system development and demonstration; computer analysis method development and application; and ground and flight system safety analysis.

\section{Thermoelectric Space Nuclear Power System Technology}

284. SP-100 Ground Engineering System Project

FY 1994

DOE Contact: Lyle Rutger, (301) 903-6470

$\$ 3,205,000$

Martin Marietta Astro Space Contact: Richard H. Hemler, (610) 354-3045

The objective of this program was to develop space reactor power system components for use in future civil, commercial, and defense applications. Included in this comprehensive program were numerous activities related to materials development, fabrication, and testing. This project was discontinued in FY 1994. The work described below was accomplished in closing out the program:

Principal materials activities are:

Thermoelectric Cell Materials Development $\mathbf{( \$ 8 6 0 , 0 0 0 )}$ - Silicon-germanium multicell converters incorporating $\mathrm{Al}_{2} \mathrm{O}_{3}$ insulators, niobium fiber compliant pads, tungsten-graphite electrodes using a variety of coatings, foils, brazes, and hot isostatic pressure bonds were tested. conducted.

Reactor Materials $(\mathbf{\$ 1 5 5 , 0 0 0 )}$ - Stress tests of niobium zirconium alloys were

Heat Transport Materials $\mathbf{( \$ 5 1 0 , 0 0 0 )}$ - Assembly of a thermoelectric electromagnetic pump consisting of niobium alloy ducts, thermoelectric cells, permanent magnets and niobium clad copper bus-bars was demonstrated.

Reactor Control Drive Materials $\mathbf{( \$ 1 , 6 8 0 , 0 0 0 )}$ - Reactor control drive motor components were tested. These components incorporated a variety of technologies including wear resistant surfaces, bearings, and lubricants for use in a high temperature-radiation vacuum environment.

Keywords: Thermoelectric Cells, Refractory Metals, Tribology, Space Reactors 
Thermionic Space Nuclear Power System Technology

In June 1991, DOE, the Strategic Defense Initiative Organization, now the Ballistic Missile Defense Organization (BMDO), and the U.S. Air Force signed a Memorandum of Understanding establishing a Thermionic Space Nuclear Power System Technology Program, jointly funded by the three agencies, and managed by the DOE Headquarters Office of Nuclear Energy. The focus of the program is the Thermionic Space Nuclear Reactor Design and Technology Demonstration program, but also encompasses the Thermionic Fuel Element (TFE) Verification program which was initiated in 1986. The MOU is still in effect, though funding shortfalls have curtailed several aspects of the agreement.

285. Thermionic Fuel Element (TFE) Verification Program

FY 1994

$\$ 4,300,000$ - DOE

\$O - DOD

DOE Contact: J. Warren, (301) 903-6491

Hanford Contact: J. Hales, (509) 376-4069

The TFE Verification Program was initially established in 1986 to resolve the outstanding feasibility associated with the use of in-core TFEs in space reactor power systems. It was primarily aimed at demonstrating the long-term operational lifetimes of TFE materials, components, and fully-assembled TFEs through accelerated and real-time testing at high temperatures and under high radiation environments. This project was also terminated in FY 1994, with the principal effort during FY 1994 focused on program closeout activities. Some closeout tasks, including post irradiation examinations (PIEs) of TFE test articles, will be completed during FY 1995. TFE materials tested during the program included uranium dioxide fueled tungsten emitters, niobium collectors, alumina and yttria ceramic insulators and seals, and radiation resistant graphite cesium storage reservoirs.

Keywords: Thermionic, Uranium Dioxide, Ceramics, Graphite, Tungsten, Niobium, Alumina, Yttria, Space Reactors 
286. Thermionic Space Nuclear Reactor Design and Technology Demonstration Plan

\author{
FY 1994 \\ $\$ 0-\mathrm{DOE}$ \\ $\$ 1,800,000$ - DOD
}

DOE Contact: D. Culp, (301) 903-3667

Rocketdyne Contact: R. Harty, (818) 586-3140

Space Power, Inc. Contact: K. Koester, (408) 434-9500

The overall objective of this program is to design, develop, demonstrate, and advance the technology for a thermionic space nuclear reactor power system for military applications. A $40 \mathrm{kWe}$ end-of-life point design will be developed as a baseline using technology that is applicable over a 5 to $40 \mathrm{kWe}$ power range. Two separate contract teams began work in 1992, Rocketdyne Division of Rockwell International and Space Power, Inc., with both pursuing in-core thermionic power conversion systems and utilizing Russian subcontractors. Significant accomplishments include one and two dimensional creep testing of single crystal molybdenum-niobium thermionic emitter materials in Russia; fabrication of an advanced 320-watt single cell thermionic fuel element in Russia with preparations for testing in the U.S.; testing of an advanced beryllium-yttrium hydride neutron moderator design in both the U.S. and Russia to assess lifetime and performance under irradiation as well as hydrogen retention at prototypic temperature conditions; and completion of preparations for lifetime testing of alumina sheath insulator specimens in Russia under prototypic thermal, applied voltage and fluence conditions.

Keywords: Thermionic, Molybdenum-Niobium, Berryllium-Yttrium Hydride, Alumina, Emitters, Moderators, Space Reactors

287. Space Power and Propulsion Application Studies

FY 1994

$\$ 535,000$

DOE Contact: Don Culp, (301) 903-3667

Assistance grants have been awarded to U.S. industry in response to a DOE Notice of Program Interest entitled, Invitation for Proposals Designed to Support Federal Agencies and Commencial Interests in Meeting Special Power and Propulsion Needs for Future Space Missions. Materials-related work to be accomplished includes compatibility tests of Russian binary uranium carbide fuel pellets with tungsten emitter sheaths for high temperature thermionic converter applications; investigating oxygen-ion-implanted niobium electrodes for higher thermionic power conversion efficiencies at lower temperatures; and evaluating design concepts for venting hydrogen from liquid-metal heat pipes in bimodal reactor applications. A few of the grant awardees have subcontracts with Russian entities which 
may provide technology transfer of Russian expertise or manufacturing capability to U.S. industry.

Keywords: Thermionics, Uranium Carbide, Tungsten, Niobium, Heat Pipes, Space Reactors

\section{Office of Naval Reactors}

The materials program supports the clevelopment and operation of improved and longer life reactors and pressurized water reactor plants for naval nuclear propulsion.

The objective of the materials program is to develop and apply, in operating service, materials capable of use under the high power density and long life conditions required of naval ship propulsion systems. This work includes irradiation testing of reactor fuel, poison, and cladding materials in the Advanced Test Reactor at the Idaho National Engineering Laboratory. This testing and associated exarnination and design analysis demonstrates the performance characteristics of existing materials as well as defining the operating limits for new materials.

Corrosion, mechanical property, and wear testing is also conducted on reactor plant structural materials under both primary reactor and secondary steam plant conditions to confirm the acceptability of these materials for the ship life. This testing is conducted primarily at two Government laboratories-Bettis Atomic Power Laboratory in Pittsburgh and Knolls Atomic Power Laboratory in Schenectady, New York.

One result of the work on reactor plant structural material is the issuance of specifications defining the processing and final product requirements for materials used in naval propulsion plants. These specifications also cover the areas of welding and nondestructive testing.

Funding for this materials program is incorporated in naval projects jointly funded by the Department of Defense and the Department of Energy. This funding amounts to approximately $\$ 97$ million in FY 1994 including approximately $\$ 54$ million as the cost for irradiation testing in the Advanced Test Reactor. The Naval Reactors contact is David I. Curtis, (703) 603-5565. 


\section{OFFICE OF CIVILIAN RADIOACTIVE WASTE MANAGEMENT}

Office of Civilian Radioactive Waste Management - Grand Total

Materials Properties, Behavior, Characterization or Testing

Waste Packages

Device or Component Fabrication, Behavior or Testing

Alternate Defense Waste Processing Facility (DWPF) Canister

Fabrication Methods
FY 1994

$\$ 2,200,000$

$\$ 2,100,000$

$\$ 2,100,000$

$\$ 100,000$

$\$ 100,000$ 


\section{OFFICE OF CIVILIAN RADIOACTIVE WASTE MANAGEMENT}

Materials research is ongoing in the Office of Civilian Radioactive Waste Management in two areas: the development of canisters for containing the glass waste from the Defense Waste Processing Facility at the Savannah River Laboratory and the design of waste packages for eventual geologic disposal.

Materials Properties, Behavior. Characterization or Testing

288. Waste Packages

FY 1994

DOE Contact: Dean Stucker, (702) 794-7275

$\$ 2,100,000$

B\&W Fuel Company Contact: Hugh Benton, (702) 794-1891

The waste package and waste form materials effort continued. Waste form studies include oxidation of spent fuel and dissolution of waste glasses, uranium oxides, spent fuel, and oxidized spent fuel. Degradation modes for corrosion-allowance materials were surveyed. The potential use of nonmetallic barriers was studied. Development of a qualityassured database of materials properties was begun. More realistic thermal and criticality models were developed, and the effects of rock fall were analyzed. Methods for fabricating waste containers were studied. Models for degradation of container materials were developed.

Keywords: Waste Packages, Ferrous Metals, Geologic Repository

Device or Component Fabrication. Behavior or Testing

289. Alternate Defense Waste Processing Facility (DWPF)

Canister Fabrication Methods

FY 1994

DOE Contact: Timothy C. Gunter, (803) 557-2524

$\$ 100,000$

Westinghouse Contact: John Harbour, (803) 725-8725

Savannah River Technology Center (SRTC) has initiated a program to develop second generation canisters for capture and isolation of high-level radioactive waste glass produced at the Defense Waste Processing Facility (DWPF). Currently DWPF uses conventional rolland-welded fabrication for production of the cylindrical portion of the canister. The top and bottom heads are hot formed and then welded onto the ends of the cylinder. A machined nozzle is then welded onto the top head to complete the canister. All components are made of $304 \mathrm{~L}$ stainless steel. 
The initial phase of this work began by ordering two developmental deep-drawn canisters from Norris, a Division of NI Industries, Inc. In the first prototype, one central girth weld at half-height and one nozzle-to-top head weld were required. The two developmental deep-drawn canisters, produced by Norris Industries, arrived on site in April 1993.

Glass filling of one of the canisters at DWPF was completed on August 20, 1994. This canister has been decontaminated but not yet final welded. It is still located within the vitrification building. The second deep-drawn canister was scheduled to be glass-filled in December 1994. It is anticipated that one of the canisters will be drop tested and the other sectioned in order to obtain coupons for metallographic examination and corrosion testing. Dimensional measurements and surface analysis will be carried out prior to these tests. Estimated completion for this testing is mid-1995.

Canister fabrication by spin forming is also being investigated. In this process, the metal is flow-formed through the application of forming rolls. In this process a forged cup is placed on a mandrel and the piece is then spun into a cylinder. What results is an integral unit $\sim 9$ feet in length having an internal diameter equal to the diameter of the mandrel. A preformed integral head and nozzle unit is then electron beam welded onto the spun cylinder. Final machining is performed in order to meet the dimensional specification.

An order was placed with Spin Forge International for two developmental canisters. The two canisters were estimated to have a delivery date of November 1994.

Keywords: Waste Canisters, Glass Waste, Testing 
OFFICE OF DEFENSE PROGRAMS

FY 1994

Office of Defense Programs - Grand Total

$\$ 78,279,848$

The Weapons Research, Development and Test Program

$\$ 78,279,848$

Sandia National Laboratories

$\$ 32,222,000^{*}$

Device or Component Fabrication. Behavior or Testing

$\$ 5,682,000$

Analysis

$\$ 1,540,000$

Wavelength Selective Devices on a Chip for a Miniature Spectrometer

300,000

Advanced Materials for Electrostatic Chucks

Alternate Modules

150,000

340,000

Porous Silicon Humidity Sensor

100,000

Protected Volumes Liner

200,000

Thin-Film Capacitors for Advanced Packaging

450,000

Metals

$\$ 3,193,000$

Advanced Welded Turbine Engine Alloys

Intelligent Systems for Induction Hardening Processes

300,000

Low-Residue Flux, Lead-Free Solder Project

Materials Engineering for the Press/CM

Materials Replacement Engineering for the Stockpile

SMARTWELD

277,000

$1,100,000$

301,000

$1,084,000$

131,000

Organics

$\$ 949,000$

Advanced Gas Transfer Materials Studies

Inertial Confinement Fusion Target Fabrication

474,000

475,000

"Budget summary numbers do not inclucle funding for projects that were not reported because of CRADA proprietary, patent, or classification restrictions. 


\section{OFFICE OF DEFENSE PROGRAMS}

FY 1994

The Weapons Research. Development and Test Program (continued)

Sandia National Laboratories (continued)

Instrumentation and Facilities

$\$ 885,000$

Analysis.

$\$ 735,000$

Noninvasive Blood Alcohol Monitor

135,000

Noninvasive Blood Glucose Monitor

600,000

Metals

$\$ 150,000$

Laser Welding Diagnostics

150,000

Materials Preparation, Synthesis, Deposition, Growth or Forming

Ceramics

$\$ 2,145,000$

Advanced Materials for Biomedical and Aerospace Applications

Biomimetic Processing of Oriented Crystalline Ceramic Films

Novel Approach to the Production of Thick, Patterned

Diamond Films

Scalable, Flat-Flame Technology for the Synthesis of

Diamond Films

Surface, Interface, and Bulk Properties of Advanced

Ceramics

Synthesis and Microstructural Development of Oxide

Thin Films

350,000

300,000

200,000

415,000

179,000

Synthesis Of Ceramics Using Supercritical Fluids

345,000

356,000 
OFFICE OF DEFENSE PROGRAMS

FY 1994

The Weapons Research, Development and Test Program (continued)

Sandia National Laboratories (continued)

Materials Preparation, Synthesis, Deposition, Growth or Forming (continued)

Metals

$\$ 7,127,000$

Advanced Brazing Technology Development

200,000

Advanced Laser Processing Technology

150,000

Advanced Welding Technology

500,000

Development of Novel Laser Coating and Joining Technology

180,000

Electro-Slag Remelting - Fundamentals and

Controller Development

FASTCAST Rapid Prototyping Development

$1,175,000$

250,000

750,000

FASTCAST Software Development And Experiments

560,000

Lightweight Materials For Automotive Applications

660,000

Maria

870,000

114,000

Solidification Studies

250,000

Titanium Facecoat Development

200,000

Titanium Nitride Dissolution In Molten Titanium

$1,068,000$

Welding and Processing of an Advanced Titanium Alloy

200,000

Organics

$\$ 5,744,000$

Advanced Materials Synthesis

300,000

Development of Sticky Foams Without Chlorofluorocarbons

200,000

Engineered Monodisperse Porous Materials

320,000

Environmental Conscience Manufacturing Technology

672,000

Fullerene-Based Materials

420,000

Low-Dielectric Insulating Films for Microelectronics

175,000

Microengineered Materials

350,000

Microporous and Composite Materials

$1,774,000$ 


\section{OFFICE OF DEFENSE PROGRAMS}

\section{FY 1994}

The Weapons Research, Development and Test Program (continued)

Sandia National Laboratories (continued)

Materials Preparation, Synthesis, Deposition, Growth or Forming (continued)

Organics (continued)

New Adhesive Systems Based on Functionalized Block

Copolymers

228,000

Organic Electronic and Optical Materials

400,000

Polymeric Nonlinear Optical Materials and Devices

Development

355,000

Polyphosphaacetylenes: New Organic-Inorganic

Electrical Conductors

300,000

Polysilane Photoresist Technology

250,000

Materials Structure and Composition

$\$ 2,229,000$

Analysis

$\$ 984,000$

Phase Identification in a Scanning Electron Microscope

Pyrolytically Derived Carbon

304,000

200,000

Thin Film X-Ray Diffraction Development

X-Ray Micro-Tomography

180,000

300,000

$\underline{\text { Ceramics }}$

$\$ 136,000$

Defect Studies of $\mathrm{ZnO}$ Phosphors

136,000

Metals

$\$ 409,000$

Containment Materials for Transferable Explosives

409,000 


\section{OFFICE OF DEFENSE PROGRAMS}

FY 1994

The Weapons Research. Development and Test Program (continued)

Sandia National Laboratories (continued)

Materials Structure and Composition (continued)

Organics

$\$ 700,000$

Polymer Blends and Interfaces

Polymer Degradation and Lifetime

350,000

350,000

Materials, Properties. Behavior. Characterization or Testing

$\$ 8,410,000$

Analysis

$\$ 2,006,000$

Chemometric Development

Dismantled Weapon Hardware - Characterization and Analysis

Materials Characterization Using Ultrafast Optical

Techniques

Materials Identification for Weapon Dismantlement

Metal Deposition On Semiconductor Surfaces

Non-Nuclear Laboratory Operation Reconfiguration Support

Process Applications

300,000

180,000

250,000

229,000

150,000

230,000

667,000

Ceramics

$\$ 1,190,000$

A Mechanical Test for Qualifying Ceramic Granules

92,000

Analysis of Glass Properties for Stockpile Components

118,000

Electrical and Optical Properties of Ferroelectric

Thin Films

325,000

Ferroelectric Read/Write Optical Disc

550,000

Lead Magnesium Niobate-Lead Titanate Granules

105,000 
OFFICE OF DEFENSE PROGRAMS

FY 1994

The Weapons Research, Development and Test Program (continued)

Sandia National Laboratories (continued)

Materials. Properties, Behavior. Characterization or Testing (continued)

Metals

$\$ 2,155,000$

A Novel Technique for the Mechanical Characterization of Thin Films

Development of Alternatives for Lead Based Solders

NCMS Printed Wiring Board Surface Finishes Program

Specialty Metals Product Characterization and Quality

Welding of AerMet 100

307,000

278,000

650,000

695,000

225,000

Organics

$\$ 3,059,000$

Carbons For Electrochemical Energy Storage

298,000

Catalytic Carbon Foam Filters

338,000

Chlorinated Polyethylene

358,000

High Density Electronic Interconnects

890,000

Materials For Improved Tire Technology

$1,000,000$

Semiconductor Application of IRIS to Semiconductor

Processing

175,000

Lawrence Livermore National Laboratory

$\$ 19,030,848$

Materials Preparation. Synthesis. Deposition. Growth or Forming

$\$ 3,403,000$

Engineered Nanostructure Laminates

$1,300,000$

325,000

Sol Gel Coatings

900,000

KDP Growth Development

300,000

Doped Polymers for ICF

50,000

ICF Capsule Ablators via Plasma Polymerization

428,000

Excimer Laser Micromachining

100,000 


\section{OFFICE OF DEFENSE PROGRAMS}

FY 1994

The Weapons Research, Development and Test Program (continued)

Lawrence Livermore National Laboratories (continued)

Materials Properties, Behavior, Characterization or

Testing

$\$ 3,618,000$

Advanced Synchrotron Radiation Study of Materials

Structural Transformation and Precursor Phenomena

Very High Energy Density Materials

Interfaces, Adhesion, and Bonding

Laser Damage: Modeling and Characterization

KDP Characterization

Damage Testing

Energy Transfer Dynamics in Energetic Materials

Processing-Structure-Property Correlation in Laminated

Metal Composites

200,000

169,000

$1,060,000$

300,000

400,000

400,000

800,000

120,000

169,000

Instrumentation and Facilities

$\$ 12,009,848$

Scanning Tunneling Microscopy (STM) and Atomic Force

Microscopy (AFM)

Thermoelectric Materials with Exceptional Figures of Merit

Capacitive Deionization as an Alternative to Ion Exchange

Trilayer Josephson Junctions (Technology Transfer Initiative)

Lithium Cell Development

Environmentally Safe Disposal of Explosive Wastes:

SERDP Project

Laminated Metal Composites for Aerospace Applications

Fatigue of Metal Matrix Composites

Molecular Dynamics Simulation Studies of Radiation Effects in Solids

Fundamental Studies of Particle-Solid Interactions

Radiation Effects in Materials for Inertial Confinement

Fusion

Novel Materials for Optoelectronics and Photonics

Uranium Manufacturing Lead Lab Program

390,000

325,000

795,000

425,000

200,000

800,000

700,000

450,000

60,000

176,000

50,000

500,000

$3,000,000$ 
OFFICE OF DEFENSE PROGRAMS

FY 1994

The Weapons Research. Development and Test Program (continued)

Lawrence Livermore National Laboratory (continued)

Instrumentation and Facilities (continued)

Plutonium Manufacturing Lead Lab Program

$3,000,000$

Novel Materials Studies at High Pressures and Temperatures

by Using In-Situ X-ray Laser Heating Experiments in a DAC

Advanced Molecular Dynamics Simulations of Molecular-Beam Induced Surface Processes

High-Speed Tribology of the Head Disk Interface by Computer Simulation

Massively Parallel Simulation of Large Molecular Systems with Long-Range Interactions

Advanced Atomic-Level Materials Design for Massively

Parallel Environment (High Performance Parallel

Processor Computing Initiative: H4P)

Growth and Formation of Advanced Heterointerfaces

Materials Produced with Dynamic High Pressure

Properties of Hydrogen at High Shock Pressures and

Temperatures

Low Density Foam Shells for Cryogenic ICF Experiments

Molecular Hydrodynamics

Metastable Solid-Phase High Energy Density Materials

Sub-Picosecond Laser Induced Damage

Novel High Energy Density Materials: Synthesis by

Megabar Hot Pressing

AFM Investigations of Crystal Growth

Plutonium Process Technology Development

400,000

607,000

300,000

200,000

175,000

500,000

500,000

250,000

700,000

500,000

207,000

100,000

328,000

210,000

$6,000,000$ 
OFFICE OF DEFENSE PFIOGRAMS (Continued)

$\underline{\text { Los Alamos National Laboratory }}$

$\$ 27,027,000$

Materials Preparation, Synthesis, Deposition. Growth or Forming

$\$ 5,055,000$

Actinide Processing Development

Plutonium Oxide Reduction

Low Density Microcellular Plastic Foams

Physical Vapor Deposition and Surface Analysis

Chemical Vapor Deposition (CVD) Coatings

Polymers and Adhesives

Tritiated Materials

Salt Fabrication

Slip Casting of Ceramics

Plasma-Flame Spraying Technology

Rapid Solidification Technology

Bulk Ceramic Processing

Synthesis of Ceramic Coatings

FY 1994

$1,350,000$

150,000

200,000

300,000

150,000

430,000

175,000

800,000

300,000

300,000

500,000

250,000

150,000

Materials Structure or Composition

$\$ 1,237,000$

Actinide Surface Properties

Neutron Diffraction of Pu and Pu Alloys and Other Actinides

Surface, Material and Analytical Studies

700,000

237,000

300,000

Materials Properties, Behavior. Characterization or Testing

$\$ 2,500,000$

Mechanical Properties of Plutonium and Its Alloys

450,000

Phase Transformations in $\mathrm{Pu}$ and $\mathrm{Pu}$ Alloys

450,000

350,000

Non-Destructive Evaluation

550,000

Powder Characterization

50,000

Shock Deformation in Actinide Materials

300,000

Dynamic Mechanical Properties of Weapons Materials

350,000 
OFFICE OF DEFENSE PROGRAMS (Continued)

FY 1994

Los Alamos National Laboratory (continued)

Device or Component Fabrication, Behavior or Testing

$\$ 3,900,000$

Target Fabrication

$1,500,000$

100,000

Filament Winder

800,000

High Energy Density Welding in Hazardous Environments

$1,500,000$

Laboratory Directed Research and Development

$\$ 10,802,000$

Electronically Correlated Materials at Ambient and

Extreme Conditions

Organometallic Chemical Vapor Deposition

Polymer Sorbents for Hazardous Metal Uptake

Microscopic Materials Modeling: Textures and Dynamics

Surface Modification of Materials

Integration of Fundamental Knowledge in Plasticity and

Textures to Provide Technical Tools for Microscopic

Applications

High Resolution Electron Microscopy of Materials

Nano-Fabrication

Thin Film Micro-Electrochemical Sensor Development

Liquid Crystal Thermosets

Neutron and Resonant X-ray Scattering by Materials

Structural and Electronic Competitions in Low-

Dimensional Materials

328,000

248,000

164,000

109,000

315,000

Fundamental Aspects of Photoelectron Spectroscopy in

Highly Correlated Electronic Systems

Development of High Strength High Conductivity

Materials for High Magnetic Field Devices

Low Temperature STM for Structural and Spectroscopic

Studies of High Temperature Superconductors and

Other Electronic Materials

Materials with Fine Microstructures

290,000

350,000

255,000

210,000

200,000

350,000

360,000

300,000

100,000

50,000

365,000

330,000

Ion Beam Materials Research

Texture Studies of Highly Deformed Composite Materials

192,000 


\section{OFFICE OF DEFENSE PROGRAMS (Continued)}

Los Alamos National Laboratory (continued)

Laboratory Directed Research and Development (continued)

Pressure Dependency of the Structure of High Explosives: Nitromethane

Neutron Reflection Studies of Thin Film and Multilayer Structures

Neutron Reflectivity Studies of In Situ Corrosion of Metal Surfaces

The Dynamics of Amorphous Materials

Advanced Material Science Algorithms for Supercomputer Architectures

Metal Vapor Synthesis in Organometallic Chemistry

Separation Chemistry of Toxic Metals

Polymers for Integrated Optical Interconnects

High Temperature Materials Synthesis Without Heat:

Oxide Layer Growth on Electronic Materials Using

High Kinetic Energy Atomic Species

192,000

300,000

145,000

330,000

75,000

235,000

250,000

266,000

Dynamic Deformation of Advanced Materials

Strain Measurements in Individual Phases of Multi-

Phase Materials

Artificially Structured Nonlinear Optic and Electro-

Optic Materials

Structural Phase Transitions in Non-Stoichiometric

Oxides

164,000

855,000

130,000

465,000

275,000

Strongly Correlated Electronic Materials

Plasma Immersion Ion Implantation for Semiconductor

495,000

Film Growth

261,000

Analysis of Structure and Orientation of Adsorbed

Polymer in Solution Subject to Dynamic Shear

Stress

172,000

Development of Pair Distribution Function Analysis

of Mesostructural Details in Single Crystal

Perovskites and Nanocrystalline Materials

170,000 


\section{OFFICE OF DEFENSE PROGRAMS (Continued)}

FY 1994

Los Alamos National Laboratory (continued)

Laboratory Directed Research and Development (continued)

Neutron Scattering as a Probe of the Structure of

Liquid Crystal Polymer-Reinforced Composite

Materials

180,000

Strain Measurements in Individual Phases of Multi-

Phased Materials During Thermomechanical Loading:

LANSCE Neutron Scattering Experiment Support

318,000

A New Approach to Texture Measurements: ODF

Determination by Rietveld Refinement

Applications of Fullerenes in Nuclear Technology

Ceramic Oxide Foams for Separation

Materials Modeling Project

Synthesis and Optical Characterization of Novel

Fullerene-Based Composites

Technology Transfer Initiative

A Pilot Program: Chemical Vapor Deposition of

Diamond in a Fluidized-Bed for Cutting Tool and

Tribological Applications

250,000

632,000

Advanced Beryllium Processing

130,000

Plasma Source Ion Implantation for the Automotive Industry

Processing Modeling and Control for U.S. Steel

$1,326,000$

Industry

$1,195,000$ 


\section{OFFICE OF DEFENSE PROGRAMS}

Summaries of materials activities which were selected to present the diversity of materials research, development and application projects conducted for the Office of the Assistant Secretary for Defense Programs are included in this section. Activities are organized in groupings that indicate the Defense Program Laboratory at which the specific project was performed. Funds for FY94 materials activities within Defense Programs were provided by the Weapons Research, Develojment and Test program including the Core Research and Development program and the Technology Transfer Initiative program and by the Inertial Confinement Fusion program, the Production and Surveillance program, and Laboratory Research and Development program. Projects with proprietary, patentable, or classified information were not reported.

The Weapons Research, Development and Test Program

Sandia National Laboratories

Device or Component Fabrication, Behavior or Testing

290. Wavelength Selective Devices on a Chip for a

Miniature Spectrometer

FY 1994

DOE Contact: Maurice Katz, (202) 586-5799

$\$ 300,000$

SNL Contact: Brian R. Stallard, (505) 844-2,631

Miniature, rugged, low cost sensors for industrial process and for environmental monitoring are needed for a variety of applications. Infrared and optical spectrometers can be used as monitors, but size, cost and a lack of robustness limit their use for many applications. We are pursuing the design, fabrication and characterization of one element of such a spectrometer, the wavelength selective device on a semiconductor surface. We have demonstrated the feasibility of one design using it to measure diethanol amine in ethanol and are investigating two other designs.

Keywords: Analysis, Spectroscopy 
291. Advanced Materials for Electrostatic Chucks

FY 1994

$\$ 150,000$

DOE Contact: J. L. VanFleet, (202) 586-5782

SNL Contact: · Michael J. Hurst, (505) 845-0809

In collaboration with Sematech companies and Oak Ridge, Sandia has begun to synthesize and screen candidate dielectrics and conductors for high temperature electrostatic chuck (ESC) components. The goal is to design a chuck appropriate for advanced tungsten deposition and aluminum etching processes of the type that will be found in future processing equipment. ESCs have distinct advantages over mechanical chucks: no lost real estate, no moving parts, thermal uniformity, and minimal particle generation. ESCs work by columbic attraction between a wafer (maintained at a potential by the processing plasma) and the chuck. The trick is to find materials that work at elevated temperatures. Our most promising attempt, tested at Sematech, has been a combination of plasma-sprayed and solgel ceramics, although a darkhorse ESC etched from a single Si wafer is showing promise as well.

Keywords: Ceramics, Coating, Plasma, Plasma-Sprayed, Silicon

292. Alternate Modules

FY 1994

DOE Contact: G. J. D'Alessio, (301) 903-6688

$\$ 340,000$

SNL Contact: Michael J. Hurst, (505) 845-0809

Secure containers are used for the protection of important assets such as critical information, circuitry, or money. Potential threats are not just deliberate theft and entry, but also damage by fire or vibration. The ideal container should be scalable from the size of a Brinks truck down to the package around an integrated circuit. A scheme for the design of such scalable modules was investigated through the development of materials and processes to fabricate fault-tolerant devices whose proclivity toward failure is independent of enclosed volume. Most of the work is classified at this time.

Keywords: Ceramics, Packaging, Protected Volumes, Secure Containers, Surety

293. Porous Silicon Humidity Sensor

FY 1994

DOE Contact: J. L. VanFleet, (202) 586-5782

$\$ 100,000$

SNL Contact: Alan J. Hurd, (505) 845-8629

The purpose of this CRADA project is to compare the performance of porous silicon humidity sensors with that of commercially available aluminum oxide humidity sensors with an intent to commercialize the porous silicon sensor. In our approach, we seek to define 
the morphological differences between these two sensors and examine their electrical response. Performance comparisons are performed using a prototype test cell made at Sandia. We calibrated the sensors in both "wetting up" (increasing humidity) and "drying down" (decreasing humidity) modes and analyzed the sensor impedance as a function of humidity. In modeling, we are using RC circuit analysis and permitivity mixing rule to gain insight into the mechanism of capacitance change with humidity; our goal is a predictive model of sensor behavior that can be used for further sensor refinement in future device generations. We are supplementing our modeling effort with examinations of the comparative microstructures of our porous silicon prototype sensors and the commercial alumina sensors manufactured by Thunder Scientific to understand how differences in pore geometry and size affect sensor response.

Keywords: Ceramics, Microporous, Silicon

294. Protected Volumes Liner

FY 1994

DOE Contact: G. J. D'Alessio, (301) 903-6688

$\$ 200,000$

SNL Contact: Alan J. Hurd, (505) 845-8629

Protected volumes (PVs) are needed for the surety of weapons components against undetected or unmitigated entry by an adversary. Basically a burglar alarm, PVs in weapons should be immune to cold, heat, corrosion, shock, and vibration while remaining exquisitely sensitive to penetration. Our research focused on materials and process development for a new generation of PV protection that promises to supplant existing technology in the stockpile. In addition to laboratory-level work, we teamed with the Sandia manufacturing groups to develop a scalable manufacturing process for future commercialization. Much of the work is classified.

Keywords: Ceramics, Surety

295. Thin-Film Capacitors for Advanced Packaging

FY 1994

DOE Contact: G. J. D'Alessio, (301) 903-6688

$\$ 450,000$

SNL Contact: Duane B. Dimos, (505) 844-6385

To improve the performance and decrease the size and weight of next-generation multichip module (MCM) systems, it is necessary to develop decoupling and filter capacitors that can be more fully integrated into electronic packages than current multi-layer ceramic capacitors. To address this need, we have been developing thin-film capacitors using high dielectric constant, lead zirconate titanate sol-gel films. Two approaches are being investigated for integrating these capacitors into MCMs. The first is to develop a solder bump bonded, flip-chip compatible format. This approach requires the development of an 
appropriate wetting/nonwetting materials combination for solder deposition and reflow. The second is to incorporate free-standing, thin-film capacitors directly onto integrated circuits and connect them together as part of a standard repattering process. This approach requires development of a technique for preparing free-standing thin films $(<25 \mu \mathrm{m})$. Studies to improve process reproducibility, capacitor yield, and metallization are also being carried out. Capacitor performance will be assessed by characterizing the properties of individual capacitors and the performance of systems with integrated capacitors.

Keywords: Ceramics, Dielectric, Ferroelectric, Film, Packaging, Sol Gel

296. Advanced Welded Turbine Engine Alloys

FY 1994

$\$ 300,000$

DOE Contact: J. L. VanFleet, (202) 586-5782

SNL Contact: Gerald A. Knorovsky, (505) 844-1129

The goal of this project (a CRADA with GE Aircraft Engines) is to enhance the commercial and defense application of selected advanced alloys. The approach is to increase understanding of their metallurgy and mechanical properties, particularly as affected by welding and associated processing (including welds to dissimilar materials). The materials of interest include: a high-strength controlled thermal expansion alloy, Thermospan, a high strength Ni-base superalloy with enhanced properties and weldability beyond that of Alloy 718, GTD-222, a high performance cast g-Titanium Aluminide, and a high strength orthorhombic Ti-Al-Nb alloy. In addition to an initial literature survey, the project includes differential thermal analysis, weldability testing, kinetic investigations of phase transformation behavior, and mechanical testing. Analytic Electron Microscopy will also be an important feature.

Keywords: Metals, Alloy, Joining, Melting, Microstructure, Weld

297. Intelligent Systems for Induction Hardening Processes

FY 1994

$\$ 277,000$

DOE Contact: J. L. VanFleet, (202) 586-5782

SNL Contact: J. Bruce Kelley, (505) 845-3105

Induction heat treating is widely used to produce high strength automotive and industrial components. Current technology requires that process development be accomplished by trial and error and that the process be run with open loop process controllers. As part of a CRADA with the Saginaw Division of GM, research is being conducted in four areas: experimental process characterization, materials characterization to evaluate dominant process parameters, computational modeling, and neural net controller development. Aspects of these efforts will be incorporated into process controllers which allow the hardened case depth to be selected and then achieved via closed loop control. 
Intelligent process controllers have the potential to save millions of dollars per year in scrap, waste, and inefficiency. This project requires development of advanced sensor technologies, process diagnostics and controls, complex computational models, and advanced computer architectures for handling very high speed data acquisition and analysis.

Keywords: Metals, Induction Heat Treating, Intelligent Neural Net Controllers, Materials Characterization, Modeling, Process Characterization

298. Low-Residue Flux, Lead-Free Solder Project

FY 1994

DOE Contact: G. J. D'Alessio, (301) 903-6638

$\$ 1,100,000$

SNL Contact: Floyd M. Hosking, (505) 845-3401

Ozone depleting chemicals and lead-containing solders have been identified as significant hazards to the environment. Since both types of materials have been routinely used for assembling microelectronic circuits, their proposed phase out presents significant problems to the DOE DP sector. New materials and processes must be developed to replace the current list of offending technologies, while still yielding the same level of product reliability. Low-residue soldering technologies are presently being validated for fabricating commercial and military electronic devices. Most of this work has focused on printed wiring assembly (PA) technology. Activities related to hybrid microcircuit (HMC) assembly are less mature. The principal objectives of this project are to develop and demonstrate a low-residue, lead-free soldering technology for manufacturing reliable HMCs for radars. The wetting, aging, and mechanical behavior of prototype solder joints are under investigation. Results are intended for DP and other commercial/military use.

Keywords: Metals, Solder, Alloy, Cleaning, Joining, Joint, Packaging

299. Materials Engineering for the Press/CM

FY 1994 $\$ 301,000$

DOE Contact: G. J. D'Alessio, (301) 903-6688

SNL Contact: John E. Smugeresky, (510) 294-2910

Advanced surety system components are being developed which require new candidate materials both as ES\&H driven replacements and as substitutes to increase the margin of safety in abnormal environments, such as accidents involving fuel fires and conditions under which materials may be degraded from exposure to elevated temperature conditions. Design guidance for materials selection and evaluation requires the understanding of the interactions between materials and the ability to survive normal and abnormal stockpile conditions. Appropriate projects are initiated to evaluate the compatibility of new material combinations in accelerated aging tests, to design appropriate moisture control for the entire PRESS/CM system, to determine molten metal interaction 
rates, and to evaluate lightning burn through resistant coatings for exclusion region materials. These activities are coordinated with the corporate activities for Reliability, Safety, Security, Production, Enhancements for Enduring Stockpile, including Manufacturing, Electrical \& Electronic MCM related Materials Issues where ever possible. Materials analysis and testing, including mechanical property and fatigue testing, and microstructureproperty relationships for solid and foamed/porous materials are provided as needed.

Keywords: Metals, Coating, Composite, Failure, Melting, Net Shape, Packaging

300. Materials Replacement Engineering for the Stockpile

$\underline{\text { FY } 1994}$

DOE Contact: G. J. D'Alessio, (301) 903-6688

$\$ 1,084,000$

SNL Contact: Bennie C. Odegard, (510) 294-2789

Components are regularly remanufactured and replaced in weapons system in the stockpile for a number of reasons, including the designed limited lifetime for special components such as neutron generators. Because of environmental, safety and health considerations, old technologies no longer available, and the ability to upgrade the performance of non-nuclear components, new materials and processes are needed to support the Stockpile Management Program. Engineering has been done to incorporate MDA-free epoxies in encapsulant applications, provide support from development through specification for foams and rubbers, procure o-rings, correct cleaning activities for environmental protection, and provide materials and process consulting for the reclamation of returned hydrogen reservoirs. There have been a wide range of support services provided including radiography, metallography, chemical analysis, surface analysis, welding, and metal finishing.

Keywords: Metals, Corrosion, Cleaning, Coating, Failure

\section{SMARTWELD}

FY 1994

$\$ 131,000$

DOE Contact: G. J. D'Alessio, (301) 903-6688

SNL Contact: Kim W. Mahin, (505) 844-2222

SMARTWELD is a concurrent engineering system which integrates product design and processing decisions within an electronic desktop engineering environment. It is being developed to provide the designer with transparent access to people, information tools and past experience. Empirical understanding along with process models are synthesized within a knowledge-based system to identify the best fabrication procedures based on cost, schedule, performance or environmental impact. Integration of process simulation tools with design tools will enable the designer to rapidly assess a number of design and process options on the computer, rather than on the manufacturing floor. Task models and generic process models are being embedded within user friendly graphical user interfaces to enable 
customers to use the system without extensive training. The integrated system architecture under development will provide interactive communications and shared application capabilities across a variety of workstation and PC-type platforms locally and at remote sites.

Keywords: Metals, Bond, Joining, Modeling, Weld

302. Advanced Gas Transfer Materials Studies

FY 1994

DOE Contact: G. J. D’Alessio, (301) 903-6688

$\$ 474,000$

SNL Contact: Bernice E. Mills, (510) 294-3230

For improved gas transfer systems, materials development supports the component engineers in materials processing, characterization, and cleaning studies. The performance of gas transfer systems strongly depends on the properties and compatibility of gas storage materials. The aging behavior of materials is also critical to the reliability of gas transfer systems. Our project is designed to address these issues by developing processes and establishing WR specifications for new materials with well-characterized properties to be used for gas transfer systems. We are also developing cleaning procedures for these materials through concurrent engineering with the design engineers.

Keywords: Organics, Gas-Transfer, Aging, Cleaning, Materials Characterization

303. Inertial Confinement Fusion Target Fabrication

FY 1994

DOE Contact: G. J. D’Alessio, (301) 903-6688

$\$ 475,000$

SNL Contact: James H. Aubert, (505) 844-4481

In this project we have developed materials and fabrication techniques to prepare complex targets for Sandia's inertial confinement fusion program (ICF). This program is studying the interactions of energetic lithium ions, produced in Sandia's particle beam fusion accelerator (PBFA II), with materials and the resulting radiating plasmas. The recent campaigns involved targets composed of $1 \mu \mathrm{m}$ thick gold wall hohlraums containing a very low density foam, $0.005 \mathrm{~g} / \mathrm{cm} 3$. The gold is fairly transparent to the high energy lithium ions but the foam is efficient at stopping them and adsorbing their energy. Hohlruam temperatures as high as $60 \mathrm{eV}$ were obtained. In the future, such hot plasmas will be used to drive fuel capsules contain deuterium and tritium fuel.

Keywords: Organics, ICF, Fabrication, Foam, Foil 


\section{Instrumentation and Facilities}

\section{Noninvasive Blood Alcohol Monitor}

FY 1994

DOE Contact: G. J. D’Alessio, (301) 903-6688

$\$ 135,000$

SNL Contact: Ann M. Bouchard, (505) 845-0552

Current methods for the quantitative analysis of blood alcohol is accomplished through so-called "breathalyzers." For a variety of reasons, these instruments are unreliable and sometimes inaccurate. We have developed a method for using near infrared spectroscopy through the finger combined with chemometrics for data analysis which can determine the alcohol concentration in a patient's blood noninvasively. The methods to reduce this to commercial feasibility are currently being investigated.

Keywords: Analysis, Spectroscopy, Chemometric

305. Noninvasive Blood Glucose Monitor

FY 1994

DOE Contact: G. J. D’Alessio, (301) 903-6688

$\$ 600,000$

SNL Contact: James A. Borders, (505) 844-8855

There are currently 2.5 million diabetic patients in the United States who must monitor the glucose concentrations in their blood. Compliance is poor due to the pain of drawing blood. Improved compliance would result in a decrease in the secondary effects of diabetes which are the most debilitating and costly. We have developed a method for using near infrared spectroscopy through the finger combined with chemometrics for data analysis which can determine the glucose concentration in a patient's blood noninvasively. A fully funds in CRADA has been established with Rio Grande Medical Technologies to commercialize the technology in partnership with the University of New Mexico School of Medicine.

Keywords: Analysis, Spectroscopy, Chemometric

306. Laser Welding Diagnostics

FY 1994

DOE Contact: G. J. D'Alessio, (301) 903-6688

$\$ 150,000$

SNL Contact: Marcelino Essien, (505) 845-0574

In order to optimize the laser welding process, it is necessary to characterize the propagation of the laser beam and the interaction of the beam with the metal. Critical to this optimization are knowledge of the laser parameters and a knowledge of the response of the metal to the laser radiation. Characterization of continuous-wave and pulsed 
Nd:YAG laser beams is a central focus of this project, as well as a study of the propagation of these laser systems through focusing optics. This projects entails characterization of Nd:YAG laser radiation in terms of pertinent laser parameters, as well as identification of the factors which limit the focusibility of the laser radiation, including plume refraction of the laser beam.

Keywords: Metals, Optics

Materials Preparation, Synthesis, Deposition, Growth or Forming

307. Advanced Materials for Biomedical and Aerospace

Applications

FY 1994

$\$ 350,000$

DOE Contact: Maurice Katz, (202) 586-5799

SNL Contact: Richard K. Brow, (505) 845-8047

Advanced aerospace electronic components and commercial biomedical electronic components, such as pace makers, require glasses which are capable of forming reliable hermetic seals with titanium metal. Currently, the compositions of most commercial sealing glasses are based on silicates which undergo deleterious interfacial reactions with Ti metal thus rendering them unreliable. Consequently, the development of such technologies is hampered by the lack of appropriate commercial sealing glasses. We have, however, discovered that certain glasses whose compositions are based on borates offer considerable advantages over silicates. We are currently working on (1) the development of new borate based sealing glass compositions, (2) the appropriate sealing technologies and (3) the manufacturing of reliable hermetic titanium glass-to-metal seals.

Keywords: Ceramics, Glass, Electronic, Modeling, Packaging, Structure

308. Biomimetic Processing of Oriented Crystalline Ceramic Films

FY 1994

DOE Contact: Maurice Katz, (202) 586-5799

$\$ 300,000$

SNL Contact: Michael J. Hurst, (505) 845-0809

The performance of optoelectronic ceramic films for optical memories, computers, and displays depends on crystalline, oriented material. Biomimetic growth, Nature's pathway for fabricating oriented films, uses an organic template to nucleate inorganic crystals, e.g. protein-controlled growth of bone. In our biomimetic technique to grow oriented cadmium sulfide (CdS) on gold-coated silicon, Langmuir-Blodgett (LB) films of cadmium stearate serve as a $100 \mu$-thick organic template, and CdS grows on the LB film from solutions with 
the assistance of an alternating electric field. Atomic force microscopy reveals that $\mathrm{CdS}$ crystals are templated to the underlying LB film.

Keywords: Ceramics, Biometric, Film, Membrane

309. Novel Approach to the Production of Thick, Patterned Diamond Films

FY 1994 $\$ 200,000$

DOE Contact: Maurice Katz, (202) 586-5799

SNL Contact: Michael J. Hurst, (505) 845-0809

Thick, stress-free diamond coatings and free-standing pieces with tailored surface topographies can be formed economically in short processing time by adapting techniques developed for thick-film screen printing. We used artificial diamond powder precursors from diamond ink, then densified this powder deposit in a chemical vapor deposition (CVD) diamond reactor. A number of factors define limits of the product. The porosity of the powder has a major effect on the in the CVD reactor: high density precursors with small pores densify more readily. System geometry and operating conditions are important to the amount of diamond relative to other forms of carbon present. Variations in the fluorescence bands indicate silicon and boron impurities (from the doped substrate) and defects in the diamond lattice. Under some conditions we observed the growth of euhedral, homogeneous, $20 \mu \mathrm{m}$-diameter diamond spheres and hemispheres.

Keywords: Ceramics, Diamond, CVD, Film

\section{Scalable, Flat-Flame Technology for the Synthesis of Diamond Films}

FY 1994

$\$ 415,000$

DOE Contact: Maurice Katz, (202) 586-5799

SNL Contact: Kevin F. McCarty, (510) 294-2067

We are developing a combustion technology that can be scaled to manufacture diamond films of arbitrary size. Flat-flames based on inherently scalable stagnation flows give rapid and uniform diamond growth. A novel flow manifold, called a "trumpet bell," is used to produce all the ideal properties of an infinite stagnation flow, but on a finite scale that maximizes the use of reagent gas. Computational modeling is used to understand and optimize the deposition process and to investigate potentially advantageous but high risk processes. In the near future, we will take our technology to the point where it can be quantitatively evaluated against competing technologies.

Keywords: Ceramics, Diamond, Film, Modeling 
311. Surface, Interface, and Bulk Properties of Advanced Ceramics

FY 1994

$\$ 179,000$

DOE Contact: G. J. D'Alessio, (301) 903-66i88

SNL Contact: Kevin F. McCarty, (510) 294-2067

The major focus of this program is the synthesis of novel thin ceramic films using pulsed laser deposition. We strive for a fundamental understanding of the film growth process, including the microscopic mechanisms controlling phase selection in the boron nitride system. In addition, we study the microstructure, phonon spectrum, and electronic defect structure of advanced ceramics with emphasis on ultrahard materials and wide bandgap semiconductors. We emphasize the techniques of Raman spectroscopy, infrared spectroscopy, photoluminescence, and transmission electron microscopy.

Keywords: Ceramics, Nitride, Film, Microstructure

312. Synthesis and Microstructural Development of Oxide Thin Films

FY 1994

DOE Contact: G. J. D'Alessio, (301) 903-6688

$\$ 345,000$

SNL Contact: Duane B. Dimos, (505) 844-6385

Sol-gel processing is a versatile technique for fabricating multicomponent oxide thin films. To develop an intelligent approach to sol-gel processing, the effects of various ligands, chelating agents, and solvents are studied. Furthermore, side reactions and hydrolysis that occur in solution need to be taken into account. These solution effects are being studied for three model multicomponent perovskite systems, $\mathrm{Pb}(\mathrm{Zr}, \mathrm{Ti}) \mathrm{O}_{3}$, $\mathrm{Pb}(\mathrm{Mg}, \mathrm{Nb}) \mathrm{O}_{3}$ and $(\mathrm{Ba}, \mathrm{Sr}) \mathrm{TiO}_{3}$. In addition, the performance and reliability of devices based on ferroelectric thin films depends on producing films with optimized microstructures. The main issue that governs microstructural development of these films is control of the nucleation and growth of the perovskite phase. The influence of the substrate on nucleation and growth are determined by studying microstructural evolution of $\mathrm{Pb}(\mathrm{Zr}, \mathrm{Ti}) \mathrm{O}_{3}$ films as a function of substrate type, morphology, orientation, and grain size. To achieve additional control of film microstructure, the effects of firing conditions (temperature, heating rate) and processing environments (oxygen partial pressure, lead partial pressure) are also investigated.

Keywords: Ceramics, Ferroelectric, Film, Sol Gel 
DOE Contact: Maurice Katz, (202) 586-5799

$\$ 356,000$

SNL Contact: Carol L. Jones Adkins, (505) 845-9119

Supercritical fluids such as $\mathrm{H}_{2} \mathrm{O}, \mathrm{CO}_{2}, \mathrm{NH}_{3}$, etc., have unique solvation properties that make them appealing for the synthesis of materials that cannot be made by conventional means. If a solute-laden supercritical fluid is rapidly expanded through a nozzle, a powder is produced as the fluid expands. The rapid expansion of the fluid can lead to the production of unusual, nonequilibrium phases of the solute that might prove to be more readily sinterable. This technique combines the benefits of gas-phase powder synthesis with the high throughputs possible using spray technology. Waste minimization is automatic since the working fluid can be recycled. We are exploring the use of supercritical fluids to synthesize novel (e.g., ultrafine, more reactive) ceramic powders. The synthesis and reactivity of materials leading to the formation of ceramic powders in supercritical water is being investigated. In addition, we are examining the possibility of using surfactants to facilitate the formation of ceramics of interest in supercritical carbon dioxide -- a easier supercritical fluid to work with.

Keywords: Ceramics, Synthesis, Powder, Super Critical

\section{Advanced Brazing Technology Development}

FY 1994

DOE Contact: G. J. D'Alessio, (301) 903-6688

$\$ 200,000$

SNL Contact: John J. Stephens, (505) 845-9209

This program is aimed at developing the technology required to manufacture ultra high reliability nuclear weapons hardware. Included in this program is a project that will develop and characterize active metal brazing processes and materials for hermetic cermet/metal braze joints. Other projects characterize and correlate the microstructure in titanium alloy braze joints with the resultant mechanical properties, and characterize the evolution of braze joint microstructure subject to long time, high temperature environments.

Keywords: Metals, Joining, Alloy, Bond, Braze, Microstructure, Modeling

315. Advanced Laser Processing Technology

FY 1994

DOE Contact: G. J. D’Alessio, (301) 903-6688

$\$ 150,000$

SNL Contact: David M. Keicher, (505) 845-8365

The goal of this project is to develop a fundamental understanding of the process controlling parameters associated with laser welding, soldering, and machining. Specific 
tasks include: calorimetric study of energy transfer during laser welding of aluminum alloys and stainless steels, design and development of frequency multiplied solid state laser systems, the development of unique laser focusing optics for specific applications, and optics modeling of the spatial distribution of laser energy for commercial focusing optics.

Keywords: Metals, Joining, Laser, Modeling, Solder, Weld

316. Advanced Welding Technology

FY 1994

$\$ 500,000$

DOE Contact: G. J. D'Alessio, (301) 903-6688

SNL Contact: Phillip W Fuerschbach, (505) 845-8877

This program is aimed at developing the technology required to manufacture ultra high reliability nuclear weapons hardware. Included in this program are projects that will model the solidification and mechanical behavior of weld joints, assess the weldability of advanced gall-resistant stainless steels, establish a process for friction joining metals to ceramics, and develop a model for energy transfer efficiency during $\mathrm{CO}_{2}$ and Nd:YAG laser welding of stainless steel and aluminum alloys.

Keywords: Metals, Weld, Joining, Laser, Microstructure

317. Development of Novel Laser Coating and Joining Technology

FY 1994

DOE Contact: J. L. VanFleet (202) 586-5782

$\$ 180,000$

SNL Contact: David M. Keicher, (505) 845-8365

Laser deposition of metallic materials is an emerging technology which will allow material properties of various hardware components to be tailored to specific requirements. Hard, wear resistant surfaces can be selectively deposited onto ductile components to enhance the lifetime of these components without compromising the overall metallurgical properties of the entire component. Other materials can be deposited to enhance corrosion resistance, weldability, etc. The localized heating properties associated with lasers allow materials to be deposited with a minimum heat affected zone or alloying in the base material. As part of this effort, we have now established a capability at Sandia to perform laser powder deposition in a controlled atmosphere. We are presently performing tests to evaluate our system and then will use statistically designed experiments to develop response surface models of the laser deposition process. These results will lead to a fundamental understanding of the process and identify key parameters for use in process control. This technique will allow placement of metal during manufacturing to obtain high strength welds 
on weapons hardware and allow development of near-net shape components from powder metals. This project is a CRADA with Pratt \& Whitney.

Keywords: Metals, Alloy, Coating, Corrosion, Joining, Laser, Net Shape, Surface, Weld

318. Electro-Slag Remelting - Fundamentals and Controller Development

FY 1994

DOE Contact: J. L. VanFleet, (202) 586-5782

$\$ 1,175,000$

SNL Contact: M. Eric Schlienger, (505) 845-3105

Electro-Slag Remelting is a melt refining process used by the Specialty Metals Processing Consortium members to remove unwanted impurities from high performance steels and nickel-based alloys. The process melts an electrode suspended in a bath of molten slag which is heated by passing current from the electrode through the slag and into an ingot, formed below the slag pool. This project includes research into fundamental process phenomena and application to design and optimize process controls. Aspects of the process such as current pathways, impedance spikes, slag metal interfaces, and fluid flows can significantly impact process stability. Lack of stability can cause solidification defects and ingot surface quality problems, both of which affect product yield. The goal of this project is to derive and optimize process control methodologies to extend the operating window for process stability. Laboratory and industrial experiments are combined with process modeling to optimize process controls.

Keywords: Metals, Melting, Modeling

319. FASTCAST Rapid Prototyping Development

FY 1994

DOE Contact: J. L. VanFleet, (202) 586-5782

$\$ 250,000$

SNL Contact: Michael C. Maguire, (505) 845-3105

Rapid prototyping technologies have developed dramatically over the past several years. The ability to rapidly produce a functional representative of a design in a day is now a reality. However, to use these parts in the investment casting process requires substantial process development. The use of stereolithography or selective laser sintering, two of the most advanced technologies for rapid prototyping, in investment casting has resulted in significant lead time reduction for first run parts. This project was focused on how to incorporate the new pattern materials into investment casting, improvements in build parameters and post processing to improve surface finish, and dimensional accuracy studies to benchmark the performance of these processes.

Keywords: Metals, Fastcast, Net Shape 
320. FASTCAST Software Development and Experiments

FY 1994

$\$ 750,000$

DOE Contact: G. J. D'Alessio, (301) 903-6688

SNL Contact: Michael C. Maguire, (505) 845-3105

The FASTCAST consortium was formed this year from 17 industrial partners to advance the science of investment casting process simulation, and to improve the performance of rapid prototyping technologies. The work to achieve these goals started in 1990 with the development of an integrated software environment to combine casting design, simulation, and production. The ultimate goal of the project is to provide software and hardware solutions to member companies that will improve the quality and reduce the lead time for investment castings.

Keywords: Metals, Fastcast, Modeling

321. Lightweight Materials for Automotive Applications

FY 1994

DOE Contact: J. L. VanFleet, (202) 586-5782

$\$ 560,000$

SNL Contact: Michael C. Maguire, (505) 845-3105

This is a multi-lab CRADA with General Motors, Sandia National Laboratories, Oak Ridge National Laboratory, and Lawrence Livermore National Laboratory. Each laboratory has an individual CRADA with GM. There is a increasing demand both in the automobile industry and the weapons community for new alloys and processes for production of lightweight, wear resistant aluminum castings. The resulting casting can be used effectively to reduce size, fuel consumption, and weight while maintaining crash worthiness and performance standards. Sandia is studying the casting production processes by evaluating porosity in green sand cast aluminum over varying casting conditions, using fusible salt cores to produce localized regions of increased wear resistance, and using real-time X-ray radiography to validate gating design and modeling efforts to predict mold filling.

Keywords: Metals, Alloy, Melting, Microstructure, Porosity, X-ray

322. Materials Projects in the Former Soviet Union

FY 1994

DOE Contact: G. J. D’Alessio, (301) 903-15688

$\$ 660,000$

SNL Contact: Frank J. Zanner, (505) 845-3085

During the past year a program was funded and implemented to invest in science and technology in the former Soviet Union (FSU) for the purposes of commercialization. For Sandia's part of this US Lab-to-FSU Institute program, 20 contracts were written with Russian Institutes and 10 contracts were written with Ukrainian Institutes to work on 
materials technologies involving coating processes and metals processing. These contracts were placed and the work is currently underway.

Keywords: Metals, FSU, Coating, Liquid Metal Processing

323. Materials Projects in the Ukraine and Russia

FY 1994

$\$ 870,000$

DOE Contact: G. J. D'Alessio, (301) 903-6688

SNL Contact: Frank J. Zanner, (505) 845-3085

Under the auspices of the Specialty Metals Processing Consortium (SMPC), materials technology projects of interest to SMPC members were initiated with Ukrainian and Russian Institutes. These projects include porous metal technology, Alloy 718 phase relationships, and characterization of $\mathrm{Al}-\mathrm{Si}$ hypereutectic alloys at the Dnepropetrovsk Metallurgical Institute in Dnepropetrovsk, electron beam casting of fine grain ingots at the Paton Electric Welding Institute in Kiev, measurement of liquid metal temperature with a sapphire window at the Institute of Foundry Problems in Kiev, and gyrotron microwave processing technology at the Institute of Applied Physics in Nizhniy Novgorod. As the equipment and technology is received from Russia and the Ukraine it will be tested in SMPC member plants.

Keywords: Metals, FSU, Liquid Metal Processing, Microwave Processing, Sensors

324. Solidification Studies

FY 1994

DOE Contact: G. J. D'Alessio, (301) 903-6688

$\$ 114,000$

SNL Contact: James A. Van Den Avyle, (505) 845-3105

The process response and performance of nickel-base superalloys are strongly affected by their solidification structures, as characterized by microstructural scale, amounts of microconstituents, overall homogeneity, extent of micro and macrosegregation, and occurrence of solidification defects. Solidification processes such as ingot growth, welding, and casting are carried out under characteristic conditions which produce varying structures. The goal of this study is to characterize the response of a superalloy, Alloy 718, over a wide range of controlled solidification conditions. Experiments are conducted in a controlled directional solidification furnace under thermal gradients and growth rates representative of those observed in industrial scale remelting processes. Microstructural analyses include dendrite structure, compositional variations by X-ray analysis, and distribution of intermetallics and melt defects.

Keywords: Metals, Alloy, Melting, Microstructure, X-ray 
325. Titanium Facecoat Development

FY 1994

$\$ 250,000$

DOE Contact: Maurice Katz, (202) 586-5799

SNL Contact: Michael C. Maguire, (505) 845-3105

The titanium investment casting industry has suffered from the formation of a brittle surface layer on the castings owing to a mold/metal reaction. This brittle layer, termed alpha case, is usually removed by chemical milling. The existence of this layer has limited the use and increased the cost of investment cast titanium parts. This project is aimed at first determining which components of the investment casting mold material contribute to the alpha case, and then develop materials that reduce the formation of the layer.

Keywords: Metals, Net Shape

326. Titanium Nitride Dissolution in Molten Titanium

FY 1994

DOE Contact: J. L. VanFleet, (202) 586-5782

$\$ 200,000$

SNL Contact: Michael D. Baldwin, (505) 845-3105

A common problem associated with the production of titanium alloys is the retention of titanium nitride inclusions through melt processing. These inclusions can act as initiation sites for low cycle fatigue failures in rotating parts for aircraft engines. Research currently being conducted under the Specialty Metals Processing Consortium is directed toward understanding the dissolution kinetics of TilN in molten titanium. The goal of this study is to predict the dissolution rate and characterize the diffusion mechanism. The variables in the study include type and nitrogen content of the TiN seed and time. The study will be conducted using a levitation furnace, computer tomography and microprobe analysis.

Keywords: Metals, Melting, Microstructure, Nitride

327. Vacuum Arc Remelting Process Control

FY 1994

DOE Contact: J. L. VanFleet, (202) 586-5782

$\$ 1,068,000$

SNL Contact: Rodney L. Williamson, (505) 845-3105

Vacuum arc remelting (VAR) is a process used throughout the specialty metals industry in the production of reactive and segregation sensitive alloys. The process must be carefully controlled to minimize or eliminate transient conditions in the solidification zone of the ingot formed during remelting. In general, this is difficult to achieve because of random disturbances in uncontrolled state variables. The goal of this project is to better characterize these disturbances and to design process control responses that minimize their effects on the solidifying ingot, and to transfer this technology to our industrial partners in 
the Specialty Metals Processing Consortium. The problem is being addressed theoretically, using computer simulations, and experimentally, by carrying out both laboratory-scale and industrial-scale experiments.

Keywords: Metals, Alloy, Melting, Modeling

328. Welding and Processing of an Advanced Titanium Alloy

FY 1994

DOE Contact: G. J. D'Alessio, (301) 903-6688

$\$ 200,000$

SNL Contact: Gerald A. Knorovsky, (505) 844-1129

The goal of the project (a CRADA with United Technologies Corp.) is to enhance the commercial and defense application of the advanced alloy under study (Titanium Alloy C, Ti-35V-15Cr) by characterizing its processing metallurgy, weldability and formability. This alloy is of interest because of its atypical (in $\mathrm{Ti}$ alloys) resistance to combustion in combination with attractive high temperature mechanical properties. Despite generally favorable initial experience in secondary processing and welding, a grain boundary separation phenomenon has been encountered in the weld fusion zone and during deformation processing which is as yet incompletely understood. Our investigation of this alloy will employ the tools of differential thermal analysis, weldability testing, kinetic investigations of phase transformation behavior and Analytic Electron Microscopy

Keywords: Metals, Alloy, Joining, Melting, Microstructure, Weld

329. Advanced Materials Synthesis

FY 1994

DOE Contact: G. J. D'Alessio, (301) 903-6688

$\$ 300,000$

SNL Contact: Roger Lee Clough, (505) 844-3492

Microengineered materials offer the possibility of controlling material properties in very specific ways, and should allow the production of advanced materials having higher strength, or controlled porosity. We are developing micro-phase-separated ceramic-polymer ( $\mathrm{SiO}_{2}$-epoxy) composites for encapsulation of electronic components. Compared with conventional composites now in use, these advanced materials offer the advantages of: wider processing latitude, more consistent batch-to-batch properties, and curing chemistry involving non-toxic materials. We are also synthesizing nanoporous silsesquioxane materials which will allow the production of high-efficiency, lower cost battery membranes and hydrogen getters.

Keywords: Organics, Encapsulant, Membrane, Microporous, Polymer 
330. Development of Sticky Foams Without Chlorofluorocarbons

FY 1994

$\$ 200,000$

DOE Contact: G. J. D’Alessio, (301) 903-6688

SNL Contact: Peter B. Rand, (505) 845-8695

Sticky foam is a unique one-container foam developed as a dispensable deterrent to protect nuclear weapons and materials. The original material used dichlorodifluoromethane (R-12) as the solvent/foaming agent. It is necessary to replace the R-12 to protect the ozone layer. Requirements for the replacement include: non flammability, boiling point below $-20^{\circ} \mathrm{C}$, adequate solvent for the resin blend, and slow diffusion through the foam structure to prevent rapid collapse. A wide variety of low boiling halocarbons and hydrocarbons have been evaluated as potential solvent/blowing agents for this foam. The only materials which meet all the requirements were the hydrofluorochlorocarbons such as difluorchloromethane. Resin reformulation was necessary to regain the foam volume stability required for this application. The new hydrochlorofluorocarbon formulations have been evaluated and are ready for use.

Keywords: Organics, Foam, Polymer

331. Engineered Monodisperse Porous Materials

FY 1994

$\$ 320,000$

DOE Contact: G. J. D'Alessio, (301) 903-6688

SNL Contact: Randall S. Saunders, (505) 844-1760

Porous materials are available with pore sizes ranging from Angstroms to hundreds of microns. However, above $1.5 \mathrm{~nm}$ it is difficult to obtain complete control over pore size, size-distribution, and ordering. This project is using the novel properties of block copolymers to create monodisperse, controllable, ordered porous materials spanning the nanoporous range $(2-50 \mathrm{~nm})$. The blocks of a block copolymer want to phase separate from each other but are limited by the chemical attachment. This results in well-ordered, monodisperse, $\mathrm{nm}$-size domains of one polymer surrounded by the other. We are synthesizing block copolymers by Ring Opening Metathesis Polymerization (ROMP). Our synthesis will allow one phase to be crosslinked and the other phase to be either chemically or thermally removed. This will lead to unique nanoporous materials. These materials could impact several technologies including polymer and gas separations, remote sensor and bio-sensor materials, and catalyst supports.

Keywords: Organics, Foam, Microporous, ROMP, Separations 
332. Environmental Conscience Manufacturing Technology

FY 1994

$\$ 672,000$

DOE Contact: G. J. D'Alessio, (301) 903-6688

SNL Contact: Linda A. Domeier, (510) 294-2350

This project consists of two sub-projects: MDA Free Epoxy Formulations and Environmentally Optimized Chemical Processing for CAP Assemblies. For the first subproject, we developed new epoxy formulations with improved properties to replace methylene dianiline (MDA), which is an OSHA regulated aromatic diamine, in epoxy encapsulants, for neutron generators, thermal batteries, and other applications. For the second sub-project, we address the current environmental issues involving chemical processes for cleaning, etching, passivation and plating on heater and gas transfer system CAP assemblies. We identified several ES\&H and stockpile problems concerning hazardous materials and developed processes to eliminate or minimize the use of these materials.

Keywords: Organics, MDA, CAP, ECM, Encapsulant, Gas-Transfer

333. Fullerene-Based Materials

FY 1994 $\$ 420,000$

DOE Contact: Maurice Katz, (202) 586-5799

SNL Contact: Paul A. Cahill, (505) 844-5754

Carbon-in the form or diamond or graphite-provides key properties for many commercial and defense materials technologies. A third form of carbon-the fullerenes-are soluble, roughly spherical molecular form of carbon with the potential to be a building block for new materials. Work this year supported investigations into the fundamental aspects of the chemistry and physics of fullerenes and was focused on four topics: (1) polymer science of fullerenes, (2) experimental investigations of the fundamental aspects of the chemistry of $\mathrm{C}_{60}$ and $\mathrm{C}_{70}$, (3) computational/theoretical models of the relative stability of fullerene derivatives, and (4) measurement of the rotational correlation time constant of $\mathrm{C}_{60} \mathrm{H}_{2}$. Sandia researchers have largely defined the fundamental nature of the chemistry of $\mathrm{C}_{60}$ and $\mathrm{C}_{70}$, and recommended further investigations into the use of fullerenes in composite materials.

Keywords: Organics, Fullerene, Modeling, Polymer 
334. Low-Dielectric Insulating Films for Microelectronics

FY 1994

DOE Contact: Maurice Katz, (202) 586-5799

$\$ 175,000$

SNL Contact: Randall S. Saunders, (505) 844-1760

Thin low-dielectric constant and high-temperature films are used to separate multiple layers of patterned conductors in multichip module packaging. Significant improvements in processing speed could be obtained from the use of lower dielectric constant material. In this project, we obtain lower dielectric constant material by preparing porous polymer films. Since the dielectric constant of air is about 1.0, incorporation of porosity into the insulating film reduces the average dielectric constant in proportion to the amount of porosity. Porous polyimide films are prepared by spin coating polyimide/solvent films and then phase separating the polyimide/solvent film by exposure to a nonsolvent. After removal of the solvent and nonsolvent a porous film results. Control over the porosity is obtained primarily by controlling the phase separation process. We are measuring the complete phase diagram for the ternary polyimide system under study in order to optimize the phase separation process and resulting microporous structure.

Keywords: Organics, Dielectric, Electronic, Foam, Microporous, Packaging

335. Microengineered Materials

FY 1994

DOE Contact: G. J. D’Alessio, (301) 903-6688

$\$ 350,000$

SNL Contact: Tamara A. Ulibarri, (505) 844-5279

Since silicone materials are inherently weak, reinforcement methods are required. However, while current these methods are effective, they are costly since they involve the ex situ preparation of pyrogenic silica and energy intensive mixing steps. Our work seeks to develop a new manufacturing process for reinforced elastomers. The basic strategy is to use our existing knowledge of silica sol-gel chemistry to control the condensation and phase separation of silica produced in a silicone matrix. The project is designed to develop the scientific and engineering knowledge base required for the successful production of in situ silica reinforced silicone elastomers.

Keywords: Organics, Composite, Polymer 
336. Microporous and Composite Materials

FY 1994

$\$ 1,774,000$

DOE Contact: G. J. D’Alessio, (301) 903-6688

SNL Contact: Jill M. Hruby, (510) 294-2596

This activity consists of two independent projects: microporous materials research, and composite materials research. In the microporous materials project, research on the synthesis, processing, and characterization of microporous materials is conducted to achieve the basic knowledge to tailor the structure and properties of the materials. In addition, a fundamental understanding of the materials in their potential applications is also developed. The emphasis is on polymer and carbon materials. Potential applications include electrodes for electrochemical storage, chemical or physical separations, low dielectric materials, encapsulents, etc. In the composite materials project, the activities are centered on (1) understanding improved chemical vapor infiltration processing of carbon-carbon materials, and (2) embedded sensors in organic composites.

Keywords: Organics, Microporous, Composite, Polymer

337. New Adhesive Systems Based on Functionalized Block Copolymers

FY 1994

$\$ 228,000$

DOE Contact: G. J. D’Alessio, (301) 903-6688

SNL Contact: Michael S. Kent, (505) 845-8178

The need to control and optimize the properties of polymer/solid interfaces is critical in a host of technologies. Often the adhesive strength of the interface, the resistance to moisture, and the ability to transfer stress through the interface are critical to the overall performance of the product. Recent evidence indicates that the adhesive failure often occurs a very short distance into the polymer matrix, typically $10-100 \mathrm{~nm}$. This "interphase" region has proved difficult to design from first principles. In this project we are designing and testing (by X-ray and neutron reflectivity) new adhesives systems based upon block copolymers, where one block (A) attaches to the surface while the second block (B) is compatible with and bonds to the polymeric matrix. An important advantage of a block copolymer is that the B block can easily be made long enough to span the weak region of $10-100 \mathrm{~nm}$ and form a strong interlock with the matrix. These systems may lead to improved adhesion and a more systematic design of the interphase region.

Keywords: Organics, Adhesive, Bond, Copolymer, Reflectivity 
338. Organic Electronic and Optical Materials

FY 1994

DOE Contact: G. J. D'Alessio, (301) 903-66i88

$\$ 400,000$

SNL Contact: Roger Lee Clough, (505) 844.3492

Electronic devices are critical parts of weapon systems. The technology for highspeed, advanced capability electronic and optoelectronic materials is advancing rapidly. We are developing organic light-emitting diodes which could make possible the production of large, flat panel displays for computer monitors, video sets, etc. This work involves developing an understanding of the fundamental physics of the light emission process in these devices (particularly charge-transport in the materials), and the synthesis of new polymeric materials designed for longer lifetime in the application. We are also developing resist materials, based on new silylation techniques, which function efficiently in the deepU.V. range, thus permitting smaller feature sizes in microelectronic devices. We are developing new polymeric nonlinear optical materials, for use in interconnects between computer chips, which will make data transmission between chips, in multi-chip modules, more efficient.

Keywords: Organics, Electronic, Electrooptic, Nonlinear, Polymer

339. Polymeric Nonlinear Optical Materials and Devices Development

FY 1994

DOE Contact: J. L. VanFleet, (202) 586-5782

$\$ 355,000$

SNL Contact: Paul A. Cahill, (505) 844-5754

Optical interconnects, for example between chips on a board, between boards in a parallel processor, or between a central database and the home, will require a means of modulating light within a fiber or waveguide. This CRADA with Amoco Chemical Co. combines Amoco's polyimide technology with Sandia's modeling and synthesis capabilities to produce new electrooptical compositions for this emerging optical interconnect market. A change in the market for optical interconnects has forced a change in the direction of this project toward passive interconnects based on Amoco polyimides and a Sandia developed photosensitive dye. This project is focused on the design and fabrication of optical devices such as splitters, bi-directional transmitters, and fiber-to-guide couplers using these new jointly developed compositions.

Keywords: Organics, Polymer, Electrooptic, Modeling, Nonlinear, Optical 
340. Polyphosphaacetylenes: New Organic-Inorganic Electrical Conductors

FY 1994

$\$ 300,000$

DOE Contact: Maurice Katz, (202) 586-5799

SNL Contact: Clifford L. Renschler, (505) 844-0324

A large effort has been expanded worldwide on the development of electrically conducting organic materials. This extraordinary level of interest is due to the high degree of flexibility and control such materials would lend to both electrical and mechanical properties. However, the promise of these materials has yet to be realized, largely due to myriad processing problems associated with the materials classes studied thus far. In this project, we are developing a new class of formable, electrically conducting hybrid organicinorganic materials, the polyphosphaacetylenes, that should display the high conductivity of doped organic conductors with much better processing characteristics. Our approach is to take advantage of the high reactivity of low-coordinate phosphorus-carbon triple bonds under favorable reaction conditions to induce polymerization to form polyene-analogous backbones bearing solubilizing substituents. This project utilizes Sandia's expertise in computer-aided molecular design and hybrid synthesis and characterization.

Keywords: Organics, Electronic, Modeling, Polymer

341. Polysilane Photoresist Technology

FY 1994

$\$ 250,000$

DOE Contact: G. J. D’Alessio, (301) 903-6688

SNL Contact: Clifford L. Renschler, (505) 844-0324

Printed Wiring Boards are used to make the necessary interconnects between integrated circuit chips in modern electronic assemblies for computers, telecommunications, consumer electronics, and military and automotive applications. The photoresists used to define the conductive traces produce large volumes of organic and aqueous waste. A much more environmentally friendly process would result from a resist that could be applied to the board using only an alcohol solvent, and imaged without any further use of solvent. Polysilanes are a class of materials that can be used as self-developing resists,i.e. resists in which the imaging and development steps occur simultaneously via volatilization of the resist material. Working in collaboration with Stanford University, we are developing specific polysilanes that have not been previously synthesized, and whose properties can be optimized for this application. An added advantage of our approach is that the materials produced by the new synthetic method can be made much more safely than conventional polysilanes.

Keywords: Organics, Electronic, Lithography, Packaging, Polymer 
Materials Structure and Composition

342. Phase Identification in a Scanning Electron Microscope

FY 1994

DOE Contact: G. J. D'Alessio, (301) 903-6688

$\$ 304,000$

SNL Contact: Joseph R. Michael, (505) 844-9115

Phase identification is classically accomplished using diffraction, either electron or $\mathrm{X}$-ray. In very small particles or thin films, electron diffraction in a transmission electron microscope is normally used, but this involves time-consuming and sometimes unsuccessful sample preparation. We are developing a method for phase determination by analyzing backscattered electron Kikuchi patterns in a scanning electron microscope using a Sandiadesigned charge-coupled device based detector system. We have shown that the addition of a special electron filter to the CCD detector system permit high quality X-ray Kossel patterns to be obtained. Using this system crystallographic parameters can be measured with an accuracy of better than one part in 10,000 .

Keywords: Analysis, Microstructure, Microscopy, X-ray

343. Pyrolytically Derived Carbon

FY 1994

DOE Contact: G. J. D'Alessio, (301) 903-6688

$\$ 200,000$

SNL Contact: Clifford L. Renschler, (505) 844-0324

This project develops carbon films with well-controlled properties via pyrolitic decomposition of organic polymers. We have developed methods to produce pyrolitic carbon films with well-controlled electrical conductivity, adhesion, and morphology. Applications have been identified in electronic devices, protective coatings, fuel cell fabrication, as well as direct weapon applications. In collaboration with New Mexico State University, we have developed extremely small, robust, carbon film electrodes (termed "nanoband" electrodes) for metals analysis in remote, harsh environments. We recently set "world records" for the smallest volume sample ever characterized electrochemically (500 nanoliters) and the smallest total analyte ever determined electrochemically (500 attomoles of lead).

Keywords: Analysis, Electronic, Polymer 
344. Thin Film X-ray Diffraction Development

FY 1994

$\$ 180,000$

DOE Contact: G. J. D'Alessio, (301) 903-6688

SNL Contact: Michael O. Eatough, (505) 844-7761

Residual strain in thin films can affect the properties of the films. Current methods measure only average strain throughout the film. There are currently no methods for the determination of the anisotropic strain distribution as a function of film depth. Such a capability would particularly benefit the development of nonvolatile optical and electronic memories where thin films are extensively used. Grazing incidence X-ray diffraction is being investigated and a microdiffractometer is being constructed using a two dimensional detector and total reflection collimation for the analysis of 10-1000 micrometer diameter areas. Proof of principle has been attained for this strain profiling technique.

Keywords: Analysis, Diffraction, X-ray

345. X-ray Micro-Tomography

FY 1994

DOE Contact: G. J. D’Alessio, (301) 903-6688

$\$ 300,000$

SNL Contact: Monte C. Nichols, (510) 294-2906

Advanced materials exhibiting micro-nonhomogeneity such as ceramic matrix composites are increasingly used in high technology applications. The fabrication of these materials requires a better understanding of processing variables and how they control the development of the composite microstructure. We have developed high-resolution methods of X-ray tomography to measure density and porosity in such materials. This information can be used to adjust the processing variables to achieve the desired microstructure. A load frame associated with the X-ray tomography apparatus is enabling us to understand the fundamental mechanisms associated with the fracture process in continuous fiber composites.

Keywords: Analysis, X-ray, Microstructure, Porosity

346. Defect Studies of $\mathrm{ZnO}$ Phosphors

FY 1994

DOE Contact: G. J. D'Alessio, (301) 903-6688

$\$ 136,000$

SNL Contact: Duane B. Dimos, (505) 844-6385

Low-voltage phosphor materials for red, green, and blue light are required for improved flat-panel displays. Based on its electrical properties, $\mathrm{ZnO}$ is the most promising candidate material for developing low-voltage phosphors. Fabrication of phosphors requires doping of the $\mathrm{ZnO}$ to suppress the intrinsic luminescence and to enhance luminescence of 
the desired wavelengths. To develop an understanding of the origin of the background luminescence and the role of potentially useful dopants, the defect states of intrinsic point defects and dopants need to be studied. Defect studies using electron paramagnetic resonance and photothermal deflection spectroscopy will be used to determine the defect structures and energy levels of dopants used to enhance electroluminescence of $\mathrm{ZnO}$.

Keywords: Ceramics, Electronic, Optical

347. Containment Materials for Transferable Explosives

FY 1994

DOE Contact: G. J. D’Alessio, (301) 903-6688

$\$ 409,000$

SNL Contact: Steven H. Goods, (510) 294-3274

First-wall materials must be identified for containment vessels that can withstand prolonged exposure to transferable paste explosives, prevent permeation of liquid constituents and function properly on demand for transfer of energetic fluids. We are evaluating the compatibility of energetic fluicls with candidate containment materials. The energetic fluids are constituents of various extrudable explosives developed by Lawrence Livermore National Laboratory. These paste-like explosives consist of explosive particulates (HMX, TATB for example) suspended in mixtures of energetic liquids and are designed to remain extrudable over a wide temperature range for many years. It is important to preclude or minimize interactions between the constituents of the paste and the containment materials since such interactions could result in decreased reliability or failure of the containment vessel as well as intrinsic changes in the flow or explosive characteristics of the paste. This work focuses on one specific paste formulation: RX-52-AE, composed principally of the solid explosive TATB and the energetic liquid, FEFO (BIS-(2-FLUORO2,2-DINITROETHYL) Formal). Compatibility between a number of organic and metallic materials with neat FEFO has been evaluated.

Keywords: Metals, Corrosion, Coating, Embrittlement, Failure

348. Polymer Blends and Interfaces

FY 1994

$\$ 350,000$

DOE Contact: G. J. D’Alessio, (301) 903-6688

SNL Contact: Roger Lee Clough, (505) 844.3492

Preparation of materials through the blending of two or more different polymers offers the ability to tailor materials properties for specific application requirements. However, polymers exhibit very limited solubility in one another, thereby limiting the usefulness of this approach to advanced materials development. A closely related problem involves the adhesion between two different organic materials; here, the interaction of polymer chains at the interface is of paramount importance. We have developed successful 
models for predicting the phase diagrams of polymer blends. This work is being applied to the development of polymer-based additives to enhance the solubility and bondability of polymeric materials. Scattering techniques are being applied to verify the degree of intermixing of polymers at the interfaces of surfaces and phase boundaries.

Keywords: Organics, Adhesive, Modeling, Polymer

349. Polymer Degradation and Lifetime

FY 1994

DOE Contact: G. J. D'Alessio, (301) 903-6688

$\$ 350,000$

SNL Contact: Roger Lee Clough, (505) 844-3492

Prediction of material lifetimes is of extreme importance to the viability of the stockpile. Polymers undergo a steady aging process, which leads to a deterioration of their properties, over the course of years. This deterioration carries with it the potential of failure of the device in which the material is incorporated. Aging predictions, which are based on accelerated aging tests, are prone to incorrect conclusions due to the fact that the nature of the aging process may be fundamentally different under accelerated (laboratory) conditions versus real-world aging conditions. We are developing advanced accelerated aging methodologies based on the use of highly sensitive techniques (microcalorimetry, oxygen consumption) that allow us to monitor degradation rates under both application conditions and accelerated aging conditions. This approach will allow us to verify extrapolations of aging rates based on accelerated tests.

Keywords: Organics, Modeling, Polymer

\section{Materials, Properties, Behavior. Characterization or Testing}

350. Chemometric Development

FY 1994

DOE Contact: G. J. D'Alessio, (301) 903-6688

$\$ 300,000$

SNL Contact: David M. Haaland, (505) 844-5292

Chemometrics involves the use of modern statistical methods to analyze chemical data. The deconvolution of a peak into overlapping constituent peaks and the smoothing of noisy data are very simple and classical examples. At Sandia, we have been working for over 15 years to develop new methods which can increase the information which we can glean from chemical data. Techniques are being developed and refined for the quantitation of chemical species from infrared spectroscopy, for frequency selection in applying multivariate calibration and prediction methods to infrared and near-infrared spectroscopy and for the reduction of data from "two-dimensional" or "hyphenated" methods (e.g. TGAFTIR). We have developed transfer of calibration algorithms to use models developed on 
one spectrometer on another. Applications of the software developed have ranged from more sensitive analysis of gases evolving from explosive components used in missiles to methods for the on line analysis of passivating dielectrics films used on integrated circuits to the instruments for noninvasive blood chemistry determinations.

Keywords: Analysis, Chemometric, Spectroscopy

351. Dismantled Weapon Hardware - Characterization and Analysis

FY 1994

$\$ 180,000$

DOE Contact: G. J. D'Alessio, (301) 903-6688

SNL Contact: William B. Chambers, (505) 844-3849

The waste characterization issues surrounding the disposition of excess component hardware from dismantled weapons are a potential regulatory bottleneck that could impact the dismantlement schedule. The functional design characteristics of complex electronic assemblies are well known, however, the quantitative material composition of electronic parts was not well documented if not specific to the function. Our project has focused on analyzing the chemical and material characteristics of electronic hardware which dictate the disposal options. Inductively Coupled Plasma (ICP) and X-ray Fluorescence spectroscopic analyses have shown that the majority of components tested contain enough lead and cadmium to be considered hazardous solid waste which requires controlled disposal in a chemical waste landfill. Analyses have also shown that these same components contain sufficient precious metal ( $\mathrm{Au}, \mathrm{Ag}, \mathrm{Pd})$ to warrant reclamation through pyrometallurgical processing. The reclamation option provides for a disposal route which is not only economical but promotes waste minimization through material resource recovery.

Keywords: Analysis, Chemical, Metals, Spectroscopy, X-ray

352. Materials Characterization Using Ultrafast Optical Techniques

FY 1994

DOE Contact: G. J. D’Alessio, (301) 903-6688

$\$ 250,000$

SNL Contact: Richard H. Stulen, (510) 294-2070

The long term objective of this task is to apply techniques of optical spectroscopy to the characterization of materials, especially wide band gap materials whose utility can be related to their optical properties. We currently focus on materials used as photoconductive sensors for radiation detectors, and also on novel materials synthesized in a companion task, "Surface, Interface, and Bulk Properties of Advanced Ceramics." Successful application of photoconductive radiation sensors depends critically on the dynamics of charge carriers photogenerated within the bulk of the material; this charge must be efficiently collected if the detector is to function properly. These charge carriers lose energy, evolve into collective pseudoparticles, fall into traps, and recombine in sub-picosecond time scales. Thus we 
utilize ultrashort laser pulses, extending into the femtosecond regime, and ultrafast detectors to determine the detailed dynamics of charge carriers in pure materials, and in those containing dopants, impurities, and defects. The objective of such characterization is to enhance charge collection efficiency by determining the mechanisms limiting the lifetime and mobility of charge carriers in such materials. Also, novel materials synthesized in the companion task are probed via photoluminescence spectroscopy to characterize impurity and structural defects, and to determine band gap structure.

Keywords: Analysis, Semiconductor, Compound, Spectroscopy

353. Materials Identification for Weapon Dismantlement

FY 1994

$\$ 229,000$

DOE Contact: G. J. D'Alessio, (301) 903-6688

SNL Contact: Mark W. Perra, (510) 294-2093

Sandia/California is developing and applying materials chemical analysis methods to obtain needed materials identification for California weapons components. We use these methodologies when we cannot adequately define required information through reviews of drawings, reports and specifications. When ambiguity or uncertainty exists, we assist in materials specification interpretation and provide independent confirmation by analysis of materials to assure the accuracy and integrity of information in the dismantlement database. Sandia/California measures and assesses the significance of service contamination, including residual tritium contamination on and within California weapon components. (The component specifications will not reflect this contamination.) Lastly, we will identify materials from on-site, undocumented development hardware and from WR-like components.

Keywords: Analysis, Chemical, Diffraction, Microscopy, Microstructure, Spectroscopy

354. Metal Deposition on Semiconductor Surfaces

FY 1994

DOE Contact: G. J. D’Alessio, (301) 903-6688

$\$ 150,000$

SNL Contact: Victoria E. Granstaff, (505) 844-8789

Metal contaminant deposition on semiconductor wafer surfaces is a primary cause of defects which leads to lower yields of functional devices from a wafer. Very low levels of metallic impurities in chemicals used in integrated circuit processing can be a source of this contaminant deposition. Understanding the mechanism of deposition may allow easily implemented steps to be taken to reduce or eliminate the deposition. Electrochemical studies have been undertaken to understand these mechanisms. Methods for the analysis of very low level impurities in these chemicals either do not exist or are exceedingly timeconsuming and labor- intensive. New Inductively-coupled-plasma/mass spectrometry 
techniques are being investigated as a relatively rapid method for the quantitation of metallic species to the part/per/trillion level.

Keywords: Analysis, Surface, Chemical

355. Non-Nuclear Laboratory Operation Reconfiguration Support

FY 1994

DOE Contact: G. J. D'Alessio, (301) 903-6688

$\$ 230,000$

SNL Contact: James R. Brangan, (505) 844-1.832

We are supporting the transfer of neutron generator and neutron tube manufacturing from the DOE's Pinellas Plant. This support includes all non-radioactive materials analysis for the development and production of the new and recertified generator and tube components. During FY94, a project plan was developed to allow for the implementation of a materials qualification program that is fully compliant with DOE requirements, addressing the needs for documentation; identifying all applicable requirements, and $\mathrm{QA} / \mathrm{QC}$ needs. In addition, this program seeks the fulfillment of customer needs, defining and designing processes for WR qualification of materials including equipment calibration, identifying the needed resources of manpower and equipment, and teaming with Neutron Generator Manufacturing Facility personnel to provide seamless laboratory support.

Keywords: Analysis, Reconfiguration

356. Process Applications

FY 1994

$\$ 667,000$

DOE Contact: G. J. D'Alessio, (301) 903-6688

SNL Contact: Mark W. Perra, (510) 294-2093

Sandia/California is acquiring, developing, extending and applying materials capabilities required to execute core DP missions in science-based stockpile stewardship, strategic surety and product realization. Specifically, we use materials and process capabilities to quickly diagnose and understand failures in the stockpile, replace limited life components, as well as to maintain, upgrade and dismantle weapons. We support the product realization process for components and subsystems. We develop analytical tools needed to meet DP requirements in production support and problem solving. To understand and validate predictive models of aging stockpile materials, we develop, demonstrate and extend specialized materials characterization tools.

Keywords: Analysis, Chemical, Diffraction, Microscopy, Microstructure, Spectroscopy 
357. A Mechanical Test for Qualifying Ceramic Granules

FY 1994

$\$ 92,000$

DOE Contact: G. J. D'Alessio, (301) 903-6688

SNL Contact: S. Jill Glass, (505) 845-8050

Lightning arrestor connectors (LACs) provide protection for electronic components from over voltages. Ceramic granules which are fabricated from zinc oxide, rutile and lead magnesium niobate-lead titanate, play an important role in the operation of LACs. While these granules must meet specified electrical requirements, there are important mechanical requirements which they must satisfy. They should exhibit sufficient mechanical integrity so that they do not fracture under specified vibrational and shock loading conditions. A loss of granule fragments as a result of fracture could lead to a loss of protection. This project is developing a reliable mechanical test and doing the subsequent testing of the granules to ensure the mechanical integrity of the granules during service.

Keywords: Ceramics, Varistor, Fracture

358. Analysis of Glass Properties for Stockpile Components

FY 1994

DOE Contact: G. J. D'Alessio, (301) 903-6688

$\$ 118,000$

SNL Contact: Richard K. Brow, (505) 845-8047

Glass in stockpile components experiences mechanical stresses which arise from handling and, more importantly, the service environment. The nature of the stresses that arise from handling differ fundamentally from those it experiences during service. One significant problem is the occurrence of surface defects which ultimately affect the reliability of the material since the material can potentially fail at lower than anticipated stresses when handled. Consequently, a need for fractographic analysis is essential in order to get a better estimate of the overall reliability of the material. The nature of the service environment is such that the molecular structure of the glass is affected. Consequently, spectroscopic techniques, such as nuclear magnetic resonance and Raman spectroscopy, are being combined with the studies of the mechanical properties of aged and unaged materials in order to get a better understanding of the behavior of the material and its potential service life.

Keywords: Ceramics, Glass, Fracture, Structure 
359. Electrical and Optical Properties of Ferroelectric Thin Films

FY 1994

$\$ 325,000$

DOE Contact: G. J. D'Alessio, (301) 903-6688

SNL Contact: Duane B. Dimos, (505) 844-63i85

Although psuedo-cubic ferroelectrics can exhibit $90^{\circ}$ domain switching, $90^{\circ}$ switching appears to be suppressed in thin films. However, obtaining $90^{\circ}$ switching is critical for good electrooptic responses. The influence of poteritial constraints, such as grain size, stress, and film thickness, on $90^{\circ}$ switching is evaluated by' varying these parameters and by using X-ray diffraction and optical birefringence measurements to determine the switching characteristics. High-quality ferroelectric thin films are also appropriate for smart electronics applications that require integrated piezoelectric materials. However, initial work suggests that thin films may exhibit smaller piezoelectric responses that bulk ceramics. The influence of thin-film clamping stresses and polarization relaxation on piezoelectric activity are studied. The piezoelectric response is determined directly using optical methods and indirectly using SAW devices. In addition, the effect of microstructure and porosity on electromechanical losses is investigated. Electron paramagnetic resonance studies and bandstructure calculations are used to develop an atomistic description of the ferroelectric behavior of $\mathrm{Pb}$-based ferroelectrics.

Keywords: Ceramics, Electrooptic, Ferroelectric, Film, Piezoelectric, Sol Gel

360. Ferroelectric Read/Write Optical Disc

FY 1994

DOE Contact: G. J. D'Alessio, (301) 903-6688

$\$ 550,000$

SNL Contact: Duane B. Dimos, (505) 844-6385

Optical memories are an important technology for mass data storage because they have very high storage densities, are removable/archivable, and can be used in harsh environments. However, magnetooptic materials, which are the current state-of-the-art for $\mathrm{read} /$ write optical memories, have a variety of technical limitations. Ferroelectric, lead lanthanum zirconate titanate (PLZT) thin films are being developed as an alternative optical memory medium, since they have larger Kerr effects, greater temperature stability, and lower power requirements. To optimize the electrooptic response in a memory, which improves the signal-to-noise ratio, a high reflective coating stack that is compatible with PLZT thin film processing is being developed. Ellipsometry and waveguiding refractometry are used to characterize and optimize the electrooptic response. PLZT 9/65/35 films are also being developed to optimize the intrinsic electrooptic response of the ferroelectric. To permit optical storage at laser diode wavelengths, appropriate photoconductive polymers are 
being evaluated. Finally, light scattering and spatially-resolved electrooptic measurements are being done to characterize the uniformity and optical quality of PLZT thin films.

Keywords: Ceramics, Electrooptic, Ferroelectric, Film, Optical, Sol Gel

361. Lead Magnesium Niobate-Lead Titanate Granules

FY 1994

$\$ 105,000$

DOE Contact: G. J. D'Alessio, (301) 903-6688

SNL Contact: Bruce A. Tuttle, (505) 845-8026

Zinc oxide varistor materials and rutile have been used to fabricate ceramic granules for lightning arrestor connectors (LACs). The granules are an important factor in the reliability and performance of LACs which provide protection for components from over voltages. The granules in a LAC must meet certain requirements. In addition to mechanical integrity, the granules must maintain a certain level of insulation resistance and fast rise breakdown voltage even after prolonged exposure to temperature and humidity. Recently developed granules based on lead magnesium niobate-lead titanate (PMN-PT) offer important advantages relating to reliability over rutile, $\mathrm{ZnO}$ or mixed oxide based granules. Studies are underway to identify composition ranges and processing parameters that will ensure the reliable production of PMN-PT granules that will offer improved performance over granules currently used in LACs.

Keywords: Ceramics, Varistor, Electronic

362. A Novel Technique for the Mechanical Characterization of Thin Films

FY 1994 $\$ 307,000$

DOE Contact: G. J. D'Alessio, (301) 903-6688

SNL Contact: Roy J. Bourcier, (505) 844-6638

We are developing novel test methods, through the combined use of ultralow load mechanical testing and large-strain finite element analysis, which will accurately characterize the elastic and plastic mechanical response of thin films. The accurate characterization of film properties will help guide film alloy development efforts and improve prediction of film behavior in engineering components. In developing these test methods, we are using micromachining techniques to fabricate isolated film features which are being mechanically tested using our ultralow-load indentation test system. Finite element analysis has been employed to optimize the design of the geometric features of the film to be tested. Finite element analysis will also be used, as necessary, to deconvolute the observed test specimen response to extract the constitutive response of the film. This test method will have an 
immediate impact on our ability to understand the behavior of IC interconnect metallizations, the mechanical response of micromachined devices, and the characterization of ion implanted films.

Keywords: Metals, CVD, Failure, Film, Fracture, Modeling, Packaging, Surface

363. Development of Alternatives for Lead Based Solders

FY 1994

$\$ 278,000$

DOE Contact: J. L. VanFleet, (202) 586-578.2

SNL Contact: Paul T. Vianco, (505) 844-3429

The objectives of this CRADA project (with NCMS) are to evaluate and select alternative alloys for lead-based solders used for electrical and electronic assembly interconnections. These alternative alloys will have physical and electronic properties selected for specific applications. The selection of candidate lead-free solder alloys for evaluation will be based on several factors including technical, economic, environmental, and human factor considerations.' Additionally, the selected alloys will be required to meet performance requirements at operating environments from $-70^{\circ} \mathrm{C}$ to $180^{\circ} \mathrm{C}$. Sandia will perform most of the initial alloy design, preparation, and screening and will assist the industrial participants in assessing manufacturing issues pertaining to the new alloys. This includes model joint testing, test hardware development and manufacture, environmental stress testing, and testing of manufactured printed wiring boards.

Keywords: Metals, Solder, Alloy, Joining, Joint, Packaging

364. NCMS Printed Wiring Board Surface Finishes Program

FY 1994

$\$ 650,000$

DOE Contact: J. L. VanFleet, (202) 586-5782

SNL Contact: Frederick G. Yost, (505) 844-5278

The goal of the Printed Wiring Board Interconnect Systems Program is to develop advanced technology to enable the U.S. Printed Wiring Board (PWB) industry to maintain its position at the leading edge of this crucial technology. The program addresses critical areas of generic, pre-competitive technologies needed to enable the utilization of next generation electrical components. As the operating speed and number of interconnections of individual electronic devices has increased, PWB technology has been challenged to keep pace and the fundamental limits of existing PWB manufacturing technologies are becoming increasingly apparent. The Surface Finishes component of this program emphasizes development of solderability test methodologies and development of "leap frog" technologies that provide more robust assembly processes with a more benign environmental impact. The Surface Finishes project activities are divided into 5 parts. Solderability Assessment focuses on solderability measurement and understanding the fundamental aspects of wetting 
behavior. Solderable Finish Stressing explores the results of aging and accelerated stressing on the shelf life of PWB surfaces. Baselining and Benchmarking attempts to compare PWB product from the participating companies in order to facilitate improvements. Surface Finish Improvements seeks to implement identified process enhancements. Surface Finishes for New Assembly Technologies anticipates emerging assembly technologies, such as Ball Grid Array technology, and investigates new and compatible surface finishes.

Keywords: Metals, Solder, Coating, Modeling, Packaging, Surface

365. Specialty Metals Product Characterization and Quality

FY 1994

$\$ 695,000$

DOE Contact: J. L. VanFleet, (202) 586-5782

SNL Contact: James A. Van Den Avyle, (505) 845-3105

This project, conducted for the Specialty Metals Processing Consortium (SMPC), addresses issues of ingot and final product quality for alloys produced by vacuum arc remelting or electroslag remelting processes. The effort includes metallurgical ingot analyses to evaluate solidification conditions produced by differing melt control strategies, to verify process modeling predictions, and to study melt defect formation. New X-ray analytical techniques to measure ingot composition variations are being developed. The project includes fundamental studies of micro-scale solidification processes and how they relate to melt defect formation. To assess the final product quality of Alloy 718 billets, the effects of solidification defects on fatigue properties are being evaluated.

Keywords: Metals, Alloy, Melting, Microstructure, Modeling, X-ray

366. Welding of AerMet 100

FY 1994

$\$ 225,000$

DOE Contact: J. V. VanFleet, (202) 586-5782

SNL Contact: Charles V. Robino, (505) 844-6557

AerMet 100 is a recently developed high strength, high fracture toughness alloy designed for use in structural components in aerospace applications. The alloy is basically a precipitation hardenable martensitic steel with strength levels exceeding that for AF 1410, while toughness is intermediate between AF 1410 and Marage 250. As a result of this combination of very high strength and toughness, the alloy has a number of potential applications in weapon systems. However, the ability of the welded alloy to meet service requirements for mechanical properties, corrosion resistance, etc., has not been characterized. The suitability of AerMet 100 for application in welded structures, and the processing requirements for confident application, are being addressed in this CRADA. Weld test panels are being fabricated for determination of the effects of weld processing parameters on mechanical properties of the weld fusion and heat-affected zones. In 
addition, weld simulation studies are being used for determination of the kinetics of microstructural evolution in the heat-affected zone. It is expected that knowledge of the kinetics of microstructural changes (and mechanical property changes) will allow for selection of optimal weld processing schedules. (This project is a CRADA with Carpenter Technology Corp.)

Keywords: Metals, Weld, Joining, Steel

367. Carbons for Electrochemical Energy Storage

FY 1994

$\$ 298,000$

DOE Contact: G. J. D’Alessio, (301) 903-6688

SNL Contact: Jill M. Hruby, (510) 294-2596

Advanced concepts for lithium secondary batteries and supercapacitors require microporous carbon materials as an electrode or composite electrode. The advanced batteries and capacitors will enable new power supplies for weapons as well as new surveillance and monitoring techniques. For lithium batteries, the carbon is intercalated with lithium to allow for high energy storage and long lifetimes. For supercapacitors, the carbon serves as an electrode and enables small, lightweight, high capacitance devices to be developed. In this activity we engineered microporous carbons from a variety of polymer precursors, processed the carbons using different conditions, and measured their performance as battery or supercapacitor materials. The most promising carbons were used in prototype devices and the overall component performance measured.

Keywords: Organics, Microporous, Polymer, Carbon

368. Catalytic Carbon Foam Filters

FY 1994

DOE Contact: Maurice Katz, (202)586-5799

$\$ 338,000$

SNL Contact: James C. F. Wang, (510) 294-2786

Activated carbon catalytic foam materials with low back pressure have many applications in the energy generation and storage as well as in waste minimization areas. An example is carbon foam filters that are capable of converting ozone produced in copy machines into harmless oxygen; similar filters may be used for applications in commercial airliners, the space shuttle, and the space stations. Catalytic carbon foams may also be used in converting natural gas into low-polluting liquid fuels for various users such as transportation. This project is to develop manufacturing processes of catalytic carbon filters based on our expertise in engineering of microporous foams for various energy and environment related applications.

Keywords: Organics, Catalytic, Carbon, Filter, Foam 


\section{Chlorinated Polyethylene}

FY 1994

$\$ 358,000$

DOE Contact: J. L. VanFleet, (202) 586-5782

SNL Contact: James H. Aubert, (505) 844-4481

This project includes a CRADA with an industrial partner which is a major producer of chlorinated polyethylene (CPE). The polymer is used as an impact modifier for polyvinylchloride and acrylonitrile-butadiene-styrene copolymer and as an elastomer for wire cable coatings and automotive parts. We are working towards an understanding of the relationship between the molecular structure of CPE (chlorine content, chlorine distribution, molecular weight) and the solid and liquid state structures (phases present, percent crystallinity, crystal structure, morphology). This architecture will then be related to the conditions in the reactor used to produce this product with its' unique properties. In this way we and our industrial partner can utilize these relationships to optimize CPE plant operations and expand their customer base. We are relying on many analytical techniques to develop these relationships including NMR, X-ray and neutron scattering, diffraction, and calorimetry.

Keywords: Organics, Scattering, CRADA, NMR, Polymer

370. High Density Electronic Interconnects

FY 1994

DOE Contact: G. J. D’Alessio, (301) 903-6688

$\$ 890,000$

SNL Contact: Clifford L. Renschler, (505) 844-0324

As integrated circuits with ever larger pin-outs come into use, the interconnect density of printed wiring boards (PWBs) is increasing beyond the point at which current materials and processes can be economically used. In this program, we are working with the National Center for Manufacturing Science and member companies Texas Instruments, IBM, AT\&T, GM-Hughes, United Technologies, and Allied Signal to develop the next generation materials for PWB fabrication. We are working in four general areas in support of this program: enhanced control of plasma processing of boards, improved strength between the copper/resin and glass/resin interfaces, modeling of multilayer boards, and development of board substrates with non-woven reinforcement.

Keywords: Organics, Composite, Electronic, Modeling, Plasma, Polymer 
371. Materials for Improved Tire Technology

FY 1994

$\$ 1,000,000$

DOE Contact: J. L. VanFleet, (202) 586-5782

SNL Contact: Roger Lee Clough, (505) 844-3492

We are working with an industrial partner on a highly integrated program to provide elastomeric materials having improved performance and high reliability. We are working to improve filler-elastomer interaction in conventional materials to enhance durability and mechanical performance. We are developing enhanced methodologies for lifetime prediction of elastomeric materials, based on the analysis of degradation rates and mechanisms under accelerated aging conditions. We are evaluating new filler types, with regard to molecular structure and macroscopic properties. We are applying principles of chemometrics to rapid analysis of materials formulations.

Keywords: Organics, Polymer, Modeling

\section{Application of IRIS to Semiconductor Processing}

FY 1994

$\$ 175,000$

DOE Contact: G. J. D'Alessio, (301) 903-6688

SNL Contact: Clifford L. Renschler, (505) 844-0324

Sandia researchers have recently developed a technique known as IRIS (Imaging of Radicals Interacting with Surfaces). To take an IRIS measurement, a molecular beam is extracted from a plasma and scattered off the substrate of interest while molecules in the beam are simultaneously probed before and after scattering from the substrate with laserinduced fluorescence. IRIS is currently the only technique available, worldwide, to measure the surface reaction probabilities for plasma radicals impinging on a depositing film. Accurately known reaction probabilities are essential for the development of robust plasma process control models of the type that will be required for future computer-controlled, ultra-high throughput semiconductor manufacturing. In a CRADA with Texas Instruments, Inc. (TI), we measured the surface reactivities of the $\mathrm{OH}$ and $\mathrm{NH}$ radicals that are important in the deposition of silicon dioxide and silicon nitride films during integrated circuit manufacture. These data were incorporated into plasma process control models at one of TI's manufacturing facilities. In adldition, we incorporated Sandia's patented gas phase metal precursor sensor technology into TI's process line.

Keywords: Semiconductor, Coating, Film, Plasma 
Lawrence Livermore National Laboratory

Materials Preparation, Synthesis, Deposition, Growth or Forming

373. Engineered Nanostructure Laminates

FY 1994

$\$ 1,300,000$

DOE Contact: G. J. D'Alessio, (301) 903-6688

LLNL Contact: Troy W. Barbee, Jr., (510) 423-7796

Multilayers are man-made materials in which composition and structure are varied in a controlled manner in one dimension during synthesis. Individual layers are formed using atom by atom processes (physical vapor deposition) and may have thicknesses of from one monolayer $(0.2 \mathrm{~nm})$ to hundreds of monolayers $(>100 \mathrm{~nm})$. At this time more than 75 of the 92 naturally occurring elements have been incorporated in multilayers in elemental form or as components of alloys or compounds. In this work deposits containing up to 225,000 layers of each of two materials to form up to $500 \mu \mathrm{m}$ thick samples have been synthesized for mechanical property studies of multilayer structures.

These unique man-made materials have demonstrated extremely high mechanical performance as a result of the inherent ability to control both composition and structure at the near atomic level. Also, mechanically active flaws that often limit mechanical performance are controllable so that the full potential of the structural control available with multilayer materials is accessible. Systematic studies of a few multilayer structures have resulted in free-standing foils with strengths approaching those of whiskers, approximately 70 percent of theory. Also, new mechanisms for mechanically strengthening materials are accessible with nanostructure laminates.

Applications now under development include: coatings for aircraft gas turbine engines; EUV, soft X-ray and X-ray optics spectroscopy and imaging; high performance capacitors for energy storage; capacitor structures for industrial applicatons; high performance tribological coatings; coatings for aircraft gas turbine engines; ultra-high strength materials; integrated circuit interconnects; magnetic transducers/GMR.

Keywords: Thin Films, Multilayer Technology

374. Sol Gel Coatings

FY 1994

$\$ 325,000$

DOE Contact: G. J. D’Alessio, (301) 903-6688

LLNL Contacts: I. M. Thomas, (510) 423-4430 and J. Britten, (510) 423-7653

We continue to investigate the preparation of multilayer sol-gel high reflection (HR) coatings using colloidal $\mathrm{SiO}_{2}$ with either $\mathrm{HfO}_{2}$ or $\mathrm{ZrO}_{2}$. We have found that the 
incorporation of an organic polymer binder such as polyvinyl alcohol or polyvinyl pyrolidinone into the high index component has resulted in an increase in the damage threshold and a decrease in the number of layer pairs required for high reflection.

A laboratory size meniscus coater was evaluated and found to produce mirrors of high optical performance and adequate damage threshold. This is now the preferred method of application, and a large machine capable of producing Beamlet and NIF size mirrors is to be delivered in early FY 1994.

Keywords: Sol Gel Coatings, Meniscus Coater, HR Coatings

375. KDP Growth Development

FY 1994

DOE Contact: G. J. D'Alessio, (301) 903-6688

$\$ 900,000$

LLNL Contact: J. J. DeYoreo, (510) 423-4240

Potassium dihydrogen phosphate (KDP) and its deuterated analog (DKDP) are important nonlinear crystals used both for frequency conversion as well as for a large Pockels cell. These crystals are very expensive, due in part to the very long times required to grow large boules (2-3 years) and the cost of $\mathrm{D}_{2} \mathrm{O}$ for growing DKDP. We are developing alternative growth techniques to dramatically increase the growth rate of these crystals.

In FY93 we adopted a new growth technique with which we are growing both KDP and DKDP at 10 to 20 times the rates achieved with conventional methods. We have grown crystals up to $15 \mathrm{~cm}$ on a side and have shown that crystals grown by this method are of exceptionally high quality. We have recently completed a station for the growth of $50 \times 50 \times 50 \mathrm{~cm}^{3}$ crystals and are currently testing its capabilities. We will continue to grow crystals at the $10-15 \mathrm{~cm}$ scale in order to determine optimum hydrodynamic and regeneration conditions.

Keywords: KDP, Nonlinear Crystals, Crystallization

376. Advanced Finishing Development

FY 1994

DOE Contact: G. J. D'Alessio, (301) 903-6688

$\$ 300,000$

LLNL Contact: J. S. Taylor, (510) 423-8227

Advanced optical fabrication methods will be utilized to finish optical surfaces in advanced ICF laser architectures. We are working to understand the effect of finishing parameters on optical surface characteristics, including subsurface damage and resulting damage threshold. We are also developing rapid grinding and polishing methods which will 
simultaneously reduce the cost of fabricating optical surfaces while maintaining the high quality necessary for high power laser applications.

In FY93 we began experiments on a newly installed double-sided grinder/polisher. Large versions of this machine can potentially reduce costs for the initial grinding and polishing of flat ICF components. We hope to complete and experimentally verify a model of the fundamental sources of flatness errors for this machine tool. Our model will provide performance predictions of machines that are not commercially available, thus enabling us to evaluate vendor proposals for machine development.

In addition, we will be working with LANL to characterize and optimize the use of synthetic pads as a polishing lap material on continuous polishing machines. Successful development of synthetic pad polishing is of primary importance in our quest to lower fabrication times, and hence costs, of large, precision, flat optics for future ICF lasers.

Keywords: Optical Finishing, Synthetic Pad Polishing, Cost Reduction, Manufacturing, ICF, NIF

\section{Doped Polymers for ICF}

FY 1994

$\$ 50,000$

DOE Contact: G. J. D’Alessio, (301) 903-6688

LLNL Contacts: R. Cook, (510) $422-3117$ and G. E. Overturf III, (510) $422-7280$

This program is developing covalently doped polystyrene derivatives for use as spectroscopic tracers in direct drive laser fusion experiments. The doped polymers are formed into small spherical shells that serve as the mandrel around which the ICF capsule is constructed. The dopant atoms should be atomically dispersed and thus must be covalently incorporated into the structure of the polymer. We have succeeded in producing soluble polystyrene derivatives doped with $\mathrm{Cl}, \mathrm{Br}, \mathrm{I}, \mathrm{Fe}$, and $\mathrm{Cr}$ at levels up to 3 atom percent. Current work focuses on a Ti-doped polymer.

Keywords: Polymers, Dopants, Laser Fusion Targets

378. ICF Capsule Ablators via Plasma Polymerization

FY 1994

$\$ 428,000$

DOE Contact: G. J. D'Alessio, (301) 903-6688

LLNL Contacts: R. Brusasco, (510) 422-3111, R. Cook, (510) 422-3117 and S. Letts, (510) $422-0937$

Our group uses plasma polymerization to prepare conformal coatings of organic polymer for use as ICF capsule ablators. These coatings have some unique and stringent requirements, such as a surface roughness of the order of $10 \mathrm{~nm}$ rms or less and the strength 
to hold fuel pressures of from 50 to 100 atm. This project supports development of methods to incorporate high $\mathbf{Z}$ dopants (e.g., germanium) into the polymer structure, development of coating procedures which efficiently produce useable target mandrels and basic studies to understand the mechanism of roughness evolution during deposition. A coating system with a computer interface has increased production throughput and aided the optimization of the coating process. In addition, new mass spectrometric tools are being used to increase our fundamental knowledge of the deposition mechanisms.

Keywords: Plasma, Polymer, Germanium, Fusion

379. Excimer Laser Micromachining

FY 1994

$\$ 100,000$

DOE Contact: G. J. D’Alessio, (301) 903-6688

LLNL Contact: R. Wallace, (510) 423-7864

This program is developing methods of using pulsed UV excimer laser photoablation techniques to micromachine plasma polymer coatings. Surface perturbations on microshells result in growth of Rayleigh-Taylor (RT) instabilities during the acceleration phases of an ICF implosion. To test current theories of RT growth and its effects on target performance, we are investigating methods of applying known perturbations, depth and mode distribution, to smooth capsules. Due to very high RT growth rates, excimer laser ablation etch rates in the range of a few hundred Ås are required. Micromachining at this level pushes the limits of excimer laser ablation due to low absorbtivity and incubation processes in polymer coatings.

Keywords: Excimer Laser Ablation, Plasma Polymer, Laser Fusion Targets

Materials Properties, Behavior, Characterization or Testing

380. Advanced Synchrotron Radiation Study of Materials

FY 1994

$\$ 200,000$

DOE Contact: G. J. D'Alessio, (301) 903-6688

LLNL Contacts: Joe Wong, (510) 423-6385

The objective of this materials science program is to advance and develop state-ofthe-art synchrotron radiation (SR) methods to investigate and elucidate the role of atomic and electronic structures in determining the physico-chemical properties of materials and their processing. The activities defined in this program take advantage of the various unique characteristics of synchrotron radiation such as high intensity, high collimation, high polarization and broadband tunability from VUV to soft and hard X-ray to probe the structure of matter on an element-selective basis in real-time down to the second and subsecond time scale as well as in real space. The research areas consist of both an expansion 
of our existing SR capabilities in materials characterization using these powerful photon sources and development of new capabilities (a) to investigate the in-situ mapping of phase boundaries in fusion welds; (b) to develop and implement a novel quick-scanning EXAFS capability on our PRT X-ray beamline at SSRL to study time-dependent phenomena, and (c) to develop new soft $\mathrm{X}$-ray capabilities to study low- $\mathrm{Z}$ materials containing $\mathrm{Si}, \mathrm{Al}$ and $\mathrm{Mg}$ that are of technological importance. The latter activity has been awarded a lab-wide LDRD at start of FY94. Since January 1994, Dr. Michael Fröba, a physical chemist recently graduated from the university of Hamburg, Germany, and awarded a prestigious Humboldt postdoctoral fellowship has joined our soft X-ray experimental effort. The theoretical effort in calculating and elucidating the fine structure features in the soft X-ray XANES spectra has been undertaken by Dr. Eiichi Tamura.

Keywords: Synchrotron Radiation, Fusion Welds, Phase Transformation, QEXAFS Monochromator

381. Structural Transformations and Precursor Phenomena

FY 1994

$\$ 169,000$

DOE Contact: C. B. Hillard, (301) 353-3687

LLNL Contact: P. E. A. Turchi, (510) 422-9925

A new class of alloys for which local order alone indicates a near-degeneracy between phase decomposition and order was identified. Our first-principles study showed that, for such alloys prepared in the high temperature disordered state and subsequently quenched inside the miscibility gap, an ordered phase spontaneously forms before evolving, as time progresses, toward phase separation. The microstructural evolution has been fully analyzed. Codes based on modern alloy theory have been developed to study the doping effect on the formation of complex phases. Application to Fe-Ti-V has shown the important role played by atomic orbital directionality in the stability of complex phases.

A time-resolved Auger electron spectroscopy study of statics and kinetics of surface segregation on a (111) $\mathrm{FeCr}$ single crystal, with and without C-doping, was performed. From the X-ray grazing incidence diffraction experiments done on $\mathrm{FeCr}$ single crystals at the NSLS, a strongly first order transition bcc to $\sigma$ was observed below the $\sigma$-transition temperature although no clear indications for a diffuse intensity build up above this temperature could be detected. Our work provided information on the influence of surface contaminants, like $\mathrm{C}$, on the possible surface-induced formation of the $\sigma$ phase in $\mathrm{FeCr}$.

Keywords: Electronic Structure, Phase Stability, Short Range Order, Complex Alloys, Surface Properties 
382. Very High Energy Density Materials

FY 1994

$\$ 1,060,000$

DOE Contact: G. J. D'Alessio, (301) 903-6688

LLNL Contacts: R. L. Simpson, (510) 423-(1379

Office of Munitions (\$700K): We are preparing a variety of explosive formulations to serve in hard structure munitions which are principally comprised of an explosive, oxidizer, aluminum and an energetic binder. They are being evaluated with respect to their performance, safety characteristics, and vulnerability.

LDRD: High Explosive Alloys (\$150K): We are investigating the development of high energy explosives which are made through co-crystallization of energetic components. A highly oxidized molecule is stablized in the lattice with an oxygen deficient molecule.

WSR: Synthesis of TATB (\$210K): Alternate synthesis route to 1,3,5-triamino-2,4,6trinitrobenze (TATB) using picrates instead of 1,3,5-trichlorobenzene.

Keywords: Hard Structure Munitions

383. Interfaces, Adhesion, and Bonding

FY 1994 $\$ 300,000$

DOE Contact: G. J. D'Alessio, (301) 903-6688

LLNL Contact: Wayne E. King, (510) 423-6547

We have developed a unique capability for calculation of the electronic structure at interfaces, where symmetry is reduced compared with the bulk. Specifically, the method, called the real-space multiple-scattering theory (RSMST), can treat interfaces and include the effect of atomic relaxation at the interface. We have coupled this method with the semiempirical embedded atom method (EAM), which uses modified two-body potentials with molecular dynamics, molecular statics, or Monte Carlo techniques to determine atomic rearrangements.

Our experimental effort is producing results that are directly comparable with theoretical calculations. We are investigating planar metal/metal interfaces and metal/ ceramic interfaces (in anticipation of improvements in the theory) of well defined misorientations. In order to span the entire range of length scales described above, macroscopic bicrystals a few millimeters thick, with interfacial areas on the order of a square centimeter will be required. In order to obtain such bicrystals, we plan to employ the diffusion bonding approach. An ultra-high-vacuum diffusion bonding machine has been developed in parallel with this research project.

Keywords: Interfaces, Bonding, Electronic Structure 
384. Laser Damage: Modeling and Characterization

FY 1994

$\$ 400,000$

DOE Contact: G. J. D'Alessio, (301) 903-6688

LLNL Contact: M. R. Kozlowski, (510) 424-5637

We have been working to understand the damage mechanism in thin film coatings used on Nova for a number of years, with the ultimate goal of improving the damage threshold in coatings for future laser systems. In recent years, we have utilized atomic force microscopy (AFM) to characterize laser damage as well as the laser conditioning process which allows coatings to sustain higher laser fluences. We have shown that damage threshold correlates with the density of pre-existing defects, and that nodular defects often damage but that the craters (produced by nodules "popping" out prior to laser irradiation) do not damage.

We have modeled the laser induced electromagnetic fields at "typical" nodular defects in a simple quarter-wave dielectric mirror coating. The model results demonstrated that large field enhancements are produced by these defects, which are composed of the same dielectric material as the coating materials. Previously, it was thought that defects had to be absorbing (either carbonaceous or non-stoichiometric material) to produce the large field enhancements which produce damage. We will use these results to help modify the coating process to avoid the formation or incorporation of these defects into the coating, thereby improving the damage threshold.

Keywords: Coatings, Atomic Force Microscopy, Laser Damage

385. KDP Characterization

FY 1994

$\$ 400,000$

DOE Contact: G. J. D'Alessio, (301) 903-6688

LLNL Contact: J. J. DeYoreo, (510) 423-4240

We require very large, high quality crystals of potassium dihydrogen phosphate (KDP) and its deuterated analogue (DKDP) for present and advanced high power lasers in the ICF Program. The performance of these crystals is limited by strain which induces anomalous birefringence and wavefront distortion. The level of internal strain is the single most important factor in determining the yield of useable plates from an "as-grown" boule. Our goal has been to identify the defects which are the source of strain in KDP and DKDP, understand how these defects are generated and how to avoid them during the growth process.

Using optical, X-ray topographic and crystal growth methods, we have shown that the primary sources of strain are dislocations formed during seed regeneration or following solvent inclusion and inhomogeneous impurity distributions due to anisotropies in growth 
kinetics. Using atomic force microscopy (AFM) we have been able to correlate macroscopic defects associated with regions of strain to the size of the Burgers vectors of dislocation bunches. We are now using these characterization techniques to relate the severity of these defects to the growth conditions.

Keywords: KDP, Strain, Crystal

386. Damage Testing

FY 1994

DOE Contact: G. J. D’Alessio, (301) 903-6688

$\$ 800,000$

LLNL Contact: F. Rainer, (510) 422-4376

We maintain four facilities to measure laser damage thresholds and characterize damage morphologies of optical materials at pulse durations of 3 and $10 \mathrm{~ns}$. We can conduct measurements at the first four fundamental wavelengths of Nd:YAG $(1064,532,355$ and $266 \mathrm{~nm}$ ). We are developing automated techniques to (1) detect laser damage, (2) condition optics to higher thresholds with gradual increases in laser fluence, and (3) monitor laser parameters. These techniques can be applied to small witness samples as well as fullsized optics up to $1 \mathrm{~m}$ in size. We test and document several hundred samples per year, including coatings, crystals, glasses, and the effect of finishing processes on surfaces. This information is in turn utilized to help make important decisions in the development of these materials for ICF laser systems. The ICF Program maintains one of the world's largest databases of damage results for optical materials.

Keywords: Laser Damage, ICF

387. Energy Transfer Dynamics in Energetic Materials

FY 1994

DOE Contact: G. J. D’Alessio, (301) 903-6688

$\$ 120,000$

LLNL Contact: A. Ruggiero, (510) 423-1020

When an energetic material is shocked, optical phonon energy is up-converted to intramolecular vibron modes which ultimately leads to molecular dissociation. The anharmonic potential and energy transfer rate determines, in part, a materials sensitivity. These dynamics are being probed using LLNL's unique femtosecond laser capability and are being modeled using a molecular dynamics approach.

Keywords: Explosive, Laser, Dynamics 
388. Processing-Structure-Property Correlation in Laminated Metal Composites

FY 1994

$\$ 169,000$

DOE Contact: C. B. Hilland, (301) 353-3687

LLNL Contact: Chol K. Syn, (510) 534-8226

Alternating layers of metals (e.g., Al 5182) and metal matrix composites (e.g., Al 6061$25 \mathrm{vol} . \% \mathrm{SiC}$ ) are to be press-bonded with heavy deformation to form laminated metal composites with strength, toughness, and other properties far superior to those of the constituent materials. Interfacial bonding strength and microstructure will be correlated with the processing parameters and mechanical properties and the mechanical properties will be modelled using the Laboratory's finite element codes.

Keywords: Laminated Metal Composites, Deformation Bonding

Instrumentation and Facilities

389. Scanning Tunneling Microscopy (STM) and Atomic Force Microscopy (AFM)

FY 1994 $\$ 390,000$

DOE Contact: G. J. D'Alessio, (301) 903-6688

LLNL Contact: W. Siekhaus, (510) 422-6884

A small building standing separate from noise-generating machinery and hence having a low natural vibration background, has been refurbished to house all scanning probe instrumentation. The large stage scanning probe microscope that can perform scanning tunneling as well as contact and non-contact atomic force microscopy on the surface of objects as large as 6" in diameter, a small-stage non-contact AFM and STM, and a newly acquired ultra-high vacuum instrument that can perform non-contact AFM and STM measurements and STM spectroscopy (STS) have been moved into that facility.

UHV STM has been used to determine the XeF2-Si etching mechanism and its rate at room temperature and to perform nonolithography, i.e., creating $\mathrm{nm}$-scale $\mathrm{SiO}_{2}$ lines on $\mathrm{Si}$. A new technique, nanostethoscopy, has been developed and used to determine the onset of biological biomechanical activity during the development of brine shrimp for cyst to nauplius. Nm-scale clusters of Si have been deposited by laser ablation onto the basal plane of graphite, and analyzed by STM and STS to study the physical basis for light-emission from Si. Tapping-mode AFM has been used to determine the morphology of novel gratings for NIF applications, and to determine the morphology of stress induced structural changes in aluminum thin films for microcircuitry. AFM in liquid has been used to determine the growth mechanism of KDP crystals. Large-stage AFM in air has been used to establish that inclusion-induced cones in multilayer antireflection and high-reflection optical coatings 
determine the laser damage threshold at $1.06 \mu \mathrm{m}$ if the diameter of the inclusion is above $.6 \mu \mathrm{m}$.

Keywords: NDE, Laser Damage, Optical Coatings, Optical Gratings, Nano-Lithography, Chemical Reaction, $\mathrm{XeF}_{2}$, Etching, Nano-Stethoscope, Biomechanics, Si Light Emission, Stress Induced Grain. Growth, Thin Films

390. Thermoelectric Materials with Exceptional Figures of Merit

FY 1994

DOE Contact: G. J. D'Alessio, (301) 903-6688

$\$ 325,000$

LLNL Contact: J. C. Farmer, (510) 423-6574

The relative efficiency of a thermoelectric material is measured in terms of the dimensionless figure of merit, ZT. The best known thermoelectric materials are heavily doped, mildly degenerate semiconductors and have $\mathrm{ZT} \leq 1$. If materials with $\mathrm{ZT} \geq 3$ could be found or developed, thermoelectric devices could be made that would have thermodynamic efficiencies close to that of an ideal Carnot engine. One approach to high ZT materials is the synthesis of two-dimensional quantum wells. We have synthesized several different thermoelectric multilayer films with the dimensions of quantum wells. These materials have been evaluated over a broad range of temperature, extending from the boiling point of liquid nitrogen to several hundred degrees centigrade. Though difficulties have been encountered with inadvertent doping of quantum wells by barrier layers, strategies are being developed to overcome this problem. Single layer thermoelectric thin films with very good electronic properties have been made. These single-layer films are now being incorporated into lightweight cooler designs for Boeing Defense and Space. We believe that such thin films can be used to make distributed coolers that have much less weight than comparable devices fabricated from bulk materials.

Keywords: Thermoelectric Materials

391. Capacitive Deionization as an Alternative to Ion Exchange

FY 1994

DOE Contact: Douglas Gish, DP 42, (202) 586-1741

$\$ 795,000$

LLNL Contact: J. C. Farmer, (510) 423-6574

A novel capacitive deionization process has been developed for the efficient removal of ionic contaminants from aqueous streams. Ions are held in electric double layers formed at the surfaces of porous electrodes. This new process could replace ion exchange systems and associated secondary waste. Given the high cost of disposal in mined geological repositories, there is tremendous incentive for reducing the volume of waste that must be dealt with. The mode of operation and the electrode material used in the LLNL capacitive deionizer are entirely new. Ultimately, the system will consist of two multistage capacitors 
in parallel. One capacitor will be regenerated (discharged) while the other purifies (charges). Since current produced during regeneration will be used for purification, the system will be energy efficient. This mode of operation, potential-swing ion adsorption, is analogous to pressure-swing gas absorption. In addition to conventional porous carbon electrodes $\left(250 \mathrm{~m}^{2} / \mathrm{gm}\right)$, carbon aerogel electrodes have been developed and are being used $\left(800 \mathrm{~m}^{2} / \mathrm{gm}\right)$. This work is being funded by DOD SERDP (Strategic Environmental Research and Development Program). Collaborations are underway with a variety of government facilities including Tyndall Air Force Base, Idaho National Engineering Laboratory, and Westinghouse.

Keywords: Capacitive Deionization

392. Trilayer Josephson Junctions (Technology Transfer Initiative)

FY 1994

DOE Contact: W. T. Chernock, (301) 586-7590

$\$ 425,000$

LLNL Contact: M. J. Fluss, (510) 423-6665

This TTI activity is focused on the development of the knowledge base to mature the technology of heteroepitaxial growth of planar tri-layer high-temperature superconducting Josephson junctions. The JWS calls out milestones at 6-month intervals. Milestones to be accomplished by the end of the third half year for this project are to manufacture trilayers (Varian) and pattern devices (Varian) with candidate materials, to characterize device quality by basic transport measurements (Varian/LLNL), to perform microscopic investigations of interface quality and layer characteristics (LLNL), to select techniques for testing chemical homogeneity and surface regularity (LLNL) and to develop data for the processing data base. LLNL and Varian have performed all tasks described through the third sixmonth period milestones.

Varian Associates has delivered to LLNL researchers 22 trilayer wafers for evaluation, four of which were specially prepared for this TTI project. LLNL staff have completed Auger electron spectroscopy, X-ray fluorescence spectroscopy, transmission electron microscopy, ion microprobe spectroscopy, ion microscope spectroscopy, atomic force microscopy, scanning tunneling microscopy and Rutherford backscattering spectroscopy measurements on selected samples. Features observed in LLNL measurements have resulted in modifications of Varian procedures and Varian recently announced the most uniform array of electronic Josephson junctions ever produced in high temperature superconducting materials. Results have been transmitted on a regular basis to Varian participants through technical meetings.

Keywords: Superconductors, High Transition Temperature, Josephson Junction, Tri-Layers, Heteroepitaxy 


\section{Lithium Cell Development}

FY 1994

DOE Contact: Andre Cygleman, (202) 586-8814

LLNL Contact: John R. Kolb, (510) 422-64.24

We continue to work on the development of a replacement electrolytic cell for the manufacture of lithium metal in support of the DOE Y-12 facility. Our development incorporates the introduction of a bipolar cell methodology where a bipolar electrode is one that is shared by two cells connected in electrical series. In the process being developed, lithium is electrodeposited in an aqueous cell at $\sim 30^{\circ} \mathrm{C}$ and then anodically removed and recovered as pure lithium at a molten lithium cathode. Lithium-depleted amalgam is returned to the aqueous cell after transferring heat counter-current to the incoming lithiumrich stream. The process eliminates high ternperature electrolysis of $\mathrm{LiCl}$ and multiple unit processes to produce the anhydrous $\mathrm{LiCl}$ feedstock at $\mathrm{Y}-12$ and eliminates hazards associated with chlorine evolution and lithium withdrawal. ES\&H analyses indicate a muchimproved process from the standpoint of worker safety.

Keywords: Lithium, Bipolar, Electrolytic Cell Development

394. Environmentally Safe Disposal of Explosive Wastes: SERDP Project

FY 1994 $\$ 800,000$

DOE Contact: Andre Cygleman, (202) 586-8814

LLNL Contact: John R. Kolb, (510) 422-64:24

In collaboration with researchers at Los Alamos National Laboratory and the Pantex Plant, we are exploring options to support the Department of Energy and the Department of Defense in their quest to develop envirorımentally sound techniques for the destruction of residual high explosive remnants after dismantlement and demilitarization occur. We intend to pursue, and have demonstrated positively during this year, the capacity to minimize the amount of high explosive materials to be treated as waste and subsequently destroyed. We have chosen to manage the returning, surplus energetic material as an asset to be sold or given away in lieu of destruction. Through minimization of the amount of HE waste, we believe we can reduce, by an order of magnitude, the amount of material for which environmentally sound disposition techniques must be generated. We have focused on molten salt destruction, base hydrolysis and bioremediation as the techniques to be investigated this year. We have also supported a study on the desirability of recycling and reusing insensitive high explosives with a minimum of waste generation or cleanup. We will downselect to a single technique or a suite of techniques in early calendar 1995 . We will then be in position to design a pilot-scale plant to accommodate environmentally benign treatment of energetic wastes.

Keywords: SERDP, Environmentally Benign High Explosive Waste Destruction 
DOE Contact: Warren Chernock, (202) 586-7590

LLNL Contact: Donald Lesuer, (510) $422-9633$

Laminated metal composites are materials in which two or more metal containing layers are deformation bonded. Previous work at LLNL has shown that these materials can have properties (such as fracture toughness, fatigue, damping capacity and impact behavior) that are superior to properties currently available in lightweight materials. These materials also offer the possibility to tailor properties to a prescribed application through the choice of component materials, relative volume fraction of the components, interface strength, etc. This project is funded through the Technology Transfer Initiative and is exploring the application of these materials to fan containment systems for commercial jet engines and to airframe structural components.

Keywords: Materials Properties, Behavior, Characterization or Testing

396. Fatigue of Metal Matrix Composites

FY 1994

$\$ 450,000$

DOE Contact: Warren Chernock, (202) 586-7590

LLNL Contact: Donald Lesuer, (510) 422-9633

This project involves Lawrence Livermore National Laboratory, Oak Ridge National Laboratory and General Motors. The project is studying the mechanisms of high cycle fatigue in squeeze cast metal matrix composites. The life limiting microstructural features are being determined and the processing-structure-property correlations are being established. Models that can predict lifetimes will be developed.

Keywords: Materials Properties, Behavior, Characterization or Testing

397. Molecular Dynamics Simulation Studies of Radiation Effects in Solids

FY 1994

$\$ 60,000$

DOE Contact: F. W. Wiffen, (301) 903-4963

LLNL Contacts: T. Diaz de la Rubia, (510) 422-6714 and M. W. Guinan, (510) 422-5776

The objective of this program is to develop and apply advanced computational tools to the study of radiation effects in solids. The aim of the program is to understand, at the atomistic level, the manner in which a material responds in a high radiation environment, such as that present at the first wall of a fusion reactor. We apply molecular dynamics computer simulation methods and this allows us to understand the mechanisms of formation of the primary state of damage in a material. From our simulations, we derive a fundamental understanding of the dynamics of the displacement cascade generated by 
primary recoils along the path of an irradiating beam of energetic particles, such as neutrons. Our results provide information on the number and geometry of the defects induced in the material by the irradiation as well as on the amount of atomic relocation. This atomistic approach represents a fundamental step critical to the development of a complete picture of the microstructural evaluation of a material under irradiation. Ultimately, the insight gained by these studies will lead to understanding and predicting the macroscopic response and changes in the mechanical properties of irradiated materials.

Keywords: Radiation Damage, Magnetic Fusion, Computer Simulation

398. Fundamental Studies of Particle-Solid Interactions

FY 1994

$\$ 176,000$

DOE Contact: Maury Katz, (202) 586-5799

LLNL Contact: T. Diaz de la Rubia, (510) 422-6714

The objective of this program is to develop and apply computational tools to the study of ion implantation and ion beam modification of semiconductor materials. Despite over 20 years of active research devoted to understanding radiation effects and defect properties in silicon, many questions remain as to the manner in which damage is created and accumulates in this material during irradiation. It is the aim of this program to provide atomistic insight into these phenomena. Our molecular dynamics computer simulation methods provide a unique picture and understanding of the response of silicon to energetic ion beams. From our results we are able to understand the mechanisms of amorphization of the silicon lattice during irradiation as well as the form in which Frenkel pairs are produced. The detailed dynamics of the damage process are explored and this provides insight into the evaluation of the stress state of the crystal and the amount of atomic relocation that occur during irradiation. Ultimately, the knowledge gained by these studies will allow us to make predictions that will enable true physical process modeling of semiconductor manufacturing, a critical issue in the development of $0.1 \mu \mathrm{m}$ technology.

Keywords: Ion Implantation, Semiconductor Processing, Dopant Diffusion, Computer Simulation

399. Radiation Effects in Materials for Inertial Confinement Fusion

FY 1994

$\$ 50,000$

DOE Contact: G. J. D'Alessio, (301) 903-6688

LLNL Contacts: T. Diaz de la Rubia, (510) 422-6714 and M. Tobin, (510) 423-1168

The objective of this program is to apply advanced computational tools to analyze the feasibility of using certain low activation hazard materials, such as ceramics, in the first wall of inertial fusion energy power plants. We apply molecular dynamics computer simulation methods and this allows us to understand the mechanisms of formation of the 
primary state of damage created in the high radiation environment present in an IFE plant. From our simulations, we derive a fundamental understanding of the dynamics of the displacement cascade generated by primary recoils along the path of a slowing down neutron in the first wall. Our results provide information on the number and geometry of the defects induced in the material by the irradiation as well as on the amount of atomic relocation. This atomistic approach represents a fundamental step critical to the development of a complete picture of the microstructural evolution of a material under irradiation. Ultimately, the insight gained by these studies will lead to understanding and predicting the macroscopic response and changes in the mechanical properties of irradiated ceramics and oxides. This knowledge will allow a physics-based selection of materials for use as structural components in IFE reactors.

Keywords: Radiation Damage, Inertial Fusion Energy, Low Activation Materials, Computer Simulation

400. Novel Materials for Optoelectronics and Photonics

FY 1994

DOE Contact: G. J. D'Alessio, (301) 903-6688

$\$ 500,000$

LLNL Contact: Howard W. H. Lee, (510) 423-5877

The objective of this program is to develop and implement promising new materials for optoelectronics and photonics that will substantially improve device and system performance and enable new and innovative technologies. Representative materials include nanocrystals, fullerenes, organics (polymers), and aerogels. We have developed a type of nanocrystalline silicon (fabricated from porous silicon) that photoluminesces throughout the visible spectrum (RGB). This nanocrystalline silicon is particularly easy to fabricate and can potentially serve as an efficient and inexpensive phosphor for flat panel displays. Nanocrystals of other materials were also being studied. We have also fabricated arrays of miniature junction diodes from porous and nanocrystalline silicon that emit in the visible and near infrared. Silicon-based emitters are desirable because they integrate well with standard silicon-based microelectronics. Our studies on fullerenes showed their figures of merit to be very competitive with optical fibers for all-optical switching and have demonstrated a fullerene-based all optical switch. Thin films of materials such as fullerenes permit an integrated optics approach which greatly minimizes the latency problem inherent with fiber optics. Other thin film materials are also being pursued for these applications. Finally, we are studying doped aerogels for flat panel and three-dimensional displays.

Keywords: Optoelectronics, Photonics, Nanocrystals, Porous Silicon, Fullerenes, Aerogels, Polymers, Electroluminescence, Flat Plan Displays, All-Optical Switching 
401. Uranium Manufacturing Lead Lab Program

FY 1994

DOE Contact: Andre Cygleman, (202) 586-8814

$\$ 3,000,000$

LLNL Contact: Jeff N. Kass, (510) 422-4831

We are working to improve the processing technology for depleted alloy and enriched uranium. The new technology is aimed at reducing waste generated in manufacturing weapons components. Improved melting methods, near net shape forming and machining, and inspection of near net shape parts are the areas of primary interest. Funding for this effort is coming from DOE Albuquerque Operations Office.

Keywords: Manufacturing, Depleted Uranium, Uranium Alloy, Enriched Uranium, Waste Minimization

402. Plutonium Manufacturing Lead Lab Program

FY 1994

DOE Contact: Andre Cygleman, (202) 586-8814

$\$ 3,000,000$

LLNL Contact: J. L. Robbins, (510) 422-7060

We are working with DOE, Los Alamos National Laboratory and Savannah River Plant to develop improved manufacturing methods for producing plutonium weapons components. The new technology is aimed at reducing and eliminating waste generated in the manufacturing operations. The LLNL program includes efforts in net shape casting, laser welding, and alternate assembly methods for increased efficiencies. Funding for this effort is coming from SERDP and process development resources.

Keywords: Plutonium, Manufacturing, Casting, Machining, Waste Minimization

403. Novel Materials Studies at High Pressures and Temperatures

by Using In-Situ X-ray Laser Heating Experiments in a DAC

FY 1994

$\$ 400,000$

DOE Contact: Maurice Katz, (202) 586-5799

LLNL Contact: Choong-Shik Yoo, (510) 422-5848

The objective of this project is to integrate the synchrotron X-ray, laser heating, and diamond anvil cell technology together for the studies of material structure at the PVT conditions far beyond the reach of other technology. The feasibility of this experimental approach has already been demonstrated in the studies of iron phase diagram, providing crucial information for iron industry and for modeling the Earth core. The technique is now matured and is used for synthesis and characterization of novel materials such as super-hard materials and metastable energetic phases at high pressures and temperatures. Because the materials reactivity rapidly increases with pressure and temperature, in this study we have 
been able to take a direct synthetic route between extremely inert molecules like nitrogen and hydrogen with many light elements like $\mathrm{Li}, \mathrm{Be}, \mathrm{B}, \mathrm{C}$, many of which combinations are potential for exotic novel materials like $\mathrm{C}_{3} \mathrm{~N}_{4}$ and energetic metastable phases like $\mathrm{LiH}$. Therefore, the success of this study would benefit to the US-industry by identifying one or more exotic novel materials and to DoD and DOE by providing a dual-use, state-of-the-art technology for studies of material properties at extremes of pressures and temperatures that can be carried out by a non-hazardous, table-top experiment.

Keywords: Novel Materials Applications, Energetic Metastable Materials, Nitrides, Hydrides, Oxides, Ceramics, X-ray Laser Heating Experiments, High Pressures, Temperatures

404. Advanced Molecular Dynamics Simulations of Molecular-Beam Induced Surface Processes

FY 1994

$\$ 607,000$

DOE Contact: Alex R. Larzelere, (202) 586-1101

LLNL Contacts: Christian Mailhiot, (510) $422-5873$ and James F. Belak, (510) 422-6061

The Wilson Center for Research and Technology of Xerox Corporation and Lawrence Livermore National Laboratory (LLNL) have begun work under a CRADA to develop fundamental scientific knowledge that will lead to improved performance in microelectronic devices used in a variety of industrial and consumer electronics products. LLNL's breakthrough atomic-level materials theory and modeling software extend Xerox's capabilities to study etching, passivation (making a surface less reactive chemically), growth of thin films, and other processes used in modern microelectronics. The project takes advantage of the breakthrough capabilities developed at LLNL in the area of advanced molecular dynamics simulations and the experimental capabilities to study supersonic molecular and reactive ion-beam-induced modifications of surfaces that have been developed at Xerox. In collaboration with Xerox, LLNL is developing and applying advanced molecular dynamics methods to examine energy transfer processes occurring in reactive gas/surface scattering as it relates to the etching, passivation and epitaxial growth of materials for microelectronics applications. These concurrent theoretical and experimental activities are synergistically coupled to validate LLNL's materials modeling methods and optimize Xerox's experimental processes.

Keywords: Atomic-level Materials Modeling, Ab-initio Electronic Structure Methods, Molecular Dynamics, Surface Science, Etching, Passivation, Tribology, Molecular Design 
405. High-Speed Tribology of the Head Disk Interface by Computer Simulation

FY 1994

$\$ 300,000$

DOE Contact: Alex R. Larzelere, (202) 586.1101

LLNL Contacts: Christian Mailhiot, (510) 422-5873 and James F. Belak, (510) $422-6061$

Lawrence Livermore National Laboratory (LLNL) and IBM's Almaden Research Center are collaborating under a CRADA on a research project that could help in the design of computer hard drives with greatly increased data storage capacity. Hard-drive technology currently allows storage of about 300 megabits of data per square inch of harddrive disk space. Researchers are trying to develop the components needed to store 10 gigabits (10 billion bits) per square inch. Increased data storage would allow hand-held or laptop computers to store more information, run software that could increase their usefulness many times over, and lead to smaller, more reliable hard drives that use less power. The team will use atomistic molecular dynamics modeling-describing the behavior of individual atoms of matter mathematically to better understand the chemical and physical processes at the point where the disk drive's read/write head meets the surface of the hard disk. By working interactively with the Almaden scientists who are developing new data storage technologies, the computer models can be checked for accuracy and assist IBM's engineer in the design and development of future generations of small and ultrasmall data storage products.

Keywords: Atomic-level Materials Modeling, Ab-initio Electronic Structure Methods, Molecular Dynamics, Surface Science, Etching, Passivation, Tribology, Molecular Design

406. Massively Parallel Simulation of Large Molecular Systems with Long-Range Interactions

FY 1994

$\$ 200,000$

DOE Contact: Alex R. Larzelere, (202) 586-1101

LLNL Contacts: Christian Mailhiot, (510) 422-4873 and James F. Belak, (510) $422-6061$

Lawrence Livermore National Laboratory, Cray Research, DuPont, and Bristol-Myers Squibb are collaborating under a CRADA to develop a set of computational tools that will allow the routine study of large molecular systems (hundreds of thousands of atoms) with long-range Coulomb interactions for tens of nanoseconds. These tools will enable the study of larger length-scale and longer time-scale phenomena than is currently possible on problems of interest to the pharmaceutical and polymer industries. Because of the enormous computational resources required to study these problems, all of the software will be designed for massively parallel supercomputers. In addition to developing new parallel 
methods to take advantage of the emerging hardware, we will develop and implement new algorithms to treat the long range forces implicit in these systems in a computationally efficient manner. A second goal is to apply the resulting tools to address interesting scientific and materials problems in novel organic-based materials including bio-membranes, liquid crystals, optical thin films (Langmuir-Blodgett films), and the diffusion of molecules in polymers and biomembranes.

Keywords: Atomic-level Materials Modeling, Ab-initio Electronic Structure Methods, Molecular Dynamics, Surface Science, Etching, Passivation, Tribology, Molecular Design

407. Advanced Atomic-Level Materials Design for Massively Parallel Environment (High Performance Parallel Processor Computing Initiative: H4P)

FY 1994 $\$ 175,000$

DOE Contact: Alex R. Larzelere, (202) 586-1101

LLNL Contact: christian Mailhiot, (510) $422-5873$

The objective of this Cooperative Development Project is to move massively parallel computing technology into the industrial sector rapidly by focusing Cray Research, national laboratories, and industry resources on implementing a selected set of important industrial applications written in portable MPP programming languages. Within the H4P effort, a project entitled "Advanced Materials Design for Massively Parallel Environment" teams LLNL, the Xerox Palo Alto Research Center, and Cray Research Inc. The main goal of this project is to provide U.S. industry with breakthrough capabilities in advanced atomic-level materials simulation by using innovative new MPP algorithms, methods, and computers. Moreover, many computational tasks of central importance in materials modeling and simulation have wide applicability, and their optimization will benefit other industrial areas of research outside the confines of ab-initio electronic structure calculations of materials. Another technical objective is the application of advanced ab-initio electronic structure methods, at Xerox and at LLNL, to specific physics problems of primary importance to research activities at Xerox's Electronic Materials Laboratory, including investigations of the atomic and electronic structure of amorphous silicon and defect energetics in III-V semiconductor materials. In addition, the proposed research project is to integrate LLNL's advanced ab-initio molecular dynamics simulation capabilities into UniChem, CRI's graphical interface for computational chemistry. This goal is in the interest of CRI and the DOE national laboratories.

Keywords: Atomic-level Materials Modeling, Ab-initio Electronic Structure Methods, Molecular Dynamics, Microelectronics, Optoelectronics, Molecular Design 
408. Growth and Formation of Advanced Heterointerfaces

FY 1994

$\$ 500,000$

DOE Contact: Iran Thomas, (301) 903-3427

LLNL Contacts: Louis J. Terminello, (510) $423-7956$ and Christian Mailhiot, (510) $422-5873$

The ultimate objective of this research effort is to provide a microscopic understanding of the structural aspects of solid heterointerface growth and formation. This goal is achieved by an interdisciplinary thrust based on the most comprehensive and advanced experimental and theoretical methods currently available to the materials science community. Experimental determination of the evolution of the atomic geometry and electronic structure during the early stages of interface formation are provided by a powerful combination of holographic and synchrotron-based probes of in situ prepared materials. Theoretical modeling of these effects are performed with ab-initio molecular dynamics simulations in which atomic trajectories are determined from self-consistent calculations of interatomic forces including the effects of electronic charge redistribution derived from local density-functional theory. Consequently, the novel structure and chemical information obtained by interface imaging, characterization, and dynamical ab-initio modeling with our recently pioneered experimental and theoretical techniques will serve as the basis for a rational synthesis of custom heterointerfaces and thus potentially produce atomistic control of novel materials fabrication.

Keywords: Atomic-level Materials Modeling, Ab-initio Electronic Structure Methods, Molecular Dynamics, Surface and Interface Science, Photoelectron Spectroscopy, Photoelectron Diffiaction, Photoelectron Holography

409. Materials Produced with Dynamic High Pressure

FY 1994

DOE Contact: G. J. D’Alessio, (301) 903-6688

$\$ 500,000$

LLNL Contact: William Nellis, (510) 422-7200

This project seeks to produce novel materials (crystal structures, microstructures, and properties) using high shock pressures. The terms "dynamic" and "shock" are used synonymously in this context. Tuneable shock pressure pulses are produced by the impact of a projectile launched from a small two-stage light-gas gun. Shock pressures range from 0.01-1 Mbar, temperatures range from 50 up to a few $1000^{\circ} \mathrm{C}$, strain rates on loading range above $10^{8} / \mathrm{s}$ and quench rates on release of pressure are $10^{12} \mathrm{bar} / \mathrm{s}$ and $10^{9} \mathrm{~K} / \mathrm{s}$ in specimens which are recovered intact for investigation. These conditions are the physical limits in macroscopic bodies and produce novel effects, both heterogeneous and homogeneous. A gas gun $6.5 \mathrm{~m}$ long is used to achieve these high shock pressures. Specimens range from 1 micron to $1 \mathrm{~mm}$ thick and are about $10 \mathrm{~mm}$ in diameter. The observed material structures can be correlated with computational simulations and fast real-time measurements to 
enhance understanding of the effects produced. A wide variety of materials characterization measurements are made both before and after application of high dynamic pressures. In the past year we have dynamically compacted various ceramic and magnetic powders, altered superconducting critical current densities with shock-induced defects, produced unusual glass by shocking crystalline quartz, which apparently contains small particles of $\mathrm{Si}$, and performed impact experiments to help design the containment fixture for the highvelocity flywheel to be contained in the next generation supercar.

Keywords: Shock Pressures, Gas Gun, Materials Characterization, Ceramics, Magnets, Superconductors, Glass, Flywheel Containment

\section{Properties of Hydrogen at High Shock Pressures and Temperatures}

FY 1994

$\$ 250,000$

DOE Contact: G. J. D’Alessio, (301) 903-6688

LLNL Contact: William Nellis, (510) $422-7200$ and Neil Holmes, (510) $422-7213$

This project measures temperatures and electrical conductivities of cryogenic liquid hydrogen and deuterium specimens shock-compressed to high pressures and temperatures with a two-stage light-gas gun. Impact velocities up to $8 \mathrm{~km} / \mathrm{s}$ were used. Shock temperatures were measures optically up to $1 \mathrm{Mbar}$ and $5000 \mathrm{~K}$ and show that hydrogen undergoes a continuous dissociative phase transition above 200 kbar. This partial dissociation absorbs energy, which causes lower temperatures and high densities in the Mbar shock pressure range than was thought previously. Thus, the equation of state of hydrogen is different than thought previously because of continuous molecular dissociation from the molecular to the atomic phase. These data and the resulting model have important implications for laser-driven implosion systems which use hydrogen. To investigate the metallization pressure of molecular hydrogen, electrical conductivities were measured in the range 1 to 2 Mbar at calculated temperatures up to $4000 \mathrm{~K}$ using metal electrodes. The metallization pressure is the pressure at which the molecular insulating phase transforms to the monatomic metallic phase. This phase transition also effects the equation of state. A novel technique was used to produce just enough shock heating to excite just enough electronic carriers to be able to measure the electrical conductivity of hydrogen at Mbar pressures in the short time duration of the experiment. The results are in good agreement with the theoretically predicted density-dependent energy bandgap of rotationally disordered molecular hydrogen.

Keywords: Shock Pressures, Shock Temperatures, Electrical Conductivities, Gas Gun, Hydrogen, Cryogenics, Equation of State, Dissociation, Metallization 
411. Low Density Foam Shells for Cryogenic ICF Experiments

FY 1994

$\$ 700,000$

DOE Contact: G. J. D'Alessio, (301) 903-6688

LLNL Contacts: R. Cook, (510) $422-3117$ and G. E. Overturf III, (510) $422-6774$

This program has as its goal the development of foam shells, from 1 to $2 \mathrm{~mm}$ in diameter with $100 \mu \mathrm{m}$ foam walls whose density is $50 \mathrm{mg} / \mathrm{cc}$ and whose cell size is less than $1 \mu \mathrm{m}$. These shells must also have a 5 to $10 \mu \mathrm{m}$ thick full density overcoat, and the outer surface finish must be better than $0.1 \mu \mathrm{m}$. Foam and overcoat must be composed of atoms with $Z$ less than 9. These foam shells will be used to provide symmetrization of liquid $D_{2}$ or DT in ICF experiments. The shells are formed using microencapsulation techniques. In one case a water-in-oil microencapsulated droplet is suspended in aqueous media, with a multi-functional polymerizable monomer (trimethylol propane trimethacrylate) incorporated in the $100 \mu \mathrm{m}$ thick oil phase at about $5 \mathrm{wt} \%$. A second route based on resorcinolformaldehyde $(R / F)$ foam chemistry uses an oil-in-water droplet suspended in oil since the $R / F$ chemistry is water based.

Keywords: Polymers, Laser Fusion Targets, Low Density Foam.

412. Molecular Hydrodynamics

FY 1994

$\$ 500,000$

DOE Contact: Maurice Katz, (202) 586-5799

LLNL Contacts: Clark Souers, (510) 423-4217 and James Belak, (510) 522-6061

We use molecular dynamics (MD) computer simulation methods to model the transport of shock-wave energy from intermolecular collisions into internal vibrational motion of high explosive molecules. The goal is to discover the rate of energy flow into vibrational motion and determine which vibrational modes lead to maximum energy flow and start the initiation process. The simulation code has been implemented on the emerging generation of massively parallel computers using intermolecular and intramolecular force models that realistically describe high explosive molecules. The shock wave is generated using a unique constant velocity boundary condition. The simulation is performed in the reference frame of the shock allowing arbitrarily long times to be studied with a minimum number of molecules. The simulations provide useful insight into the sequence of states through which the material transforms during shock loading. At the shock front the molecules undergo large amplitude motion into non-equilibrium structures. The calculated time for vibrational energy to reach equilibrium with translational energy (up-pumping time) is found to be quite fast, about 10 picoseconds for small molecules like nitromethane and strong shocks.

Keywords: Energetic Materials, High Explosives, Mólecular Hydrodynamics, Large Scale Molecular Dynamics, Parallel Computing, Shock Physics 
413. Metastable Solid-Phase High Energy Density Materials

FY 1994

$\$ 207,000$

DOE Contact: Maurice Katz, (202) 586-5799

LLNL Contacts: Andrew McMahan, (510) $422-7198$ and Albert Holt, (510) 423-4126

Ab-initio theoretical methods are being used to predict and characterize novel high energy density materials. The class of metastable solid phases being explored is characterized by extended and continuous networks of covalent or metallic bonds, without the weak van der Waals links of familiar chemical fuels, propellants, and explosives. Candidate materials include a phosphorus-like polymeric form of nitrogen, an aluminum-like form of boron, a distorted tetrahedrally coordinated form of carbon, as well as low-Z hydrides. These hypothetical phases are predicted to have stored energy in the range 20-34 $\mathrm{kJ} / \mathrm{cm}^{3}$, which may be compared to $12 \mathrm{~kJ} / \mathrm{cm}^{3}$ for the HMX explosive. The new phases are predicted to be high-pressure stable, which offers in many cases a natural synthesis route. Companion proof-of-existence synthesis efforts using the laser-heated high-pressure diamond anvil cell are in progress under separate funding.

Keywords: Energetic Materials, High Energy Density Materials, Atomic-level Materials Modeling, Ab-initio Electronic Structure Methods

414. Sub-Picosecond Laser Induced Damage

FY 1994

$\$ 100,000$

DOE Contact: G. J. D’Alessio, (301) 903-6688

LLNL Contacts: Mike Perry, (510) 442-4915 and Mike Feit, (510) 442-4128

We are carrying out extensive experimental and theoretical investigations of laser induced damage in dielectrics caused by intense laser pulses at 1053 and $526 \mathrm{~nm}$ wavelength to determine intrinsic limits for optical materials. A chirped pulse amplification solid state laser allows us to vary the pulselength continuously from 275 fs to 1 ns. This capability enables fundamental studies of damage as a function of continuously varying pulsewidth. We observe a new physical regime for the shorter (less than $10 \mathrm{ps)} \mathrm{pulses} \mathrm{exemplified} \mathrm{by}$ changes in the dependence of,damage threshold on pulse duration and the observed damage morphology. The damage threshold also becomes more sharply defined. This behavior is due to the fact that electrons, produced initially by multiphoton absorption, can absorb energy faster than they can transfer energy to the lattice. This short pulse regime is ultimately simpler to understand than the messier long pulse case. In addition to dielectrics, we are investigating laser-tissue interaction of short pulse lasers. We intend to demonstrate that the advantage of short pulses for surgery lies in low collateral damage and greatly reduced sensitivity to tissue type.

Keywords: Laser Damage, Dielectrics, Breakdown, Multiphoton Absorption 


\section{Novel High Energy Density Materials: Synthesis by Megabar Hot} Pressing

DOE Contact: Maurice Katz, (202) 586-5799

LLNL Contacts: H. Lorenzana, (510) $422-8982$ and A. K. McMahan, (510) $422-7198$

The goal of this proposal is to demonstrate proof-of-principle synthesis of one or more of a new class of energetic materials derived metastably from first and second row elements. Growing theoretical evidence, for example, predicts that nitrogen can be stablized under ambient conditions in a three-dimensional continuously bonded configuration characterized by a stored energy density per unit volume more than three times that of typical chemical explosives. Such a material would offer important new opportunities as an explosive as well as an environmentally transpiarent, solid fuel or monopropellant since its only reaction by-product would be innocuous $\mathrm{N} 2$ gas. The recently developed laser-heated diamond-anvil-cell offers the most promising synthesis route for proof-of-existence demonstration of these novel high-pressure phases, given the technique's diagnostic versatility and controlled access to extremes of pressure and temperature.

Keywords: Novel Energetic Materials, Synthetic Fuels, Properties and Composition, Clean Energy Storage, Advanced Propulsion Fuels, High Pressures and High Temperatures, Hot Pressing

\section{AFM Investigations of Crystal Growth}

FY 1994

$\$ 210,000$

DOE Contact: G. J. D'Alessio, (301) 903-6688

LLNL Contact: J. J. DeYoreo, (510) 423-4240

The nanometer-scale morphology of crystalline surfaces exerts a strong control on materials properties and performance. While many researchers have studied vapor deposited metal and semiconductor surfaces grown far from equilibrium, few studies have given attention to the morphology of crystal surfaces grown from melts or solutions near equilibrium despite the fact that most bulk crystals are grown in this regime. Understanding the mechanisms of growth and the origin of defects in such crystals can impact materials performance in a number of fields including optics, electronics and structural biology. We are using atomic force microscopy (AFM) to investigate the growth of single crystal surfaces from solution in order to determine the mechanisms of step advancement, the importance of surface diffusion, the effect of impurities and the origin of defects.

In 1994 we performed both ex situ and in situ AFM measurements on two systems, the ionic crystal $\mathrm{HK}_{2} \mathrm{PO}_{4}(\mathrm{KDP})$, the canonical solution grown crystal, and the protein crystal Canavalin, a prototypical macromolecular biological crystal. Our results have provided 
insight into the mechanisms of growth and defect incorporation in these systems. In 1995 we will continue with these systems and begin to investigate antibody and virus crystals.

Keywords: Morphology, Crystal Surfaces, Atomic Force Microscopy

417. Plutonium Process Technology Development

FY 1994

DOE Contact: Andre Cygleman, (202) 586-8814

$\$ 6,000,000$

LLNL Contact: Mark C. Bronson, (510) 422-3061

The scope of this activity is the development and demonstration of plutonium chemical processes for the recovery, purification, and conversion of actinide (plutonium, americium, and uranium) bearing materials. This was being carried out in support of the Reconfiguration Program and the Environmental Restoration/Waste Minimization Program. Currently this effort is supporting the Nuclear Material Disposition Program. Development emphasis is on waste minimization, worker dose reduction, and minimizing construction costs.

During FY94, development efforts were carried out in plutonium component disassembly, Pu recovery by hydride/dehydride, separation of $\mathrm{Am}$ from Pu, electrorefining, pyrochemical salt scrub, Pu purification by chloride volatility, materials to contain liquid actinides, mediated electrochemical dissolution, molten salt oxidation, $\mathrm{UV} / \mathrm{H}_{2} \mathrm{O}_{2}$ photolysis, ceramic waste forms, and treatment of Idaho National Engineering Laboratory (INEL) calcine waste.

Keywords: Pyrochemical, Plutonium Processing, Waste Treatment, Plutonium Recovery, Plutonium Immobilization

Los Alamos National Laboratory

Materials Preparation. Synthesis, Deposition, Growth or Forming

418. Actinide Processing Development

FY 1994

DOE Contact: G. J. D'Alessio, (301) 903-6688

$\$ 1,350,000$

LANL (Contract No. W-7405-ENG-36) Contact: R. L. Gutierrez, (505) 665-3919

The aim of this project is the development and characterization of fabrication processes and the study of new processing technologies for plutonium. Research involves casting, thermomechanical working, and stability studies. Measurements of resistivity, 
thermal expansion, magnetic susceptibility, and formability are made to evaluate fabrication processes and alloy stability.

Keywords: Radioactive Materials, Plutonium Alloys, Ductility, Thermal Expansion, Electrical Resistivity, Stability

419. Plutonium Oxide Reduction

FY 1994

DOE Contact: G. J. D'Alessio, (301) 903-668.8

LANL (Contract No. W-7405-ENG-36) Contact: K. Axler, (505) 667-4045

The thermodynamics of interactions among the components used in the pyrochemical processing of plutonium are determined along with the relevant phase relations.

Keywords: Radioactive Materials, Plutonium, Thermodynamics, Phase Diagrams, Direct Oxide Reduction, Electrorefining, Molten Salt Extraction

420. Low Density Microcellular Plastic Foams

FY 1994

$\$ 200,000$

DOE Contact: G. J. D'Alessio, (301) 903-6688

LANL (Contract No. W-7405-ENG-36) Contact: P. Apen, (505) 667-6887

Microstructural polyolefin foams with densities between $0.01 \mathrm{~g} / \mathrm{cc}$ and $0.2 \mathrm{~g} / \mathrm{cc}$ are manufactured by a nonconventional foaming process. Foams are both open and closed celled and have large surface areas. This process is being expanded to other polymeric materials for a wide variety of applications. Foams have cell sizes from $25 \mu \mathrm{m}$ down to the $1 \mu \mathrm{m}$ range, depending on the process. Composite foams are being produced with submicron cell sizes while maintaining structural properties.

Keywords: Foams, Polyolefins, Polyurethanes, Silicones, Polyesters

421. Physical Vapor Deposition and Surface Analysis

FY 1994

DOE Contact: G. J. D'Alessio, (301) 903-6688

$\$ 300,000$

LANL (Contract No. W-7405-ENG-36) Contact: M. Scott, (505) 667-7557

Physical vapor deposition, one electron beam sputtering, and dual ion beam sputtering are employed to produce materials for structural applications, corrosion resistance, optical properties, and thin film transducers. Materials being developed include doped, in situ laminates of aluminum and $\mathrm{Al}_{\mathrm{x}} \mathrm{O}_{\mathrm{y}}$ having high strength and smooth surface finish. Also included are ion assisted deposition and ion sputtering onto various substrates 
for corrosion resistance to gases and liquid plutonium, reflective and anti-reflective coatings for infrared, visible, ultraviolet and X-ray wavelengths. Novel photocathodes are being made and evaluated by these processes.

Keywords: Coatings and Films, Physical Vapor Deposition, Sputtering, Ion Plating, Corrosion, Nondestructive Evaluation

422. Chemical Vapor Deposition (CVD) Coatings

FY 1994 $\$ 150,000$

DOE Contact: G. J. D'Alessio, (301) 903-6688

LANL (Contract No. W-7405-ENG-36) Contacts: J. R. Laia and M. Trkula, (505) 667-0591

Chemical vapor deposition (CVD) techniques are used to deposit thin-film and bulk coatings of a wide variety of elements and compounds. Coatings are deposited by the following techniques: conventional flow-by, fluidized-bed, plasma-assisted, and chemical vapor infiltration. To support and enhance our basic CVD program, efforts are underway to study the fundamental nature of the CVD process, including in situ diagnostics in the gas phase just above the substrate and modeling efforts to predict gas flows, reactor design, and chemical behavior within the CVD systems. Another collaborative effort at Los Alamos is attempting to synthesize organometallic precursors to deposit coatings at temperatures $<300^{\circ} \mathrm{C}$. Substrates coated by the CVD technique range from particles $2.0 \mu \mathrm{m}$ diameter to infiltrations of fabrics a square meter in area.

Applications include nuclear and conventional weapons, space nuclear reactor systems (fuels and structural components), inertial confinement fusion program, high temperature engine and structural components for advanced high-performance aircraft, hard/wear resistant coatings (tribological), corrosion resistant coatings, coatings of complex geometries, near-net-shape fabrication, heat-pipe structures, precision CVD of ultra-thin, freestanding shapes.

Keywords: Chemical Vapor Deposition, Coatings (metal and ceramic)

423. Polymers and Adhesives

FY 1994

$\$ 430,000$

DOE Contact: G. J. D'Alessio, (301) 903-6688

LANL (Contract No. W-7405-ENG-36) Contact: D. A. Hemphill, (505) 667-8335

The objective of this project is to identify potential weapons engineering and physics applications for plastic and composite materials, select or develop appropriate materials, develop low cost fabrication techniques compatible with Integrated Contractor production capabilities, and characterize promising materials on a timely basis to provide optimum material choices for new weapons designs. Material or process development projects 
include: highly filled polymers, composite structural and spring components, cushioning materials, and high-explosive compatible adhesives, potting materials. This work will be compatible with all current and future ES\&H guidelines.

Keywords: Adhesives, Composites, Plastics, Polymers, Weapons Design, Weapons Engineering, Integrated Contractors

424. Tritiated Materials

FY 1994

$\$ 175,000$

DOE Contact: G. J. D’Alessio, (301) 903-6688

LANL (Contract No. W-7405-ENG-36) Contact: J. R. Bartlit, (505) 667-5419

Advanced research and development efforts are focused on tritiated materials for tritium storage. New methods for preparing, fabricating, and containing such compounds are under investigation. We are also using lase:r-Raman techniques for in situ measurements of hydrogen-deuterium-tritium gas mixtures.

Keywords: Tritium, Tritiated Materials, Radioactive Materials

425. Salt Fabrication

FY 1994

$\$ 800,000$

DOE Contact: G. J. D'Alessio, (301) 903-6688

LANL (Contract No. W-7405-ENG-36) Contact: D. Carstens, (505) 667-5849

Development and evaluation of new fabrication and containment processes for $\mathrm{LiH}$ and LiD. This includes preparation of device parts for WTS tests. Research topics include development of hot pressing, machining techniques for salt compacts.

Keywords: Tritium, Hydrides, Machining, Radioactive Materials, Near-Net-Shape Processing

426. Slip Casting of Ceramics

FY 1994

DOE Contact: G. J. D'Alessio, (301) 903-6688

$\$ 300,000$

LANL (Contract No. W-7405-ENG-36) Contact: D. S. Phillips, (505) 667-5128

We are slip casting many ceramics including alumina, zirconia-toughened alumina (ZTA), and magnesia. The technology uses colloidal chemistry and powder characterization 
techniques, along with materials engineering. Considerable progress was made in the development of ZTA ceramic alloys with a superior microstructure and improved thermal shock resistance. The scope of work has expanded to include frits and insulation materials, as well as dense crucibles.

Keywords: Ceramics, Microstructure, Strength, Transformation Toughened Ceramics, Thermal Shock

427. Plasma-Flame Spraying Technology

FY 1994

DOE Contact: G. J. D’Alessio, (301) 903-6688

LANL (Contract No. W-7405-ENG-36) Contact: R. Castro, (505) 667-5191

Free-standing shapes and metallic and ceramic coatings are fabricated by plasma spraying. Materials examined recently include $\mathrm{Be},{ }^{238} \mathrm{U}, \mathrm{MoSi}_{2}$ and $\mathrm{ZrO}_{2}$. Applications include: radiochemical detectors; temperature-, oxidation-, and corrosion-resistant coatings; and electrically insulating coatings.

Keywords: Coatings, Metals, Ceramics, Plasma-Flame Spraying, High Temperature Service, Surface Characterization and Treatment

428. Rapid Solidification Technology

FY 1994

DOE Contact: G. J. D'Alessio, (301) 903-6688

$\$ 500,000$

LANL (Contract No. W-7405-ENG-36) Contact: P. Stanek, (505) 667-6914

RSR technologies such as melt spinning, splat cooling, and rapid solidification plasma spraying, are being developed to evaluate a range of RSR alloys, intermetallics and composites for defense and energy applications. Activities include alloy development, microstructural analysis, mechanical and physical properties testing, process development and modeling.

Keywords: Rapid Solidification, Low Pressure Plasma, Alloy Development, Composites, Intermetallics 
429. Bulk Ceramic Processing

FY 1994

$\$ 250,000$

DOE Contact: G. J. D’Alessio, (301) 903-6688

LANL (Contract No. W-7405-ENG-36) Contact: J. D. Katz, (505) 665-1424

Cold pressing and cold isostatic pressing, followed by sintering, are used to produce ceramic and metal components for various physics experiments and for plutonium processing. Materials fabricated include alumina, magnesia and boron.

In addition, a collaborative effort was established with the University of New Mexico Center for Micro-Engineered Ceramics to investigate the effect of $2.45 \mathrm{GHz}$ microwave energy on the diffusion of cations in ceramic oxides. This research consists of both a theoretical and experimental component. The results have shown that although microwave enhanced diffusion of chromium in alumina does not exist, microwave sintering has been found to be a very effective engineering tool for densifying even large alumina ceramics.

Finally, considerable effort was devoted to developing methods for sintering, rather than hot pressing, boron carbide to achieve high density. This work involves a collaboration with the A.W.E. in the United Kingdom.

Keywords: Ceramics, Sintering, Microwave Sintering, Cold Pressing

430. Synthesis of Ceramic Coatings

FY 1994

$\$ 150,000$

DOE Contact: G. J. D'Alessio, (301) 903-6688

LANL (Contract No. W-7405-ENG-36) Contact: C. P. Scherer, (505) 665-3202

The objective of this effort is to synthesize ceramic films for liquid metal containment. One approach entails the use of organic and aqueous solvents to deposit erbia films, which are subsequently heat treated to densification. The second approach involves the in situ conversion of a metal surface to a nitride by precise heating in a nitrogen environment.

Keywords: Ceramic Coatings, Sol Gel, Nitration 


\section{Materials Structure or Composition}

431. Actinide Surface Properties

FY 1994

$\$ 700,000$

DOE Contact: G. J. D'Alessio, (301) 903-6688

LANL (Contract No. W-7405-ENG-36) Contact: J. M. Haschke, (505) 665-3342

Characterization of actinide metal, alloy and compound surfaces using the techniques of X-ray photoelectron spectroscopy, Auger analysis, ellipsometry and Fourier-transform infrared spectroscopy. Surface reactions, chemisorption, attack by hydrogen, and the nature of associated catalytic processes are being studied.

Keywords: Actinides, Hydrides, Surface Characterization and Treatment, Hydrogen Effects, Radioactive Materials

432. Neutron Diffraction of $\mathrm{Pu}$ and $\mathrm{Pu}$ Alloys and Other Actinides

FY 1994

$\$ 237,000$

DOE Contact: G. J. D’Alessio, (301) 903-6688

LANL (Contract No. W-7405-ENG-36) Contact: A. C. Lawson, (505) 667-8844

Physical structure and properties of plutonium are being studied by pulsed neutron diffraction at the Manuel Lujan, Jr., Neutron Scattering Center (Los Alamos) and the Intense Pulsed Neutron Source (Argonne). A time-of-flight technique is used to measure diffraction at cryogenic and elevated temperatures.

Keywords: Alloys, Radioactive Materials, Transformation, Microstructure

433. Surface, Material and Analytical Studies

FY 1994

$\$ 300,000$

DOE Contact: G. J. D’Alessio, (301) 903-6688

LANL (Contract No. W-7405-ENG-36) Contact: W. C. Danen, (505) 667-4686

Studies are underway in four key areas: surface and interfacial structures and properties, explosives dynamics, laser-based isotopic analysis, and metastable energetic materials. Current investigations in surface and interfacial studies include: surface modification, HTSC composition and structure, and the use of $\mathrm{MeV}$ ion beams. In explosives chemistry, we are using real-time optical- and mass-spectral methods to probe the early-time dynamics of detonation. Analytical studies have centered on the use of resonance ionization mass spectrometry to eliminate isobaric interferences in the measurement of high- 
dynamic range isotope ratio measurements. We continue to study the synthesis and characterization of a new class of high energy density materials consisting of atomically-thin multilayered composite materials.

Keywords: Surface, Explosives, Interfaces, Composite Materials

Materials Properties, Behavior. Characterization or Testing

434. Mechanical Properties of Plutonium and Its Alloys

FY 1994

DOE Contact: G. J. D'Alessio, (301) 903-6688

$\$ 450,000$

LANL (Contract No. W-7405-ENG-36) Contact: R. L. Gutierrez, (505) 665-3919

The mechanical properties of plutonium and its alloys are related to the pre-test and post-test microstructures of the materials using optical and electron microscopy and X-ray, electron and neutron diffraction.

Keywords: Alloys, Radioactive Materials, Microstructures, Strength, Transformation

435. Phase Transformations in Pu and Pu Alloys

FY 1994

DOE Contact: G. J. D’Alessio, (301) 903-6588

LANL (Contract No. W-7405-ENG-36) Contact: R. L. Gutierrez, (505) 665-3919

Mechanisms and crystallography of thermally and mechanically induced allotropic transformations are studied with differential scanning calorimetry, optical and electron microscopy and electron and X-ray diffraction.

Keywords: Alloys, Radioactive Materials, Microstructure, Transformations

436. Plutonium Shock Deformation

FY 1994

DOE Contact: G. J. D'Alessio, (301) 903-6688

$\$ 350,000$

LANL (Contract No. W-7405-ENG-36) Corttact: M. J. Reisfeld, (505) 667-8485

Plutonium and actinide alloys are subjected to shock deformation, recovered without further damage and examined to determine how the shock affected their microstructures and mechanical properties.

Keywords: Radioactive Materials, Plutonium Alloys, Microstructure, Strength 
437. Non-Destructive Evaluation

FY 1994

$\$ 550,000$

DOE Contact: G. J. D'Alessio, (301) 903-6688

LANL (Contract No. W-7405-ENG-36) Contact: Thomas Claytor, (505) 667-1973

Development of Nondestructive Evaluation Technology that produces quantitative estimates of material properties. Use of tomographic techniques to enhance radiographic inspection. Flash, cine-radiography, high speed video recorded optical and X-ray diagnostics of dynamic and ultra-fast events. Real-time radiography. Image enhancement of output results from all techniques. Development of ultrasonic inspection techniques.

Keywords: Nondestructive Evaluation, Radiography, Ultrasonic Microscopy, Tomography, Cine Radiography, Bonding Processes, Real-Time Radiography, Image Enhancement

\section{Powder Characterization}

FY 1994

DOE Contact: G. J. D'Alessio, (301) 903-6688

$\$ 50,000$

LANL (Contract No. W-7405-ENG-36) Contact: G. J. Vogt, (505) 667-5813

Synthesis and processing of ceramic or metal powders depends critically on the physical characterization of the starting powders being used. Typical starting powders include commercial powders of thoria, magnesia, alumina, tungsten, copper, tungsten carbide, and boron carbide. In the past year, considerable effort has been expended on characterizing palladium alloy powders. Physical properties of interest include particle size and distribution, surface area, bulk and packed densities, morphology, pore size and distribution, and zeta potential. The crystalline-phase composition of the starting powders and processed powders can be determined by X-ray diffraction.

Keywords: Ceramic Powder, Metal Powder, Particle Size, Superconducting Powder, X-ray Diffraction, Surface Area 
439. Shock Deformation in Actinide Materials

FY 1994

$\$ 300,000$

DOE Contact: G. J. D'Alessio, (301) 903-6688

LANL (Contract No. W-7405-ENG-36) Contact: R. L. Gutierrez, (505) 665-3919

Measurement of shock-wave profiles in uranium, plutonium, and plutonium alloys. Use of soft-shock recovery test to examine the microstructural changes occurring during shock deformation. Measurement of spall strength in actinide materials and examination of fracture surfaces.

Keywords: Actinides, Shock Deformation, Microstructure, Spall Strength

440. Dynamic Mechanical Properties of Weapons Materials

FY 1994

DOE Contact: G. J. D'Alessio, (301) 903-6688

$\$ 350,000$

LANL (Contract No. W-7405-ENG-36) Contact: G. Gray, (505) 667-5452

Measurements of dynamic stress-strain and fracture behavior of materials used for nuclear weapons. Development of plastic constitutive relations.

Keywords: Dynamic, Strength, Fracture, Microstructure

Device or Component Fabrication, Behavior or Testing

441. Target Fabrication

FY 1994

$\$ 1,500,000$

DOE Contact: G. J. D'Alessio, (301) 903-6688

LANL (Contact No. W-7405-ENG-36) Contact: L. Foreman, (505) 667-1846

LLNL Contact: W. Hatcher, (510) 422-1100

General Atomics Contact: Ken Schultz, (6.19) 455-4304

ICF/AGEX targets are fabricated using PVD, CVD, precision micromachining, and polymer chemistry techniques. After the parts are fabricated, the components are assembled using a variety of techniques. These targets are used to provide laser materials interactions data for the inertial confinement fusion community.

Keywords: Inertial Fusion, Target Fabrication 
442. Filament Winder

FY 1994

$\$ 100,000$

DOE Contact: G. J. D'Alessio, (301) 903-6688

LANL (Contract No. W-7405-ENG-36) Contact: B. Benicewicz, (505) 665-0101

The Entec filament winder in MST-7 Plastics is a 4-axis computer-programmed machine with a winding envelope extending up to 4 feet in diameter and 10 feet in length. It is being utilized to wind circumferential or helical cylinders, cones, spheres, and closedend vessels from a variety of fibers including glass, kevlar, carbon, tungsten, and aluminum oxide. The applications cover a host of programs from within the Laboratory as well as from outside agencies.

Keywords: Filament Winding, Composites

443. High Energy Density Welding in Hazardous Environments

FY 1994

DOE Contact: G. J. D’Alessio, (301) 903-6688

$\$ 800,000$

LANL (Contract No. W-7405-ENG-36) Contact: G. Lewis, (505) 667-9663

High power Nd/YAG lasers combined with fiber optic beam delivery systems have been evaluated for welding applications in hazardous environments. Applications include the manufacture of nuclear weapons components and nuclear power reactor repair. High quality structural welds have been achieved without exposing the operators or the welding power supplies to the hazardous environment.

Keywords: Laser Welding, Fiber Optic Beam Delivery, Hazardous Environments, Nuclear Applications

444. Uranium Scrap Conversion and Recovery

FY 1994

$\$ 1,500,000$

DOE Contact: G. J. D'Alessio, (301) 903-6688

LANL (Contract No. W-7405-ENG-36) Contact: Dan Knobeloch, (505) 667-4417

Maintain and develop technologies for conversion and recovery of uranium scrap. Maintain and upgrade facilities for processing enriched uranium and managing uranium inventories.

Keywords: Uranium, Uranium Scrap, Enriched Uranium, Recovery, Processing, Inventories 
Laboratory Directed Research and Development

\section{Electronically Correlated Materials at Ambient and Extreme Conditions}

FY 1994

$\$ 328,000$

DOE Contact: M. J. Katz, (202) 586-5799

LANL (Contract No. W-7405-ENG-36) Contact: J. D. Thompson, (505) 667-6416

This coordinated program was aimed specifically at an in-depth description of the many-body ground state in correlated electron systems. This research examined heavy-electron compounds under extreme conditions of pressure, temperature, and magnetic field, thereby allowing unique insights into the correlated ground states.

Keywords: Heavy Electron Systems, Materials Under Extreme Conditions

446. Organometallic Chemical Vapor Deposition

FY 1994

$\$ 248,000$

DOE Contact: M. J. Katz, (202) 586-5799

LANL (Contract No. W-7405-ENG-36) Contact: D. C. Smith, (505) 667-2424

Most conventional metal halide based chemical vapor deposition processes take place at temperatures in excess of $800^{\circ} \mathrm{C}$ and produce corrosive gases (e.g., $\mathrm{HCl}, \mathrm{HF}$ ). Organometallic complexes as CVD precursors are a simple and powerful method for producing coatings at low temperatures, eliminating deleterious byproducts, and removing the halide from the process completely. In this effort, new routes to metal and metal carbide thin films from volatile organometallic precursors have been developed. Potential applications for these new low-temperature materials include: weapons diagnostics, oxidation protection coatings for polymers, barrier materials for use in nuclear fuels and high-temperature $\left(>2000^{\circ} \mathrm{C}\right)$ environments, and coatings for solid propellants.

Keywords: Metal Thin Films, Metal Carbicle Thin Films, Chemical Vapor Deposition

447. Polymer Sorbents for Hazardous Metal Uptake

FY 1994

DOE Contact: M. J. Katz, (202) 586-5799

$\$ 164,000$

LANL (Contract No. W-7405-ENG-36) Contact: B. Jorgensen, (505) 667-3619

Polymer sorbents with immobilized metal complexing agents are being developed for treatment of radioactive and mixed waste. The polymers are applicable to treatment of process streams, waste streams and environmental remediation. The polymers will remove hazardous metals and radionuclides from aqueous solutions. Two types of systems are being investigated. One of these is a water soluble polymer-supported extraction system for use 
in ultrafiltration technology and the other utilizes chelating resins. In each case, selective ligands are covalently bound to polymers and the polymers tested for metal ion uptake. Los Alamos is involved in the design, synthesis, and evaluation of actinide selective ligands in collaboration with several universities. Ligands developed in this program and other promising ligands are used in the polymer sorbents. The polymers are being tested on simulated waste mixtures and we hope to be able to test them on actual DOE radioactive waste.

Keywords: Metal Complexes, Radioactive Waste, Mixed Waste, Polymer Sorbents

448. Microscopic Materials Modeling: Textures and Dynamics

FY 1994

DOE Contact: M. J. Katz, (202) 586-5799

$\$ 109,000$

LANL (Contract No. W-7405-ENG-36) Contact: A. Bishop, (505) 667-6491

We applied analytical techniques developed in nonlinear science and simulation techniques using massively parallel computation to study textures and their dynamical consequences in areas of condensed matter and materials science. Specifically we have (1) implemented a Langevin MD code on the CM-2 that allows for study of large 2D Josephson junction arrays and 2D magnets; (2) simulated spiral surface growth in the presence of Frank-Read dislocation sources; (3) developed a nonlinear-nonlocal elasticity formalism for 2D martensitic materials; (4) discovered a new "glassy" relaxation response for large arrays of Josephson junctions in the presence of thermal noise and structural disorder; (5) used collective coordinate and MC-MD techniques to analyze the classical anisotropic Heisenberg model and relate dynamics of vortices to recent experiments.

Keywords: Textures, Condensed Matter, Materials Science, CM-2, Frank-Read Dislocations, Josephson Junctions, Heisenberg Model

449. Surface Modification of Materials

FY 1994

DOE Contact: M. J. Katz, (202) 586-5799

$\$ 315,000$

LANL (Contract No. W-7405-ENG-36) Contact: M. Nastasi, (505) 667-7007

A combination of surface processing techniques, including reactive and non-reactive physical vapor deposition (PVD), ion implantation alloying, ion beam and excimer laser mixing, have been used to synthesize intermetallic, ceramic, and composite coatings with amorphous and/or ultrafine-microstructures. The influence of synthesis variables on microstructural evolution and phase formation was evaluated using X-ray diffraction and transmission electron microscopy. Composition analysis was carried out using ion backscattering. The surface mechanical properties of these materials were evaluated for 
hardness and modulus using nanoindentation techniques and, in some instance, the friction and wear performance was also evaluated using a pin-on-disk tribometer.

Keywords: Physical Vapor Deposition, Ion Implantation, Ion Beam/Laser Mixing, Intermetallic Coatings, Ceramic Coatings, Composites

450. Integration of Fundamental Knowledge in Plasticity and

Textures to Provide Technical Tools for Microscopic

Applications

FY 1994

$\$ 290,000$

DOE Contact: M. J. Katz, (202) 586-5799

LANL (Contract No. W-7405-ENG-36) Contact: U. F. Kocks, (505) 667-9323

The individual components of understanding that have been developed in basic research on mechanical properties are being integrated into a complete, coherent description of material behavior in plasticity. This involves the kinetics of flow and strain hardening, as well as texture development and the influence of textures' on plastic anisotropy. Methods are established for determining the parameters required for applications of the model. User-friendly computer codes are maintained for the analysis of experimental textures, as well as for the prediction of current anisotropies on the basis of measured textures, and for the future development of texture and anisotropy during deformation through simulation of polycrystal plasticity. One aim is to foster development of a universal materials response package for incorporation into large engineering design codes for structures as well as processing. Conversely, these codes are used to derive properties of heterogeneous materials.

Keywords: Texture, Plastic Anisotropy, Plastic Deformation, Polycrystal Plasticity, Modeling

451. High Resolution Electron Microscopy of Materials

FY 1994 $\$ 350,000$

DOE Contact: M. J. Katz, (202) 586-5799

LANL (Contract No. W-7405-ENG-36) Contact: T. E. Mitchell, (505) 667-0938

The high resolution electron microscopy (HREM) facility is based on a Philips CM30T microscope operating at $300 \mathrm{kV}$. Its point-to-point resolution of $1.9 \mathrm{~A}$ makes it possible to obtain structure images of most materials at the atomic level. Image processing and enhancement procedures are being used to optimize the images obtained. Multi-slice image simulations on proposed structures are used to compare with experimental images and obtain information on atomic positions around defects such as dislocation and interfaces. HREM is being used on a wide range of materials applications. These include interfaces in semiconductor multilayers, grain boundaries in high temperature 
superconductors, twin boundaries in molybdenum disilicide, interfaces between silicon carbide and silicon nitride, and dislocations in refractory oxides.

Keywords: High Resolution Electron Microscopy, Materials at the Atomic Level, Molybdenum Disilicide, Silicon Carbide/Silicon Nitride Interfaces, Refractory Oxides

452. Nano-Fabrication

FY 1994

$\$ 255,000$

DOE Contact: M. J. Katz, (202) 586-5799

LANL (Contract No. W-7405-ENG-36) Contact: Robert Day, (505) 667-2957

This project combines theory and experiment to investigate the limits of nanofabrication technology. We are primarily using molecular dynamics (MD) to simulate the actions and interaction of materials at the nanometer size. MD is used to study the stability of nanofeatures and to simulate nanomachining.

Keywords: Nano-fabrication, Molecular Dynamics, Nanomachining

453. Thin Film Micro-Electrochemical Sensor Development

FY 1994

DOE Contact: M. J. Katz, (202) 586-5799

$\$ 210,000$

LANL (Contract No. W-7405-ENG-36) Contact: F. H. Garzon, (505) 667-6643

The objective of this project is the development of solid state microelectrochemical sensors that are applicable to the monitoring of hazardous gases such as: chlorine containing solvent vapors, sulfur dioxide, and halogen gases.

Keywords: Chemical Sensors, Chlorinated Hydrocarbons, Sulfur Oxides, Halogen Gases

454. Liquid Crystal Thermosets

FY 1994

$\$ 200,000$

DOE Contact: M. J. Katz, (202) 586-5799

LANL (Contract No. W-7405-ENG-36) Contact: B. C. Benicewicz, (505) 665-0101

Designing composite materials at the nano-scale or molecular level is predicted to lead to mechanical properties several orders of magnitude greater than current materials. In the area of organic polymer composites, it has been shown that increases in properties are possible, but the usefulness of such materials is limited because of phase separation of the immiscible liquid crystal reinforcement and isotropic matrix components. This effort is 
a study of a new concept to make stable molecular composites using high performance liquid crystal polymers and newly developed liquid crystal thermoset matrices.

Keywords: Liquid Crystal Polymers

455. Neutron and Resonant X-ray Scattering by Materials

FY 1994

$\$ 350,000$

DOE Contact: M. J. Katz, (202) 586-5799

LANL (Contract No. W-7405-ENG-36) Contact: A. C. Lawson, (505) 667-8844

The techniques of pulsed neutron scattering and resonant X-ray diffraction are used to study materials such as actinides, f-electron ferromagnets and structural materials.

Keywords: Neutron Scattering, X-ray Scattering, Actinides, Ferromagnets

456. Structural and Electronic Competitions in Low-Dimensional

Materials

FY 1994

$\$ 360,000$

DOE Contact: M. J. Katz, (202) 586-5799

LANL (Contract No. W-7405-ENG-36) Contact: B. I. Swanson, (505) 667-5814

This represents a combined theoretical and experimental study of the structural and electronic properties of low-dimensional electronic materials as they are tuned to the phase boundary region between different broken symmetry states (charge-density-and spin-density-wave, CDW and SDW). Within the CDW/SDW phase boundary region, competitions arise between the ground and local states (doping, photoinduced) that give rise to large changes in the transport (electrical) and optical properties. Work to date has focused on (1) developing new approaches to chemically tuning these materials through the phase boundary region, (2) studies (theory and experiment) of weak CDW and SDW materials, and (3) studies of mixed-halide materials, where the properties of the dominant species can be used to control the structure and electronics of the doped species. Key findings to date include (1) a new approach to tuning these materials through a structural "template" effect, (2) many-body modeling of species near the phase boundary region that shows evidence for CDW/SDW transitions arld complex new structures, and (3) observation of the quenching of the Peierls distortion and the CDW in MX' segments of chains doped into a host MS lattice.

Keywords: Me Phase Boundary Tuning, Low-Dimensional Electronic Materials 
457. Fundamental Aspects of Photoelectron Spectroscopy in Highly Correlated Electronic Systems

FY 1994

$\$ 300,000$

DOE Contact: M. J. Katz, (202) 586-5799

LANL (Contract No. W-7405-ENG-36) Contact: A. K. Arko, (505) 665-0758

Materials displaying strong electron-electron correlations continue to occupy condensed matter physicists, particularly in view of high $T_{c}$ materials, where these correlations may be all important. Several variations of the Hubbard model are proposed as possible representations of this electronic structure. Photoelectron spectroscopy plays a major role in this research since it is one of the few experimental tools via which it is possible to observe the electronic structure directly without resorting to interpretation. We have performed numerous photoelectron spectroscopy tests on a large number of $\mathrm{Ce}$ - and $\mathrm{Yb}$-based heavy fermions and compared the results to predictions of the model. Our single crystal data continue to indicate that the features usually identified as arising from the magnetic, or Kondo interaction, are much more logically described to first order as simple core levels.

Keywords: Photoemission Spectroscopy, Electronic Correlations

458. Development of High Strength High Conductivity Materials for High Magnetic Field Devices

FY 1994

$\$ 100,000$

DOE Contact: M. J. Katz, (202) 586-5799

LANL (Contract No. W-7405-ENG-36) Contact: F. M. Mueller, (505) 667-9244

The project will cover the fabrication analysis and design of high strength high conductivity materials for pulsed magnet applications of relevance to NHMFL. New methods of fabrication will be considered based on the use of rapid solidification and cryogenic forming. An analysis of the materials will be conducted based on measurement of mechanical properties, characterization of the structure by SEM and TEM methods and measurement of the ratio of the electrical conductivity at $293 \mathrm{~K}$ and $77 \mathrm{~K}$ as a function of the material's thermal-mechanical history. Attempts will be made to link the results of the study directly to the needs of NHMFL in terms of both magnetic coil design and optimization of relevant fabrication methods.

Keywords: Conductive Materials, Magnetic Coil Designs 
459. Low Temperature STM for Structural and Spectroscopic Studies of High Temperature Superconductors and Other Electronic Materials

DOE Contact: M. J. Katz, (202) 586-5799

LANL (Contract No. W-7405-ENG-36) Contact: M. Hawley, (505) 665-3600

The STM is a powerful probe of the local density of states in the study of electronic materials. The extension of this capability to low temperatures creates an opportunity to apply this technique to such studies as phase transitions in low dimensional electronic materials and in superconductors, i.e., I-V gap measurements and vortex lattices. To this end, this program includes the design and construction of a variable low temperature STM for the study of these materials. Where possible, we will explore the utility of this technique in the study of changes in morphology of structural materials with lower temperature applications and to the fabrication of nanoscale features.

Keywords: Scanning Tunneling Microscope, Electronic Materials, Low Temperature Scanning

460. Materials with Fine Microstructures

FY 1994

DOE Contact: M. J. Katz, (202) 586-5799

$\$ 365,000$

LANL (Contract No. W-7405-ENG-36) Contact: R. B. Schwarz, (505) 667-8454

The refinement of the microstructure of multiphase alloys can lead to significant enhancements in the mechanical properties of engineered materials. One synthesis route for such materials is the consolidation of powders with fine microstructures. This program addresses both the problem of synthesizing powders with fine microstructures and the problem of consolidating these powders while preserving their fine microstructure.

Keywords: Multiphase Alloys, Microstructure, Powder Consolidation

461. Ion Beam Materials Research

FY 1994

DOE Contact: M. J. Katz, (202) 586-5799

$\$ 330,000$

LANL (Contract No. W-7405-ENG-36) Contact: C. J. Maggiore, (505) 667-6133

The synthesis of any new material cannot proceed efficiently without the quantitative characterization of the composition and structure of the material actually fabricated. The use of $\mathrm{MeV}$ ions is a well understood means of quantitative analysis and is routinely available at the IBML (Ion Beam Materials Laboratory). However, the continued development of new materials with better defined structure and composition on a finer scale 
has placed more stringent requirements on existing analytical methods. The objective of this program is to extend the analytical range and applicability of the IBML to the classes of new synthetic materials of current technological interest. Samples will be prepared by a variety of collaborators that are suitable for studying the fundamental limitations of multiple straggling on depth resolution using ion beams, improving sensitivity limits for light elements in complex samples using prompt and delayed nuclear reaction analysis, and bulk detection of hydrogen.

Keywords: Ion Beam Characterization

462. Texture Studies of Highly Deformed Composite Materials

FY 1994

$\$ 192,000$

DOE Contact: M. J. Katz, (202) 586-5799

LANL (Contract No. W-7405-ENG-36) Contact: A. C. Larson, (505) 667-2942

Recently scientists have become interested in creating composite materials, such as high Tc-superconductors encased in silver wire and then deformed to prepare a tape, aluminum with $\mathrm{SiC}$ whiskers embedded in the aluminum matrix and copper metal containing tungsten wires. These composite materials are an effort to prepare materials displaying an optimal combination of the properties of the component materials. It is important to recognize that, in the deformation of two-phase systems, two processes become of importance: (a) the development of accommodation strain or arrays of geometrically necessary dislocations around the particles of the more rigid phase and (b) a change in the patterns of the flow in each phase due to the presence of the other phase. The occurrence of these processes is dependent on the relative fractions of the phases. We propose to study the relationships among the phases present in a composite by examination of the texture or orientation distribution of the crystallites in each phase.

Keywords: Silicon Carbide Whisker Reinforced Aluminum, Tungsten Wire Reinforced Copper, Two Phase Deformation

463. Pressure Dependency of the Structure of High Explosives: Nitromethane

$\frac{F Y 1994}{\$ 192,000}$

DOE Contact: M. J. Katz, (202) 586-5799

LANL (Contract No. W-7405:ENG-36) Contact: R. B. VonDreele, (505) 667-3630

This program examines the structural changes as a function of pressure for nitromethane and correlates them with the pressure dependence of solid state ionization processes proposed as an explosion front propagation mechanism.

Keywords: Nitromethane, Pressure Dependencies, Explosive Front Propagation Mechanisms 
464. Neutron Reflection Studies of Thin Film and Multilaver Structures

FY 1994

$\$ 300,000$

DOE Contact: M. J. Katz, (202) 586-5799

LANL (Contract No. W-7405-ENG-36) Contact: M. R. Fitzsimmons, (505) 665-4045

The purpose of this research program is to understand magnetism in thin film and multilayer structures using polarized neutron reflection (PNR). In order to obtain meaningful measurements of the magnetic structures and properties of surfaces and interfaces, the capability to manufacture thin films and multilayers, while PNR measurements are made, is essential. Such a capability-a first for a neutron source-will be developed. Topics to be explored by this research program are: two-dimensional magnetism, the kinetics of diffusion within multilayers, diffusion-induced changes of the magnetic properties of multilayers, the correlation between the magnetic properties of surfaces and interfaces with their roughness, and the design of improved super-mirrors for neutron applications.

Keywords: Magnetic Properties of Thin Filnns, Polarized Neutron Diffusion in Multilayers

\section{Neutron Reflectivity Studies of In Situ Corrosion of Metal Surfaces}

FY 1994

$\$ 145,000$

DOE Contact: M. J. Katz, (202) 586-5799

LANL (Contract No. W-7405-ENG-36) Contact: G. S. Smith, (505) 665-2842

Corrosion of metallic surfaces have been studied for many years by several techniques. These studies have looked at the problem of corrosion both as a problem to be eradicated and as a useful end to the electroplating process. Never before has anyone been able to look at the microscopic details of composition as well as surface roughness at the metal-electrolyte interface. This program uses neutron reflectometry to study these features.

Keywords: Corrosion, Neutron Reflectometry

466. The Dynamics of Amorphous Materials

FY 1994

$\$ 330,000$

DOE Contact: M. J. Katz, (202) 586-5799

LANL (Contract No. W-7405-ENG-36) Contact: R. A. Robinson, (505) 667-3626

This research program studies the vibrational and magnetic dynamics of amorphous materials, using inelastic neutron scattering. While atomic and magnetic fluctuations are well understood as collective excitations (e.g., phonons, magnons) in single crystals, much 
less is understood in amorphous materials. The materials to be studied include silica, porous silica aerogels, a metallic glass and metglas.

Keywords: Vibration Dynamics, Magnetic Dynamics, Silica, Silica Aerogels, Metallic Glasses

467. Advanced Material Science Algorithms for Supercomputer Architectures

$\frac{\text { FY } 1994}{\$ 75,000}$

DOE Contact: M. J. Katz, (202) 586-5799

LANL (Contract No. W-7405-ENG-36) Contact: J. E. Gubernatis, (505) 667-6727

This project is concerned with exploiting the potential new computer architectures offer to improving the understanding and modeling of material properties and behavior through computer simulation. The focus is on developing the simulation ability to study flux line dynamics, noise, melting, and pinning in London and Ginzburg-Landau phenomenological models of thin films on high temperature superconducting materials. The emphasis of the program is also on parallizing the world-line quantum Monte Carlo method and developing procedures to extract dynamical information from imaginary-time quantum Monte Carlo data.

Keywords: High Temperature Superconducting Materials, London Phenomenological Models, Ginzburg-Landau Phenomenological Models

468. Metal Vapor Synthesis in Organometallic Chemistry

FY 1994

DOE Contact: M. J. Katz, (202) 586-5799

$\$ 235,000$

LANL (Contract No. W-7405-ENG-36) Contact: J. G. Watkin, (505) 667-4546

This program will employ the rare synthetic technique of metal vapor synthesis (MVS) to prepare a series of organometallic complexes of middle- and late-transition metals and lanthanides. Applications include catalytic processes and/or organic synthesis. The technique of metal vapor synthesis has been employed to prepare many examples of low-valent early transition metal complexes which have been shown to exhibit high reactivity, but the technique has rarely been applied to the later transition metals such as $\mathbf{R h}, \mathbf{I r}, \mathbf{P d}$, $\mathrm{Pt}$ and the lanthanides.

Keywords: Metal Vapor Synthesis, Lanthanides 
469. Separation Chemistry of Toxic Metals:

FY 1994

DOE Contact: M. J. Katz, (202) 586-5799

$\$ 250,000$

LANL (Contract No. W-7405-ENG-36) Contact: P. H. Smith, (505) 667-1604

The goal of this research is to develop a new class of chelators for toxic metals which have the capacity to bind two species and where the binding of one substrate affects the binding of the second. In the process we hope to gain a fundamental understanding of the key parameters which govern toxic metal ion selective binding as it relates to separations chemistry. We will synthesize and evaluate a class of chelators which add a new dimension to coordination chemistry, namely cooperative/antagonistic binding. The chemistry involves the development and synthesis of ditopical receptors which contain two binding sites in close proximity to each other. In systems with cation and anion sites, the simultaneous binding of both a cation and an anion can enhance the overall binding constants relative to either one binding alone.

Keywords: Cooperative/Antagonistic Binding Sites, Chelates, Ditopical Receptors

470. Polymers for Integrated Optical Interconnects

FY 1994

DOE Contact: M. J. Katz, (202) 586-5799

$\$ 266,000$

LANL (Contract No. W-7405-ENG-36) Contact: B. Laurich, (505) 665-0333

The recent discovery of electroluminescent polymers opens up, for the first time, the possibility of using optical interconnects for conventional silicon integrated circuits. If this capability can be realized, it will have a tremendous impact on the architecture and performance of the complex computing and communications systems.

Keywords: Electroluminescent Polymers, Integrated Optical Interconnects

471. High Temperature Materials Synthesis Without Heat: Oxide Layer Growth on Electronic Materials Using High Kinetic Energy Atomic Species

FY 1994 $\$ 164,000$

DOE Contact: M. J. Katz, (202) 586-5799

LANL (Contract No. W-7405-ENG-36) Contact: M. A. Hoffbauer, (505) 667-4878

This research program examines high temperature materials synthesis using high kinetic energy atomic species instead of heat. Emphasis is being placed on the direct growth of oxide and nitride insulating layers on compound semiconducting electronic materials such as $\mathrm{GaAs}$ where we have already shown the unprecedented formation of oxide layers that are thick, uniform, and of extremely high quality. Research into this novel material synthesis 
process with the aim of producing and demonstrating device-quality oxide layers is being emphasized. Application of this materials synthesis technology to space-based manufacturing technology is also being pursued.

Keywords: Ceramic Oxides, Ceramic Nitrides, Insulating Layers, KE Atomic Heating

472. Dynamic Deformation of Advanced Materials

FY 1994 $\$ 855,000$

DOE Contact: M. J. Katz, (202) 586-5799

LANL (Contract No. W-7405-ENG-36) Contact: G. T. Gray, (505) 667-5452

Composites, metal or ceramic matrix, and advanced materials, such as intermetallics, are receiving increasing attention due to their higher specific strengths, stiffness, and high temperature properties. Advanced composites also allow other physical properties besides mechanical properties to be custom tailored to specific applications. Increased utilization of these material classes under dynamic loading conditions requires an understanding of the relationship between high-rate/shock-wave response as a function of microstructure if predictive material behavior capabilities are to be attained. This program is a multidisciplinary effort to investigate the influence of microstructure, anisotropy, orientation, and structural ordering on the high-strain-rate and shock-wave deformation behavior of advanced composites and intermetallics. The long-term objective is to provide high quality experimental measurements on advanced materials to facilitate the development of predictive computational models.

Keywords: High-Strain Rate Deformation, Shock-Wave Deformation, Composites, Intermetallics

473. Strain Measurements in Individual Phases of Multi-Phase Materials

FY 1994

$\$ 130,000$

DOE Contact: M. J. Katz, (202) 586-5799

LANL (Contract No. W-7405-ENG-36) Contact: J. A. Goldstone, (505) 667-3629

Employment of metal matrix and ceramic composites in high-technology aerospace applications or as lighter (more economic) material in the auto industry requires the development of analytical methods capable of predicting the durability, debonding, and damage tolerance during the mechanical and thermal loads expected during service. Neutron diffraction has been used to measure residual stress in composites, steels, and compacted powders. We wish to extend our capability by acquiring a stress rig with a furnace to make in situ measurements of material response. This will permit measurements 
on technologically important materials under conditions close to service. Preliminary studies will address an $\mathrm{Al} / \mathrm{TiC}$ composite (under consideration for automotive use) and $\mathrm{MoSi}_{2}$.

Keywords: Neutron Diffraction, Aluminum/Titanium Carbide Composites, Molybdenum Disilicide Composites

\section{Artificially Structured Nonlinear Optic and Electro-Optic Materials}

FY 1994

$\$ 465,000$

DOE Contact: M. J. Katz, (202) 586-5799

LANL (Contract No. W-7405-ENG-36) Contact: B. I. Swanson, (505) 667-5814

New artificially structured materials that are optimized for nonlinear optic (NLO) and electro-optic applications will be synthesized, characterized, and modeled. Materials based on two new synthetic strategies will be pursued. Chromophores with optical absorptions tuned to the red and near-IR portion of the spectrum will be directly attached to optical surfaces through the use of covalent bonding of self-assembled (CBSA) mono- and multilayers. The second strategy is based on the construction of single hetero-junctions or multiple hetero-junctions in superlattice materials where charge separation across the junctions results in optimal NLO and electro-optic properties. The overall goal is to further develop these two synthetic approaches through a combined synthesis, characterization, and theory effort where materials modeling, benchmarked by observed physical properties, is used to guide rational synthesis of advanced materials.

Keywords: Nonlinear Optic Materials, Electro-Optic Materials, Superlattice Materials

475. Structural Phase Transitions in Non-Stoichiometric Oxides

FY 1994

DOE Contact: M. J. Katz, (202) 586-5799

$\$ 275,000$

LANL (Contract No. W-7405-ENG-36) Contact: A. Migliori, (505) 667-2515

Structural phase transitions (SPT) have profound effects on mechanical, magnetic, and electronic properties. In Stoichiometric compounds, SPTs are well understood and produce the magnetism in ferrites and the ferroelectricity in piezoelectric oxides that make these materials so important. However, for non-stoichiometric compounds, the situation is very far from clear, and the puzzles are not neerely academic. For example, the high $T_{c}$ perovskite $\mathrm{La}_{2-\mathrm{x}} \mathrm{Sr}_{\mathrm{x}} \mathrm{CuO}_{4}$ undergoes a second-order SPT from a tetragonal to an orthorhombic structure upon cooling through $\mathrm{T}_{s}(\mathrm{x})$. As $\mathrm{T}_{\mathrm{s}}$ is approached from either direction, one shear modulus collapses, making the material mechanically partially unstable, a non-trivial consequence for applications. The surprise is that this collapse begins $100 \mathrm{~K}$ above $\mathrm{T}_{\mathrm{s}}$, not at $2 \mathrm{~K}$ predicted by the best theoretical approach. Resonant Ultrasound Spectroscopic (RUS) studies of this and other SPTs reveal additional and subtle problems 
with current theory, not observed with any other experimental problem. Lack of just this sort of observation has stymied the theory of SPTs in heavily doped crystals because a simple observation of modulus collapse cannot distinguish between several competing possibilities. An understanding of the effects of doping on material properties near SPTs is of extreme fundamental interest and is crucial for a very broad spectrum of applications; recent observations by us suggest that only LANL's unique RUS capability can provide the necessary clues.

Keywords: Resonant Ultrasound Spectroscopy, Structural Phase Transitions

476. Strongly Correlated Electronic Materials

FY 1994

$\$ 495,000$

DOE Contact: M. J. Katz, (202) 586-5799

LANL (Contract No. W-7405-ENG-36) Contact: K. S. Bedell, (505) 665-0478

New, novel materials have a number of extraordinary and often unexpected properties and, it is likely, they will play a major role in the high-technology electronic materials of the future. To better design materials for specific applications it is necessary to understand the microscopic origins of their novel physical characteristics. To relate the microscopic models of these strongly correlated systems to specific materials properties requires the extension of and the development of new many-body techniques. This program provides the basic science component for a number of new initiatives that include the Presidential initiative in materials science, the Advanced Computing Laboratory (ACL), the use of novel electronic materials for device applications, the National High Magnetic Field Laboratory (NHMFL), the UC Los Alamos INCOR program in high temperature superconductivity (HTS), and the Program in Correlated Electron Theory.

Keywords: High-Temperature Electronic Materials, Electronic Correlations

477. Plasma Immersion Ion Implantation for Semiconductor Film Growth

FY 1994

$\$ 261,000$

DOE Contact: M. J. Katz, (202) 586-5799

LANL (Contract No. W-7405-ENG-36) Contact: M. Tuszewski, (505) 667-3566

An interdisciplinary team of plasma and semiconductor physicists will develop a novel plasma implanter for thin film growth on semiconductors with unprecedented control. The scientific objectives of this project are: (1) construction of a compact, inexpensive, and high-throughput implanter based on an inductive plasma source and on e plasma immersion ion implantation (PIII) technique; (2) extension of the PIII technique to higher frequencies, lower voltages, and higher dose rates; (3) characterization, optimization, and control of the 
plasma species concentrations and impurities; (4) generation of semiconductor dielectrics and alloys for new electronics device technologies.

Keywords: Plasma Ion Implantation, Semiconducting Materials

478. Analysis of Structure and Orientation of Adsorbed Polymer in Solution Subject to Dynamic Shear Stress

FY 1994

$\$ 172,000$

DOE Contact: M. J. Katz, (202) 586-5799

LANL (Contract No. W-7405-ENG-36) Contact: S. Baker, (505) 667-6069

Polymer based separation techniques rely on the ability of a binding portion of the polymer to interact with a specific molecule in a solution flowing past the polymer. The location of the binding site within or out of the entangled polymer chains is thus crucial to the effectiveness of these methods. For this reason, the details of flow induced deformation of the polymer chains is important in such applications as exclusion chromatography, waste water treatment, ultrafiltration, enhanced oil recovery and microbial adhesion. Few techniques exist to examine the structure and orientation of polymeric materials, and even fewer to examine systems in a dynamic fluid flow. The goal of this program is to understand the molecular structure and orientation of adsorbed polymers with and without active binding ligands as a function of solvent shear rate, solvent power, polymer molecular weight, surface polymer coverage, and heterogeneity of the surface polymer chains by neutron reflectometry in a newly Designed shear cell. Geometrical effects on binding of molecules in the flow will also be studied subject to the same parameters.

Keywords: Polymer Molecules, Neutron Reflectometry, Flow Induced Deformation

479. Development of Pair Distribution Function Analysis of Mesostructural Details in Single Crystal Perovskites and Nanocrystalline Materials

FY 1994

$\$ 170,000$

DOE Contact: M. J. Katz, (202) 586-5799

LANL (Contract No. W-7405-ENG-36) Contact: G. H. Kwei, (505) 667-8840

It has become increasingly evident that structural coherence in the $\mathrm{CuO}_{2}$ planes of high-Tc superconducting (HTSC) materials over some intermediate length scale (in the nanometer range) is important to superconductivity. Significant progress has been made in understanding these structural instabilities using pair distribution function analysis of powder diffraction data. However, PDF diffraction data on single crystals is required, both because of the greater amount of information in the latter and because of the much greater sample quality that is available in single crystals. The goal of this program is to develop analysis techniques for obtaining PDF's from single crystal diffraction data and to use these techniques to study structural instabilities and structural coherence in HTSC and other 
interesting materials. PDF techniques are also planned for studying mesostructural features in nanocrystalline materials.

Keywords: Powder Diffraction Analysis, High Temperature Superconductors, Mesostructural Nanocrystals

480. Neutron Scattering as a Probe of the Structure of Liquid Crystal Polymer-Reinforced Composite Materials

FY 1994

$\$ 180,000$

DOE Contact: M. J. Katz, (202) 586-5799

LANL (Contract No. W-7405-ENG-36) Contact: R. P. Hjelm, (505) 665-2372

The goal of this program is to obtain nanoscale and molecular level information on the mechanism of reinforcement 9 n crystal polymer-reinforced composites, and to realize the production of molecularly-reinforced LCP composites. Small-angle neutron scattering methods are proposed to study the structures on length scales ranging from 10-1000 $\AA$. The goal of the small-angle scattering measurements is to understand the morphology of separation of the reinforcing and matrix phases as a function of composition, mixing, temperature and other process conditions. This information will be correlated with mechanical properties to achieve a better understanding of the molecular mechanism of reinforcement.

Keywords: Small-Angle Neutron Scattering, Polymer Composites

481. Strain Measurements in Individual Phases of Multi-Phased

Materials During Thermomechanical Loading: LANSCE Neutron

Scattering Experiment Support

FY 1994

$\$ 318,000$

DOE Contact: M. J. Katz, (202) 586-5799

LANL (Contract No. W-7405-ENG-36) Contact: J. A. Goldstone, (505) 667-3629

Employment of metal matrix and ceramic composites in high-technology aerospace applications or as lighter (more economic) material, in the auto industry requires the development of analytical methods capable of predicting the durability, debonding, and damage tolerance during the mechanical and thermal loads expected during service. Neutron diffraction has been used to measure residual stress in composites, steels and compacted powders. We wish to extend our capability by acquiring a stress rig with a furnace to make in situ measurements of material response. This will permit measurements on technologically important materials under conditions close to service. Preliminary studies will address an $\mathrm{Al} / \mathrm{TiC}$ composite (under consideration for automotive use) and $\mathrm{MoSi}_{2}$.

Keywords: Neutron Diffraction, Metal Matrix Composites, Ceramic Matrix Composites 
482. A New Approach to Texture Measurernents: ODF Determination by Rietveld Refinement

FY 1994

$\$ 73,000$

DOE Contact: M. J. Katz, (202) 586-5799

LANL (Contract No. W-7405-ENG-36) Contact: R. B. VonDreele, (505) 667-3630

This program centers on the development of the experimental procedures and the mathematical treatment needed to produce an orientation distribution function (ODF) directly from full diffraction patterns from a sample in a limited number of orientations.

Keywords: Texture Measurement, Orientation Distribution Function, Diffraction Patterns

483. Applications of Fullerenes in Nuclear Technology

FY 1994

DOE Contact: M. J. Katz, (202) 586-5799

$\$ 360,000$

LANL (Contract No. W-7405-ENG-36) Contact: D. K. Veirs, (505) 667-9291

The major focus of our research efforts is in the use of fullerene-based materials in the solution to problems in the nuclear research and industry. Fullerene encapsulation of nuclear waste is of interest in the storage of high-level nuclear waste. Fullerene-encapsulated uranium or plutonium may be very stable with respect to the environment and may provide a safe and efficient way of disposing of nuclear waste. The metal-in-fullerene aspect or metal-doped fullerene compounds in conjunction with the high thermal stability and low density of fullerene suggests the fabrication of efficient, high-yield targets for the production of radioactive beams. It is likely that a target composed fullerene, upon proton-induced fission or spallation of the uranium, will allow the efficient release of the fission or spallation products for the purpose of producing radioactive nuclear beams. We propose to explore the production of actinide fullerides and to develop the relevant technology to generate and separate them for these purposes.

Keywords: Fullerenes, Encapsulation, Nuclear: Waste, Uranium, Plutonium

484. Ceramic Oxide Foams for Separation

FY 1994

$\$ 400,000$

DOE Contact: M. J. Katz, (202) 586-5799

LANL (Contract No. W-7405-ENG-36) Contact: P. C. Apen, (505) 665-7513

Ceramic oxide foams and novel foam structures are playing an important role in environmental R\&D, specifically in the areas of chemical separations and filtration for removal of heavy metals and particulates from contaminated waste streams and effluent. This program focusses on the investigation of virgin oxide and surface-modified oxide foams in environmental remediation applications. Processes for the preparation and modification 
of porous ceramic structures will be developed and the products characterized for functionality in the separation of heavy metal and toxic particulates from waste streams.

Keywords: Silica Foams, Silica Sol-Gels, Heavy Metal Ligands, Metal Ion Chelating Agents

485. Materials Modeling Project

FY 1994

DOE Contact: M. J. Katz, (202) 586-5799

$\$ 125,000$

LANL (Contract No. W-7405-ENG-36) Contact: R. LeSar, (505) 665-0420

This program involves the modeling of laser-assisted deposition processes with an emphasis on laser/solid interactions, plasma chemistry and dynamics, nucleation and growth, and the theoretical design of novel materials. The modeling will also involve analytical studies of strain-induced diffusion along specific interfaces and Monte Carlo studies of diffusion in polycrystalline materials. The goal of the program is to link this work with a micromechanical fracture model.

Keywords: Laser-Assisted Deposition Processes, Micromechanical Fracture Models, Plasma Chemistry

486. Synthesis and Optical Characterization of Novel Fullerene-Based Composites

FY 1994

$\$ 50,000$

DOE Contact: M. J. Katz, (202) 586-5799

LANL (Contract No. W-7405-ENG-36) Contact: J. M. Robinson, (505) 665-4834

This program takes an interdisciplinary approach to develop and study a novel family of fullerene-based organic and inorganic composites for applications as photodiodes and photovoltaic devices. The emphasis of the program is on "proof of principle" for the synthesis of new composite materials which will guide further synthetic refinements. A novel "host-guest" chemistry will result in two new classes of materials. The first class utilizes sol-gel chemistry to incorporate fullerenes into optically transparent hosts that are processable into thick glass monoliths or thin film waveguides. The principal role of the host is to protect the fullerene guests from environmental degradation, and to provide a low loss transparent medium for light transmission. The second class of materials is based on fullerene/conjugated polymer composites.

Keywords: Fullerene Composites, Photodiodes, Photovoltaic Devices, Sol-Gels 
Technology Transfer Initiative

487. A Pilot Program: Chemical Vapor Deposition of Diamond in a Fluidized-Bed for Cutting Tool and Tribological Applications

FY 1994

$\$ 250,000$

DOE Contact: W. P. Chernock (202) 586-7590

LANL (Contract No. W-7405-ENG-36) Contact: David Carroll, (505) 667-2145

A program to develop and commercialize a process to generate high-quality diamond coatings for machine tools.

Keywords: Diamond Coatings, Chemical Vapor Deposition, Cutting Tools, Tribology

488. Advanced Beryllium Processing

FY 1994

DOE Contact: W. P. Chernock (202) 586-7590

$\$ 632,000$

LANL (Contract No. W-7405-ENG-36) Contact: Loren Jacobson, (505) 667-5151

A program to produce beryllium powders and rolled beryllium sheet using improved manufacturing techniques that minimize worker exposure and reduce the environmental consequences of beryllium processing.

Keywords: Beryllium Processing, Beryllium A.lloy Processing, Centrifugal Atomization

489. Automated Pulsed Laser Deposition System

FY 1994

DOE Contact: W. P. Chernock (202) 586-7590

$\$ 130,000$

LANL (Contract No. W-7405-ENG-36) Contact: Ross Muenchausen, (505) 665-4949

A program to design an automated pullsed laser deposition system to deposit hightemperature superconducting thin films.

Keywords: Pulsed-Laser-Deposition, High-Ternperature Superconducting Films 
490. Plasma Source Ion Implantation for the Automotive Industry

FY 1994

$\$ 1,326,000$

DOE Contact: W. P. Chernock (202) 586-7590

LANL (Contract No. W-7405-ENG-36) Contact: Donald Rej (505) 665-1883

A program to develop a production-scale plasma-source ion implantation system for improving the surface properties of auto parts.

Keywords: Plasmas, Ion Implantation, Tool Hardening

491. Processing Modeling and Control for U.S.Steel Industry

FY 1994

DOE Contact: W. P. Chernock (202) 586-7590

$\$ 1,195,000$

LANL (Contract No. W-7405-ENG-36) Contact: Brian Lally, (505) 667-9954 Industry.

A program to develop new process models and control systems for the U.S. Steel

Keywords: Steel, Electric-Arc-Furnace, Scrap Steels 
OFFICE OF FOSSIL ENERGY

FY 1994

Office of Fossil Energy - Grand Total

$\$ 8,628,000$

Office of Advanced Research

$\$ 8,628,000$

Fossil Energy AR\&TD Materials Program

$\$ 8,628,000$

Materials Preparation, Synthesis, Deposition, Growth or Forming

$\$ 4,305,000$

Coating Process Development for Cr-Nb Alloys

Procurement of Advanced Austenitic and Aluminide Alloys

Development of Iron Aluminides

Ultrahigh Temperature Intermetallic Alloys

Microalloyed Iron Aluminides

Low-Aluminum Content Iron-Aluminum Alloys

Technology Transfer - Iron Aluminides

Development of a Modified 310 Stainless Steel

Technology Transfer - Advanced Austenitics

Influence of Processing on Microstructure and Properties of Aluminides

Investigation of Electrospark Deposited Coatings for

Protection of Materials in Sulfidizing Atmospheres

Technology Transfer - Electrospark-Deposited Coatings for Protection of Materials in Sulfidizing Atmospheres

Engineering-Scale Development of the Vapor-Liquid-Solid (VLS) Process for the Production of Silicon Carbide Fibrils

Ceramic Composite Processing Equipment

Fabrication of Fiber-Reinforced Composites by Chemical Vapor Infiltration and Deposition (CVID)

Development of Oxidation/Corrosion-Resistant Composite Materials and Interfaces

Optimization of the Chemical Vapor Infiltration Technique for Ceramic Composites

Transport Properties of Ceramic Composites

90,000

30,000

295,000

280,000

78,000

270,000

120,000

0

175,000

50,000

80,000

197,000

30,000

150,000

150,000

50,000

140,000 


\section{OFFICE OF FOSSIL ENERGY}

FY 1994

Office of Advanced Research (continued)

Fossil Energy AR\&TD Materials Program (continued)

Materials Preparation, Synthesis, Deposition, Growth or Forming (continued)

Modeling of Fibrous Preforms for CVD Infiltration

55,000

Corrosion Protection of SiC-Based Ceramics with CVD

Mullite Coatings

100,000

Feasibility of Synthesizing Oxide Films on Ceramic and

Metal Substrates

100,000

Oxide Coating Development

75,000

High-Temperature Heat Exchanger and Hot-Gas Filter Development 250,000

Ceramic Coating Evaluation

50,000

Low-Temperature Fabrication of Transparent Silicon Nitride

180,000

Microwave-Assisted Chemical Vapor Infiltration

50,000

Development of Microwave-Heated Diesel Particulate Filters

75,000

Carbon Fiber Composite Molecular Sieves

310,000

Activation of Carbon Fiber Composite Molecular Sieves

75,000

Production of Aluminum Reduction Electrodes from Solvent-Extracted

Coal-Derived Carbon Feedstocks

15,000

Exploration of Coal-Based Pitch Precursors for Ultra-High Thermal

Conductivity Graphite Fibers

30,000

Development of Carbon-Carbon Composites from Solvent-Extracted

Pitch

25,000

Conversion of Pitches and Cokes from Solvent-Extracted Materials

Carbon Products Consortium

40,000

175,000

Economic Analysis of West Virginia University Solvent Extraction

Process

50,000

Development of Precursors for Production of Graphites and Carbon

Products

65,000

Solvent Extraction of Coal

Radio-Wave Nano-Phase Silicon Nitride and Silicon Carbide

Processes

300,000

100,000 


\section{OFFICE OF FOSSIL ENERGY}

FY 1994

Office of Advanced Research (continued)

Fossil Energy AR\&TD Materials Program (continued)

Materials Properties, Behavior, Characterization or Testing

$\$ 2,234,000$

Investigation of the Weldability of Polycrystalline Iron

Aluminides

75,000

Stress-Assisted Corrosion of Iron Aluminides

Fireside Corrosion Tests of Candidate Advanced Austenitic Alloys, Coatings, and Claddings

Joining Techniques for Advanced Austenitic Alloys

Fatigue and Fracture Behavior of $\mathrm{Cr}-\mathrm{Nb}$ Alloys

Corrosion and Mechanical Properties of Alloys in FBC and

Mixed-Gas Environments

Mechanically Reliable Coatings and Scales for High-Temperature

Corrosion Resistance

Environmental Effects on Iron Aluminides

Investigation of Moisture-Induced Embrittlement of Iron

Aluminides

Corrosion Protection of Ultrahigh Temperature Intermetallic

Alloys

Oxide Dispersion Strengthened (ODS) Iron Aluminide

Equipment

Oxide Dispersion Strengthened (ODS) Iron Aluminides

Materials Support for HITAF

Support Services for Ceramic Fiber-Ceramic Matrix Composites

Development of Nondestructive Evaluation Methods and Effects

of Flaws on the Fracture Behavior of Structural Ceramics

Fracture Behavior of Advanced Ceramic Hot-Gas Filters

Ceramic Catalyst Materials

50,000

80,000

65,000

50,000

310,000

100,000

225,000

60,000

220,000

50,000

75,000

175,000

50,000

310,000

114,000

225,000 
OFFICE OF FOSSIL ENERGY

FY 1994

Office of Advanced Research (continued)

Fossil Energy AR\&TD Materials Program (continued)

Device or Component Fabrication, Behavior or Testing

$\$ 1,650,000$

Materials and Components in Fossil Energy Applications

(Newsletter)

Fabrication of Full-Scale Fiber-Reinforced Hot-Gas Filters by Chemical Vapor Deposition

Development of Ceramic Membranes for Gas Separation

Investigation of the Mechanical Properties and Performance of Ceramic Composite Components

Stability of Solid Oxide Fuel Cell Materials

Mixed Oxygen Ion/Electron-Conducting Ceramics for Oxygen Separation and Fuel Cells

Proton-Conducting Cerate Ceramics

Technology Transfer - Iron Aluminide Filters

Thermal and Mechanical Analysis of a Ceramic Tubesheet

Thermal and Mechanical Analysis of a Ceramic Tubesheet

Technology Transfer - Ceramic Joining

Instrumentation and Facilities

60,000

115,000

400,000

100,000

250,000

225,000

225,000

50,000

40,000

10,000

175,000

$\$ 439,000$

Management of the Fossil Energy AR\&TD Materials Program

General Technology Transfer Activities

400,000

35,000

Gordon Research Conference Support

4,000 


\section{OFFICE OF FOSSIL ENERGY}

The Office of Fossil Energy responsibilities include management of the Department's fossil fuels (coal, oil and natural gas) research and development program. This research is generally directed by the Office of Coal Technology (OCT), the Office of Gas and Petroleum Technology, and the Office of Advanced Research and Special Technologies in support of the National Energy Strategy Goals for Increasing Energy Efficiency, Securing Future Energy Supplies, Respecting the Environment, and Fortifying our Foundations. Three specific fossil energy goals are currently being pursued:

- The first is to secure liquids supply and substitution. This goal targets the enhanced production of domestic petroleum and natural gas, the development of advanced, cost-competitive alternative fuels technology, and the development of coal-based, end-use technology to substitute for oil in applications traditionally fueled by liquid and gaseous fuel forms.

- The second is to develop power generation options with environmentally superior, high-efficiency technologies for the utility, industrial, and commercial sectors. This goal targets the development of super-clean, high-efficiency power generation technologies.

- The third is to pursue a global technology strategy to support the increased competitiveness of the U.S. in fossil fuel technologies, to maintain world leadership in our fossil fuel technology base, and provide expanded markets for U.S. fuels and technology. This crosscutting goal is supported by the activities in the above two technology goals.

\section{Office of Advanced Research}

\section{Fossil Energy AR\&TD Materials Program}

Fossil Energy (FE) materials-related research is conducted under an Advanced Research and Technology Development (AR\&TD) Materials subactivity and is an integral part of the R\&D conducted by the Office of Advanced Research and Special Technologies. The AR\&TD Materials program includes cross-cutting research to obtain a fundamental understanding of materials and how they perform in fossil-based process environments and the development of new classes of generic materials that will allow the development of new fossil energy systems or major improvements in existing systems. The present program is focused on ceramics (composite structural ceramics, catalyst supports, solid state electrolytes, membranes, and ceramic filters), new alloys (aluminides, advanced austenitic steels, and coatings and claddings), corrosion research, and technology development and transfer. 
The AR\&TD research is carried through development and technology transfer to industry. Special emphasis is being given to technology transfer to ensure that the materials will be available for subsequent fossil commercial applications. This also enhances U.S. technological competitiveness not only in the fossil area but in the materials industry in general and other technology application areas as well. The research is conducted in industry, universities, not-for-profit agencies, and national laboratories. This widespread participation also helps maintain the U.S. materials technology capabilities.

The acronym PYF indicates that the work in the designated year was supported by prior-year funds.

\section{Materials Preparation, Synthesis, Deposition, Growth or Forming}

492. Coating Process Development for $\mathrm{Cr}-\mathrm{Nb}$ Alloys

FY 1994

$\$ 90,000$

DOE Contacts: J. P. Carr, (301) 903-6519 and E. E. Hoffman, (615) 576-0735

Oak Ridge National Laboratory Contact: N. C. Cole, (615) 574-4824

Ohio State University Contact: R. A. Rapp, (614) 292-6178

$\mathrm{Cr}-\mathrm{Nb}$ alloys are being developed for high temperature service, but they need protection from high temperature environments, such as oxidation. Previously developed $\mathrm{MoSi}_{2}$-base coatings have shown some promise for protecting $\mathrm{Nb}$, and the principles learned may have applicability for protective coatings of $\mathrm{Cr}-\mathrm{Nb}$. The purpose of this work is to examine the protection of $\mathrm{Cr}-\mathrm{Nb}$ alloys with either silicides or aluminides.

Keywords: Alloys, Aluminizing, Chromizing, Corrosion, Coatings

493. Procurement of Advanced Austenitic and Aluminide Alloys

FY 1994

$\$ 30,000$

DOE Contacts: J. P. Carr, (301) 903-6519 and E. E. Hoffman, (615) 576-0735

Oak Ridge National Laboratory Contact: N. C. Cole, (615) 574-4824

This task provides funds for the procurement of alloys necessary for alloy development and testing activities of the AR\&TD Materials Program.

Keywords: Alloys, Aluminides, Austenitic 
494. Development of Iron Aluminides

FY 1994

$\$ 295,000$

DOE Contacts: J. P. Carr, (301) 903-6519 and E. E. Hoffman, (615) 576-0735

Oak Ridge National Laboratory Contact: C. G. McKamey, (615) 574-6917

The objective of this project is to develop low-cost, low-density intermetallic alloys based on $\mathrm{Fe}_{3} \mathrm{Al}$ with an optimum combination of strength, ductility, and corrosion resistance for use as components in advanced fossil energy systems.

Keywords: Alloys, Aluminides, Intermetallic Compounds

495. Ultrahigh Temperature Intermetallic Alloys

FY 1994

DOE Contacts: J. P. Carr, (301) 903-6519 and E. E. Hoffman, (615) 576-0735

$\$ 280,000$

Oak Ridge National Laboratory Contact: C. T. Liu, (615) 574-4459

The objective of this project is to develop high-strength, corrosion-resistant intermetallic alloys for use as hot components in advanced fossil energy conversion systems. The successful development of these alloys is expected (1) to improve the thermal efficiency of fossil energy conversion systems, and (2) to increase the service life of hot components exposed to corrosive environments.

Keywords: Alloys, Chromium-Niobium, Corrosion, Intermetallic Compounds

496. Microalloyed Iron Aluminides

FY 1994

$\$ 78,000$

DOE Contacts: J. P. Carr, (301) 903-6519 and E. E. Hoffman, (615) 576-0735

Oak Ridge National Laboratory Contact: C. G. McKamey, (615) 574-6917

The objective of this project is to use microalloying techniques to extend the development of those $\mathrm{Fe}_{3} \mathrm{Al}$-based alloys identified as possessing improved roomtemperature tensile properties. Emphasis is on low-cost, low-density, precipitationstrengthened $\mathrm{Fe}_{3} \mathrm{Al}$-based alloys with improved high-temperature creep resistance and an optimum combination of good room- and high-temperature tensile properties, weldability, and corrosion resistance.

Keywords: Alloys, Aluminides, Microalloy 
497. Low-Aluminum Content Iron-Aluminum Alloys

FY 1994

$\$ 270,000$

DOE Contacts: J. P. Carr, (301) 903-6519 and E. E. Hoffman, (615) 576-0735

Oak Ridge National Laboratory Contact: V. K. Sikka, (615) 574-5112

The objective of this project is to develop a conventionally fabricable low-cost, lowdensity iron-aluminum alloy with a good combination of strength, ductility, weldability, and corrosion resistance for use as components in advanced fossil energy conversion systems.

Keywords: Alloys, Iron-Aluminum

498. Technology Transfer - Iron Aluminides

FY 1994

DOE Contacts: J. P. Carr, (301) 903-6519 and E. E. Hoffman, (615) 576-0735

Oak Ridge National Laboratory Contact: V. K. Sikka, (615) 574-5112

A Cooperative Research and Development Agreement (CRADA) has been established with ABB Combustion Engineering for the development of corrosion-resistant surface protection for fossil power systems.

Keywords: Alloys, Iron-Aluminum, Corrosion, Technology Transfer

499. Development of a Modified 310 Stainless Steel

FY 1994

$\$ 120,000$

DOE Contacts: J. P. Carr, (301) 903-6519 and E. E. Hoffman, (615) 576-0735

Oak Ridge National Laboratory Contact: R. W. Swindeman, (615) 574-5108

The purpose of this task is to evaluate structural alloys for improved performance of high-temperature components in advanced combined-cycle and coal-combustion systems.

Keywords: Materials, Mechanical Properties, Austenitics, Hot-Gas

500. Technology Transfer - Advanced Austenitics

FY 1994

DOE Contacts: J. P. Carr, (301) 903-6519 and E. E. Hoffman, (615) 576-0735

$\$ 0$

Oak Ridge National Laboratory Contact: R. W. Swindeman, (615) 574-5108

A Cooperative Research and Development Agreement (CRADA) has been established with $\mathrm{ABB}$ Combustion Engineering for the development of advanced austenitic alloys for fossil power systems.

Keywords: Alloys, Austenitics, Technology Transfer 
501. Influence of Processing on Microstructure and Properties of Aluminides

FY 1994

$\$ 175,000$

DOE Contacts: J. P. Carr, (301) 903-6519 and E. E. Hoffman, (615) 576-0735

Oak Ridge National Laboratory Contact: N. C. Cole, (615) 574-4824

Idaho National Engineering Laboratory Contact: R. N. Wright, (208) 526-6127

The purpose of this project is to determine the influence of processing on the properties of alloys based on $\mathrm{Fe}_{3} \mathrm{Al}$. Thermomechanical processing is pursued to improve their room-temperature ductility. The response of the microstructure to annealing will be characterized in terms of the establishment of equilibrium phases and degrees of long-range order. The mechanical properties are determined at room and elevated temperatures and related to the microstructure.

Keywords: Aluminides, Processing, Microstructure

502. Investigation of Electrospark Deposited Coatings for Protection of Materials in Sulfidizing Atmospheres

FY 1994

$\$ 50,000$

DOE Contacts: J. P. Carr, (301) 903-6519 and E. E. Hoffman, (615) 576-0735

Oak Ridge National Laboratory Contact: N. C. Cole, (615) 574-4824

Westinghouse Hanford Company Contact: R. N. Johnson, (509) 376-3582

The purpose of this task is to examine the use of the electrospark deposition coating process for the application of corrosion-, erosion-, and wear-resistant coatings to candidate superheater alloys. Materials to be deposited may include MCrAl, MCrAlY, highly wear-resistant carbides, and other hardsurfacing materials.

Keywords: Coatings, Materials, Deposition

503. Technology Transfer - Electrospark Deposited Coatings for

Protection of Materials in Sulfidizing Atmospheres

FY 1994

$\$ 80,000$

DOE Contacts: J. P. Carr, (301) 903-6519 and E. E. Hoffman, (615) 576-0735

Oak Ridge National Laboratory Contact: N. C. Cole, (615) 574-4824

Westinghouse Hanford Company Contact: R. N. Johnson, (509) 376-3582

The purpose of this task is to transfer to industry the electrospark deposition coating process technology for the application of corrosion-, erosion-, and wear-resistant coatings to candidate superheater alloys.

Keywords: Coatings, Materials, Deposition 
504. Engineering-Scale Development of the Vapor-Liquid-Solid (VLS)

Process for the Production of Silicon Carbide Fibrils

FY 1994

$\$ 197,000$

DOE Contacts: J. P. Carr, (301) 903-6519 and E. E. Hoffman, (615) 576-0735

Oak Ridge National Laboratory Contact: N. C. Cole, (615) 574-4824

The Carborundum Company Contact: William Hollar, (716) 278-2097

The purpose of this work is to transfer to industry a specific technology developed by DOE under the AR\&TD Materials Program for the production of silicon carbide fibrils for the reinforcement of ceramic matrices. The Vapor-Liquid-Solid (VLS) process has been developed at Los Alamos National Laboratory (LANL) for the growth of silicon carbide fibrils of up to $75 \mathrm{~mm}$ in length which can be reduced in length by subsequent processing. The purpose of the work is to develop the VLS process into an engineering-scale process that will enable the U.S. industrial sector to commercialize the process for the production of fibrils for the reinforcement of structural ceramic components.

Keywords: Whiskers, Fibers, Ceramic

505. Ceramic Composite Processing Equipment

FY 1994

$\$ 30,000$

DOE Contacts: J. P. Carr, (301) 903-6519 and E. E. Hoffman, (615) 576-0735

Oak Ridge National Laboratory Contact: N. C. Cole, (615) 574-4824

This task provides funds for the procurement of major equipment items necessary for AR\&TD Materials Program activities.

Keywords: Equipment

506. Fabrication of Fiber-Reinforced Composites by Chemical Vapor Infiltration and Deposition (CVID)

FY 1994

$\$ 150,000$

DOE Contacts: J. P. Carr, (301) 903-6519 and E. E. Hoffman, (615) 576-0735

Oak Ridge National Laboratory Contact: D. P. Stinton, (615) 574-4556

The purpose of this task is the development of a process for the fabrication of fiberreinforced ceramic composites having high fracture toughness and high strength. This process utilizes a steep temperature gradient and a pressure gradient to infiltrate low-density fibrous structures with gases, which deposit as solid phases to form the matrix of the composite. Modifications to the process which are being explored include controlling the porosity and permeability of the fibrous preforms and variation of the deposition conditions.

Keywords: Composites, Fiber-Reinforced, Ceramics 
507. Development of Oxidation/Corrosion-Resistant Composite Materials and Interfaces

FY 1994

$\$ 150,000$

DOE Contacts: J. P. Carr, (301) 903-6519 and E. E. Hoffman, (615) 576-0735

Oak Ridge National Laboratory Contact: D. P. Stinton, (615) 574-4556

Fiber-reinforced SiC-matrix composites have been observed to fail in fossil energy applications for two reasons. First, the mechanical properties of composites deteriorate under stressed oxidation because oxidants such as steam penetrate cracks formed in the SiC matrix and react with the carbon or boron nitride interface. The mechanical properties of composites may degrade because of corrosion due to sodium species typically present in fossil systems. Therefore, the purposes of this task are to first, develop fiber-matrix interfaces that are resistant to oxidation and yet optimize the mechanical behavior of composites, and second, to develop protective overcoats or oxide matrices that are resistant to oxidation and corrosion.

Keywords: Composites, Ceramics, Fiber-Reinforced, Interfaces

508. Optimization of the Chemical Vapor Infiltration Technique for Ceramic Composites

FY 1994 $\$ 50,000$

DOE Contacts: J. P. Carr, (301) 903-6519 and E. E. Hoffman, (615) 576-0735

Oak Ridge National Laboratory Contact: N. C. Cole, (615) 574-4824

University of Tennessee Contact: Peter Liaw, (615) 974-6356

This project is focussed on an optimization of the forced chemical vapor infiltration (CVI) technique for fabrication of ceramic matrix composites (CMCs) using process models. In particular, a process model developed at the Georgia Tech Research Institute shall be thoroughly investigated. Experimental verification of the process model shall be conducted in light of microstructural characterization using both destructive and nondestructive evaluation techniques. An optimized process for manufacturing CMCs shall be demonstrated. Moreover, mechanistic understanding regarding the effects of processing parameters on microstructural features, and fatigue and fracture behavior of CMCs shall be provided.

Keywords: Composites, Fiber-Reinforced, Ceramics 
509. Transport Properties of Ceramic Composites

FY 1994

$\$ 140,000$

DOE Contacts: J. P. Carr, (301) 903-6519 and E. E. Hoffman, (615) 576-0735

Oak Ridge National Laboratory Contact: N. C. Cole, (615) 574-4824

Georgia Institute of Technology Contact: T. L. Starr, (404) 853-0579

The purpose of this research effort is to conduct a theoretical and experimental program to identify new compositions and processing methods to improve the physical and mechanical properties of selected fiber-reinforced ceramics. The ceramic matrix material is amorphous fused silica or modified silica glass, and the focus is the development of fiberreinforced silica. Parameters studied include: (1) differences in elastic modulus between matrix and fiber, (2) differences in thermal expansion, (3) nature of interfacial bond, (4) densification of matrix, (5) nature of fiber fracture/pull-out, (6) fiber diameter and fiber length-to-diameter ratio, (7) fiber loading, and (8) fiber dispersion and orientation. A model will be developed based on the information generated in the experimental phase of the program.

Keywords: Ceramics, Composites, Fiber-Reinforced

510. Modeling of Fibrous Preforms for CVD Infiltration

FY 1994

$\$ 55,000$

DOE Contacts: J. P. Carr, (301) 903-6519 and E. E. Hoffman, (615) 576-0735

Oak Ridge National Laboratory Contact: N. C. Cole, (615) 574-4824

Georgia Institute of Technology Contact: T. L. Starr, (404) 853-0579

The purpose of this project is to conduct a theoretical and experimental program to develop an analytical model for the fabrication and infiltration of fibrous preforms. The analytical model will: (1) predict preform structure (density, porosity, fiber orientation, etc.) based on fabrication technique and fundamental fiber parameters (diameter, aspect ratio, etc.), and (2) predict permeation and heat conduction through the preform structure and, thus, predict the CVD infiltration performance.

Keywords: Ceramics, Composites, Modeling 


\section{Corrosion Protection of SiC-Based Ceramics with CVD Mullite} Coatings

DOE Contacts: J. P. Carr, (301) 903-6519 and E. E. Hoffman, (615) 576-0735

Oak Ridge National Laboratory Contact: N. C. Cole, (615) 574-4824

Boston University Contact: Vinod Sarin, (617) 353-6451

This project involves the growth of dense mullite coatings on SiC-based substrates by chemical vapor deposition. SiC and SiC-based composites have been identified as the leading candidate materials for stringent elevated temperature applications. At moderate temperatures and pressures, the formation of a thin self-healing layer of $\mathrm{SiO}_{2}$ is effective in preventing catastrophic oxidation by minimizing the diffusion of $\mathrm{O}_{2}$ to the substrate. The presence of impurities can increase the rate of passive oxidation by modifying the transport rate of oxygen through the protective scale, can cause active oxidation via formation of SiO which accelerates the degradation process, or can produce compositions such as $\mathrm{Na}_{2} \mathrm{SO}_{3}$ which chemically attack the ceramic via rapid corrosion. There is therefore a critical need to develop adherent oxidation/corrosion-resistant, and thermal-shock-resistant coatings that can withstand such harsh environments. Mullite has been identified as an excellent candidate material due to its desirable properties of toughness, corrosion resistance, and a good coefficient of thermal expansion match with $\mathrm{SiC}$.

Keywords: Ceramics, Coatings

512. Feasibility of Synthesizing Oxide Filuns on Ceramic and Metal Substrates

FY 1994

$\$ 100,000$

DOE Contacts: J. P. Carr, (301) 903-6519 and E. E. Hoffman, (615) 576-0735

Oak Ridge National Laboratory Contact: N. C. Cole, (615) 574-4824

Lawrence Berkeley Laboratory Contact: Ian Brown, (510) 486-4174

The objective of this project is the study of the feasibility of synthesizing metal oxide ceramic films on ceramic and metal substrates. This feasibility will be demonstrated by use of plasma-based deposition and ion mixing techniques. The films shall be characterized for properties such as composition, structure, hardness, high temperature oxidation resistance, adhesion to the substrate, and stability to high temperature cycling. The value of intermediate transition or buffer layers, composed of materials with suitably matched thermal expansion characteristics and atomically graded interfaces, as a technique for improving the high temperature survivability of the films, shall be explored. Samples shall be formed on substrates of various shapes and sizes, including perhaps on the inside and outside of pipes, as well as on small flat coupons. The issue of deposition onto and atomic mixing into substrates which are insulating shall be addressed experimentally. The work is 
divided into two parts: (1) $\mathrm{Al}_{2} \mathrm{O}_{3}$ films on alumina-forming alloy substrates, and (2) oxides on $\mathrm{SiC}$.

Keywords: Ceramics, Films, Oxides

\section{Oxide Coating Development}

FY 1994

$\$ 75,000$

DOE Contacts: J. P. Carr, (301) 903-6519 and E. E. Hoffman, (615) 576-0735

Oak Ridge National Laboratory Contact: D. P. Stinton, (615) 574-4556

Monolithic SiC heat exchangers and fiber-reinforced SiC-matrix composite heat exchangers and filters are susceptible to corrosion by alkali metals at elevated temperatures. Protective coatings are currently being developed to isolate the $\mathrm{SiC}$. materials from the corrodants. Unfortunately, these coatings typically crack and spall when applied to SiC substrates. The purpose of this task is to determine the feasibility of using a compliant material between the protective coating and the substrate. The low-modulus compliant layer could absorb stresses and eliminate cracking and spalling of the protective coatings.

Keywords: Ceramics, Oxides, Coatings

514. High-Temperature Heat Exchanger and Hot-Gas Filter Development

FY 1994

DOE Contacts: J. P. Carr, (301) 903-6519 and E. E. Hoffman, (615) 576-0735

$\$ 250,000$

Oak Ridge National Laboratory Contact: N. C. Cole, (615) 574-4824

Pennsylvania State University Contact: R. E. Tressler, (814) 865-7961

This project has two principal parts: (1) screening analysis of candidate ceramic hotgas filter materials, and (2) development of ceramic heat exchanger materials with chromium surface treatments for corrosion resistance. A flow-through screening test will be developed to test ceramic hot-gas filter elements in simulated coal combustion environments. Corrosion-resistant heat exchanger tubes will be fabricated by incorporating chromium in the surface layers.

Keywords: Ceramics, Corrosion

515. Ceramic Coating Evaluation

$\frac{\text { FY } 1994}{\$ 50,000}$

DOE Contacts: J. P. Carr, (301) 903-6519 and E. E. Hoffman, (615) 576-0735

Oak Ridge National Laboratory Contacts: P. F. Tortorelli, (615) 574-5119

The purpose of this work is to generate the information needed for the development of improved (slow growing, adherent, sound) protective oxide coatings and scales The 
specific objectives are to (1) systematically investigate the relationships among substrate composition and surface oxide structure, adherence, soundness, and micromechanical properties, (2) use such information to predict scale and coating failures, and (3) identify and evaluate compositions and synthesis routes for producing materials with damage-tolerant scales and coatings.

Keywords: Coatings, Corrosion

516. Low-Temperature Fabrication of Transparent Silicon Nitride

FY 1994

$\$ 180,000$

DOE Contacts: J. P. Carr, (301) 903-6519 and E. E. Hoffman, (615) 576-0735

Oak Ridge National Laboratory Contact: N. C. Cole, (615) 574-4824

National Institute of Standards and Technology Contact: S. G. Malghan, (301) 975-6101

The objective of this research is the production of dense, hard, transparent ceramics from nanosize particles without the use of sintering aids. The work will concentrate on the fabrication of samples of transparent silicon nitride using the cryogenic compaction technique. TEM, SEM, X-ray diffraction, and laser light scattering will be used to characterize the microstructure. Hardness at various temperatures will be measured to assess the creep resistance of the material. Fracture toughness and bending strength will also be measured.

Keywords: $\quad$ Ceramics, Mechanical Properties

517. Microwave-Assisted Chemical Vapor Infiltration

FY 1994

DOE Contacts: J. P. Carr, (301) 903-6519 and E. E. Hoffman, (615) 576-0735

$\$ 50,000$

Oak Ridge National Laboratory Contact: M. A. Janney, (615) 574-4281

The purpose of this research effort is to explore the feasibility of using microwave heating to enhance the chemical vapor infiltration (CVI) process developed under the Fossil Energy Materials Program (FEMP) sponsorship. The goal is to achieve faster deposition rates, greater control over deposition conditions and resulting microstructures, and perhaps lower temperature infiltration.

Keywords: $\quad$ Ceramics, Microwave Processing 
518. Development of Microwave-Heated Diesel Particulate Filters

FY 1994

$\$ 75,000$

DOE Contacts: J. P. Carr, (301) 903-6519 and E. E. Hoffman, (615) 576-0735

Oak Ridge National Laboratory Contact: M. A. Janney, (615) 574-4281

The purpose of this research is to help develop microwave-heated diesel engine particulate filter/burner devices. The goal is to develop materials that will perform both as filter and heater in such a device. A Cooperative Research and Development Agreement (CRADA) between Martin Marietta Energy Systems (MMES) and the Cummins Engine Company is in place that supports this work, CRADA No. ORNL93-0172. The Department of Energy (DOE) CRADA monies come from both the Fossil Energy AR\&TD Materials Program and the Energy Efficiency and Renewable Energy - Office of Transportation Technologies (EE-OTT), Heavy Duty Transport Program.

The project will develop a ceramic composite structure of SiC-coated ceramic fiber that can be used as a diesel engine particulate filter. For commercial usage a particulate filter must: (1) filter carbon particles from high temperature diesel exhaust gas at an acceptable (low) backpressure; (2) survive thousands of thermal transients caused by regeneration (cleaning) of the filter by oxidizing the collected carbon; (3) be durable and reliable over the life of the filter, which is in excess of 300,000 miles $(10,000$ hours of operation); and, (4) provide a low overall operating cost which is competitive with other filtering techniques.

Keywords: $\quad$ Ceramics, Microwave Processing

519. Carbon Fiber Composite Molecular Sieves

FY 1994

$\$ 310,000$

DOE Contacts: J. P. Carr, (301) 903-6519 and E. E. Hoffman, (615) 576-0735

Oak Ridge National Laboratory Contact: T. D. Burchell, (615) 576-8595

The purpose of this work is to develop carbon molecular sieves starting with porous carbon fiber composites manufactured from petroleum pitch-derived carbon fibers. The carbon fiber composite molecular sieves will be used in pressure swing adsorption units for the efficient recovery of hydrogen from refinery purge gases and for other gas separation operations associated with petroleum refining.

Keywords: $\quad$ Carbon Fibers, Sieves, Composites 
520. Activation of Carbon Fiber Composite Molecular Sieves

FY 1994

$\$ 75,000$

DOE Contacts: J. P. Carr, (301) 903-6519 and E. E. Hoffman, (615) 576-0735

Oak Ridge National Laboratory Contact: N. C. Cole, (615) 574-4824

University of Kentucky Contact: Frank Derbyshire, (606) 257-0305

A novel monolithic adsorbent carbon, manufactured from carbon fibers, has been invented jointly by researchers at ORNL and at the University of Kentucky Center for Applied Energy Research (UKCAER). The novel material, referred to as a carbon-fiber composite molecular sieve (CFCMS) is fabricated at ORNL in the Carbon Materials Technology Group. The purpose of this activity is to activate samples of the CFCMS and to perform subsequent analyses of the surface area, pore width distributions, and micropore volume. Activities are directed toward an understanding of the relationships between the activation process and the micro- or mesopore structure that develops.

Keywords: $\quad$ Carbon Fibers, Sieves, Cornposites

521. Production of Aluminum Reduction Electrodes from Solvent-Extracted Coal-Derived Carbon Feedstocks

DOE Contacts: J. P. Carr, (301) 903-6519 and E. E. Hoffman, (615) 576-0735

Oak Ridge National Laboratory Contact: N. C. Cole, (615) 574-4824

Alcoa Aluminum Company Contact: Dave Eielitskus, (412) 337-4812

This research is directed toward the objective of producing aluminum reduction electrodes from solvent-extracted coal-derived carbon feedstocks obtained from West Virginia University (WVU) and Koppers Inclustries, Inc.

Keywords: Carbon, Feedstocks, Coal-Derived

522. Exploration of Coal-Based Pitch Precursors for Ultra-High Thermal Conductivity Graphite Fibers

FY 1994

$\$ 30,000$

DOE Contacts: J. P. Carr, (301) 903-6519 and E. E. Hoffman, (615) 576-0735

Oak Ridge National Laboratory Contact: N. C. Cole, (615) 574-4824

Amoco Performance Products, Inc. Contact: G. V. Deshpande

The preparation of high-performance carbon (graphite) fibers requires a mesophase pitch precursor. Traditionally, in the USA, this has been derived from a petroleum precursor. Overseas suppliers have, however, developed high- performance fibers from coal 
derived precursors. Amoco Performance Products' goal is to explore coal-based pitch precursors' utility for use in ultra-high thermal conductivity graphite fibers.

Keywords: $\quad$ Carbon, Fibers, Graphite, Precursors

\section{Development of Carbon-Carbon Composites from Solvent-Extracted Pitch}

FY 1994

$\$ 25,000$

DOE Contacts: J. P. Carr, (301) 903-6519 and E. E. Hoffman, (615) 576-0735

Oak Ridge National Laboratory Contact: N. C. Cole, (615) 574-4824

Fiber Materials, Inc. Contact: Cliff Baker, (207) 282-5911

The manufacture of carbon-carbon composites for use in the aerospace industry has been heavily reliant on petroleum and coal tar pitches as matrix precursors. It is of great importance to strategic materials production for the Department of Defense that a stable, long-lived source of pitch be developed. Consequently, Fiber Materials, Inc. (FMI) will work with staff members at the Oak Ridge National Laboratory (ORNL) and at West Virginia University (WVU) to develop carbon-carbon composite materials from pitches derived from coal via a solvent extraction process. The objectives of this project shall be twofold. First, FMI shall use solvent extracted pitch to develop carbon-carbon composites with similar or improved properties over those currently manufactured from Allied $15 \mathrm{~V}$ coal tar or Ashland A-240 petroleum pitches. Second, FMI shall develop improved, lower-cost composites from improved solvent extracted pitches supplied by WVU.

Keywords: _ Carbon, Composites, Pitch

524. Conversion of Pitches and Cokes from Solvent-Extracted Materials

FY 1994

$\$ 40,000$

DOE Contacts: J. P. Carr, (301) 903-6519 and E. E. Hoffman, (615) 576-0735

Oak Ridge National Laboratory Contact: N. C. Cole, (615) 574-4824

Koppers Industries, Inc. Contact: R. McHenry, (412) 826-3989

The closure of by-product coke ovens has caused the domestic production of coal tar pitch to decline at 3 percent to 4 percent per annum during the mid-1990s. This reduction has directly affected Koppers' capability to produce required quantities of quality binder and impregnating pitches used in the aluminum and commercial carbon and graphite industries. Moreover, the other major constituent of carbon anodes and graphites is a coke, usually produced from petroleum pitch precursors, 50 percent of which are imported. The objectives of this research are to develop dependable domestic coal-based raw materials for the production of: binder pitches for aluminum cell anodes and commercial carbon and graphite products; impregnating pitches for commercial carbon and graphite products and 
specialty materials; oils for wood treatment and carbon black production; chemicals for phthalic anhydride and other products; and metallurgical and foundry grade cokes.

Keywords: Coke, Pitch, Conversion

525. Carbon Products Consortium

FY 1994

$\$ 175,000$

DOE Contacts: J. P. Carr, (301) 903-6519 and E. E. Hoffman, (615) 576-0735

Oak Ridge National Laboratory Contact: T. D. Burchell, (615) 576-8595

Hydrogen and Methane gas recovery technologies are required to (1) allow the upgrading of heavy hydrocarbons to transport fuels, thus reducing the amount of carbon rejected during crude oil refining, and (2) to improve the yield and process economics of natural gas wells. The purpose of this work is to develop carbon fiber composite molecular sieves (CFCMS) from porous carbon fiber composites (CFC) manufactured from solvent extracted coal tar pitch derived carbon fibers. The work will be performed in collaboration with other members of the Cooperative Research Partnership on Carbon Products and the Non Fuel Uses of Coal.

Keywords: Consortium, Carbon Products

526. Economic Analysis of West Virginia University Solvent Extraction Process

FY 1994 $\$ 50,000$

DOE Contacts: J. P. Carr, (301) 903-6519 and E. E. Hoffman, (615) 576-0735

Oak Ridge National Laboratory Contact: N. C. Cole, (615) 574-4824

Pittsburgh Energy Technology Center Contact: M. A. Nowak, (412) 892-6020

This project will analyze the West Virginia University solvent extraction process for producing pitch from coal. The aim of the project is to determine the economic viability of the process when scaled to commercial size.

Keywords: Solvent Extraction 


\section{Development of Precursors for Production of Graphites and}

Carbon Products

FY 1994

$\$ 65,000$

DOE Contacts: J. P. Carr, (301) 903-6519 and E. E. Hoffman, (615) 576-0735

Oak Ridge National Laboratory Contact: N. C. Cole, (615) 574-4824

UCAR Carbon Company Contact: Irv Lewis, (216) 676-2203

The manufacture of graphite utilizes cokes and pitches derived from petroleum refining by-products and by-product coke ovens. These include isotropic and anisotropic cokes, binder, and impregnant pitches. Assuring feedstock quality is of great importance to the graphite industry. Therefore, a stable long-lived source of feedstock pitch (and hence coke) would be of considerable benefit to the industry. Consequently, UCAR Carbon Company Inc. shall work with staff members at the Oak Ridge National Laboratory (ORNL) and at the West Virginia University to develop suitable precursor pitches, binders, impregnants, and cokes for the production of graphites and other carbon products.

Keywords: $\quad$ Carbon Products, Precursors, Graphites

528. Solvent Extraction of Coal

FY 1994 $\$ 300,000$

DOE Contacts: J. P. Carr, (301) 903-6519 and E. E. Hoffman, (615) 576-0735

Oak Ridge National Laboratory Contact: N. C. Cole, (615) 574-4824

West Virginia University Contact: Al Stiller, John Zondlo

This project is to develop a process for the solvent extraction of coal to produce an extract suitable for the production of a variety of carbon products, such as coke, graphite, carbon anodes, and carbon fibers. The process uses $\mathrm{N}$-methyl pyrolodone as the extraction medium and is based on a West Virginia University patent.

Keywords: $\quad$ Solvent Extraction

529. Radio-Wave Nano-Phase Silicon Carbide and Silicon Nitride Processes

FY 1994 $\$ 100,000$

DOE Contacts: J. P. Carr, (301) 903-6519 and E. E. Hoffman, (615) 576-0735

Oak Ridge National Laboratory Contact: N. C. Cole, (615) 574-4824

Sandia National Laboratories Contact: R. J. Buss, (505) 844-3504

This program examines the use of radio-frequency plasma discharges as a synthetic route to nanometer-size silicon carbide and silicon nitride particles.

Keywords: $\quad$ Nanophase, Silicon Nitride, Silicon Carbide 


\section{Materials Properties, Behavior, Characterization or Testing}

530. Investigation of the Weldability of Polycrystalline Iron Aluminides

FY 1994

DOE Contacts: J. P. Carr, (301) 903-6519 and E. E. Hoffman, (615) 576-0735

$\$ 75,000$

Oak Ridge National Laboratory Contact: N. C. Cole, (615) 574-4824

Colorado School of Mines Contact: G. R. Edwards, (303) 273-3773

The purpose of this project is the investigation of the weldability of polycrystalline aluminides. The major thrust of the project is to determine the role of microstructure in the intergranular cracking of aluminides, with special emphasis on weld cracking susceptibility. The weldability of polycrystalline $\mathrm{Fe}_{3} \mathrm{Al}-\mathrm{X}$ alloys is being evaluated, and the weldability is correlated with composition, phase equilibria, grain size and morphology, domain size, and degree of long-range order.

Keywords: Joining, Welding

531. Stress-Assisted Corrosion of Iron Alurninides

FY 1994

DOE Contacts: J. P. Carr, (301) 903-6519 and E. E. Hoffman, (615) 576-0735

$\$ 50,000$

Oak Ridge National Laboratory Contact: N. C. Cole, (615) 574-4824

University of Tennessee Contact: R. A. Buchanan, (615) 974-4858

The objective of this project is to investigate (1) evaluation of the effects of surface conditions on the corrosion and embrittlement of Fe-Al alloys, and (2) corrosion fatigue properties of $\mathrm{Fe}-\mathrm{Al}$ alloys.

Keywords: $\quad$ Alloys, Aluminides, Corrosion, Stress

532. Fireside Corrosion Tests of Candidate Advanced Austenitic Alloys,

Coatings, and Claddings

$\frac{\text { FY } 1994}{\$ 80,000}$

DOE Contacts: J. P. Carr, (301) 903-6519 and E. E. Hoffman, (615) 576-0735

Oak Ridge National Laboratory Contact: N. C. Cole, (615) 574-4824

Foster Wheeler Development Corporation Contact: J. L. Blough, (201) 535-2355

The purpose of this project is to provide comprehensive corrosion data for selected advanced austenitic tube alloys in simulated coal ash environments. ORNL-modified alloys and standard comparison alloys have been examined. The variables affecting coal ash corrosion and the mechanisms governing oxide breakdown and corrosion penetration are 
being evaluated. Corrosion rates of the test alloys are determined as functions of temperature, ash composition, gas composition, and time.

Keywords: $\quad$ Austenitics, Alloys, Corrosion

533. Joining Techniques for Advanced Austenitic Alloys

FY 1994

$\$ 65,000$

DOE Contacts: J. P. Carr, (301) 903-6519 and E. E. Hoffman, (615) 576-0735

Oak Ridge National Laboratory Contact: N. C. Cole, (615) 574-4824

University of Tennessee Contact: C. D. Lundin, (615) 974-5310

Weldability is an important consideration in the selection of a suitable alloy for the fabrication of boiler components such as superheaters and reheaters. It is often a challenge to select joining materials and establish procedures that will allow advanced materials to function at their full potential. The purpose of this research is to examine important aspects of newly developed austenitic tubing alloys intended for service in the temperature range $550^{\circ}$ to $700^{\circ} \mathrm{C}$.

Keywords: $\quad$ Alloys, Austenitics, Joining, Welding

534. Fatigue and Fracture Behavior of $\mathrm{Cr}-\mathrm{Nb}$ Alloys

FY 1994

DOE Contacts: J. P. Carr, (301) 903-6519 and E. E. Hoffman, (615) 576-0735

$\$ 50,000$

Oak Ridge National Laboratory Contact: N. C. Cole, (615) 574-4824

University of Tennessee Contact: Peter Liaw, (615) 974-6356

The objective of this research shall be to characterize the fatigue and fracture behavior of $\mathrm{Cr}_{2} \mathrm{Nb}$-based alloys and other intermetallic materials at ambient and elevated temperatures in controlled environments. These studies are expected to lead to mechanistic understanding of the fatigue and fracture behavior of these alloys. Fatigue tests shall be conducted for the purpose of evaluating crack initiation and fatigue life of $\mathrm{Cr}_{2} \mathrm{Nb}$-based alloys as well as other intermetallic alloys. The fatigue properties shall be evaluated as functions of test environment, cyclic frequency and test temperature. Additional tensile tests will be required to characterize the fracture behavior of these structural alloys. Mechanical tests shall be performed to determine the fatigue and fracture behavior of $\mathrm{Cr}_{2} \mathrm{Nb}$-based alloys. The microstructure of the alloys shall be characterized and correlated with the mechanical properties.

Keywords: Fracture, Fatigue, Alloys 
535. Corrosion and Mechanical Properties of Alloys in FBC and Mixed-Gas Environments

DOE Contacts: J. P. Carr, (301) 903-6519 and E. E. Hoffman, (615) 576-0735

Oak Ridge National Laboratory Contact: N. C. Cole, (615) 574-4824

Argonne National Laboratory Contact: K. Natesan, (708) 252-5103

The purposes of this task are to (1) evaluate the corrosion mechanisms for chromiaand alumina-forming alloys in mixed-gas environments, (2) develop an understanding of the role of several microalloy constituents in the oxidation/sulfidation process, (3) evaluate transport kinetics in oxide scales as functions of temperature and time, (4) characterize surface scales that are resistant to sulfidation attack, and (5) evaluate the role of deposits in corrosion processes.

Keywords: $\quad$ Corrosion, Gasification, Creep Rupture, Fluidized-Bed Combustion

536. Mechanically Reliable Coatings and Scales for High-Temperature Corrosion Resistance

FY 1994 $\$ 100,000$

DOE Contacts: J. P. Carr, (301) 903-6519 and E. E. Hoffman, (615) 576-0735

Oak Ridge National Laboratory Contact: N. C. Cole, (615) 574-4824

Argonne National Laboratory Contact: K. Natesan, (708) 252-5103

This project involves the development of mechanically reliable coatings and scales for high-temperature corrosion resistance. ANL shall systematically generate the knowledge required to establish a scientific basis for design and synthesis of improved (slow growing, adherent, sound) protective oxide coatings and scales on high temperature materials, without compromising the requisite bulk material properties. In addition, ANL shall provide information on the performance of advanced candidate materials from the standpoint of corrosion resistance and residual mechanical properties, after exposure in simulated combustion environments typical of indirectly-fired gas turbines. The work shall emphasize corrosion evaluation of materials in air, salt, and coal/ash environments at temperatures between $1000^{\circ}$ and $1400^{\circ} \mathrm{C}$, and measurement of residual toughness properties of the materials after corrosion.

Keywords: $\quad$ Corrosion, Coatings, Scales 
537. Environmental Effects on Iron Aluminides

FY 1994

$\$ 225,000$

DOE Contacts: J. P. Carr, (301) 903-6519 and E. E. Hoffman, (615) 576-0735

Oak Ridge National Laboratory Contact: J. H. DeVan, (615) 574-4451

The purpose of this task is to evaluate the corrosion properties of $\mathrm{Fe}$. Al-based alloys as they relate to fossil energy applications. A primary objective is to measure the resistance of the alloys to mixed-oxidant [oxygen-sulfur] environments that arise in the combustion or gasification of coal. This includes a determination of the effects of sulfur on oxidation kinetics and oxide microstructures, the effects of rare earth additions on sulfidation and oxidation resistance, and the mechanical behavior of reaction product scales in mixed-gas environments.

Keywords: $\quad$ Corrosion, Aluminides, Mixed-Gas, Scales

538. Investigation of Moisture-Induced Embrittlement of Iron Aluminides

FY 1994 $\$ 60,000$

DOE Contacts: J. P. Carr, (301) 903-6519 and E. E. Hoffman, (615) 576-0735

Oak Ridge National Laboratory Contact: N. C. Cole, (615) 574-4824

Rensselaer Polytechnic Institute Contact: N. S. Stoloff, (518) 276-6371

The purpose of this work is to study hydrogen embrittlement of iron aluminide alloys. Moisture in air can significantly reduce the room-temperature tensile ductility of $\mathrm{Fe}_{3} \mathrm{Al}-$ based alloys by combining with the aluminum in the alloys to form atomic hydrogen. The atomic hydrogen diffuses rapidly into the material causing embrittlement. Experiments are being conducted on selected $\mathrm{Fe}_{3} \mathrm{Al}$ alloys that will lead to an understanding of the phenomenon. The work focuses on the effects of moisture on relevant mechanical properties such as fatigue and tensile strengths, and correlates important microstructural variables such as degree of order, grain size, and phases present with the alloy's susceptibility to embrittlement.

Keywords: $\quad$ Aluminides, Embrittlement, Moisture

539. Corrosion Protection of Ultrahigh Temperature Intermetallic Alloys

FY 1994 $\$ 220,000$

DOE Contacts: J. P. Carr, (301) 903-6519 and E. E. Hoffman, (615) 576-0735

Oak Ridge National Laboratory Contact: P. F. Tortorelli, (615) 574-5119

The purpose of this activity is to support the development of high-strength, corrosionresistant intermetallic alloys by conducting critical experiments and analyses to evaluate the 
best alloy design and surface treatments to offer protection for environmental degradation at high temperatures.

Keywords: $\quad$ Corrosion, Chromium-Niobium, Mixed-Gas, Scales

540. Oxide Dispersion Strengthened (ODS) Iron Aluminide Equipment

FY 1994 $\$ 50,000$

DOE Contacts: J. P. Carr, (301) 903-6519 and E. E. Hoffman, (615) 576-0735

Oak Ridge National Laboratory Contact: N. C. Cole, (615) 574-4824

This task provides funds for the procurement of major equipment items necessary for AR\&TD Materials Program activities.

Keywords: Equipment

541. Oxide Dispersion Strengthened (ODS) Iron Aluminides

$\frac{\text { FY } 1994}{\$ 75,000}$

DOE Contacts: J. P. Carr, (301) 903-6519 and E. E. Hoffman, (615) 576-0735

Oak Ridge National Laboratory Contact: N. C. Cole, (615) 574-4824

The purpose of this task is to develop fabrication procedures for making oxide dispersion-strengthened (ODS) iron-aluminum alloys based on $\mathrm{Fe}_{3} \mathrm{Al}$. The suitability of the procedures is measured in terms of the high temperature oxidation resistance and creep strength of the ODS alloys compared with $\mathrm{Fe}_{3} \mathrm{Al}$ alloys fabricated by conventional ingot and powder processes.

Keywords: $\quad$ Aluminides

542. Materials Support for HITAF

FY 1994

$\$ 175,000$

DOE Contacts: J. P. Carr, (301) 903-6519 and E. E. Hoffman, (615) 576-0735

Oak Ridge National Laboratory Contact: N. C. Cole, (615) 574-4824

This task involves the measurement of selected mechanical and physical properties of structural ceramics which are proposed for use in the construction of the High Temperature Advanced Furnace (HITAF) air heater design being developed under the Combustion 2000 program for PETC/DOE. The purpose of the research is to evaluate candidate structural ceramics for this application by studying the fast fracture and fatigue (both dynamic and interrupted static) properties at temperatures from 1100 to $1400^{\circ} \mathrm{C}$ in 
air, their corrosion behavior, property uniformity of components and long term degradation of ceramic properties due to exposure in prototype HITAF systems.

Keywords: $\quad$ Furnace, Materials, HITAF

543. Support Services for Ceramic Fiber-Ceramic Matrix Composites

FY 1994

$\$ 50,000$

DOE Contacts: J. P. Carr, (301) 903-6519 and E. E. Hoffman, (615) 576-0735

Oak Ridge National Laboratory Contact: N. C. Cole, (615) 574-4824

University of North Dakota Energy and Environmental Research Center (UNDEERC)

Contact: J. P. Hurley, (701) 777-5159

This task will review and, if appropriate, propose modifications to plans, materials, and tests planned by researchers on the AR\&TD Materials Program in work to test materials for coal-fueled energy systems. The changes shall be suggested in order to make the corrosion experiments more reflective of the actual conditions that will be encountered by the materials in the energy systems. UNDEERC shall accomplish this task by reviewing the major advanced energy system projects being funded by the DOE, and by working with the company's technical monitor and staff to prepare a summary of the expected corrosion problems. Both gasification and combustion systems will be included. Ceramic materials in two subsystems will be the focus of this work: (1) hot gas cleanup systems and (2) hightemperature heat exchangers. UNDEERC shall review and suggest improvements to materials testing procedures that are used to determine material behavior when used in hotgas cleanup or heat exchanger applications. A limited amount of computer modeling and laboratory experimentation shall be a part of this effort.

Keywords: $\quad$ Composites, Ceramics, Fibers

544. Development of Nondestructive Evaluation Methods and Effects of Flaws on the Fracture Behavior of Structural Ceramics

FY 1994 $\$ 310,000$

DOE Contacts: J. P. Carr, (301) 903-6519 and E. E. Hoffman, (615) 576-0735 Oak Ridge National Laboratory Contact: N. C. Cole, (615) 574-4824

Argonne National Laboratory Contacts: W. A. Ellingson, (708) 252-5068 and J. P. Singh, (708) 252-5123

The purpose of this project is to study and develop acoustic and radiographic techniques and possible novel techniques such as nuclear magnetic resonance, to characterize structural ceramics with regard to presence of porosity, cracking, inclusions, 
amount of free silicon, and mechanical properties, and to establish the type and character of flaws that can be found by nondestructive evaluation (NDE) techniques. Both fired and unfired specimens are being studied to establish correlations between NDE results and failure of specimens.

Keywords: Nondestructive Evaluation, Ceramics, Flaws, Fracture

545. Fracture Behavior of Advanced Ceramic Hot-Gas Filters

FY 1994

DOE Contacts: J. P. Carr, (301) 903-6519 and E. E. Hoffman, (615) 576-0735 $\$ 114,000$ Oak Ridge National Laboratory Contact: N. C. Cole, (615) 574-4824

Argonne National Laboratory Contacts: W. A. Ellingson, (708) 252-5068 and J. P. Singh, (708) 252-5123

The purpose of this project is to study the fracture behavior of ceramic hot-gas filters. ANL shall evaluate mechanical/ph ysical properties and microstructure, identify critical flaws and failure modes, and correlate mechanical/ph ysical properties with microstructure and critical flaws to provide much needed information for selection of materials and optimization of fabrication procedures for hot- gas ceramic filter modules. As part of the information base, requirements for strength and fracture toughness of the filter material shall be established from stress and fracture mechanics analyses of typical filters subjected to loadings expected during operation and pulse-cleaning cycles.

Keywords: Ceramics, Flaws, Fracture, Failure

546. Ceramic Catalyst Materials

FY 1994 $\$ 225,000$

DOE Contacts: J. P. Carr, (301) 903-6519 and E. E. Hoffman, (615) 576-0735

Oak Ridge National Laboratory Contact: N. C. Cole, (615) 574-4824

Sandia National Laboratories Contact: A. G. Sault, (505) 844-8723

The purpose of this research is to investigate the role of ceramic material properties in the catalytic activity of a novel class of catalytic supports, known as hydrous titanium oxides (HTO). Catalysts prepared on these materials show particular promise as economically and environmentally attractive alternatives to present commercial catalysts for the direct liquefaction of coal. In these studies, improved understanding and control of the synthesis process is being pursued in order to tailor the composition, molecular structure, microporosity, and physical/mechanical properties of the HTO thin films. The effects of altered structure, composition, and other material properties of the thin film ceramic support material on catalytic activity are being assessed.

Keywords: Ceramics, Catalysts 


\section{Device or Component Fabrication, Behavior or Testing}

547. Materials and Components in Fossil Energy Applications (Newsletter)

FY 1994

$\$ 60,000$

DOE Contacts: J. P. Carr, (301) 903-6519 and E. E. Hoffman, (615) 576-0735

Oak Ridge National Laboratory Contact: N. C. Cole, (615) 574-4824

Battelle-Columbus Laboratories Contact: I. G. Wright, (614) 424-4377

The purpose of this task is to publish a periodic (bimonthly) newsletter to address current developments in materials and components in fossil energy applications.

Keywords: Materials, Components

548. Fabrication of Full-Scale Fiber-Reinforced Hot-Gas Filters by

Chemical Vapor Deposition

FY 1994

$\$ 115,000$

DOE Contacts: J. P. Carr, (301) 903-6519 and E. E. Hoffman, (615) 576-0735

Oak Ridge National Laboratory Contact: N. C. Cole, (615) 574-4824

3M Company Contact: M. A. Leitheiser, (612) 733-9394

The purpose of this project is to scale-up the chemical vapor infiltration and deposition (CVID) process developed at Oak Ridge National Laboratory for fabricating ceramic fiber-ceramic matrix composites. The goal is to use the scaled-up CVID process to produce composite filters that have the requisite strength and toughness, but which also have sufficient porosity to be permeable to gas streams and the appropriate size and distribution of porosity to be an effective filter. A practical process for fabricating porous ceramic fiber-ceramic matrix candle filters (full-size) with increased surface area will be developed.

Keywords: Ceramics, Composites, Filters

549. Development of Ceramic Membranes for Gas Separation

FY 1994 $\$ 400,000$

DOE Contacts: J. P. Carr, (301) 903-6519 and E. E. Hoffman, (615) 576-0735

Oak Ridge National Laboratory Contact: N. C. Cole, (615) 574-4824

Oak Ridge K-25 Site Contact: D. E. Fain, (615) 574-9932

The purpose of this activity is to fabricate inorganic membranes for the separation of gases at high temperatures and/or in hostile environments, typically encountered in fossil energy conversion processes such as coal gasification. This work is performed in conjunction 
with a separate research activity that is concerned with the development and testing of the ceramic membranes.

Keywords: Ceramics, Membranes, Filters, Separation

550. Investigation of the Mechanical Properties and Performance of Ceramic Composite Components

FY 1994 $\$ 100,000$

DOE Contacts: J. P. Carr, (301) 903-6519 and E. E. Hoffman, (615) 576-0735

Oak Ridge National Laboratory Contact: N. C. Cole, (615) 574-4824

Virginia Polytechnic Institute Contact: K. L. Reifsnider, (703) 231-5259

The purpose of this project is to develop a test system and test methods to obtain information on the properties and performance of ceramic composite materials. The work involves a comprehensive mechanical characterization of composite engineering components such as tubes, plates, shells, and beams subjected to static and cyclic multiaxial loading at elevated temperatures for extended time periods.

Keywords: Ceramics, Composites, Mechanical Properties, Testing

551. Stability of Solid Oxide Fuel Cell (SOFC) Materials

FY 1994

DOE Contacts: J. P. Carr, (301) 903-6519 and E. E. Hoffman, (615) 576-0735

$\$ 250,000$

Oak Ridge National Laboratory Contact: N. C. Cole, (615) 574-4824

Pacific Northwest Laboratory Contact: L. R. Pederson, (509) 375-2579

The purpose of this task is to evaluate the chemical and physical stability of fuel cell materials and interfaces under conditions relevant to an operating SOFC and to identify features in SOFC operation that would limit system performance.

Keywords: Fuel Cells, SOFC 
552. Mixed Oxygen Ion/Electr on-Conducting Ceramics for Oxygen

Separation and Fuel Cells

FY 1994 $\$ 225,000$

DOE Contacts: J. P. Carr, (301) 903-6519 and E. E. Hoffman, (615) 576-0735

Oak Ridge National Laboratory Contact: N. C. Cole, (615) 574-4824

Pacific Northwest Laboratory Contact: L. R. Pederson, (509) 375-2579

The purpose of this task is to develop ceramic compositions and physical forms that will provide the highest possible oxygen separation efficiencies from air at the lowest cost.

Keywords: Fuel Cells, Electrochemical, Electrolytes

553. Proton-Conducting Cerate Ceramics

FY 1994 $\$ 225,000$

DOE Contacts: J. P. Carr, (301) 903-6519 and E. E. Hoffman, (615) 576-0735

Oak Ridge National Laboratory Contact: N. C. Cole, (615) 574-4824

Pacific Northwest Laboratory Contact: L. R. Pederson, (509) 375-2579

The purpose of this task is to develop cerate perovskites for use as hydrogen separation membranes, as hydrogen sensors, in membrane reactors, and in gas cleanup.

Keywords: Fuel Cells, Electrochemical, Electrolytes

554. Technology Transfer - Iron Aluminide Filters

$\frac{\text { FY } 1994}{\$ 50,000}$

DOE Contacts: J. P. Carr, (301) 903-6519 and E. E. Hoffman, (615) 576-0735

Oak Ridge National Laboratory Contact: N. C. Cole, (615) 574-4824

Oak Ridge K-25 Site Contact: D. E. Fain, (615) 574-9932

The purpose of this activity is to establish a Cooperative Research and Development Agreement (CRADA) with an industrial partner for the development of iron aluminide filters.

Keywords: Filters, Aluminides 
555. Thermal and Mechanical Analysis of a Ceramic Tubesheet

FY 1994

DOE Contacts: J. P. Carr, (301) 903-6519 and E. E. Hoffman, (615) 576-0735

$\$ 40,000$

Oak Ridge National Laboratory Contact: N. C. Cole, (615) 574-4824

Mallett Technology Contact: R. H. Mallett, (919) 406-1500

A transport combustor is being commissioned at the Southern Services facility in Wilsonville, Alabama, to provide a gaseous product for the assessment of hot-gas filtering systems. These hot-gas filtration systems will include granular-bed and barrier filter concepts. Filters will be evaluated for carbonizer and gasifier gaseous products. In addition, a pressurized fluidized-bed combustor (PFBC) will be installed to burn the carbonizer product, and a hot gas filter will be installed in the PFBC gas stream. Compositions of the gas streams will range from oxidizing to reducing, and the partial pressures of oxygen and sulfur will vary substantially. Temperatures of the gas streams will range from 840 to $980^{\circ} \mathrm{C}$ (or higher). One of the barrier filters under consideration incorporates a ceramic tubesheet to support the candle filters. This system, to be designed and built by Industrial Filter \& Pump Manufacturing Company (IF\&PM) is unique and may offer distinct advantages over metal/ceramic systems that have been tested extensively in other EPRI/DOE projects. To gain an insight that could prove to be useful in the scaleup of a commercial-size, all-ceramic system, work will be undertaken to develop a design methodology applicable to the thermalmechanical analysis of the all-ceramic system.

Keywords: Ceramics, Tubesheet

556. Thermal and Mechanical Analysis of a Ceramic Tubesheet

FY 1994

$\$ 10,000$

DOE Contacts: J. P. Carr, (301) 903-6519 and E. E. Hoffman, (615) 576-0735

Oak Ridge National Laboratory Contact: N. C. Cole, (615) 574-4824

The purpose of this task is to perform thermal and mechanical analyses of critical regions in a ceramic tubesheet support for barrier filters in a hot gas cleanup vessel designed for use in gasifier, carbonizer, and pressurized fluidized bed combustion gas streams.

Keywords: Ceramics, Tubesheet 
557. Technology Transfer - Ceramic Joining

FY 1994

$\$ 175,000$

DOE Contacts: J. P. Carr, (301) 903-6519 and E. E. Hoffman, (615) 576-0735

Oak Ridge National Laboratory Contact: N. C. Cole, (615) 574-4824

Idaho National Engineering Laboratory Contact: B. H. Rabin, (208) 526-0058

The purpose of this project is to explore and develop joining techniques for silicon carbide fiber-reinforced silicon carbide ceramics produced by chemical vapor infiltration and deposition (CVID). The research goals include identifying appropriate joining methods, establishing experimental procedures for fabricating joints, and characterizing the structure and properties of joined materials. An understanding of the factors that control joint performance is sought through studies of the relationships among processing variables, joint microstructures, and mechanical properties.

Keywords: Ceramics, Joining, Technology Transfer

Instrumentation and Facilities

558. Management of the Fossil Energy AR\&TD Materials Program

FY 1994 $\$ 400,000$

DOE Contacts: J. P. Carr, (301) 903-6519 and E. E. Hoffman, (615) 576-0735

Oak Ridge National Laboratory Contact: N. C. Cole, (615) 574-4824

The overall objective of the Fossil Energy Advanced Research and Technology Development (AR\&TD) Materials program is to conduct a fundamental, long-range research and development program that addresses, in a generic way, the materials needs of fossil energy systems and ensures the development of advanced materials and processing techniques. The purpose of this task is to manage the Fossil Energy AR\&TD Materials program in accordance with procedures described in the Program Management Plan approved by DOE. This task is responsible for preparing the technical program implementation plan for DOE approval; submitting budget proposals for the program; recommending work to be accomplished by subcontractors and by Oak Ridge National Laboratory (ORNL); placing and managing subcontracts for fossil energy materials development at industrial research centers, universities, and other government laboratories; and for reporting the progress of the program.

Keywords: Management, Materials Program 
559. General Technology Transfer Activities.

FY 1994

$\$ 35,000$

DOE Contacts: J. P. Carr, (301) 903-6519 and E. E. Hoffman, (615) 576-0735

Oak Ridge National Laboratory Contact: N. C. Cole, (615) 574-4824

The task provides funds for the initiation of technology transfer activities to identify and develop relationships with industrial partners for the transfer of AR\&TD Materials Program technologies to industry.

Keywords: Technology Transfer

560. Gordon Research Conference Support

DOE Contacts: J. P. Carr, (301) 903-6519 and E. E. Hoffman, (615) 576-0735

Oak Ridge National Laboratory Contact: N. C. Cole, (615) 574-4824

The task provides funds to support the annual Gordon Research Conference.

Keywords: Technology Transfer 


\section{DIRECTORY}

J. D. Achenbach

Department of Civil Engineering Northwestern University

Evanston, IL 60201

(312) 491-5527

R. H. Adler

LLNL

University of California

P.O. Box 808

Livermore, CA 94550

(415) $423-4417$

Iqbal Ahmad

Associate Professor

Far East Liaison Office

ONR/AFOSR/ARO

7-23-17, Roppongi

Minato-ku, Tokyo 106

(03) 3401-8924, 3423-1374

Ilhan Aksay

Dept. of Chem. Eng.

A313 Engineering Quad

Princeton University

Princeton, NJ 08544

L. F. Allard

ORNL

P.O. Box 2008

Bldg. 4515, MS 064

Oak Ridge, TN 37831

(615) 574-4981
Mark D. Allendorf

Sandia National Labs

Dept. 8361

7011 East Avenue

Livermore, CA 94551-0969

R. E. Allred

Division 1812

Sandia National Laboratories

Albuquerque, NM 87185

(505) 844-5538

Richard Anderson

Kroftt-Brakston International, Inc.

5836 Sunrise Avenue

Claendon Hills, IL 60514

(708) 655-3207

P. Angelini

ORNL

P.O. Box 2008

Bldg. 4515, MS 6065

Oak Ridge, TN 37830-6065

(615) 574-4565

C. Arnold, Jr.

Division 1811

Sandia National Laboratories

Albuqeurque, NM 87185

(505) 844-8728

T. W. Arrigoni

U.S. Dept. of Energy

P.O. Box 10940

Pittsburgh, PA 15236

(312) $972-4450$ 
J. S. Arzigian

Division 1815

Sandia National Laboratories

Albuquerque, NM 87185

(505) 844-2465

R. A. Assink

Division 1811

Sandia National Laboratories

Abuquerque, NM 87185

(505) 844-6372

D. G. Austin

1060 Sun Valley Drive

Annapolis, MD 21401

(410) 626-7826

V. Saimasarma Avva

N. Carolina State Univ.

Grahm Hall \#8

Greensboro, NC 27411

(919) $379-7620$

Walter C. Babcock

Bend Research, Inc.

64550 Research Road

Bend, OR 97701-8599

(503) 382-4100

Murray Bailey

NASA Lewis Research Center

MS 77-6

21000 Brookpark Road

Cleveland, $\mathrm{OH} 44135$

(216) $433-3416$

Charles D. Baker

Technical Res. Assoc., Inc. 410 Chipeta Way, Suite 222

Salt Lake City, UT 84108

(801) 582-8080
Samuel J. Barish

ER-16/GTN

U.S. Dept. of Energy

Washington, DC 20545

(301) 903-3054

W. Barnett

NE-53/FORS

U.S. Dept. of Energy

Washington, DC 20585

(301) 903-3097

Harold N. Barr

Hittman Mat. \& Med. Components, Inc.

9190 Red Branch Road

Columbia, MD 21045

(301) $730-7800$

Dr. Bulent Basol

Internl. Solar Electric Tech., Inc.

8635 Aviation Boulevard

Inglewood, CA 90301

(310) $216-4427$

J. L. Bates

Pacific Northwest Laboratories

P.O. Box 999

Richland, WA 99352

(509) 375-2579

S. Bauer, Division G314

Sandia National Laboratory

P.O. Box 5800

Albuquerque, NM 87185

(505) 846-9645

D. J. Baxter

Material Science \& Tech. Div.

Argonne National Laboratories

9700 South Cass Ave

Argonne, IL 60439

(312) $972-5117$ 
M. B. Beardsley

Caterpillar, Inc.

100 N.E. Adams Street

Peoria, IL 61629

(309) $578-8514$

R. L. Beatty

ORNL

P.O. Box 2008

Bldg. 4508, MS 088

Oak Ridge, TN 37831

(615) 574-4536

B. Beaudry

Ames Laboratory

Iowa State University

Ames, Iowa 50011

(515) 294-1366

P. F. Becher

ORNL

P.O. Box 2008

Bldg. 4515, 068, Room 275

Oak Ridge, TN 37831-6088

(615) 574-5157

T. R. Beck

Electrochemical Tech. Corp.

3935 Leary Way, NW

Seattle, WA 98107

(206) 632-5965

David J. Beecy

FE-72/FORS

U.S. Dept. of Energy

Washington, DC 20585

(301) 903-2787
Dr. James A. Begley

Packer Engineering, Inc.

200 Fleet Street

Pittsburgh, PA 15220

(412) 921-6441

Mohamad M. Behravesh

Nuclear Plant Corrosion Control

Electric Power Research Institute 3412 Hillview Avenue

Palo Alto, CA 94303

(415) 855-2388

R. G. Behrens

LANL

Los Alamos, NM 87545

(505) 667-8327

Dr. William L. Bell

TDA Research, Inc.

12345 West 52nd Avenue

Wheat Ridge, CO 80033

(303) $940-2301$

John Benner

Solar Electric Conversion Div.

NREL

1617 Cole Blvd.

Golden, CO 80401

(303) 231-1396

Dave Benson

NREL

1617 Cole Blvd

Golden, CO 80401

(303) 231-1162 
Clifton G. Bergeron

University of Illinois

105 South Goodwin Avenue

204 Ceramics Building

Urbana, IL 61801

(217) $333-1770$

Sam Berman

Bldg. 90, Rm. 3111

Lawerence Berkeley Laboratory

University of California

Berkeley, CA 94720

(415) 486-5682

Theodore M. Besmann

Metals and Ceramics Division

Oak Ridge National Laboratory

P.O. Box 2008

Oak Ridge, TN 37831

(615) 574-6852

R.M. Biefeld

Division 1150

Sandia National Laboratories

Albuquerque, NM 87185

(505) 844-1556

Dr. Fritz Bien

Spectral Sciences, Inc.

99 South Bedford Street, \#7

Burlington, MA 01803-5169

(617) 273-4770

L. Blair

Los Alamos National Lab

P.O. Box 1663

Los Alamos, NM 87545

(505) 667.6250
David W. Bobrek

Blasch Precision Ceramics

99 Cordell Road

Schenectady, NY 12304

(518) 372-9416

J. Bockris

Texas A\&M University

College Station, TX 77843-3255

(713) 845-5335

Robert Boettner

EE-112/FORS

U.S. Dept. of Energy

Washington, DC 20585

(202) 252-9136

W. D. Bond

Oak Ridge National Laboratory

P.O. Box 2008

Bldg. 7920, 384, Room 0014

Oak Ridge, TN 37831-6088

(615) 574-7071

J. A. Borders

Division 1823

Sandia National Laboratories

Albuquerque, NM 87185

(505) 844-8855

J. A. M. Boulet

University of Tennessee

310 Perkins Hall

Knoxville, TN 37996

(615) $974-8376$

R. J. Bourcier

Division 1832

Sandia National Laboratories

Albuquerque, NM 87185

(505) 844-6638 
H. K. Bowen

Dept. of Mat. Science \& Eng. MIT

77 Massachusetts Avenue

Cambridge, MA 02139

(617) 253-6892

D. J. Bradley

Pacific Northwest Laboratory

Richland, WA 99352

(509) 375-2587

R. A. Bradley

ORNL

P.O. Box 2008

Bldg. 4515

Oak Ridge, TN 37831-6067

(615) 574-6094

Joyce M. Brien

Research International, Inc.

18706-142nd Avenue, NE

Woodinville, WA 98072

(206) 486-7831

C. R. Brinkman

ORNL

P.O. Box 2008

Bldg. 4500-S, MS 154

Oak Ridge, TN 37831

(615) 574-5106

Leslie Bromberg

Plasma Fusin Center

MA Institute of Tech.

Cambridge, MA 02139

(617) 253-6919

S. E. Bronisz

LANL

Los Alamos, NM 87545

(505) 667-4665
J. A. Brooks

Division 8312

Sandia National Laboratories

Livermore, CA 94550

(415) 422-2051

K. L. Brower

Division 1110

Sandia National Laboratories

Abuquerque, NM 87185

(505) 844-6131

Dr. Alexander Brown

Chesapeake Composites Corporation

239 Old Churchman's Road

New Castle, DE 19720

(302) 324-9110

Ian G. Brown

Lawrence Berkeley Laboratory

Berkeley, CA 94720

(510) 486-4147

J. J. Brown, Jr.

Materials Engineering

Virginia Polytechnic Inst.

Blacksburg, VA 24061

(703) $961-6777$

N. E. Brown

Division 1821

Sandia National Laboratories

Albuquerque, NM 87185

(505) 844-2747

J. Budny

Busek Company

19 Kearney Road

Needham, MA 92194

(617) 449-3929 
S. T. Buljan

GTE Laboratories, Inc.

40 Sylvan Road

Waltham, MA 02254

(617) $890-8460$

R. F. Bunshah

Mat. Science \& Eng. Dept.

Univ. of CA, Los Angeles

6532 Boelter Hall

Los Angeles, CA 90024

(213) $825-2210$

Richard Burrows

NASA Lewis Research Center

21000 Brookpark Road

MS 77-6

Cleveland, OH 44135

(216) $433-3388$

R. J. Buss

Division 1812

Sandia National Laboratories

Albuquerque, NM 87185

(505) 844-7494

Kenneth R. Butcher

Selee Corporation

700 Shepherd Street

Hendersonville, NC 28792

(704) 697-2411

Dr. J. F. Butler

Aurora Technologies Corporation

7408 Trade Street

San Diego, CA 92121-2410

(619) $549-4645$
Stephen A. Butter

ER-142/GTN

U.S. Dept. of Energy

Washington, DC 20585

(301) 903-2367

Oral Buyukozturk

MIT

77 Massachussetts Avenue

Cambridge, MA 02139

(617) 253-7186

E. Buzzeli

Westinghouse R\&D Center

1310 Beulah Rd

Pittsbugh, PA 15235

(412) 256-1952

Elton Cairns

Lawrence Berkeley Laboratory

University of California

Berkeley, CA 94720

(415) 486-5028

A. J. Caputo

ORNL

P.O. Box 2008

Bldg. 9202, 002

Oak Ridge, TN 37831

(615) 574-4566

Juan Carbajo

ORNL

P.O. Box Y

Oak Ridge, TN 37831

(615) 574-3784

R. W. Carling, Div. 8313

Sandia National Laboratories

Livermore, CA 94550

(415) 422-2206 
P. T. Carlson

Oak Ridge National Laboratory

P.O. Box 2008

Oak Ridge, TN 37831

(615) 574-6094

J. P. Carr

FE-14/GTN

U.S. Dept. of Energy

Washington, DC 20545

(301) 903-6519

D. W. Carroll

LANL

Los Alamos, NM 87545

(505) 667-2145

D. H. W. Carstens

LANL

Los Alamos, NM 87545

(505) 667-5849

Gesina C. "Cynthia" Carter

Div. of Adv. Energy Projects

Office of Basic Energy Sciences

ER-16/GTN

U.S. Dept. of Energy

Washington, DC 20585

(301) 903-5995

Lawrence A. Casper

2630 Zanzibar Lane

Plymouth, MN 55447

(612) 541-2508

G. M. Caton

ORNL

P.O. Box 2008

Bldg. 4515

Oak Ridge, TN 37831-6065

(615) 574-7782
Ken Chacey

EM-34/GTN

U.S. Dept. of Energy

Washington, DC 20545

(301) 903-7186

W. F. Chambers

Division 1822

Sandia National Laboratories

Albuquerque, NM 87185

(505) 844-6163

A. T. Chapman

Georgia Institute of Technology

Georgia Tech Research Institute

Atlanta, GA 30332-0420

(404) $894-4815$

Yok Chen

ER-131/GTN

U.S. Dept. of Energy

Washington, DC 20585

(301) 903-3428

Lalit Chhabildas

Org. 1433 Mail Stop 0821

P.O. Box 5800

Sandia National Laboratory

Albuquerque, NM 87185

(505) 844-4147

Russell Chou

Materials Research Center

Lehigh University

Bethlehem, PA 18015

(215) 861-4235

D. C. Christensen

LANL

Los Alamos, NM 87545

(505) 667-2556 
Richard Christensen

LLNL

University of California

P.O. Box 808

Livermore, CA 94550

(415) $422-7136$

L. Christophorou

ORNL

P.O. Box 2008

Bldg. 4500S, 122, Rm. H156

Oak Ridge, TN 37831

(615) 574-6199

Russel J. Churchill

American Research Corp. of Va.

642 First Street

P.O. Box 3406

Radford, VA 24143-3406

(703) 731-0836

M. J. Cieslak

Division 1833

Sandia National Laboratories

Albuquerque, NM 87185

(505) 846-7500

D. E. Clark

Materials Technology Div

Idaho National Eng. Laboratory

Idaho Falls, ID 83415

FTS 583-2627

Robert Clark

Sandia National Laboratory

Albuquerque, NM 87185

(505) 844-6332
S. K. Clark

Dept. of Mech. Eng. \& App. Mech.

University of Michigan

Ann Arbor, MI 48109

(313) $764-4256$

David Clarke

Univ. of California

Materials Department

Engineering III

Santa Barbara, CA 93106

(805) 893-8275

A. H. Claver

Battelle-Columbus Labs

505 King Avenue

Columbus, OH 43201

(614) 424-4377

Michael O. Cloninger

Yucca Mountain Project

DOE Nevada Operations Office

P.O. Box 98518

Las Vegas, NV 89195-8518

(702) 794-7847

R. L. Clough

Sandia National Laboratories

Albuquerque, NM 87185

(505) 844-3492

Joe K. Cochran, Jr.

School of Ceramic Eng.

Georgia Inst. of Technology

Atlanta, GA 30332

(404) 894-2851

Marvin M. Cohen

ER-533/GTN

U.S. Dept. of Energy

Washington, DC 20545

(301) 903-4253 
Robert Cook

LLNL

University of California

P.O. Box 808

Livermore, CA 94550

(415) $422-6993$

Alastair N. Cormack

NYS College of Ceramics

Alfred University

Alfred, NY 14802

(607) $871-2180$

J. E. Costa

Division 8314

Sandia National Laboratories

Livermore, CA 94550

(415) $422-2352$

Bruce Cranford

EE-222/FORS

U.S. Dept. of Energy

Washington, DC 20585

(202) 586-9496

Frederick A. Creswick

ORNL

P.O. Box 2009

Oak Ridge, TN 37831

(615) 574-2009

James V. Crivello

Department of Chemistry

Rensselaer Polytechnic Institute

Troy, NY 12180-3590

(518) 276-6825
Gary M. Crosbie

Ceramics Research

Ford Motor Company

P.O. Box 2053

Dearborn, MI 48121-2053

(313) 327-1208

Randy Curlee

ORNL

P.O. Box 2008

Oak Ridge, TN 37831

(615) 576-4864

M. J. Curry

Plastics Inst. of America

Stevens Inst. of Tech.

Castle Point Station

Hoboken, NJ 07030

(201) 420-5552

David I. Curtis

NE-60/NR

U.S. Dept of Energy

(703) 603-5565

Steinar Dale

ORNL

P.O. Box 2008

Bldg. 5500, 366, Room A217

Oak Ridge, TN 37831

(615) 574-4829

G. J. D'Alessio

DP-242/GTN

U.S. Dept. of Energy

Washington, DC 20585

(301) 903-6688 
Dr. Kevin L. D'Amico

X-Ray Analytics, Ltd.

Box 678

Upton, NY 11973

(708) 887-9941

\section{S. J. Dapkunas}

National Institute of Standards and Technology

Gaithersburg, MD 20899

(301) 975-6119

\section{John Davis}

McDonnell Douglas Astro. Co.

Fusion Energy Program

P.O. Box 516, Bldg 278

St. Louis, MO 63166

(314) $234-4826$

Robert F. Davis

Dept. of Materials Eng.

North Carolina State University

232 Riddick Lab, Box 7907

Raleigh, NC 27695

(919) 737-3272

Victor Der

ER-531/FORS

U.S. Dept. of Energy

Washington, DC 20585

(301) 903-5736

R. Diegle

Division 1841

Sandia National Labs

Albuquerque, NM 87185

(505) 846-3450
D. R. Diercks

Mat. Science \& Tech. Div. Argonne National Labs

9700 South Cass Ave Argonne, Illinois 60439 (312) $972-5032$

Joseph A. Dodson

Space Power, Inc.

621 River Oaks Parkway

San Jose, CA 95134

(408) $434-9500$

Larry A. Dominey

Covalent Associates, Inc.

10 State Street

Woburn, MA 01801

(617) $938-1140$

A. D. Donaldson

Materials Technology Div.

Idaho National Eng. Lab

Idaho Falls, ID 83415

(208) 526-2627

Donald G. Doran

Sanford Eng. Dev. Lab

P.O. Box 1970

Richland, WA 99352

(509) 444-3187

Alan Dragoo

ER-131, G236/GTN

U.S. Dept. of Energy

Washington, DC 20585

(301) 903-4895

Ms. Elaine Drew

Supercon, Inc.

830 Boston Turnpike

Shrewsbury, MA 01545

(508) 842-0174 
W. D. Drotning

Division 1824

Sandia National Laboratories

Albuquerque, NM 87185

(505) 844-7934

T. J. Drummond

Division 1150

Sandia National Laboratories

Albuquerque, NM 87185

(505) 844-9677

Jerry Duane

Director of Implementation \& Deploy.

EE-223/FORS

U.S. Dept. of Energy

Washington, DC 20585

(202) $586-7448$

C. Michael Dube

Dynamics Technology, Inc.

22939 Hawthorne Blvd., \#200

Torrance, CA 90505

(213) 373-0666

George Duda

ER-72/FORS

U.S. Dept. of Energy

Washington, DC 20585

(301) 903-3651

C. Duffy

LANL P.O. Box 1663

Los Alamos, NM 87545

(505) $843-5154$

Keith F. Dufrane

Battelle-Columbus Labs

505 King Avenue

Columbus, OH 43201

(614) 424-4618
E. M. Dunn

GTE Laboratories, Inc.

40 Sylvan Road

Waltham, MA 02254

(617) 466-2312

Sunil Dutta

NASA Lewis Research Center

21000 Brookpark Road, MS 49-3

Cleveland, $\mathrm{OH} 44135$

(216) $433-3282$

T. E. Easler

Material Science \& Tech. Div. Argonne National Laboratories 9700 S. Cass Avenue, Bldg. 212 Argonne, Illinois 60439

(312) $972-5084$

Christopher A. Ebel

Norton Company

Goddard Road

Northboro, MA 01532-1545

(617) 393-5950

James J. Eberhardt

EE-34/FORS

U.S. Dept. of Energy

Washington, DC 20585

(202) $586-5377$

K. H. Eckelmeyer

Division 1822

Sandia National Laboratories

Albuquerque, NM 87185

(505) 844-7775

G. R. Edwards

Colorado School of Mines

Golden, CO 80401

(303) 273-3773 
Mr. Paul Eggerstedt

Ind. Filter \& Pump Man. Co.

5900 Ogden Avenue

Cicero, IL 60650

(708) 656-7800

W. A. Ellingson

Argonne National Laboratories

Mat. Science Div., Bldg. 212

9700 South Cass

Argonne, Illinois 60439

(312) 972-5068

J. W. Elmer

MIT

77 Massachusetts Avenue

Cambridge, MA 02139

(617) 253-2233

Mr. Norbert B. Elsner

Hi-Z Technology, Inc.

6373 Nancy Ridge Drive

San Diego, CA 92121-2247

(619) 535-9343

James Ely, Thermophys. Prop.

Ctr. for Chemical Engineering

National Eng. Laboratory

NIST

Boulder, CO 80303

(303) 320-5467

Dr. Gerald Entine

Radiation Monitoring Devices, Inc.

44 Hunt Street

Watertown, MA 02172

(617) 926-1167
Mike Epstein

Battelle-Columbus Labs

505 King Avenue

Columbus, OH 43201

(614) 424-6424

R. H. Ericksen

Division 1813

Sandia National Laboratories

Albuquerque, NM 87185

(505) 844-8333

Albert Evans

ER-13/GTN

U.S. Dept. of Energy

Washington, DC 20585

(301) 903-3427

Bob Evans

NASA Lewis Research Center

21000 Brookpark Road, MS 77-6

Cleveland, $\mathrm{OH} 44135$

(216) 433-3400

Deane Evans

Steven Winter Associates

350 5th Avenue

New York, NY 10001

(212) $564-5800$

John Fairbanks

EE-322/FORS

U.S. Dept. of Energy

Washington, DC 20585

(202) 586-8066

P. D. Fairchild

ORNL

P.O. Box Y

Bldg. 9102-2, 001, Room 0210

Oak Ridge, TN 37831

(615) 574-2009 
D. A. Farkas

Virginia Polytechnic Institute and University

Blacksburg, VA 24061

(703) $961-4742$

Cynthia K. Farrar

Montec Associates, Inc.

P.O. Box 4182

Butte, MT 59702

(406) 494-2596

G. C. Farrington

University of Pennsylvania

Philadelphia, PA 19104

(215) 898-8337

W. Feduska

Westinghouse Electric Corp.

R\&D Center

1310 Beulah Road

Pittsburgh, PA 15235

(412) 256-1951

Robert S. Feigelson

Center for Materials Research

Stanford University

Stanford, CA 94305

(415) 723-4007

Mattison K. Ferber

ORNL

P.O. Box 2008

Building 4515

Oak Ridge, TN 37831-6064

(615) 576-0818
Nicholas Fiore

Carpenter Technology Corp.

101 West Bern Street

P.O. Box 14662

Reading, PA 19612

(215) 371-2556

Ronald J. Fiskum

EE-422/FORS

U.S. Dept. of Energy

Washington, DC 20585

(202) 586-9130

Timothy J. Fitzsimmons

ER-32, G-236/GTN

U.S. Dept. of Energy

Washington, DC 20585

J. E. Flinn

Materials Technology Div.

Idaho National Eng. Laboratory

Idaho Falls, ID 83415

(208) 526-8127

P. S. Follansbee

LANL

Los Alamos, NM 87545

(505) 667-8021

D. M. Follstaedt

Division 1110

Sandia National Laboratories

Albuquerque, NM 87185

(505) 844-2102

F. Forsyth

Brookhaven National Lab

Upton, NY 11973

(516) 282-4676 
Christopher A. Foster

Cryogenic Applications F, Inc.

450 Bacon Springs Lane

Clinton, TN 37716

(615) 435-5433

Earle Fowler

ER-226/FORS

U.S. Dept. of Energy

Washington, DC 20585

(301) 903-4801

Mark Frei

EM-34/FORS

U.S. Dept. of Energy

Washington, DC 20585

(301) 903-7201

Ehr-Ping Huang Fu

Thermal Science

EE-232/FORS

U.S. Dept. of Energy

Washington, DC 20585

(202) 586-1493

P. W. Fuerschbach

Division 1833

Sandia National Laboratories

Albuquerque, NM 87185

(505) 846-2464

E. R. Fuller

National Institute of Standards and Technology

Gaithersburg, MD 20899

(301) 921-2942

M. J. Furnam

Federal Building

Richland, WA 99352

(509) 376-7062
F. D. Gac

LANL/MS G771

Los Alamos, NM 87545

(505) 667.5126

G. F. Gallegos

LLNL

University of California

P.O. Box 808

Livermore, CA 94550

(415) 422-7002

Yogendra S. Garud

S. Levy, Inc.

3425 South Bascom Avenue

Campbell, CA 95008

(408) $377-4870$

George E. Gazza

U.S. Army Materials Tech. Lab

405 Arsenal Street

Watertown, MA 02172

(617) 923-5408

F. P. Gerstle, Jr.

Sandia National Laboratories

Albuquerque, NM 87185

(505) 844-4304

C. P. Gertz

Yucca Mountain Project Mgr.

U.S. Dept. of Energy

P.O. Box 98518

Las Vegas, NV 89193

(702) 794-7920

Larry Gestaut

Eltech Systems Corp.

Painsville, $\mathrm{OH} 44077$

(216) $357-4041$ 
E. R. Gilbert

Pacific Northwest Laboratory

Richland, WA 99352

(509) 375-2533

D. S. Ginley

Division 1150

Sandia National Laboratories

Albuquerque, NM 87185

(505) 844-8863

\section{A. Glass}

KMS Fusion

3621 South State Road

Ann Harbor, MI 48106

(313) 769-8500

R. Glass

LLNL

University of California

P.O. Box 808

Livermore, CA 94550

(415) 423-7140

Leon Glicksman

MIT

77 Massachussetts Avenue

Cambridge, MA 02139

(617) 253-2233

Martin Glicksman

Rensselear Polytechnic Inst.

Materials Research Ctr. - 104

8th Street

Troy, NY 12180-3690

(518) 276-6721

F. D. Gmeindl

METC

P.O. Box 880

Morgantown, WV 26505

(304) 291-4751
Dr. Neil J. Goldfine

Jentek Sensors, Inc. 1616 Soldiers Field Road

Boston, MA 02135

(617) 254-5552

John Goldsmith

EE-332/FORS

U.S. Dept. of Energy

Washington, DC 20585

(202) 586-8171

Dr. Robert L. Goldsmith

CeraMem Corporation

12 Clematis Avenue

Waltham, MA 02154

(617) 899-0467

Gerald Goldstein

ER-74/GTN

U.S. Dept. of Energy

Washington, DC 20545

(301) 903-5348

Dr. Mark Goldstein

Quantum Group, Inc.

11211 Sorrento Valley Road

San Diego, CA 92121

(619) 457-3048

B. Goodman

NREL

1617 Cole Blvd

Golden, CO 80401

(303) 231-1005

S. H. Goods

Divison 8314

Sandia National Laboratories

Livermore, CA 94550

(415) $422-3274$ 
Paul D. Gorsuch

Space Systems Division

General Electric Company

P.O. Box 8555

Philadelphia, PA 19101

(215) 354-5047

R. J. Gottschall

ER-13/FORS

U.S. Dept. of Energy

Washington, DC 20585

(301) 903-3427

Fred S. Goulding

Instrumentation Division

Lawerence Berkeley Laboratory

Berkeley, California 94720

(415) 486-6432

R. A. Graham

Division 1130

Sandia National Laboratories

Albuquerque, NM 87185

(505) 844-1931

Allen R. Grahn

Bonneville Scientific

918 East 900 South

Salt Lake City, UT 84105

(801) 359-0402

Anton C. Greenwald

Spire Corporation

One Patriots Park

Bedford, MA 01730-2396

(617) 275-6000

N. Grossman

NE-42/FORS

U.S. Dept. of Energy

Washington, DC 20585

(301) 903-3745
Dieter M. Gruen

Materials Science Division

Argonne National Laboratory

9700 South Cass Avenue

Argonne, IL 60439

(708) 252-3513

T. R. Guess

Division 1812

Sandia National Laboratories

Albuquerque, NM 87185

(505) 844-5604

Marvin E. Gunn

EE-14/FORS

U.S. Dept. of Energy

Washington, DC 20585

(202) $586-2826$

M. Gurevich

EE-332/FORS

U.S. Dept. of Energy

Washington, DC 20585

(202) 586-6104

Adi R. Guzdar

Foster-Miller, Inc.

350 Second Avenue

Waltham, MA 02154

(617) 890-3200

John P. Gyeknyesi

NASA Lewis Research Center

2100 Brookpark Road, MS 49-7

Cleveland, $\mathrm{OH} 44135$

(216) 433-3210

J. S. Haggarty

MIT

77 Massachussetts Avenue

Cambridge, MA 02139

(617) 253-2129 
Kathleen Hain

EM-54/FORS

U.S. Dept. of Energy

Washington, DC 20585

(301) 903-7917

Phil Haley

Allison Turbine Operations

P.O. Box 420

Indianapolis, IN 46206-0420

(317) $230-2272$

John M. Halstead

SOHIO Engineered Materials

P.O. Box 1054

Niagara Falls, NY 14302

(716) 278-2330

David G. Hamblen

Advanced Fuel Research, Inc.

87 Church Street

P.O. Box 380379

East Hartford, CT 06138-0379

(203) 528-9806

Edward P. Hamilton

American Superconductor Corp.

2 Technology Drive

Westboro, MA 01581

(508) 836-4200

Michael T. Harris

Chemical Tech. Div.

Oak Ridge National Lab

P.O. Box 2008

Oak Ridge, TN 37831

(615) 574-5962
Pat Hart

Pacific Northwest Labs

P.O. Box 999

Richland, WA 99352

(504) 375-2906

R. W. Haskell

GE Research Laboratory

P.O. Box 8

Schenectady, NY 12301

(518) $385-4226$

Debbie Haught

EE-34/FORS

U.S. Dept. of Energy

Washington, DC 20585

(202) 586-2211

Jeff Hay

Chem.-Mat. Science Div.

Los Alamos National Lab

Los Alamos, NM 87545

(505) 843-2097

A. K. Hays

Division 1831

Sandia National Labs

Albuquerque, NM 87185

(505) 844-9996

Norman L. Hecht

University of Dayton

300 College Park, KL165

Dayton, OH 45469-0001

(513) 229-4343

Richard L. Heestand

ORNL

P.O. Box 2008

Bldg. 4508, 083, Room 128

Oak Ridge, TN 37831

(615) 574-4352 
H. E. Helms

General Motors Corp.

T-18

P.O. Box 420

Indianapolis, IN 46206-0420

(317) 242-5355

Kamithi Hemachalam

Intermagnetics General Corp.

1875 Thomaston Avenue

Waterbury, CT 06704

(203) $753-5215$

Timothy Henderson

KMS Fusion, Inc.

Ann Arbor, MI 48106

(313) $769-8500$

Mary T. Hendricks

Alabama Cryogenic Engineering, Inc.

P.O. Box 2470

Huntsville, AL 35804

(205) 536-8629

Carolyn J. Henkens

Andcare, Inc.

2810 Meridian Parkway

Suite 152

Durham, NC 27713

(919) $544-8220$

Carl Henning

Lawrence Livermore Nat. Lab

P.O. Box 5511

Livermore, CA 94550

(415) 532-0235

Thomas P. Herbell

NASA Lewis Research Center 21000 Brookpark Road, 105-1

Cleveland, OH 44135

(216) 433-3246
Carl B. Hilland

DP-28/GTN

U.S. Dept. of Energy

Washington, DC 20545

(301) 903-3687

Dr. G. Duncan Hitchens

Lynntech, Inc.

7610 Eastmark Drive

Suite 105

College Station, TX 77840

(409) 693-0017

Kai-Ming Ho

Inst. for Physical

Research and Technology

Ames Labatory

Ames, IA 50011

(515) 294-1960

J. M. Hobday

METC

P.O. Box 880

Morgantown, WV 26505

(304) 291-4347

D. M. Hoffman

Lawrence Livermore Nat. Lab

University of California

P.O. Box 808

Livermore, CA 94550

(415) $422-7759$

E. E. Hoffman

U.S. Dept. of Energy

P.O. Box 2001

Oak Ridge, TN 37831-8600

(615) 576-0735 
G. J. Hooper

EE-324/FORS

U.S. Dept. of Energy

Washington, DC 20585

(202) 586-4153

Linda L. Horton

Oak Ridge National Laboratory

Box 2008, Bldg. 4500-S

Oak Ridge, TN 37831-6118

(615) 574-5081

E. Philip Horwitz

Chemistry Division

Argonne National Laboratory

9700 South Cass Avenue

Argonne, IL 60439

(708) 252-3653

F. M. Hosking

Division 1833

Sandia National Laboratories

Albuquerque, NM 87185

(505) 844-8401

Charles R. Houska

Dept. of Materials Eng.

Holden Hall

Virginia Polytechnic Institute

Blacksburg, VA 24061

(703) $961-5652$

Stephen M. Hsu

Center for Materials Science

National Measurements Lab

NIST

Gaithersburg, MD 20899

(301) 975-6119
W. J. Huber

METC

P.O. Box 880

Morgantown, WV 26505

(304) 291-4663

Donald R. Huffman

Dept. of Physics

University of Arizona

Tucson, AZ 85721

(602) 621-4804

Robert A. Huggins

Dept. of Mat. Science \& Eng.

Peterson 550I

Stanford University

Stanford, CA 94305

(415) $497-4110$

Arlon Hunt

Lawrence Berkeley Laboratory

University of California

Berkeley, CA 94720

(415) 486-5370

Dr. Thomas K. Hunt

Advanced Modular Power Systems, Inc.

4667 Freedom Drive

Ann Arbor, MI 48108

(313) $677-4260$

George F. Hurley

Chemistry-Materials Sci. Div.

Los Alamos National Laboratory

Los Alamos, NM 87545

(505) 667-9498 
Gerald C. Huth

Univ. of Southern California

Inst. for Phys. \& Imag. Sci.

4676 Admiralty Way

Marina del Rey, CA 90292

(213) 822-9184

Mallika D. Ilindra

Sumi Tech, Inc.

3006 McLean Court

Blacksburg, VA 24060

(703) 552-8334

D. David Ingram

Universal Energy Systems, Inc.

4401 Dayton-Xenia Road

Dayton, OH 45432

(513) $426-6900$

Robert B. Isaacson

Director of Advanced Technology

Hoeschst-Celanese

51 John F. Kennedy Parkway

Short Hills, NJ 07928

(201) 912-4954

L. K. Ives

National Institute of Standards and Technology

Gaithersburg, MD 20899

(301) 921-2843

Jan S. Iwanczyk

Xsirius, Inc.

1220 Avenida Acaso

Camarillo, CA 93012

(805) $484-8300$
David A. Jackson

Energy Photovoltaics, Inc. 276 Bakers Basin Road Lawrenceville, NJ 08648

(609) 587-3000

Jonah Jacob

Science Research Lab, Inc.

15 Ward Street

Somerville, MA 02143

(617) 547-1122

N. S. Jacobson

NASA Lewis Research Center

21000 Brookpark Road

Cleveland, $\mathrm{OH} 44135$

(216) $433-5498$

Dr. Radha Jalan

ElectroChem, Inc.

400 West Cummings Park

Woburn, MA 01801

(617) 932-3383

Mark A. Janney

ORNL

P.O. Box 2008

Bldg. 4515, 069, Room 228

Oak Ridge, TN 37831-6088

(615) 574-4281

C. E. Jaske

Physical Metallurgy Section

Battelle-Columbus Labs

505 King Avenue

Columbus, OH 43201

(614) 424-4417 
J. L. Jellison

Division 1833

Sandia National Laboratories

Albuquerque, NM 87185

(505) 844-6397

M. M. Jenior

EE-332/FORS

U.S. Dept. of Energy

Washington, DC 20585

(202) 586-2998

J. E. Jensen

CVI Inc.

P.O. Box 2138

Columbus, $\mathrm{OH} 43216$

(614) 876-7381

Carl E. Johnson

Chemical Technology Division Argonne National Laboratory 9700 Cass Ave, Bldg. 205 Argonne, IL 60439

(312) 972-7533

Curtis A. Johnson

GE Research Laboratory

P.O. Box 8

Bldg. 31 \#3C7

Schenectady, NY 12301

(518) 387-6421

D. L. Johnson, Chairman

Dept. of Mat. Science \& Eng. 2145 Sheridan Road, Rm 1034 Northwestern University

Evanston, IL 60201

(312) $492-3537$
D. Ray Johnson

ORNL, Metals \& Ceramics Div.

P.O. Box 2008

Bldg. 4515, 066, Room 206

Oak Ridge, TN 37831-6088

(615) 576-6832

R. J. Johnson

Hanford Eng. Dev. Lab.

P.O. Box 1970

Richland, WA 99352

(509) 376-0715

T. Johnson

Bldg. 205

9700 South Cass Avenue

Argonne, IL 60439

(312) $972-5964$

H. Jones

GA Technologies

P.O. Box 81608

San Diego, CA 92138

(615) $455-2360$

Robert Jones

Los Alamos National Lab.

P.O. Box 1663, M/S J577

Los Alamos, NM 87545

(505) 667-6441

Robert A. Jones

DP-28/GTN

U.S. Dept. of Energy

Washington, DC 20545

(301) 903-4236

W. B. Jones

Division 1832

Sandia National Laboratories

Albuquerque, NM 87185

(505) 844-4026 
Ram Kachare

M/S 238-343

Flat Plate Solar Array Project

Jet Propulsion Laboratory

Pasadena, CA 91109

(213) $354-4583$

Neil Kaminar

Solar Eng. Applications Corp.

P.O. Box 62246

Sunnyvale, CA 94088

(408) 986-9231

Chris Kang

EE-142/FORS

U.S. Dept. of Energy

Washington, DC 20585

(202) 586-4563

M. J. Kania

ORNL

P.O. Box 2008

Bldg. 3525, 390, Room 109

Oak Ridge, TN 37831

(615) 576-4856

Landis Kannberg

Pacific Northwest Lab

Battlelle Blvd.

P.O. Box 999

Richland, WA 99352

(509) 375-3919

Michael E. Karpuk

TDA Research, Inc. 12345 West 52nd Avenue

Wheat Ridge, CO 80033

(303) 940-2301
M. E. Kassner

LLNL

University of California

P.O. Box 808

Livermore, CA 94550

(415) $422-7002$

Carlos Katz

Cable Technology Lab

P.O. Box 707

New Brunswick, NJ 08903

(201) $846-3220$

Joel Katz

LANL

P.O. Box 1663/MS G771

Los Alamos, NM 87545

(505) 665-1424

Robert N. Katz

Worcester Polytechnical Inst.

Dept. of Mechanical Eng.

100 Institute Street

Worcester, MA 01609

(508) 831-5336

Larry Kazmerski

Solar Electric Conv. Div.

NREL

1617 Cole Blvd.

Golden, CO 80401

(303) 231-1115

M. R. Keenan

Division 1813

Sandia National Laboratories

Albuquerque, NM 87185

(505) 844-6631 
J. R. Keiser

ORNL

P.O. Box 2008

Bldg. 4500-S, 156, Room 0734

Oak Ridge, TN 37830

(615) 574-4453

J. A. Kelber

Division 1812

Sandia National Laboratories

Albuquerque, NM 87185

(505) 844-3408

Dr. Rudolf Keller

EMEC Consultants

4221 Roundtop Road

Export, PA 15632

(412) $325-3260$

R. G. Kepler

Sandia National Laboratories

Albuquerque, NM 87185

(505) 844-7520

Paul T. Kerwin

NASA Lewis Research Center

21000 Brookpark Road, MS 77-6

Cleveland, $\mathrm{OH} 44135$

(216) 433-3409

Lawrence W. Kessler

Sonoscan, Inc.

530 East Green Street

Bensenville, IL 60106

(213) 766-7088

Han Kim

GTE Labs

40 Sylvan Road

Waltham, MA 02254

(617) 466-2742
O. F. Kimball

General Electric Co.

1 River Road

Schenectady, NY 12345

(518) 385-1427

Christopher N. King

Planar Systems, Inc.

1400 Northwest Compton Drive

Beaverton, OR 97006

(503) 690-1100

Richard King

EE-131/FORS

U.S. Dept. of Energy

Washington, DC 20585

(202) 586-1693

J. H. Kinney

LLNL

University of California

P.O. Box 808

Livermore, CA 94550

(415) 422-6669

G. S. Kino

Edward Ginzton Laboratory

Stanford University

Stanford, CA 94305

(415) 497-0205

Thomas Kitchens

ER-7/GTN

U.S. Dept. of Energy

Washington, DC 20585

(301) 903-3426

E. E. Klaus

Penn State

Room 108, Fenske Laboratory

Univ Park, PA 16802

(814) 865-2574 
Paul Klemmens

University of Connecticut

Box U-46

Storrs, CT 06268

(203) 486-3134

\section{S. J. Klima}

NASA Lewis Research Center MS 106-1

21000 Brookpark Road

Cleveland, $\mathrm{OH} 44135$

(216) $433-6020$

\section{J. A. Knapp}

Division 1110

Sandia National Laboratories

Albuquerque, NM 87185

(505) 844-2305

G. A. Knorovsky

Division 1833

Sandia National Laboratories

Albuquerque, NM 87185

(505) 844-1109

Dr. Timothy R. Knowles

Energy Science Labs, Inc.

6888 Nancy Ridge Drive

San Diego, CA 92121-2232

(619) 552-2034

C. C. Koch

Materials Eng. Department

North Carolina State University

Raliegh, NC 27650

(919) 737-2377

Victor R. Koch

Covalent Associates, Inc.

10 State Street

Woburn, MA 01801

(617) $938-1140$
D. Krajcinovic

Dept. of Civil Eng., Mechanics \& Metallurgy

University of Illinois

Chicago, IL 60680

(312) 996-7000

K. G. Kreider

National Institute of Standards and Technology

Washington, DC 20234

(301) 921-3281

D. M. Kreiner

Garrett Auxiliary Power Div.

P.O. Box 5217

Phoenix, AZ 85034

(602) 220-3465

L. E. Kukacka

Brookhaven National Laboratory

Upton, NY 11973

(516) 282-3065

David Kurtz

Advanced Technology Materials, Inc.

7 Commerce Drive

Danbury, CT 06810

(203) $794-1100$

S. R. Kurtz

Division 1811

Sandia National Laboratories

Albuquerque, NM 87185

(505) 844-5436

Richard J. Lagow

Department of Chemistry

The Univ. of Texas at Austin

Austin, TX 78712

(512) 471-1032 
C. M. Lampert

Lawerence Berkeley Laboratory

University of California

Berkeley, CA 94720

(415) 486-6093

P. E. Lamont

Federal Building

Richland, WA 99352

(509) 376-6117

A. Landgrebe

EE-32/FORS

U.S. Dept. of Energy

Washington, DC 20585

(202) $586-1483$

P. M. Lang

NE-45/FORS

U.S. Dept. of Energy

Washington, DC 20585

(301) 903-3313

James Lankford

Southwest Research Inst.

6220 Culebra Road

P.O. Drawer 28510

San Antonio, TX 78284

(512) 684-5111

Herbert J. Larson

Caterpillar, Inc.

Building F

100 N.E. Adams

Peoria, IL 61629

(309) 578-6549

R. LaSala

EE-122/FORS

U.S. Dept. of Energy

Washington, DC 20585

(202) $586-4198$
W. N. Lawless

CeramPhysics, Inc.

921 Eastwind Drive, Suite 110

Westerville, OH 43081

(614) 882-2231

Ed LeBaker

ARACOR

425 Lakeside Drive

Sunnyvale, CA 94086

(408) $733-7780$

Robert LeChevalier

U.S. Dept. of Energy

San Fransisco Oper. Office

1333 Broadway

Oakland, CA 94612

(415) 273-6362

S. R. Lee

U.S. Dept. of Energy

P.O. Box 10940

Pittsburgh, PA 15236

(412) 675-6137

Franklin D. Lemkey

United Tech. Research Ctr.

Silver Lane

East Hartford, CT 06108

(203) 727-7318

Douglas Lemon

Pacific Northwest Labs

P.O. Box 999

Richland, WA 99352

(509) 375-2306 
Dr. Alexander Lempicki

ALEM Associates/Radiation

Monitoring Devices

303A Commonwealth Avenue

Boston, MA 02115

(617) 353-9581

S. R. Levine

NASA Lewis Research Center 21000 Brookpart Road

Cleveland, OH 44135

(216) 433-3276

\section{A. V. Levy}

Lawerence Berkley Lab

University of California

One Cyclotron Road

Berkley, CA 94720

(415) 486-5822

John Lewellen

NE-46/FORS

U.S. Dept. of Energy

Washington, DC 20585

(301) 903-2899

Patrick Lin

Chemat Technology, Inc.

19365 Business Center Drive

Suite 8

Northridge, CA 91324

(818) 727-9786

L. J. Lindberg

Garrett Turbine Engine Co.

111 South 34th Street

P.O. Box 5217

Phoenix, AZ 85010

(602) 231-4002
J. Lipkin

Sandia National Laboratories

Livermore, CA 94550

(415) $422-2417$

C. T. Liu, Mtl. Ceram. Div.

ORNL

P.O. Box 2008

Bldg. 4500-S, 115, Rm. S280

Oak Ridge, TN 37831

(615) 574-5516

K. C. Liu

ORNL

P.O. Box 2008

Bldg. 4500-S, MS 155

Oak Ridge, TN 37831

(615) 574-5116

Charles Liucci

LEL Corp.

5 Burns Place

Cresskill, NY 07626

Earl L. Long, Jr.

ORNL, Metals \& Ceramics Div.

P.O. Box 2008

Bldg. 4515, 069, Room 229

Oak Ridge, TN 37831

(615) 574-5127

Richard W. Longsderff

Thermacore, Inc.

780 Eden Road

Lancaster, PA 17601

(717) 569-6551 
Michael Lopez

U.S. Dept. of Energy

San Francisco Oper. Office

1333 Broadway

Oakland, CA 94612

(415) $273-4264$

Dr. R. O. Loutfy

Mat. \& Electro. Research Corp.

7960 South Kolb Road

Tucson, AZ 85706

(602) $574-1980$

T. C. Lowe

Divison 8316

Sandia National Laboratories

Livermore, CA 94550

(415) 422-3187

C. D. Lundin

307 Dougherty Eng. Bldg.

University of Tennessee

Knoxville, TN 37996

(615) $974-5310$

MAJ Ross E. Lushbough

DP-225.2/FORS

U.S. Dept. of Energy

Washington, DC 20585

(301) $903-3912$

William C. Luth

ER-15

U.S. Dept. of Energy

Washington, DC 20585

(301) $903-5822$
E. A. Maestas

West Valley Project Office

U.S. Dept. of Energy

P.O. Box 191

West Valley, NY 14171-0191

(716) $942-4314$

Richard Mah

Los Alamos National Lab

P.O. Box 1663

Los Alamos, NM 87545

(505) 607-3238

Arturo Maimoni

Lawrence Livermore Nat. Lab

P.O. Box 808

Livermore, CA 94450

(415) $422-8575$

Mokhtas S. Maklad

EOTEC Corporation

420 Frontage Road

West Haven, CT 06516

(203) 934-7961

Dr. Frederick M. Mako

FM Technologies

10529-B Braddock Road

Fairfax, VA 22032

(703) 425-5111

A. C. Makrides

EIC Laboratories, Inc.

111 Downey Street

Norwood, MA 02062

(617) 769-9450

Subhas G. Malghan

NIST

A-258/223

Gaithersburg, MD 20899

(301) 975-6101 
Mark K. Malmros

MKM Research/Ohmicron

P.O. Box I

Washington Crossing, PA 18977

(609) 737-9050

Oscar P. Manley

ER-15/FORS

U.S. Dept. of Energy

Washington, DC 20585

(301) 903-5822

Dr. Matthew Marrocco

Maxdem, Inc.

140 East Arrow Highway

San Dimas, CA 91773

(909) 394-0644

R. G. Martin

Analysis Consultants

21831 Zuni Drive

El Toro, CA 92630

(714) 380-1204

H. Maru

Energy Research Corporation

3 Great Pasture Road

Danbury, CT 06810

(412) $578-2700$

Tadeusz Massalski

$69 \mathrm{MI}$

Naval Postgraduate School

Monterey, CA 93943

(412) $578-2700$

K. Masubuchi

Lab for Manuf. and Prod.

MIT

Cambridge, MA 02139

(617) 255-6820
Ronald D. Matthews

Dept. of Mechanical Engineering

The University of Texas at Austin

Austin, TX 78712

(512) 471-3108

W. A. May, Jr.

LANL

Los Alamos, NM 87545

(505) 667-6362

Jacob Maya

GTE Products Corp

Silvania Lighting Center

Danvers, MA 01923

(617) $777-1900$

Dr. Douglas McAllister

BIODE, Inc.

2 Oakwood Road

Cape Elizabeth, ME 04107

(207) 883-1492

T. B. McCall

Rockwell Hanford Operations

P.O. Box 800

Richland, WA 99352

(509) 376-7114

James W. McCauley, Dean

New York State College of Ceramics

Alfred University

Alfred, NY 14802

(607) 871-2411

Robert W. McClung

ORNL

P.O. Box 2008

Bldg. 4500-S, 151, Rm. D63

Oak Ridge, TN 37831-6088

(615) $574-4466$ 


\section{J. I. McCool}

SKF Industries, Inc. 1100 First Avenue

King of Prussia, PA 19406

(215) 265-1900

Dr. Scott B. McCray

Bend Research, Inc. 64550 Research Road Bend, OR 97701-8599 (503) $382-4100$

D. McCright

LLNL

University of California

Livermore, CA 94550

(213) 423-7051

R. McCrory

University of Rochester Lab for Laser Energetics

250 E. River Road

Rochester, NY 14623

J. M. McDonald

Sandia National Laboratories

Albuquerque, NM 87185

(505) 846-7735

Roger J. McDonald

Brookhaven National Laboratory

Bldg. 475

Upton, NY 11973

(515) 282-4197

Patrick N. McDonnell

Spire Corporation

One Patriots Park

Bedford, MA 01730-2396

(617) 275-6000
H. K. McDowell

LANL

Los Alamos, NM 87545

(505) 667-4686

David L. McElroy

ORNL

P.O. Box 2008

Bldg. 4508, 092, Rm. 239

Oak Ridge, TN 37831-6088

(615) 574-5976

A. J. McEvily

Metallurgy Dept., U-136

University of Connecticut

Storas, CT 06268

(203) 486-2941

T. D. McGee

Mat. Science \& Engineering 110 Engineering Annex

Iowa State University

Ames, IA 50011

(515) 294-9619

R. R. McGuire

Lawrence Livermore Nat. Lab

University of California

P.O. Box 808

Livermore, CA 94550

(415) 422-7792

Carl McHargue

University of Tennessee

Materials \& Eng. Dept.

434 Doughtery Eng. Bldg.

Knoxville, TN 37996-2200

(615) 974-8013 
M. J. McMonigle

EE-234/FORS

U.S. Dept. of Energy

Washington, DC 20585

(202) $\cdot 586-2082$

Arthur S. Mehner

NE-53/FORS

U.S. Dept. of Energy

Washington, DC 20585

(301) 903-4474

G. H. Meier

848 Benevum Hall

University of Pittsburgh

Pittsburgh, PA 15261

(412) 624-5316

J. E. Mendel

Pacific Northwest Lab.

P.O. Box 999

Richland, WA 99352

(509) 375-2905

P. D. Metz

Brookhaven National Lab.

Upton, NY 11973

(516) 282-3123

A. Meyer

International Fuel Cells

P.O. Box 739

195 Governors Hwy.

South Windsor, CT 06074

(203) 727-2214

B. E. Mills

Sandia National Laboratories

Livermore, CA 94550

(415) $422-3230$
M. V. Mitchell

AiResearch Casting Co.

19800 Van Ness

Torrance, CA 90509

(213) 618-7411

Andrew Morrison

M/S 238-343

Flat Plate Solar Array Project

Jet Propulsion Laboratory

Pasadena, CA 91109

(213) 354-7200

Craig Mortenson

BPA/FORS

U.S. Dept. of Energy

Washington, DC 20585

(202) 586-5656

J. Moteff

University of Cincinnati

Department of Material Science

Metallurgical Engineering

498 Rhodes Hall

Cincinnati, $\mathrm{OH}$ 45221-0012

(513) 475-3096

Leszek R. Motowidlo

IGC Advanced Superconductors

1875 Thomaston Avenue

Waterbury, CT 06704

(203) 753-5215

Arnulf Muan

Pennsylvania State University

EMS Experiment Station

415 Walker Bldg.

University Park, PA 16802

(814) 865-7659 
L. Marty Murphy

NREL

1617 Cole Blvd

Golden, CO 80401

(303) 231-1050

J. Narayan

Materials Science \& Eng.

North Carolina State Univ.

Box 7916

Raleigh, NC 27695-7916

(919) 515-7874

J. E. Nasise

LANL

Los Alamos, NM 87545

(505) 667-1459

Michael Nastasi

Los Alamos National Lab

Los Alamos, NM 87545

(505) 667-7007

K. Natesan

Argonne National Lab.

Materials Science Division

9700 South Cass

Argonne, IL 60439

(312) $972-5068$

M. Naylor

Cummins Engine Co., Inc.

Box 3005

Mail Code 50183

Columbus, IN 47202-3005

(812) $377-5000$

Fred Nichols

Argonne National Laboratory

9700 South Cass

Argonne, IL 60439

(312) $972-8292$
M. C. Nichols

Sandia National Laboratories

Livermore, CA 94550

(415) $422-2906$

P. J. Nigrey

Division 1150

Sandia National Laboratories

Albuquerque, NM 87185

(505) 844-8985

F. B. Nimick, Division G313

Sandia National Laboratory

P.O. Box 5800

Albuquerque, NM 87185

(505) 844-6696

D. A. Nissen

Sandia National Laboratories

Livermore, CA 94550

(415) $422-2767$

R. Gerald Nix

NREL

1617 Cole Blvd

Golden, CO 80401

(303) 231-1757

T. A. Nolan

ORNL

P.O. Box 2008

Bldg. 4515, MS 064

Oak Ridge, TN 37831

(615) 574-0811

Dr. Paul C. Nordine

Containerless Research, Inc.

910 University Place

Evanston, IL 60201-3149

(708) 467-2678 
P. C. Odegard

Divison 8216

Sandia National Laboratories

Livermore, CA 94550

(415) 422-2789

G. R. Odette

Dept. of Chem. \& Nuclear Eng.

University of California

Santa Barbara, CA 93106

(805) 961-3525

Thomas Ohlemiller

Center for Bldg. Technology

National Institute of Standards and Technology

Gaithersburg, MD 20899

(301) 921-3771

Ben Oliver

Materials Science \& Eng.

421 Dougherty Hall

Knoxville, TN 37996

(615) 974-5326

Randall B. Olsen

Chronos Research Labs, Inc.

3025 Via de Caballo

Olivenhaim, CA 92024

(619) 756-1447

Mark J. O’Neill

ENTECH, Inc.

P.O. Box 612246

DFW Airport, TX 75261

(214) 456-0900

G. C. Osbourn

Division 1130

Sandia National Laboratories

Albuquerque, NM 87185

(505) 844-8850
Roland Otto

Lawrence Berkeley Lab.

Bldg 73, 106A

Berkeley, CA 94720

(415) 486-5289

V. Oversby

LLNL

University of California

Livermore, CA 94550

(213) $423-2228$

G. M. Ozeryansky

IGC Superconductors, Inc.

1875 Thomaston Avenue

Waterbury, CT 06704

(203) $753-5215$

J. K. G. Panitz

Division 1834 SNL

Albuquerque, NM 87185

(505) 844-8604

Richard H. Pantell

Electrical Engineering Dept.

Stanford University

Stanford, CA 94305

(415) $723-2564$

E. R. Parker

456 Hearst

Univ. of Ca., Berkeley

Berkeley, CA 24720

(415) 642-0863

Bill Parks

EE-221/FORS

U.S. Dept. of Energy

Washington, DC 20585

(202) 586-2093 
D. O. Patten

Norton Company

High Performance Ceramics

Goddard Road

Northboro, MA 01532

(617) 393-5963

H. C. Peebles

Divsion 1831

Sandia National Laboratories

Albuquerque, NM 87185

(505) 844-1647

David Pellish

EE-231/FORS

U.S. Dept. of Energy

Washington, DC 20585

(202) $586-6436$

Joseph M. Perez

EE-34/FORS

U.S. Dept. of Energy

Washington, DC 20585

(202) 586-8060

Ahmad Pesaran

NREL

1617 Cole Blvd.

Golden, CO 80401

(303) 231-7636

Randy Petri

IGT

3424 S. Stale St.

Chicago, IL 60616

(312) $567-3985$

John Petrovic

Chemistry-Mat. Science Div.

Los Alamos National Laboratory

Los Alamos, NM 87545

(505) 667-5452
S. T. Picraux

Division 1110

Sandia National Laboratories

Albuquerque, NM 87185

(505) 844-7681

R. D. Pierce

Argonne National Laboratories

Chemical Tech Division

Bldg. 205, Room W-125

Argonne, IL 60439

(312) $972-4450$

Melvin A. Piestrup

Adelphi Technology

13800 Skyline Blvd.

Woodside, CA 94062

(415) 851-0633

James E. Plank

Charles Evans and Associates

301 Chesapeake Drive

Redwood City, CA 94063

(415) 369-4567

Walter Polansky

ER-16/FORS

U.S. Dept. of Energy

Washington, DC 20585

(301) 903-5995

L. E. Pope

Division 1834

Sandia National Laboratories

Albuquerque, NM 87185

(505) 844-5041

Joseph Prahl

Case Western Reserve Univ.

Cleveland, $\mathrm{OH} 44106$

(216) $368-2000$ 
Mark A. Prelas

Nuclear Engineering Program

University of Missouri

Columbia, MO 65211

(314) 882-3550

Donald Priesty

ER-542/FORS

U.S. Dept. of Energy

Washington, DC 20585

(301) 903-3421

G. T. Privon

ORNL

P.O. Box 2009

Building 9102-2, Rm. 209

Oak Ridge, TN 37831

(615) 574-1013

Peter Pronko

Universal Energy Systems

4401 Dayton-Xenia Road

Dayton, OH 45432

(513) 426-6900

Michael Pulscak

EE-352/FORS

U.S. Dept. of Energy

Washington, DC 20585

(202) 586-1726

Herbert Pummes

Altex Corporation

P.O. Box 10084

Chicago, IL 60610

(312) $372-3440$

R. Quinn

Division 1846

Sandia National Labs

Albuquerque, NM 87185

(505) 844-1933
Herschel Rabitz

Dept. of Chemistry

Princeton University

Princeton, NJ 08544-1009

(609) 258-3917

K. S. Ramesh

Mail Stop K3-59

Pacific Northwest Laboratory

P.O. Box 999

Richland, WA 99352

P. B. Rand

Division 1813

Sandia National Labs

Albuquerque, NM 87185

(505) 844-7953

Robert Rapp

Dept. of Metal. Eng.

Ohio State University

Columbus, $\mathrm{OH} 43210$

(614) 422-2491

Bhakta B. Rath, Assoc. Dir. Res.

Naval Research Laboratory

Mat. Science \& Component Tech.

Building 43, Room 212 - Code 6000

Washington, DC 20375-5000

(202) $767-3566$

Dr. Rod Ray

Bend Research, Inc.

64550 Research Road

Bend, OR 97701-8599

(503) $382-4100$

Richard Razgaitis

Battelle-Columbus Labs

505 King Avenue

Columbus, OH 43201

(614) $424-4212$ 
Brian Rennex

Natl. Institute of Standards and Technology

Center of Bldg. Technology

Gaithersburg, MD 20899

(301) 921-3195

W. G. Reuter

Materials Technology Div.

Idaho National Eng. Lab

Idaho Falls, ID 83415

(205) 526-0111

William Richards

EE-121/FORS

U.S. Dept. of Energy

Washington, DC 20585

(202) $586-5410$

S. Richlen

EE-221/FORS

U.S. Dept. of Energy

Washington, DC 20585

(202) $586-2078$

R. O. Ritchie

456 Hearst

University of Cal., Berkeley

Berkeley, CA 24720

(415) 642-0863

P. L. Rittenhouse

ORNL

P.O. Box 2008

Bldg. 45005, 138, Rm. A158

Oak Ridge, TN 37831

(615) 574-5103
H. F. Rizzo

Lawrence Livermore Nat. Lab

University of California

P.O. Box 808

Livermore, CA 94550

(415) 422-6369

D. I. Roberts

GA Technologies

P.O. Box 81608

San Diego, CA 92138

(619) $455-2560$

S. L. Robinson

Division 8314

Sandia National Laboratories

Livermore, CA 94550

(415) 422-2209

A. D. Romig

Division 1832

Sandia National Laboratories

Albuquerque, NM 87185

(505) 844-8358

Timothy L. Rose

EIC Laboratories, Inc.

111 Downing Street

Norwood, MA 02062

(617) 764-9450

R. S. Rosen

LLNL

University of California

P.O. Box 808

Livermore, CA 94550

(415) 422-9559 
John H. Rosenfeld

Thermacore, Inc.

780 Eden Road

Lancaster, PA 17601

(717) 569-6551

P. N. Ross

Mat. \& Metal. Research Div.

Lawrence Berkeley Labs

University of Berkeley

Berkeley, CA 94720

(415) $486-4000$

Giulio A. Rossi

Norton Company

Goddard Road

Northboro, MA 01532-1545

(617) 393-5829

Walter Rossiter

Center for Bldg. Technology

National Institute of Standards and Technology

Gaithersburg, MD 20899

(301) 921-3109

Arthur Rowcliffe, Met/Ceram Div.

ORNL

P.O. Box 2008

Bldg. 5500, 376, Rm. A111

Oak Ridge, TN 37831

(615) 576-4864

M. Rubin

Lawrence Berkeley Laboratory

University of California

Berkeley, CA 94720

(415) 486-7124
E. Russell

LLNL

University of California

Livermore, CA 94550

(213) 423-6398

C. O. Ruud

159 MRL

University Park, PA 16802

(814) 863-2843

John Ryan

EE-422/FORS

U.S. Dept. of Energy

Washington, DC 20585

(202) $586-9130$

J. R. Sadoway

MIT

77 Massachussetts Avenue

Cambridge, MA 02139

(617) 253-3300

Djordjiji R. Sain

Nuclear Con. Services, Inc.

P.O. Box 29151

Columbus, $\mathrm{OH} 43229$

(614) $846-5710$

Robert Salat

Vactronic Laboratory Equipment, Inc.

160 Wilbur Place

Bohemia, NY 11716

(516) 567-0520

Peter H. Salmon-Cox

Dir. of Office Ind. Processes

EE-23/FORS

U.S. Dept. of Energy

Washington, DC 20585

(202) $586-2380$ 
F. Salzano

Brookhaven National Laboratory

Upton, NY 11973

(516) 282-4458

R. J. Salzbrenner

Division 1832

Sandia National Laboratories

Albuquerque, NM 87185

(505) 844-5041

Anthony F. Sammells

Eltron Research, Inc.

2830 Wilderness Place, Suite E

Boulder, CO 80301-5455

(303) $440-8008$

Eileen E. Sammells

Eltron Research, Inc.

2830 Wilderness Place, Suite E

Boulder, CO 80301-5455

(303) $440-8008$

Stuart Samuelson

Deltronic Crystal Industries, Inc.

60 Harding Avenue

Dover, NJ 07801

(201) 361-2222

J. Sankar

Dept of Mechanical Engineering

North Carolina A\&T University

Greensboro, NC 27411

(919) $379-7620$

Mike L. Santella

ORNL

P.O. Box 2008

Oak Ridge, TN 37831-6088

(615) 574-4805
Srinivasan Sarangapani

ICET, Inc.

916 Pleasant Street

Unit 12

Norwood, MA 02062

(617) 679-6064

V. K. Sarin

GTE

40 Sylvan Road

Waltham, MA 02254

(617) $890-8460$

Suri A. Sastri

Surmet Corporation

33 B Street

Burlington, MA 01803

(617) 272-3250

C. M. Scheuerman

NASA Lewis Research Center

21000 Brookpark Road, MS 49-1

Cleveland, $\mathrm{OH} 44135$

(216) 433-3205

Y. Schienle

Garrett Turbine Engine Co.

111 South 34th Street

P.O. Box 5217

Phoenix, AZ 85034

(602) 231-4666

Paul Schissel

NREL

1617 Cole Blvd.

Golden, CO 80401

(303) $231-1226$ 
Jerome J. Schmidt

Jet Process Corporation

25 Science Park

New Haven, CT 06511

(203) $786-5130$

R. A. Schmidt

Battelle Columbus Labs

Mechanics Section

505 King Avenue

Columbus, OH 43201-2693

(614) 424-4396

\section{S. J. Schneider}

National Institute of Standards and Technology

Gaithersburg, MD 20899

(301) 921-2901

G. D. Schnittgrund

Rockwell International

Rocketdyne Division

6633 Canoga Avenue

Canoga Park, CA 91304

(818) $710-5972$

W. K. Schubert

Division 1815, SNL

Albuquerque, NM 87185

(505) 846-2466

Erland M. Schulson

33 Haskins Road

Hanover, NH 03755

(603) 646-2888

Robert B. Schulz

EE-34/FORS

U.S. Dept. of Energy

Washington, DC 20585

(202) $586-8051$
James Schwarz

Dept. Chem. Eng/Mat Science

Syracuse University

320 Hinds Hall

Syracuse, NY 13244

(315) $423-4575$

R. Schwerzel

Battelle-Columbus Labs

505 King Avenue

Columbus, OH 43201

FTS 976-5637

Peter Scofield

EE-421/FORS

U.S. Dept. of Energy

Washington, DC 20585

(202) 586-9193

James L. Scott

Metals and Ceramics Div.

ORNL

P.O. Box 2008, Bldg. 4508

Oak Ridge, TN 37831-6091

(615) 624-4834

Timothy C. Scott

Chemical Technology Division

Oak Ridge National Laboratory

P.O. Box 2008

Oak Ridge, TN 37831

(615) $574-5962$

R. E. Setchell

Division 1130

Sandia National Labs

Albuquerque, NM 87185

(505) 844-5459 
J. A. Seydel

Materials Science Division

Idaho National Eng. Lab

Idaho Falls, ID 84315

(208) 526-0111

D. J. Sharp

Division 1831

Sandia National Laboratories

Albuquerque, NM 87185

(505) 844-8604

B. J. Shaw

Westinghouse R\&D Center

1310 Beuliah Road

Pittsburgh, PA 15235

(412) 256-1201

Suzanne C. Shea

Praxis Engineers, Inc.

852 North Hillview Drive

Milpitas, CA 95035

(408) $945-4282$

D. E. Shelor

RW-3/FORS

U.S. Dept. of Energy

Washington, DC 20585

(202) 586-9433

M. W. Shupe

U.S. Dept. of Energy

785 DOE Place

Idaho Falls, ID 83402

(208) 526-9534

V. K. Sikka

ORNL

P.O. Box 2008

Bldg. 4508, 083, Rm. 129

Oak Ridge, TN 37831

(615) $574-5112$
Richard Silberglitt

FM Technologies, Inc.

Patriot Square

10529-B Braddock Road

Fairfax, VA 22032

(703) $425-5111$

T. B. Simpson

FE-34/FORS

U.S. Dept. of Energy

Washington, DC 20585

(301) 903-3913

J. P. Singh

Argonne National Labs

9700 South Cass

Argonne, IL 60439

(312) $972-5068$

Maurice J. Sinnott

Chemical and Metall. Eng.

University of Michigan

$\mathrm{H}$ Dow Building

Ann Arbor, MI 48109-2136

(313) $764-4314$

Piran Sioshamsi

Spire Corporation

Patriots Park

Bedford, MA 02173

(617) 275-6000

Kurt D. Sisson

EE-222/FORS

U.S. Dept. of Energy

Washington, DC 20585

(202) $586-6750$ 
Hal Sliney

NASA Lewis Research Center 21000 Brookpark Road

MS 23-2

Cleveland, $\mathrm{OH} 44135$

(216) 433-6055

Jerry Smith

ER-132/GTN

U.S. Dept. of Energy

Washington, DC 20545

(301) 903-3426

M. F. Smith

Division 1834

Sandia National Laboratories

Albuquerque, NM 87185

(505) $846-4270$

Paul Smith

Materials Dept.

Univ. of CA, Santa Barbara

Santa Barbara, CA 93103

(805) 893-8104

Peter L. Smith

Newton Optical Technologies

167 Valentine Street

Newton, MA 02165

(617) 495-4984

J. E. Smugeresky

Division 8312

Sandia National Laboratories

Livermore, CA 94550

(415) 422-2910

N. R. Sorensen

Division 1841

Sandia National Laboratories

Albuquerque, NM 87185

(505) 844-1097
Charles A. Sorrell

AIM Program

EE-232/FORS

U.S. Dept. of Energy

Washington, DC 20585

(202) 586-1514

R. R. Sowell

Division 8131

Sandia National Laboratories

Albuquerque, NM 87185

(505) 844-1038

David B. Spencer

Waste Energy Technology Corp.

One DeAngelo Drive

Bedford, MA 01730

(617) 275-6400

R. F. Sperlein

U.S. Dept. of Energy

P.O. Box 10940

Pittsburgh, PA 15236

(312) 972-5985

Dr. Bernard F. Spielvogel

Boron Biologicals, Inc.

533 Pylon Drive

Raleigh, NC 27606

(919) 832-2044

J. R. Springarn

Division 8312, SNL

Livermore, CA 94550

(415) 422-3307

William Sproul

Borg-Warner Company

1200 South Wolf Road

Des Plaines, IL 60018

(312) 827-3131 
Mark B. Spitzer

Spire Corporation

Patriots Park

Bedford, MA 01730

(617) 275-6000

Gregory C. Stangle

School of Cer. Eng.

2 Pine Street

Alfred University

Alfred, NY 14802

(607) 871-2798

T. L. Starr

Georgia Tech Res. Inst.

Georgia Inst. of Technology

Atlanta, GA 30332

(404) 894-3678

Carl A. Stearns

NASA Lewis Research Center

MS 106-1

21000 Brookpark Road

Cleveland, OH 44135

(216) 433-5504

Wayne S. Steffier

Hyper-Therm, Inc.

18411 Gothard Street

Units B \& C

Huntington Beach, CA 92648

(714) 375-4085

Dr. Charles Stein

Thermal Electric Devices, Inc. 1009 Bradbury Drive, Southeast

Albuquerque, NM 87106

(505) 272-7505
H. J. Stein

Division 1110

Sandia National Laboratories

Albuquerque, NM 87185

(505) 844-6279

Joseph R. Stephens

NASA Lewis Research Center

21000 Brookpark Road

Cleveland, OH 44135

(216) 433-3195

Helmut F. Stern

Arcanum Corporation

P.O. Box 1482

Ann Arbor, MI 48106

(313) $665-4421$

George Stickford

Battelle-Columbus Labs

505 King Avenue

Columbus, OH 43201

(614) 424-4810

Thomas J. Stiner

AstroPower, Inc.

Solar Park

Newark, DE 19716

(302) 366-0400

Robert J. Stinner

ISM Technologies, Inc.

9965 Carroll Canyon Road

San Diego, CA 92131

(619) $530-2332$

D. P. Stinton

ORNL

P.O. Box 2008

Bldg. 4515, 063, Rm. 111

Oak Ridge, TN 37831

(615) $574-4556$ 
Thomas G. Stoebe

Chairman, Mat. Sci. \& Eng.

University of Washington

Roberts Hall, FB-10

Seattle, WA 98195

(206) $543-2600$

Norman Stoloff

Materials Engineering Dept.

Rensselaer Polytechnic Inst.

Troy, NY 12181

(518) 266-6436

Paul D. Stone

The Dow Chemical Company

1776 Eye Street, NW, \#575

Washington, DC 20006

J. E. Stoneking

Dept. of Eng. Science \& Mech.

310 Perkins Hall

Knoxville, TN 37996

(615) $974-2171$

G. Stoner

University of Virginia

Charlottesville, VA 22901

(804) 924-3277

Roger S. Storm

Carborundum

Government Programs

P.O. Box 832

Niagara Falls, NY 14302

(716 278-2000

Edwin E. Strain

Garrett Corporation

111 S. 34th Street

P.O. Box 5217, MS 301-2N

Phoenix, AZ 85010

(602) 231-2797
Reinhold N. W. Strnot

KJS Associates

1616 Hillrose Place

Fairborn, OH 45324

(513) 879-0114

Thomas N. Strom

NASA Lewis Research Center

21000 Brookpark Road, MS 77-6

Cleveland, $\mathrm{OH} 44135$

(216) 433-3408

David Sutter

ER-224/FORS

U.S. Dept. of Energy

Washington, DC 20585

(301) 903-5228

Patrick Sutton

EE-151/FORS

U.S. Dept. of Energy

Washington, DC 20585

(202) $586-8012$

Jeffrey J. Swab

U.S. Army Materials Tech. Lab

405 Arsenal Street

Watertown, MA 02172

(617) $923-5410$

Dr. Richard Swanson

SunPower Corporation

435 Indio Way

Sunnyvale, CA 94086

(408) $991-0900$

Arthur D. Sweet

Goremotive Industries, Inc.

20944 Sherman Way

Suite 206

Canoga Park, CA 91303

(818) 884-0015 
R. W. Swindeman

ORNL

P.O. Box 2008

Bldg. 4500-S, 155, Rm. 0040

Oak Ridge, TN 37831

(615) 574-5108

W. Tabakoff

Dept. of Aerospace Eng.

$\mathrm{M} / \mathrm{L} 70$

University of Cincinnati

Cincinnati, $\mathrm{OH} 45221$

(513) 475-2849

L. E. Tanner

LLNL

University of California

P.O. Box 808

Livermore, CA 94550

(415) $423-2653$

H. L. Tardy

Sandia National Laboratories

Org. 6213

P.O. Box 5800

Albuquerque, NM 87185-5800

(505) 846-6548

Victor J. Tennery

ORNL, High Temp. Mat. Lab

P.O. Box 2008

Bldg. 4515, 062, Rm. 146

Oak Ridge, TN 37831-6088

(615) 574-5123

Michael Teresinski

ER-13/GTN

U.S. Dept. of Energy

Washington, DC 20545

(301) 903-5155
Giuliana Tesoro

Plastics Institute of America

Stevens Institutes of Tech.

Castle Point Station

Hoboken, NJ 07030

(201) 420-5552

C. A. Thomas

U.S. Dept. of Energy

P.O. Box 10940

Pittsburgh, PA 15236

(312) $972-5731$

Iran L. Thomas

ER-10/GTN

U.S. Dept. of Energy

Washington, DC 20545

(301) 903-3426

D. O. Thompson

Ames Laboratory

Iowa State University

Ames, IA 50011

(515) 294-5320

John K. Tien

Columbia University

1137 S.W. Mudd Building

New York, NY 10027

(212) 280-5192

T. Y. Tien

Mat. and Metal. Eng.

University of Michigan

Ann Arbor, MI 48109

(813) 764-9449 
T. N. Tiegs

ORNL

Bldg. 4515, 069, Rm. 230

P.O. Box 2008

Oak Ridge, TN 37831-6088

(615) 574-5173

Jyh-Ming Ting

Applied Sciences, Inc.

141 West Xenia Avenue

P.O. Box 579

Cedarville, OH 45314

(513) $766-2020$

R. H. Titran

NASA Lewis Research Center

21000 Brookpark Road, MS 49-1

Cleveland, OH 44135

(216) $433-3198$

Zygmunt Tomezuk

Chemical Technology Division

Argonne National Laboratory

9700 South Cass Avenue

Argonne, IL 60439

(708) 252-7294

Micha Tomkiewicz

Physics Department

Brooklyn College of City

University of New York

Brooklyn, NY 11210

(718) 951-5357

John J. Tomlinson

ORNL

Bldg. 9204-1, MS 8045

P.O. Box 2009

Oak Ridge, TN 37831-8045

(615) 574-0768
Timothy Tong

Dept.of Mechanical Eng.

University of Kentucky

Lexington, KY 40506

(606) 257-3236

J. A. VanDenAvyle

Division 1832

Sandia National Laboratories

Albuquerque, NM 87185

(505) 844-1016

D. van Rooyen

Brookhaven National Lab.

Upton, NY 11973

(516) $282-4050$

Carl R. Vander Linden

Vander Linden \& Associates

AIC Materials Program

5 Brassie Way

Littleton, CO 80123

(303) 794-8309

William VanDyke

NE-33/GTN

U.S. Dept. of Energy

Washington, DC 20545

(301) 903-4201

Richard D. Varjian

Dow Chemical Company, Inc.

Central Research - Catalysis

1776 Building

Midland, MI 49675

(517) 636-6557

Alex Vary

NASA Lewis Research Center

21000 Brookpark Road

Cleveland, $\mathrm{OH} 44135$

(216) 433-6019 
Krishna Vedula

Dept. of Metal. \& Mat. Science

Case Western Reserve University

10900 Euclid Avenue

Cleveland, $\mathrm{OH} 44115$

(216) 368-4211

Shannon Vinyard

Southwest Research Institute

P.O. Drawer 28510

San Antonio, TX 78284

(512) 684-5111

Ted Vojnovich

ER-80/FORS

U.S. Dept. of Energy

Washington, DC 20585

(202) $586-2343$

Brian G. Volintine

EE-232

5F-059/FORS

U.S. Dept. of Energy

Washington, DC 20585

(202) 586-1739

Robert W. Vukusich

UES, Inc.

4401 Dayton-Xenia Road

Dayton, OH 45432-1894

(513) 426-6900

David Waksman

National Institute of Standards and Technology

Building 226

Gaithersburg, MD 20899

(301) 921-3114
H. F. Walter

EM-34/GTN

U.S. Dept. of Energy

Washington, DC 20545

(301) 903-7192

J. B. Walter

Materials Technology Div.

Idaho National Eng. Lab

Idaho Falls, ID 83415

(208) 526-2627

John Walter

IntraSpec, Inc.

P.O. Box 4579

Oak Ridge, TN 37831

(615) 483-1859

William $\mathrm{K}$. Warburton

X-ray Instrumentation Associates

1300 Mills Street

Menlo Park, CA 94025-3210

(415) $903-9980$

Craig N. Ward

Ultramet

12173 Montague Street

Pacoima, CA 91331

(818) 899-0236

Gary S. Was

Dept. of Nuclear Eng.

University of Michigan

Ann Arbor, MI 48109

(313) $763-4675$

Michael R. Wasielewski

Chemistry Division

Argonne National Laboratory

9700 South Cass Avenue

Argonne, IL 60439

(708) 252-3538 
Joseph K. Weeks, Jr.

Technical Res. Assoc., Inc. 410 Chipeta Way, Suite 222

Salt Lake City, UT 84108

(802) 582-8080

Rolf Weil

Dep. of Mat. \& Metal. Eng.

Stevens Inst. of Technology

Castle Point Station

Hoboken, NJ 07030

(201) $420-5257$

Roy Weinstein

Instit. for Particle Beam Dynamics

University of Houston

Houston, TX 77204-5502

(713) $743-3600$

C. D. Weiss

Caterpillar, Inc.

100 N.E. Adams Street

Peoria, IL 61629

(309) $578-8672$

Elizabeth G. Weiss

Membrane Technology and Research, Inc. 1360 Willow Road, Suite 103

Menlo Park, CA 94025

(415) 328-2228

Haskell Weiss

LLNL

University of California

P.O. Box 808

Livermore, CA 94550

(415) $422-6268$
Joseph F. Wenkus

Areas Corporation

202 Boston Road

North Billerica, MA 01862

(617) 667-3000

James Wert

Dept. of Mat. Science \& Eng.

Vanderbilt University

Station B, P.O. Box 1621

Nashville, TN 37235

(615) 322-3583

Stanley Whetstone

ER-23/GTN

U.S. Dept. of Energy

Washington, DC 20545

(301) 903-3613

A. D. White

DELTA M Corporation

525 Warehouse Road

Oakridge, TN 37830

(615) 483-1569

J. B. Whitley

Sandia National Laboratories

Albuquerque, NM 87185

(505) 844-5353

Sheldon M. Wiederhorn

National Institute of Standards and Technology

Bldg. 223, \#A329

Gaithersburg, MD 20899

(301) $975-2000$

F. W. Wiffen

ER-543/GTN

U.S. Dept. of Energy

Washington, DC 20545

(301) 903-4963 
Daniel E. Wiley

Dir. of Improved Energy Prod.

EE-231/FORS

U.S. Dept. of Energy

Washington, DC 2085

(202) 586-2099

William Wilhelm

Brookhaven National Lab

Solar Technology Group

Building 701

Upton, NY 11973

(516) 282-4708

Frank Wilkins

EE-222/FORS

U.S. Dept. of Energy

Washington, DC 20585

(202) 586-8072

A. D. Wilks

Signal UOP Research Center

50 UOP Plaza

Des Plaines, IL 60016

(312) 492-3179

Robin Williams

ORNL

P.O. Box 2008

Bldg. 4508, 092, Rm. 243

Oak Ridge, TN 37831

(615) 576-2631

\section{A. Wilson}

LANL

Los Alamos, NM 87545

(505) 667-6404
Ward O. Winer

Mechanical Eng. Department

Georgia Inst. of Technology

Atlanta, GA 30332

(404) 894-3270

C. E. Witherell

LLNL

University of California

P.O. Box 808

Livermore, CA 94550

(415) $422-8341$

J. C. Withers

Mat. \& Electro. Res. Corp.

7960 South Kolb Road

Tucson, AZ 85706

(602) $574-1980$

D. E. Wittmer

S. Illinois Univ./Carbondale

Dept. of Mech. Eng. \& Egy Pro.

Carbondale, IL 62901

(618) 536-2396, ext. 21

T. Wolery

LLNL

University of California

Livermore, CA 94550

(213) 423-5789

Stanley M. Wolf

EM-54/GTN

U.S. Dept. of Energy

Washington, DC 20545

(301) 903-7962 
James C. Wood

NASA Lewis Research Center

MS 500-210

21000 Brookpark Road

Cleveland, $\mathrm{OH} 44135$

(216) $433-4000$

J. R. Wooten

Rocketdyne

6633 Canoga Avenue

Mail Code BA-26

Canoga Park, CA 91303

(818) $710-5972$

I. G. Wright

Battelle-Columbus Labs

505 King Ave

Columbus, OH 43201-2693

(614) 424-4377

John D. Wright

TDA Research, Inc. 12345 West 52nd Avenue

Wheat Ridge, CO 80033

(303) $940-2301$

R. N. Wright

Materials Technology Div.

Idaho National Eng. Laboratory

Idaho Falls, ID 83415

FTS 583-2627

Howard Yacobucci

NASA Lewis Research Center 21000 Brookpark Road, MS 77-6

Cleveland, OH 44135

(216) $433-3415$
David Yarbrough

Department of Chem. Eng. Tennessee Tech. University 1155 N. Dixie Ave.

Cookville, TN 38505

(615) 528-3494

H. C. Yeh

Air Research Casting Co. 19800 VanNess Avenue

Torrance, CA 90509

(213) 618-7449

Thomas M. Yonushonis

Cummins Engine Co., Inc.

Box 3005

Mail Code 50183

Columbus, IN 47202-3005

(812) 377-7078

J. Yow

LLNL

University of California

Livermore, CA 94550

(213) $423-3521$

Dr. Dingan Yu

Supercon, Inc.

830 Boston Turnpike

Shrewsbury, MA 01545

(508) 842-0174

Charlie Yust

ORNL

P.O. Box 2008

Bldg. 4515, 063, Rm. 106

Oak Ridge, TN 37830

(615) 574-4812 
Frederica Zangrando

NREL

1617 Cole Blvd.

Golden, CO 80401

(303) 231-1716

F. J. Zanner

Division 1833

Sandia National Laboratories

Albuquerque, NM 87185

(505) 844-7073

C. M. Zeh

METC

P.O. Box 880

Morgantown, WV 26505

(304) 291-4265
B. A. Zeitlin

IGC Adv. Superconductors, Inc. 1875 Thomaston Avenue

Waterbury, CT 06704

(203) 753-5215

R. M. Zimmerman, Division 6313

Sandia National Laboratory

P.O. Box 5800

Albuquerque, NM 87185

(505) 846-0187

Kenneth Zwiebel

NREL

1617 Cole Blvd

Golden, CO 80401

(303) 231-7141 
This page is intentionally left blank. 


\section{KEYWORD INDEX}

A

Ab-initio Electronic Structure Methods (293-296), (299)

AC Application (99)

AC Losses (97)

Acid (94)

Acoustic Manipulation (159)

Acoustic Sensors (146)

Actinides (162), (307), (310), (316)

Adherence (64), (65)

Adhesive Bonding (69)

Adhesives (25), (259), (265), (304)

Adsorbing Materials (102)

Adsorption Refrigeration (102)

Advanced Batteries (80)

Advanced Heat Engines (62)

Advanced Materials (27)

Advanced Metal Forming (69)

Advanced Propulsion Fuels (300)

Aerogels (30), (291)

Aging (244)

AGT (62)

Alcohol Fuels (86)

All-Optical Switching (291)

Alloy Development (172), (305)

Alloys (35), (241), (242), (249), (251-253), (255), (272), (273), (307), (308), (337-339), (352), (353)

Alternative Final Waste Form (205), (206), (208)

Alternative Fuels (86)

Alumina (50), (56), (59), (220), (221)

Aluminides (337), (338), (340), (352), (355), (356), (361)

Aluminizing (337)

Aluminum Titanate (51)

Aluminum/Titanium Carbide Composites (324)

Amorphous Materials (89)

Amphiboles (154)

Analysis (238), (245), (262), (263), (266-268)

Aquifer (101)

Arc (212) 
Ash (200)

Atomic Force Microscopy (167), (283), (301)

Atomic-level Materials Modeling (293-296), (299)

Austenitics (337), (339), (353)

Automotive Catalysts (33)

B

Basalt (203)

Batteries (74), (78), (79), (83), (84)

Behavior (289)

Bench-Scale (200), (207), (210)

Beryllium (176)

Beryllium Alloy Processing (330)

Beryllium Processing (330)

Beryllium-Yttrium Hydride (221)

Biaxial Stress (144)

Bifunctional Air Electrodes (85)

Binary Alloys (142)

Binder (61)

Biobased Materials (38)

Biodegradable (26)

Biomechanics (286)

Biometric (247)

Biomimetic (37)

Bipolar (288)

Bismuth (97)

Bitter Magnets (169)

Blue-Emitting Devices (169)

Bonding (244), (249), (259), (282), (309)

Borosilicate Glass (199), (202)

Brazing (66), (249)

Breakdown (299)

Brittle Failure (156)

Buckyballs (158)

Bulk Characterization (93) 
C

C-O-H Fluids (155)

CAP (257)

Capacitive Deionization (287)

Capacitors (31)

Carbon (274), (348), (349)

Carbon Fibers (347), (348)

Carbon Products (350), (351)

Carbon-Carbon (218)

Carbon-Fiber Composite (176)

Carbonate Minerals (152)

Carbonation (93)

Casting (292)

Catalyst Performance (86)

Catalysts (86), (149), (274), (358)

Cathodes (77)

Cation Diffusion (150)

Cement (93), (199), (201)

Cementation (156)

Centrifugal Atomization (330)

Centrifugal Forces (142)

Centrifugal Furnace (209)

Ceramic Coatings (37), (306), (314)

Ceramic Composites (22), (23), (36), (327)

Ceramic Fibers (28)

Ceramic Nitrides (323)

Ceramic Oxides (323)

Ceramic Powder (309)

Ceramic Precursors (161)

Ceramics (27), (29), (31), (34), (158), (161), (163), (172), (173), (175-178), (200), (208), (220), (239), (240), (241), (246-249), (264), (269-271), (293), (297), (305), (306), $(341-347),(357-360),(362),(363)$

CFC (15)

Characterization (211), (289)

Chelates (322)

Chemical (266-268)

Chemical Analysis (55)

Chemical Reaction (286)

Chemical Sensors (315)

Chemical Vapor Deposition (32), (63), (89), (90), (161), (303), (312), (330)

Chemical Vapor Infiltration (31), (36), (39) 
Chemometric (245), (266)

Chlorinated Hydrocarbons (315)

Chromium-Niobium (338), (356)

Chromizing (337)

Cine Radiography (309)

Claddings (27), (29)

Clean Energy Storage (300)

Cleaning (242-244)

CM (313)

CMZP (51)

Coal-Derived (348)

Coatings (28), (29), (39), (63-65), (75), (89), (90), (239), (243), (251), (253), (264), (273), (276), (283), (303), (305), (337), (340), (344), (345), (346), (354)

Cogeneration (24)

Coils (99)

Coke (350)

Cold Pressing (306)

Combustion Chemical Vapor Deposition (28)

Compatibility (172), (175), (176), (178)

Complex Alloys (281)

Complex Compound (102)

Component Designs (71-73)

Component Test (72)

Components (52), (53), (359)

Composite Conductors (99)

Composites (23), (25), (28), (31), (32), (34), (38), (39), (49), (50), (72), (73), (92), (101), (159), (161), (173), (174), (218), (243), (258), (259), (275), (304), (305), (308), (311), (314), (323), (341-343), (347-349), (357), (359), (360)

Composition (211)

Compound (267)

Computational Model (133)

Computed Microtomography (153)

Computed Tomography (60)

Computer Simulation (290), (291)

Concentrated Sunlight (27)

Condensed Matter (313)

Conductive Materials (317)

Conduit (179)

Consolidation of Powder (216)

Consortium (350)

Constitutive Model (130), (150)

Consumable Arc Melt (217) 
Contact (139)

Continuous Fiber (22)

Control (136)

Convection (142)

Conversion (350)

Cooperative/Antagonistic Binding Sites (322)

Coordination (62)

Copolymer (259)

Copper (178)

Corrosion (21), (54), (63), (74), (92), (102), (243), (251), (264), (303), (320), (337-339), (345), (346), (352-356)

Corrosion Resistance (64)

Cost Effective Ceramics (47), (48), (50), (52), (53), (66-69)

Cost Reduction (279)

Coupled Processes (151)

CRADA (275)

Creep (54), (56-59), (128)

Creep Rupture (354)

Cryogenics (297)

Crystal (284)

Crystal Growth (140)

Crystal Silicon (91)

Crystal Surfaces (301)

Crystallization (278)

Crystallographic Slip (130)

Cutting Tools (330)

CVD (64), (247), (272)

Cyclic Fatigue (56)

\section{D}

Damage (143)

Database (55), (68)

DC (212)

Debris (206)

Defect Structure (150)

Deformation (151)

Deformation Bonding (285)

Dendrites (140)

Depleted Uranium (292)

Deposition (340) 
Design Codes (54)

Diamond (160), (247)

Diamond Coatings (330)

Diamond Powders (158)

Diamond-like Carbon (160)

Dielectric (145), (241), (258), (299)

Diesel (62)

Diesel Combustion (59)

Diffraction (263), (267), (268), (328)

Diffusion (151), (152)

Diffusion Mechanism (150)

Diffusivity (155)

Direct Oxide Reduction (302)

Disordered Media (142)

Dissociation (297)

Ditopical Receptors (322)

Dopant Diffusion (290)

Dopants (279)

Drill Cores (153)

Drilling (93)

Ductility (302)

Durability (94)

Dynamic Stress Testing (85)

Dynamics (284), (310)

$\mathbf{E}$

ECM (257)

Elastic (145)

Elasticity (147)

Electric Vehicles (74), (79), (83), (84)

Electric-Arc-Furnace (331)

Electrical Conductivities (297)

Electrical Properties (172), (173), (177), (178)

Electrical Resistivity (302)

Electrically Conducting Polymers (31)

Electro-Optic Materials (324)

Electrocatalysts (81), (82)

Electrochemical (75), (77), (79), (152), (361)

Electrochromic Windows (170)

Electrodeposition (90), (97) 
Electrodes (78), (80), (83), (84)

Electroluminescence (291)

Electroluminescent Polymers (322)

Electrolytes (79), (361)

Electrolytic Cell Development (288)

Electron Beam Processing (162)

Electronic (246), (258), (260-262), (264), (271), (275)

Electronic Correlations (317), (325)

Electronic Materials (158), (318)

Electronic Structure (281), (282)

Electrooptic (260), (270), (271)

Electrooxidation (81)

Electrorefining (162), (302)

Embrittlement (264), (355)

Emitters (221)

Encapsulation (102), (200), (255), (257), (328)

Energetic Materials (298), (299)

Energetic Metastable Materials (293)

Energy Storage Devices (165)

Engines (57), (59), (63-65)

Enriched Uranium (292), (311)

Environmental Effects (59)

Environmentally Benign High Explosive Waste Destruction (288)

Equation of State (297)

Equipment (341), (356)

Erosion (176)

Etching (286), (293-295)

EXAFS (78)

Excimer Laser Ablation (280)

Experimental Rock Deformation (156)

Experiments (130)

Explosive Front Propagation Mechanisms (319)

Explosives (284), (308)

Extrusion (217)

$\mathbf{F}$

Fabrication (72), (92), (94), (244)

Failure (243), (264), (272), (358)

Failure Analysis (57), (58), (131), (147)

Failure Mechanism (54) 
Failure Testing (57), (58)

Fastcast (251), (252)

Fatigue (59), (128), (353)

Fault Current Limiter (100)

Feedstocks (348)

Feldspar (152)

Ferric Hyrdoxides (155)

Ferric Oxides (155)

Ferroelectric (241), (248), (270), (271)

Ferromagnets (316)

Ferrous Metals (224)

Fertilizer (26)

Fiber Architecture (22)

Fiber Optic Beam Delivery (311)

Fiber-Reinforced (341-343)

Fibers (218), (341), (349), (357)

Field Tests (94)

Field-Scale (208)

Filament Winding (311)

Filaments (30)

Film (241), (247), (248), (270-272), (276), (345)

Filters (274), (359-361)

Final Form (207), (208), (210)

Final Waste Form (199), (200), (203)

Flat Plan Displays (291)

Flaws (358)

Flow Induced Deformation (326)

Fluid Flow (151)

Fluidized-Bed Combustion (354)

Fluids (138)

Flux Flow (143)

Flux Pinning (97)

Flywheel Containment (297)

Foam (244), (256), (258), (274), (302)

Foam Insulation (15)

Foil (244)

Forming (61)

Fouling Coefficient (92)

Four-Wave Mixing (146)

Fracture (54), (59), (128), (131), (132), (137), (143), (147), (175), (269), (272), (310), (353), (358)

Fracture Evolution (150) 
Fracture Mechanics (129)

Fracture Toughness (57)

Frank-Read Dislocations (313)

Friction (64), (65)

FSU (253)

Fuel Cells (81), (82), (360), (361)

Full-Scale (207)

Fullerene Composites (329)

Fullerenes (27), (158), (160), (161), (168), (257), (291), (328)

Furnace (357)

Fusion (280)

Fusion Welds (281)

G

Gallium Nitride (169)

Galvanic Cells (78)

Galvanostatic Charge/Discharge (79)

Garnets (150)

Gas Gun (297)

Gas Separation (31)

Gas Turbines (24), (71), (72)

Gas-Phase Chemistry (32)

Gas-Transfer (244), (257)

Gasification (354)

Gel Casting (49)

Generator (100)

Geologic Repository (224)

Germanium (280)

Ginzburg-Landau Phenomenological Models (321)

Glass (149), (200), (201), (204), (246), (269), (297)

Glass Waste (225)

Gold Sulfides (154)

Grain Boundary (130)

Graphite (212), (220), (349), (351)

Green State (60)

Grout (200) 
H

Hall-Heroult Cell (39)

Halogen Gases (315)

Hard Structure Munitions (282)

Hazardous Environments (311)

Heat Exchangers (23)

Heat Pipes (222)

Heat Storage (101)

Heat Transfer (15), (92)

Heavy Electron Systems (312)

Heavy Metal Ligands (329)

Heisenberg Model (313)

Heteroepitaxy (287)

High Efficiency Energy Conversion (167)

High Energy Density Materials (299)

High Explosives (298)

High Pressure (138), (293)

High Pressures and High Temperatures (300)

High Resolution Electron Microscopy (315)

High Temperature (129), (130), (138), (209)

High Temperature Microstructure (35)

High Temperature Properties (56), (57), (59)

High Temperature Service (57), (218), (305)

High Temperature Superconducting Materials (321)

High Temperature Superconductors (139), (287), (327)

High-Strain Rate Deformation (323)

High-Temperature Electronic Materials (325)

High-Temperature Superconducting Films (330)

History Dependent Damage (129)

HITAF (357)

Hot Carrier Solar Cells (167)

Hot Pressing (300)

Hot-Gas (339)

HR Coatings (278)

HVOF Sprays (141)

Hydrides (293), (304), (307)

Hydrogen (297)

Hydrogen Effects (307)

Hydrothermal Stability (93)

Hydroxide Sludge (205) 
ICF (244), (279), (284)

IEA (62), (63)

Image Enhancement (309)

Imperfections (135)

In Drum Melting (205)

Incoloy (179)

Induction Heat Treating (242)

Industrial Waste Heat Recovery (21)

Inertial Fusion (291), (310)

Infrared Spectroscopy (149)

Inhomogeneities (135)

Instrumentation or Technique Development (54)

Insulating Layers (323)

Insulation (15)

Insulation Sheathing (15)

Insulators/Thermal (218)

Integrated Contractors (304)

Integrated Optical Interconnects (322)

Intelligent Neural Net Controllers (242)

Intercalation Electrodes (77)

Interfaces (157), (282), (308), (342)

Interior Processing of Materials (159)

Intermetallic Coatings (314)

Intermetallics (28), (34), (162), (305), (323), (338)

Inventories (311)

Ion Beam Characterization (319)

Ion Beam/Laser Mixing (314)

Ion Beams (160), (164)

Ion Exchange (199)

Ion Implantation (80), (164), (290), (314), (331)

Ion Plating (303)

Ion Source (164)

Ion Transport (76)

Iron Aluminide (33)

Iron Aluminides (29)

Iron-Aluminum (339)

Irradiated Microstructures (166)

Irradiation Effects (172-178)

Irrigation (26) 


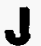

Joining (66), (176), (241), (242), (244), (249-251), (255), (272), (274), (352), (353), (363)

Josephson Junctions (287), (313)

Joule Heated Glass Melter (210)

K

KDP (278), (284)

KE Atomic Heating (323)

Kinetic-Gas Theory (74)

$\mathbf{L}$

Lactic Acid (26)

Lactide Plastic (26)

Laminated Metal Composites (285)

Lanthanides (321)

Large Scale Molecular Dynamics (298)

Laser (250), (251), (284)

Laser Damage (283), (284), (286), (299)

Laser Fusion Targets (279), (280), (298)

Laser Welding (311)

Laser-Assisted Deposition Processes (329)

Lead (201), (206)

Li Batteries (75), (76), (78), (85)

Life Prediction (54), (57), (58)

Light and Electron Optical Analysis (33)

Liquid Crystals (168), (316)

Liquid Metal Processing (253)

Lithium (172), (288)

Lithium Ceramics (175), (176)

Lithography (261)

London Phenomenological Models (321)

Long Length Wire (99)

Low Activation Materials (291)

Low Conductivity Gases (15)

Low Density Foam (298)

Low Heat Rejection Diesel Engines (72), (73) 
Low Pressure Plasma (305)

Low Resistivity (139)

Low Temperature Scanning (318)

Low-Dimensional Electronic Materials (316)

Low-Level Mixed Waste (207), (208), (210)

Low-Level Waste (201)

\section{M}

Machining (66-69), (292), (304)

Macrocrystallization of Metals (78)

Macroencapsulation (201)

Magnesium Alloys (61)

Magnet Materials (178), (179)

Magnetic Coil Designs (317)

Magnetic Dynamics (321)

Magnetic Field Processing (30), (35)

Magnetic Fields (142)

Magnetic Fusion (290)

Magnetic NDE Techniques (144)

Magnetic Properties of Thin Films (320)

Magnets (297)

Management (62), (363)

Manufacturing (279), (292)

Material Degradation (93)

Materials (339), (340), (357), (359)

Materials at the Atomic Level (315)

Materials Characterization (242), (244), (297)

Materials Program (363)

Materials Properties (289)

Materials Science (145), (313)

Materials Under Extreme Conditions (312)

MAWS (209), (211)

MDA (257)

Me Phase Boundary Tuning (316)

Mechanical Alloying (216)

Mechanical Miniaturization (159)

Mechanical Properties (35), (38), (55), (57), (62), (63), (339), (346), (360)

Melter (212)

Melting (241), (243), (251-255), (273)

Membrane (247), (255), (360) 
Meniscus Coater (278)

Mesostructural Nanocrystals (327)

Metal Carbide Thin Films (312)

Metal Complexes (313)

Metal Ion Chelating Agents (329)

Metal Matrix Composites (29), (69), (327)

Metal Powder (309)

Metal Thin Films (312)

Metal Transport (154)

Metal Vapor Synthesis (321)

Metal-Air Batteries (85)

Metallic Glasses (321)

Metallization (27), (297)

Metals (65), (66), (241-244), (246), (249-255), (264), (266), (272-274), (305)

Metals: Ferrous (128), (132)

Methanol Oxidation (82)

Micas (154)

Micro-mechanical Modeling (28)

Microalloy (338)

Microelectronics (295)

Micromechanical (130)

Micromechanical Fracture Models (329)

Microporous (240), (255), (256), (258), (259), (274)

Microscopy (262), (267), (268)

Microstructure (55), (97), (152), (241), (248-250), (252-255), (262), (263), (267), (268), (273), (305), (307), (308), (310), (318), (340)

Microstructure and Solar Cells (91)

Microwave Joining (35)

Microwave Processing (30), (31), (35), (36), (39), (253), (346), (347)

Microwave Sintering (47), (163), (306)

Microwave Solidification (205)

Minerals (101), (151)

Mixed Waste (313)

Mixed-Gas (355), (356)

Mixtures (138)

Modeling (32), (64), (173-175), (242), (244), (246), (247), (249-252), (255), (257), (260), (261), (265), (272), (273), (275), (276), (314), (343)

Moderators (221)

Moisture (355)

Molecular Design (293-295)

Molecular Dynamics (293-296), (315)

Molecular Hydrodynamics (298) 
Molten Salt Extraction (302)

Molybdenum Disilicide (315)

Molybdenum Disilicide Composites (324)

Molybdenum-Niobium (221)

Morphology (301)

Motor (100)

Mulch (26)

Mullite (64)

Multicomponent Diffusion (156)

Multilayer Capacitors (39)

Multilayer Fabrication (170)

Multilayer Technology (277)

Multiphase Alloys (318)

Multiphoton Absorption (299)

$\mathbf{N}$

$\mathrm{Na}$ /polymer Cells (77)

$\mathrm{Na} / \mathrm{S}$ Batteries (75)

Nano-fabrication (315)

Nano-Lithography (286)

Nano-Stethoscope (286)

Nanocrystals (291)

Nanomachining (315)

Nanoparticles (158)

Nanophase (70), (351)

Nanostructures (159)

Natural Gas Adsorbent Materials (86)

$\mathrm{Nb}_{3} \mathrm{Sn}(178)$

NDE (60), (134), (286)

Net Shape (243), (251), (254), (304)

Neutron Diffraction (324), (327)

Neutron Embrittlement (144)

Neutron Reflectometry (320), (326)

Neutron Scattering (316)

Nickel Aluminide (34)

Nickel Aluminides (33), (38)

NIF (279)

Niobium (220), (222)

Nitrate Salts (206)

Nitration (306) 
Nitride (248), (254), (293)

Nitromethane (319)

NMR (81), (275)

Noble Metal (217)

Nondestructive Evaluation (49), (58), (60), (61), (68), (71), (91), (140), (146), (303), (309), (358)

Noninvasive Diagnostics (163)

Nonlinear (150), (260)

Nonlinear Crystals (278)

Nonlinear Optic (165), (324)

Novel Energetic Materials (300)

Novel Materials Applications (293)

Nuclear Applications (311)

Nuclear Magnetic Resonance (61)

Nuclear Waste (328)

NZP (51)

Optical (246), (260), (264), (271)

Optical Coatings (286)

Optical Devices (160)

Optical Fibers (135), (165), (177)

Optical Finishing (279)

Optical Gratings (286)

Optical Properties (177)

Optical Sensing (132)

Optical Switch (165)

Optimization (133)

Opto-electronic Switches (168)

Optoelectronics (291), (295)

Ordered Alloys (34)

Organic Interfaces (37)

Organic Polymers (35)

Organics (244), (255-261), (265), (274-276)

Orientation Distribution Function (328)

Oxidation (26), (58), (64)

Oxides (293), (345) 
$\mathbf{P}$

Packaging (239), (241-243), (246), (258), (261), (272), (273)

Parallel Computing (298)

Particle Size (309)

Particle/Plasma Interaction (131)

Passivation (293-295)

Patterning (160)

Performance Criteria (211)

Permeability (93), (101), (151)

Petroleum (149)

Phase Change Materials (86), (101), (102)

Phase Development (97)

Phase Diagrams (302)

Phase Stability (281)

Phase Transformation (93), (134), (281)

Phosphate (208)

Photo-initiated Electron Transfer (168)

Photocatalyst (26)

Photodiodes (329)

Photoelectron Diffraction (296)

Photoelectron Holography (296)

Photoelectron Spectroscopy (296)

Photoemission Spectroscopy (317)

Photonics (291)

Photovoltaic Devices (329)

Photovoltaics (168)

Physical Properties (33)

Physical Vapor Deposition (90), (303), (314)

Physical/Mechanical Properties (49-51)

Piezoelectric (145), (270)

Pinning (143)

Pitch (349), (350)

Plasma (146), (207-210), (212), (239), (275), (276), (280), (331)

Plasma Chemistry (329)

Plasma Diagnostics (138)

Plasma Ion Implantation (326)

Plasma Polymer (280)

Plasma Processing (131), (133), (138)

Plasma-Enhanced CVD (74)

Plasma-Facing Components, (176)

Plasma-Flame Spraying (305) 
Plasma-Sprayed (239)

Plastic Anisotropy (314)

Plastic Deformation (128), (151), (156), (314)

Plastics (304)

Plastics Recycling (37)

Plutonics (160)

Plutonium (292), (302), (328)

Plutonium Alloys (302), (308)

Plutonium Immobilization (301)

Plutonium Processing (301)

Plutonium Recovery (301)

Polarized Neutron Diffusion in Multilayers (320)

Polycrystal Plasticity (314)

Polyesters (302)

Polyethylene (205), (208)

Polymer Composites (94), (327)

Polymer Electrolytes (75), (76)

Polymer Extrusion (206)

Polymer Macroencapsulation (206)

Polymer Microencapsulation (206)

Polymer Molecules (326)

Polymer Solidification (205)

Polymer Sorbents (313)

Polymeric Electrolytes (74-76), (79)

Polymers (30), (39), (92), (94), (199), (200), (255-262), (265), (274-276), (279), (280), (291), (298), (304)

Polyolefins (302)

Polyurethanes (302)

Pore Structure (153)

Poroelasticity (151)

Porosity (252), (263)

Porosity Structure (155)

Porous Carbons (165)

Porous Materials (153)

Porous Silicon (291)

Powder (249)

Powder Characterization (46), (47), (62), (63)

Powder Consolidation (318)

Powder Diffraction Analysis (327)

Powder Processing (46), (49)

Powder Synthesis (47), (216)

Precursors (349), (351) 
Preforms (36)

Pressure Dependencies (319)

Process Characterization (242)

Process Control (47), (49), (52), (53), (199)

Processing (38), (47), (49), (311), (340)

Properties and Composition (300)

Propylene Glycol (26)

Protected Volumes (239)

Proton Adsorption (155)

Proton Exchange Membranes, (82)

Pulse Propagation (135)

Pulsed-Laser-Deposition (330)

Pumpable Slurries (93)

PV-Powered Windows (170)

Pyrochemical (301)

Pyrolysis (25), (37)

Pyroxenes (150)

QEXAFS (281)

Quantum Wells (164)

Quartz (152)

$\mathbf{R}$

Radiation Damage (166), (290), (291)

Radioactive Materials (302), (304), (307), (308)

Radioactive Waste (313)

Radioactive Waste Host (199), (202)

Radiography (60), (309)

Rapid Prototyping (69)

Rapid Solidification (35), (305)

Reactive Metal Infiltration (29)

Real-Time Radiography (309)

Rechargeable Batteries (77), (80)

Reconfiguration (268)

Recovery (311)

Reference Material (46), (63)

Reflective Films (15) 
Reflectivity (259)

Refractory Metals (219)

Refractory Oxides (315)

Resonant Ultrasound Spectroscopy (325)

Retarders (93)

Rig and Engine Testing (71)

Rock Permeability (155)

Rocks (152)

Romp (256)

Roofs (15)

\section{$\mathbf{S}$}

Salt Solutions (142)

Scale-Resistant (92)

Scales (354-356)

Scanning Electron Microscopy (55)

Scanning Tunneling Microscope (318)

Scattering (140), (275)

Scrap Steels (331)

Secure Containers (239)

Semiconductor Processing (290)

Semiconductors (89-91), (139), (216), (267), (276), (326)

Sensors (253)

Separation (162), (256), (360)

SERDP (288)

Shape Memory Alloys (34)

Shear Strain Localization (150)

Shock Deformation (310)

Shock Physics (298)

Shock Pressures (297)

Shock Temperatures (297)

Shock-Wave Deformation (323)

Short Range Order (281)

Si Light Emission (286)

SiAlON (50), (52), (54), (57)

Sieves (347), (348)

Silica (321)

Silica Aerogels (321)

Silica Foams (329)

Silica Sol-Gels (329) 
Silicate Liquids (149)

Silicate Melts (156)

Silicate Minerals (149), (150)

Silicon (239), (240)

Silicon Carbide (35), (49), (50), (54-56), (63), (66), (71), (173), (174), (351)

Silicon Carbide Whisker Reinforced Aluminum (319)

Silicon Carbide/Silicon Nitride Interfaces (315)

Silicon Nitride (46-50), (52), (54-61), (63), (66-69), (71), (351)

Silicon Oxide (25)

Silicones (302)

Sintering (36), (48), (306)

Small-Angle Neutron Scattering (327)

Smart Windows (170)

SOFC (360)

Soil Washing (204)

Sol Gel (30), (329), (241), (248), (270), (271), (306)

Sol Gel Coatings (278)

Sol-Gel Electrolytes (76)

Sol-Gel Processing (39)

Solar Cells (90), (91), (168)

Solar Furnaces (27)

Solar Processing (27)

Solder (242), (250), (272), (273)

Solid Electrolyte Batteries (170)

Solid State Batteries (170)

Solid-State Cells (74)

Solid-State Electrodes (84)

Solidification (142), (206), (208)

Solubility (152), (155)

Solution Calorimetry (154)

Solvent Extraction (350), (351)

Space Reactors (219-222)

Spall Strength (310)

Speciation (149)

Spectroscopy (79), (81), (238), (245), (266-268)

Sputtering (75), (303)

Sputtering and Solar Cells (89), (90)

SRBSN (48)

Stability (99), (201), (302)

Starch (26)

Statistics (54)

Steels (172-175), (178), (274), (331) 
Strain (134), (284)

Strength (93), (305), (308), (310)

Stress (134), (352)

Stress Analysis (145)

Stress Corrosion Cracking (166)

Stress Induced Grain Growth (286)

Structural and Sheet Applications (61)

Structural Ceramics (21), (24), (51), (53-55), (57), (59), (60), (62-68), (71-73)

Structural Phase Transitions (325)

Structure (23), (246), (269)

Sulfur (199)

Sulfur Oxides (315)

Super Critical (249)

Superalloys (162)

Superconducting Powder (309)

Superconductors (134), (140), (143), (158), (169), (178), (287), (297)

Superlattice Materials (324)

Surety (239), (240)

Surface (251), (268), (272), (273), (308)

Surface Activation (25)

Surface Analytical Analysis (33)

Surface and Interface Science (296)

Surface Area (309)

Surface Characterization and Treatment (66-69), (91), (305), (307)

Surface Coatings (141)

Surface Complexation (154), (157)

Surface Morphology (145)

Surface Properties (281)

Surface Reactivity (155)

Surface Science (293-295)

Surface Structure (155)

Surface Treatment (164)

Surface Waves (153)

Synchrotron Radiation (153), (281)

Synchrotron X-ray Absorption Spectroseopy (157)

Synthesis (249)

Synthetic Fuels (300)

Synthetic Pad Polishing (279) 
$\mathbf{T}$

Target Fabrication (310)

Technology Transfer (339), (363), (364)

Temperatures (293)

Tensile Testing (56), (57), (59)

Test Procedures (16), (53), (59), (63)

Testing (225), (360)

Texture Measurement (328)

Textures (313), (314)

Thallium (97)

Thallium Conductor (99)

Thermal Barrier Coatings (72), (73)

Thermal Conductivity (65)

Thermal Diffusion (156)

Thermal Expansion (302)

Thermal Fatigue (176)

Thermal Insulation (30)

Thermal Modeling (80)

Thermal Resistance (16)

Thermal Shock (305)

Thermionic (220-222)

Thermochemistry (154)

Thermodynamics (302)

Thermoelectric Cells (219)

Thermoelectric Devices (164)

Thermoelectrics (216, (286)

Thermomechanical Testing (38)

Thermophotovoltaics (167)

Thermophysical Properties (29), (138)

Thermoplastic (200), (208)

Thermoset Plastic (206)

Thick Film (97)

Thin Films (277), (286)

Thin-Film Batteries (84)

Time-Dependent (56), (57), (59)

Tires (25)

Titanium Dioxide (26)

Tomography (32), (309)

Tool Hardening (331)

Toughened Ceramics (50), (56)

Toughening (28) 
TR-XRD (281)

Transformation (93), (307), (308)

Transformation Toughened Ceramics (305)

Transformation-Toughened (59)

Transition Metals (149)

Transmission Cable (100)

Transport Current (97)

Treatment (69)

Tri-Layers (287)

Tribology (219), (293-295), (330)

Tritiated Materials (304)

Tritium (304)

Tritium Release (175), (176)

Tubesheet (362)

Tungsten (220), (222)

Tungsten Wire Reinforced Copper (319)

Turbine Blades (162)

Two Phase Deformation (319)

$\mathbf{U}$

Ultra-low Expansion (51)

Ultracapacitors (70)

Ultrasonic Microscopy (309)

Ultrasonic Sensing (132)

Ultrasonic Wave Propagation (153)

Ultrasonics (60)

Uranium (311), (328)

Uranium Alloy (292)

Uranium Carbide (222)

Uranium Dioxide (220)

Uranium Scrap (311)

V

Vacuum (15)

Vanadium (172-176), (178)

Variable Frequency (39)

Varistor (269), (271)

Vibration Dynamics (321) 
Viscoplasticity (130)

Vitrification (201), (204), (205), (209), (210), (212)

Vortex Motion (143)

\section{W}

Waste (25), (202)

Waste Acceptance Specifications (202)

Waste Canisters (225)

Waste Conversion (25)

Waste Form (202), (211)

Waste Minimization (292)

Waste Packages (224)

Waste Recovery (25)

Waste Streams (37)

Waste Treatment (301)

Weapons Design (304)

Weapons Engineering (304)

Wear (53), (64), (65)

Weibull (54)

Welding (132), (136), (172), (241), (244), (250), (251), (255), (274), (352), (353)

Well Completions (93)

Whiskers (22), (341)

Wood (25)

$\mathbf{X}$

X-ray (32), (252), (253), (262), (263), (266), (273)

$\mathrm{X}$-ray Absorption (82)

X-ray Diffraction (309)

X-ray Laser Heating Experiments (293)

X-ray Scattering (316)

$\mathrm{XeF}(286)$

$\mathbf{Y}$

Yttria (220) 
Keyword Index

$\mathbf{Z}$

Zirconia (51), (59)

Zirconia-Toughened Alumina (36)

Zircons (154)

Zn/Air Cells (85)

440 